DISTRIBUTION AND VARIABILITY OF PRECIPITATION CHEMISTRYIN THE
CONTERMINOUS UNITED STATES, JANUARY THROUGH DECEMBER 1983

BY JOSEPH F. RINELLA AND TIMOTHYL. MILLER

U.S. GEOLOGICAL SURVEY

OPEN-FILE REPORT 87-558

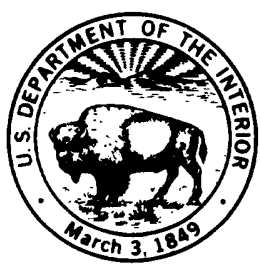


DEPARTMENT OF THE INTERIOR

DONALD PAUL HODEL, Secretary

U.S. GEOLOGICAL SURVEY

Dallas L. Peck, Director

For additional information write to:

Oregon Office Chief U.S. Geological Survey 847 N.E. 19th Ave., Suite 300 Portland, Oregon 97232
Copies of this report can be purchased from:

U.S. Geological Survey Books and Open-File Reports Section Box 25425

Federal Center, Building 810

Denver, CO 80225 
Abstract

Introduction

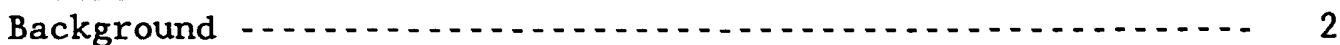

Purpose and scope

Methods of analysis - 3

Data- and site-selection criteria -

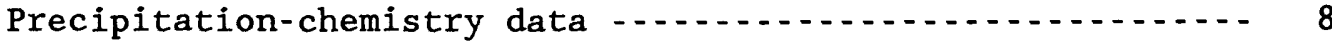

Data-collection sites - 9

Regional distribution and variability of precipitation

chemistry by individual constituents

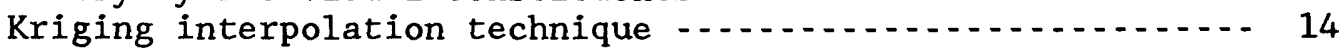

Results of analysis

Volume-weighted chemical concentrations ......... 16

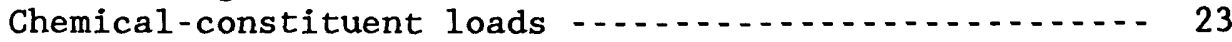

Selected ionic ratios -

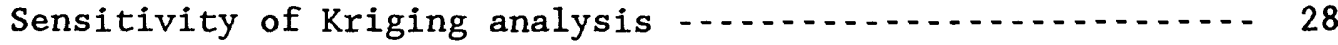

Regional distribution and variability of precipitation

chemistry by chemical group

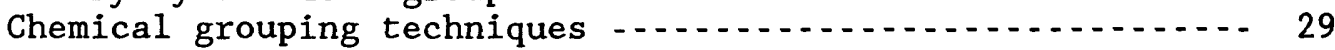

Graphical procedure using trilinear diagrams ....... 29

Cluster analysis ............ 30

Results of analyses

Volume-weighted ionic percentages

Annual comparisons -

Seasonal comparisons -... 35

Chemical concentrations

Weekly chemical concentrations

Summer and winter volume-weighted concentrations -

Selected ionic ratios

Cation-to-anion ratios -..... 42

Sulfate-to-nitrate ratios

Acid-related chemical species .............. 45

Relations between quantity and chemistry of precipitation -.... 47

Kendall Tau correlation and regression-analysis

techniques -......... 47

Results of analysis

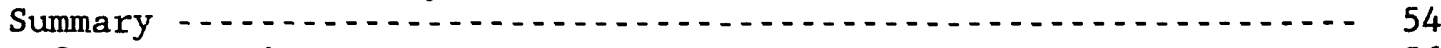

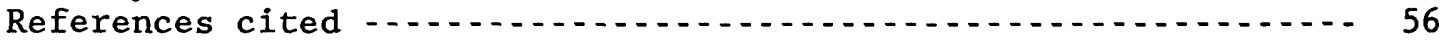

Appendix I. Description of statistical computations, tables, and figures for individual station summaries .................. 58

Appendix II. Statistical summaries for stations with sufficient data for characterizing precipitation-chemistry data in 1983

Appendix III. Statistical summaries for stations with partial records of precipitation-chemistry data in 1983 


\section{ILLUSTRA'TIONS}

Page

Figure 1. Map showing location of National Trends Network sites, $1983 \ldots \ldots$

2. Maps showing volume-weighted constituent means in precipitation at National Trends Network sites and selected Canadian sites, 1983:

a. Potassium concentrations -

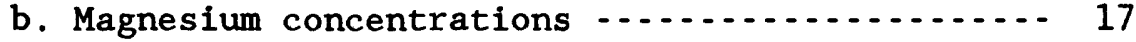

c. Hydrogen-ion concentrations in $\mathrm{pH}$ units ..... 18

d. Sulfate concentrations .................... 18

e. Nitrate concentrations - .

f. Ammonium concentrations ................. 19

g. Specific conductance values ............... 21

h. Sodium concentrations -...................... 21

i. Chloride concentrations .................... 22

j. Calcium concentrations .......................... 22

3. Maps showing annual constituent loads in precipitation, 1983:

a. Hydrogen ion

b. Sulfate $\ldots \ldots \ldots \ldots+24$

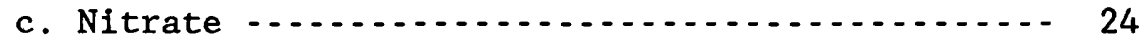

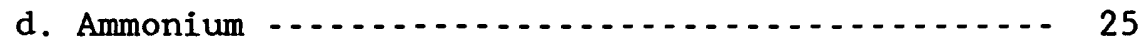

4. Maps showing volume-weighted ionic ratios in precipitation, 1983:

a. Sulfate-to-nitrate values -................ 26

b. Sulfate-plus-nitrate to hydrogen-ion values -.- 27

c. Sulfate-plus-nitrate to hydrogen-ion-plusammonium-plus-calcium values ............ 27

5. Map showing lines of equal volume-weighted hydrogen-ion concentrations in precipitation at National Trends Network sites, $1983 \ldots \ldots$

6. Trilinear diagram showing ionic percentages used to delineate National Trends Network precipitation into chemical groups -.........

7. Map showing chemical groups that were delineated for precipitation collected in the National

Trends Network, 1983

8. Trilinear diagrams showing annual volume-weighted ionic ratios for each

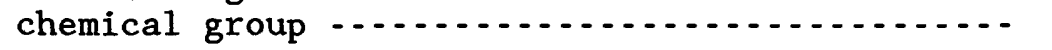


Table 1. National Trends Network stations included in 1983 calendar year annual summary report ... 5

2. Summary of statistics for determining which National Trends Network sites will be included in national maps ................ 11

3. Selected precipitation-chemistry composition based on weekly concentrations, by chemical group, January through December, $1983 \ldots \ldots . . . . .31$

4. Selected precipitation-chemistry composition based on annual volume-weighted concentrations, by chemical group, January through December,

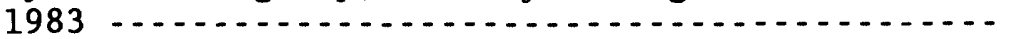

5. Selected precipitation-chemistry composition based on seasonal volume-weighted concentrations, January through December,

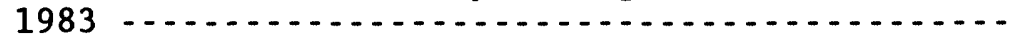

6. Comparison of summer and winter precipitationchemistry concentrations ................... 37

7. Ranking of the median weekly chemical concentrations and precipitation quantity

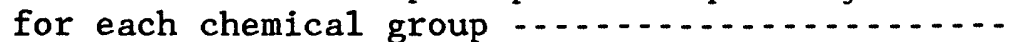

8. Computed Kenda11-tau statistic between precipitation quantity and chemical chemical concentrations in weekly precipitation samples

9. Regression relations between selected chemical concentrations and precipitation quantities .................. 51

10. Predicted precipitation chemistry for selected

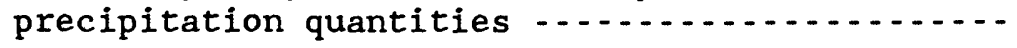


9. Boxplots showing summer-winter comparison of volume-weighted mean concentrations for each chemical group:

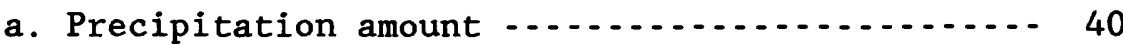

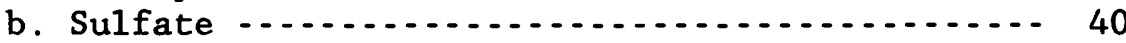

c. Nitrite plus nitrate

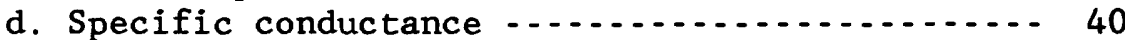

e. $\mathrm{pH}$

f. Ammonia

g. Calcium $\ldots \ldots \ldots \ldots \ldots$

h. Sodium $\ldots \ldots \ldots \ldots \ldots$

i. Chloride

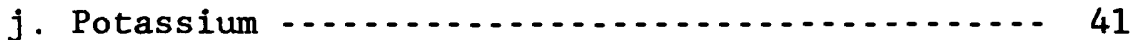

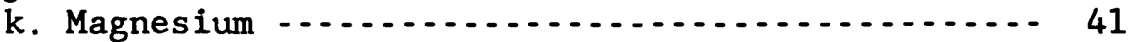

10. Boxplots showing the comparison of cation to anion ionic ratios, in weekly precipitation samples, by chemical group

11. Plot showing relation between annual volumeweighted mean $\mathrm{pH}$ values and the ionic ratio of cations to anions in precipitation .........

12. Boxplots of summer and winter ionic ratios of cations to anions for each chemical group ......

13. Box plots showing the ionic ratios of sulfate to nitrate in weekly precipitation

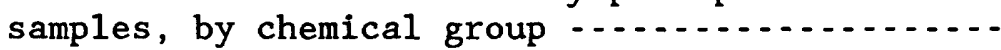

14. Box plots showing summer-winter comparisons of ionic ratios of sulfate-to-nitrate concentrations, by chemical group -.........

15. Boxplots of annual volume-weighted ionic ratios, by chemical group:

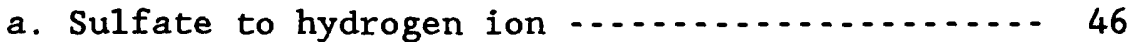

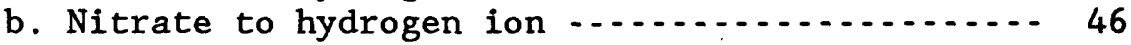

c. Sulfate plus nitrate to hydrogen ion ........ 46

d. Sulfate plus nitrate to hydrogen ion plus ammonium ................................... 46

e. Sulfate plus nitrate to hydrogen ion plus ammonium plus calcium .................. 46

16. Plot showing sulfate concentrations as a function of precipitation amounts for

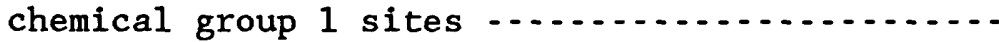

17. Plots showing the logarithmic relation between sulfate concentrations and precipitation amounts :

a. Chemical group 1 sites

b. Chemical group 6 sites $\ldots \ldots \ldots \ldots$ 
For readers who may prefer to use inch-pound units rather than the metric units (International System) used in this report, values may be converted by using the following factors:

\begin{tabular}{|c|c|c|}
\hline Multiply metric unit & By & To obtain inch-pound unit \\
\hline \multicolumn{3}{|c|}{ Length } \\
\hline $\begin{array}{l}\text { millimeter }(\mathrm{mm}) \\
\text { centimeter }(\mathrm{cm}) \\
\text { meter }(\mathrm{m}) \\
\text { kilometer }(\mathrm{km})\end{array}$ & $\begin{array}{l}0.03937 \\
0.3937 \\
3.281 \\
0.6214 \\
\\
\quad \text { Area }\end{array}$ & $\begin{array}{l}\text { inch (in.) } \\
\text { inch (in.) } \\
\text { foot (ft) } \\
\text { mile (mi) }\end{array}$ \\
\hline square meter $\left(\mathrm{m}^{2}\right)$ & $\begin{array}{l}10.76 \\
\text { Volume }\end{array}$ & square foot $\left(f t^{2}\right)$ \\
\hline \multicolumn{3}{|c|}{ Mass } \\
\hline $\begin{array}{l}\text { gram (g) } \\
\text { milligram (mg) }\end{array}$ & $\begin{array}{l}0.03527 \\
0.000003527\end{array}$ & $\begin{array}{l}\text { ounce, avoirdupois (oz) } \\
\text { ounce, avoirdupois (oz) }\end{array}$ \\
\hline \multicolumn{3}{|c|}{ Specific Conductance } \\
\hline $\begin{array}{l}\text { microsiemens per centimeter } \\
\text { at } 25 \text { degrees Celsius } \\
\left(\mu \mathrm{s} / \mathrm{cm} \text { at } 25^{\circ} \mathrm{C}\right)\end{array}$ & 1.0 & $\begin{array}{l}\text { micromhos per centimeter } \\
\text { at } 25 \text { degrees Celsius } \\
\text { (umho/cm at } 25^{\circ} \mathrm{C} \text { ) }\end{array}$ \\
\hline
\end{tabular}




\title{
DESTRIBUTION AND VARIABILITY OF PRECIPITATION CHEMISTRY IN THE CONTERMINOUS UNITED STATES, JANUARY THROUGH DECEMBER 1983
}

\author{
By Joseph F. Rinella and Timothy L. Miller
}

\begin{abstract}
Analyses of atmospheric precipitation samples, collected during the 1983 calendar year from 109 National Trends Network sites in the United States, are presented in this report. The sites were grouped into six geographical regions based on the chemical composition of the samples. Precipitation chemistry in these regions was influenced by proximity to (1) oceans, (2) major industrial and fossil-fuel consuming areas, and (3) major agricultural and livestock areas.
\end{abstract}

Frequency distributions of ionic composition, determined on 10 chemical constituents and on precipitation quantities for each site, showed wide variations in chemical concentrations and precipitation quantities from site to site. Of the 109 sites, 55 had data coverage for the year sufficient to characterize precipitation-quality patterns on a nationwide basis. Except for ammonium and calcium, both of which showed largest concentrations in the agricultural midwest and plains states, the largest concentrations and loads generally were in areas that include the heavily industrialized population centers of the eastern United States.

Precipitation quantity was found to relate to chemical-ion concentrations. Except for hydrogen, all chemical ions are inversely related to the quantity of precipitation depth. Precipitation quantities generally account for less than 30 percent of chemical variation in precipitation samples. However, precipitation quantities account for 30 to 65 percent of the variations of calcium concentrations in precipitation. Calcium concentrations are affected by increased dilution and increased soil moisture as precipitation quantities increase. Increased soil moisture reduces the availability of windborne calcareous-soil particles in the atmosphere. For samples containing the largest precipitation quantities, baseline chemical concentrations in all six regions of the United States approached mean background concentrations observed in precipitation in remote areas of the world. Baseline concentrations at sites in the western coastal region of the United States were most similar to concentrations in remote areas, and baseline concentrations in other regions were generally greater than those concentrations in remote areas.

For purposes of comparison, selected ratios of equivalent chemical concentrations in precipitation were examined. In regions where precipitation has a large ionic proportion of hydrogen-ion equivalents, much of the hydrogen-ion concentration could be balanced by sulfate equivalents and partly balanced by nitrite-plus-nitrate equivalents. Furthermore, in the regions where hydrogen-ion equivalents in precipitation were smaller, ammonium- and calcium-ion equivalents were necessary, along with the hydrogen-ion equivalents, to balance the sulfate plus nitriteplus-nitrate equivalents. These two relations in precipitation samples indicate that in some regions the hydroxide ions or other basic anions associated with ammonium and calcium ions are neutralizing some of the hydrogen ions derived from sulfuric or nitric acids. 


\section{INTRODUCTION}

\section{Background}

Over the last few decades, concern about acid precipitation has intensified, because effects of acid precipitation on natural and manmade systems can be detrimental. Precipitation that passes through an atmosphere contaminated by man-made emissions of sulfur and nitrogen oxides is chemically altered to a mixture of sulfuric and nitric acids. These acids, if present in sufficient quantity, adversely affect biological growth patterns in aquatic and terrestial systems and accelerate rates of corrosion and degradation of man-made materials. Industry, power production, residential heating, and transportation consume large amounts of fossil fuel and emit oxides of sulfur and nitrogen. These emissions now surpass those from natural processes, particularly in the northeastern United States (Likens and Butler, 1981). Atmospheric processes that control the formation and transport of acid-related pollutants are not well understood.

In 1980, Congress established the National Acid Precipitation Assessment Program to broaden support for research activities in causeand-effect atmospheric processes and to develop a comprehensive national data base for use by decision makers and resource managers. In response to the need for a national data base on acid precipitation, the National Trends Network (NTN) was established for collection of precipitationquality data to determine the spatial and temporal variations in precipitacion chemistry.

Since 1978 and prior to establishment of NTN, atmosphericdeposition data were collected under the sponsorship of State Agricultural Experiment Stations as part of the National Atmospheric Deposition Program (NADP). In 1983, about 81 of the NADP sites were selected for inclusion in the NTN, and about 31 new NTN sites were established during the year. Operational coordination for NTN is provided by the NADP. NTN was designed to be fully operational with 150 sites, each located more than $10 \mathrm{~km}$ from cities or other area- or pointsource emissions (Bigelow, 1984). Data from the network represent broad regional characteristics of the quality and quantity of precipitation in 54 ecoregions throughout the United States (Robertson and Wilson, 1985). Different geographical areas have widely differing geochemical capacities for neutralizing acid precipitation; thus precipitation of similar quality in different areas may not necessarily have comparable effects on aquatic or terrestrial ecosystems.

\section{Purpose and Scope}

The purposes of this report are threefold. The first is to determine spatial and seasonal variations of chemical concentrations and loads in precipitation in the United States by using network sites with sufficient data to characterize 1983 precipitation quality. The second is to relate the precipitation quality to the corresponding quantity of precipitation collected weekly. The third purpose is to summarize for each NTN site the precipitation-chemistry data collected in the 1983 calendar year and to provide the range of values (constituent concentrations or quantities) and frequency distribution of values for each constituent in precipitation. 
Appendix I contains computations for the statistical summaries of the weekly composited chemical concentrations. The statistical summaries for each site are not individually discussed in this report. These summaries show wide variations in the frequency distributions of chemical concentrations and precipitation quantities from site to site. Summaries of the precipitation chemistry (10 measured chemicals and precipitation quantity) for each of the 109 NTN sites are shown in Appendices II and III. Those sites that have complete precipitationchemistry records in 1983 (as defined by criteria outlined later in this report) are summarized in Appendix II. Summary statistics for those sites that have partial records are included in Appendix III.

The spatial and seasonal variations of chemical concentrations discussed in this report were determined by grouping and analyzing the annual loads and volume-weighted means of constituent concentrations listed in Appendices II and III. Chemical concentrations of the weekly composited precipitation samples also were analyzed to help determine spatial and seasonal variations and to relate the quality of precipitation to the quantity of precipitation.

\section{Methods of Analysis}

The approach used to meet the report objectives is descriptive and uses tabular and graphical presentations of the data. Unlike data obtained under controlled laboratory conditions, atmospheric-deposition data commonly are affected by many different factors. For example, pollutant emissions rates and wind speed and direction each may have values that vary widely between consecutive observations. Because of this variability, these data reflect a complex mixture of daily, monthly, seasonal, and annual influences, commonly of varying intensity. Data-analysis techniques, including the Kriging interpolation technique, nonparametric correlation analysis (Kendall Tau), regression analysis, cluster analysis for grouping data, and graphical displays that include histograms, box plots, and trilinear plots, are used to examine precipitation-quality and -quantity characteristics. Though these techniques may be used to gain insight into atmospheric processes, they generally do not explain cause-effect relations between potential contaminant sources and the chemistry of precipitation. As with other kinds of monitoring networks, information may be derived about spatial and temporal variations in precipitation quality, but determining the cause of these differences requires a different method of study.

\section{DATA- AND SITE-SELECTION CRITERIA}

The wet-deposition data summarized in this report were obtained from the Acid Deposition System (ADS) in April, 1985. This system is a centralized data repository for atmospheric-deposition chemistry data collected by monitoring networks in North America (Watson and 01sen, 1984). About 109 NTN sites were operating during 1983 (fig. 1; table 1). Not all of these NTN stations had a complete year of record, and about one-fourth of them began operation after June 1983. The number of sites operating during most of 1983 represents slightly more than half the total of 150 sites that will eventually make up the NTN. 


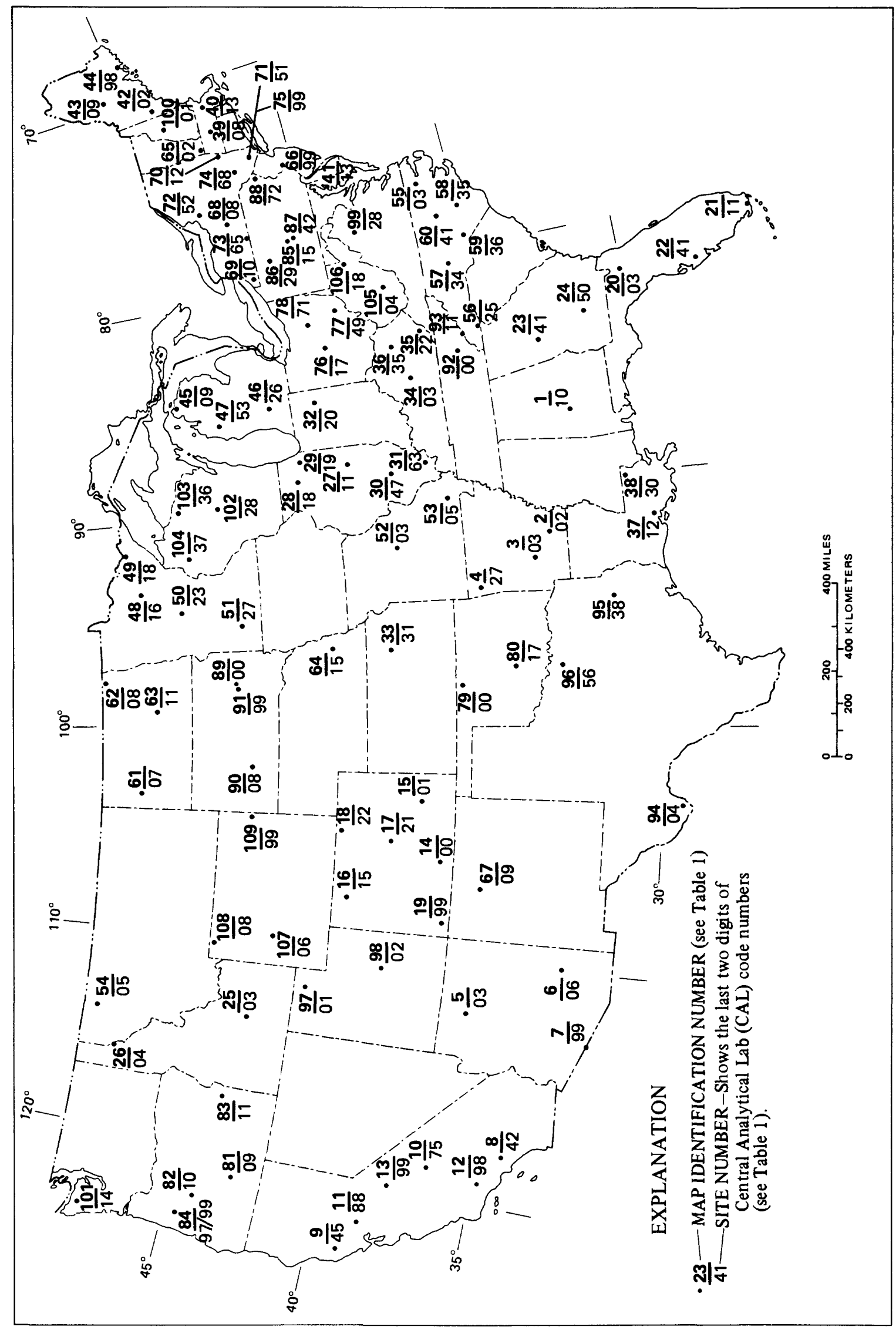


Map ID number $=$ numbers used to identify station locations in figure 1 ; CAL Number $=$ Illinois State Water Survey central analytical laboratory number: the last two characters also identify station locations shown in figure 1.; ADS number = Acid Deposition System number; NADP = National Atmospheric Deposition Program.

\begin{tabular}{|c|c|c|c|c|c|c|c|}
\hline Map & & & NADP & & & & Starting \\
\hline $\begin{array}{l}\text { ID } \\
\text { number }\end{array}$ & $\begin{array}{l}\text { CAL } \\
\text { number }\end{array}$ & $\begin{array}{c}\text { ADS } \\
\text { number }\end{array}$ & $\begin{array}{l}\text { network } \\
\text { number }\end{array}$ & Station name & Latitude & Longitude & $\begin{array}{l}\text { operation } \\
\text { date }\end{array}$ \\
\hline
\end{tabular}

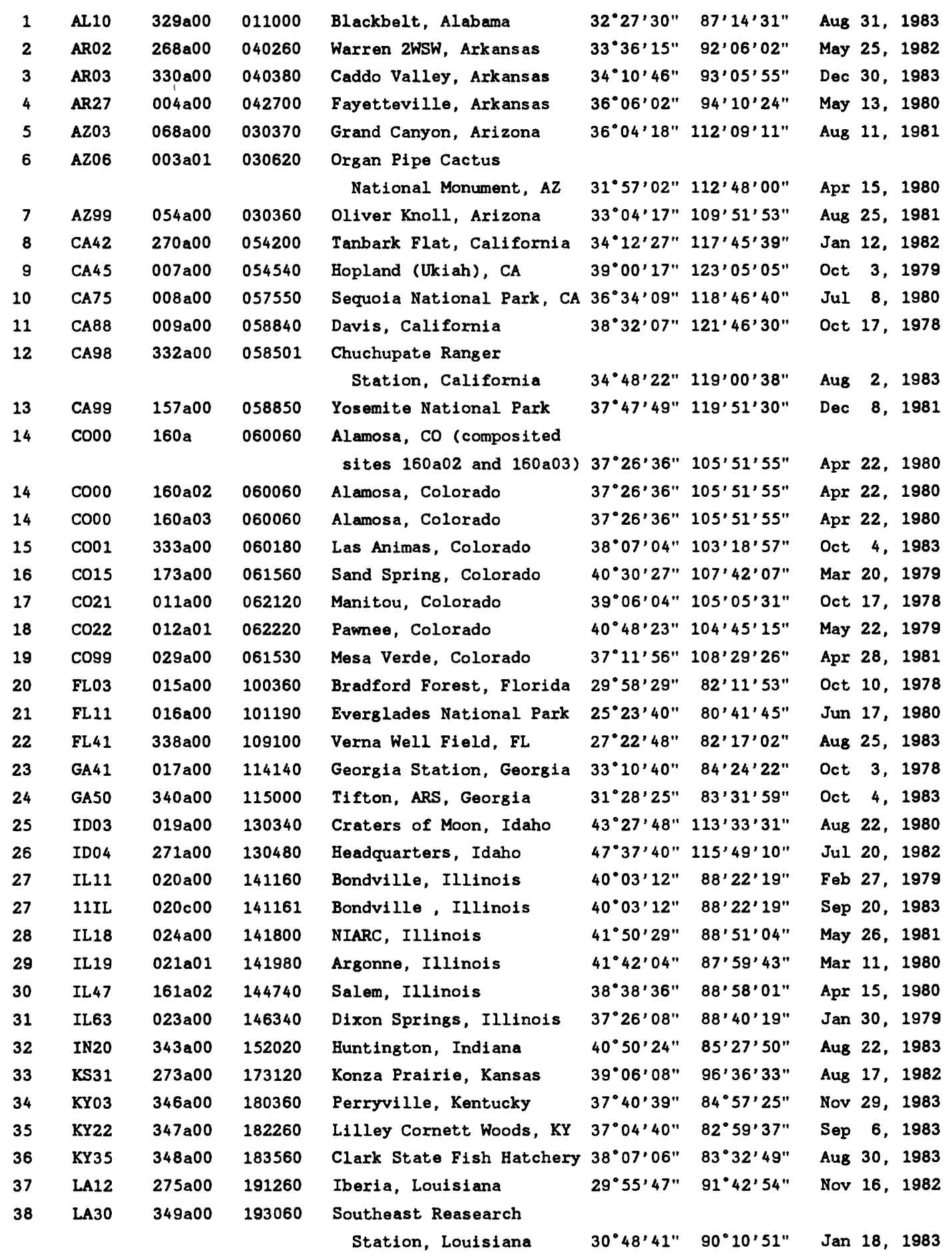


Table 1.--National Trends Network stations included in 1983 calendar year annual summary report--Continued

\begin{tabular}{|c|c|c|c|c|c|c|c|}
\hline Map & & & NADP & & & & Starting \\
\hline $\begin{array}{l}\text { ID } \\
\text { number }\end{array}$ & $\begin{array}{c}\text { CAL } \\
\text { number }\end{array}$ & $\begin{array}{c}\text { ADS } \\
\text { number }\end{array}$ & $\begin{array}{l}\text { network } \\
\text { number }\end{array}$ & & & & operation \\
\hline
\end{tabular}

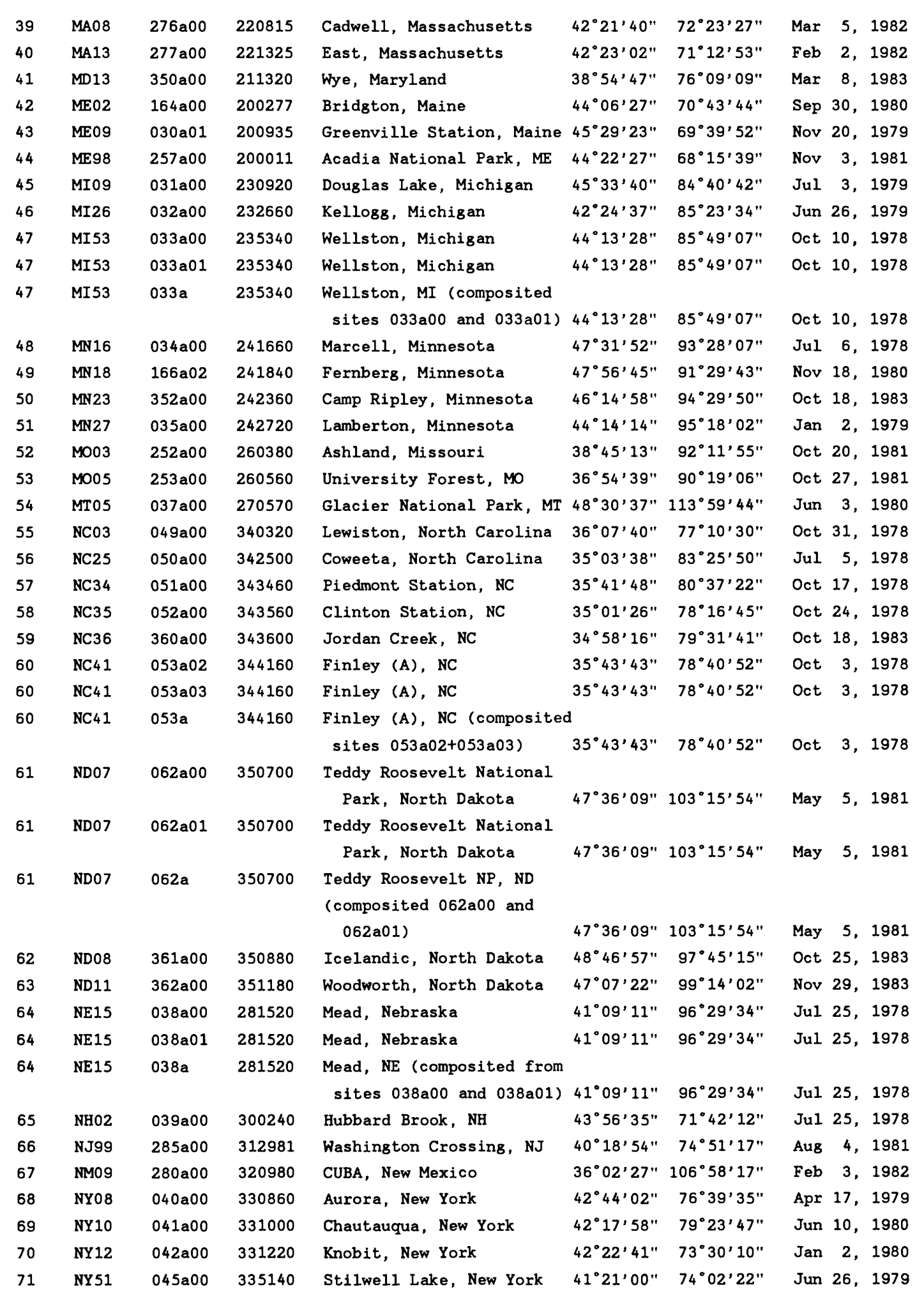


Table 1.--National Trends Network stations included in 1983

calendar year annual summary report--Continued

\begin{tabular}{|c|c|c|c|c|c|c|c|}
\hline Map & & & NADP & & & & Starting \\
\hline $\begin{array}{l}\text { ID } \\
\text { number }\end{array}$ & $\begin{array}{c}\text { CAL } \\
\text { number }\end{array}$ & $\begin{array}{c}\text { ADS } \\
\text { number }\end{array}$ & $\begin{array}{l}\text { network } \\
\text { number }\end{array}$ & Station name & Latitude & Longitude & $\begin{array}{l}\text { operation } \\
\text { date }\end{array}$ \\
\hline
\end{tabular}

\begin{tabular}{|c|c|c|c|c|c|c|c|c|c|}
\hline 72 & NY52 & $046 \mathrm{a} 00$ & 335240 & Bennett Bridge, New York & $43^{\circ} 31^{\prime} 34^{\prime \prime}$ & $75^{\circ} 56^{\prime} 50^{\prime \prime}$ & Jun & 10 , & 1980 \\
\hline 73 & NY65 & $047 \mathrm{a} 00$ & 336500 & Jasper, New York & $42^{\circ} 06^{\prime} 22^{\prime \prime}$ & $77^{\circ} 32^{\prime} 08^{\prime \prime}$ & Feb & 19, & 1980 \\
\hline 74 & NY68 & $359 a 00$ & 336840 & Biscuit Brook, New York & $41^{\circ} 59^{\prime} 39^{\prime \prime}$ & $74^{\circ} 30^{\prime} 13^{\prime \prime}$ & Oct & 11 & 1983 \\
\hline 75 & NY99 & $358 \mathrm{a} 00$ & 335141 & West Point, New York & $41^{\circ} 21^{\prime} 03^{\prime \prime}$ & $74^{\circ} 02^{\prime} 54^{\prime \prime}$ & Sep & 6 , & 1983 \\
\hline 76 & OH17 & $055 \mathrm{a} 00$ & 361760 & Delaware, Ohio & $40^{\circ} 21^{\prime} 19^{\prime \prime}$ & $83^{\circ} 03^{\prime} 58^{\prime \prime}$ & Oct & 3 , & 1978 \\
\hline 77 & $\mathrm{OH} 49$ & $056 \mathrm{a} 00$ & 364900 & Caldwell, Ohio & $39^{\circ} 47^{\prime} 34^{\prime \prime}$ & $81^{\circ} 31^{\prime} 52^{\prime \prime}$ & Sep & 26 , & 1978 \\
\hline 78 & OH71 & $058 \mathrm{a} 00$ & 367160 & Wooster, Ohio & $40^{\circ} 46^{\prime} 48^{\prime \prime}$ & $81^{\circ} 55^{\prime} 31^{\prime \prime}$ & Sep & 26 & 1978 \\
\hline 79 & OKOO & $363 \mathrm{a} 00$ & 370060 & Salt Plains National & & & & & \\
\hline & & & & Wildlife Refuge, OK & $36^{\circ} 48^{\prime} 08^{\prime \prime}$ & $98^{\circ} 12^{\prime} 37^{\prime \prime}$ & Dec & 13 & 1983 \\
\hline 80 & OK17 & $364 \mathrm{a} 00$ & 371740 & Great Plains Apiaries, OK & $34^{\circ} 58^{\prime} 48^{\prime \prime}$ & $97^{\circ} 31^{\prime} 16^{\prime \prime}$ & Mar & 29 & 1983 \\
\hline 81 & ORO9 & $367 \mathrm{a} 00$ & 380980 & $\begin{array}{c}\text { Silver Lake Ranger } \\
\text { Station, Oregon }\end{array}$ & $43^{\circ} 07^{\prime} 22^{\prime \prime}$ & $121^{\circ} 03^{\prime} 28^{\prime \prime}$ & Aug & 23 & 1983 \\
\hline 82 & OR10 & $061 \mathrm{a} 00$ & 381020 & H.J. Andrews, Oregon & $44^{\circ} 13^{\prime} 23^{\prime \prime}$ & $122^{\circ} 14^{\prime} 32^{\prime \prime}$ & May & 13 & 1980 \\
\hline 83 & OR11 & $027 \mathrm{a} 00$ & 381120 & Vines Hill, Oregon & $43^{\circ} 53^{\prime} 57^{\prime \prime}$ & $117^{\circ} 25^{\prime} 37^{\prime \prime}$ & Jul & 15 & 1980 \\
\hline 84 & OR97 & $366 a 00$ & 380202 & Hyslop, Oregon & $44^{\circ} 38^{\prime} 04^{\prime \prime}$ & $123^{\circ} 11^{\prime} 24^{\prime \prime}$ & Apr & 26 & 1983 \\
\hline 84 & OR99 & $060 \mathrm{a} 00$ & 380201 & Schmidt Farm, Oregon & $44^{\circ} 37^{\prime} 35^{\prime \prime}$ & $123^{\circ} 12^{\prime} 50^{\prime \prime}$ & Dec & 26 & 1979 \\
\hline 84 & \multicolumn{2}{|c|}{ OR97 plus } & & Composited from sites & & & & & \\
\hline & \multicolumn{2}{|c|}{ OR99 } & & $060 \mathrm{a} 00$ and $366 \mathrm{a} 00$ & $44^{\circ} 38^{\prime}$ & $123^{\circ} 12^{\prime}$ & Dec & 26 , & 1979 \\
\hline 85 & PA15 & $065 \mathrm{~b} 00$ & 391520 & Penn State NTN, PA & $40^{\circ} 47^{\prime} 18^{\prime \prime}$ & $77^{\circ} 56^{\prime} 47^{\prime \prime}$ & Jun & 7 & 1983 \\
\hline 85 & $15 \mathrm{PA}$ & $065 \mathrm{c00}$ & 391521 & Penn State NTN-2, PA & $40^{\circ} 47^{\prime} 18^{\prime \prime}$ & $77^{\circ} 56^{\prime} 47^{\prime \prime}$ & Oct & 4, & 1983 \\
\hline 86 & PA29 & $063 a 00$ & 392940 & Kane, Pennsylvania & $41^{\circ} 35^{\prime} 52^{\prime \prime}$ & $78^{\circ} 46^{\prime} 04^{\prime \prime}$ & Jul & 18 & 1978 \\
\hline 87 & PA 42 & $064 \mathrm{a} 00$ & 394200 & Leading Ridge, PA & $40^{\circ} 39^{\prime} 32^{\prime \prime}$ & $77^{\circ} 56^{\prime} 10^{\prime \prime}$ & Apr & 25 & 1979 \\
\hline 88 & PA72 & $371 \mathrm{a} 00$ & 397220 & Milford, Pennsylvania & $41^{\circ} 19^{\prime} 39^{\prime \prime}$ & $74^{\circ} 49^{\prime} 13^{\prime \prime}$ & Dec & 27 & 1983 \\
\hline 89 & SDOO & $067 \mathrm{a} 00$ & 430060 & Huron, South Dakota & $44^{\circ} 23^{\prime} 02^{\prime \prime}$ & $98^{\circ} 13^{\prime} 14^{\prime \prime}$ & Apr & 30 & 1980 \\
\hline 90 & SD08 & $373 \mathrm{a} 00$ & 430880 & Cottonwood, South Dakota & $43^{\circ} 56^{\prime} 57^{\prime \prime}$ & $101^{\circ} 51^{\prime} 30^{\prime \prime}$ & Oct & 11 & 1983 \\
\hline 91 & SD99 & $372 \mathrm{a} 00$ & 430061 & Huron Well Field, SD & $44^{\circ} 21^{\prime} 18^{\prime \prime}$ & $98^{\circ} 17^{\prime} 38^{\prime \prime}$ & Nov & 29 & 1983 \\
\hline 92 & TNOO & $171 \mathrm{a} 00$ & 440040 & $\begin{array}{l}\text { Walker Branch Watershed, } \\
\text { Tennessee }\end{array}$ & $35^{\circ} 57^{\prime} 41^{\prime \prime}$ & $84^{\circ} 17^{\prime} 14^{\prime \prime}$ & $\operatorname{Mar}$ & 11 & 1980 \\
\hline 93 & TN11 & $028 a 00$ & 441190 & Elkmont, Tennessee & $35^{\circ} 39^{\prime} 52^{\prime \prime}$ & $83^{\circ} 35^{\prime} 25^{\prime \prime}$ & Aug & 12 , & 1980 \\
\hline 94 & TX04 & $070 \mathrm{a} 00$ & 450425 & $\mathrm{~K}$-Bar, Texas & $29^{\circ} 18^{\prime} 07^{\prime \prime}$ & $103^{\circ} 10^{\prime} 38^{\prime \prime}$ & Apr & 10 & 1980 \\
\hline 95 & $\mathrm{TX38}$ & $254 \mathrm{a} 00$ & 453800 & Forest Seed Center, Texas & $31^{\circ} 33^{\prime} 38^{\prime \prime}$ & $94^{\circ} 51^{\prime} 39^{\prime \prime}$ & Aug & 18, & 1981 \\
\hline 96 & $\mathrm{TX} 56$ & $378 \mathrm{a} 00$ & 455640 & $\begin{array}{l}\text { LBJ National Grasslands, } \\
\text { Texas }\end{array}$ & $33^{\circ} 23^{\prime} 30^{\prime \prime}$ & $97^{\circ} 38^{\prime} 23^{\prime \prime}$ & Sep & 20 & 1983 \\
\hline 97 & UTO1 & $357 a 00$ & 460120 & Logan, Utah & $41^{\circ} 39^{\prime} 30^{\prime \prime}$ & $111^{\circ} 53^{\prime} 49^{\prime \prime}$ & Dec & 6 , & 1983 \\
\hline 98 & UT02 & $069 a 00$ & 460280 & Cedar Mountain, Utah & $39^{\circ} 10^{\prime} 15^{\prime \prime}$ & $110^{\circ} 37^{\prime} 05^{\prime \prime}$ & May & 11 & 1981 \\
\hline 99 & VA28 & $250 \mathrm{a} 01$ & 482890 & Big Meadows, Virginia & $38^{\circ} 30^{\prime} 51^{\prime \prime}$ & $78^{\circ} 25^{\prime} 45^{\prime \prime}$ & May & 12 & 1981 \\
\hline 100 & VT01 & $249 a 00$ & 470100 & Bennington, Vermont & $42^{\circ} 52^{\prime} 34^{\prime \prime}$ & $73^{\circ} 09^{\prime} 48^{\prime \prime}$ & Apr & 28 & 1981 \\
\hline 101 & WA14 & $074 a 00$ & 491410 & Olympic National Park, WA & $47^{\circ} 51^{\prime} 36^{\prime \prime}$ & $123^{\circ} 55^{\prime} 57^{\prime \prime}$ & May & 20 & 1980 \\
\hline 102 & WI 28 & $283 \mathrm{a} 00$ & 512800 & Lake Dubay, Wisconsin & $44^{\circ} 39^{\prime} 53^{\prime \prime}$ & $89^{\circ} 39^{\prime} 08^{\prime \prime}$ & Jun & 29, & 1982 \\
\hline 103 & WI36 & $076 a 00$ & 513640 & Trout Lake, Wisconsin & $46^{\circ} 03^{\prime} 09^{\prime \prime}$ & $89^{\circ} 39^{\prime} 11^{\prime \prime}$ & Jan & 22, & 1980 \\
\hline 104 & WI37 & $077 a 00$ & 513700 & Spooner, Wisconsin & $45^{\circ} 49^{\prime} 21^{\prime \prime}$ & $91^{\circ} 52^{\prime} 30^{\prime \prime}$ & Jun & 3 & 1980 \\
\hline 105 & WV0 4 & $379 a 00$ & 500460 & Babcock State Park, WV & $37^{\circ} 58^{\prime} 47^{\prime \prime}$ & $80^{\circ} 56^{\prime} 59^{\prime \prime}$ & Sep & 6 , & 1983 \\
\hline 106 & WV18 & $075 a 00$ & 501860 & Parsons, West Virginia & $39^{\circ} 05^{\prime} 23^{\prime \prime}$ & $79^{\circ} 39^{\prime} 44^{\prime \prime}$ & Jul & 5, & 1978 \\
\hline 107 & WY06 & $284 \mathrm{a} 00$ & 520680 & Pinedale, Wyoming & $42^{\circ} 55^{\prime} 44^{\prime \prime}$ & $109^{\circ} 47^{\prime} 12^{\prime \prime}$ & Jan & 26 , & 1982 \\
\hline 108 & WY0 8 & $078 \mathrm{a} 00$ & 520860 & Yellowstone National Park, & & & & & \\
\hline & & & & Wyoming & $44^{\circ} 55^{\prime} 02^{\prime \prime}$ & $110^{\circ} 25^{\prime} 13^{\prime \prime}$ & Jun & 5, & 1980 \\
\hline 109 & WY99 & $255 a 00$ & 520820 & Newcastle, Wyoming & $43^{\circ} 52^{\prime} 24^{\prime \prime}$ & $104^{\circ} 11^{\prime} 32^{\prime \prime}$ & Aug & 11 & 1981 \\
\hline
\end{tabular}




\section{Precipitation-chemistry Data}

Criteria used to determine which data from ADS qualify for data base for this study are based on the following guidelines:

1. SAMPLE-START DATE AND SAMPLE-END DATE (beginning and ending dates for a composited sample)

Composited samples qualify if collected between $12 / 28 / 82$ and $01 / 03 / 84$. In a few instances, when either the beginning sampling period or the ending sampling period extended beyond 7 days, the period used in the 1983 summary could have had a SAMPLE-START DATE as early as 12/21/82 and a SAMPLE-END DATE as late as 1/10/84.

2. QC-FLAG (quality-control indicator)

Only those samples that have a blank quality-control indicator field qualify. A nonblank field such as a "Q" indicates that the sample is a quality-assurance sample and that the analytical results cannot be used to describe precipitation quality.

3. ACTUAL-SAMPLE-PERIOD (actual sampling interval)

Samples qualify if sampling intervals are less than 28 days. Most of the samples had 7-day intervals; less than 2 percent of the samples had sampling intervals longer than 8 days.

4. PRECIP-OCCUR (indicates whether precipitation occurred and whether the quantity of precipitation is available)

Precipitation data coded with a "M" or "Z" qualify. The code "M" indicates that precipitation occurred and quantity is available. The code " $Z$ " indicates that no precipitation occurred during the sampling interval.

5. DEPOSITION-TYPE (indicates type of atmospheric-deposition sample)

Only those precipitation data coded with a "W" (indicating wet deposition) or those coded with a "N" (indicating no precipitation and no system blank) qualify. Bulk or undefined samples do not qualify.

6. SAMPLE-QUANTITY (indicates amount of precipitation)

Only those precipitation data coded with a non-missing RAIN-GAGE depth or a non-missing SAMPLE-VOLUME qualify. RAIN-GAGE depth is computed from the weight of precipitation that collects in the rain gage. If the rain gage is malfunctioning, SAMPLE-VOLUME (precipitation quantity) may be obtained from the weight of precipitation collected in the wet-deposition sampling bucket.

\section{REASON-NO-COMPONENT}

Precipitation data that have a blank field or are coded with an "N" qualify. A blank field indicates that at least one physical or chemical determination was reported; an " $N$ " indicates that no precipitation occurred and that no analysis is available. 
8. NOTE-CODES (indicating the performance of the site observer or equipment, or additional information concerning whether the sample or analysis qualify)

Chemical samples and analyses did not qualify for entry into the data base if they contained any of the following NOTE-CODES:

A01 -- Trace precipitation and dilution was unwarranted.

A07 -- No information was available for this collection period.

A10 - - No sample or no data available. Data excluded from report for various reasons, including extreme contamination, lack of conformation to a definable sample, leakage, or loss in the mail.

Al1 - - Sampler malfunction.

A36 - - Trace of precipitation; no analysis.

A37 -- Quality control sample.

B03 - - Sample contains floating matter

B44 - - Bird droppings present.

B45 -- Sample cloudy or discolored.

B46 - - Unusual amounts of soot or dirt for this site.

B48 - - Collector did not operate properly and did not sample all precipitation events during entire sample period.

\section{RESULT-NOTE (contains information concerning results for each} analysis)

Precipitation data qualify if the field is coded with a blank. If field is coded with an "S," the results are suspect; if coded with an "I," comment concerning this analysis is given in the sample record. All 1983 NTN data were coded with a blank.

10. RESULT-FLAG (contains additional information concerning reported values)

Precipitation data qualify if the fields were coded with a blank or " $<"$ (indicating value below detection limit).

\section{Data-collection Sites}

As part of the approach for determining spatial variations in the chemical quality of precipitation, maps were prepared to show annual mean volume-weighted chemical concentrations and loads on a national basis. To provide a consistent portrayal of these annual concentrations and loads on a national basis, site data must be available throughout most of the year. A complete record of weekly data is not available at some sites for such reasons as equipment malfunction, sample contamination, and shipping problems. For this report, four criteria were used to determine whether there were sufficient data at a site to include the data in the maps. These criteria are applied to each site and are similar to criteria used in the National Atmospheric Deposition Program 1982 Annual Summary Report (National Atmospheric Deposition Program Subcommitte Number 3, Data Management and Analysis, 1985). 
The four criteria are:

1. PERCENT OF SUMMARY PERIOD WITH PRECIPITATION-QUANTITY MEASUREMENTS -Precipitation quantity from either the rain gage or wet bucket of the wet/dry deposition collector must be available for at least 85 percent of the 1983 calendar-year summary period.

2. PERCENT OF SUMMARY PERIOD WITH SAMPLES THAT QUALIFY FOR THE DATA BASE - - Samples must be available for at least 65 percent of the summary period.

3. PERCENT OF TOTAL MEASURED PRECIPITATION QUANTITY WITH SAMPLES THAT QUALIFY FOR THE DATA BASE -- The total quantity of precipitation corresponding to the samples qualifying for the data base must be at least 65 percent of the measured precipitation quantity that occurred during the sampling period.

4. PERCENT OF TOTAL MEASURED PRECIPITATION IN RAINGAGE THAT WAS COLLECTED IN WET-DEPOSITION BUCKET - - When precipitation quantities are available for both the rain gage and the wet-sample bucket, the total precipitation quantity collected for qualifying samples in the wet bucket during the summary period must be at least 75 percent of the total precipitation quantity collected in the rain gage.

Each site that met all four of the above criteria was included in the data base. About 49 percent of the NTN sites (55 sites) met all four criteria. About 27 percent of the sites did not meet criterion 1 , 48 percent did not meet criterion 2, 32 percent did not meet criterion 3 , and 8 percent did not meet criterion 4. Percentages for each criterion are listed in table 2. NTN sites that met or exceeded the criteria are denoted by symbol "*" in the table.

In addition to the NTN sites, sites from the Canadian Network for Sampling Acid Precipitation (CANSAP) were used to supplement data for the maps of the United States. The CANSAP data were collected on a monthly basis instead of weekly, and the analyses were made for many of the same constituents analyzed by NTN. On the basis of the criteria listed above, 18 of the 28 CANSAP sites had sufficient data in 1983 to be included in the maps. The Canadian sites have site-selection protocol that differ from the protocol established for NTN sites. The CANSAP sites are commonly located at airports where upper-air meteorology stations are established, and they are also located near cities where spatial changes in precipitation chemistry are large over relatively short distances (D. S. Bigelow, National Atmospheric Deposition Program Coordinator's office, oral commun., January 1986). The close proximity of area- or point-source emissions from airports and cities potentially influences the quality of wet deposition at CANSAP sites. 
[Map ID number = numbers used to identify station locations in figure 1; CAL number $=$ National Atmospheric Deposition Program central analytical laboratory number; "*" indicates those sites meeting criteria for inclusion in maps; characters in parenthesis list the Atmospheric Deposition System number for those sites that had changes in site protocol during 1983 (for example, changing the brand of wet/dry deposition collector); "--" indicates no data; PPT = precipitation

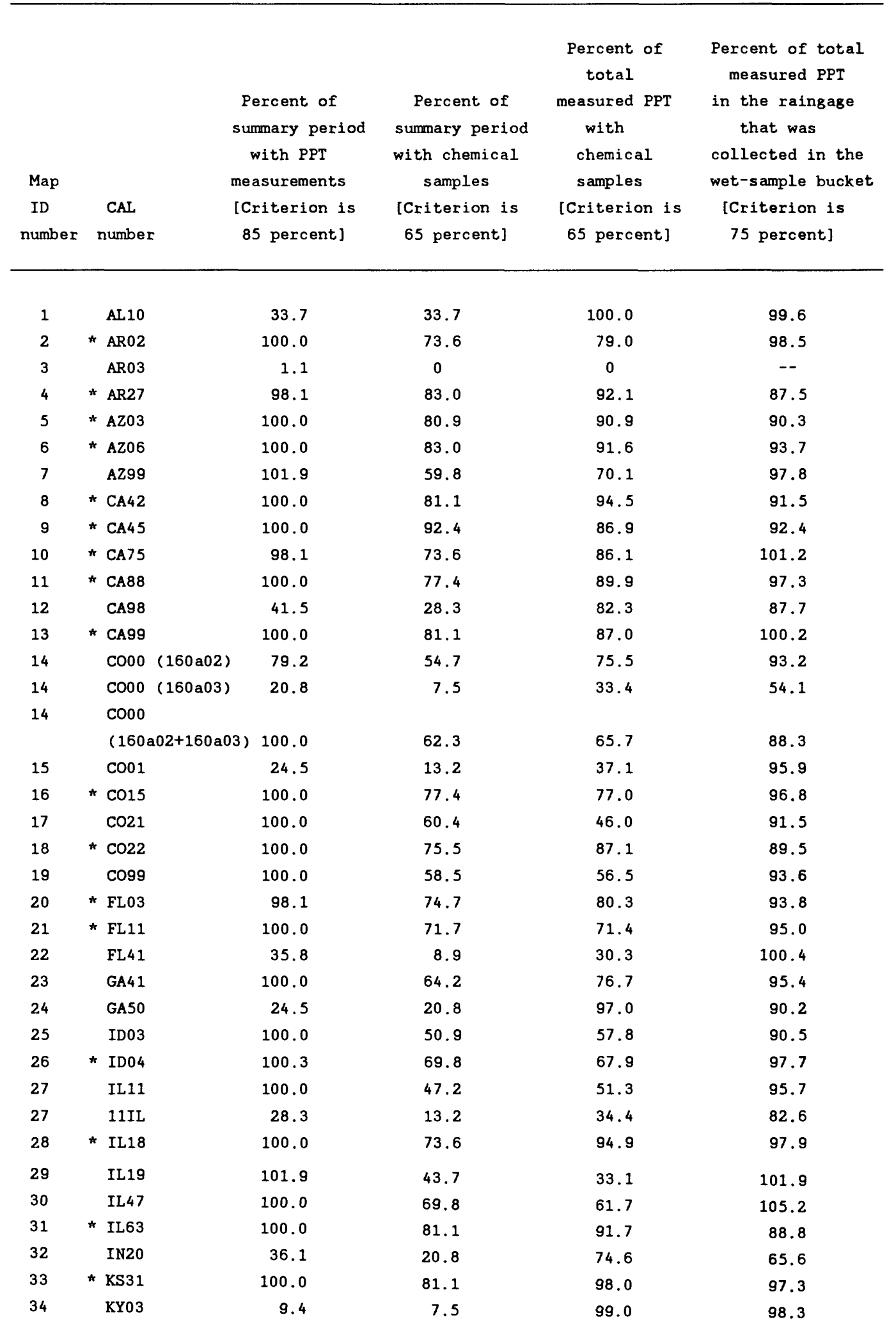




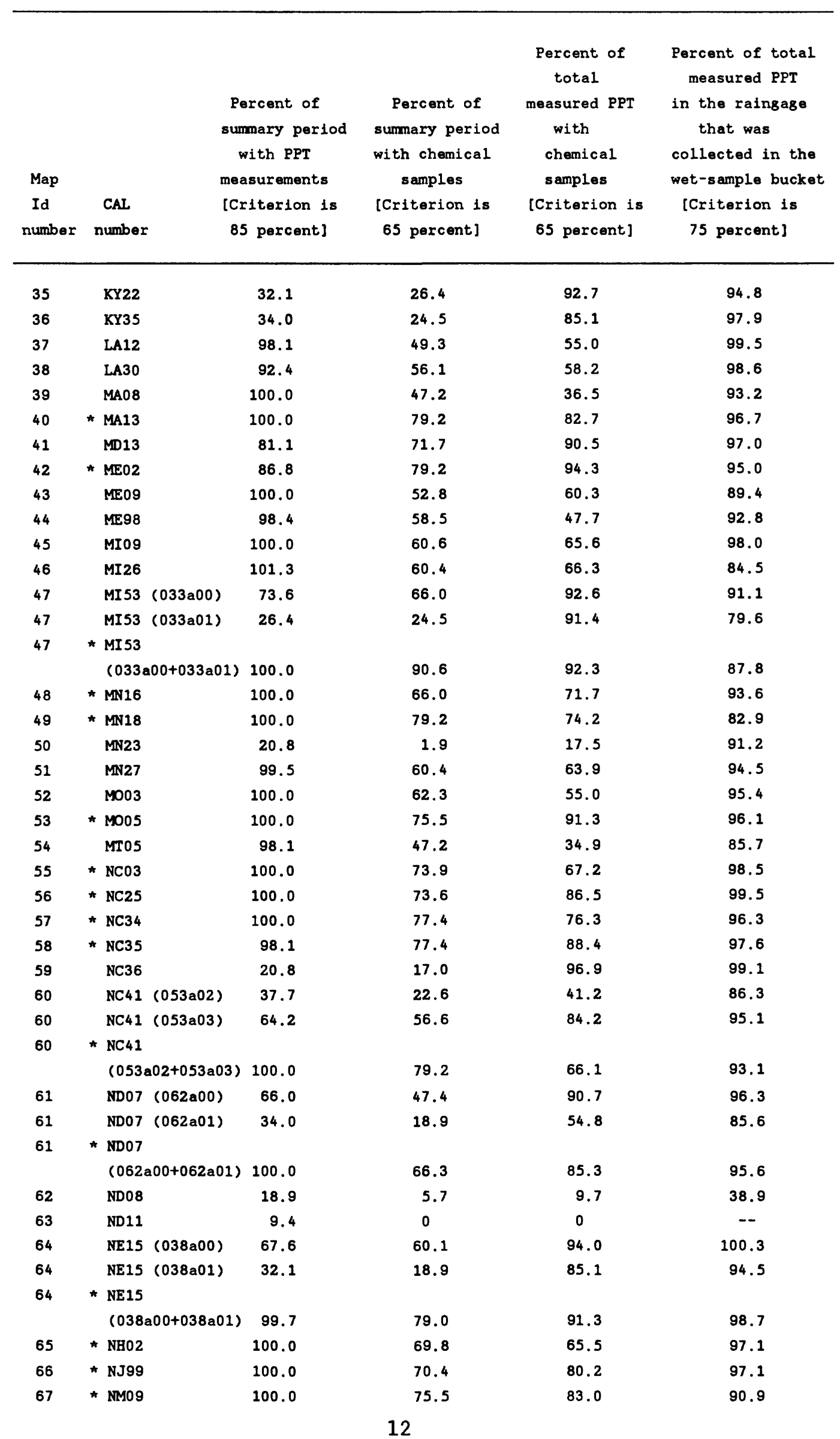




\begin{tabular}{|c|c|c|c|c|c|}
\hline $\begin{array}{l}\text { Map } \\
\text { ID } \\
\text { number }\end{array}$ & $\begin{array}{c}\text { CAL } \\
\text { number }\end{array}$ & $\begin{array}{l}\text { Percent of } \\
\text { summary period } \\
\text { with PPT } \\
\text { measurements } \\
\text { [Criterion is } \\
85 \text { percent] }\end{array}$ & $\begin{array}{l}\text { Percent of } \\
\text { sumary period } \\
\text { with chemical } \\
\text { samples } \\
\text { [Criterion is } \\
65 \text { percent] }\end{array}$ & $\begin{array}{l}\text { Percent of } \\
\text { total } \\
\text { measured PPT } \\
\text { with } \\
\text { chemical } \\
\text { samples } \\
\text { [Criterion is } \\
65 \text { percent] }\end{array}$ & $\begin{array}{l}\text { Percent of total } \\
\text { measured PPT } \\
\text { in the raingage } \\
\text { that was } \\
\text { collected in the } \\
\text { wet-sample bucket } \\
\text { [Criterion is } \\
75 \text { percent] }\end{array}$ \\
\hline 68 & * NY08 & 99.7 & 80.9 & 90.4 & 91.2 \\
\hline 69 & * NY10 & 100.0 & 75.5 & 82.2 & 97.0 \\
\hline 70 & * NY12 & 100.0 & 88.9 & 94.5 & 93.8 \\
\hline 71 & * NY51 & 100.0 & 81.1 & 86.5 & 93.7 \\
\hline 72 & * NY52 & 98.1 & 88.9 & 88.0 & 94.2 \\
\hline 73 & * NY65 & 100.0 & 86.8 & 96.2 & 95.8 \\
\hline 74 & NY68 & 22.6 & 13.5 & 70.8 & 81.4 \\
\hline 75 & NY99 & 30.2 & 30.2 & 100.0 & 96.2 \\
\hline 76 & * OH17 & 100.0 & 77.4 & 83.5 & 100.2 \\
\hline 77 & $\mathrm{OH} 49$ & 100.0 & 66.3 & 56.2 & 99.6 \\
\hline 78 & * OH>1 & 100.0 & 67.9 & 70.5 & 98.9 \\
\hline 79 & OKOO & 5.7 & 3.8 & 50.0 & -- \\
\hline 80 & OK17 & 74.7 & 62.3 & 93.0 & 101.6 \\
\hline 81 & ORO9 & 35.8 & 22.6 & 30.2 & 77.9 \\
\hline 82 & OR10 & 100.0 & 64.4 & 59.4 & 95.8 \\
\hline 83 & * OR11 & 100.0 & 74.4 & 81.0 & 95.9 \\
\hline 84 & OR97 & 67.9 & 56.6 & 94.9 & 91.8 \\
\hline 84 & OR99 & 32.1 & 28.3 & 95.2 & -- \\
\hline \multirow[t]{2}{*}{84} & * OR97 plus & & & & \\
\hline & OR99 & 100.0 & 84.9 & 95.0 & 91.8 \\
\hline 85 & PA15 & 56.6 & 43.4 & 80.7 & 98.0 \\
\hline 85 & $15 P A$ & 24.5 & 20.8 & 78.9 & 94.6 \\
\hline 86 & PA29 & 100.0 & 54.7 & 61.3 & 94.8 \\
\hline 87 & * PA42 & 100.0 & 92.4 & 96.0 & 90.3 \\
\hline 88 & $\mathrm{PA} 72$ & 1.9 & 1.9 & 100.0 & 101.2 \\
\hline 89 & SDOO & 73.5 & 58.5 & 91.2 & 82.2 \\
\hline 90 & SD08 & 22.6 & 13.2 & 60.9 & 80.9 \\
\hline 91 & SD99 & 9.4 & 0 & 0 & -- \\
\hline 92 & * TNOO & 100.0 & 83.0 & 80.0 & 102.0 \\
\hline 93 & TN1I & 100.0 & 63.9 & 69.1 & 96.8 \\
\hline 94 & * TXO4 & 100.0 & 83.0 & 88.2 & 101.5 \\
\hline 95 & * TX38 & 100.0 & 81.1 & 71.8 & 99.1 \\
\hline 96 & TX56 & 28.3 & 22.6 & 99.9 & 93.4 \\
\hline 97 & UTO1 & 7.5 & 0 & 0 & -- \\
\hline 98 & * UT02 & 100.0 & 75.2 & 72.2 & 82.4 \\
\hline 99 & VA28 & 100.0 & 45.3 & 56.8 & 100.2 \\
\hline 100 & * VT01 & 100.0 & 73.6 & 77.3 & 92.0 \\
\hline 101 & * WA14 & 100.0 & 80.6 & 80.2 & 97.0 \\
\hline 102 & * WI28 & 99.5 & 84.4 & 90.0 & 95.5 \\
\hline 103 & * WI36 & 100.0 & 66.0 & 76.1 & 96.4 \\
\hline 104 & * WI37 & 100.0 & 66.0 & 74.3 & 92.8 \\
\hline 105 & WV0 4 & 32.1 & 18.9 & 48.2 & 87.4 \\
\hline 106 & * WV18 & 100.0 & 86.8 & 80.8 & 91.2 \\
\hline 107 & WY06 & 100.0 & 62.3 & 61.5 & 72.2 \\
\hline 108 & WY08 & 100.0 & 37.7 & 38.0 & 105.0 \\
\hline 109 & * WY99 & 100.0 & 86.5 & 81.9 & 84.8 \\
\hline
\end{tabular}




\section{REGIONAL DISTRIBUTION AND VARIABILITY OF PRECIPITATION CHEMISTRY BY INDIVIDUAL CONSTITUENT}

\section{Kriging Interpolation Technique}

Maps that depict the spatial distribution of chemical concentrations and loads in precipitation across the United States show wide variations for most chemical concentrations and precipitation quantities. Lines of equal chemical concentrations and loads depicted on these maps may be used (1) to identify areas of large chemical concentrations or loads and (2) to compare the quality of precipitation to the geographic distributions of such variables as population density, energy consumption, and wind patterns in order to discover possible relations between sources and the resulting quality.

Locations for lines of equal concentration could be determined by two types of methods. With a subjective contouring method, the individual scribe interprets line placement on the basis of points of observed data. A different method would use an objective, mathematical approach, in which the lines are drawn on the basis of some feature of the observed data described mathematically. Shortcomings of the subjective method include (1) uncertainty over the amount of influence a single observed value should exert over adjacent observations of considerably different magnitude, (2) the tendency for convoluted or "bullseye" contours (that cannot be substantiated by the existing data) to result when equal influence is allowed for each data point, and (3) a lack of repeatability because of varying individual interpretations of the data in the subjective process.

After a consideration of the shortcomings of the subjective method, the objective mathematical approach was chosen because (1) an objective method could provide repeatable results, and (2) control could be exercised on the weight assigned to local observations so that regional patterns would not be unduly influenced by singular points. The major consideration for number 2 above is that if there is "noise" in the data (unwanted or unexplained variation in the observed values) along with a regional pattern, the noise should not have an excessive influence on the regional pattern. The objective method selected was Kriging, which bases estimates at unmeasured locations on the spatial autocorrelation in observed data. For this study, the spatial pattern of precipitationchemistry results was a primary interest.

Kriging results provide a smoothing of the observed data and so describe the general regional pattern, but not the local details. Therefore, while direct comparison of lines of equal concentration (drawn from the Kriged data) to the observed data at specific points is unavoidable, the reader should remember that observed data on some maps may contain significant noise. Noise present in the data may cause specific observation values to appear not to support the placement of the lines which are drawn to reflect a regional (not local) data pattern.

This report will focus attention on the application of Kriging to precipitation data that meet the previously discussed criteria. However, some aspects of the Kriging theory should be addressed in order to understand better the maps that show regional patterns on a nationwide scale. 
Theoretical aspects of Kriging are discussed in detail by Olea (1975). Two theoretical components of Kriging are the semi-variogram and drift. The semi-variogram is expressed as a function that describes the relation between variance of the observed values with respect to distance between observation sites. Drift is the spatial trend of the mean values for a variable over a region (for this study the region is the United States). Skrivan and Karlinger (1980) provide five functional forms for the semi-variogram. The forms are: (1) linear or parabolic or root, (2) spherical, (3) exponential, (4) Gaussian, and (5) De Wijsian. Drift and the semi-variogram are interrelated. If the drift is constant, the semi-variogram is the variance of the difference between numerical values of the variables related to the distance between observation sites. If drift is not a constant, the semivariogram is the variance of the differences between residuals of the variables off the drift as related to distance between observation sites (Skrivan and Karlinger, 1980).

Because the semi-variogram for this project is a function only of the distance between sites and not a function of direction, the semivariogram was considered to be isotropic. Anisotropy could not be accounted for because the data (number of sites) were not sufficiently dense to distinguish any regional variations or anistrophy in the semivariogram. About 80 percent of all comparisons between sites (used to calculate the semi-variogram) were oriented in an east-west direction; thus, directional differences in the semi-variogram between north-south and east-west could not be determined.

Skrivan and Karlinger (1980) point out that Kriging (1) provides unbiased estimates of variables in areas where the available data show spatial autocorrelation, and (2) minimizes the variance of the estimated values. These points are applicable if the true drift and semivariogram are known and used. However, because the drift and semivariogram are estimated from the data, the claims of unbiased estimates and minimum variance cannot be substantiated for these results (although use of any other mathematical scheme would have the same limitations).

Kriging programs used in this study made use of a neighborhood approach for estimating an interpolation value. The neighborhood approach results in the estimated value being calculated from a linear combination of the closest two observation locations per quadrant. Thus an estimated value results from a linear combination of (at most) eight observation points. An examination of figure $2 a$ shows more sites in the northeastern United States than in the rest of the country.

Neighborhoods for many sites in the northeastern United States are in a rather homogeneous climatological-physiographic region close to the location being estimated, whereas neighborhoods in the western United States often cover vast areas that are not climatologically or physiographically homogeneous. Differences in climatological and physiographic features are partially reflected in the semi-variogram, which usually has much lower variance for sites that are closer together (such as in the eastern United States) and has higher variances for sites separated by greater distances. In calculating the estimated value, observation sites closer to the location of the interpolated value are given more weight than sites farther away. 


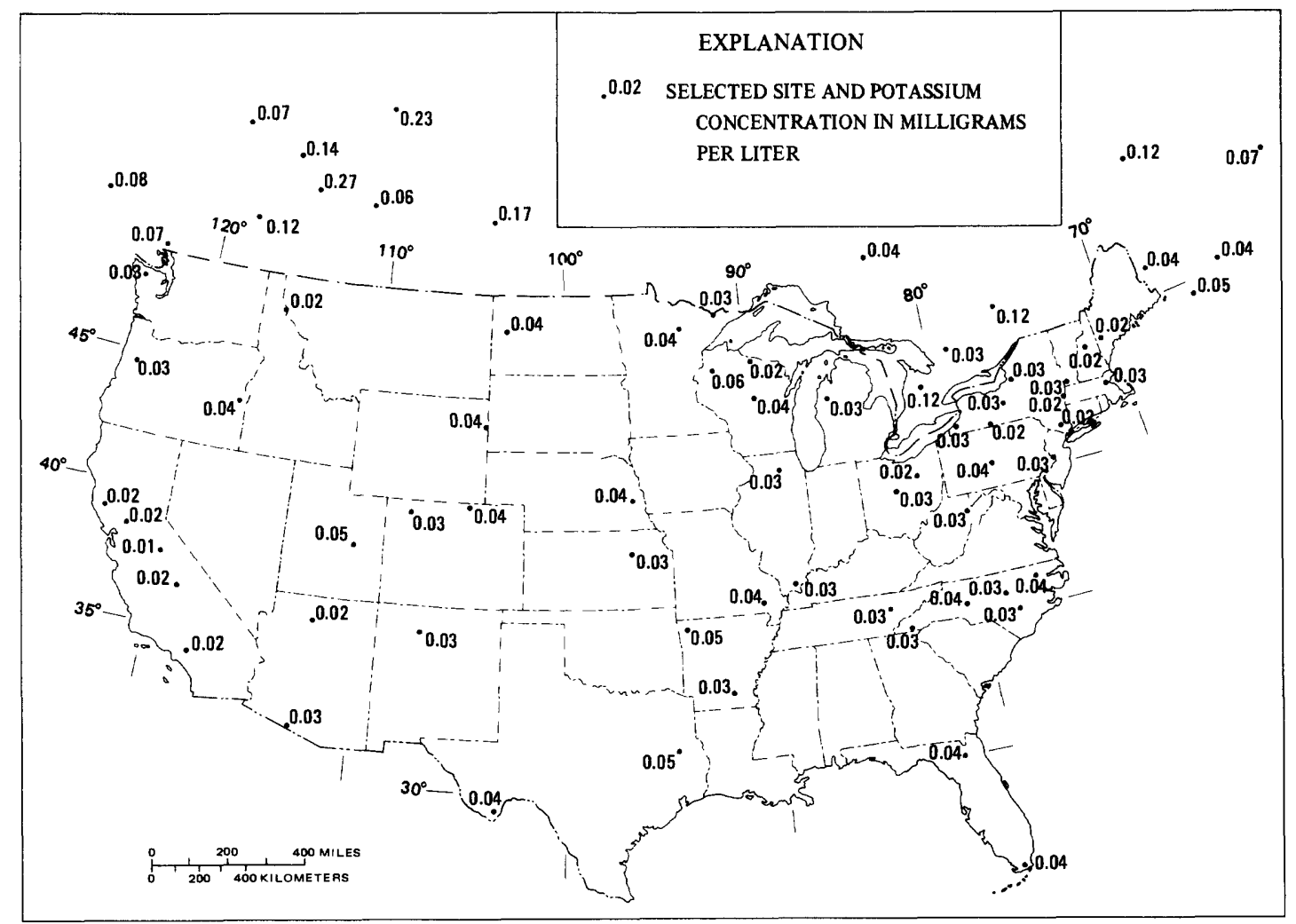

Figure 2a.--Volume-weighted constituent means in precipitation at National Trends Network sites and selected Canadian sites, 1983: Potassium concentrations.

Geographical areas with more sites that are close together and neighborhoods that encompass areas of similar climatological conditions and contaminant-source emissions will have lower variance for the estimated values. Although variance for estimated values will be higher in areas other than those previously mentioned, it is precisely in the areas with sparse data that Kriging provides an opportunity to estimate the values of missing data. Contouring the estimated values can then reveal an underlying pattern to the data that may not be obvious when only the observation points are examined. Pattern identification in the western United States is particularly noticeable for the large population centers in southern California and the Pacific Northwest, where man's activities may have considerable effect on the quality of precipitation.

\section{Results of Analysis}

\section{Volume-weighted Chemical Concentration}

Ten maps were prepared to show lines of equal annual mean volumeweighted chemical concentrations for 1983. Line intervals on the maps generally were selected to include the largest value possible for constructing a complete line. Because of the different ranges and magnitudes of chemical values, intervals vary considerably from map to map. Two of the ten maps have no lines, because within the United States the ranges of values for potassium (fig. 2a) and magnesium (fig. 2b) were not significantly different enough for spatial distribution comparisons. The other eight maps of chemical concentrations reveal some distinct patterns. 


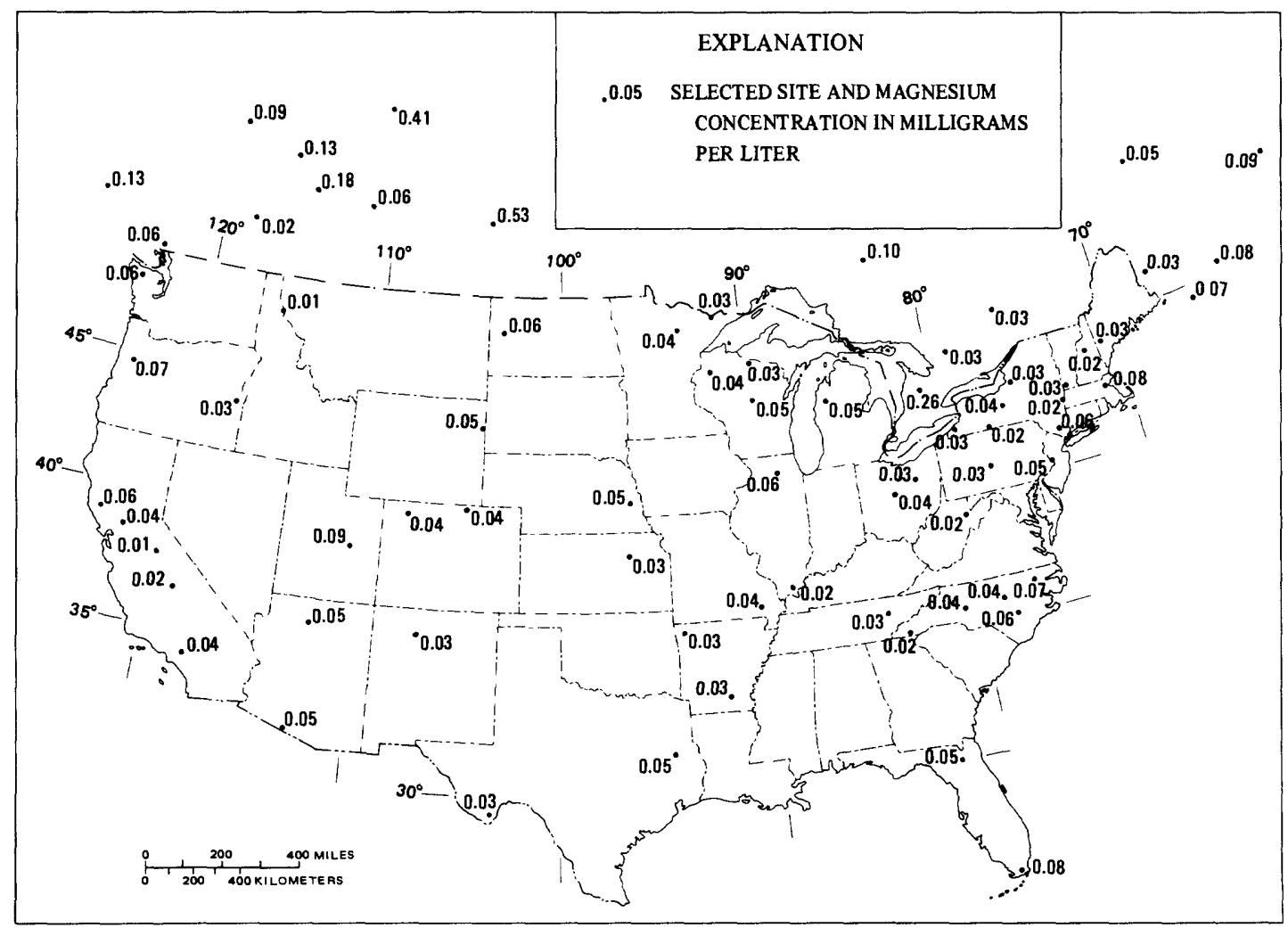

Figure 2b.--Volume-weighted constituent means in precipitation at National Trends Network sites and selected Canadian sites, 1983: Magnesium concentrations.

The $\mathrm{pH}$ map shows a marked difference between the western and eastern United States (fig. 2c). Lowest $\mathrm{pH}$ values are centered around the industrialized northeastern United States; $\mathrm{pH}$ values are higher elsewhere, especially to the south and west. Values become higher in a westerly direction. The pattern of $\mathrm{pH}$ lines coincides with the presence of large population and manufacturing centers coincident with the lowest $\mathrm{pH}$ values. A slight decrease in $\mathrm{pH}$ values also occurs in the densely populated areas of southern California. Concentrations of sulfate ( $f i g$. 2d) and nitrate (fig. 2e) exhibit patterns somewhat similar to that of $\mathrm{pH}$. The similarity of the lines of equal concentrations and $\mathrm{pH}$ values suggests a strong association between the large concentrations of sulfate and nitrate with the low values of $\mathrm{pH}$.

Lines of equal ammonium concentration (fig. 2f) are quite different from the lines of equal concentrations previously discussed. Largest ammonium-ion concentrations are centered much farther west than the large sulfate or nitrate concentrations. Relatively large (but not the largest) ammonium concentrations are centered around the Great Lakes region, which is also the location of large concentrations of sulfate and nitrate; this association suggests that ammonia is neutralizing some of the acidity (hydrogen ions) associated with the large sulfate and nitrate concentrations, according to the following reactions:

(1) Source of hydroxide ions

$$
\mathrm{NH}_{3}+\mathrm{H}_{2} \mathrm{O}=\mathrm{NH}_{4}^{+}+{\underline{\mathrm{OH}^{-}}}^{-}
$$




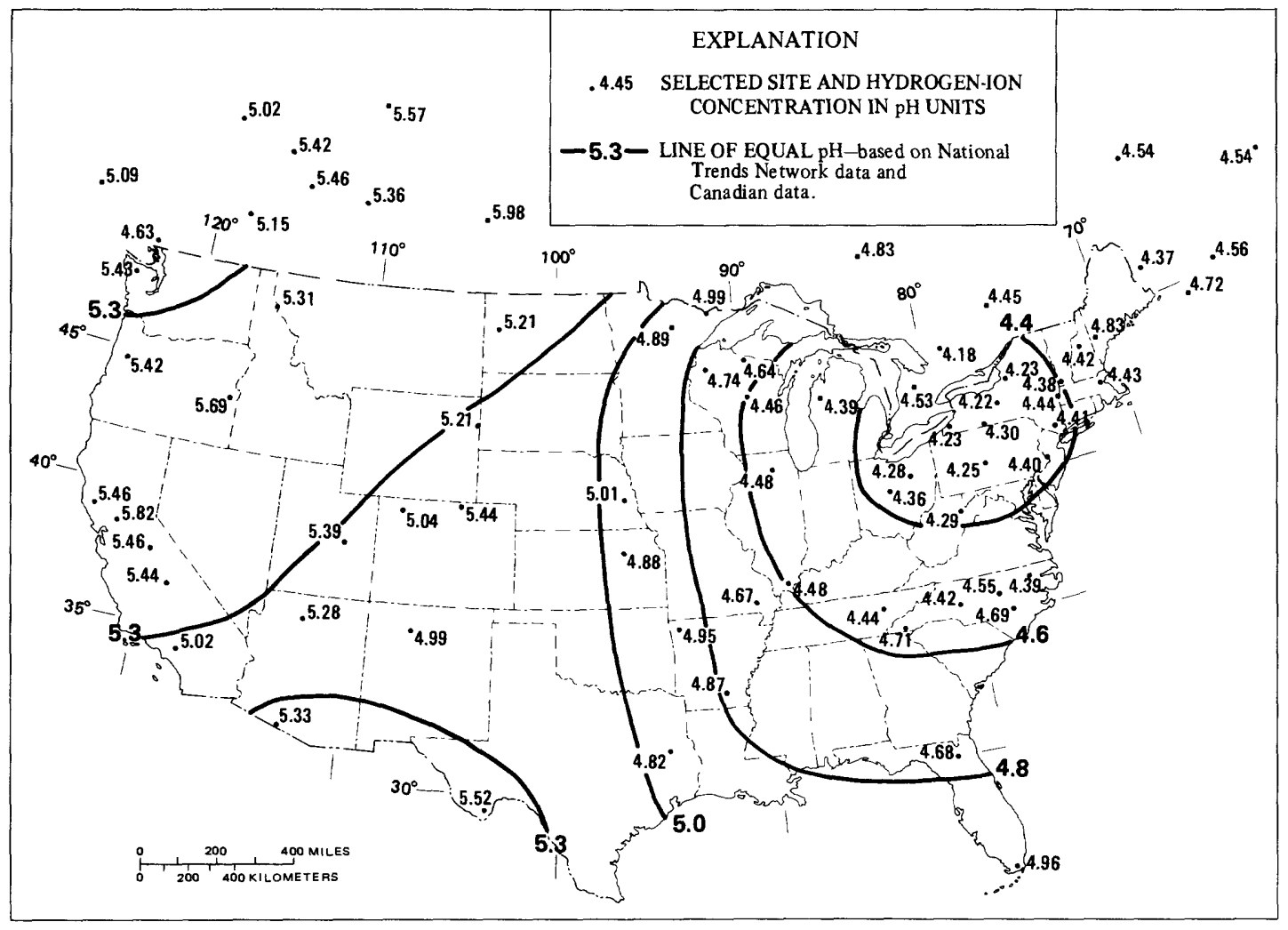

Figure 2c.--Volume-weighted constituent means in precipitation at National Trends Network sites and selected Canadian sites, 1983: Hydrogen-ion concentrations, in pH units.

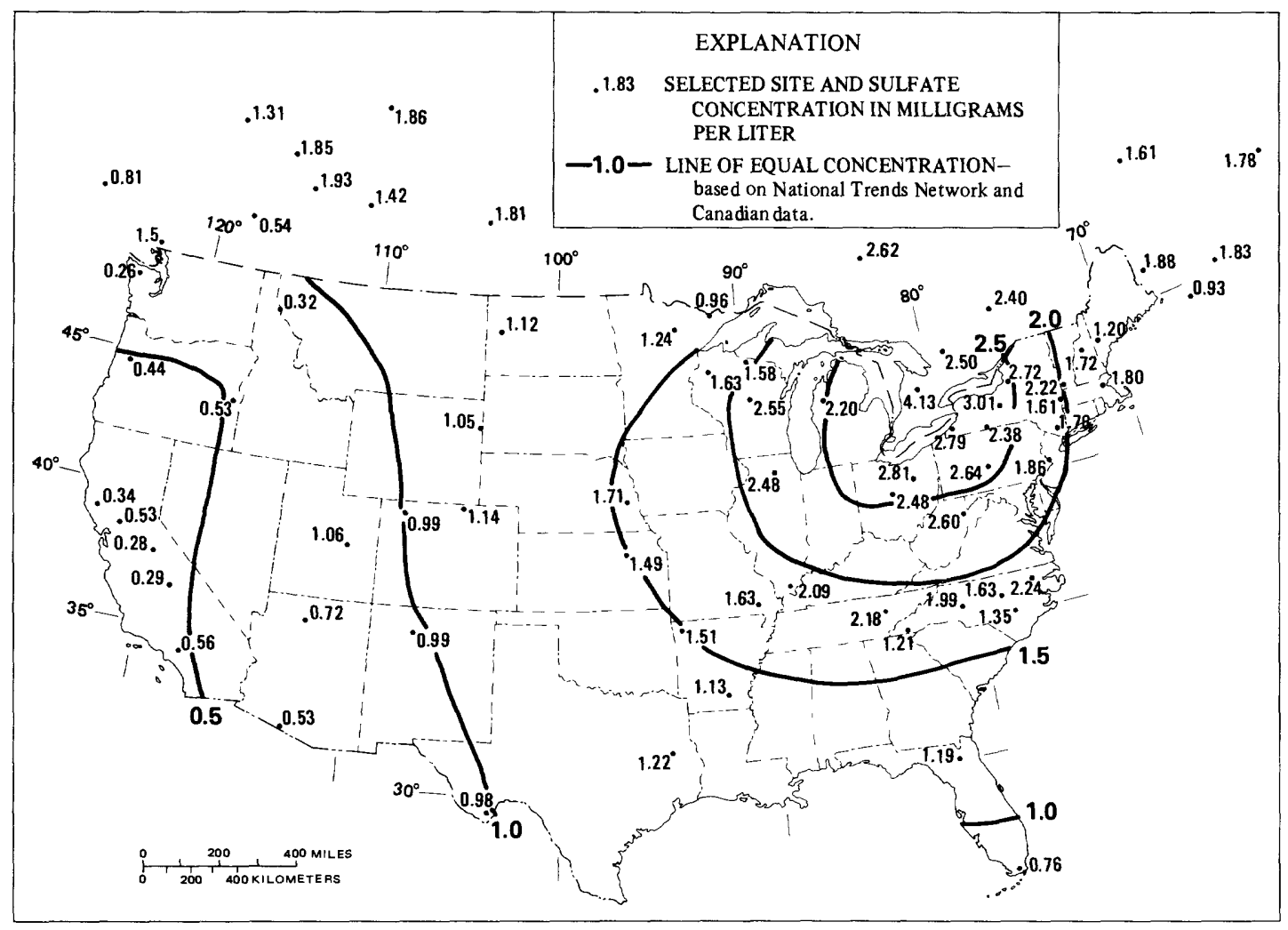

Figure 2d.--Volume-weighted constituent means in precipitation at National Trends Network sites and selected Canadian sites, 1983: Sulfate concentrations. 


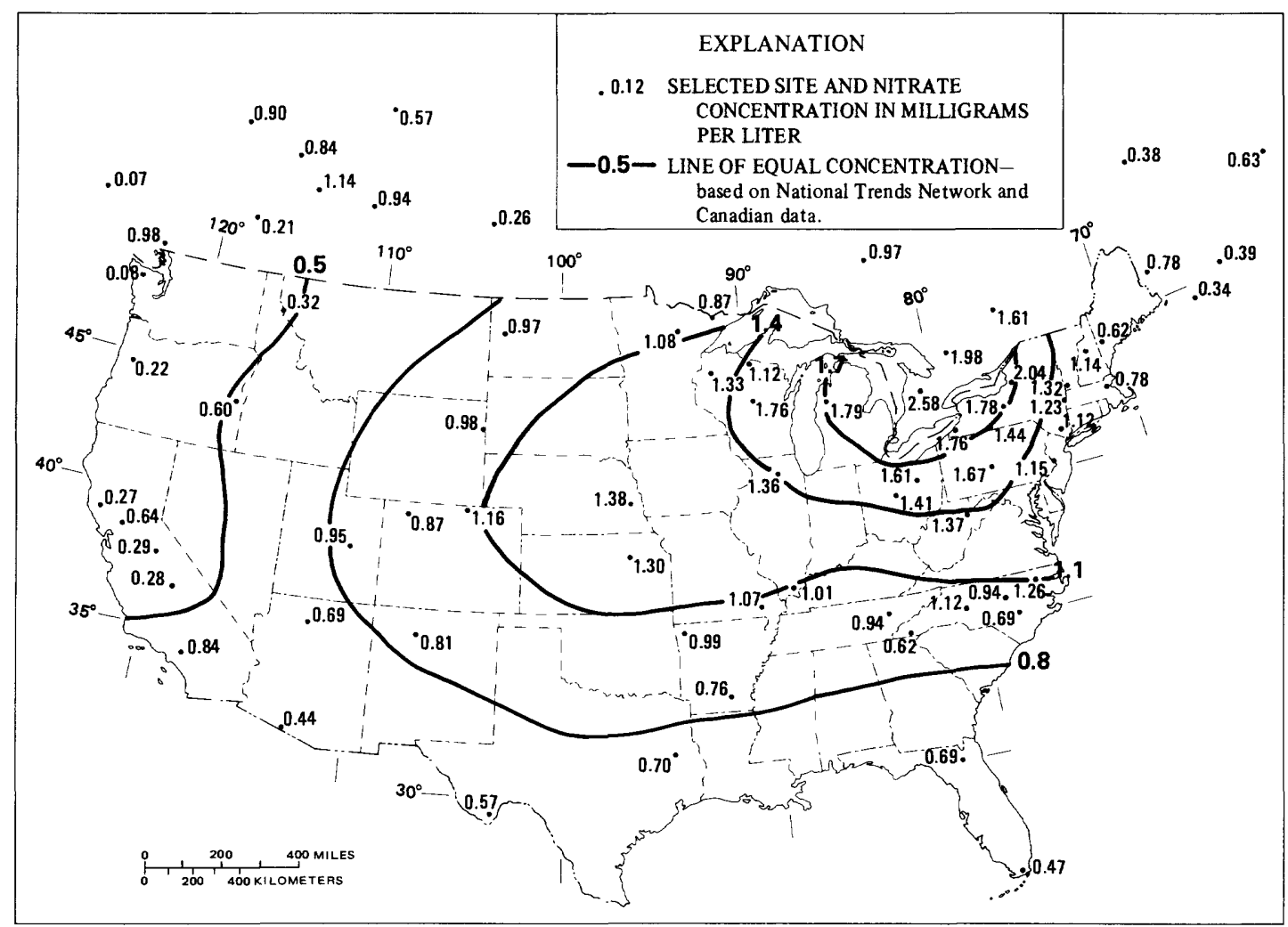

Figure 2e.--Volume-weighted constituent means in precipitation at National Trends Network sites and selected Canadian sites, 1983: Nitrate concentrations.

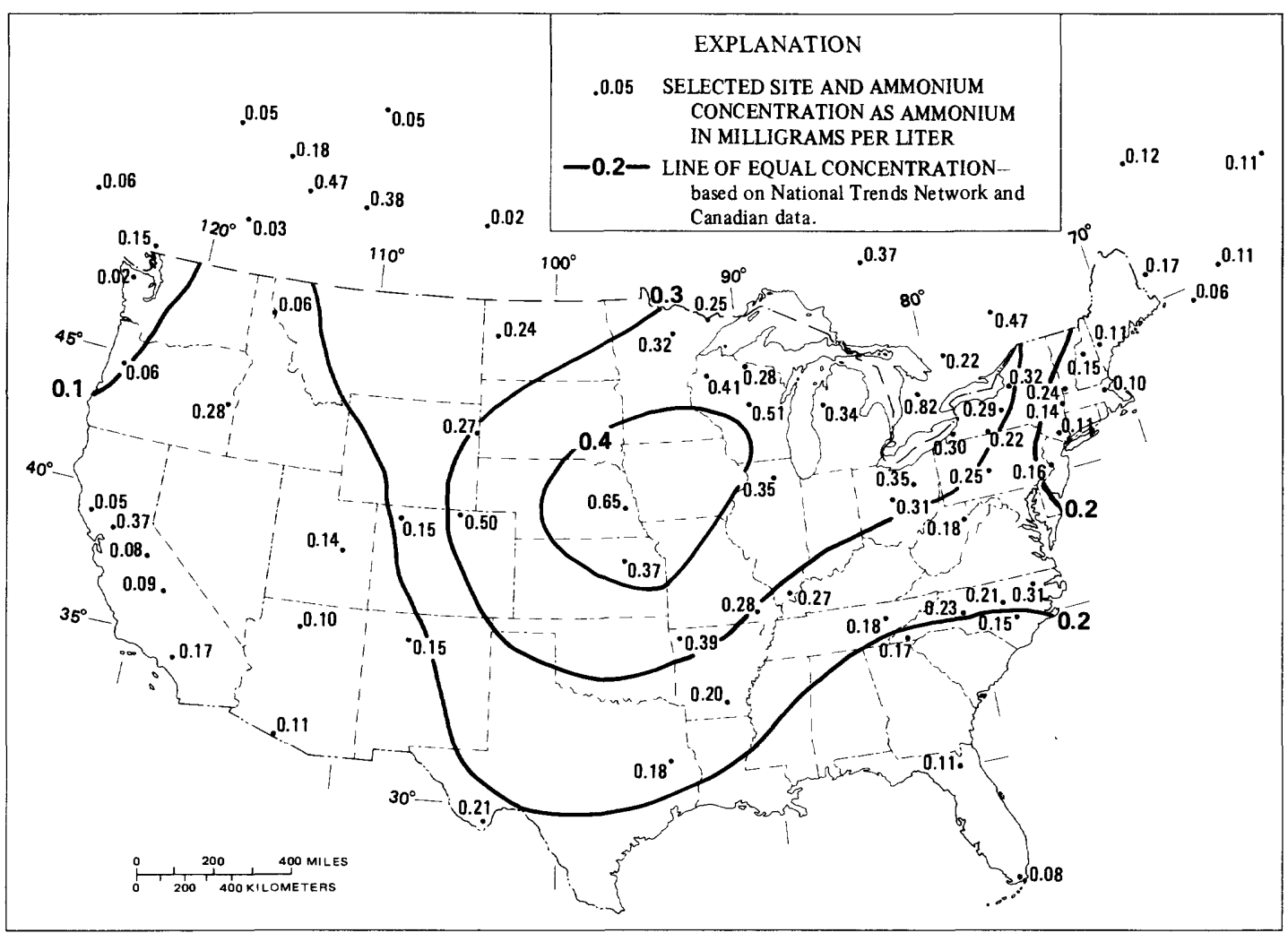

Figure 2f.--Volume-weighted constituent means in precipitation at National Trends Network sites and selected Canadian sites, 1983: Ammonium concentrations. 
(2) Sources of hydrogen ions (acid rain)

$$
\begin{aligned}
& \mathrm{HNO}_{3}=\underline{\mathrm{H}}^{+}+\mathrm{NO}_{3}{ }^{-} \\
& \mathrm{H}_{2} \mathrm{SO}_{4}=\underline{\mathrm{H}}^{+}+\mathrm{HSO}_{4}^{-} \\
& \mathrm{HSO}_{4}^{-}=\underline{\mathrm{H}}^{+}+\mathrm{SO}_{4}^{-2}
\end{aligned}
$$

(3) Neutralizing reactions

$$
\begin{aligned}
& \mathrm{OH}^{-}+\mathrm{H}^{+}=\mathrm{H}_{2} \mathrm{O} \text { (indirect) } \\
& \mathrm{NH}_{3}+\mathrm{H}^{+}=\mathrm{NH}_{4}^{+} \text {(direct) }
\end{aligned}
$$

If ammonia is neutralizing some of the acidity, then, in the absence of the ammonia source in the Great Lakes Region, the $\mathrm{pH}$ of the precipitation in that region would be lower. The location of the 0.4$\mathrm{mg} / \mathrm{L}$ line for ammonium suggests that livestock, dairy, and agricultural activities supply much of the ammonia available to the atmosphere in that area. Major livestock and dairy activities in the United States are contained within the area outlined by the $0.4-\mathrm{mg} / \mathrm{L}$ line (U.S. Geological Survey, 1970). In addition, major agricultural activities could account for the supply of ammonia in the North Central states, but the abundance of commercially fertilized lands in the Southeast is inconsistent with the small ammonia concentrations in that region. Junge (1958) pointed out that the small ammonia concentrations in precipitation are associated with areas that have low soil $\mathrm{pH}$, as in the Southeast. The loss of ammonia from soils starts at $\mathrm{pH}=6$, with no observable escape below this value (Junge, 1958). In near neutral or alkali soils, as those in North Dakota, South Dakota, Utah, Idaho, Colorado, New Mexico, and Wyoming (U.S. Department of Agriculture, 1957), ammonia concentrations are generally larger. Livestock, dairy, and agricultural activities account for the supply of ammonia, but one factor that controls the release of ammonia to the atmosphere is the $\mathrm{pH}$ of the soil.

Annual mean volume-weighted specific conductance values (fig. $2 \mathrm{~g}$ ) show a pattern similar to those for $\mathrm{pH}$, sulfate, and nitrate. Note that conductance lines do not show increases in the vicinity of either ocean, but instead seem to be most influenced by man's activities. Sodium concentrations ( $\mathrm{fig}$. 2h) show that ocean influence is dominant, as maximum concentrations are found along each coast. It is also notable that the smallest-valued line of equal concentration in the east $(0.1$ $\mathrm{mg} / \mathrm{L}$ ) encompasses an area with a relatively high usage of salt for road de-icing. The small sodium concentration in this area suggest that the NTN sites are in isolated areas, away from major roads and the potential effects of de-icing salts. Chloride concentrations (fig. 2i) have a pattern similar to the sodium pattern, but with a higher concentration gradient (in milligrams per liter). In terms of chemical equivalents per liter, the sodium and chloride gradients are quite similar.

Calcium-ion concentrations ( $f i g .2 j$ ) did not vary greatly across the United States, but a regional pattern was evident. The lines of equal calcium concenstration indicate that the largest concentrations occur in the plains states of the north-central United States. The larger calcium concentrations may be associated with wind-blown soils from this semi-arid region. 


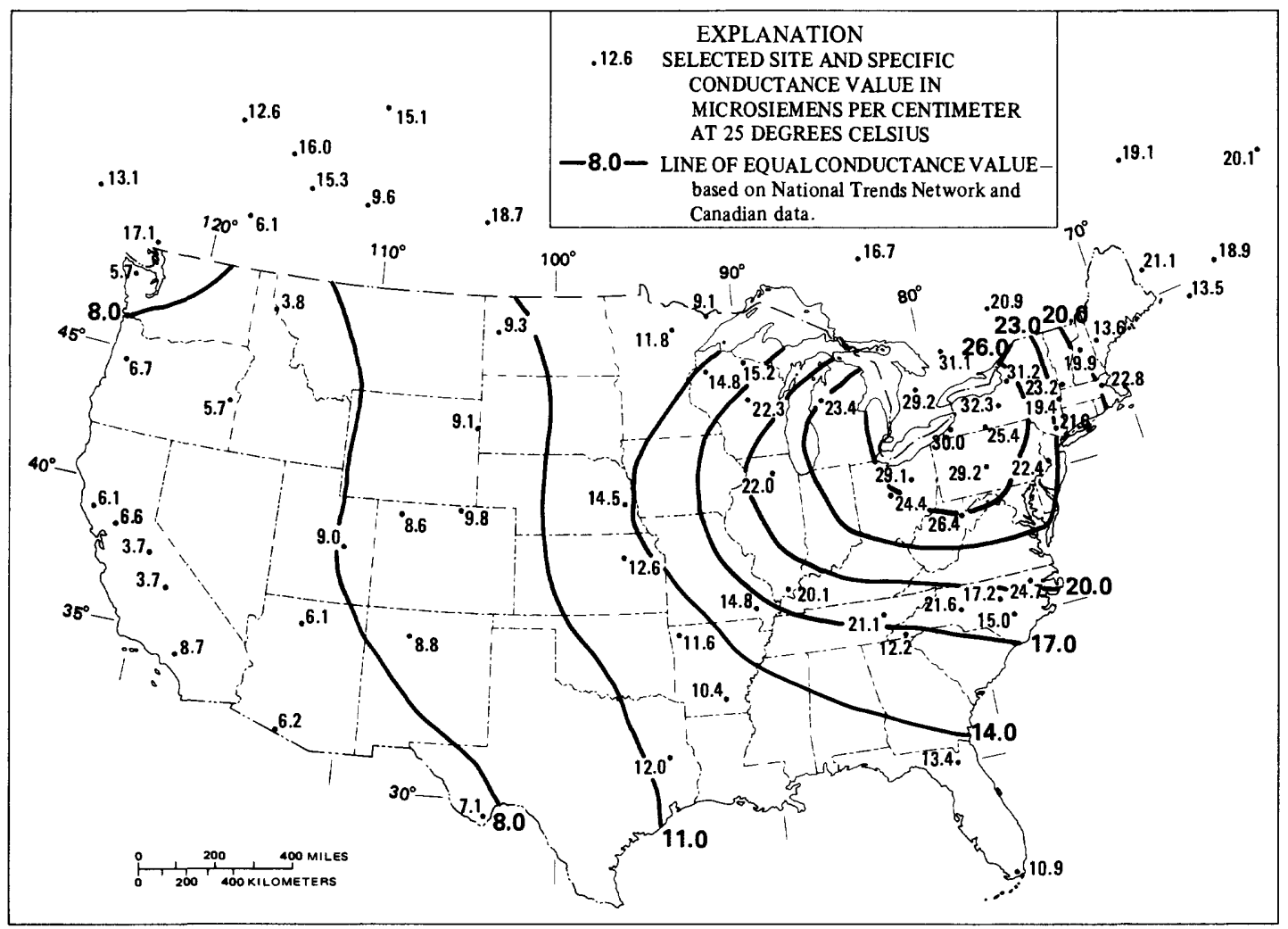

Figure 2g.--Volume-weighted constituent means in precipitation at National Trends Network sites and selected Canadian sites, 1983: Specific conductance values.

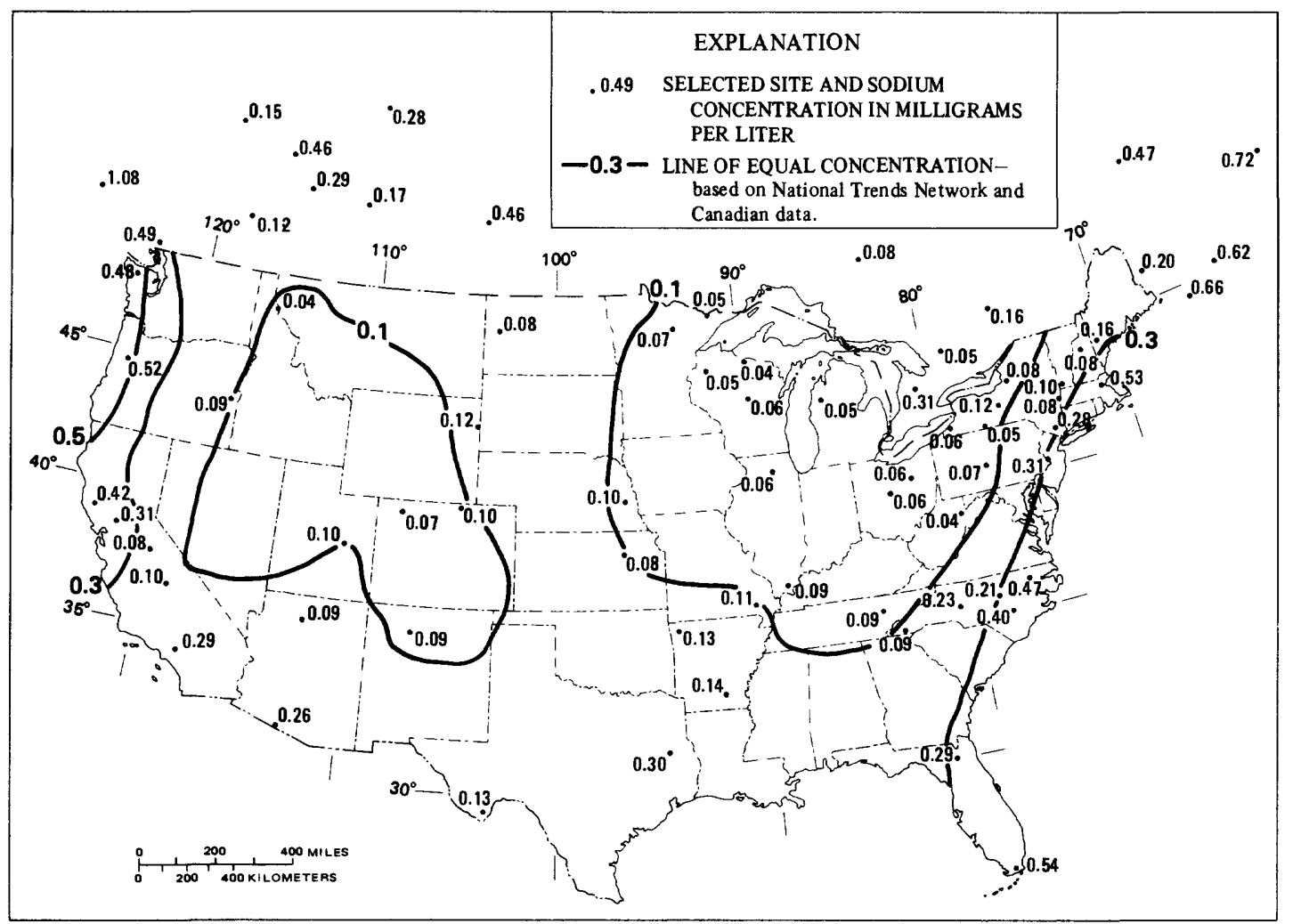

Figure 2h.--Volume-weighted constituent means in precipitation at National Trends Network sites and selected Canadian sites, 1983: Sodium concentrations. 


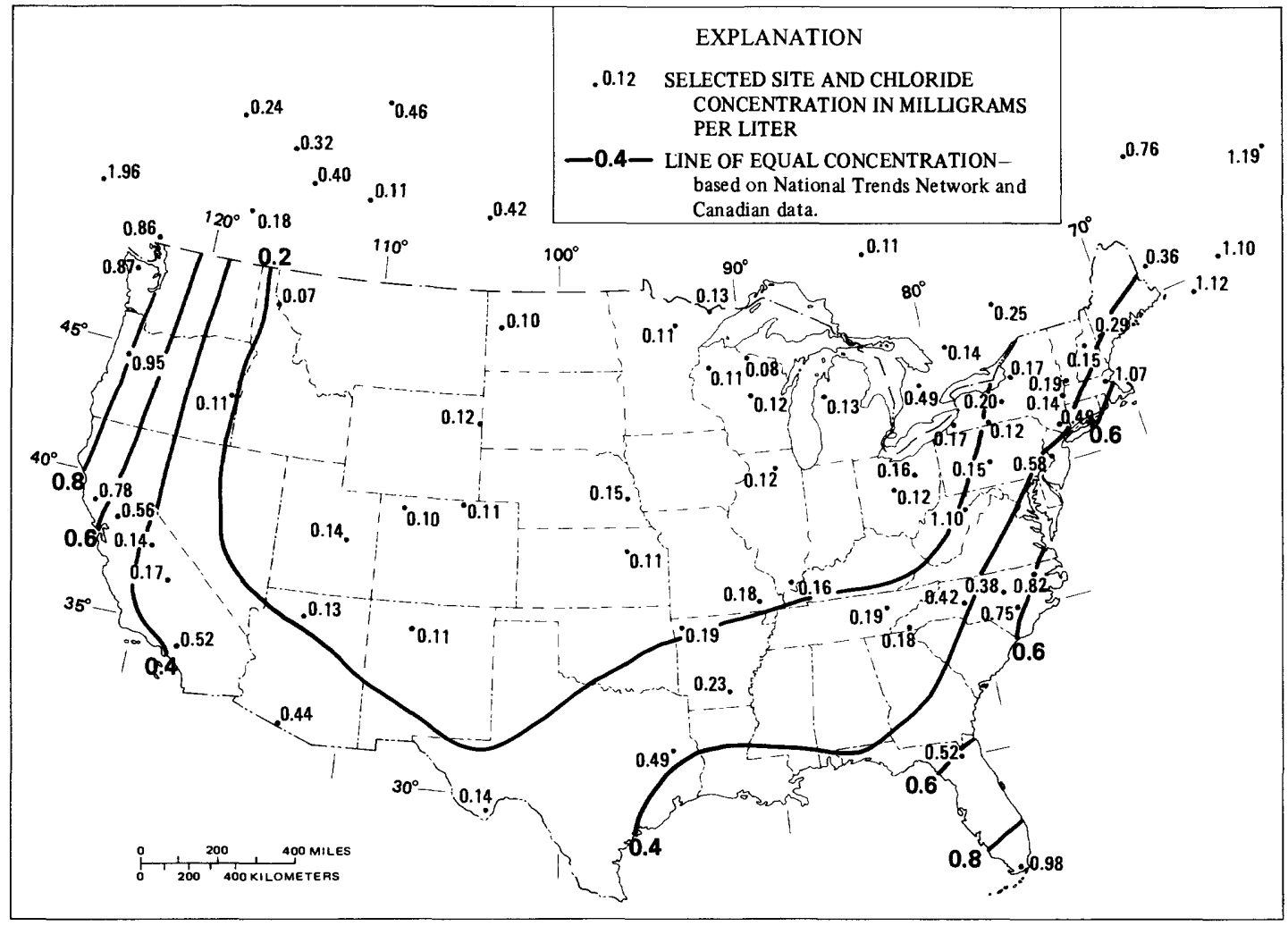

Figure 2i.--Volume-weighted constituent means in precipitation at National Trends Network sites and selected Canadian sites, 1983: Chloride concentrations.

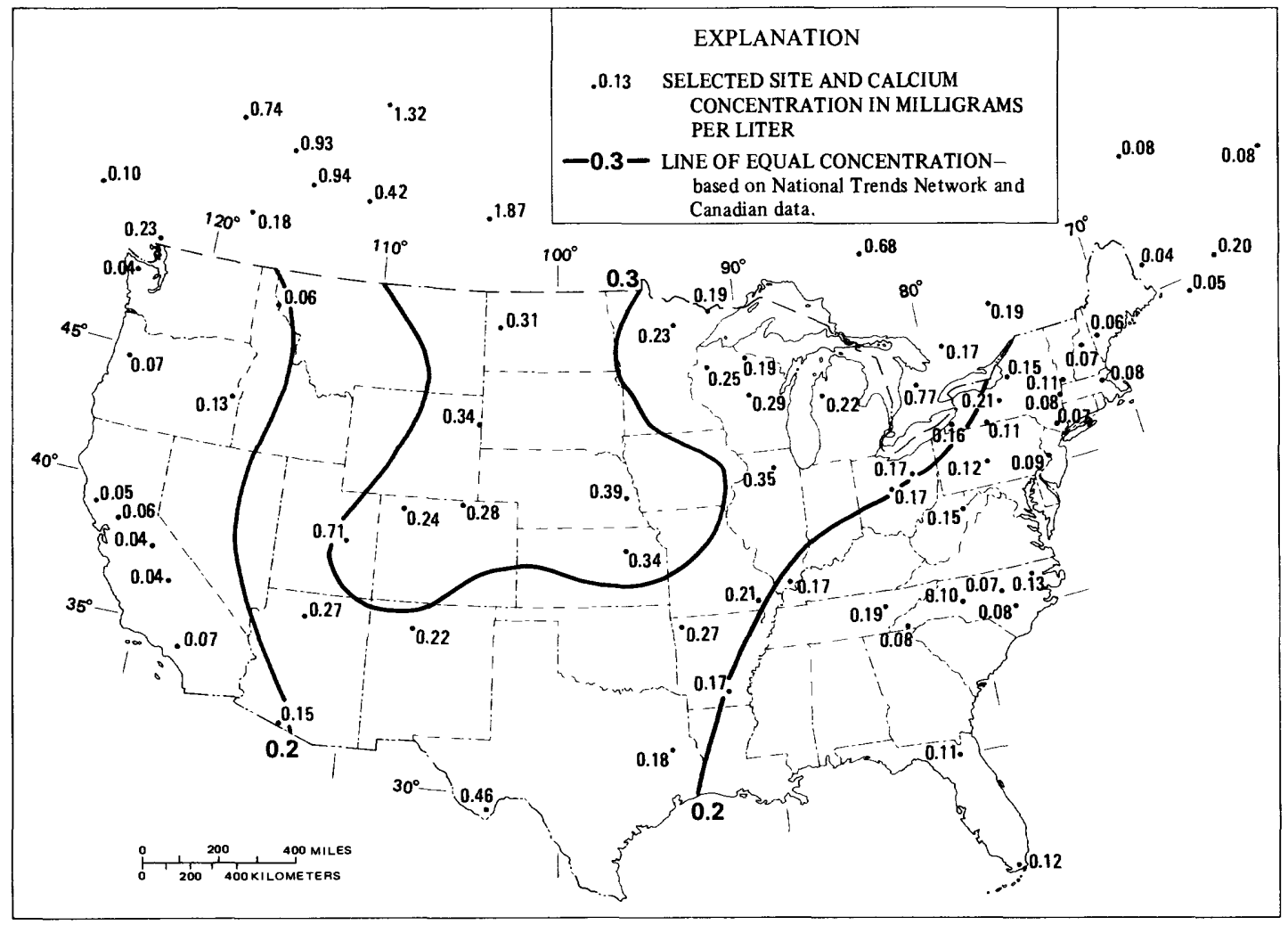

Figure 2j.--Volume-weighted constituent means in precipitation at National Trends Network sites and selected Canadian sites, 1983: Calcium concentrations. 
Constituent loading maps incorporate influences of both chemical concentrations and precipitation quantities. The loading patterns are different from the concentration patterns. Maximum hydrogen-ion loads are located east of the smallest $\mathrm{pH}$ values, reflecting increasing precipitation quantities at sites closer to the Atlantic Ocean (fig. 3a). Loads of hydrogen ion decrease from east to west across the country, but a slight increase in loading occurs around the population centers of the Pacific Northwest and southern California. However, loadings in these western coastal areas are almost an order of magnitude below the largest values in the east. A similar pattern is apparent for sulfate load (fig. $3 b$ ) and nitrate load (fig. 3c). The largest loads for $\mathrm{pH}$, sulfate, and nitrate encompass the same general geographic area. Loading for sulfate decreases from east to west, with a slight increase in the Pacific Northwest. Also, nitrate loads decrease from east to west, with a western coastal increase in southern California. Increased nitrate loading in that area is indicative of the large numbers of both people and cars. Both the sulfate- and nitrate-load maps show that the second largest line of equal concentration extends considerably to the west, encompassing many of the major industrial population centers of the eastern United States.

of the loads mapped, ammonium-ion loads differ from the other three previously discussed. The load map (fig. 3d) is quite similar to the ammonium-ion concentration map, with a slight shift to the east. One interesting difference between the concentration and load maps is that the loads are somewhat larger in the Pacific Southwest. Larger loads in the Pacific Southwest reflect a combination of intensive agricultural activities in California and increasing precipitation quantities near the ocean (U.S. Geological Survey, 1970).

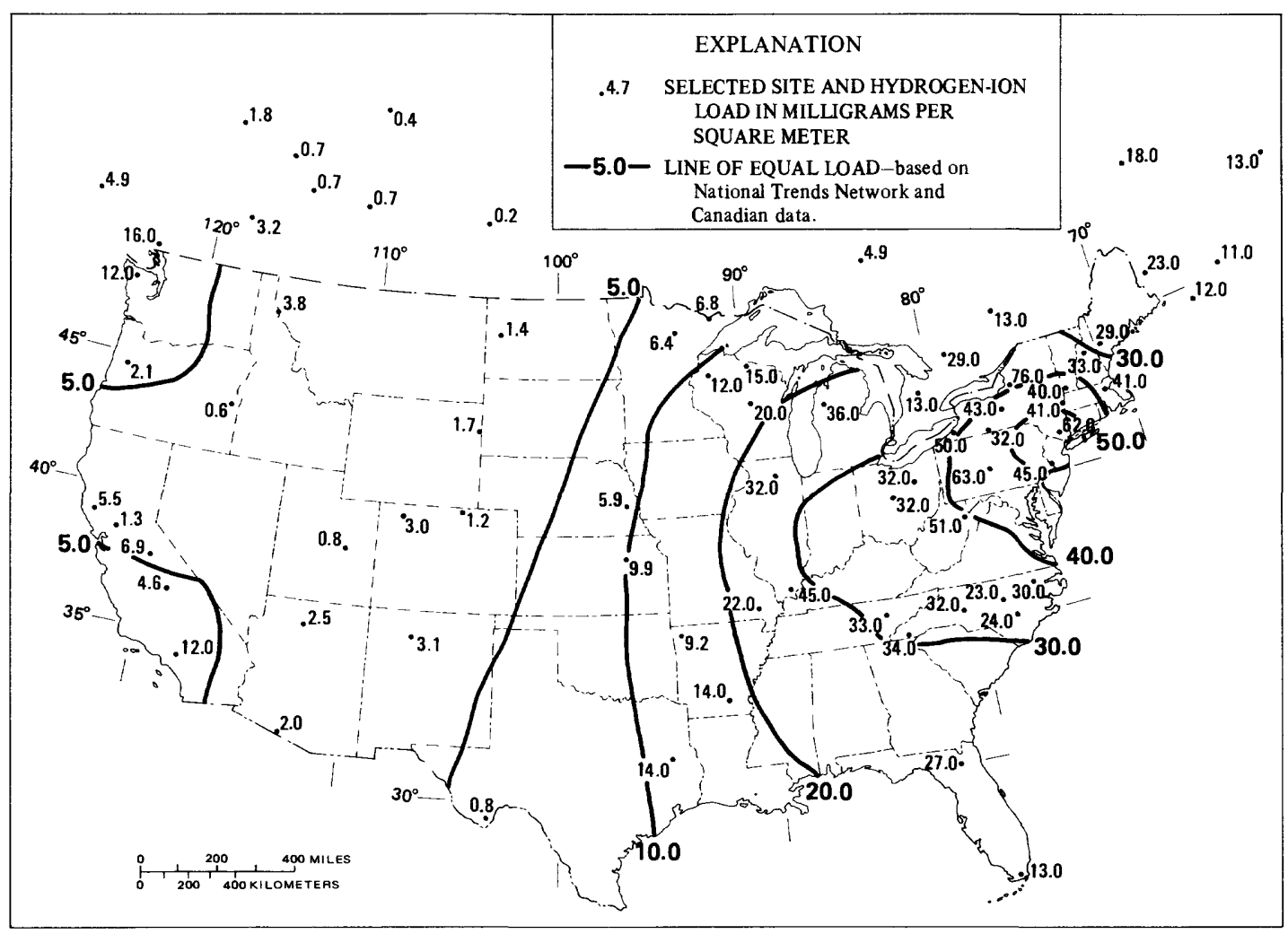

Figure 3a.--Annual constituent loads in precipitation, 1983: Hydrogen ion. 


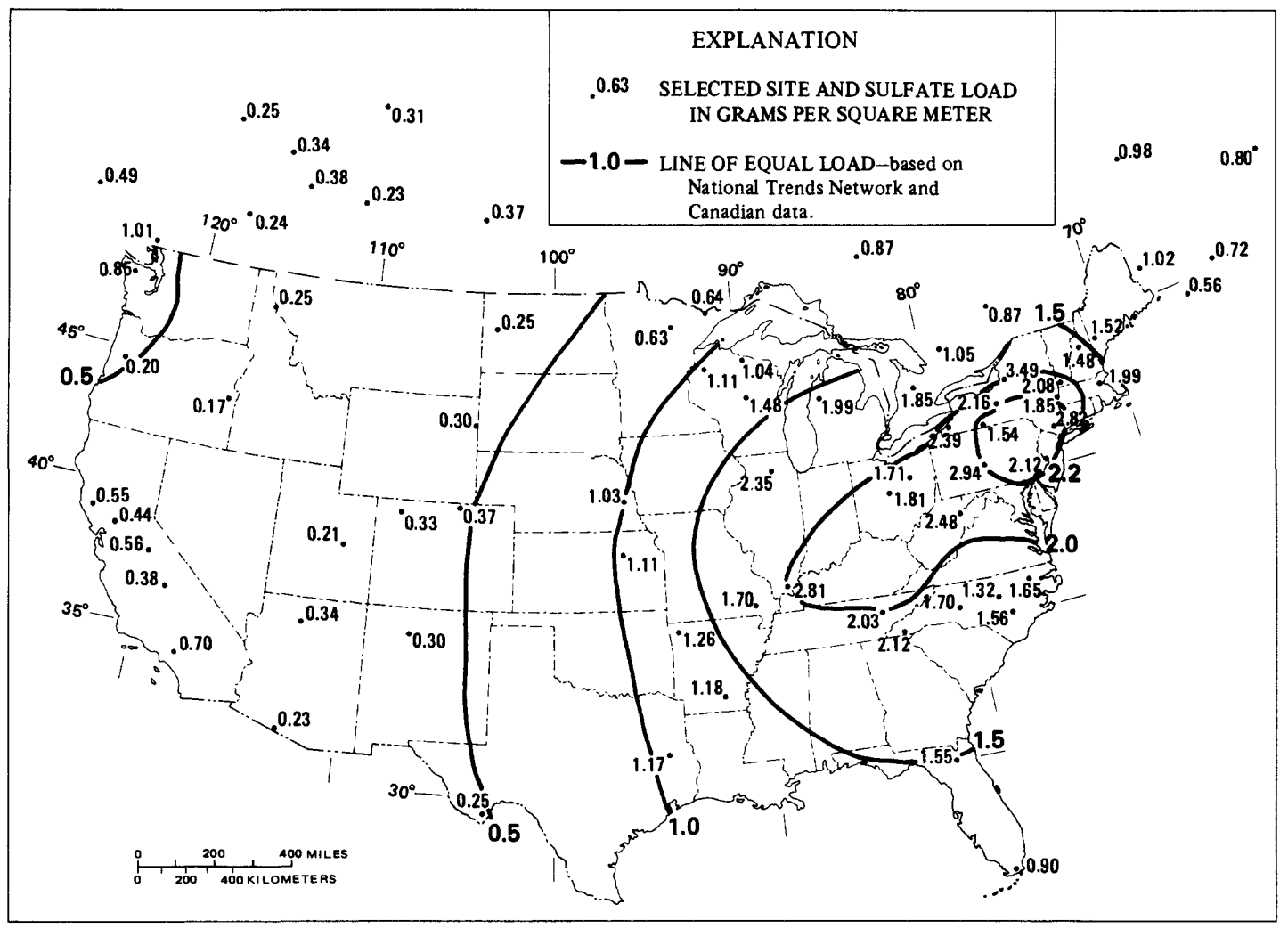

Figure 3b.--Annual constituent loads in precipitation, 1983: Sulfate.

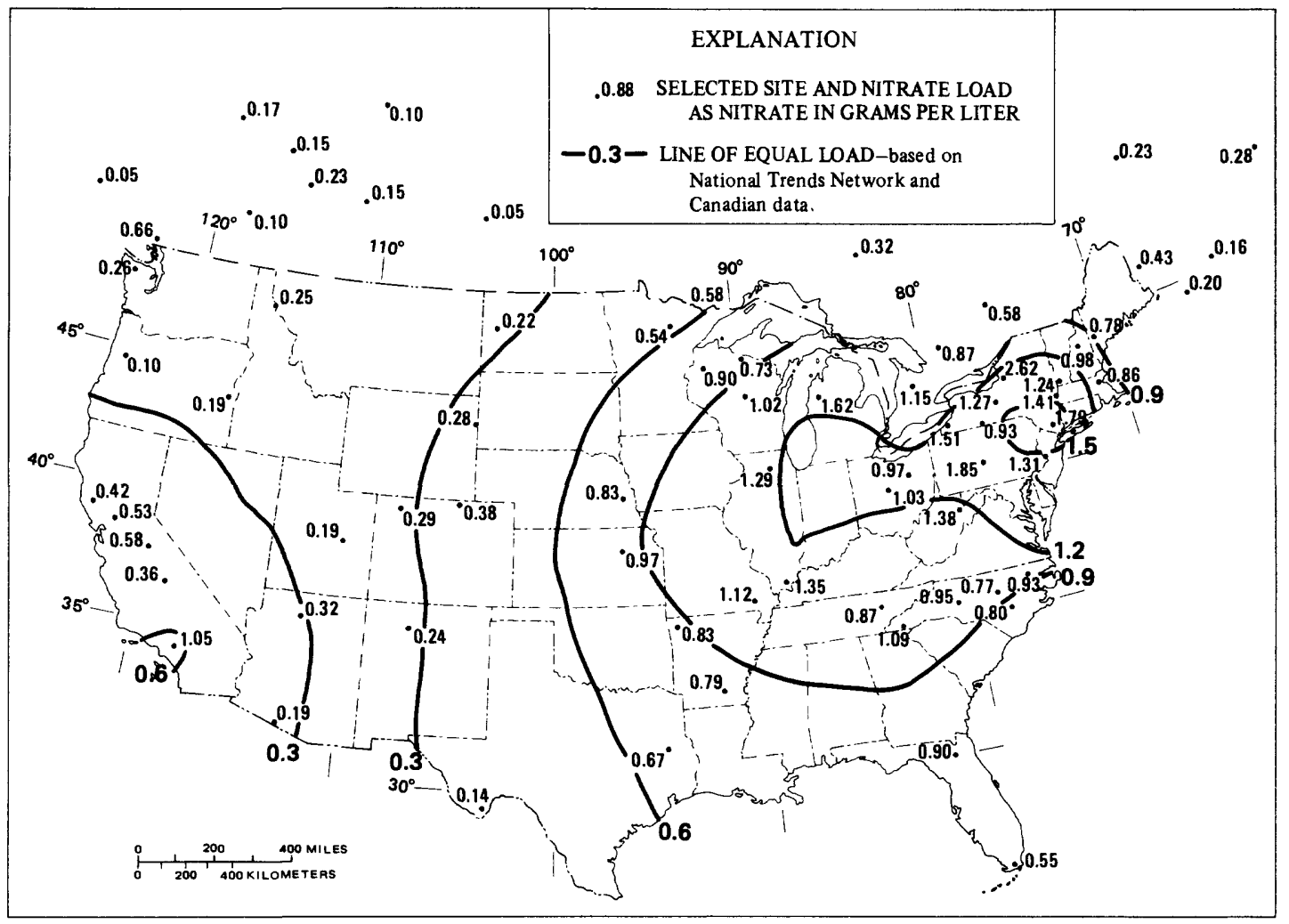

Figure 3c.--Annual constituent loads in precipitation, 1983: Nitrate. 


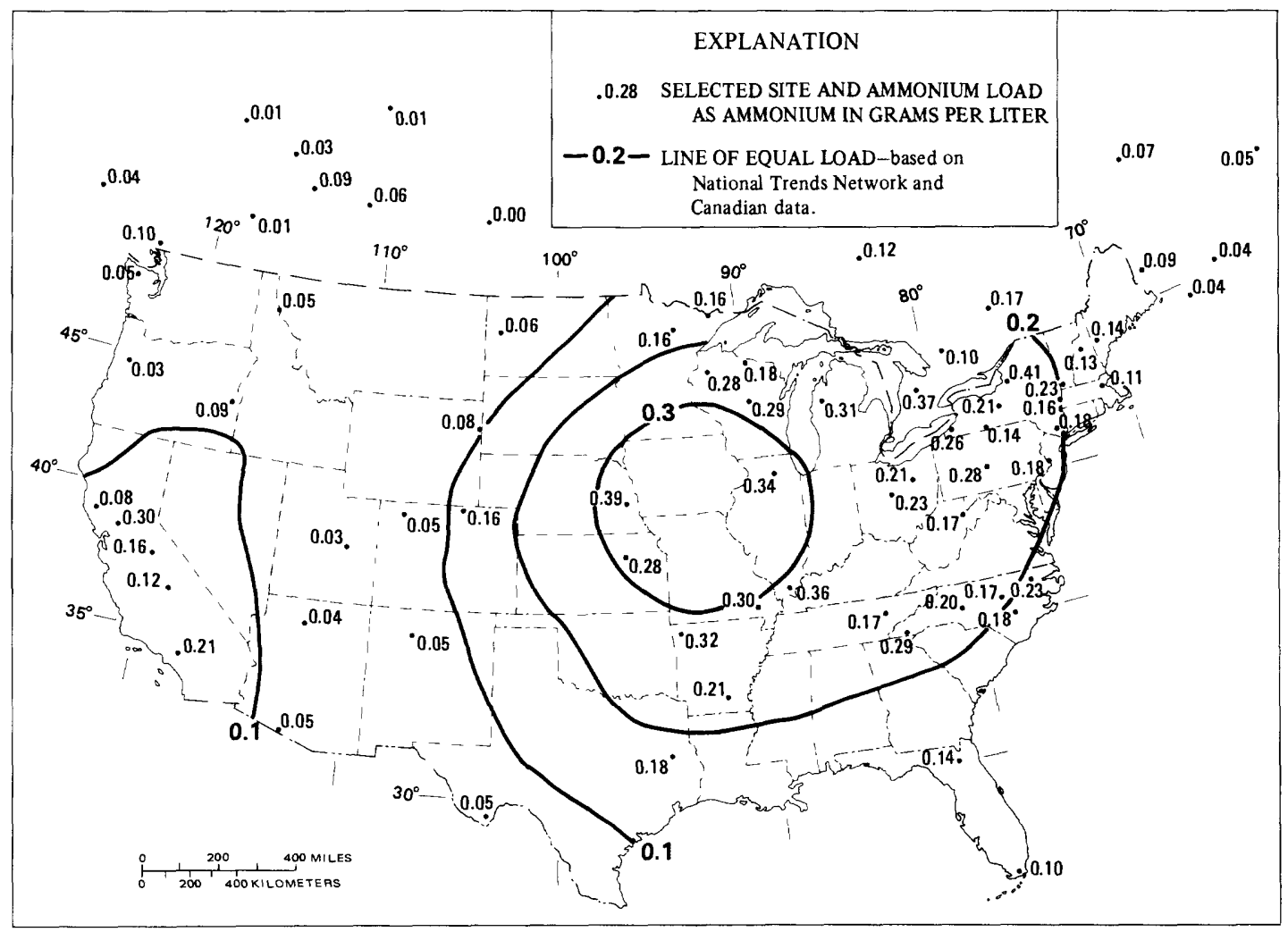

Figure 3d.--Annual constituent loads in precipitation, 1983: Ammonium.

\section{Selected Ionic Ratios}

Several maps were constructed to examine spatial distributions of selected ionic ratios. Ratios of annual mean volume-weighted sulfate to nitrate equivalents per liter were used to determine if areas exist where the predominance of these ions differ. The resulting map (fig. 4a) shows that in the eastern United States, where considerable fossil fuel containing larger concentrations of sulfur is used (U.S. Department of Energy, 1985), sulfate predominates and the ratio of sulfate to nitrate is greater than 2:1. In the western United States the ratio is lower than in the east; a large, semi-arid region extending from southern California to the Dakotas has ratios below 1.5:1. The only ratio below $1: 1$ is found near the dense southern California population center, where automobile traffic contributes significantly to oxides of nitrogen and where sulfur-dioxide emissions are closely regulated.

Ratios increase to greater than 2:1 in the Pacific Northwest, reflecting the contribution of sulfate from sea salts. Based on comparison of mean sulfate-to-chloride ratios in ocean water, those volume-weighted concentration ratios in 1983 NTN wet deposition, sea salts are found to account for 23 to 35 percent of the sulfate in wet deposition in Oregon and Washington. In the northeastern United States, the area with the largest sulfate concentrations, sea salts contribute less than 1 percent of the sulfate. 


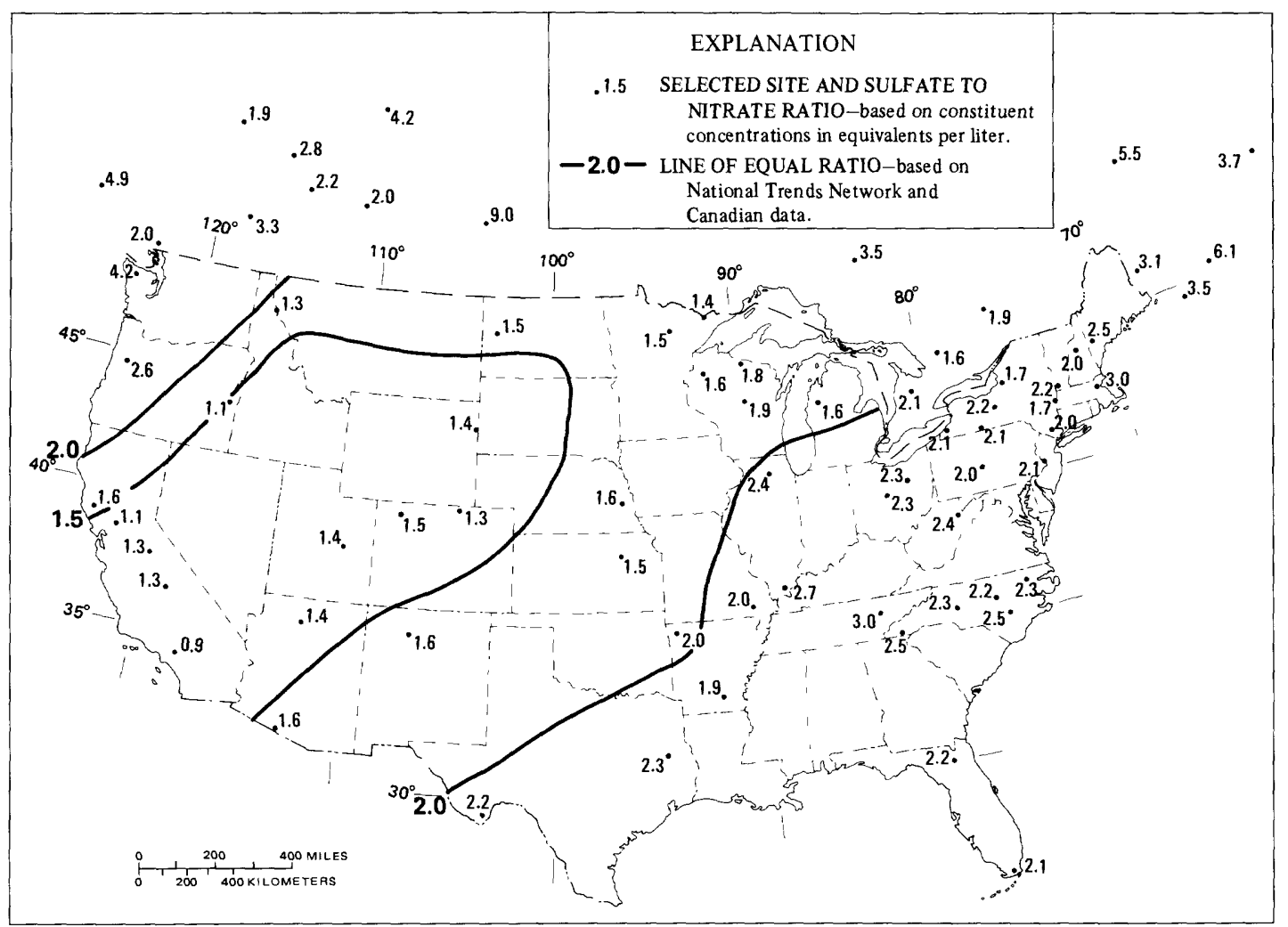

Figure 4a.--Volume-weighted ionic ratios in precipitation, 1983: Sulfate-to-nitrate values.

Another ratio of interest compares the sum of the sulfate and nitrate equivalents to the hydrogen-ion equivalents. Ratios are generally below $2: 1$ in the eastern United States, compared to ratios well above $2: 1$ elsewhere, (fig. 4b). The lower ratios indicate that large concentrations of sulfate and nitrate in the eastern United States may be primarily associated with hydrogen-ion concentrations. Sulfate and nitrate are often considered to be the principal acid-related ions in precipitation (U.S. Environmental Protection Agency, 1980). Ratios of sulfate-plus-nitrate equivalents to hydrogen plus ammonium plus calcium result in values generally near 1.0 , above $1: 1$ in the eastern United States and generally below $1: 1$ in those areas to the west previously identified as having large ammonium-ion and calcium concentrations (fig. 4c). In the plains states, some of the hydrogen ions may be neutralized by constituents such as ammonia or anions associated with calcium. Calcium-associated anions neutralize hydrogen ions, according to the reactions:

(1) Source of hydroxide ions

$\mathrm{CaO}$ (combustion product) $+\mathrm{H}_{2} \mathrm{O}=\mathrm{Ca}(\mathrm{OH})_{2}=\mathrm{Ca}^{+2}+2 \mathrm{OH}^{-}$

(2) Source of basic compounds

$$
\mathrm{Ca}(\mathrm{OH})_{2}+\mathrm{CO}_{2}=\mathrm{CaCO}_{3}+\mathrm{H}_{2} \mathrm{O}
$$$$
\mathrm{CaCO}_{3} \text { (in windblown soils) }+\mathrm{H}_{2} \mathrm{O}+\mathrm{CO}_{3}=\mathrm{Ca}\left(\mathrm{HCO}_{3}\right)_{2}=\mathrm{Ca}^{+2}+2 \mathrm{HCO}_{3}{ }^{-}
$$

(3) Neutralizing reactions

$$
\begin{aligned}
& \mathrm{OH}^{-}+\mathrm{H}^{+}=\mathrm{H}_{2} \mathrm{O} \\
& \mathrm{HCO}_{3}{ }^{-}+\mathrm{H}^{+}=\mathrm{H}_{2} \mathrm{CO}_{3}
\end{aligned}
$$




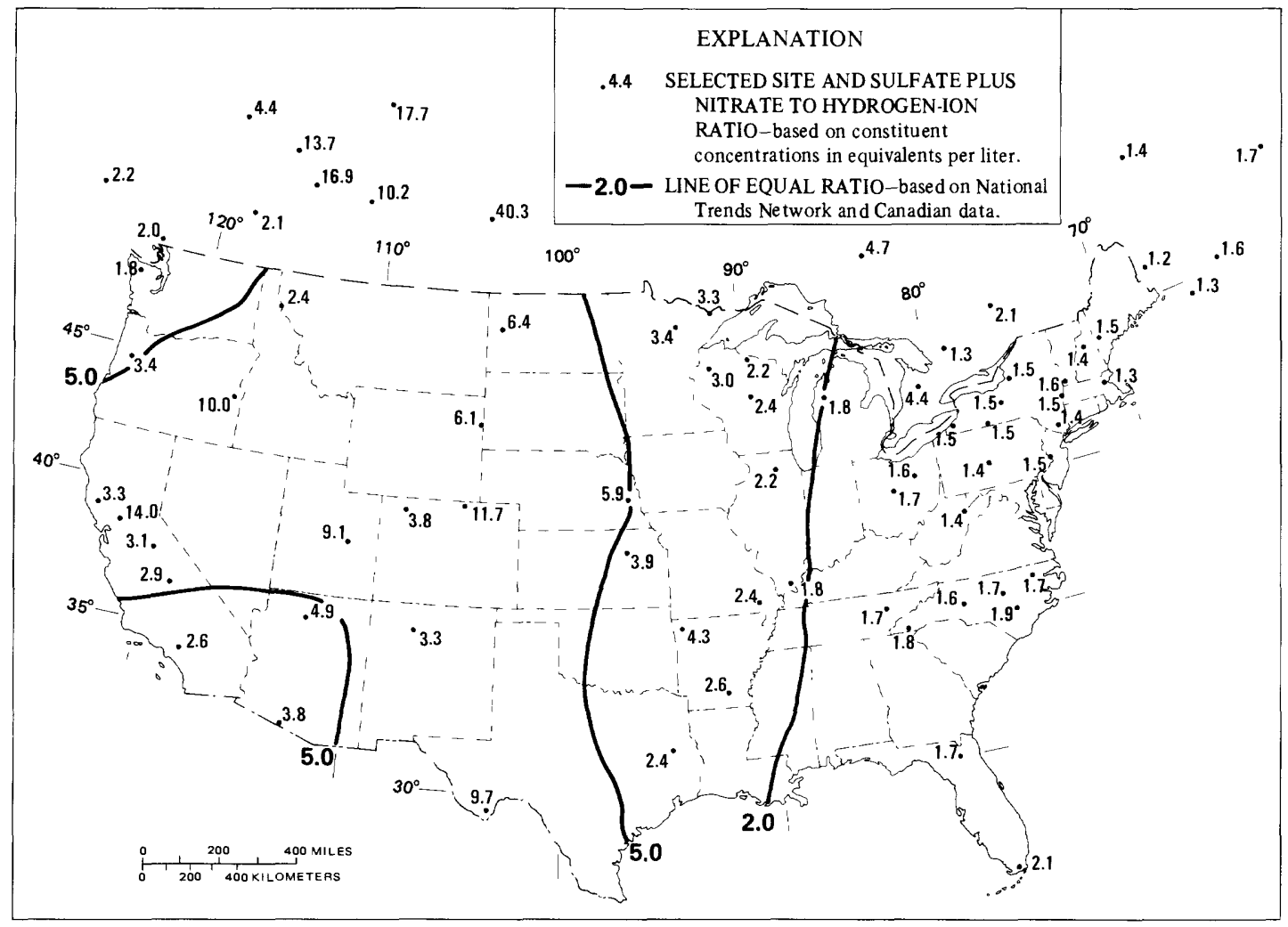

Figure 4b.--Volume-weighted ionic ratios in precipitation, 1983: Sulfate-plus-nitrate to hydrogen-ion values.

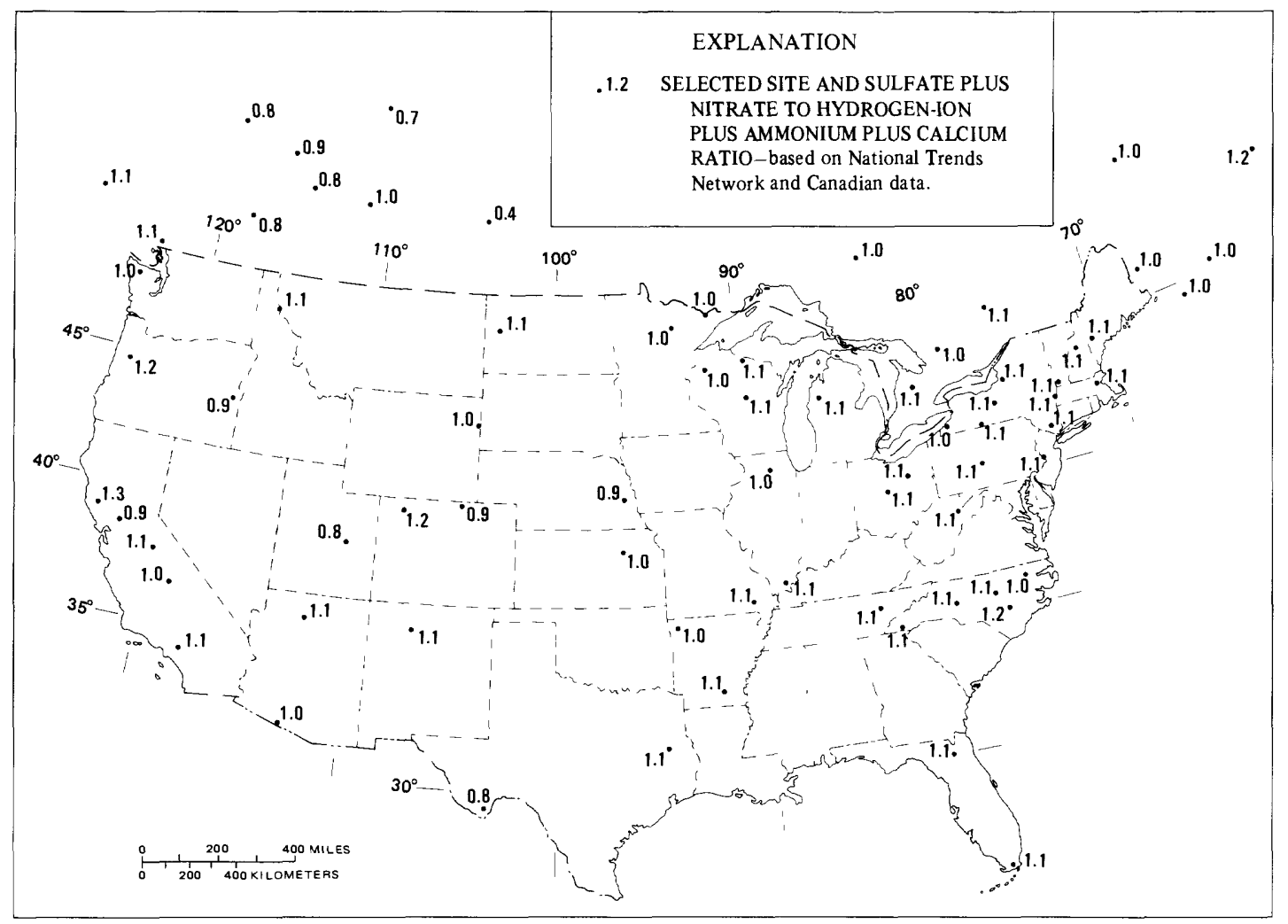

Figure 4c.--Volume-weighted ionic ratios in precipitation, 1983: Sulfate-plus-nitrate to hydrogen-ion-plus-ammonium-plus-calcium values. 


\title{
Sensitivity of Kriging Analysis
}

Although a detailed sensitivity analysis was not done, the following observations were made during the analysis.

(1) Increasing the number of observation points above the eight used per neighborhood tended to result in smoother lines, but the general pattern did not change. Considering that some uncertainty surrounds each line, the smoothing that results from using more observation points is not significant.

(2) Selecting different mathematical forms for the semi-variogram did not significantly change patterns and locations of contours. These results were not surprising, because many of the different

functional forms for the semi-variogram are quite similar for short distances. Results from different semi-variogram forms may appear quite similar, because Kriging procedures use a neighborhood of several points close to the location to be estimated, and the procedures give more weight to the closest points.

(3) A single observation point with a value considerably different from the surrounding observation points does have a noticeable effect on lines near that point. One Canadian site was not included in Kriging procedures for several constituents because it was very different from surrounding sites and caused an increase in the mapping gradient that was inconsistent with observed United States data. Because ancillary data were not readily available to support the relatively large concentrations at that site, the observed data from the Canadian site were not used.

(4) Because the CANSAP site protocol was different from the NTN site protocol and allowed CANSAP sites to be located near airports and cities, the effect on creating lines using only the 55 NTN sites was examined for $\mathrm{pH}$ values (fig. 5). Although differences between western CANSAP and western NTN data were notable, the CANSAP data did not have much apparent effect on lines in the United States. Only the $5.3-\mathrm{pH}$ lines changed noticeably, and those changes were not large enough to alter previous interpretations regarding $\mathrm{pH}$ values. Thus, even though CANSAP data may appear different from NTN data and even though the sites are located under different protocols, this inclusion of Canadian data does not significantly alter the Kriged lines in the United States.

\author{
REGIONAL DISTRIBUTION AND VARIABILITY OF \\ PRECIPITATION-CHEMISTRY DATA BY CHEMICAL GROUP
}

Regionalization of data is a process in which data from a large geographic area are partitioned into categories that represent smaller homogeneous geographic areas known as regions. The homogeneity of each region is based on preselected variables that exhibit much less variability within a region than they do between regions, making each region distinct. Variables selected for regionalization provide insight into the structure of the data so that causes may be related to the resultant measured values. In the previous section, each map was a regionalization of a single variable, with emphasis placed on one value, either annual mean volume-weighted concentration values or annual loads. 


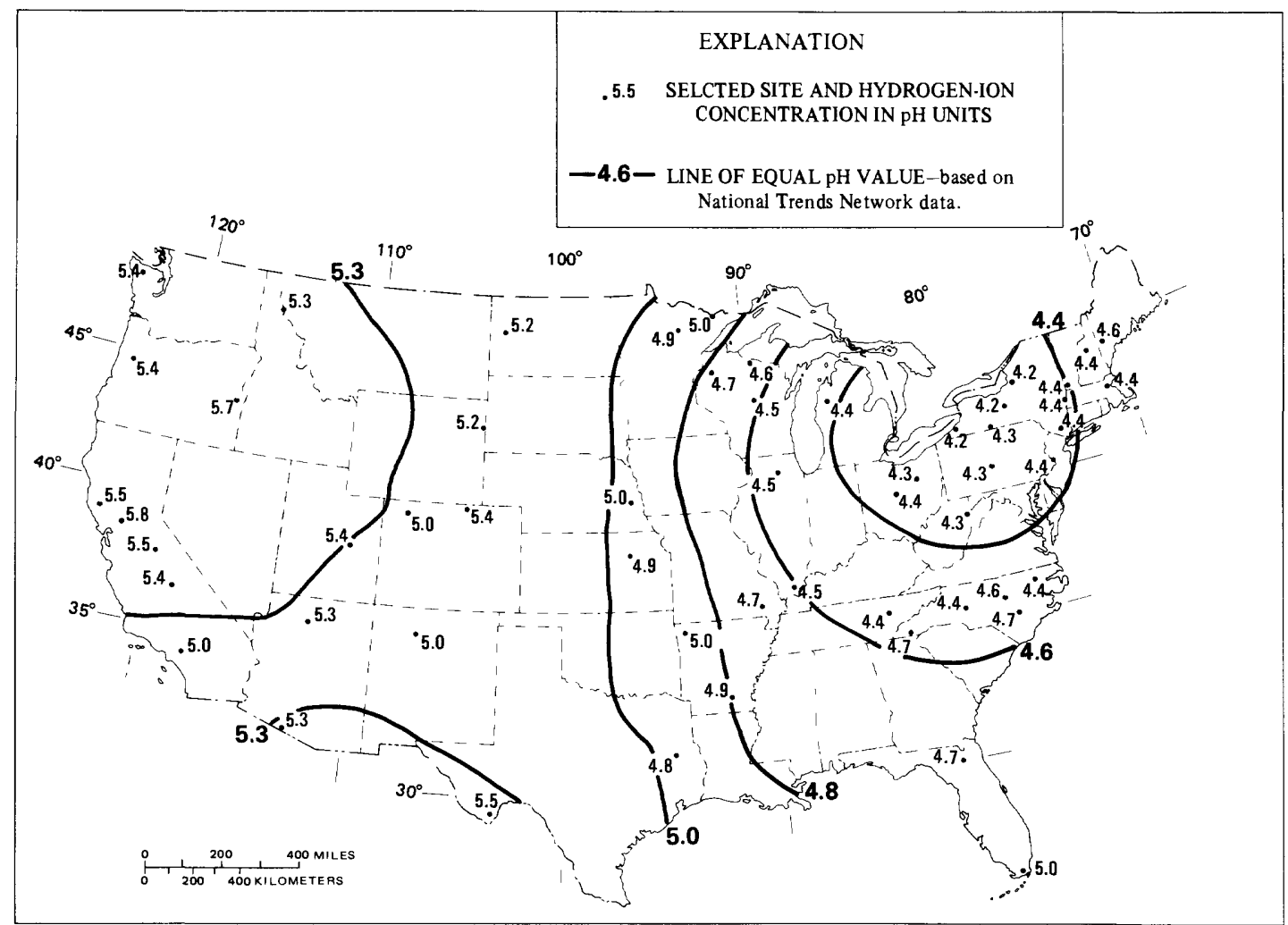

Figure 5.--Lines of equal volume-weighted hydrogen-ion concentrations in precipitation at National Trends Network sites, 1983.

Regions were identified by drawing lines of equal concentration that indicate geographic areas of similar values for a single variable. A broader, more generalized approach to regionalization, that employs numerous variables from each site simultaneously, is examined in this section of the report. Ratios of ionic equivalent concentrations are used to provide a chemical fingerprint for each site, assuming that the fingerprints are similar in areas where regional influences on the chemical composition are similar. CANSAP data were not included in this regional analysis.

\section{Chemical Grouping Techniques}

\section{Graphical Procedures Using Trilinear Diagrams}

Trilinear diagrams (Hem, 1985) were used as an effective visual aid for comparing data from different sites and for grouping the precipitation analyses into chemically similar groups. These diagrams show the concentrations of major dissolved ions reported in percentage of total equivalents per liter of cations $\left(\mathrm{H}, \mathrm{NH}_{4}, \mathrm{Ca}, \mathrm{Mg}, \mathrm{Na}\right.$, and $\mathrm{K}$ ) or anions $\left(\mathrm{SO}_{4}, \mathrm{NO}_{3}\right.$, and $\left.\mathrm{Cl}\right)$. Diagrams for each site are shown in Appendices II and III.

For a specific weekly analysis, an increase in the chemical concentration of just one cation or anion will change the total equivalents per liter of the cations or anions; consequently, the percentages of all other cations or anions for that sample will also change. For example, large sodium concentrations from sea salts will increase the total cation concentration (equivalents per liter), resulting in sodium percentage increases and corresponding decreases in other cation percentages (even though the other cation concentrations did not decrease). Caution should therefore be exercised in interpreting triliear plots, because the plots depict percentages and not concentrations. 
Concern regarding the subjectivity of the graphical procedures led to the use of two mathematical procedures to cluster the precipitation data. The two clustering procedures were (1) Ward's method and (2) average linkage on squared Euclidean distances. Ward's method is biased toward producing clusters with small and roughly the same number of observations, whereas the average linkage method is biased toward producing clusters with small and roughly the same variance (SAS, 1982). Both of these procedures have been commonly used in many studies (SAS Institute, 1982). Variables used in the cluster analysis were the median values of:

hydrogen, ammonium, and calcium, as a percentage of the total cations; and sulfate and nitrate, as a percentage of the total anions. The inclusion of ammonium and calcium ions is based on their importance in balancing ionic equivalents of the acid-related species, sulfate and nitrate.

\section{Results of Analyses}

Site data were classified into six different chemical groups, on the basis of concentrations of the hydrogen ion and sulfate-plus-nitrate ions in the weekly precipitation samples (table 3 ). Areas of the trilinear diagrams used to identity different chemical groups are shown in figure 6 . Chemical groups tended to cluster into separate geographic areas throughout the United States (fig. 7). These groups are group 1 in the northeast, group 2 just west of group 1 sites, groups 3 and 4 in the midsection of the United States, group 5 along the eastern coast, and group 6 along the western coast.

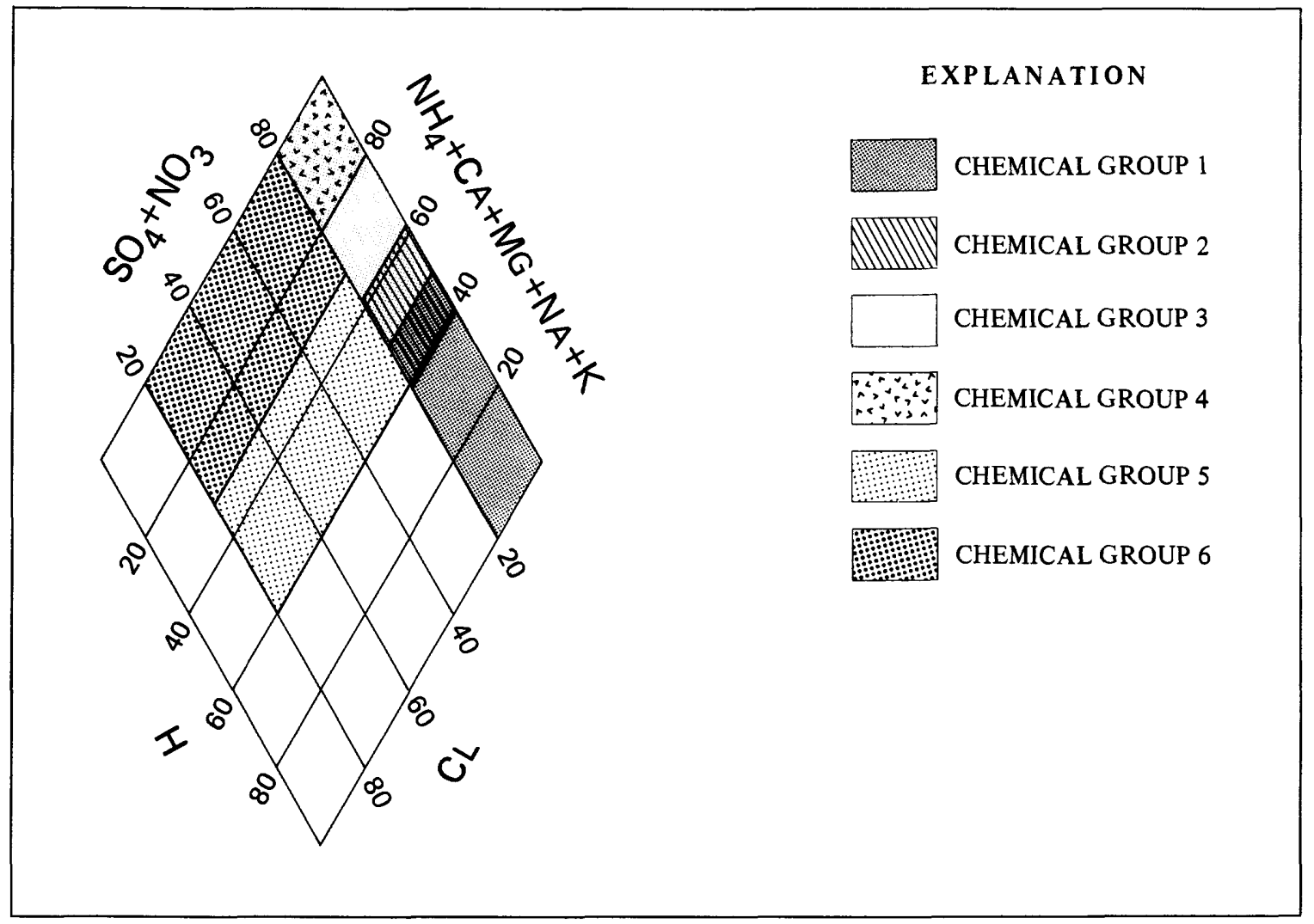

Figure 6.--Ionic percentages used to delineate National Trends Network precipitation into chemical groups. 
Table 3.-- Selected precipitation-chemistry composition based on weekly concentrations, by chemical group, January through December, 1983

[Example: for group 1, 50 percent of the analyses had hydrogen-ion compositions less than or equal to 62 percent of the total equivalents of cations]

\begin{tabular}{|c|c|c|c|c|c|c|}
\hline \multirow{2}{*}{$\begin{array}{c}\text { Chemical } \\
\text { group }\end{array}$} & \multicolumn{3}{|c|}{$\begin{array}{c}\text { Hydrogen, in } \\
\text { percent of total } \\
\text { equivalents of cations }\end{array}$} & \multicolumn{3}{|c|}{$\begin{array}{l}\text { Sulfate plus nitrate, } \\
\text { in percent of total } \\
\text { equivalents of anions }\end{array}$} \\
\hline & 10 & 50 & 90 & 10 & 50 & 90 \\
\hline 1 & 32 & 62 & 78 & 82 & 94 & 97 \\
\hline 2 & 13 & 51 & 72 & 86 & 95 & 97 \\
\hline 3 & 1 & 23 & 55 & 79 & 91 & 97 \\
\hline 4 & 1 & 3 & 22 & 80 & 90 & 96 \\
\hline 5 & 8 & 36 & 68 & 39 & 73 & 94 \\
\hline 6 & 2 & 14 & 42 & 22 & 64 & 90 \\
\hline
\end{tabular}

Results of the clustering procedures generally were similar to the results obtained using trilinear diagrams. Both Ward's method and the average linkage method indicated similarity between groups 1 and 2, as did the trilinear plots. The western and eastern coastal sites clustered into separate groups. In a few instances, some western coastal sites (as defined by the trilinear plots) were clustered with group 3 or group 4 sites; some eastern coastal sites were clustered with group 1 sites; and some group 3 sites clustered with group 4 sites. Thus, although a few sites were placed in geographically adjacent regions using the mathematical procedures, the different cluster techniques generally support the patterns found using the trilinear diagrams .

Chemical groups 1 through 4 differ primarily in hydrogen-ion percentage, with group 1 having the largest percentage and group 4 having the smallest percentage (table 3 ). Group 2 has hydrogen-ion percentages intermediate between group 1 and 3 ; group 2 sites are located in a transitional area between groups 1 and 3 . Both coastal groups appear to be ocean-influenced, with resulting increases in the chloride percentage accounting for observed decreases in the sulfateplus-nitrate percentage. Sodium percentages also increase at the coastal sites with corresponding decreases in the hydrogen-ion percentage. The western coastal group has a hydrogen-ion percentage noticeably smaller than that of the eastern coastal group; precipitation along the eastern coast may reflect influences of downwind effects of sources in proximity to group 1 sites. 


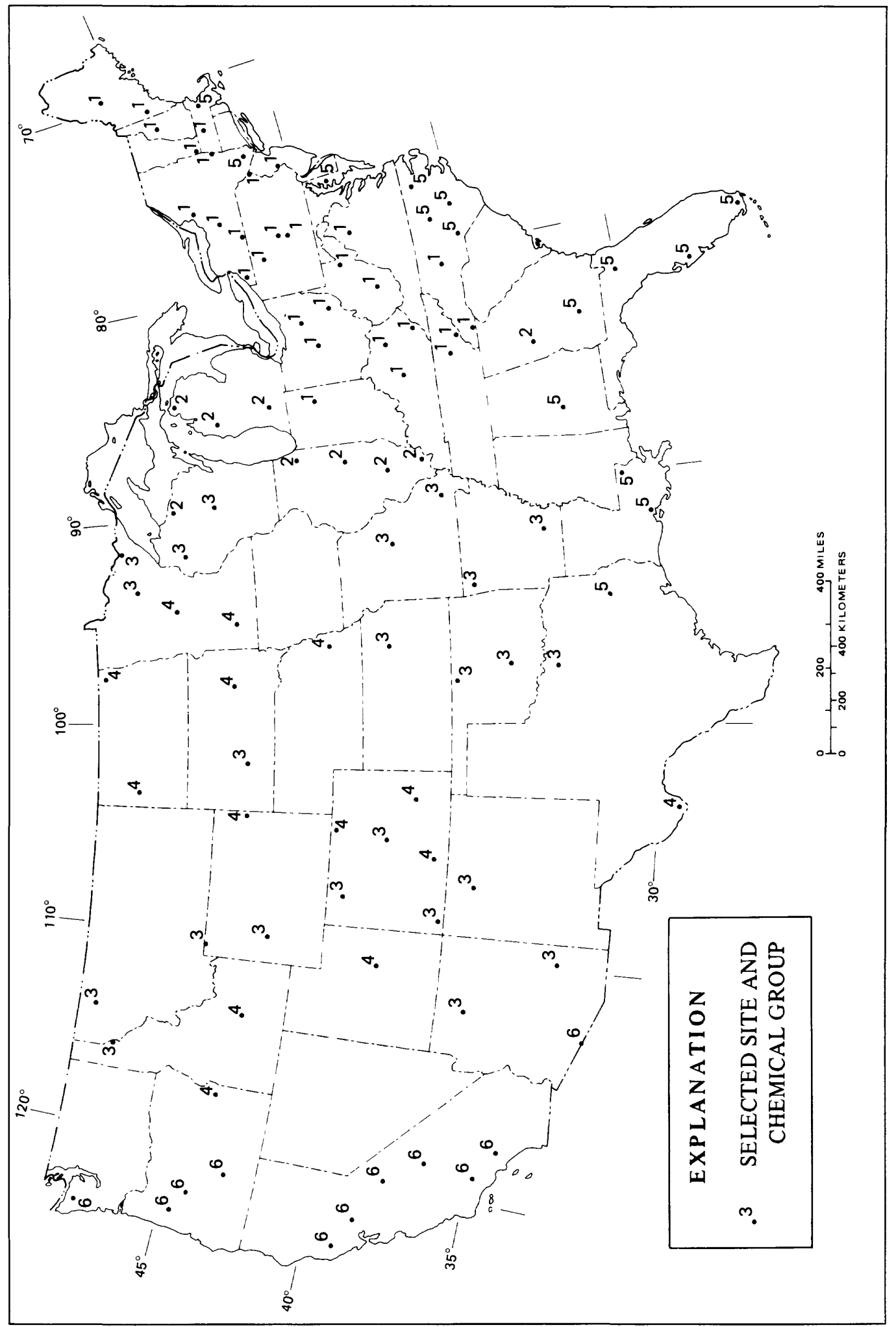

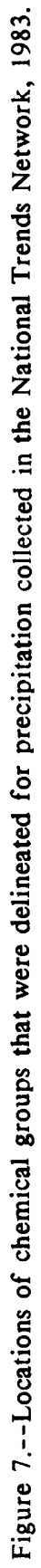




\section{Annual comparisons}

Annual mean volume-weighted chemical concentrations that were used for the Kriged maps (figs. $2 a$ through $2 j$ ) subsequently were used to compute annual mean ionic percentages. Each site was assigned (using weekly values) to the groups previously defined using the trilinear diagrams. Groupings of annual values tended to minimize some of the variability observed in the weekly precipitation data (fig. 8). Results of these calculations are shown in table 4, and implications of the results are discussed below.

Group 6 to group 4 sites --

From group 6 (west coastal sites) to group 4 sites, the ion percentages of ammonium, sulfate, and nitrate increased; hydrogen and chloride decreased. Decreases in chloride percentage correspond to increasing distances from the ocean. An increase in ammonium percentage could chemically influence the hydrogenion percentage because ammonia or ammonium-hydroxide released to the atmosphere will react with the hydrogen ion, reducing acidity and causing a reduction in the hydrogen-ion percentage.

Therefore, increases in hydrogen ion associated with increases in sulfate and nitrate may be counteracted by increases in ammonia release. Soils at group 4 sites are drier and basic. At these group 4 sites more windblown soil particulates may be in the sample and neutralizing the hydrogen ion.

Group 4 to group 3 sites --

The quality of precipitation at these sites is comparable, except for the notable increases in the hydrogen-ion percentage from group 4 to group 3 sites. Slight increases in sulfate percentage may be associated with the hydrogen-ion percentage increases. Slight decreases in the ammonium-ion percentage may be associated with the hydrogen-ion percentage increases.

Group 3 to group 2 sites --

Group 2 and group 3 sites have similar percentages of ammonium, sulfate, and nitrate except that group 2 sites generally have larger hydrogen-ion percentages.

Group 2 to group 1 sites --

Group 1 sites have larger hydrogen-ion percentages, that may be partly related to the smaller ammonium-ion percentages at group 1 sites; that is, less ammonia or ammonium hydroxide is available to neutralize acidity (by reacting with hydrogen ions).

Group 1 to group 5 sites -

Group 5 sites have smaller percentages of hydrogen ion, sulfate, and nitrate. Larger percentages of chloride at the coastal sites probably are the result of the close proximity of these sites to the Atlantic Ocean. 


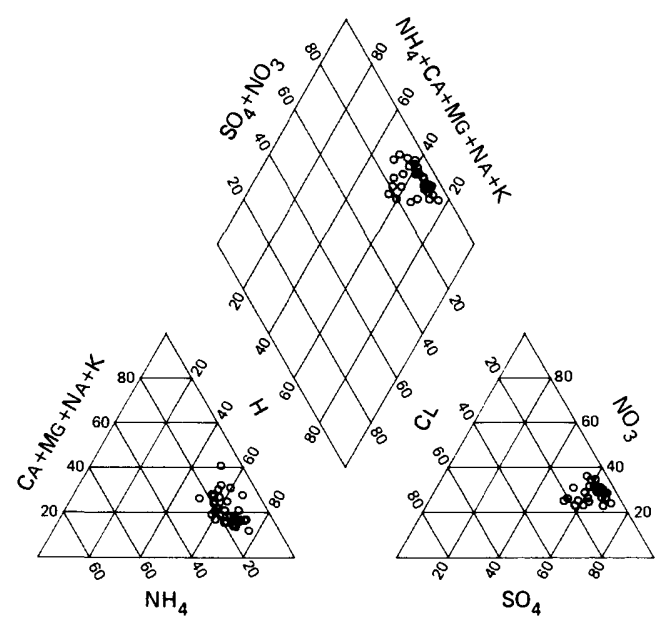

CHEMICAL GROUP 1

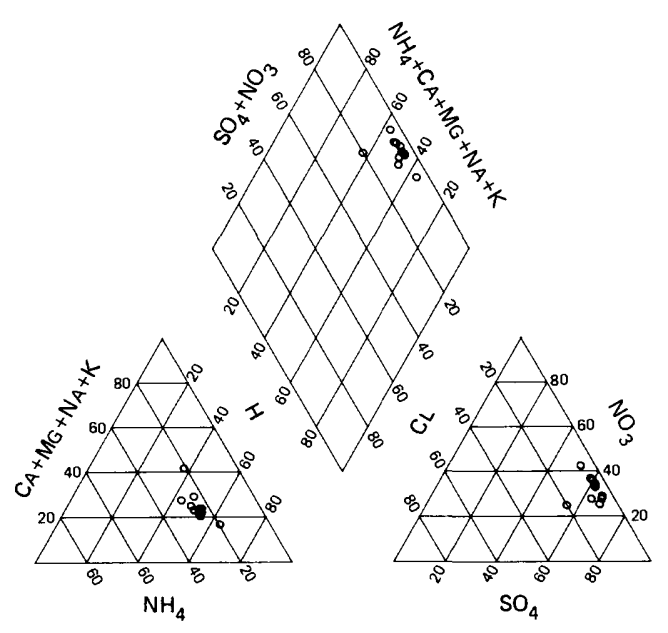

CHEMICAL GROUP 2

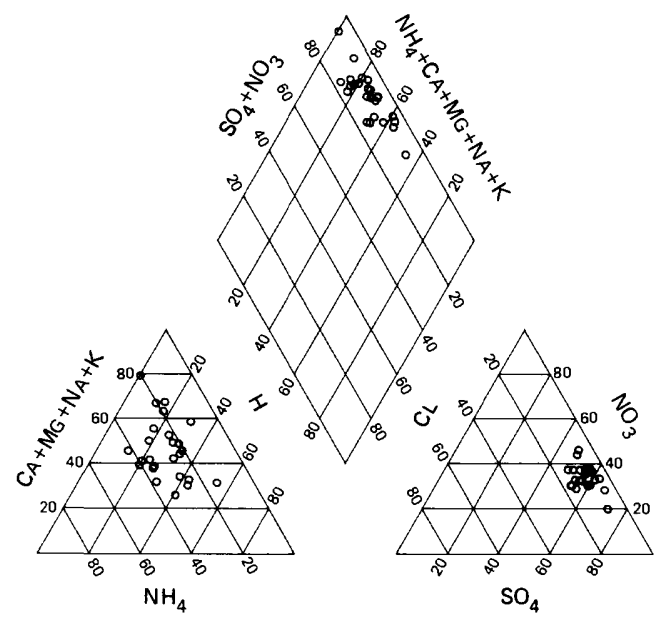

CHEMICAL GROUP 3

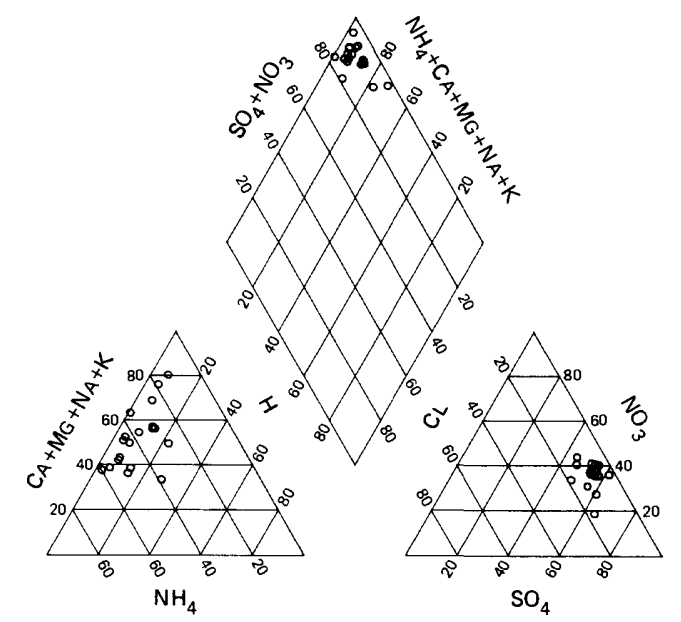

CHEMICAL GROUP 4

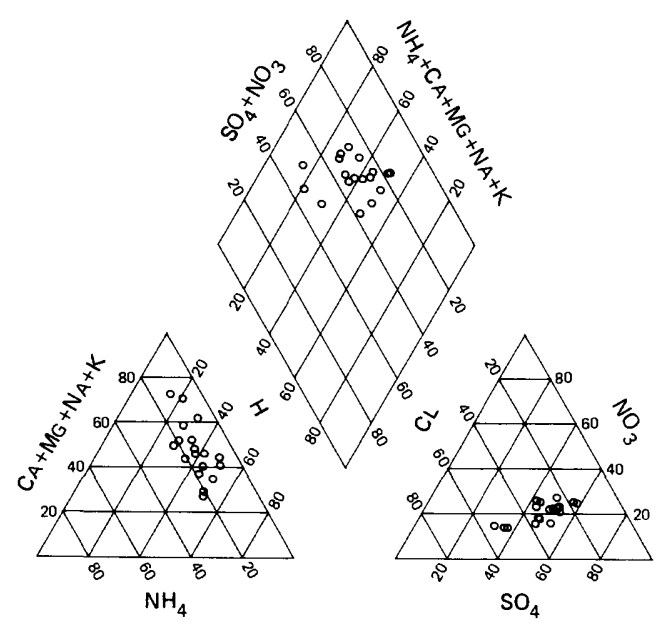

CHEMICAL GROUP 5

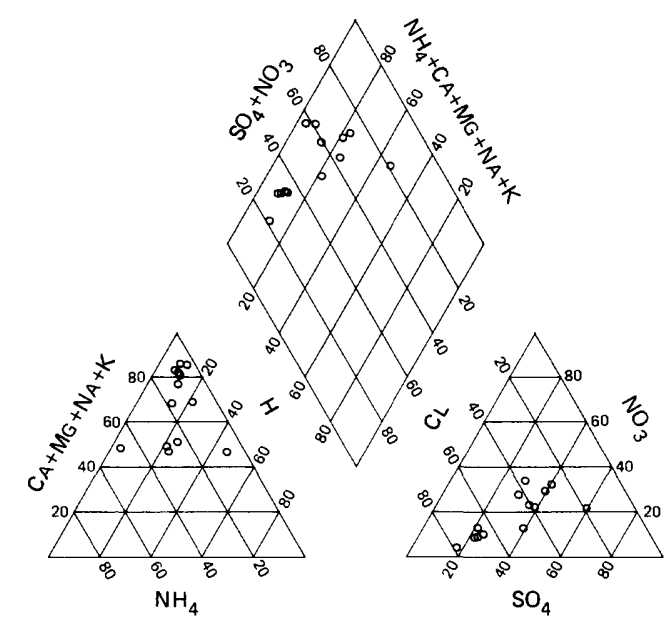

CHEMICAL GROUP 6

Figure 8.--Annual volume-weighted ionic ratios for each chemical group. 
Table 4.--Selected precipitation-chemistry composition based on annual volume-weighted concentrations, by chemical group. January through December 1983.

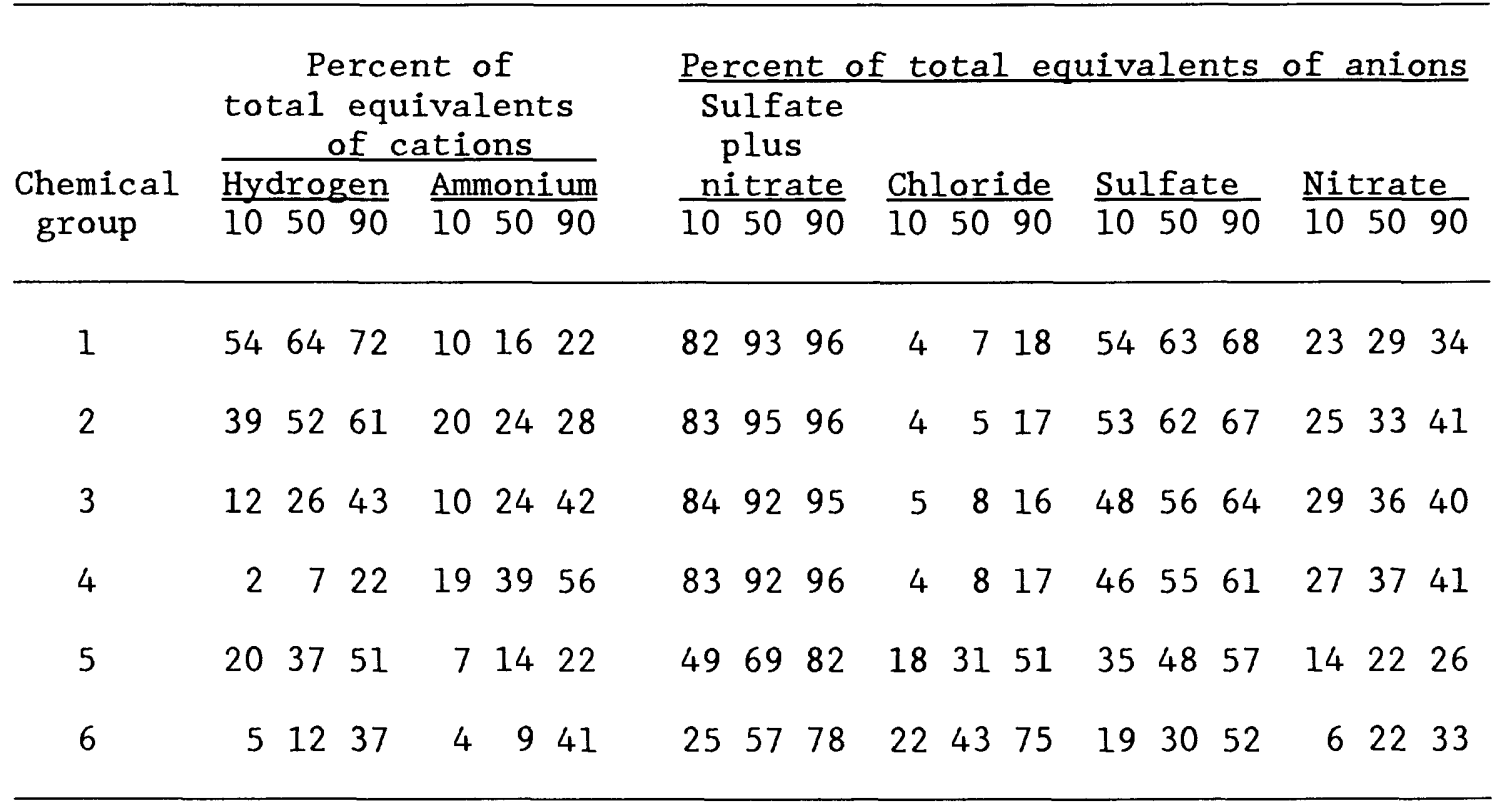

Results of this comparison (using 50-percentile values; table 4) indicate that groups 1 and 2 have large percentages of sulfate-plusnitrate ions and correspondingly large hydrogen-ion percentages. At group 4 sites the sulfate-plus-nitrate percentage is large, but the ammonium-ion percentage is considerably larger than those percentages for group 1 and 2 sites, and the hydrogen-ion percentage is smaller than those at group 1 and 2 sites, possibly reflecting the neutralizing mechanism discussed above. In contrast, group 3 sites have large sulfate-plus-nitrate percentages, but hydrogen-ion percentage is small, without the correspondingly large ammonium-ion percentage observed at group 4 sites. However, maps show that group 3 sites have concentrations of sulfate, hydrogen ion, and nitrate concentrations considerably smaller than those at group 1 sites. Thus, a hydrogen-ion neutralizing constituent other than ammonia or ammonium hydroxide may be present at group 3 sites; or the sulfate and nitrate may be associated with the same proportion of hydrogen ions as those at group 1 and 2 sites. The western and eastern coastal sites (groups 5 and 6 ) show ocean influences of chloride that cause corresponding decreases in the sulfate-plus-nitrate percentages. Notice, however, that the hydrogenion percentage for eastern coastal sites is three times larger than that of western coastal sites because of the close proximity of eastern coastal sites to group 1 sites.

\section{Seasonal comparisons}

Ionic percentages based on annual mean volume-weighted concentrations were separately computed for the winter and summer time periods for each chemical group. The 10-, 50- (median), and 90percentiles of selected ionic percentages are listed in table 5 . 
Table 5.--Selected precipitation-chemistry composition based on seasonal volume-weighted concentrations,

January through December, 1983.

["SU" indicates summer months of June, July, and August; "WI" indicates winter months of December, January, and February]

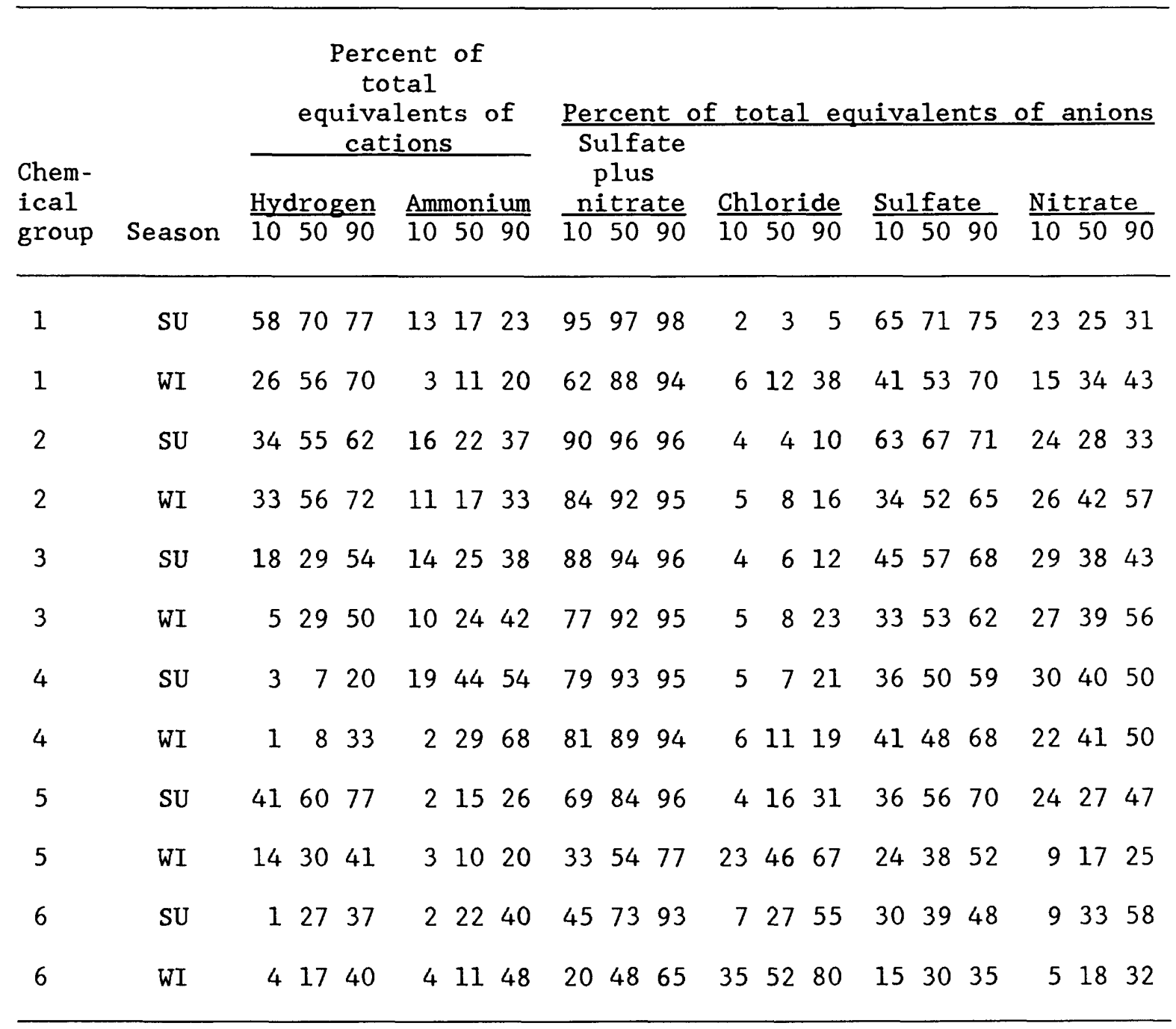

Seasonal differences from summer to winter months (table 6) are as follows :

1. The median chloride percentage increases by more than 5 percent from summer to winter months at coastal sites and also at group 1 sites that are adjacent to the eastern coastal sites. These increases may be ocean-influenced, reflecting increased frontal storm activity during the winter. Frontal storms draw in large amounts of oceanic moisture, whereas summer storms are of a more localized convective form. A convective storm generally does not draw in large amounts of moisture. In the west, frontal storms involve strong advection of oceanic air (westerly wind flows), both ahead of the warm front and north of the center of low pressure. 
Table 6.-- Comparison of summer and winter precipitation-chemistry compositions

"I" indicates median ion percentage increases from summer-to-winter months; "D" indicates median ion percentage decreases from summer to winter months; "--" indicates that a change was less than 5 percent of total cations or anions; The significance of these changes were not statistically determined.

\begin{tabular}{ccccccc} 
& \multicolumn{5}{c}{ Change in median ion percentage of wet deposition } \\
$\begin{array}{c}\text { Chemical } \\
\text { group }\end{array}$ & Hydrogen & Ammonium & Sulfate & Nitrate & Chloride \\
\cline { 2 - 5 } 1 & D & D & D & I & I \\
2 & -- & -- & D & I & - - \\
3 & - - & - - & - - & - - & - - \\
4 & - - & D & - - & - - & - - \\
5 & D & D & D & D & I \\
6 & D & D & D & D & I \\
\hline
\end{tabular}

2. Summer-to-winter decreases in median hydrogen, ammonium, and sulfate percentages occur at the coastal sites and at group 1 sites. These decreases seem to be merely the result of increased sodium and chloride percentages.

3. Median nitrate percentages increase during the winter at group 1 and 2 sites and decrease during the winter at the coastal sites. The decrease in the nitrate percentage may also be the result of increased sodium and chloride percentages.

\section{Chemical Concentrations}

Weekly chemical concentrations

Statistical distributions that describe chemical concentrations of weekly composited samples give equal weight to each sample, regardless of the quantity of precipitation associated with each. Unweighted weekly data are more appropriate, as opposed to volume-weighted data, for relating to environmental processes that are affected by not only the concentration, but also by the duration (amount of time, in weeks) of the acidic effects of precipitation.

Median chemical concentrations for each chemical group are ranked in table 7. Rankings for each group are summarized as follows:

Group 1: among the largest median values of the acid-related constituents (hydrogen, sulfate, and nitrate) and specific conductance. The hydrogen-ion concentration and the large equivalent ionic conductance of the hydrogen ion are primary controls on the specific conductance of a sample. 
Table 7.--Ranking of the median weekly chemical concentrations and precipitation quantity for each chemical group

The number indicates the ranking of median chemical concentrations; "1" indicates group with the largest median chemical concentration, and "6" indicates group with the smallest median chemical concentration.

Chemical constituent or physical property

Chemical Sul- Ni-Chlor-Am- Sod- Hy- Cal- Mag- Potas-Conduc- Rain group fate trate ide monia ium drogen cium nesium sium tance gage

\begin{tabular}{llllllllllll}
\hline 1 & 2 & 2 & 4 & 4 & 5.5 & 1 & 4 & 6 & 6 & 1 & 3 \\
2 & 1 & 1 & 5 & 2 & 5.5 & 2 & 3 & 5 & 4 & 2 & 4 \\
3 & 4 & 4 & 6 & 3 & 4 & 4 & 2 & 3 & 3 & 4 & 5 \\
4 & 5 & 3 & 3 & 1 & 3 & 6 & 1 & 1 & 1 & 5 & 6 \\
5 & 3 & 5 & 1 & 5 & 1 & 3 & 5 & 2 & 2 & 3 & 2 \\
6 & 6 & 6 & 2 & 6 & 2 & 5 & 6 & 4 & 5 & 6 & 1 \\
\hline
\end{tabular}

Group 2: among the largest median values of the acid-related constituents (hydrogen, sulfate, nitrate, and ammonium) and specific conductance; among the smallest median values of sodium and chloride.

Group 3: among the largest median values of calcium; among the smallest median values of chloride and weekly precipitation quantities.

Group 4: among the largest median values of ammonium, calcium, and potassium; among the smallest median values of hydrogen, sulfate, specific conductance, and weekly precipitation quantities.

Group 5: among the largest median values of sodium, potassium, chloride, and weekly precipitation quantities; among the smallest median values of nitrate and ammonium.

Group 6: among the largest median values of sodium, chloride, and weekly precipitation quantities; among the smallest median values of hydrogen, sulfate, nitrate, ammonium, calcium, potassium, and specific conductance.

From the western to eastern chemical groups across the United States, median concentrations of hydrogen, sulfate, nitrate, and specific conductance tend to increase. Chemical groups having the largest median concentrations of sulfate, nitrate, and specific conductance tend to have the largest hydrogen-ion concentrations. Ocean influences account for the larger concentrations of sodium and chloride at the eastern and western coastal sites. 
Group 4 sites have the largest concentrations of ammonium, calcium, magnesium, and potassium. Group 4 sites also have the smallest weekly precipitation quantities, a trend which is consistent with potentially dusty areas, suggesting that these ions originate from wind-blown dust in semi-arid or highly cultivated areas. Large ammonium concentrations may in part be caused by livestock-farming activities, by the application of fertilizer in cultivated farming areas, and the release of ammonia to the atmosphere from near neutral or alkali soils. The small hydrogen-ion concentrations at group 4 sites may be due in part to (1) minimal loadings from hydrogen-ion sources and (2) the neutralizing effects of calcareous dust and large concentrations of ammonia and ammonium hydroxide.

\section{Summer and winter volume-weighted concentrations}

Seasonal volume-weighted chemical concentrations and precipitation quantities are presented in figures $9 \mathrm{a}$ through $9 \mathrm{k}$, which are box plots. Summertime concentrations of chemicals in precipitation tend to be larger than wintertime concentrations, except for sodium and chloride. The larger wintertime concentrations of sodium and chloride probably are related to the passage of ocean-influenced storm fronts during the winter. Largest decreases from summertime to wintertime in the median chemical concentrations (in milligrams per liter) occur consistently at group 1 sites. The relative decreases in the median concentrations of sulfate, nitrate, and hydrogen ion are generally comparable within a group. For example, the median winter concentrations of sulfate, nitrate, and hydrogen are about $25-40$ percent of the median summer concentrations for group 1; the median winter values for group 4 are about 90 to 100 percent of the median summer values. Larger summertime chemical concentrations may be associated with:

(1) increased residence times of air masses during the summer (Bloxam and others, 1984);

(2) increased summertime rates of reaction (resulting from warmer air temperatures) for the oxidation of sulfur dioxide or nitric oxide to sulfite or nitrogen dioxide, chemical species that readily react with water to form sulfuric and nitric acids;

(3) increased summertime occurrence of convective storms, which are more efficient than frontal storms in scrubbing contaminants from an air mass (Bloxam and others, 1984); and

(4) larger summertime air-pollutant loadings due to increased power generation for cooling (Harry Lins, U.S. Geological Survey, oral commun., 1986). 
a. Precipitation amount.

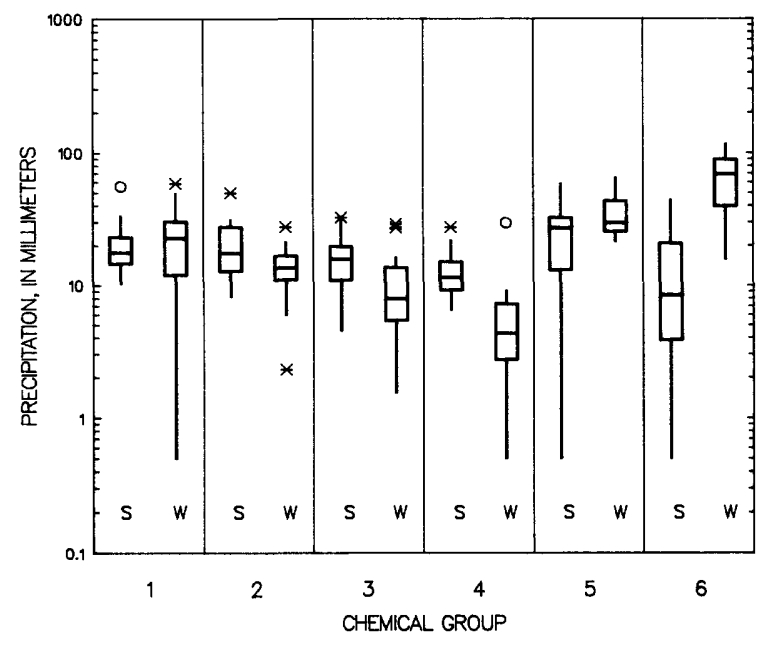

c. Nitrate.

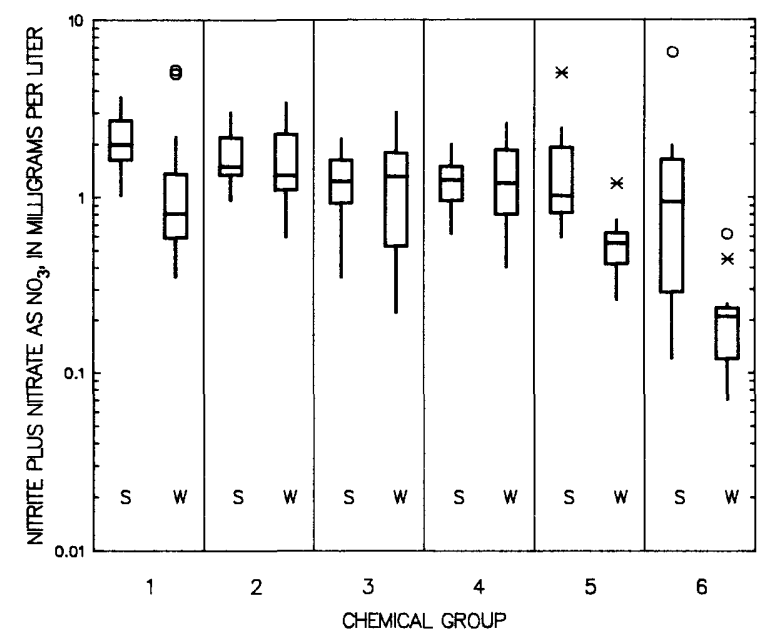

e. $\mathrm{pH}$.

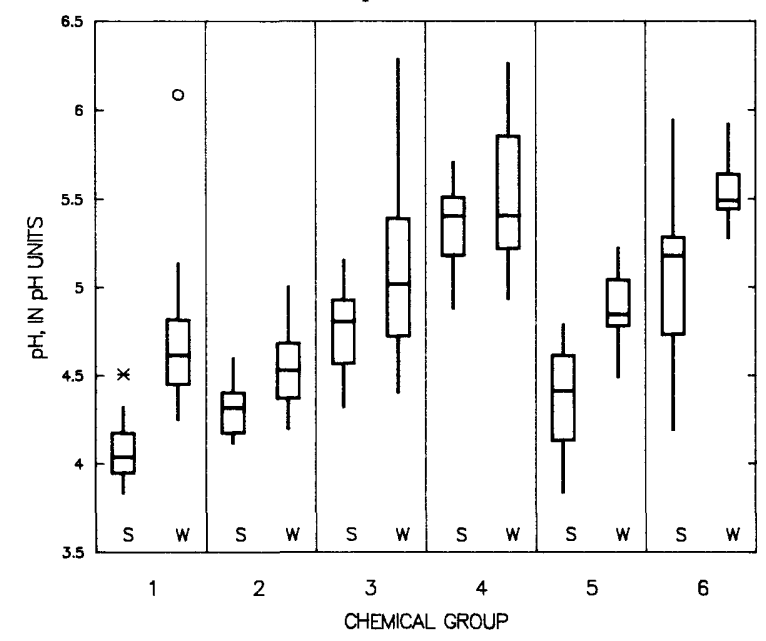

b. Sulfate.

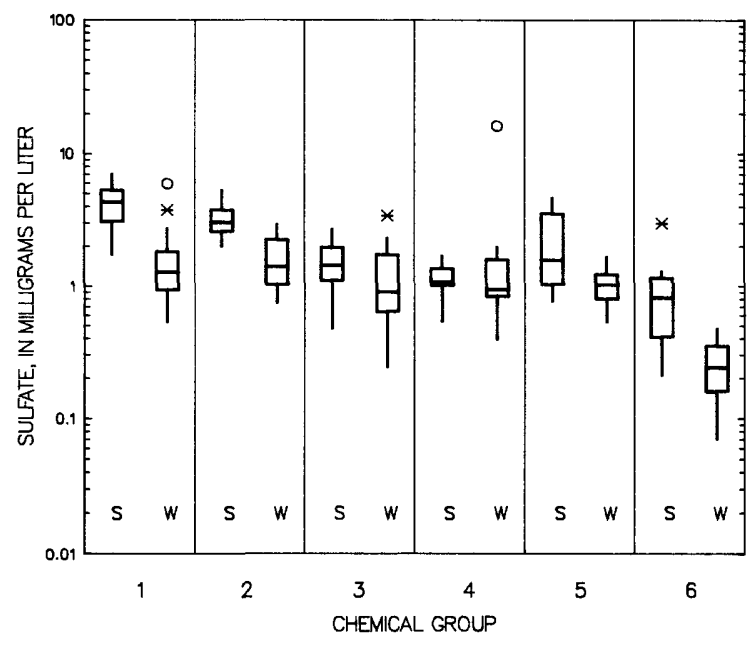

d. Specific conductance.

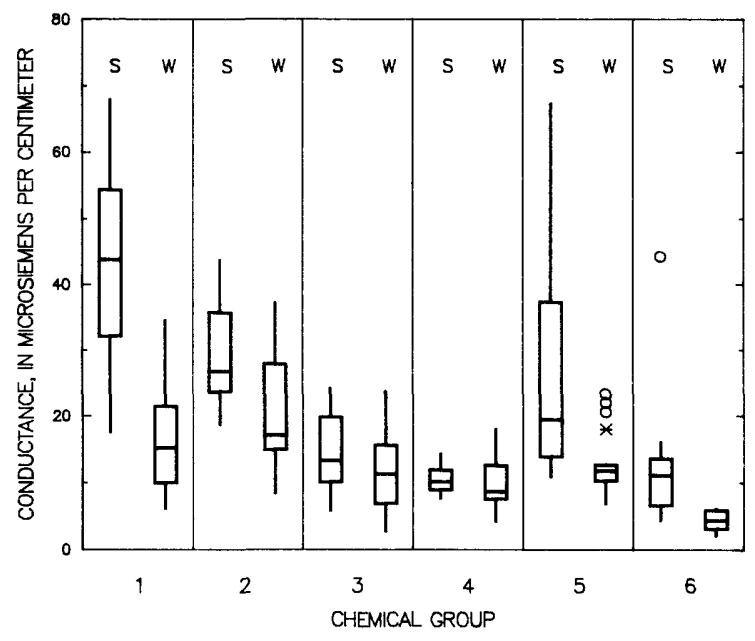

f. Ammonium.

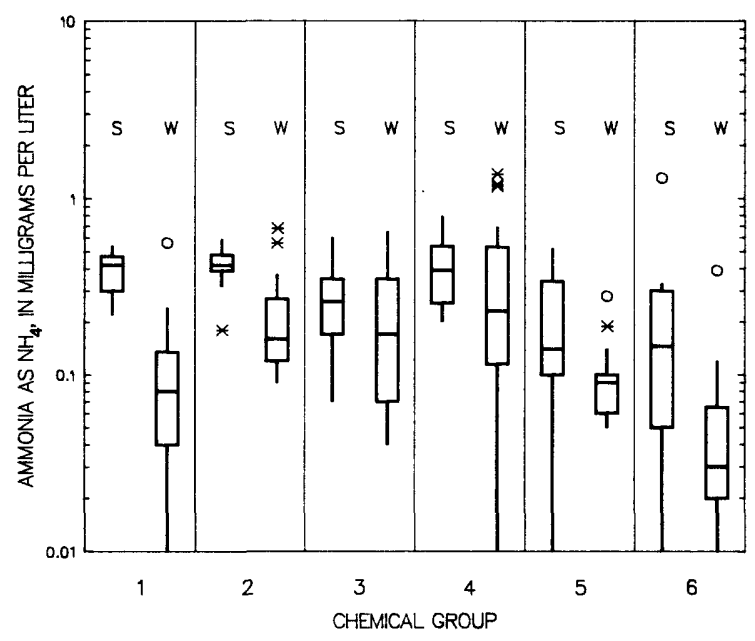

Figure 9.--Summer-winter comparison of volume-weighted mean concentrations for each chemical group. 
g. Calcium.

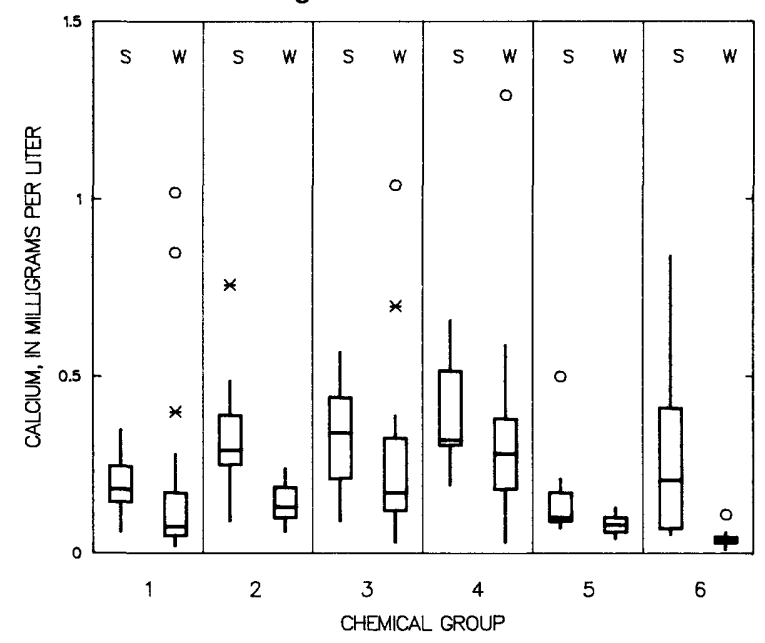

i. Chloride.

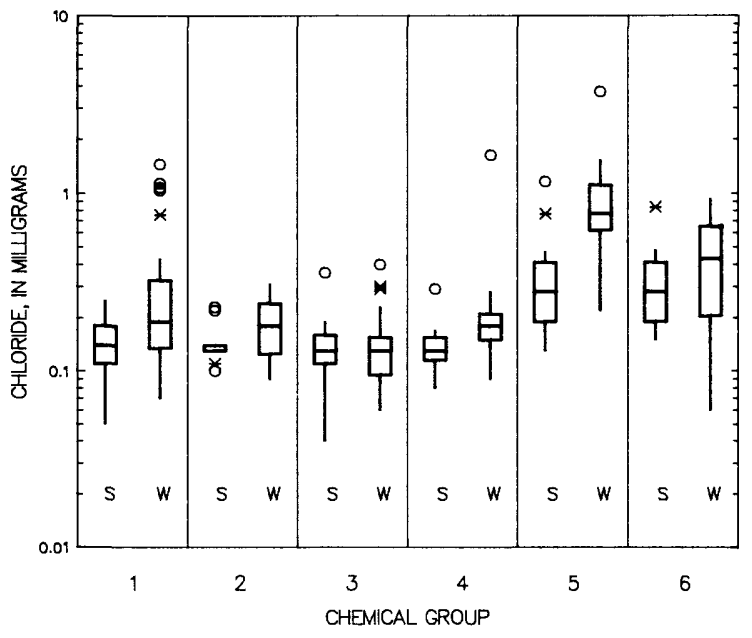

k. Magnesium.

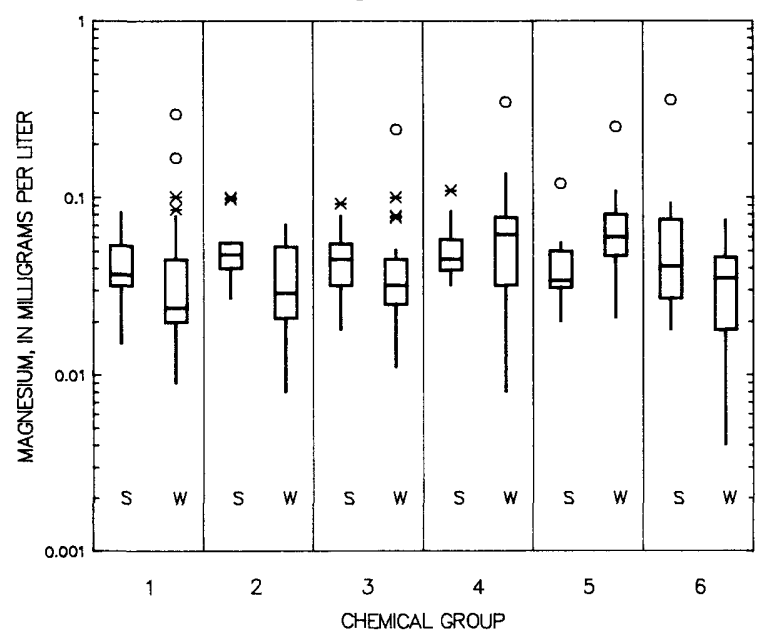

h. Sodium.

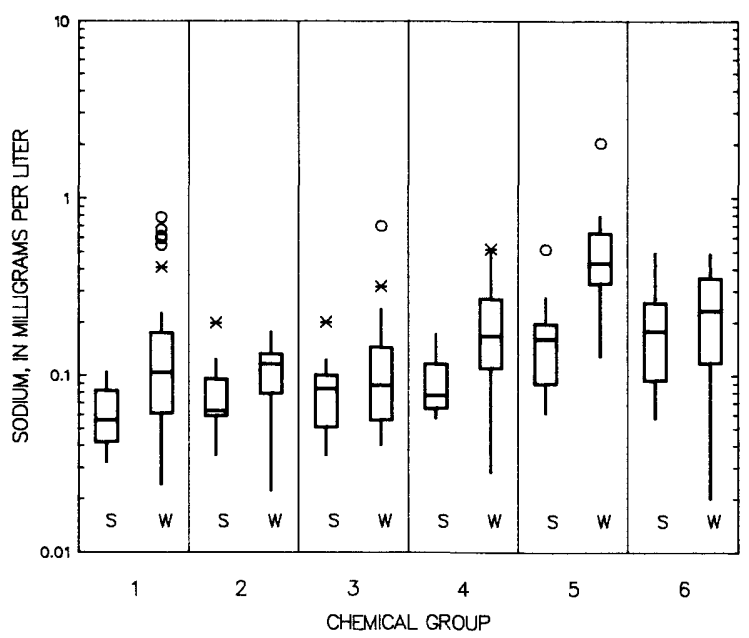

j. Potassium.

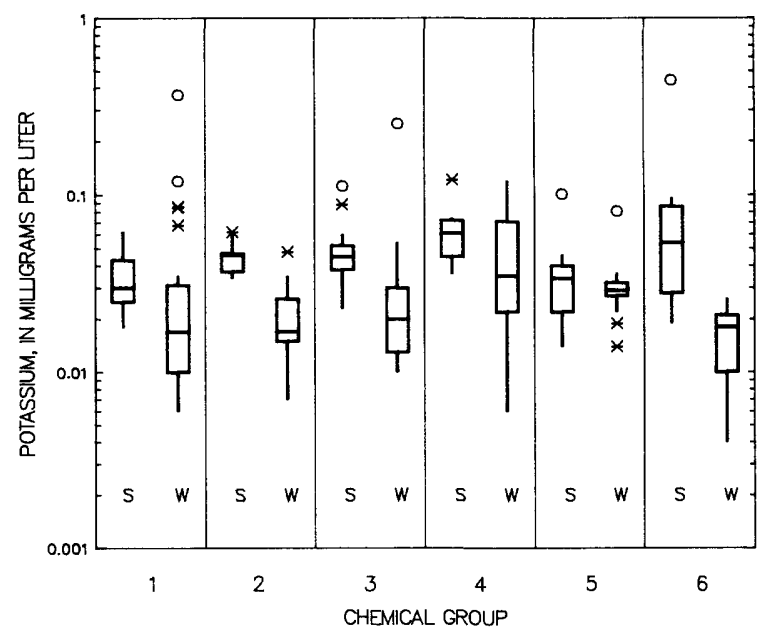

EXPLANATION

Interquartile range equals the value of the 75 th percentile minus the value of the 25th percentile.

- More than 3 times the interquartile range from the 75-percentile value

* 1.5 to 3 times the interquartile range from the 75-percentile value

Less than 1.5 times the interquartile range from the 75-percentile value

75-percentile value

Median value

25-percentile value

Less than 1.5 times the interquartile range from the 25-percentile value

* 1.5 to 3 times the interquartile range from the 25-percentile value

- More than 3 times the interquartile range from the 25-percentile value

S Summer (June, July, August)

W Winter (December, January, February)

Figure 9.--Summer-winter comparison of volume-weighted mean concentrations for each chemical group-- continued. 


\section{Cation-to-anion ratios}

Chemical analyses of precipitation may be checked by computing cation/anion balances based on ratios of the measured equivalents of cations and anions. If all the major cations and anions are accurately measured in an electrically neutral precipitation sample, the sum of the equivalents of cations divided by the sum of the equivalents of anions should be 1.0 .

Median ratios of cations to anions for all chemical groups except group 4 were within plus or minus 0.1 units of 1.0 ( $f i g .10$ ). Group 4 sites, the sites with the highest weekly $\mathrm{pH}$ levels, have the largest median ratios (about 1.2), indicating that the sums of cation equivalents are larger than the sums of anion equivalents. The larger ratios observed in the weekly analyses of precipitation from group 4 sites could result from a positive bias in one or more of the cations or a negative bias in one or more of the anions. Another possibility is that one of the major anions is not being analyzed. Theoretical alkalinities, based on the laboratory $\mathrm{pH}$ of precipitation samples, were computed and added to the sums of the anions to examine changes in the ratios of the cations to anions. The computed ratios were basically the same as those shown in figure 10, except in group 4 and 6 sites, where median ratios dropped about 0.05 units; however, ratios for group 4 sites were still positively biased, generally above 1.15. A plot of the ratios of volume-weighted cations to anions versus volume-weighted $\mathrm{pH}$ levels indicates that the ratios increase as $\mathrm{pH}$ levels increase (fig. 11). The relation between the ratio of cations to anions for weekly samples and $\mathrm{pH}$ levels also shows a significant positive correlation (Kendall Tau statistic $=0.29$ and $\mathrm{p}$-level $=0.0001$ ). Ratios of cations to anions need not be directly related to the $\mathrm{pH}$ of the precipitation samples, because $\mathrm{pH}$ could be acting as a surrogate for other factors. For example, as $\mathrm{pH}$ increases, some chemical concentrations in precipitation may be decreasing, and an analytical bias may only occur when certain constituents have small concentrations.

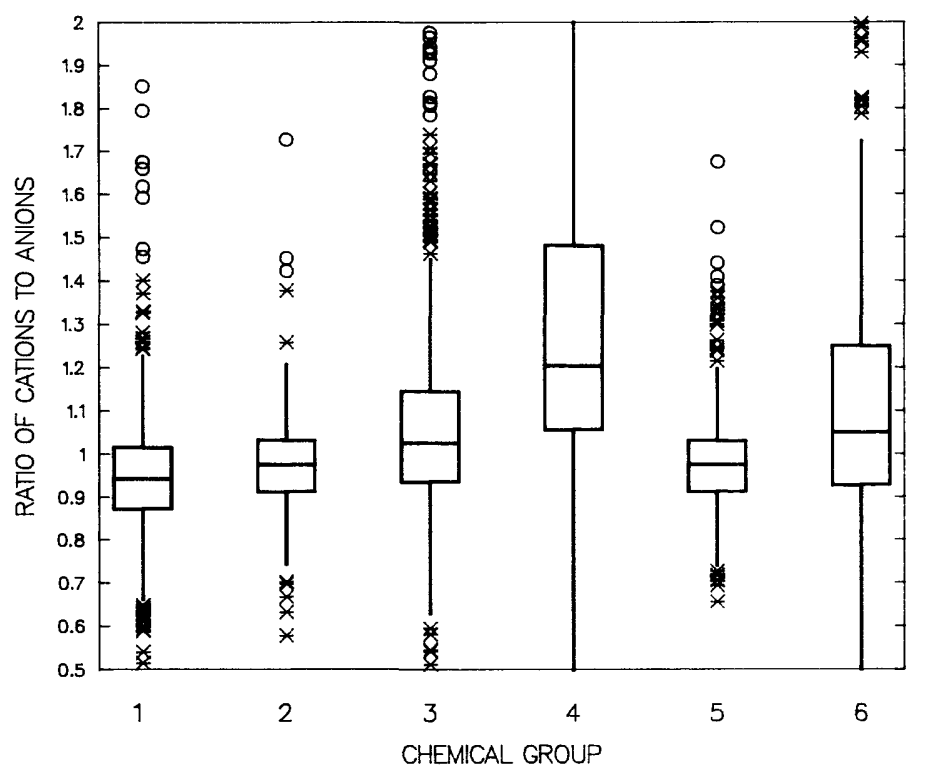

\begin{tabular}{|} 
EXPLANATION \\
Interquartile range equals the value of the 75 th \\
percentile minus the value of the 25 th percentile. \\
0 More than 3 times the interquartile range from \\
the 75 -percentile value \\
* 1.5 to 3 times the interquartile range from the \\
75 -percentile value \\
Less than 1.5 times the interquartile range from \\
the 75 -percentile value \\
75 -percentile value \\
Median value \\
25 -percentile value \\
Less than 1.5 times the interquartile range from \\
the 25 -percentile value \\
* 1.5 to 3 times the interquartile range from the \\
25 -percentile value \\
More than 3 times the interquartile range from \\
the 25 -percentile value
\end{tabular}

Figure 10.--Comparison of cation to anion ionic ratios, in weekly precipitation samples, by chemical group. Some extreme values are not shown. 


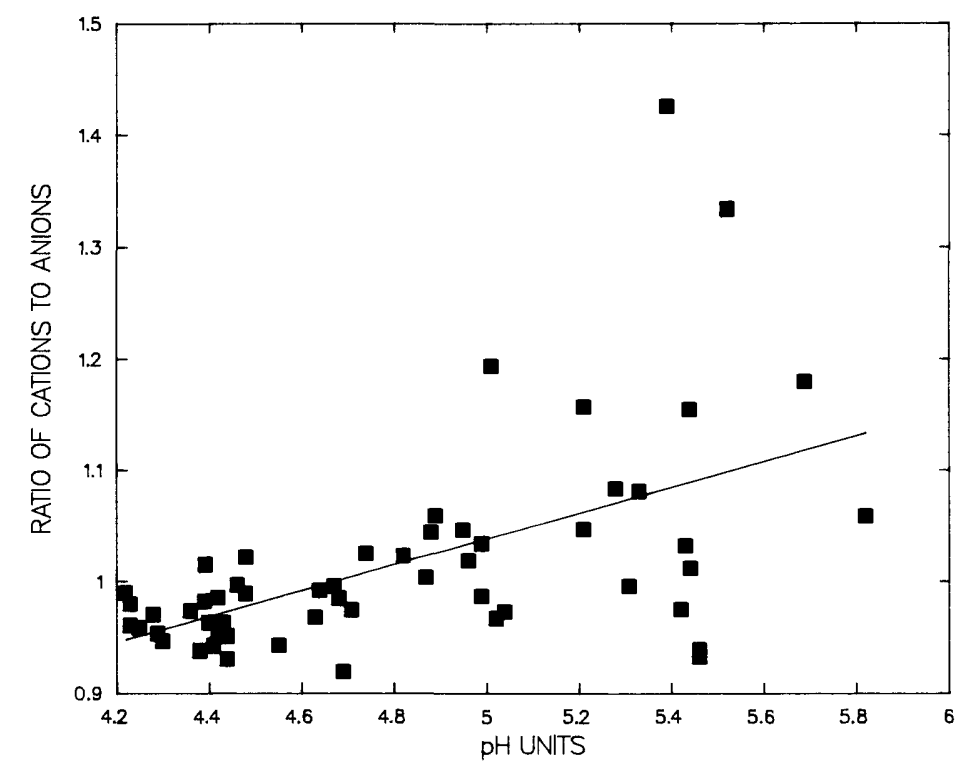

Figure 11.--Relation between annual volume-weighted mean pH values and the ionic ratios of cations to anions in precipitation.

Procedures outlined by Miles and Yost (1981) were used to further explain why the cation-to-anion ratios were generally larger than 1.0 at the group 4 sites. DION values (differences between the sum of anions and cations, in equivalents per liter) were plotted against DSC values (differences between the measured and calculated specific conductances). The DION and DSC relation indicates that most of the DION values were near zero and that most of the DSC values were near zero. Zero values indicate that the major ions are ionically balanced (because the sum of anions minus sum of cations is zero and because measured specific conductance minus the calculated specific conductance is zero). The major pattern observed in the scatter plot indicated that the largest deviations from DION $=0$ and DSC $=0$ occurred when DION values were less than zero and when DSC values were greater than zero. The most likely explanations for this combination of DION and DSC values are that one or more anion concentrations are too small or that one or more anions were not included in the analyses.

Comparisons of summer and winter cation-to-anion ratios indicate that summer median ratios are consistently larger than winter median ratios (fig. 12).

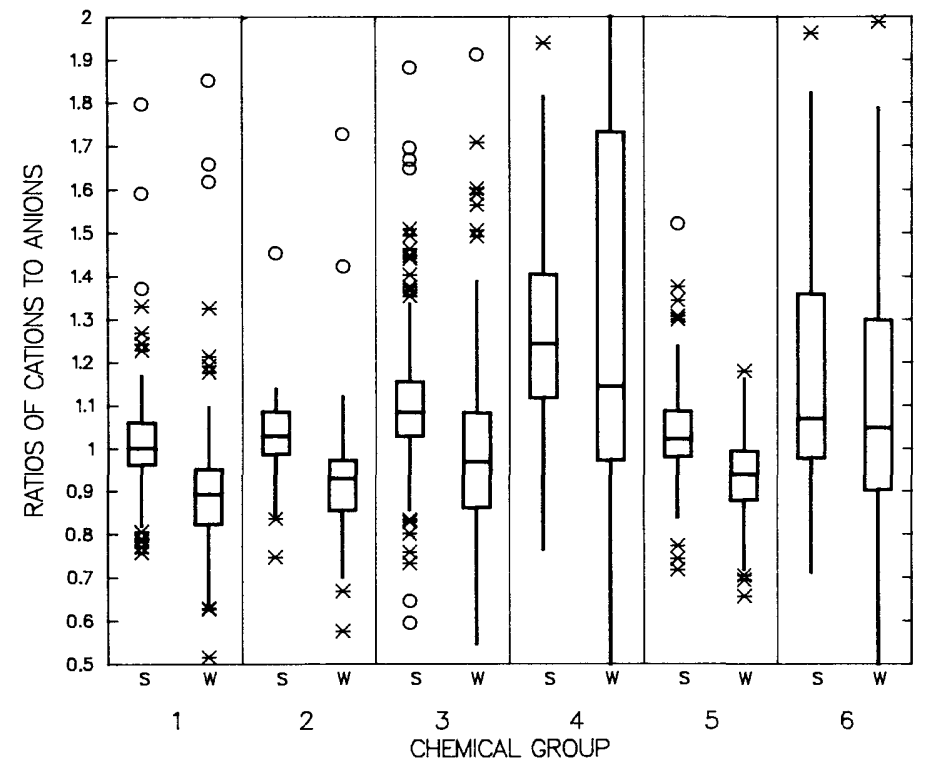

EXPLANATION
Interquartile range equals the value of the 75 th
percentile minus the value of the 25 th percentile.
o More than 3 times the interquartile range from
the 75 -percentile value
* 1.5 to 3 times the interquartile range from the
75 -percentile value
Less than 1.5 times the interquartile range from
the 75 -percentile value
75 -percentile value
Median value
25 -percentile value
Less than 1.5 times the interquartile range from
the 25 -percentile value
* 1.5 to 3 times the interquartile range from the
25 -percentile value
More than 3 times the interquartile range from
the 25 -percentile value
S Summer (June, July, August)
W Winter (December, January, February)

Figure 12.--Comparison of summer and winter ionic ratios of cations to anions by chemical group. Some extreme values are not shown. 
In all chemical groups except group 4, the median ratios for both the summer and winter analyses are plus or minus 0.1 units of 1.0 . At group 4 sites, the majority of ratios are considerably above 1.0 and indicate that larger measured concentrations of cations than of anions occur for both the summer and winter analyses.

\section{Sulfate-to-nitrate ratios}

Variations in sulfate-to-nitrate equivalent ratios in precipitation may reflect the type of fuel consumed or types of industrial processes that are occurring in various chemical groups throughout the United States. Largest median ratios of sulfate to nitrate occur at the eastern coastal sites (group 5) and gradually decrease toward the West (group 6; fig. 13). Median ratios at the western coastal sites are about 75 percent of those at the eastern sites, a difference which agrees with the fact that eastern energy sources contain larger sulfur concentrations than energy sources in the western United States. The larger interquartile range in the western coastal region could be indicative of sulfate from ocean influences (Laird and others, 1986). The smallest ratios are observed at group 4 sites, the region that had the largest $\mathrm{pH}$ values in the weekly precipitation samples.

Sulfate-to-nitrate ratios tend to vary from summer to winter months (fig. 14), although both the summer and winter ratios tend to decrease from the eastern to the western chemical groups. At group 1 and 2 sites, the ratios during the summer tend to be larger than those during the winter; at group 3, 4, and 6 sites, the ratios during the summer and winter are similar; and at group 5 sites, the summer ratios are slightly smaller than those during the winter. At group 1 and 2 sites, the smaller ratios during the winter result from smaller winter concentrations of both sulfate and nitrate, although the nitrate values do not decline nearly as much as the sulfate concentrations. Reasons for the large winter decline in sulfate concentrations are not apparent; dilution does not appear to be significant, as the weekly precipitation quantities are seasonally similar. The summer and winter sources of nitrate at group 1 and 2 sites appear to be relatively constant, compared to summer and winter sources of sulfate.

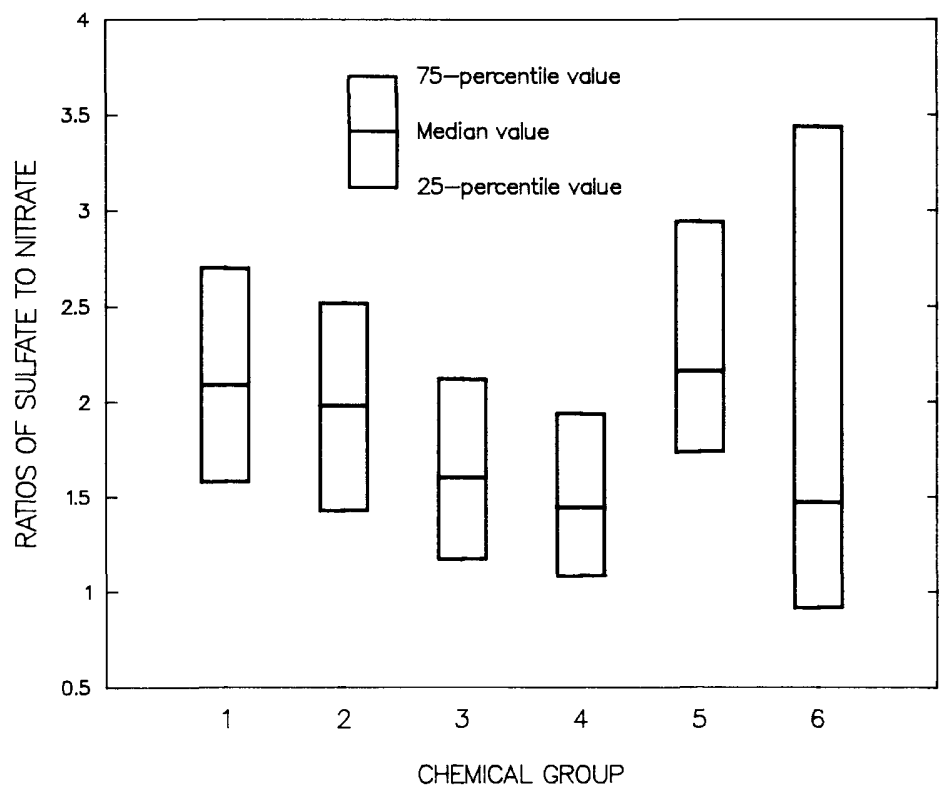

Figure 13.--Comparison of ionic ratios of sulfate to nitrate concentrations in weekly precipitation samples by chemical group. 


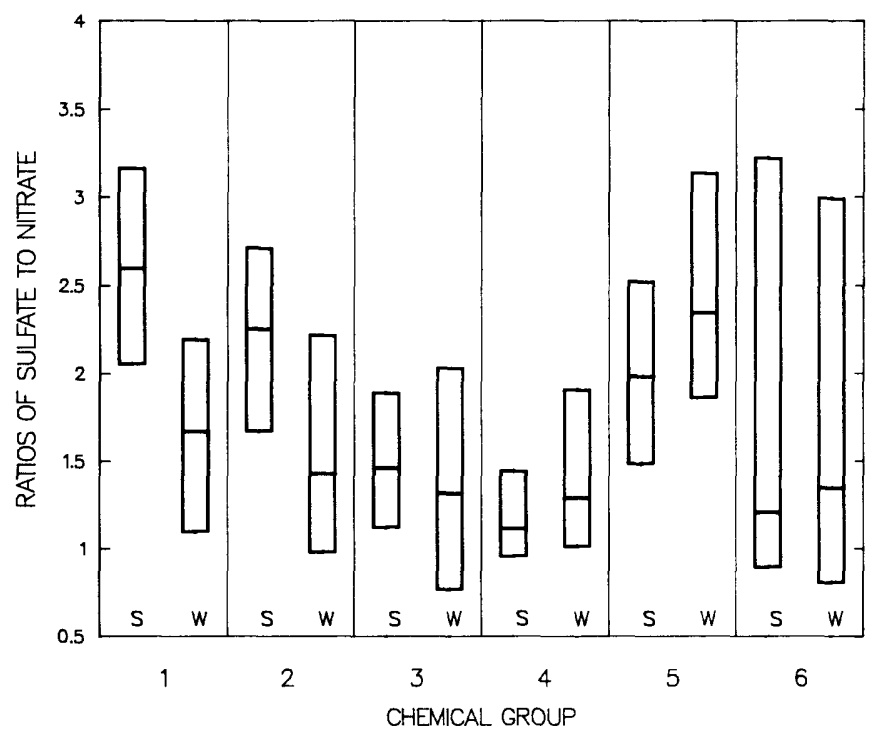

EXPLANATION

Interquartile range equals the value of the 75 th percentile minus the value of the 25 th percentile.

7 75-percentile value

Median value

25-percentile value

$S$ Summer (June, July, August)

W Winter (December, January, February)

Figure 14.--Comparison of ionic ratios of sulfate to nitrate concentrations by chemical group. Only the quartile values are shown.

One hypothesis for the relatively constant nitrate concentrations in precipitation is that the increased consumption of heating fuels during the winter months produces oxides of nitrogen emissions that compare to emissions resulting from the increased fuel consumption for transportation and electrical needs during the summer months. Concentrations of sulfate and nitrate at group 3,4 , and 6 sites are smaller than those at group 1 and 2 sites. These concentrations at group 3, 4, and 6 sites decline similarly from summer to winter, so that ratios during summer and winter are relatively constant. The eastern coastal sites may have larger ratios because of the region's proximity to group 1 sites.

\section{Acid-related Chemical Species}

of particular interest among the ions measured in precipitation are those associated with acidity. Two major components of acidity in precipitation are sulfuric and nitric acids (U.S. Environmental Protection Agency, 1980). In wet deposition, these acids dissociate to anions of sulfate and nitrate and to cations of hydrogen (often referred to as the hydronium ion). An examination of the equivalent ratios of various combinations of these acid-forming chemical species in precipitation may help to determine atmospheric chemical processes.

Ion ratios of sulfate to hydrogen for the six chemical groups in the United States are generally greater than 1.0 (fig. 15a). Ratios greater than 1.0 show that sulfate concentrations are large enough to electrically balance the hydrogen-ion concentrations and indicate that (1) some of the sulfate ions were associated with cations other than the hydrogen ion, or (2) some of the hydrogen ions that originated from sulfuric acid were neutralized by such constituents as ammonia or bicarbonate. The sulfate-to-hydrogen ion ratio tends to be inversely related to the hydrogen-ion concentration. Group 4 sites have the largest ratios (generally larger than 4.0 ) and the smallest hydrogen-ion concentrations; conversely, group 1 sites have the smallest ratios (near 1.0) and have among the largest hydrogen-ion concentrations.

As with sulfate, the largest ratios of nitrate to hydrogen ions occur at group 4 sites, and the smallest ratios occur at group 1 sites (fig. 15b). Ratios are greater than 1.0 for group 3,4 , and 6 sites, whereas ratios are less than 1.0 for group 1, 2, and 5 sites. In areas where the ratio is greater than 1.0, nitrate may have been associated with cations other than hydrogen-ion or some of the hydrogen ions that originated from nitric acid were neutralized by some other constituent. 
a. Sulfate to hydrogen-ion.

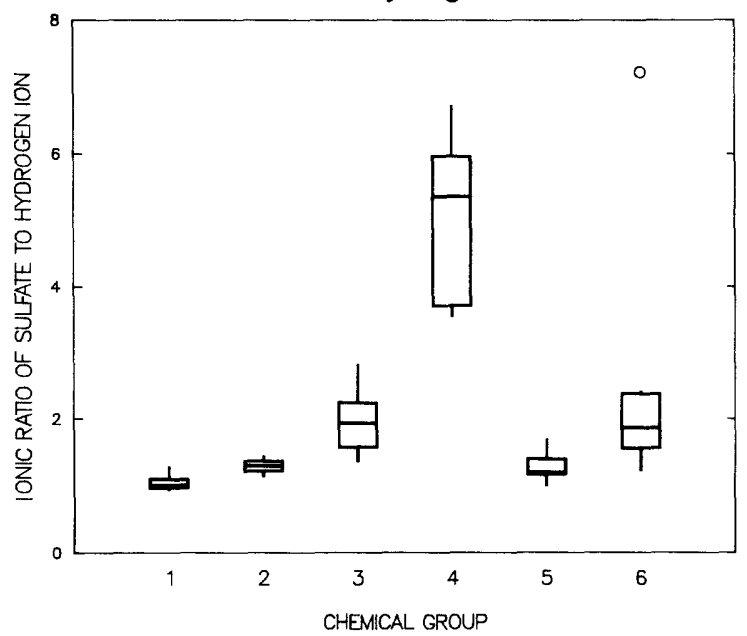

c. Sulfate plus nitrate to hydrogen-ion.

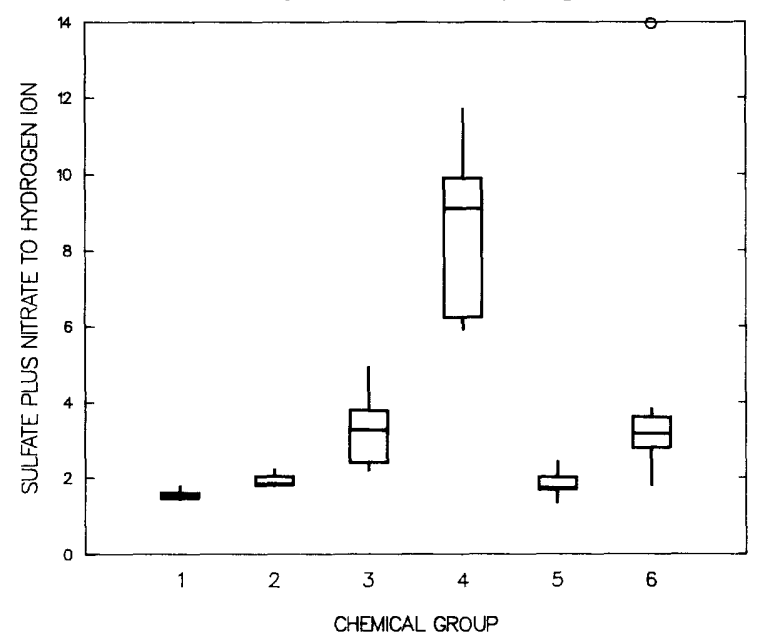

e. Sulfate plus nitrate to hydrogen-ion plus ammonium plus calcium.

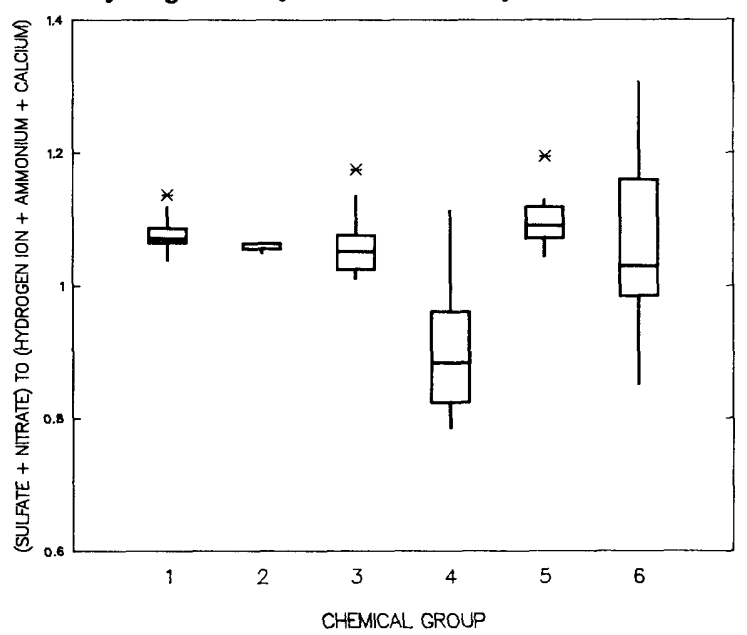

b. Nitrate to hydrogen-ion.

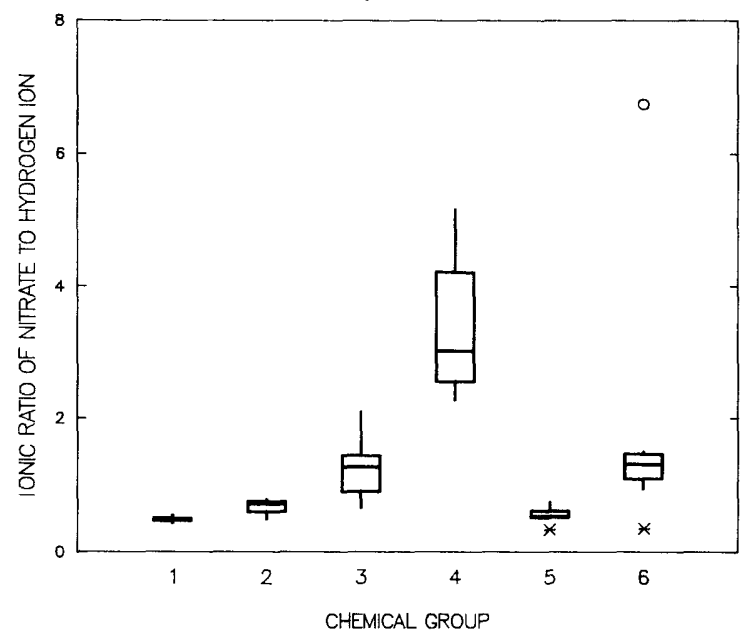

d. Sulfate plus nitrate to hydrogen-ion plus ammonium.

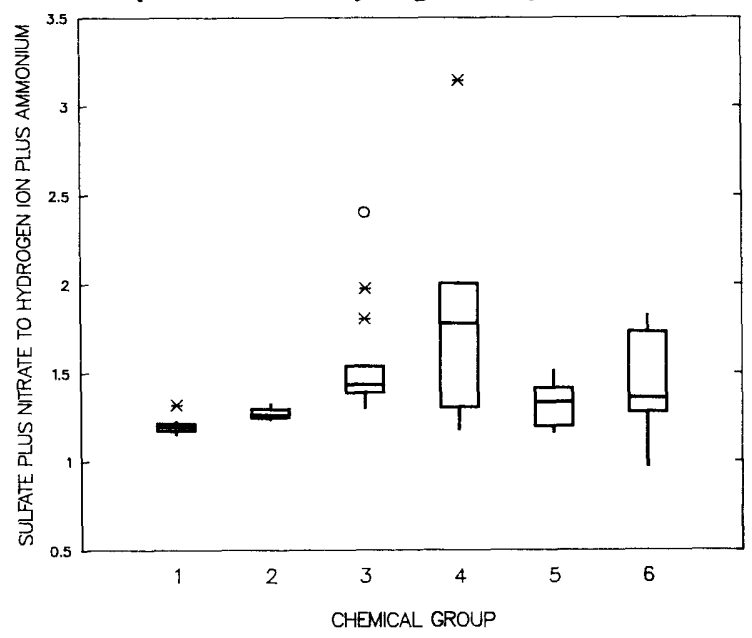

EXPLANATION

Interquartile range equals the value of the 75th percentile minus the value of the 25 th percentile.

- More than 3 times the interquartile range from the 75-percentile value

* 1.5 to 3 times the interquartile range from the 75-percentile value

Less than 1.5 times the interquartile range from the 75-percentile value

75-percentile value

Median value

25-percentile value

Less than 1.5 times the interquartile range from the 25 -percentile value

* 1.5 to 3 times the interquartile range from the 25 -percentile value

Figure 15.--Comparison of annual volume-weighted mean ionic ratios by chemical group. 
Because the hydrogen ion equivalents are insufficient to balance the sulfate-plus-nitrate equivalents (fig. $15 \mathrm{c}$; ratios are above 1.0 in all chemical groups), other cations needed to electrically balance the equivalents of sulfate-plus-nitrate were examined. When the ammonium was added to the hydrogen ion, the ratios were substantially reduced, especially for group 4 sites (fig. 15d). With the addition of the ammonium, ratios were generally less than 2.0 , and in most instances median ratios were less than 1.5. The ammonium could have been directly associated with one of the anions, such as sulfate (from an ammonium sulfate source), or ammonia could have neutralized hydrogen ions. Even though the most dramatic change occurred at group 4 sites (fig. 15c compared to fig. 15d), each of the chemical groups showed reductions. Reductions were pronounced at group 3 and 6 sites. These results indicate that ammonia may partly account for the lower hydrogen-ion concentrations observed at group 3,4 , and 6 sites. Although the addition of the ammonium changed the ratios considerably, all chemical groups still have ratios above 1.0 .

of the remaining measured cations (calcium, magnesium, potassium, and sodium), each was used separately to reduce the remaining ratio closer to 1.0. Results of the inclusion of all cations except calcium were essentially the same as shown in figure $15 \mathrm{~d}$ and indicate that these cations had minimal effect. Addition of calcium reduced the ratios for each of the chemical groups (fig. 15e). Resulting ratios near 1.0 indicate either that calcium was associated with one of the anions (sulfate or nitrate), or that calcareous material may be neutralizing some of the hydrogen-ion concentrations. All chemical groups have slight positive biases (median ratios slightly less than 1.1), except group 4, which has a slight negative bias (median ratio near 0.9 ).

Ratios of acid-related species suggest that at some chemical groups (particularly 3 and 4) the neutralizing effects of ammonia and calcareous materials may partially account for the smaller observed hydrogen-ion concentrations. Consequently, the hydrogen-ion concentrations at group 1 sites may be large not only because of significant sources of oxides of sulfur and nitrogen, but also because of a lack of airborne ammonia and calcareous material.

In the presence of source loadings of ammonia, the loading of hydrogen ions, as determined from $\mathrm{pH}$ and precipitation quantity, may not be accurately reflecting the magnitude of the hydrogen-ion load to soils. Ammonia increases the $\mathrm{pH}$ of precipitation, but in the soil zone the hydrogen ion bound to ammonium may be released by oxidation of ammonium, causing a greater acidification than would occur if precipitation of the same $\mathrm{pH}$ did not contain ammonium (Junge, 1958).

\section{RELATIONS BETWEEN QUANTITY AND CHEMISTRY OF PRECIPITATION}

\section{Kendall Tau Correlation and Regression Analysis Techniques}

Chemical concentrations in precipitation are related to many factors, including the type and location of pollutant sources, ambient chemical loadings, chemical characteristics, and atmospheric reactions. Another important factor is the quantity of precipitation passing through the atmosphere and coming in contact with gases, aerosols, and particulates. As precipitation quantities increase, the finite supply of airborne chemicals may be removed and subsequently diluted, causing decreases in the overall chemical concentrations in precipitation. 
To explore relations between chemical concentrations in weekly precipitation samples and the quantity of weekly precipitation, correlation coefficients in the form of the Kendall Tau statistic (Conover, 1980) were computed for each constituent at each NTN site (results shown in Appendices II and III). Positive correlations indicate that as precipitation quantities increase, chemical concentrations increase. Negative correlations indicate that as precipitation quantities increase, chemical concentrations decrease.

Regression analyses were used to examine and develop quantitative relations between precipitation quantity and selected chemical concentrations among the chemical groups. Correlation analysis (in the previous section) was used to determine the degree to which the variables precipitation quantity and chemical concentrations were related. The primary goal of the regression analyses was to develop equations to (1) compute mean predicted values of chemical concentrations for specific precipitation quantities and (2) make regional comparisons.

Two terms used in this report to describe the error in a regression equation are the coefficient of determination, $r^{2}$, and the standard error of estimate, SE (Draper and Smith, 1981). The coefficient of determination is a measure of how well the equation fits the data. This coefficient, times 100 , is defined as the percent of dependent-variable variation explained by the equation. The standard error of estimate is a measure of the variance about the regression. For example, a standard error of estimate of $0.20 \mathrm{log}$ units would indicate that approximately two-thirds of the measured values would fall within plus or minus $0.20 \mathrm{log}$ units from the predicted value.

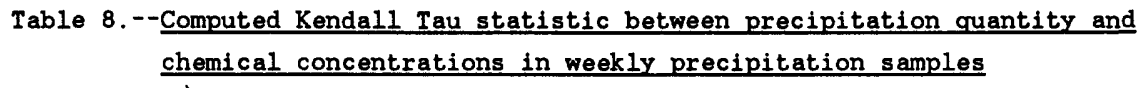

This table shows the percentages of NTN sites in each chemical group with Kendall Tau coefficients that are significantly correlated at at the 90-percent confidence level ( $p-1 e v e 1<0.10$ ). "p" indicates the percentage of sites with positive correlations, and " $N$ " indicates the percentage of sites with negative correlations; for example, 68 percent of the 31 sites in chemical group 1 have negative correlations between precipitation quantity and specific conductance, and 0 percent of the 31 sites had positive correlations.

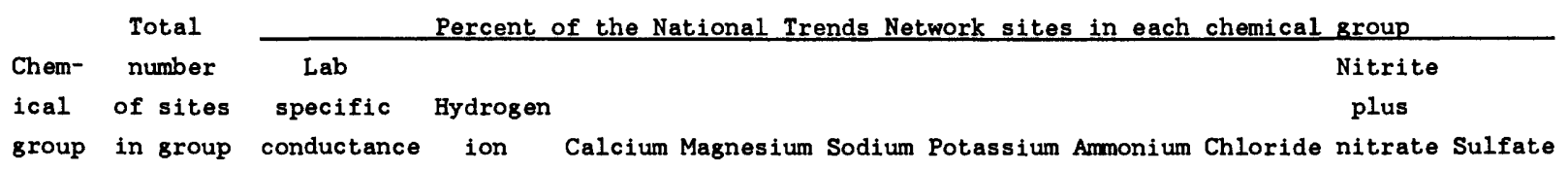

\begin{tabular}{|c|c|c|c|c|c|c|c|c|c|c|c|c|c|c|c|c|c|c|c|}
\hline \multirow[t]{2}{*}{1} & 31 & $68 \mathrm{~N}$ & 391 & $N$ & 94 & $\mathbf{N}$ & 87 & $\mathbf{N}$ & 681 & $\mathbf{N}$ & 84 & $\mathrm{~N}$ & 64 & $\mathrm{~N}$ & 71 & & 87 & $\mathbf{N}$ & $81 \mathrm{~N}$ \\
\hline & & $0 F$ & 0 & $\mathbf{P}$ & 0 & $\mathbf{P}$ & 0 & $\mathbf{P}$ & 01 & $\mathbf{P}$ & 0 & $\mathbf{P}$ & 0 & $\mathbf{P}$ & 0 & $\mathbf{P}$ & 0 & $\mathbf{P}$ & $0 \mathrm{P}$ \\
\hline \multirow[t]{2}{*}{2} & 10 & $50 \mathrm{~N}$ & 20 & $N$ & 90 & $\mathrm{~N}$ & 100 & $\mathrm{~N}$ & 801 & $N$ & 100 & $\mathbf{N}$ & 50 & $\mathrm{~N}$ & 80 & $\mathrm{~N}$ & 100 & $N$ & $60 \mathrm{~N}$ \\
\hline & & $0 \mathrm{~F}$ & 0 & $\mathbf{P}$ & 0 & $\mathbf{P}$ & 0 & $\mathbf{P}$ & 01 & $\mathbf{P}$ & 0 & $\mathbf{P}$ & 0 & $\mathbf{P}$ & 0 & $P$ & 0 & $\mathbf{P}$ & $0 \mathrm{P}$ \\
\hline \multirow[t]{2}{*}{3} & 23 & $61 \mathrm{~N}$ & 91 & $\mathbf{N}$ & 91 & $\mathrm{~N}$ & 100 & $\mathrm{~N}$ & 961 & $\mathbf{N}$ & 78 & $N$ & 39 & $\mathbf{N}$ & 91 & $\mathbf{N}$ & 87 & $\mathbf{N}$ & $65 \mathrm{~N}$ \\
\hline & & $0 \mathrm{~F}$ & 43 & $\mathbf{P}$ & 0 & $\mathbf{P}$ & 0 & $\mathbf{P}$ & 0 & $\mathbf{P}$ & 0 & $\mathbf{P}$ & 0 & $\mathbf{P}$ & 0 & $\mathbf{p}$ & 0 & $\mathbf{P}$ & $0 \mathrm{P}$ \\
\hline \multirow[t]{2}{*}{4} & 13 & $92 N$ & 8 & $\mathbf{N}$ & 92 & $\mathbf{N}$ & 85 & $\mathrm{~N}$ & 921 & $\mathrm{~N}$ & 77 & $\mathbf{N}$ & 38 & $\mathbf{N}$ & 92 & $\mathbf{N}$ & 85 & $\mathrm{~N}$ & $92 \mathrm{~N}$ \\
\hline & & $0 \mathrm{~F}$ & 69 & $\mathbf{P}$ & 0 & $\mathbf{P}$ & 8 & $\mathbf{P}$ & 0 & $\mathbf{P}$ & 8 & $\mathbf{P}$ & 0 & $\mathbf{P}$ & 0 & $\mathbf{P}$ & 0 & $\mathbf{P}$ & $0 \mathrm{P}$ \\
\hline \multirow[t]{2}{*}{5} & 16 & $94 \mathrm{~N}$ & 50 & $\mathrm{~N}$ & 94 & $\mathbf{N}$ & 88 & $N$ & 501 & $N$ & 81 & $\mathrm{~N}$ & 69 & $\mathrm{~N}$ & 44 & $N$ & 100 & $\mathrm{~N}$ & $94 \mathrm{~N}$ \\
\hline & & $0 \mathrm{~F}$ & & $P$ & 0 & $\mathbf{P}$ & 0 & $\mathbf{P}$ & 01 & $\mathbf{P}$ & 0 & $\mathbf{P}$ & 0 & $P$ & 0 & $P$ & 0 & $\mathbf{P}$ & $0 \mathrm{P}$ \\
\hline \multirow[t]{2}{*}{6} & 13 & $69 N$ & 23 & $\mathrm{~N}$ & 100 & $\mathbf{N}$ & 54 & $\mathbf{N}$ & 461 & $N$ & 85 & $N$ & 54 & $N$ & 54 & $\mathrm{~N}$ & 85 & $\mathrm{~N}$ & $92 \mathrm{~N}$ \\
\hline & & $0 \mathrm{~F}$ & & $\mathbf{P}$ & 0 & P & 0 & $\mathbf{P}$ & 81 & $\mathbf{P}$ & 0 & $\mathbf{P}$ & 0 & $P$ & 0 & $\mathbf{P}$ & 0 & $\mathbf{P}$ & $0 \mathrm{P}$ \\
\hline
\end{tabular}




\section{Results of Analysis}

Results of the correlation analysis (table 8) indicate that most chemicals in weekly precipitation samples, except hydrogen-ion concentrations, are negatively correlated with precipitation quantities. In addition, most of the correlations that were not significant ( $p$-levels greater than 0.1 ) had positive Kendall Tau coefficients. Hydrogen was generally the only chemical constituent to show positive correlations with precipitation quantity; these positive correlations were predominant of group 3 and 4 sites. Group 2 and 6 sites that border group 3 and 4 sites showed the fewest significant correlations.

Results of the regression analyses show an inverse curvilinear relation between the variables, indicating that chemical concentrations decrease as precipitation quantities increase (fig. 16). The reason for an inverse relation is that the initial quantities of precipitation can efficiently remove a large amount of chemical constituents from the atmosphere. This removal process produces wide variations in chemical concentrations for small precipitation quantities, and the chemical concentrations in precipitation depend upon the level of chemical concentrations in the atmosphere. Large amounts of precipitation dilute the concentration of chemicals in the weekly samples. The dilution caused by increasing amounts of precipitation continues until chemical concentrations approach ambient baseline concentrations.

To aid in the evaluation of these inverse relations, the data were plotted on log-log diagrams and fitted with least squares regression lines (figs. $17 \mathrm{a}$ and $17 \mathrm{~b}$; table 9). Chemical concentrations reported below the analytical detection level were included in the calculations as values equal to one-half the detection level.

Regression equations that are based on the logarithms of variables will underestimate the predicted mean value of the dependent variable (chemical concentrations) for any fixed value of the independent variable (precipitation quantity); therefore, a correction factor (one-half of the square of the standard error of estimate) has been added to the predicted values shown in table 9 (Ferguson, 1986).

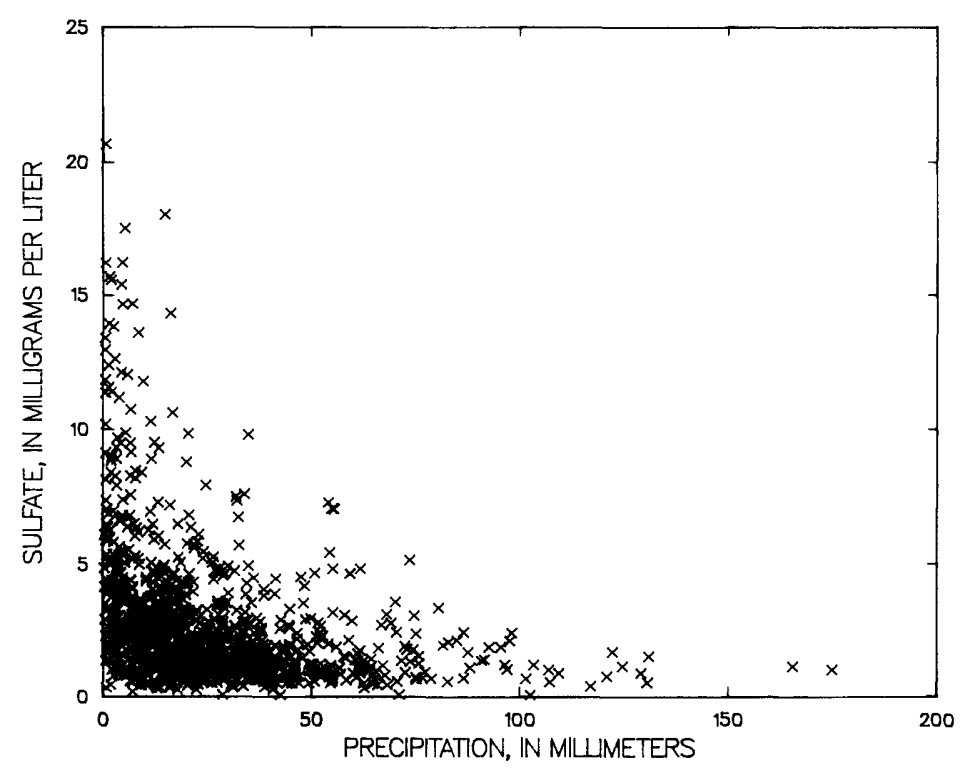

Figure 16.--Sulfate concentrations as a function of precipitation amounts for chemical group 1 sites. 


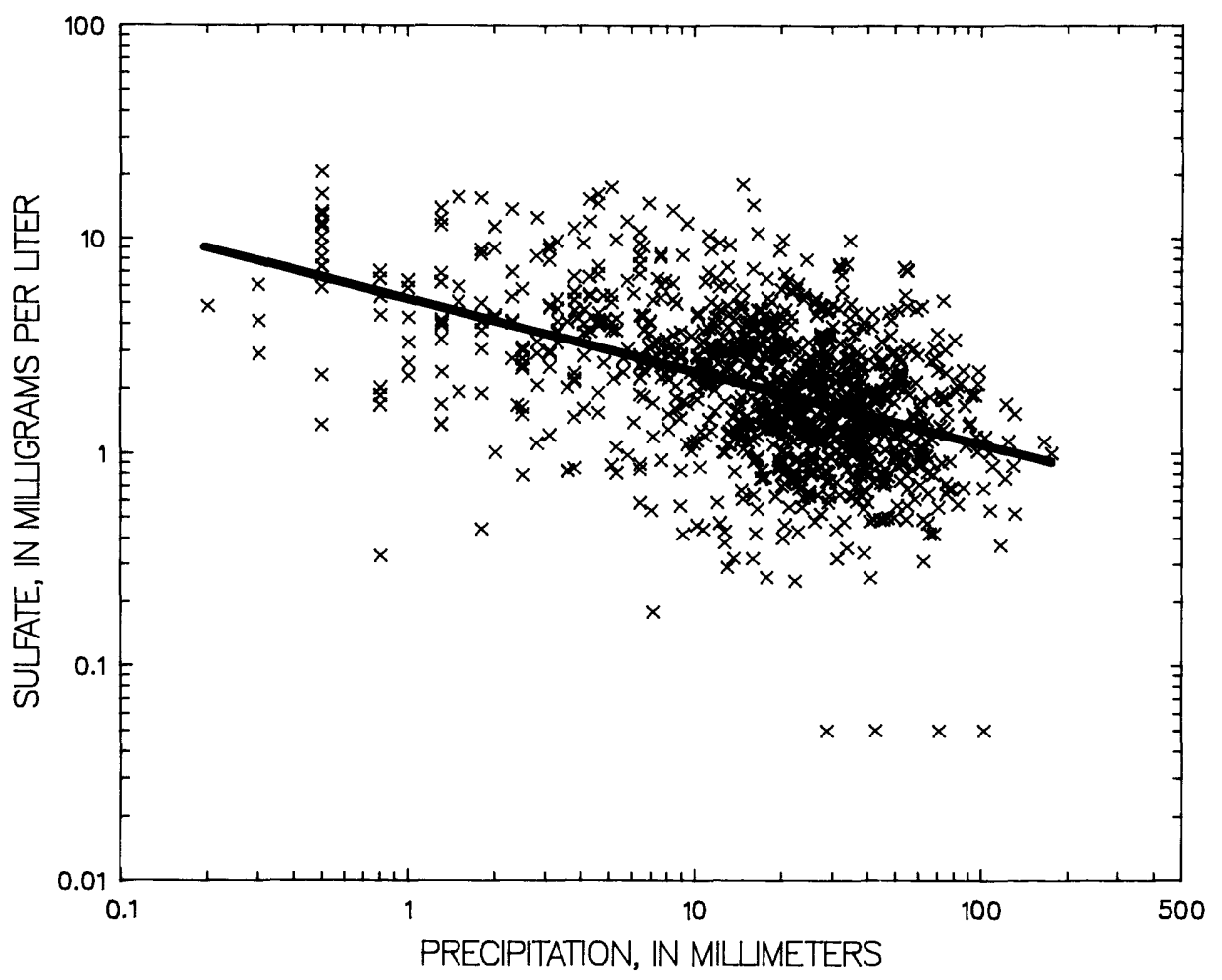

Figure 17a.--Logarithmic relation between sulfate concentrations and precipitation amounts for weekly samples collected from chemical group 1 sites.

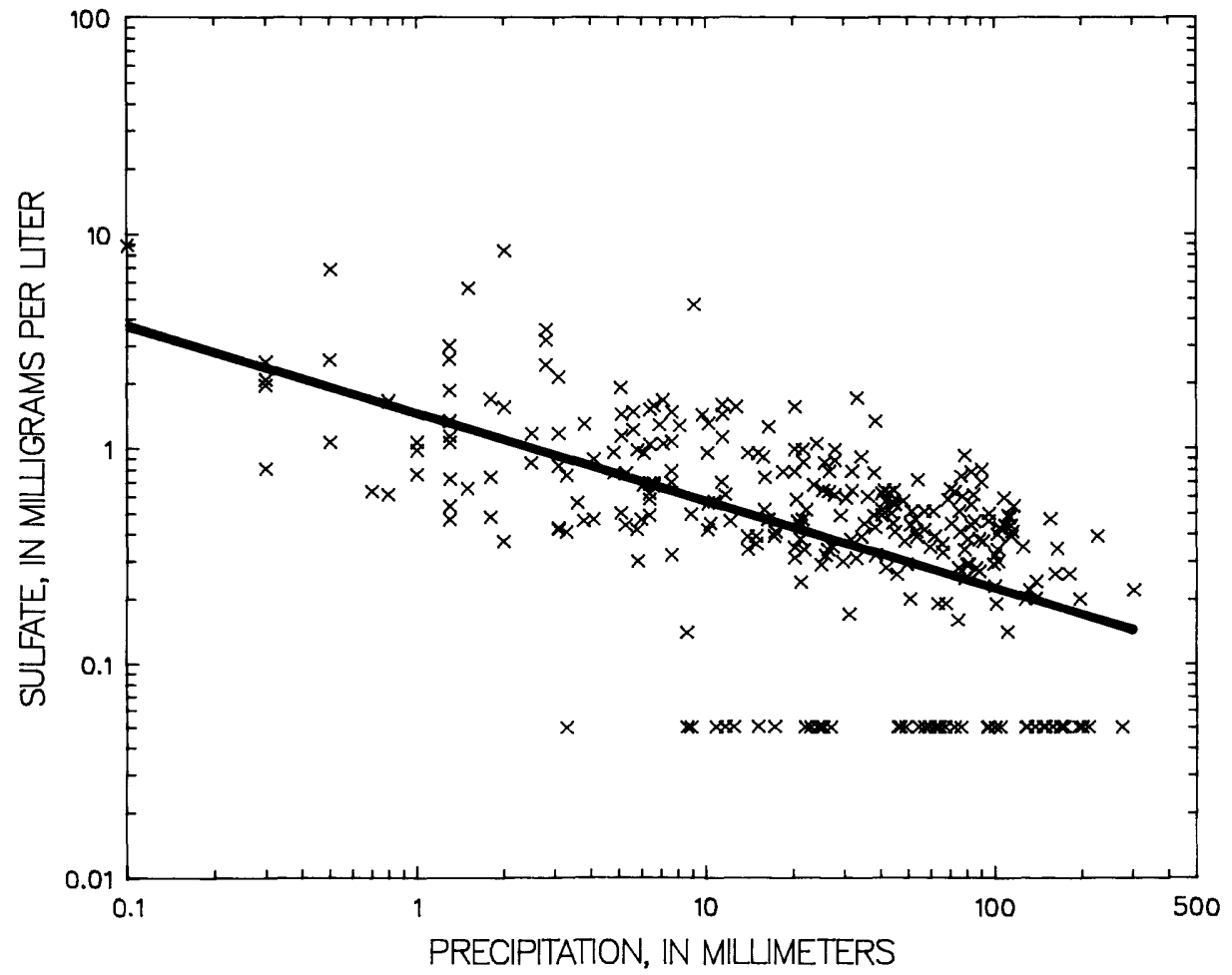

Figure 17b.--Logarithmic relation between sulfate concentrations and precipitation amounts for weekly samples collected from chemical group 6 sites (western coastal sites).

Except the calcium, the regression equations for each of the ions had small $r^{2}$ values (table 9). The small $r^{2}$ values in many cases reflect the large amount of variability in the data and the fact that precipitation quantity may not be a good predictor of concentration for several ions. Calcium exhibited the best relation with precipitation quantity, possibly because the major source of calcium (windblown soil) is considerably reduced (because of high soil moisture) during the period of a year when precipitation quantities tend to be largest. 
Table 9.--Regression relations between selected chemical concentrations and precipitation quantities

The form of the regression equation is: $\ln C=\ln a+b$ [ $\ln Q$ ], where $C=$ chemical concentration, in milligrams per liter; "a" is the regression constant and "b" is the regression coefficient; and $Q=$ precipitation quantity, in millimeters. SE = standard error of estimate, in log units; $r^{2}$ = coefficient of determination; p-level = probability level; "N" = the number of data pairs of precipitation quantity and constituent concentration.

\begin{tabular}{|c|c|c|c|c|c|c|}
\hline \multirow{2}{*}{$\begin{array}{l}\text { Chemical } \\
\text { group }\end{array}$} & \multirow{2}{*}{$\mathrm{N}$} & \multicolumn{5}{|c|}{ Equation coefficients } \\
\hline & & $\ln a$ & $\mathrm{~b}$ & $\mathrm{SE}$ & $r^{2}$ & P-level \\
\hline & & \multicolumn{5}{|c|}{ Hydrogen ion } \\
\hline $\begin{array}{l}1 \\
2 \\
3 \\
4 \\
5 \\
6\end{array}$ & $\begin{array}{l}929 \\
283 \\
684 \\
316 \\
427 \\
295\end{array}$ & $\begin{array}{l}-2.94 \\
-3.55 \\
-5.69 \\
-6.78 \\
-3.66 \\
-5.64\end{array}$ & $\begin{array}{r}-0.147 \\
0.017 \\
0.326 \\
0.308 \\
-0.118 \\
0.001\end{array}$ & $\begin{array}{l}1.006 \\
1.007 \\
1.355 \\
1.159 \\
1.188 \\
1.023\end{array}$ & $\begin{array}{r}0.03 \\
.00 \\
.09 \\
.10 \\
.01 \\
.00\end{array}$ & $\begin{array}{l}0.0001 \\
.73 \\
.0001 \\
.0001 \\
.0072 \\
.98\end{array}$ \\
\hline 6 & & \multicolumn{5}{|c|}{ Sulfate } \\
\hline $\begin{array}{c}1 \\
2 \\
3 \\
4 \\
5 \\
\text { W }\end{array}$ & $\begin{array}{l}929 \\
283 \\
684 \\
316 \\
427 \\
295\end{array}$ & $\begin{array}{c}1.65 \\
1.54 \\
.645 \\
.726 \\
1.48 \\
.351\end{array}$ & $\begin{array}{r}-0.338 \\
-.271 \\
-. .199 \\
-.306 \\
-.366 \\
-. .405\end{array}$ & $\begin{array}{r}0.757 \\
.607 \\
.871 \\
.825 \\
.584 \\
.921\end{array}$ & $\begin{array}{r}0.21 \\
.22 \\
.08 \\
.18 \\
.41 \\
.32\end{array}$ & $\begin{array}{r}0.0001 \\
.0001 \\
.0001 \\
.0001 \\
.0001 \\
.0001\end{array}$ \\
\hline & & \multicolumn{5}{|c|}{ Nitrite plus nitrate } \\
\hline $\begin{array}{l}1 \\
2 \\
3 \\
4 \\
5 \\
6\end{array}$ & $\begin{array}{l}929 \\
283 \\
684 \\
316 \\
427 \\
295\end{array}$ & $\begin{array}{l}1.43 \\
1.42 \\
.626 \\
.580 \\
1.10 \\
-.120\end{array}$ & $\begin{array}{r}-0.424 \\
-. .363 \\
-.277 \\
-.282 \\
-.441 \\
-.384\end{array}$ & $\begin{array}{r}0.750 \\
.577 \\
.865 \\
.839 \\
.804 \\
1.36\end{array}$ & $\begin{array}{r}0.30 \\
.35 \\
.15 \\
.15 \\
.34 \\
.16\end{array}$ & $\begin{array}{r}0.0001 \\
.0001 \\
.0001 \\
.0001 \\
.0001 \\
.0001\end{array}$ \\
\hline & & \multicolumn{5}{|c|}{ Ammonium ion } \\
\hline $\begin{array}{l}1 \\
2 \\
3 \\
4 \\
5 \\
6\end{array}$ & $\begin{array}{l}929 \\
283 \\
684 \\
316 \\
427 \\
295\end{array}$ & $\begin{array}{r}-0.912 \\
-. .534 \\
-1.52 \\
-1.14 \\
-1.07 \\
-1.90\end{array}$ & $\begin{array}{r}-0.365 \\
-. .295 \\
-.114 \\
-.059 \\
-.362 \\
-.340\end{array}$ & $\begin{array}{l}1.23 \\
1.04 \\
1.31 \\
1.31 \\
1.16 \\
1.49\end{array}$ & $\begin{array}{r}0.10 \\
.10 \\
.01 \\
.00 \\
.14 \\
.11\end{array}$ & $\begin{array}{l}0.0001 \\
.0001 \\
.0032 \\
.32 \\
.0001 \\
.0001\end{array}$ \\
\hline & \multicolumn{6}{|c|}{ Calcium } \\
\hline $\begin{array}{l}1 \\
2 \\
3 \\
4 \\
5 \\
6\end{array}$ & $\begin{array}{l}929 \\
283 \\
684 \\
316 \\
427 \\
295\end{array}$ & $\begin{array}{r}-0.130 \\
-.096 \\
-.288 \\
-.132 \\
-.291 \\
-.684\end{array}$ & $\begin{array}{r}-0.688 \\
-.550 \\
-.492 \\
-.485 \\
-.620 \\
-.617\end{array}$ & $\begin{array}{r}0.731 \\
.755 \\
.907 \\
.881 \\
.653 \\
.712\end{array}$ & $\begin{array}{r}0.54 \\
.42 \\
.33 \\
.32 \\
.61 \\
.65\end{array}$ & $\begin{array}{r}0.0000 \\
.0000 \\
.0000 \\
.0000 \\
.0000 \\
.0000\end{array}$ \\
\hline
\end{tabular}


Predicted values from the regression analysis provide an estimate of the lower baseline concentrations for each of the chemical groups (table 10). Baseline concentrations are not considered to be background (meaning without man's influence), but instead represent the lowest expected mean concentration for a chemical group in 1983. Baseline values are estimated as being associated with a precipitation amount of $400 \mathrm{~mm}$, which is about the maximum precipitation quantity measured for samples in 1983 (constituent values associated with $200 \mathrm{~mm}$ of precipitation were similar to those values associated with $400 \mathrm{~mm}$ ). Baseline concentrations at most of the western coastal sites (group 6) show minimal direct influences by man because airflow is generally from the Pacific Ocean.

Precipitation quantity accounts for a small amount of the variation observed in the weekly $\mathrm{pH}$ values within a chemical group. Perhaps $\mathrm{r}^{2}$ values would increase if regressions were computed on storm-event data that were analyzed separately for each site. Results (table 10) of the regression between precipitation quantity and hydrogen-ion concentration show that the group with the largest baseline $\mathrm{pH}$ value is chemical group 6 (western coastal sites). The regressions for group 1 and 5 data show positive relations between $\mathrm{pH}$ and precipitation quantity, those for groups 3 and 4 show negative relations, and those for groups 2 and 6 show no relation. The regression for group 6 data may be showing no relation because influences by man are minimal.

The concentration of hydrogen ions is inversely related to $\mathrm{pH}$ : as the concentration increases, $\mathrm{pH}$ values decrease. The positive relation between $\mathrm{pH}$ and precipitation quantities at group 1 and 5 sites is, therefore, consistent with the theory that as precipitation quantities increase, the finite supply of airborne hydrogen ions may be removed and subsequently diluted. The rationale for the statistically significant negative relations between $\mathrm{pH}$ and precipitation quantities at group 3 and 4 sites is not known, but the negative relations could be associated with relatively large decreases in acid-neutralizing anions as precipitation quantities increase. Both of the major acid-related constituents, sulfate and nitrate, evidently do decrease with increasing precipitaticn. Baseline nitrate levels are about $0.5 \mathrm{mg} / \mathrm{L}$, for interior regions of the United States, and about 0.2 to $0.3 \mathrm{mg} / \mathrm{L}$ for coastal areas. Baseline sulfate levels reflect areas of high fossil fuel consumption, with values for group 1 and 2 sites being about 4 to 5 times the $0.2-\mathrm{mg} / \mathrm{L}$ level for group 6 sites.

Predicted ammonium-ion concentrations associated with $400 \mathrm{~mm}$ of precipitation varied considerably among the chemical groups. Coastal sites had small values and group 4 sites had the largest concentrations (livestock wastes, fertilizer, and soil $\mathrm{pH}$ may contribute to large ammonium concentrations in region 4). The fact that concentrations changed the least with precipitation at group 3 and 4 sites may indicate a relatively large ammonia source. Calcium concentrations dropped considerably with increasing precipitation. As noted earlier, calcium had the best relation with precipitation quantity. Group 3 and 4 sites had the largest baseline values, coincident with largest ammonium concentrations. The larger concentrations of calcium at group 3 and 4 sites probably reflect the windblown soil particulate contributions from agricultural activities. Baseline calcium concentrations are about 0.03 $\mathrm{mg} / \mathrm{L}$ in all groups, except 3 and 4 , where baseline concentrations are about $0.06 \mathrm{mg} / \mathrm{L}$. 
Table 10.--Predicted precipitation chemistry for selected precipitation quantities

The equations shown in table 9 were used to calculate the predicted chemical concentrations. The predicted hydrogen-ion concentrations, in milligrams per liter, were converted to $\mathrm{pH}$ values in this table.

\begin{tabular}{|c|c|c|c|c|c|c|c|}
\hline \multirow{2}{*}{$\begin{array}{l}\text { Chemical } \\
\text { group }\end{array}$} & \multicolumn{7}{|c|}{ Precipitation quantity, in millimeters } \\
\hline & 0.3 & 1 & 10 & 50 & 100 & 200 & 400 \\
\hline \multicolumn{8}{|c|}{$\mathrm{pH}$, in $\mathrm{pH}$ units } \\
\hline $\begin{array}{l}1 \\
2 \\
3 \\
4 \\
5 \\
6\end{array}$ & $\begin{array}{l}3.98 \\
4.33 \\
5.24 \\
5.81 \\
4.22 \\
5.22\end{array}$ & $\begin{array}{l}4.06 \\
4.32 \\
5.07 \\
5.65 \\
4.28 \\
5.22\end{array}$ & $\begin{array}{l}4.20 \\
4.30 \\
4.75 \\
5.34 \\
4.40 \\
5.22\end{array}$ & $\begin{array}{l}4.31 \\
4.29 \\
4.52 \\
5.13 \\
4.48 \\
5.22\end{array}$ & $\begin{array}{l}4.35 \\
4.29 \\
4.42 \\
5.04 \\
4.52 \\
5.22\end{array}$ & $\begin{array}{l}4.40 \\
4.28 \\
4.32 \\
4.94 \\
4.55 \\
5.22\end{array}$ & $\begin{array}{l}4.44 \\
4.28 \\
4.22 \\
4.85 \\
4.59 \\
5.22\end{array}$ \\
\hline \multicolumn{8}{|c|}{ Sulfate, in milligrams per liter } \\
\hline $\begin{array}{l}1 \\
2 \\
3 \\
4 \\
5 \\
6\end{array}$ & $\begin{array}{c}10.4 \\
7.73 \\
3.54 \\
4.20 \\
8.08 \\
3.54\end{array}$ & $\begin{array}{l}6.92 \\
5.58 \\
2.78 \\
2.91 \\
5.20 \\
2.17\end{array}$ & $\begin{array}{r}3.18 \\
2.99 \\
1.76 \\
1.44 \\
2.23 \\
.86\end{array}$ & $\begin{array}{r}1.84 \\
1.93 \\
1.28 \\
.88 \\
1.24 \\
.44\end{array}$ & $\begin{array}{r}1.46 \\
1.60 \\
1.11 \\
0.71 \\
.96 \\
.34\end{array}$ & $\begin{array}{r}1.15 \\
1.33 \\
0.97 \\
.57 \\
.74 \\
.25\end{array}$ & $\begin{array}{r}0.91 \\
1.10 \\
.84 \\
.46 \\
.58 \\
.19\end{array}$ \\
\hline \multicolumn{8}{|c|}{ Nitrite plus nitrate, in milligrams per liter } \\
\hline $\begin{array}{l}1 \\
2 \\
3 \\
4 \\
5 \\
6\end{array}$ & $\begin{array}{l}9.26 \\
7.59 \\
3.79 \\
3.57 \\
7.03 \\
3.54\end{array}$ & $\begin{array}{l}5.56 \\
4.90 \\
2.72 \\
2.54 \\
4.13 \\
2.23\end{array}$ & $\begin{array}{l}2.09 \\
2.13 \\
1.44 \\
1.33 \\
1.50 \\
0.92\end{array}$ & $\begin{array}{r}1.06 \\
1.19 \\
0.92 \\
.84 \\
.74 \\
.50\end{array}$ & $\begin{array}{r}0.79 \\
.92 \\
.76 \\
.69 \\
.54 \\
.38\end{array}$ & $\begin{array}{r}0.59 \\
.72 \\
.63 \\
.57 \\
.40 \\
.29\end{array}$ & $\begin{array}{r}0.44 \\
.56 \\
.52 \\
.47 \\
.29 \\
.22\end{array}$ \\
\hline \multicolumn{8}{|c|}{ Ammonium ion, in milligrams per liter } \\
\hline $\begin{array}{l}1 \\
2 \\
3 \\
4 \\
5 \\
6\end{array}$ & $\begin{array}{r}1.32 \\
1.44 \\
0.59 \\
.81 \\
1.05 \\
.68\end{array}$ & $\begin{array}{r}0.85 \\
1.01 \\
.52 \\
.75 \\
.68 \\
.45\end{array}$ & $\begin{array}{r}0.37 \\
.51 \\
.40 \\
.66 \\
.29 \\
.21\end{array}$ & $\begin{array}{r}0.20 \\
.32 \\
.33 \\
.60 \\
.16 \\
.12\end{array}$ & $\begin{array}{r}0.16 \\
.26 \\
.30 \\
.57 \\
.13 \\
.09\end{array}$ & $\begin{array}{r}0.12 \\
.21 \\
.28 \\
.55 \\
.10 \\
.07\end{array}$ & $\begin{array}{r}0.10 \\
.17 \\
.26 \\
.53 \\
.08 \\
.06\end{array}$ \\
\hline \multicolumn{8}{|c|}{ Calcium, in milligrams per liter } \\
\hline $\begin{array}{l}1 \\
2 \\
3 \\
4 \\
5 \\
6\end{array}$ & $\begin{array}{l}2.63 \\
2.34 \\
2.04 \\
2.32 \\
1.95 \\
1.37\end{array}$ & $\begin{array}{r}1.15 \\
1.21 \\
1.13 \\
1.29 \\
.92 \\
.65\end{array}$ & $\begin{array}{r}0.23 \\
.34 \\
.36 \\
.42 \\
.22 \\
.16\end{array}$ & $\begin{array}{r}0.08 \\
.14 \\
.16 \\
.19 \\
.08 \\
.06\end{array}$ & $\begin{array}{r}0.05 \\
.10 \\
.12 \\
.14 \\
.05 \\
.04\end{array}$ & $\begin{array}{r}0.03 \\
.06 \\
.08 \\
.10 \\
.03 \\
.02\end{array}$ & $\begin{array}{r}0.02 \\
.04 \\
.06 \\
.07 \\
.02 \\
.02\end{array}$ \\
\hline
\end{tabular}


The baseline chemical concentrations in precipitation for the six chemical groups (table 10) were compared to the chemical concentrations in precipitation measured at five remote sites around the world. These remote sites are located in Alaska, Australia, Bermuda, South Indian Ocean, and Venezuela. Effects of man's activities on precipitation chemistry at these remote sites were expected to be minimal, and the data from these sites used for this comparison were collected from December 3, 1979, to May 1, 1981 (Calloway and others, 1982). The median volume-weighted concentrations of sulfate, nitrate, and ammonia at the remote sites $(0.34,0.16,0.038$ milligrams per liter respectively) are most similar to those baseline concentrations $(0.19$, 0.22 , and 0.06 milligrams per liter respectively; listed in table 10) for chemical group 6 (western coastal sites). The baseline concentrations for the other chemical groups were generally more than twice those concentrations at the remote sites. The median $\mathrm{pH}$ for the remote sites ( $\mathrm{pH}-4.81$, based on the median of the volume-weighted hydrogen-ion concentrations) was most similar to the baseline $\mathrm{pH}$ of chemical group 5. Except for group 6, which has a baseline pH (pH $5.22)$ slightly larger than the median $\mathrm{pH}$ of the remote sites, the baseline $\mathrm{pH}$ values of the other chemical groups were all smaller (smaller $\mathrm{pH}$ values indicate larger hydrogen-ion concentrations). These comparisons indicate that, for large precipitation quantities, the chemical concentrations at the western coastal sites in chemical group 6 are minimally influenced by man's activities and tend to be most representative of median chemical concentrations at remote sites around the world.

\section{SUMMARY}

Frequency distributions of precipitation-chemistry data for the 1983 calendar year are tabulated for 10 measured chemicals in precipitation and for precipitation quantities from 109 NTN sites in the United States. Generally, the constituent concentrations in precipitation vary widely from site to site. Data from the NTN sites and from 28 CANSAP sites were screened against a set of criteria to insure the representativeness of precipitation samples. Subsequently, each site was evaluated under four criteria to insure representative data coverage for the year. Application of screening criteria reduced the data set to 55 NTN and 18 CANSAP sites. The data from these 73 sites were used to construct maps that show annual mean volume-weighted concentrations and annual loads in precipitation for several chemicals for the conterminous United States. An interpolation technique (Kriging) was used to delineate lines of equal constituent concentrations nationwide. These maps show that the largest chemical concentrations and loads in precipitation are found mostly in the geographic areas of the highly industrialized and densely populated northeastern United States. Ammonium and calcium concentrations in precipitation were largest in the agricultural midwest and plains states.

Trilinear diagrams of chemical ionic concentration were used to group NTN data into six chemical groups. The groups, each having precipitation with a distinctive chemical composition, are located in well-defined geographical areas. The chemical groups show influences on precipitation chemistry from the following sources: proximity of sites to the oceans, proximity of sites to the major industrial and fossilfuel consuming areas, and proximity of sites to the major areas of agricultural activity. 
Finally, selected ionic ratios in precipitation were examined for each chemical group. Cation-to-anion ratios generally were between 0.9 and 1.1 , but group 4 sites had a positive bias, with a ratio of about 1.2. The most likely cause of a high cation-to-anion ratio is that one of the anion determinations is consistently biased low or that one of the anions is not being determined. Ratios of sulfate to nitrate in precipitation are much larger in chemical groups 1 and 2 than in group 6 (western coastal sites). Regional differences in sulfate-to-nitrate ratios may reflect differences in the type of fossil fuel consumption; eastern regions may exhibit larger sulfate concentrations because of greater consumption of high-sulfur coal. Large hydrogen-ion concentrations in milliequivalents per liter (groups 1 and 2) were approximately balanced by sulfate-plus-nitrate ion concentrations. For chemical groups that have small hydrogen-ion concentrations (groups 3 and 4), ammonium and calcium-ion concentrations, along with hydrogen-ion concentrations, are necessary to ionically balance the sulfate-plusnitrate concentrations. Thus ammonium and calcium in precipitation may partly account for the high $\mathrm{pH}$ values in chemical groups 3 and 4 because they may have neutralized some of the hydrogen ions.

Constituent concentrations in precipitation and precipitation quantity relations were evaluated by using correlation and regression analysis. Kendall Tau correlation analysis indicated that significant $(\rho$-level $<0.10)$ negative correlations between constituent concentrations in precipitation and precipitation quantity occur at most of the NTN sites for the following constituents: specific conductance, calcium, magnesium, sodium, potassium, chloride, nitrite plus nitrate, and sulfate. Although significant correlations for ammonium were all negative, almost 50 percent of sites showed that ammonium in precipitation and precipitation quantity were not significantly correlated. Correlations between the $\mathrm{pH}$ of precipitation and precipitation quantity generally were negative for chemical groups 3 and 4 and were positive for groups 1 and 5 . Few significant correlations between hydrogen ion in precipitation and precipitation quantity were observed in chemical groups 2 and 6 . These few significant correlations may be found in chemical group 6 (western coastal sites) because of minimal influences by man and the relative uniformity of ambient air quality over the Pacific Ocean. Regression analysis indicated that precipitation quantities collected on a weekly basis account for a small amount of the variation observed in the corresponding concentrations of most constituents in precipitation, especially hydrogen. Calcium was the only exception. Precipitation quantity accounted for more than 30 percent of the calcium variation in precipitation, possibly because of increased dilution of samples and the effects of soil moisture. Increased soil moisture reduces the availability of windborne calcareous-soil particulates in the atmosphere.

The baseline chemical concentrations in precipitation for the six chemical groups in the conterminous United States were compared to chemical concentrations in precipitation measured at five remote sites around the world. These comparisons indicate that, for large precipitation quantities, the chemical concentrations at the western coastal sites in chemical group 6 are minimally influenced by man's activities and tend to be most representative of median chemical concentrations at remote sites around the world. 


\section{REFERENCES CITED}

Bigelow, D. S., 1984, Instruction Manual NADP/NTN site selection and installation: National Atmospheric Deposition Program, $23 \mathrm{p}$. and appendices.

Bloxam, Robert M., Hornbeck, James W., and Martin, C. Wayne, 1984, The influence of storm characteristics on sulfate in precipitation: Water, Air, and Soil Pollution, v. 23, p. 359-374.

Conover, W. J., 1980, Practical nonparametric statistics (2nd ed.): New York, John Wiley and Sons, $493 \mathrm{p}$.

Draper, N. R., and Smith, H., 1981, App1ied regression analysis (2nd ed): New York, John Wiley and Sons, 709 p.

Ferguson, R. I., 1986, River loads underestimated by rating curves: Water Resources Research, v. 22, no. 1, p. 74-76.

Galloway, J. N., Likens, G. E., Keene, W. C., and Miller, J. M. , 1982, The composition of precipitation in remote areas of the world: Journal of Geophysical Research, v. 87, no. 11, p. 8771-8786.

Hem, John D., 1985, Study and interpretation of the chemical characteristics of natural water: U.S. Geological Survey Water Supply Paper 2254 (3rd ed.), 263 p.

Junge, Christian E., 1958, The distribution of ammonia and nitrate in rain water over the United States: Transactions, American Geophysical Union, v. 39, no. 2, p. 241-248.

Laird, L. B., Taylor, H. E., and Kennedy, V. C., 1986, Snow chemistry of the Cascade-Sierra Nevada Mountains: Environmental Science and Technology, v. 20, no. 3, p. 275-290.

Likens, G. E., and Butler, T. J., 1981, Recent acidification of precipitation in North America: Atmospheric Environment, v. 15, p. 1103 .

Miles, Larry J., and Yost, Kenneth J., 1982, Quality analysis of USGS precipitation chemistry data for New York: Atmospheric Environment, v. 16, no. 12 , p. 2889-2899.

Nationa1 Atmospheric Deposition Program Subcommittee Number 3, Data Management and Analysis, 1985, NADP annual data summary of precipitation chemistry in the United States 1982: National Atmospheric Deposition Program, 134 p.

01ea, Ricardo A., 1975, Optimum mapping techniques using regionalized variable theory: Kansas Geological Survey, 137 p.

Robertson, J. K., and Wilson, J. W., 1985, Design of the National Trends Network for monitoring the chemistry of atmospheric precipitation: U.S. Geological Survey Circular 964, 46 p.

SAS Institute, 1982, User's Guide: Basics, SAS Institute, Inc., Cary, North Carolina, 921 p. 
Skriven, James A., and Karlinger, Michael R., 1980, Semi-variogram estimation and universal Kriging program: U.S. Geological Survey Computer Contribution, $98 \mathrm{p}$.

U.S. Department of Agriculture, 1957, The yearbook of agriculture 1957, 85 th Congress, 1st Session, House Document No. 30, 784 p.

U.S. Department of Energy, 1985, Cost and quality of fuels for electric utility plants, 1984: DOE/EIA-0191(84), 222 p.

U.S. Environmental Protection Agency, 1980, Acid rain: EPA-600/9-79-036, $36 \mathrm{p}$.

U.S. Geological Survey, 1970, The national atlas of the United States of America: U.S Department of Interior, Washington, D.C., 417 p.

Watson, C. R., and 0lsen, A. R., 1984, Acid deposition system (ADS) for statistical reporting, system design and user's code manual: EPA$600 / 8-84-023,32 \mathrm{p}$. and appendices. 


\section{APPENDIX I: DESCRIPTION OF STATISTICAL COMPUTATIONS, TABLES, AND FIGURES FOR INDIVIDUAL STATION SUMMARIES}

Chemical analyses of the weekly composited precipitation samples collected in calendar year 1983 are summarized for each of the National Trends Network sites. Laboratory analytical results reported in this section are specific conductance, $\mathrm{pH}$, ammonium, calcium, magnesium, potassium, sodium, chloride, nitrite plus nitrate, and sulfate. Analyses of each of the weekly composited precipitation samples are available in the 1983 National Atmospheric Deposition Program Quarterly Reports (National Atmospheric Deposition Program, 1985). The quarterly reports also include determinations of phosphate and field measurements of $\mathrm{pH}$ and specific conductance of precipitation. Phosphate determinations are not summarized in this report, because the majority of the reported concentrations are below the analytical detection limit of $0.003 \mathrm{mg} / \mathrm{L}$.

Individual site data are summarized in the Appendices II and III. One section includes those sites that have complete precipitationchemistry records in 1983 (as defined by criteria outlined earlier in the report); the other site-summary section includes those sites having partial precipitation-chemistry records (site data not meeting criteria for annual statistical computations, such as annual volume-weighted means and annual totals).

The following is a description of selected information, statistical computations, and figures for each NTN site shown in Appendices II and III :

(1) Station name -- NADP/NTN (National Atmospheric Deposition Program/National Trends Network) station name.

(2) CAL number -- Site code designated by the CAL (Central Analytical Laboratory) of Illinois State Water Survey in Champaign, Illinois. CAL analyzes precipitation samples for the NADP/NTN network.

(3) ADS number - - Site code used in the Acid Deposition System data repository system.

(4) Total measured ppt (precipitation) - - Total measured precipitation from the rain gage. Precipitation amounts from the precipitation (wet-deposition) sample bucket were substituted for missing raingage measurements.

(5) Distribution percentiles of selected constituents - - Percentiles provide a measure of the variability of the data. The tables show the 0 (minimum), 10, 25, 50 (median), 75, 90, and 100 (maximum) percentiles.

(6) Arithmetic mean - - Arithmetic mean is equal to the sum of constituent values divided by the number of measurements. 
(7) Volume-weighted mean chemical concentration is computed as follows:

$\begin{aligned} & \text { Volume-weighted } \\ & \text { mean } \\ & \text { concentration }\end{aligned}=\frac{\begin{array}{l}\text { Sum of the products: constituent concentrations } \\ \text { times the precipitation volumes for each sample }\end{array}}{\text { Sum of the precipitation volumes for each sample }}$

Precipitation volumes for each sample are from the rain gage; precipitation amounts from the precipitation (wet-deposition) sample bucket are substituted for missing rain-gage measurements.

Precipitation volume-weighted means correspond to chemical concentrations that would occur in annual-composited, precipitation samples, assuming that chemical species are conservative.

For volume-weighted $\mathrm{pH}$ values, each $\mathrm{pH}$ value was first converted to a hydrogen-ion concentration, using the equation:

$$
\left(\mathrm{H}^{+}\right) \text {, in moles per liter }=10^{-\mathrm{pH}} \text {. }
$$

The volume-weighted mean hydrogen-ion concentration was computed (using the above equation) and then converted back to a $\mathrm{pH}$ value.

(8) Total load - - The total constituent load is computed based on the annual mass of the chemical constituent that collects in the precipitation (wet-deposition) bucket. The chemical mass is the sum of the products of the rain-gage amounts and chemical concentration for each precipitation sample. The rain-gage amount is the predicted volume of precipitation (based on the rain-gage depth) that would have collected in the precipitationsample bucket.

(9) Kendall tau correlations - - A nonparametric statistic that shows the degree of association between precipitation quantities and chemical concentrations in wet deposition. Positive Kendall tau coefficients show a positive relation between precipitation quantities and chemical concentrations in precipitation (as precipitation quantities increase, chemical concentrations increase); negative coefficients show negative relations between precipitation quantities and chemical concentrations in precipitation (as precipitation quantities increase, chemical concentrations decrease).

(10) Percentiles of volume-weighted means -- Percentile distributions for volume-weighted means were computed for the 55 sites that met criteria for having complete precipitation-chemistry records for 1983. These percentiles are graphically shown for each volume-weighted mean for each site (that had complete records).

If a particular site has a mean volume-weighted mean sulfate concentration in precipitation that ranks at the 50 th percentile, 50 percent of the 55 sites ( 27 sites) have volumeweighted mean nitrate concentrations less than or equal to the mean for the particular site, and 50 percent of the sites have volume-weighted mean sulfate concentrations greater than or equal to the mean for the particular site. 
(11) Date bar plot of selected constituents -- Date bar plots show weekly rain-gage measurements and weekly concentrations of $\mathrm{pH}$, sulfate, and nitrate for weekly precipitation samples from the 55 sites that had complete precipitation-chemistry records in 1983. The overlying line plots show cumulative constituent loads. Constituent loads are a function of rain-gage quantities and constituent concentrations. As quantity or concentration increase, the constituent load increases.

(12) Trilinear diagrams - - Diagrams that show the percentage composition of major cations and anions in precipitation for each site. Percentages are based on the percent of total equivalents per liter. 


\section{APPENDIX II: \\ Statistical Summaries for \\ Stations with Sufficient Data for Characterizing \\ Precipitation Chemistry in 1983}

(Station summaries are ordered numerically by
Map ID numbers listed in table 1) 


\section{NATIONAL TRENDS NETWORK - 1983 CALENDER YEAR SUMMARY DATA}

[ppt $=$ precipitation $; \mathrm{mm}=$ millimeters $; \mathrm{cm}=$ centimeters $; \mathrm{mg}=$ milligrams; $\mathrm{L}=1$ iters; $\mathrm{g}=\mathrm{grams} ; \mathrm{m}=$ metex; $\mu \mathrm{s}=$ microsiemens; cond $=$ specific conductance $]$

STATION: Warren 2WSW, Arkansas

CAL number: AR02

ADS number: $268 \mathrm{a} 00$

Station altitude above mean sea level, in meters: 78 Number of sampling intervals (days in parenthesis):

-- With ppt measurements: 52 (371)

- When ppt occurred: 49

-- When ppt did not occur: 3 (21)

-- When sample volume was substituted for missing rain gage: 0 ( 0 )

-- With chemical samples: 35 (252)
Latitude: $33^{\circ} 36^{\prime} 15^{\prime \prime}$ Longitude: $92^{\circ} 06^{\prime} 02^{\prime \prime}$

Station surmary period: $12 / 28 / 1982$ to $01 / 03 / 1984$

Length of surmary period: 52 sampling intervals ( 371 days)

Percent summary period with ppt measurements: $\quad 100.0$

Percent sumary period with chemical samples or no ppt: 73.6

Percent of total measured ppt with chemical samples: 79.0

Percent of total measured ppt in raingage that was

collected in the wet-sample bucket:

98.5

Total measured ppt, in m: 1324.8

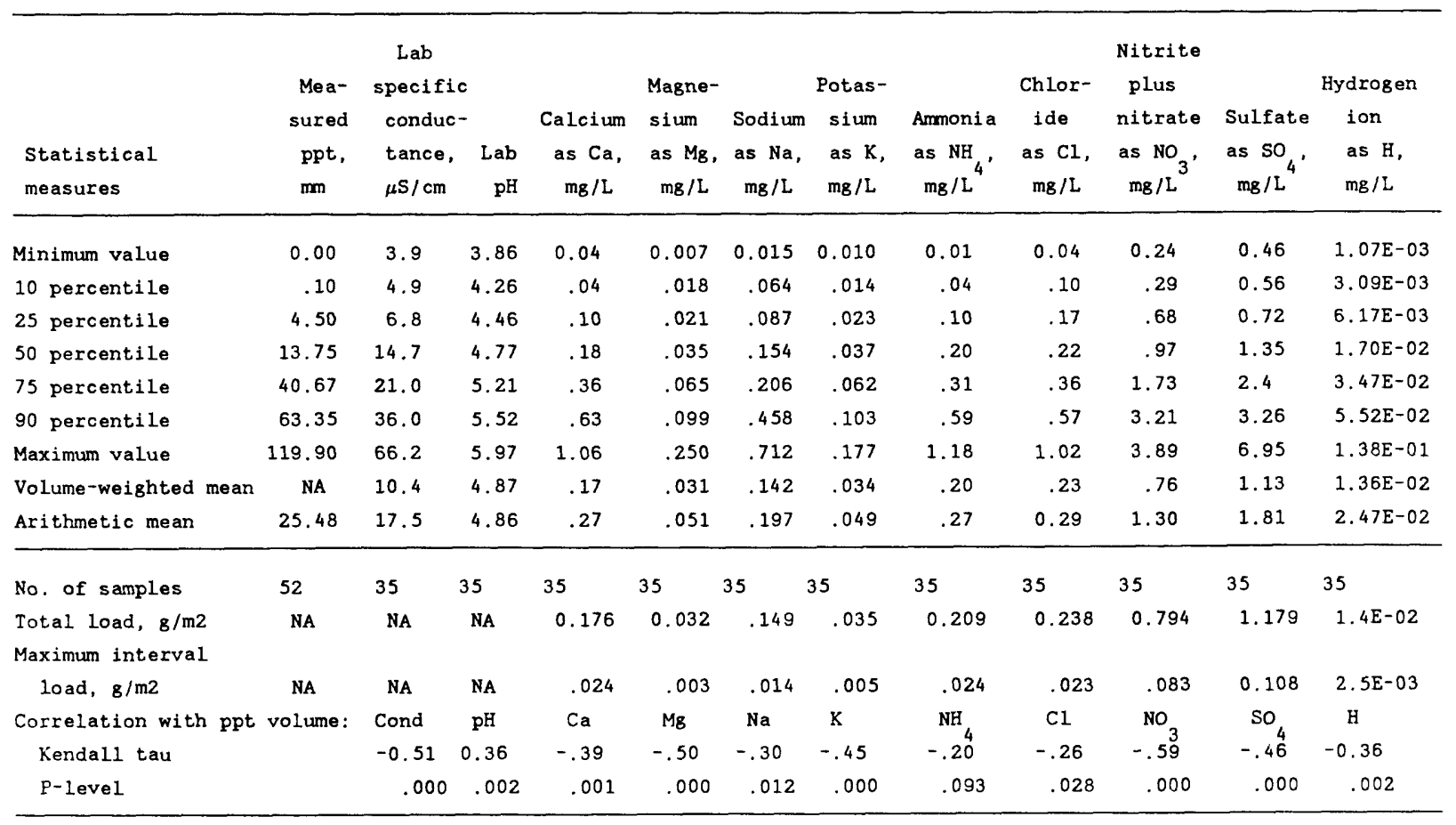

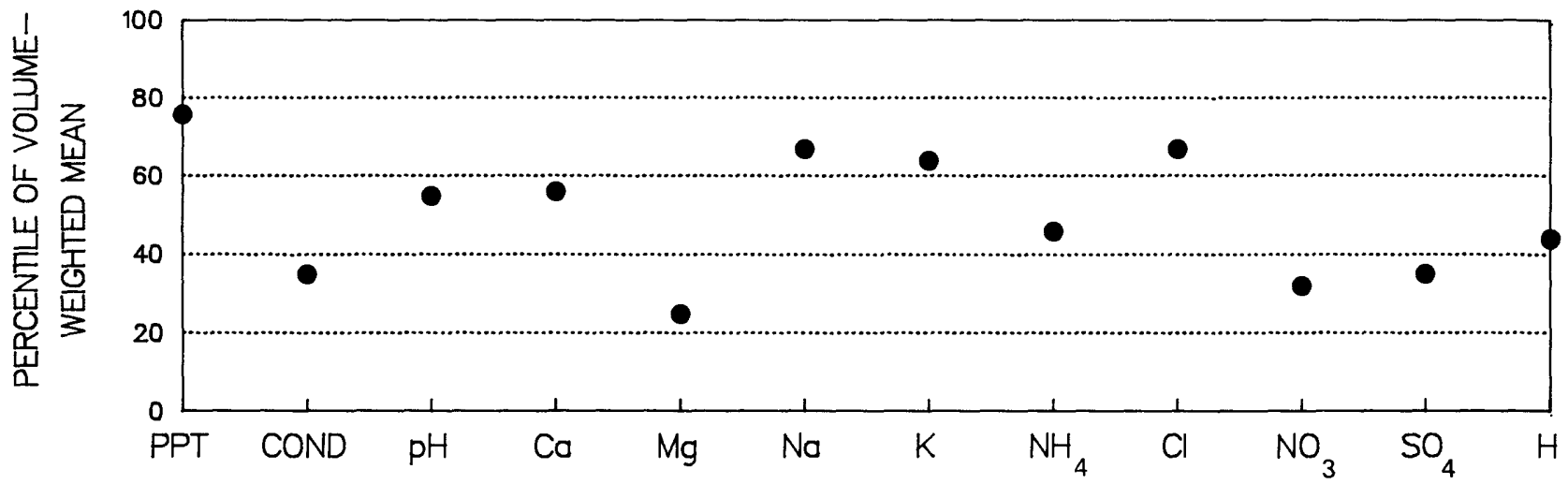

Percentiles of volume-weighted mean concentrations for site AR02, based on frequency distributions of data from 55 National Trends Network sites. 

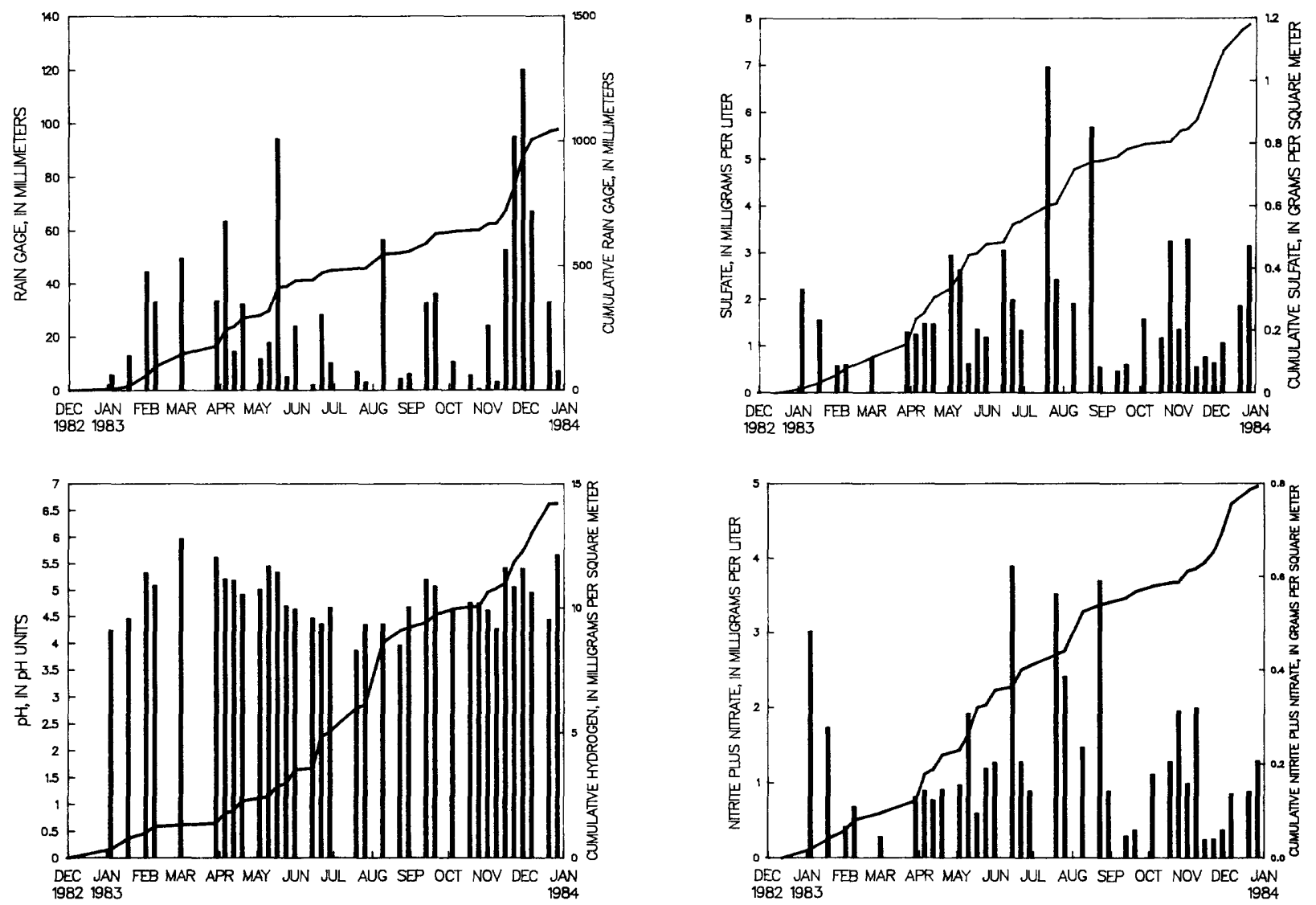

Bar plots of concentrations and cumulative line plots of loads for site AR02. Nitrite plus nitrate are reported as $\mathrm{NO}_{3}$ and sulfate as $\mathrm{SO}_{4}$.

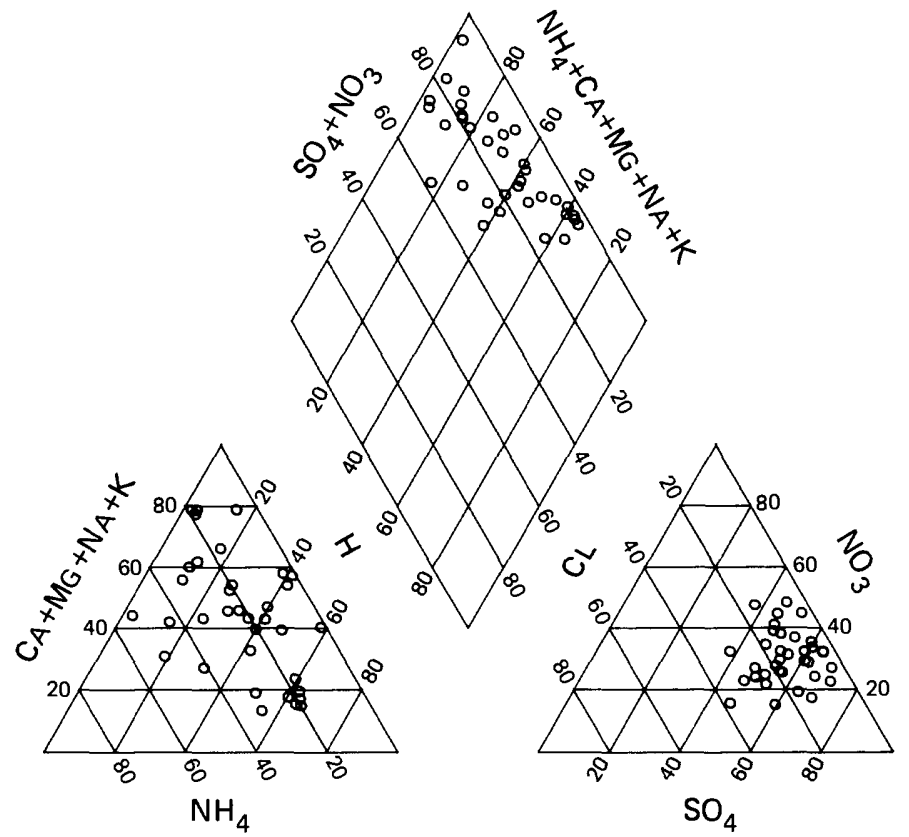

Percentage composition of major ions for site AR02. 
lppt = precipitation; $\mathrm{mm}=$ millimeters; $\mathrm{cm}=$ centimeters; $\mathrm{mg}=$ milligrams; $\mathrm{L}=11$ ters;

$8=$ grams; $m=$ meter; $\mu \mathrm{s}=$ microsiemens; cond = specific conductance $]$

STATION: Fayetteville, Arkanses

CAL number: AR27

ADS number: $004 \mathrm{a} 00$

Station altitude above mean sea level, in meters: 391

Number of sampling intervals (days in parenthesis):

-- With ppt measurements: $52 \quad$ (364)

-- When ppt occurred: $46 \quad$ (322)

-- When ppt did not occur: 6 (42)

- When sample volume was substituted for missing rain gage: 0 ( 0 )

-- With chemical samples: 38
Latitude: $36^{\circ} 06^{\prime} 02^{\prime \prime}$ Longitude: $94^{\circ} 10^{\prime} 24^{\prime \prime}$

Station sumery period: $12 / 28 / 1982$ to $01 / 03 / 1984$

Length of summary period: 53 sampling intervals ( 371 days)

Percent summary period with ppt measurements: $\quad 98.1$

Percent surmary period with chemical samples or no ppt: 83.0

Percent of total measured ppt with chemical samples: 92.1

Percent of total measured ppt in raingage that was

collected in the wet-sample bucket:

87.5

Totel meesured ppt, in $\mathrm{mm}: 906.5$

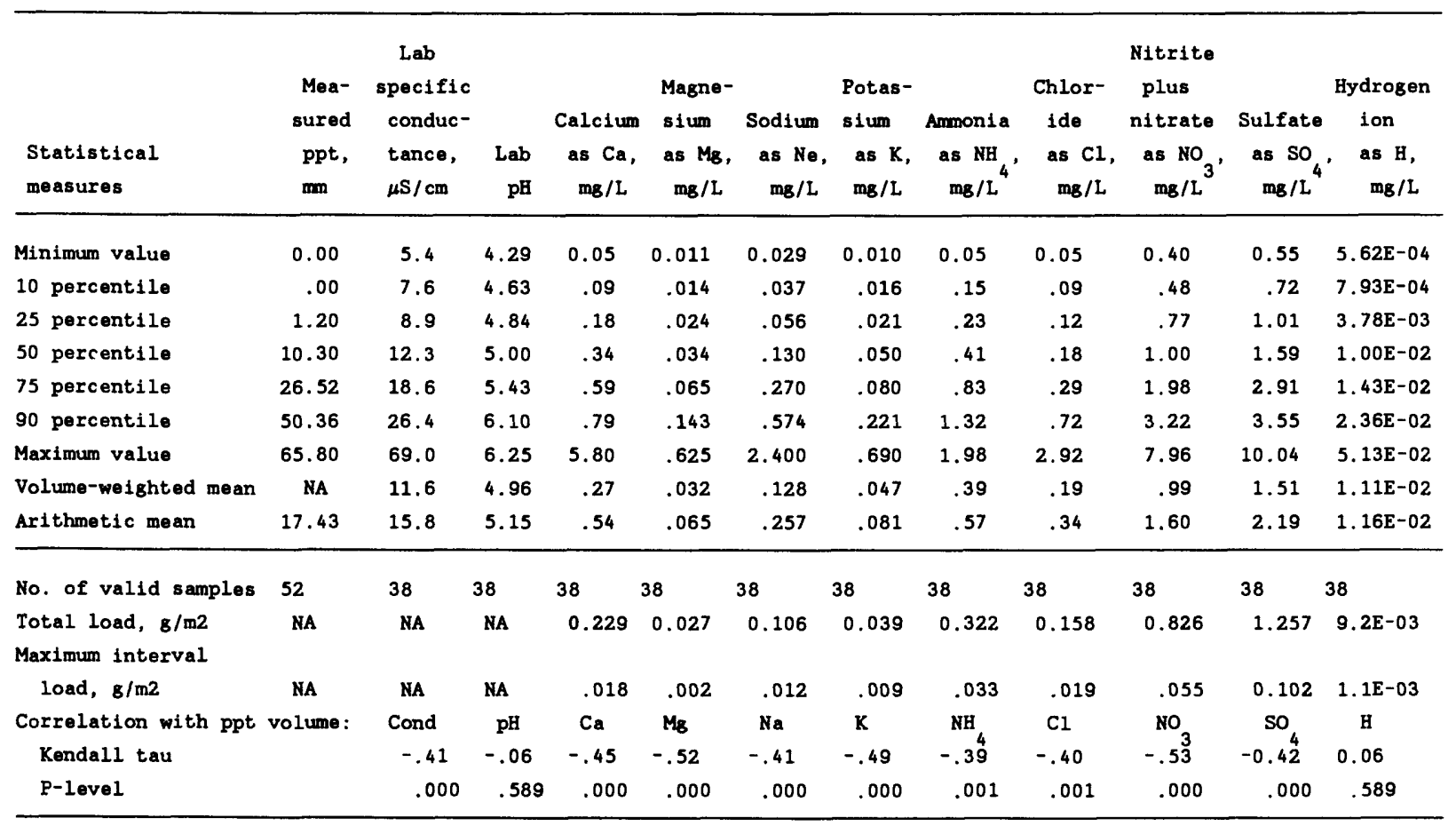

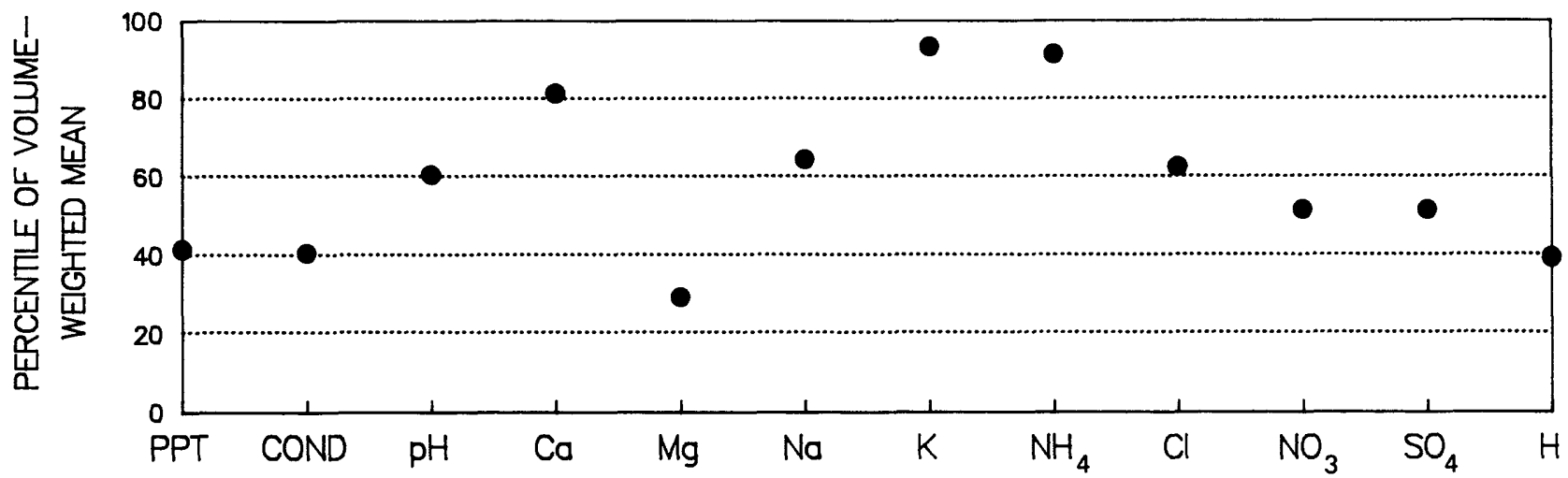

Percentiles of volume-weighted mean concentrations for site AR27, based on frequency distributions of data from 55 National Trends Network sites. 

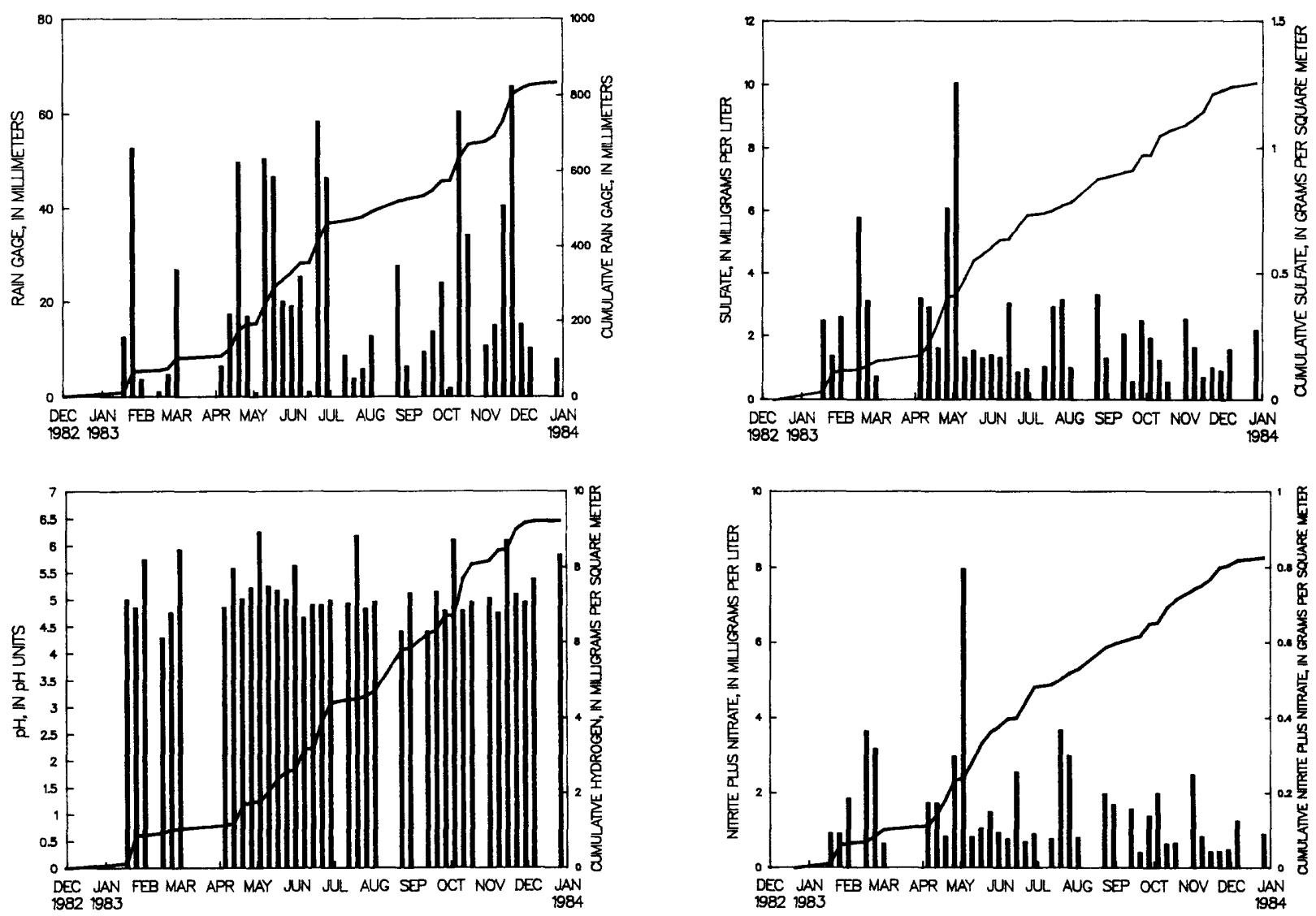

Bar plots of concentrations and cumulative line plots of loads for site AR27. Nitrite plus nitrate are reported as $\mathrm{NO}_{3}$ and sulfate as $\mathrm{SO}_{4}$.

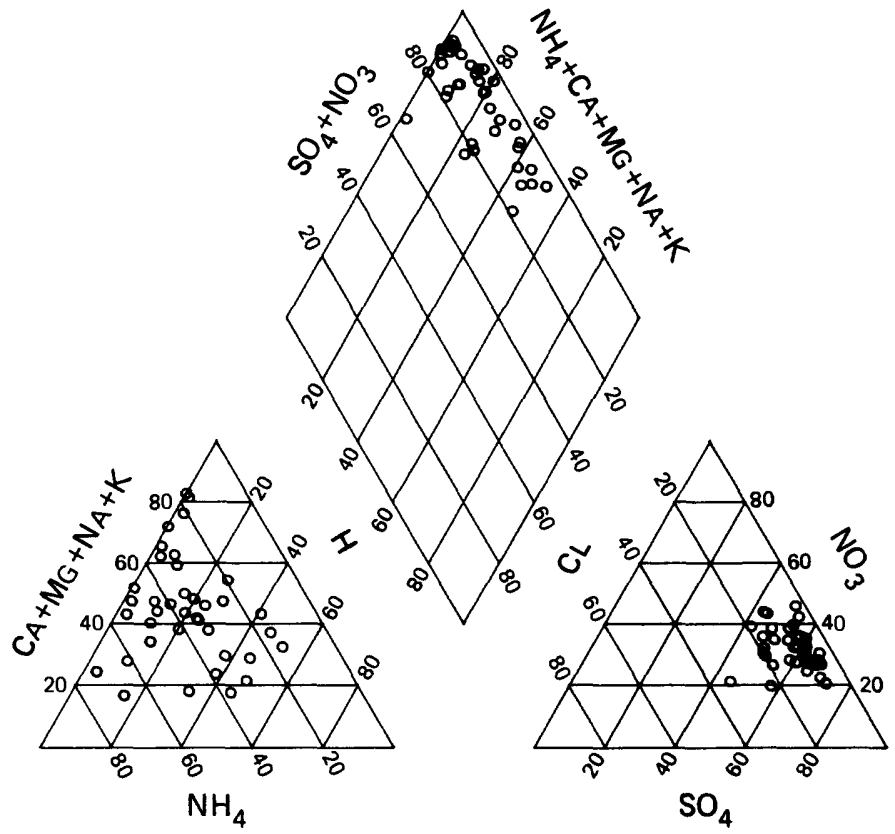

Percentage composition of major ions for site AR27. 


\section{NATIONAL TRENDS NETWORK -- 1983 CALENDER YEAR SUMMARY DATA}

[ppt $=$ precipitation; $\mathrm{mm}=$ millimeters; $\mathrm{cm}=$ centimeters; $\mathrm{mg}=$ milligrams; $\mathrm{L}=1$ iters;

$\mathbf{g}=$ grams; $\mathbf{m}=$ meter $; \mu \mathrm{s}=$ microsiemens; cond $=$ specific conductance $]$

STATION: Grand Canyon, Arizona

CAL number: AZO3

ADS number: 068a00

Station altitude above mean sea level, in meters: 2152

Number of sampling intervals (days in parenthesis):

-- With ppt measurements: 53 (371)

-- When ppt occurred: $44 \quad$ (308)

-- When ppt did not occur: 9 (63)

-- When sample volume was substituted for missing rain gage:

-- With chemical samples:
Latitude: $36^{\circ} 04^{\prime} 18^{\prime \prime}$ Longitude: $112^{\circ} 09^{\prime} 11^{\prime \prime}$

Station summary period: $12 / 28 / 1982$ to $01 / 03 / 1984$

Length of summary period: 53 sampling intervals ( 371 days)

$\begin{array}{ll}\text { Percent summary period with ppt measurements: } & 100.0\end{array}$

Percent summary period with chemical samples or no ppt: 80.9

Percent of total measured ppt with chemical samples: 90.9

Percent of total measured ppt in raingage that was

collected in the wet-sample bucket:

90.3

Total measured ppt, in $\mathrm{mm}: 518.5$

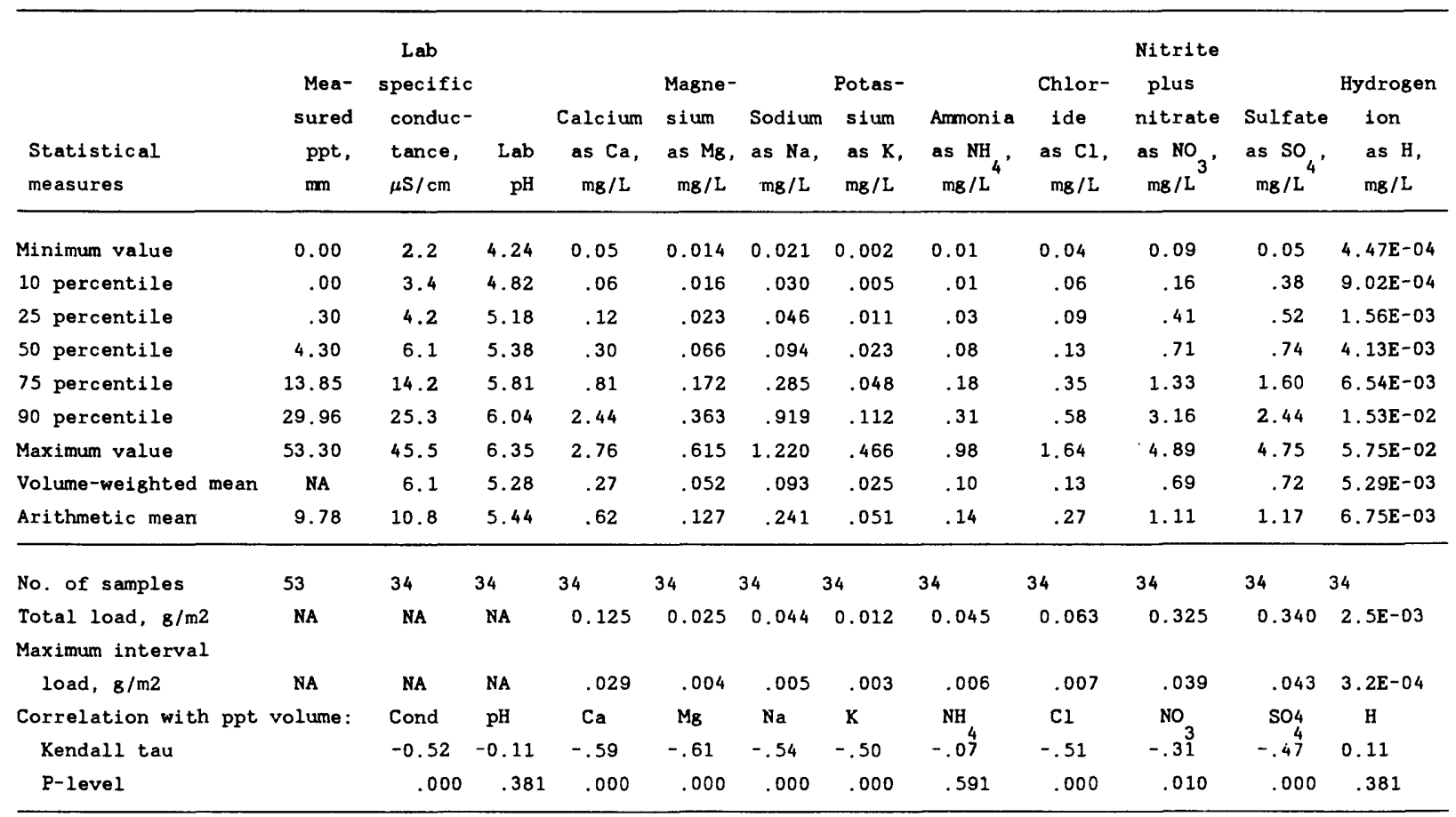

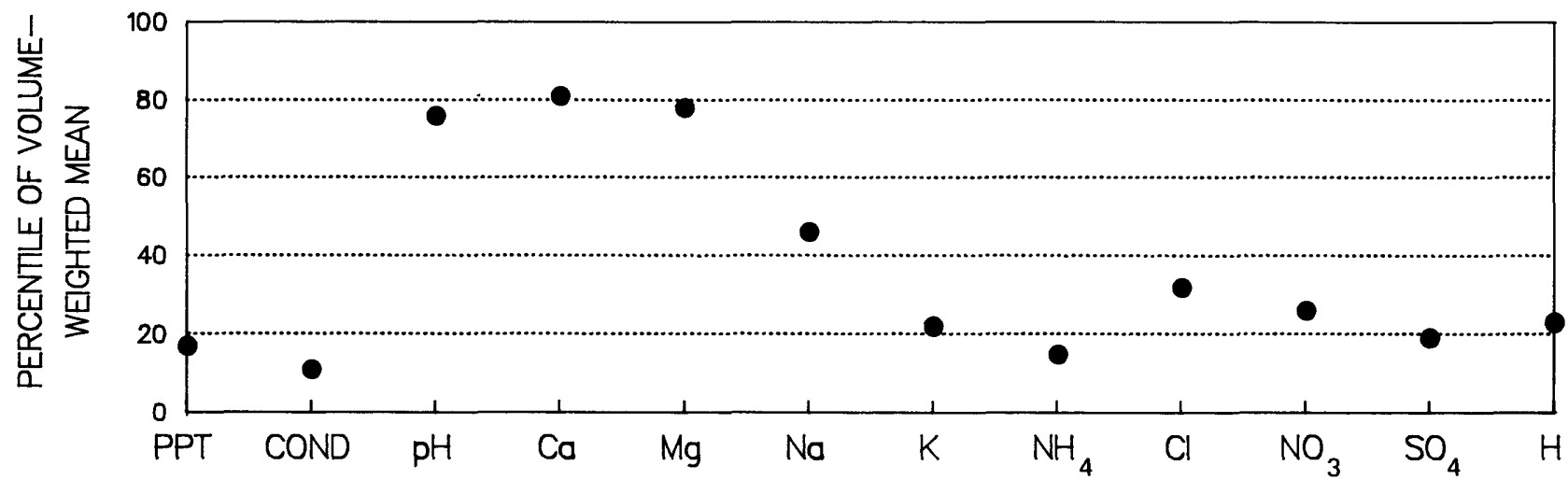

Percentiles of volume-weighted mean concentrations for site AZ03, based on frequency distributions of data from 55 National Trends Network sites. 

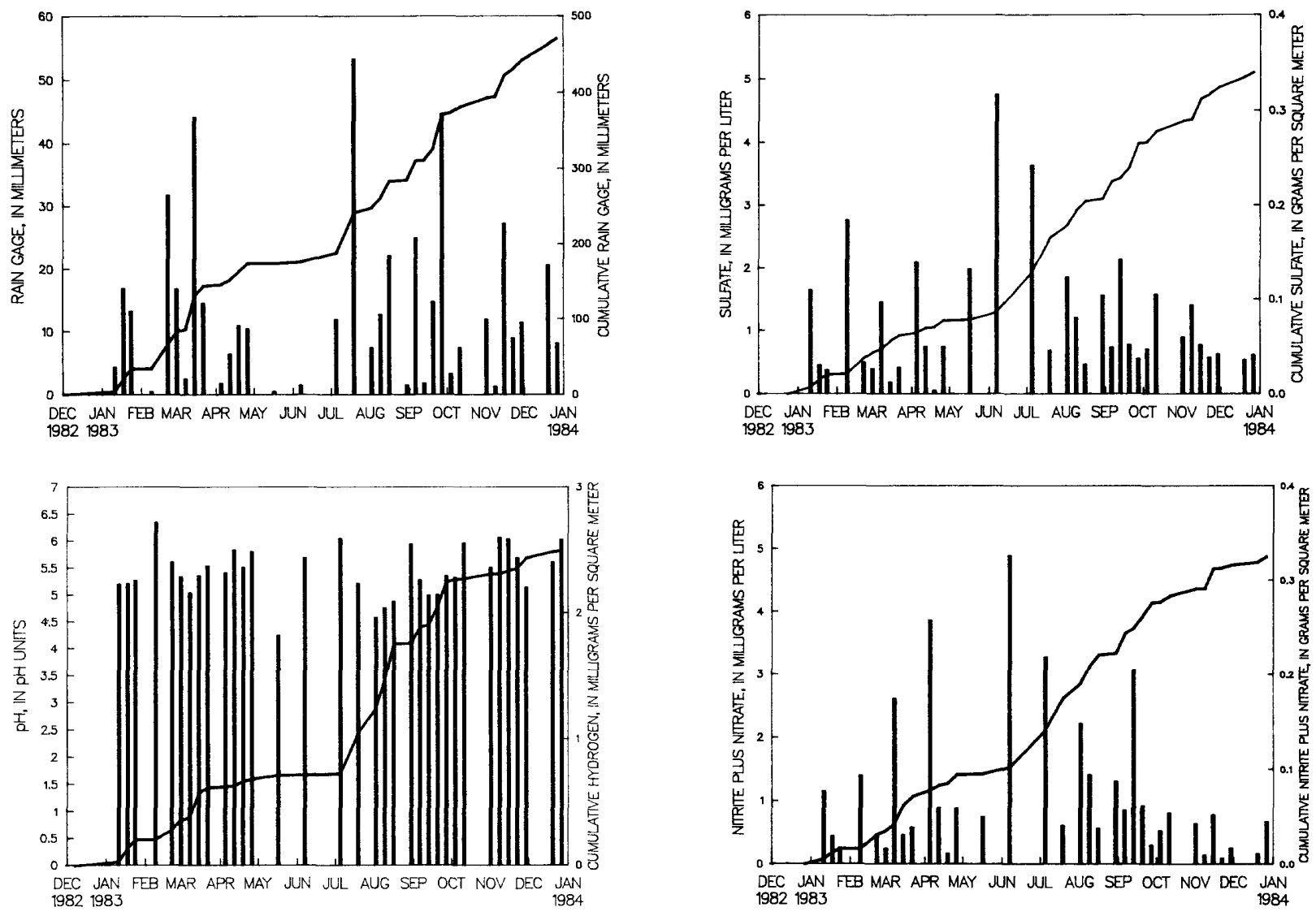

Bar plots of concentrations and cumulative line plots of loads for site AZ03. Nitrite plus nitrate are reported as $\mathrm{NO}_{3}$ and sulfate as $\mathrm{SO}_{4}$.

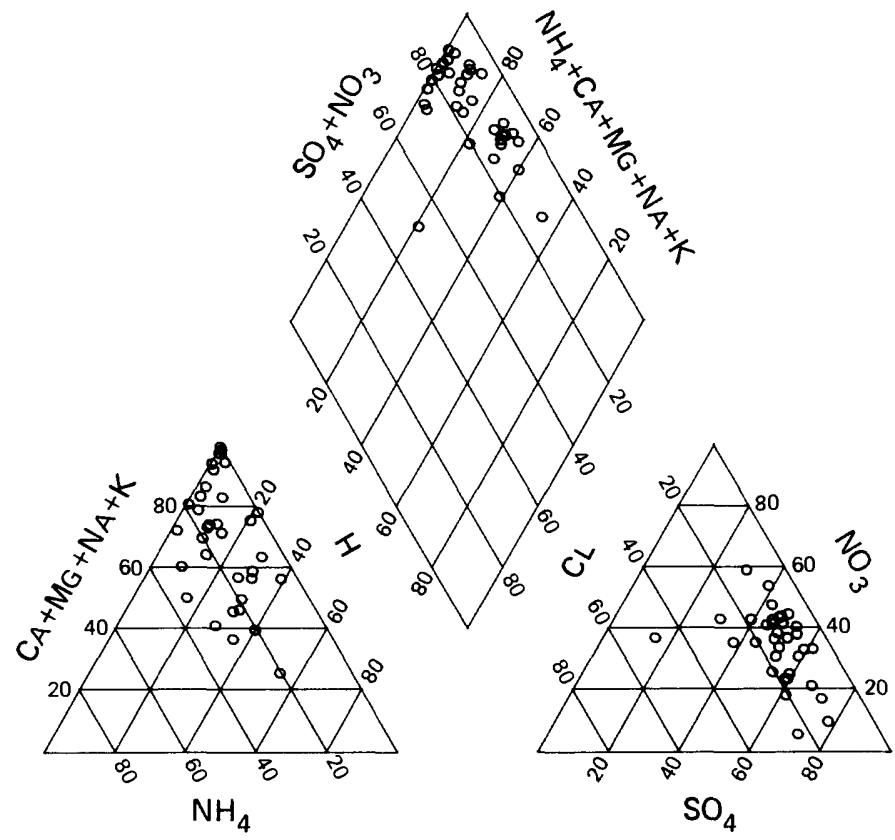

Percentage composition of major ions for site AZ03. 


\section{NATIONAL TRENDS NETWORK -- 1983 CALENDER YEAR SUMMARY DATA}

[ppt = precipitation; $\mathrm{mm}=$ millimeters; $\mathrm{cm}=$ centimeters; $\mathrm{mg}=$ milligrams; $\mathrm{L}=1 \mathrm{lters}$; $\mathrm{g}=\mathrm{grams} ; \mathrm{m}=$ meter $\boldsymbol{\mu} \mathrm{s}=$ microsiemens; cond $=$ specific conductance $]$

STATION: Organ Pipe Cactus National Monument, Arizona

CAL number: AZO6

ADS number: $003 \mathrm{a} 01$

Map ID number: 6

Station altitude above mean sea level, in meters: 506 Number of sampling intervals (days in parenthesis):

-- With ppt measurements: $53 \quad$ (371)

-- When ppt occurred: $34 \quad$ (238)

-- When ppt did not occur: 19 (133)

-- When sample volume was substituted for missing rain gage: 1 ( 7)

-- With chemical samples: 25 (175)
Latitude: $31^{\circ} 57^{\prime} 02^{\prime \prime}$ Longitude: $112^{\circ} 48^{\circ} 00^{\prime \prime}$

Station summary period: $12 / 28 / 1982$ to $01 / 03 / 1984$

Length of summary period: 53 sampling intervals ( 371 days)

Percent summary period with ppt measurments: $\quad 100.0$

Percent summary period with chemical samples or no ppt: 83.0

Percent of total measured ppt with chemical samples: 91.6

Percent of total measured ppt in raingage that was

collected in the wet-sample bucket:

93.7

Total measured ppt, in m: 469.6

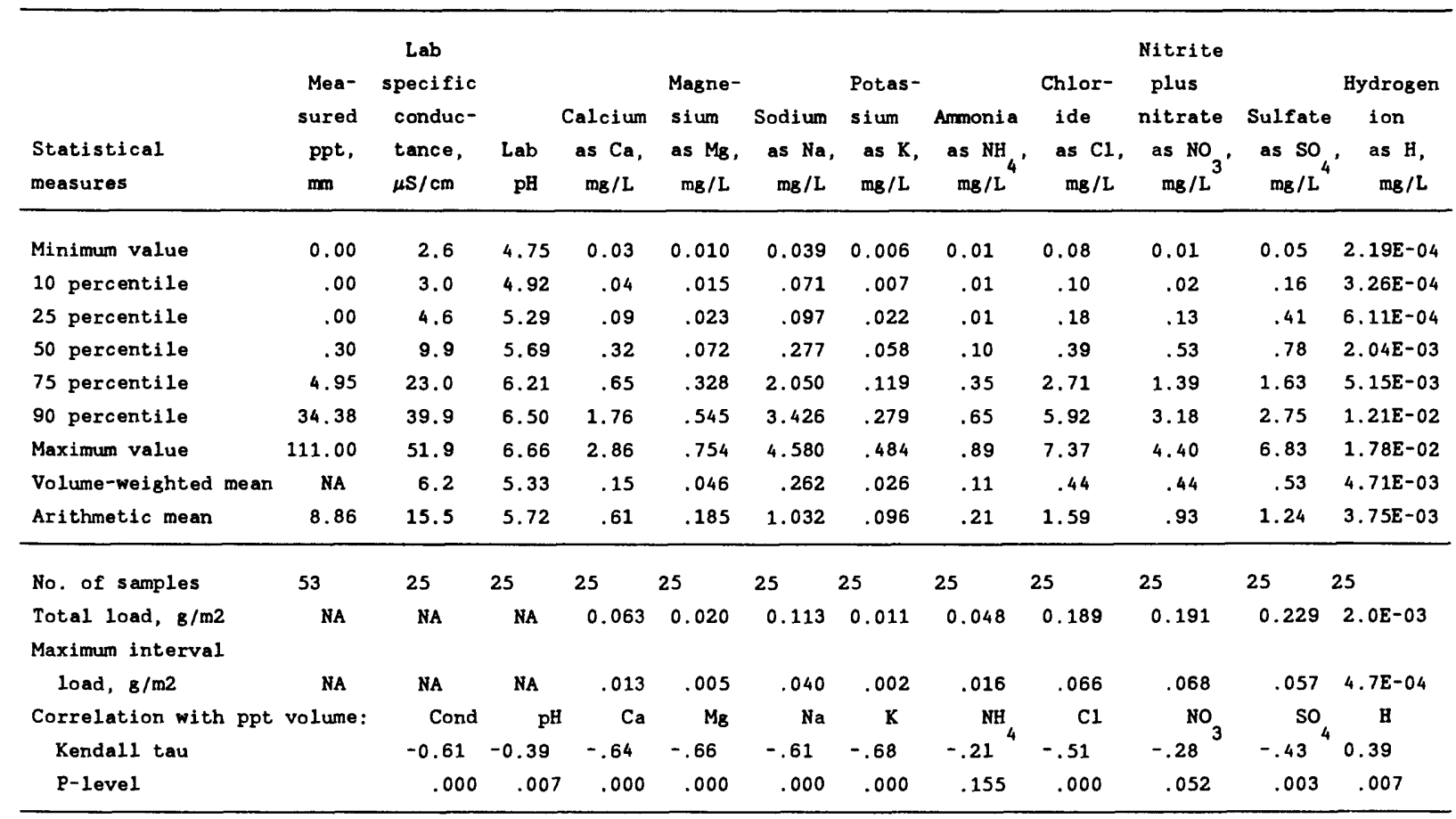

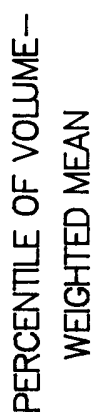

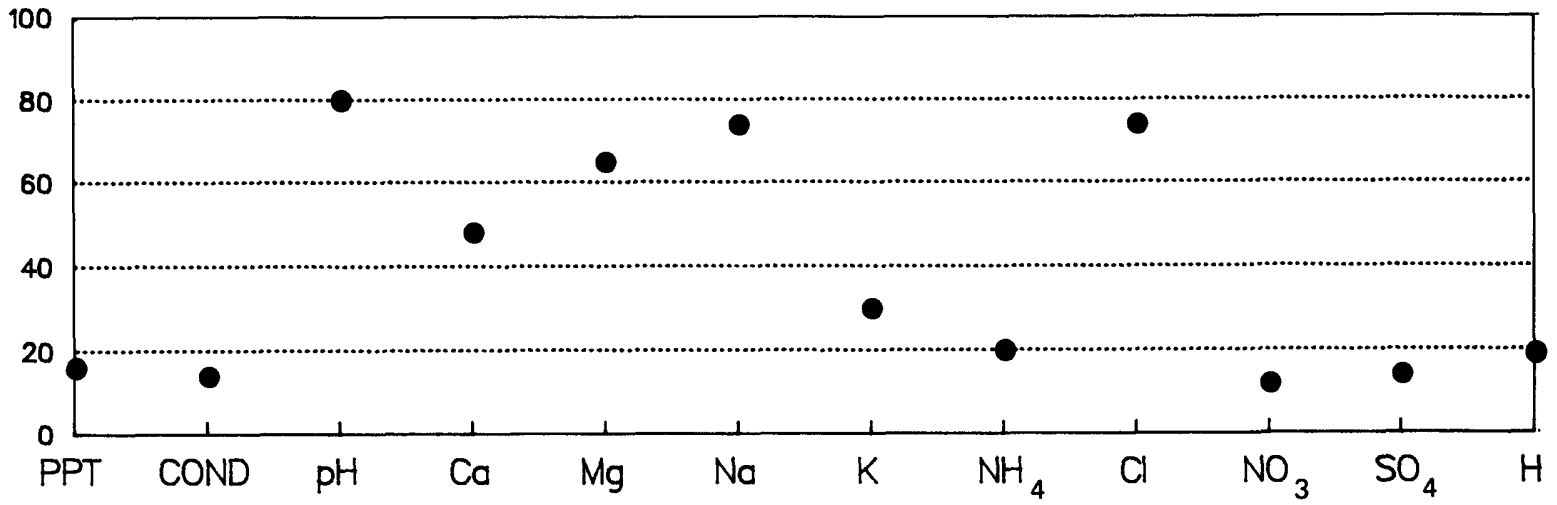

Percentiles of volume-weighted mean concentrations for site AZ06, based on frequency distributions of data from 55 National Trends Network sites. 

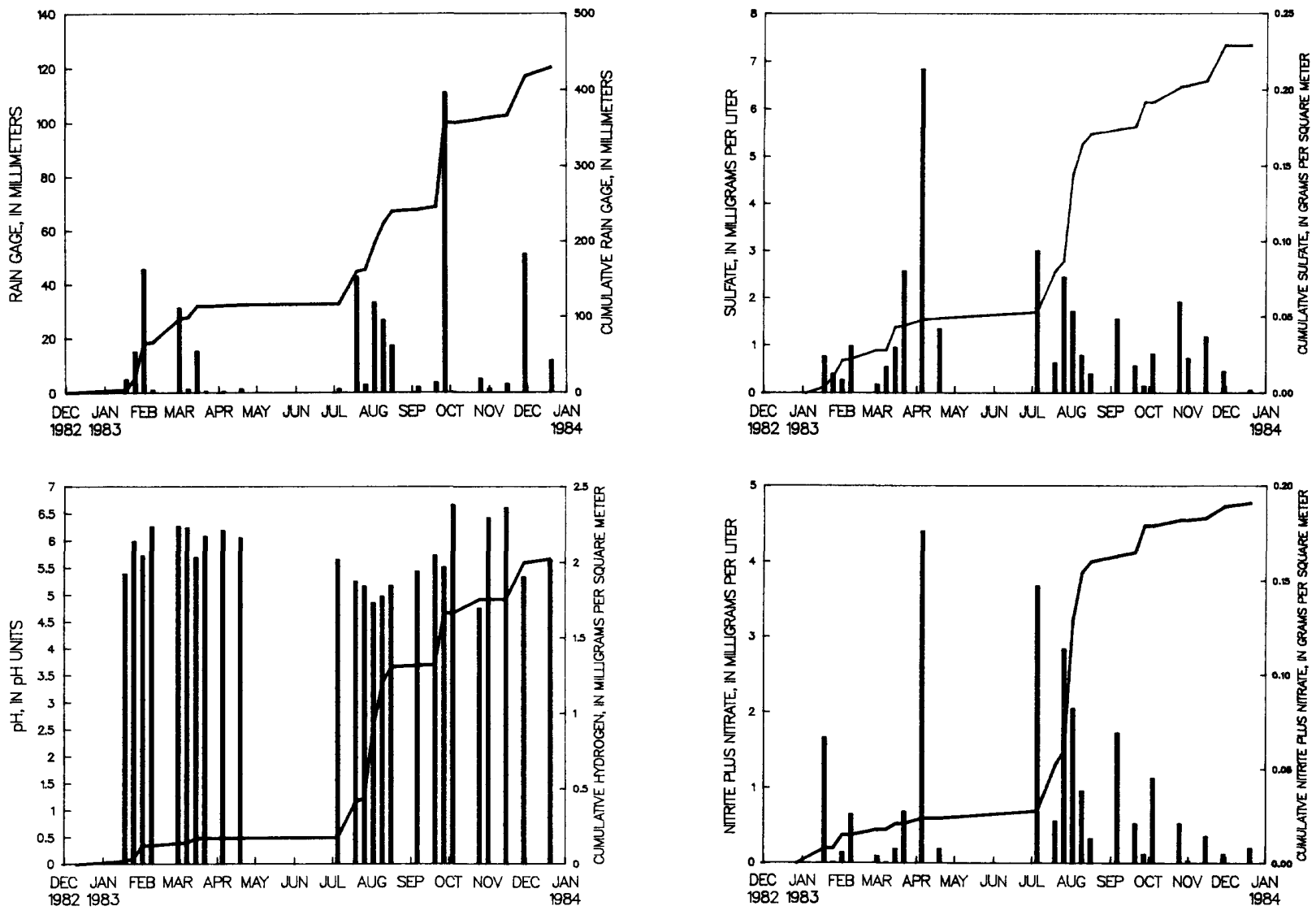

Bar plots of concentrations and cumulative line plots of loads for site AZ06.

Nitrite plus nitrate are reported as $\mathrm{NO}_{3}$ and sulfate as $\mathrm{SO}_{4}$.

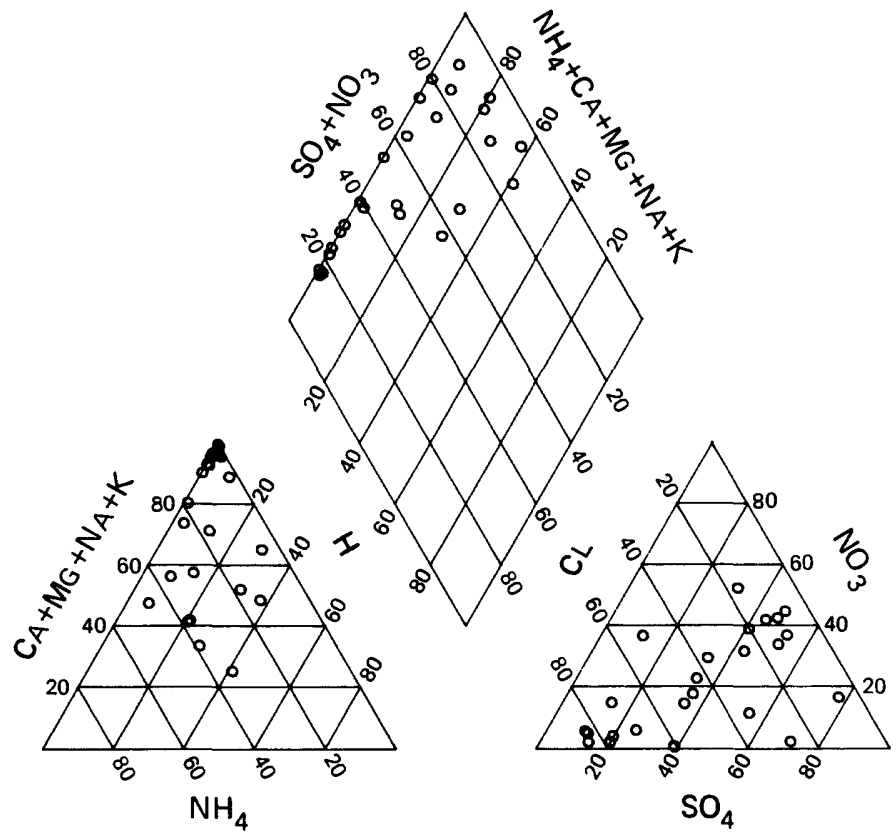

Percentage composition of major ions for site AZ06. 


\section{NATIONAL TRENDS NETWORK - - 1983 CALENDER YEAR SUMMARY DATA}

lppt $=$ precipitation; $\mathrm{mm}=$ millimeters; $\mathrm{cm}=$ centimeters; $\mathrm{mg}=$ milligrams; L = liters;

$\mathbf{g}=\mathrm{grams} ; \mathrm{m}=$ meter $\mu \mathrm{s}=$ microsiemens; cond $=$ specific conductance

STATION: Tanbark Flat, California

CAL number: CA42

ADS number: $270 \mathrm{a00}$

Station altitude above mean sea level, in meters: 853

Number of sampling intervals (days in parenthesis):

-- With ppt measurements: $53 \quad$ (371)

-- When ppt occurred: 37 (259)

-- When ppt did not occur: $16 \quad$ (112)

-- When sample volume was substituted for missing rain gage: 0 ( 0$)$

-- With chemical samples: 27 (189)
Latitude: $34^{\circ} 12^{\prime} 27^{\prime \prime}$ Longitude: $117^{\circ} 45^{\prime} 39^{\prime \prime}$

Station summary period: $12 / 28 / 1982$ to $01 / 03 / 1984$

Length of summary period: 53 sampling intervals ( 371 days)

Percent summary period with ppt measurements: $\quad 100.0$

Percent summary period with chemical samples or no ppt: 81.1

Percent of total measured ppt with chemical samples: 94.5

Percent of total measured ppt in raingage that was

collected in the wet-sample bucket:

91.5

\begin{tabular}{|c|c|c|c|c|c|c|c|c|c|c|c|c|}
\hline $\begin{array}{l}\text { Statistical } \\
\text { measures }\end{array}$ & $\begin{array}{c}\text { Mea- } \\
\text { sured } \\
\text { ppt, } \\
\text { mm }\end{array}$ & $\begin{array}{c}\text { Lab } \\
\text { specific } \\
\text { conduc- } \\
\text { tance, } \\
\mu S / \mathrm{cm}\end{array}$ & $\begin{array}{r}\text { c } \\
- \\
\text { Lab } \\
\text { pH }\end{array}$ & $\begin{array}{c}\text { Calcium } \\
\text { as Ca, } \\
\text { mg/L }\end{array}$ & $\begin{array}{l}\text { Magne- } \\
\text { sium } \\
\text { as Mg, } \\
\mathrm{mg} / \mathrm{L}\end{array}$ & $\begin{array}{l}\text { Sodium } \\
\text { as Na, } \\
\text { mg/L }\end{array}$ & $\begin{array}{l}\text { Potas- } \\
\text { sium } \\
\text { as } \mathrm{K} \text {, } \\
\mathrm{mg} / \mathrm{L}\end{array}$ & $\begin{array}{l}\text { Ammonia } \\
\text { as } \mathrm{NH}^{\prime} \\
\mathrm{mg} / \mathrm{L}^{\prime}\end{array}$ & $\begin{array}{l}\text { Chlor- } \\
\text { ide } \\
\text { as } \mathrm{Cl} \text {, } \\
\mathrm{mg} / \mathrm{L}\end{array}$ & $\begin{array}{l}\text { Nitrite } \\
\text { plus } \\
\text { nitrate } \\
\text { as } \mathrm{NO}_{3} \text { ' } \\
\mathrm{mg} / \mathrm{L}\end{array}$ & $\begin{array}{l}\text { Sulfate } \\
\text { as } \mathrm{SO}^{\prime} \\
\mathrm{mg} / \mathrm{L}^{\prime}\end{array}$ & $\begin{array}{l}\text { Hydrogen } \\
\text { ion } \\
\text { as } \mathrm{H}, \\
\mathrm{mg} / \mathrm{L}\end{array}$ \\
\hline Minimun value & 0.00 & 3.3 & 3.57 & 0.01 & 0.006 & 0.024 & 0.003 & 0.03 & 0.05 & 0.22 & 0.05 & $9.77 \mathrm{E}-04$ \\
\hline 10 percentile & .00 & 4.0 & 4.14 & .02 & .012 & .039 & .007 & .04 & .07 & .42 & .27 & $2.66 \mathrm{E}-03$ \\
\hline 25 percentile & .00 & 5.9 & 4.47 & .04 & .026 & .162 & .013 & .11 & .27 & .49 & .46 & $6.61 \mathrm{E}-03$ \\
\hline 50 percentile & 2.00 & 12.9 & 4.84 & .07 & .055 & .241 & .031 & .16 & .42 & 1.22 & .91 & $1.45 E-02$ \\
\hline 75 percentile & 36.45 & 29.6 & 5.18 & .34 & .121 & .598 & .064 & .85 & .93 & 4.50 & 1.66 & $3.39 E-02$ \\
\hline 90 percentile & 91.60 & 63.5 & 5.58 & .66 & .300 & 1.184 & .184 & 1.28 & 1.84 & 9.53 & 4.86 & $7.36 E-02$ \\
\hline Maximum value & 228.60 & 156.6 & 6.01 & 2.11 & .422 & 2.540 & .351 & 2.44 & 4.52 & 20.30 & 8.35 & $2.69 \mathrm{E}-01$ \\
\hline Volume-weighted mean & NA & 8.7 & 5.02 & .07 & .044 & .286 & .020 & .17 & .52 & .84 & .56 & $9.52 E-03$ \\
\hline No. of samples & 53 & 27 & 27 & 27 & 27 & 27 & 27 & 27 & 27 & 27 & 27 & 27 \\
\hline $\begin{array}{l}\text { Total load, } 8 / \mathrm{m} 2 \\
\text { Maximum interval }\end{array}$ & NA & NA & NA & 0.082 & 0.054 & 0.357 & 0.025 & 0.214 & 0.652 & 1.048 & 0.700 & $1.2 \mathrm{E}-02$ \\
\hline $\begin{array}{l}\text { load, } 8 / \mathrm{m} 2 \\
\text { Correlation with ppt } \\
\text { Kendall tau }\end{array}$ & $\begin{array}{c}\text { NA } \\
\text { volume: }\end{array}$ & $\begin{array}{l}\text { NA } \\
\text { Cond } \\
-0.63\end{array}$ & $\begin{array}{l}\text { NA } \\
\mathrm{pH} \\
0.54\end{array}$ & $\begin{array}{c}.011 \\
\mathrm{Ca} \\
-.66\end{array}$ & $\begin{array}{l}.014 \\
M g \\
-.50\end{array}$ & $\begin{array}{l}.100 \\
\mathrm{Na} \\
-.34\end{array}$ & $\begin{array}{l}.005 \\
\mathrm{~K} \\
-.63\end{array}$ & $\begin{array}{c}.037 \\
\mathrm{NH} \\
-.41\end{array}$ & $\begin{array}{l}.197 \\
C 1 \\
-.21\end{array}$ & $\begin{array}{l}.096 \\
\mathrm{NO}_{3} \\
-.68\end{array}$ & $\begin{array}{l}.089 \\
\text { so } \\
-.73\end{array}$ & $\begin{array}{l}1.2 \mathrm{E}-03 \\
\mathrm{H} \\
-0.54\end{array}$ \\
\hline P-level & & .000 & .000 & .000 & .000 & .014 & .000 & .003 & .118 & .000 & .000 & .000 \\
\hline
\end{tabular}

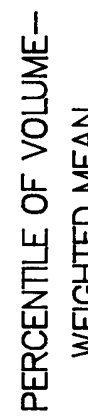

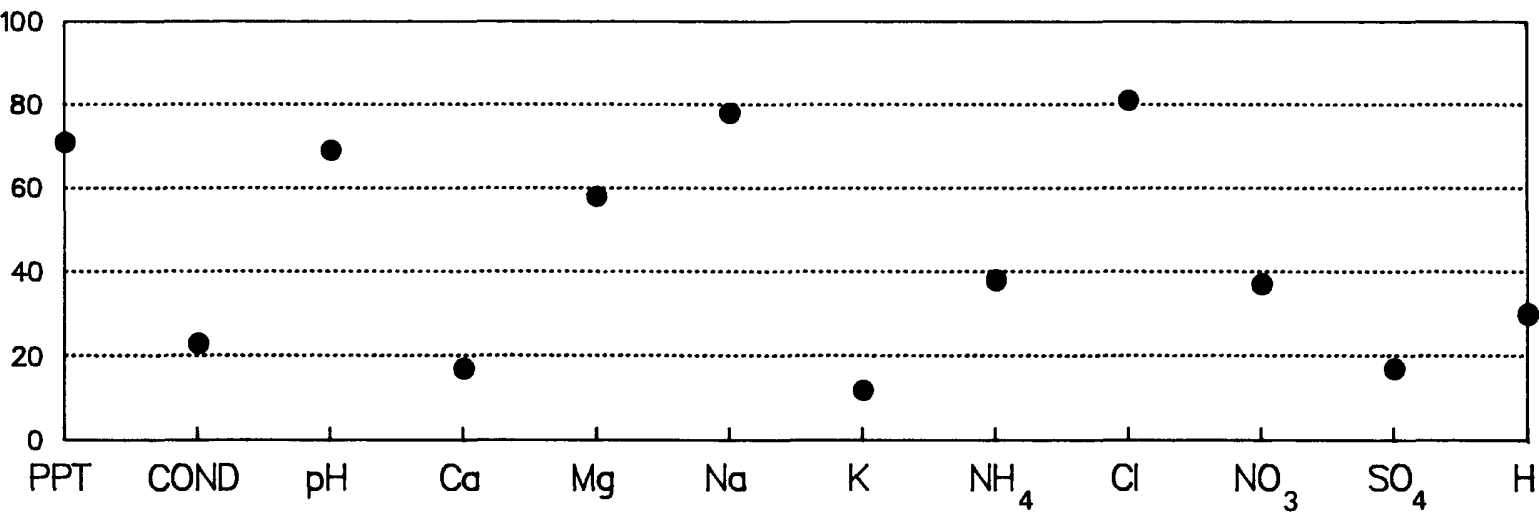

Percentiles of volume-weighted mean concentrations for site CA42, based on frequency distributions of data from 55 National Trends Network sites. 

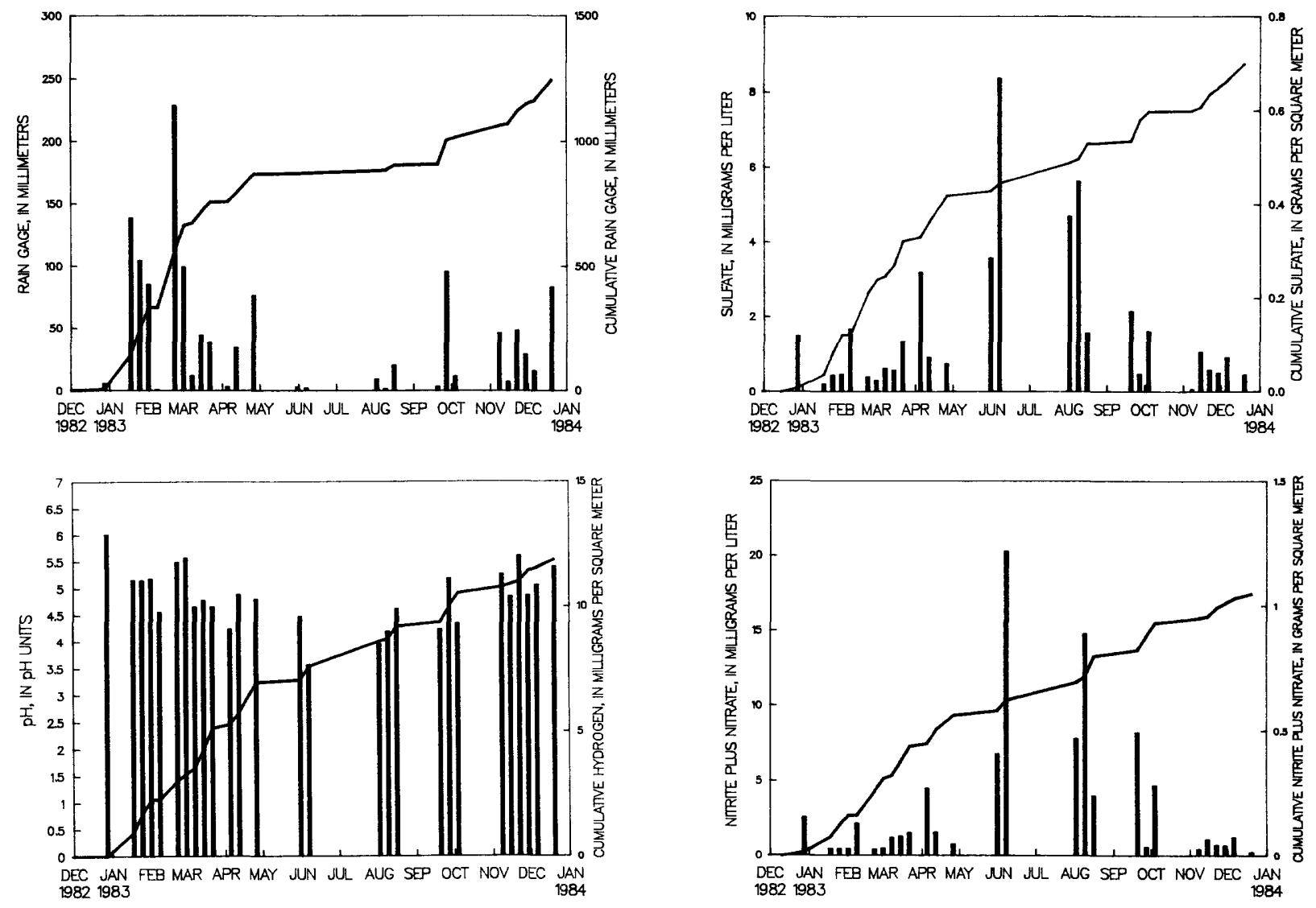

Bar plots of concentrations and cumulative line plots of loads for site CA42. Nitrite plus nitrate are reported as $\mathrm{NO}_{3}$ and sulfate as $\mathrm{SO}_{4}$.

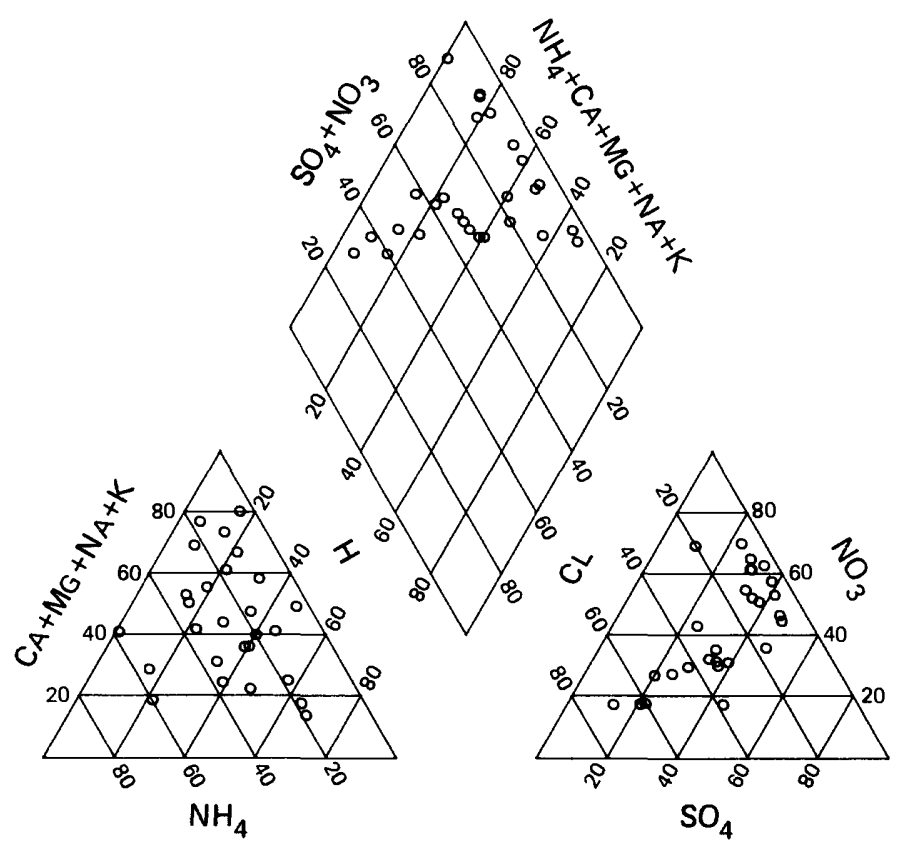

Percentage composition of major ions for site CA42. 


\section{NATIONAL TRENDS NETWORK -- 1983 CALENDER YEAR SUMMARY DATA}

[ppt = precipitation; $\mathrm{mm}=$ millimeters; $\mathrm{cm}=$ centimeters; $\mathrm{mg}=$ milligrams; L $=1$ liters;

$\mathbf{B}=$ grams; $m=$ meter; $\mu \mathrm{s}=$ microsiemens; cond $=$ specific conductance $]$

STATION: Hopland (Ukiah), California

CAL number: CA45 Map ID number: 9

ADS number: 007 a00

Station altitude above mean sea level, in meters: 253

Number of sampling intervals (days in parenthesis):

-- With ppt measurements: $53 \quad$ (371)

-- When ppt occurred: $36 \quad$ (252)

-- When ppt did not occur: 17 (119)

-- When sample volume was subst1tuted for missing raln gage: 0 ( 0 )

-- With chemical samples: $32 \quad$ (224)
Latitude: $39^{\circ} 00^{\prime} 17^{\prime \prime}$ Longitude: $123^{\circ} 05^{\prime} 05^{\prime \prime}$

Station summary period: $12 / 28 / 1982$ to $01 / 03 / 1984$

Length of sumary period: 53 sampling intervals ( 371 days)

Percent sumnary period with ppt measurments: 100.0

Percent summary period with chemical samples or no ppt: 92.4

Percent of total measured ppt with chemical samples: 86.9

Percent of total measured ppt in raingage that was

collected in wet-sample bucket:

99.1

Total measured ppt, in $\mathrm{mm}: 1827.9$

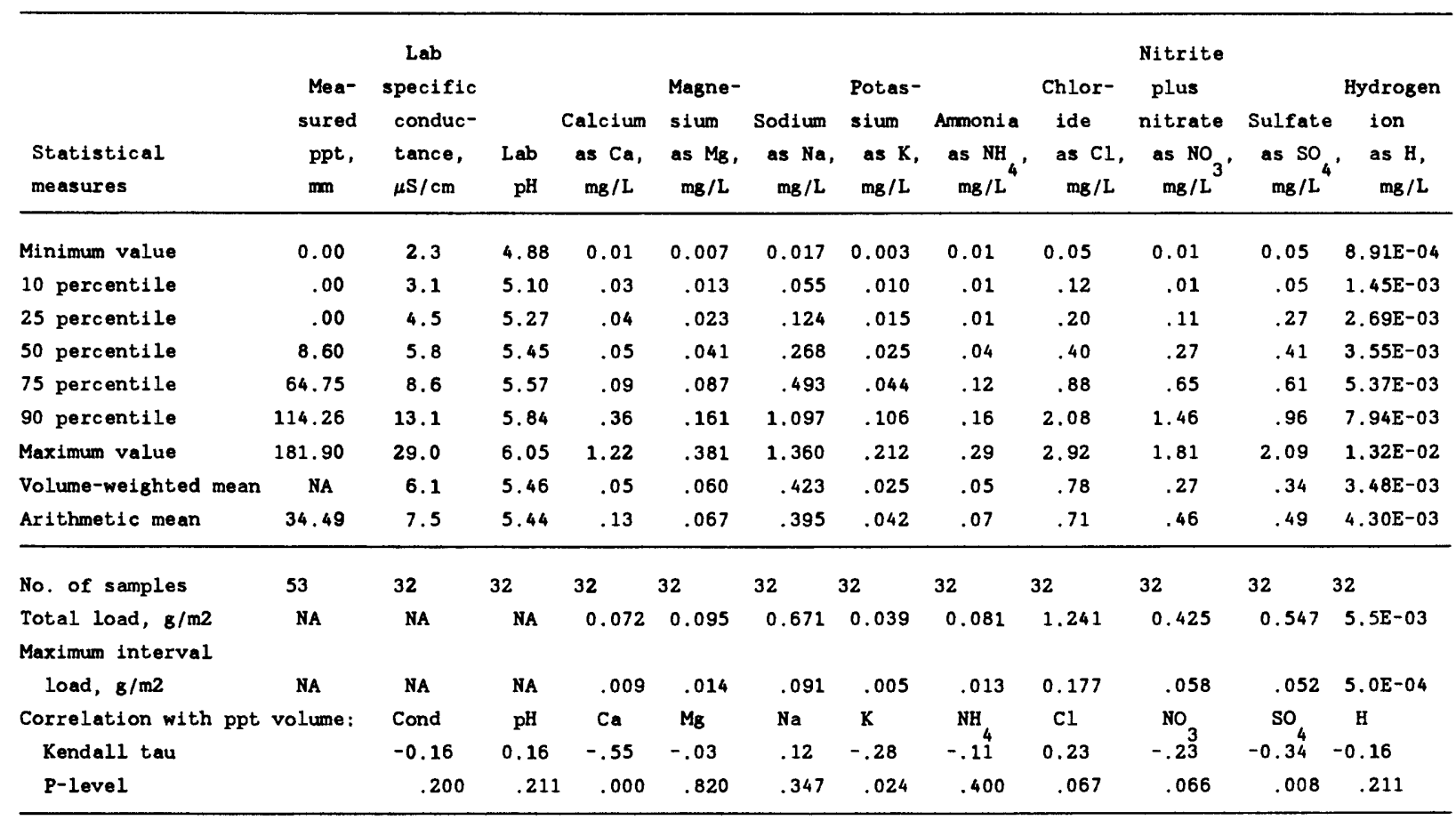

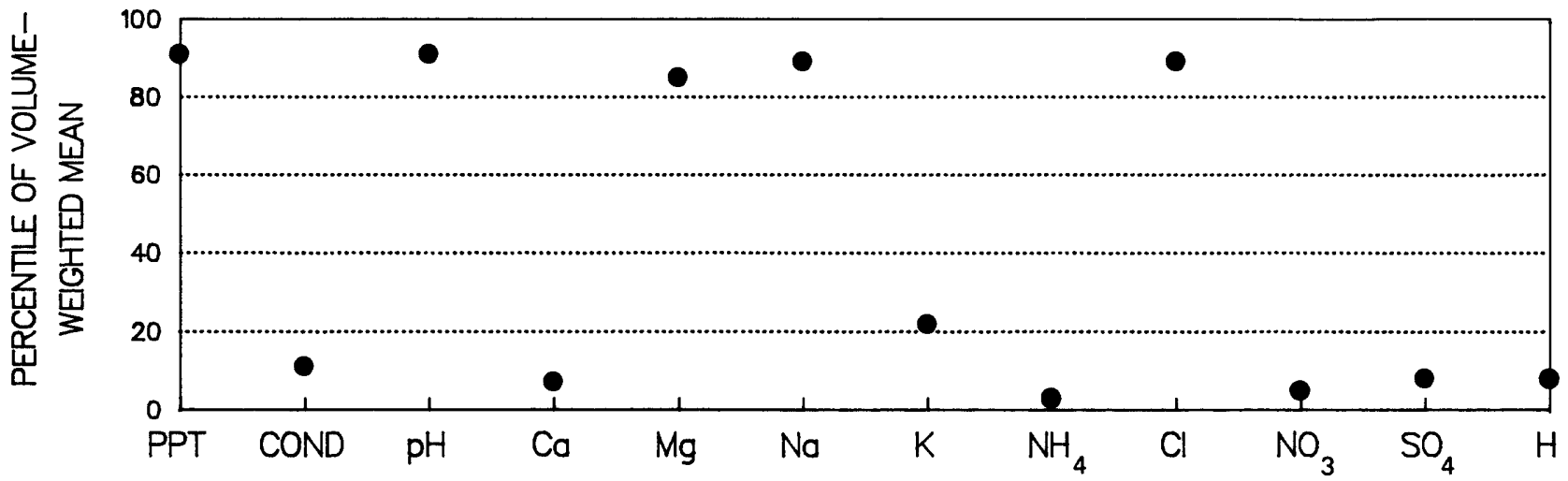

Percentiles of volume-weighted mean concentrations for site CA45, based on

frequency distributions of data from 55 National Trends Network sites. 

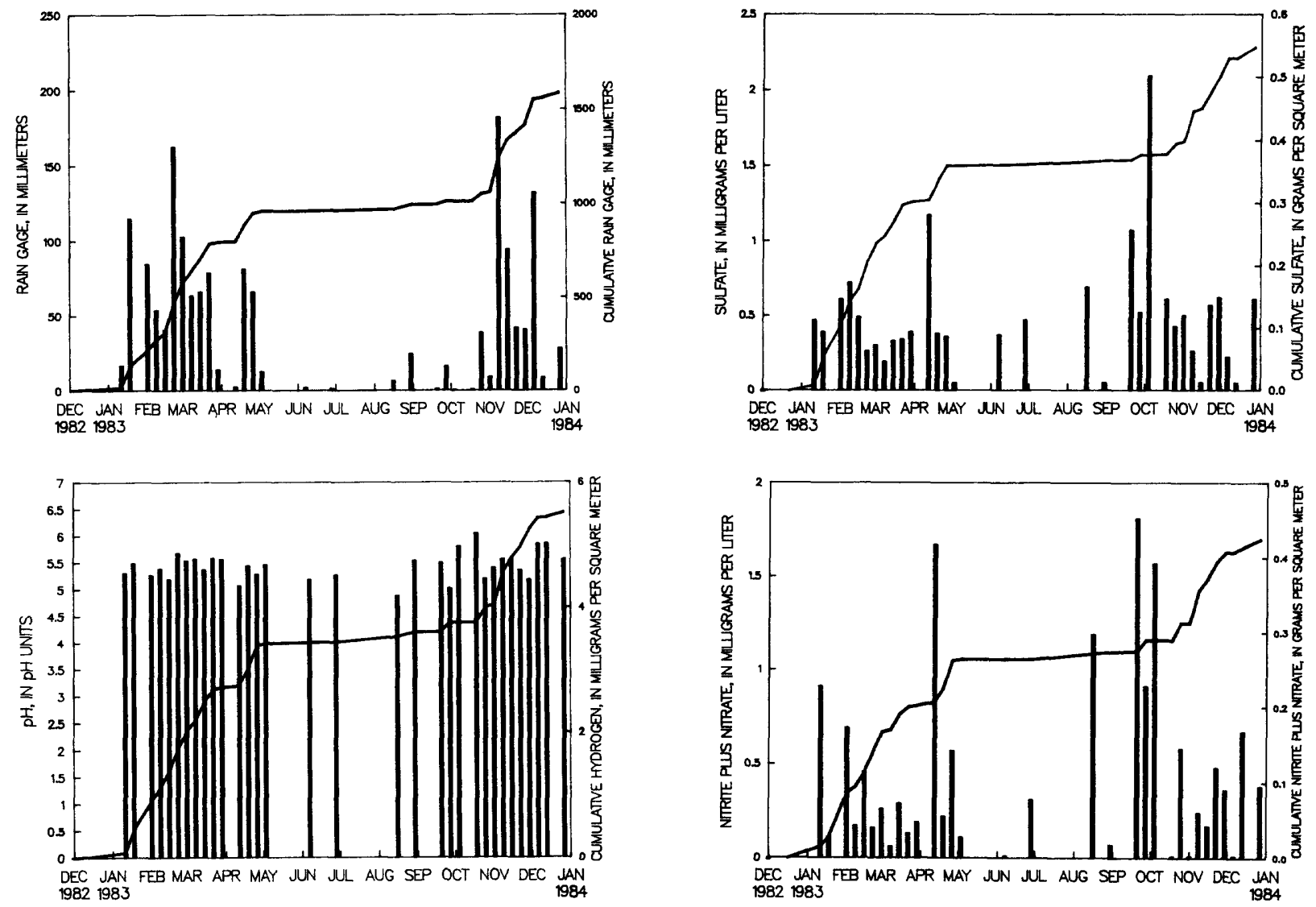

Bar plots of concentrations and cumulative line plots of loads for site CA45. Nitrite plus nitrate are reported as $\mathrm{NO}_{3}$ and sulfate as $\mathrm{SO}_{4}$.

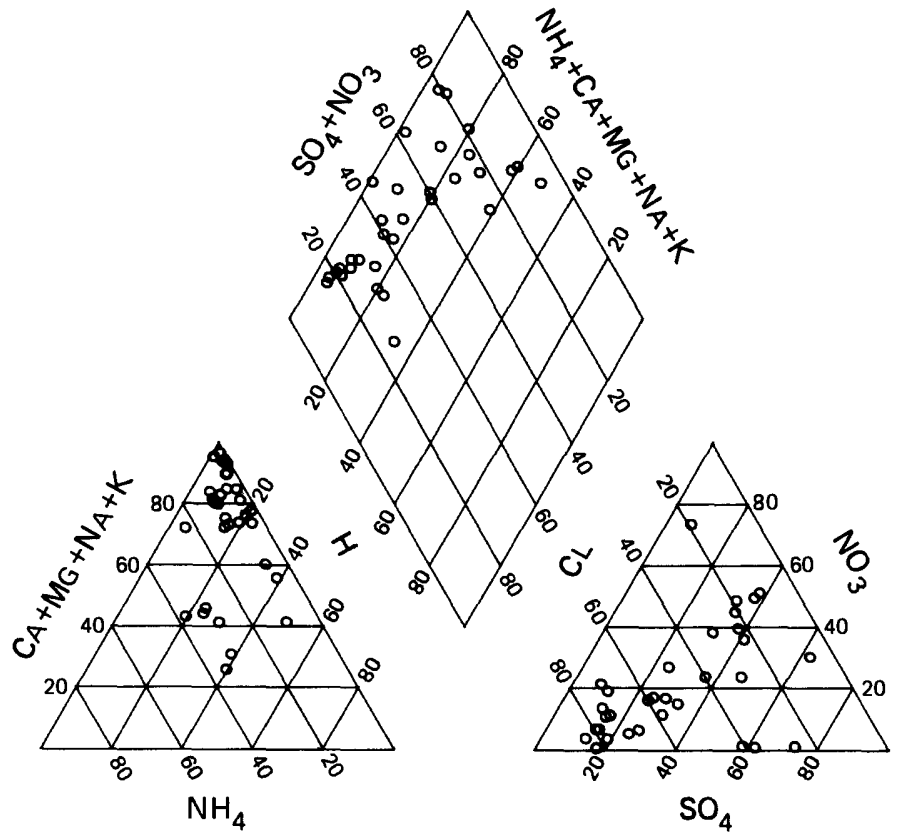

Percentage composition of major ions for site CA45. 
[ppt $=$ precipitation; $\mathrm{mm}=$ millimeters; $\mathrm{cm}=$ centimeters; $\mathrm{mg}=\mathrm{milligrams;} \mathrm{L=} \mathrm{liters;}$ $B=8 r a m s ; m=$ meter $; \mu s=$ microsiemens; cond $=$ specific conductance $]$

STATION: Sequoia National Park, California

Latitude: $36^{\circ} 34^{\prime} 09^{\prime \prime}$ Longitude: $118^{\circ} 46^{\prime} 40^{\prime \prime}$

CAL number: CA75

ADS number: $008 \mathrm{a} 00$

Map ID number: 10

Station altitude above mean sea level, in meters: 1856

Number of sampling intervals (days in parenthesis):

-- With ppt measurements: $52 \quad$ (364)

-- When ppt occurred: $37 \quad$ (259)

-- When ppt did not occur: 15 (105)

-- When sample volume was subst1tuted for missing rain gage: 12 ( 84 )

-- With chemical samples: $24 \quad$ (168)
Station summary period: $12 / 28 / 1982$ to $01 / 03 / 1984$

Length of summary period: 53 sampling intervals ( 371 days)

Percent summary period with ppt measurements:

98.1 Percent summary period with chemical samples or no ppt: 73.6 Percent of total measured ppt with chemical samples: 86.1 Percent of total measured ppt in raingage that was collected in the wet-sample bucket:

\begin{tabular}{|c|c|c|c|c|c|c|c|c|c|c|c|c|}
\hline $\begin{array}{l}\text { Statistical } \\
\text { measures }\end{array}$ & $\begin{array}{c}\text { Mea- } \\
\text { sured } \\
\text { ppt, } \\
\text { mm }\end{array}$ & $\begin{array}{c}\text { Lab } \\
\text { specific } \\
\text { conduc- } \\
\text { tance, } \\
\mu \mathrm{S} / \mathrm{cm}\end{array}$ & $\begin{array}{r}\mathrm{Lab} \\
\mathrm{pH}\end{array}$ & $\begin{array}{c}\text { Calcium } \\
\text { as } \mathrm{Ca}, \\
\mathrm{mg} / \mathrm{L}\end{array}$ & $\begin{array}{l}\text { Magne- } \\
\text { sium } \\
\text { as } \mathrm{Mg} \text {, } \\
\mathrm{mg} / \mathrm{L}\end{array}$ & $\begin{array}{l}\text { Sodium } \\
\text { as } \mathrm{Na} \text {, } \\
\mathrm{mg} / \mathrm{L}\end{array}$ & $\begin{array}{l}\text { Potas- } \\
\text { sium } \\
\text { as } K \text {, } \\
\mathrm{mg} / \mathrm{L}\end{array}$ & $\begin{array}{l}\text { Ammonia } \\
\text { as } \mathrm{NH} \\
\mathrm{mg} / \mathrm{L}^{\prime}\end{array}$ & $\begin{array}{l}\text { Chlor- } \\
\text { ide } \\
\text { as Cl, } \\
\mathrm{mg} / \mathrm{L}\end{array}$ & $\begin{array}{l}\text { Nitrite } \\
\text { plus } \\
\text { nitrate } \\
\text { as } \mathrm{NO}_{3} \text { ' } \\
\mathrm{mg} / \mathrm{L}\end{array}$ & $\begin{array}{l}\text { Sulfate } \\
\text { as } \mathrm{SO}_{4}, \\
\mathrm{mg} / \mathrm{L}^{\prime}\end{array}$ & $\begin{array}{c}\text { Hydrogen } \\
\text { ion } \\
\text { as } \mathrm{H}, \\
\mathrm{mg} / \mathrm{L}\end{array}$ \\
\hline Minimum value & 0.00 & 2.1 & 4.44 & 0.01 & 0.006 & 0.017 & 0.007 & 0.01 & 0.01 & 0.01 & 0.05 & $6.03 E-04$ \\
\hline 10 percentile & .00 & 2.3 & 4.70 & .02 & .009 & .028 & .008 & .01 & .07 & .07 & .05 & $1.01 E-03$ \\
\hline 25 percentile & .00 & 3.0 & 5.29 & .03 & .012 & .057 & .013 & .05 & .09 & .17 & .21 & $1.72 E-03$ \\
\hline 50 percentile & 6.25 & 5.1 & 5.50 & .06 & .026 & .078 & .021 & .11 & .14 & .36 & .51 & $3.16 E-03$ \\
\hline 75 percentile & 43.27 & 8.4 & 5.76 & .18 & .051 & .240 & .072 & .25 & .28 & 1.39 & .91 & $5.07 \mathrm{E}-03$ \\
\hline 90 percentile & 97.08 & 15.3 & 5.99 & .35 & .078 & .354 & .164 & .75 & .50 & 2.33 & 1.62 & $1.97 E-02$ \\
\hline Maximum velue & 170.60 & 27.8 & 6.22 & .58 & .096 & .414 & .200 & 1.02 & .76 & 4.40 & 2.60 & $3.63 E-02$ \\
\hline Volume-weighted mean & NA & 3.7 & 5.44 & .04 & .019 & .097 & .022 & .09 & .17 & .28 & .29 & $3.60 E-03$ \\
\hline No. of samples & 52 & 24 & 24 & 24 & 24 & 24 & 24 & 24 & 24 & 24 & 24 & 24 \\
\hline $\begin{array}{l}\text { Total load, } \mathrm{g} / \mathrm{m} 2 \\
\text { Maximum interval }\end{array}$ & NA & NA & NA & 0.054 & 0.024 & 0.124 & 0.028 & 0.118 & 0.214 & 0.355 & 0.376 & $4.6 \mathrm{E}-03$ \\
\hline load, $\mathrm{g} / \mathrm{m} 2$ & NA & NA & NA & .007 & .004 & .027 & .008 & .017 & .050 & .041 & .074 & $7.1 E-04$ \\
\hline $\begin{array}{l}\text { Correlation with ppt } \\
\text { Kendall tau }\end{array}$ & volume : & $\begin{array}{l}\text { Cond } \\
-0.60\end{array}$ & $\begin{array}{c}\mathrm{pH} \\
0.00\end{array}$ & $\begin{array}{c}\mathrm{Ca} \\
-.68\end{array}$ & $\begin{array}{l}\mathrm{Mg} \\
-.57\end{array}$ & $\begin{array}{c}\mathrm{Na} \\
-.34\end{array}$ & $\begin{array}{c}\mathbf{K} \\
-.56\end{array}$ & $\begin{array}{r}\mathrm{NH} \\
-.49\end{array}$ & $\begin{array}{l}\mathrm{Cl} \\
-.35\end{array}$ & $\begin{array}{l}\mathrm{NO}_{3} \\
-.57\end{array}$ & $\begin{array}{l}\text { So } \\
-.62\end{array}$ & $\begin{array}{c}\mathrm{H} \\
0.00\end{array}$ \\
\hline P-level & & .000 & .980 & .000 & .000 & .020 & .000 & .001 & .020 & .000 & .000 & .980 \\
\hline
\end{tabular}

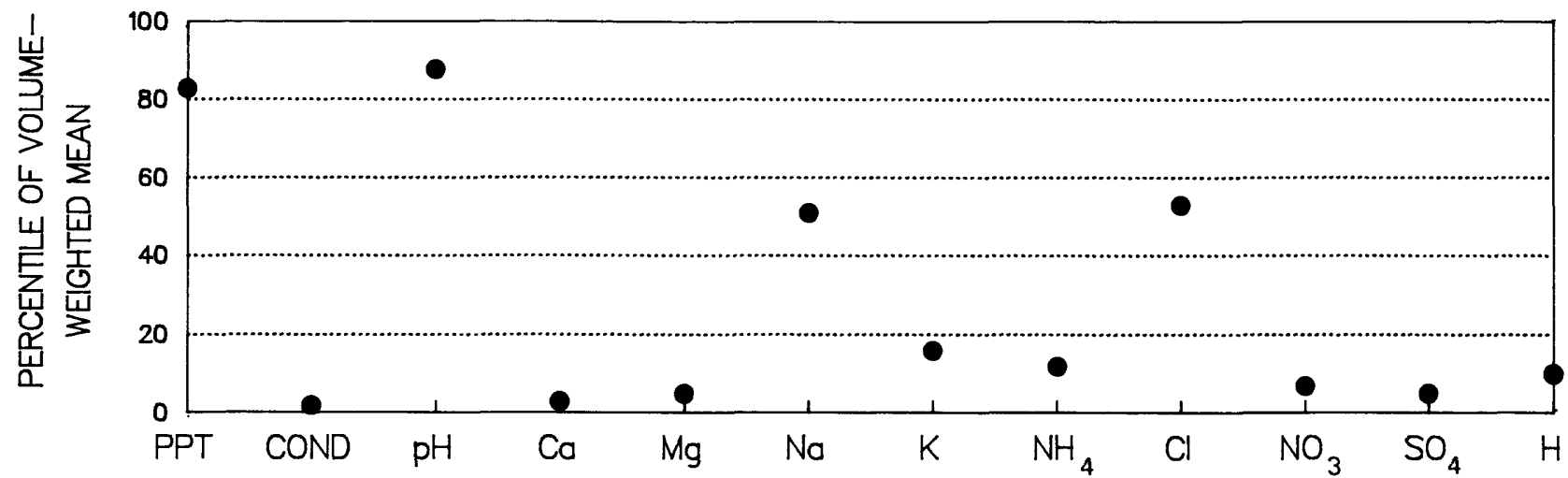

Percentiles of volume-weighted mean concentrations for site CA75, based on frequency distributions of data from 55 National Trends Network sites. 

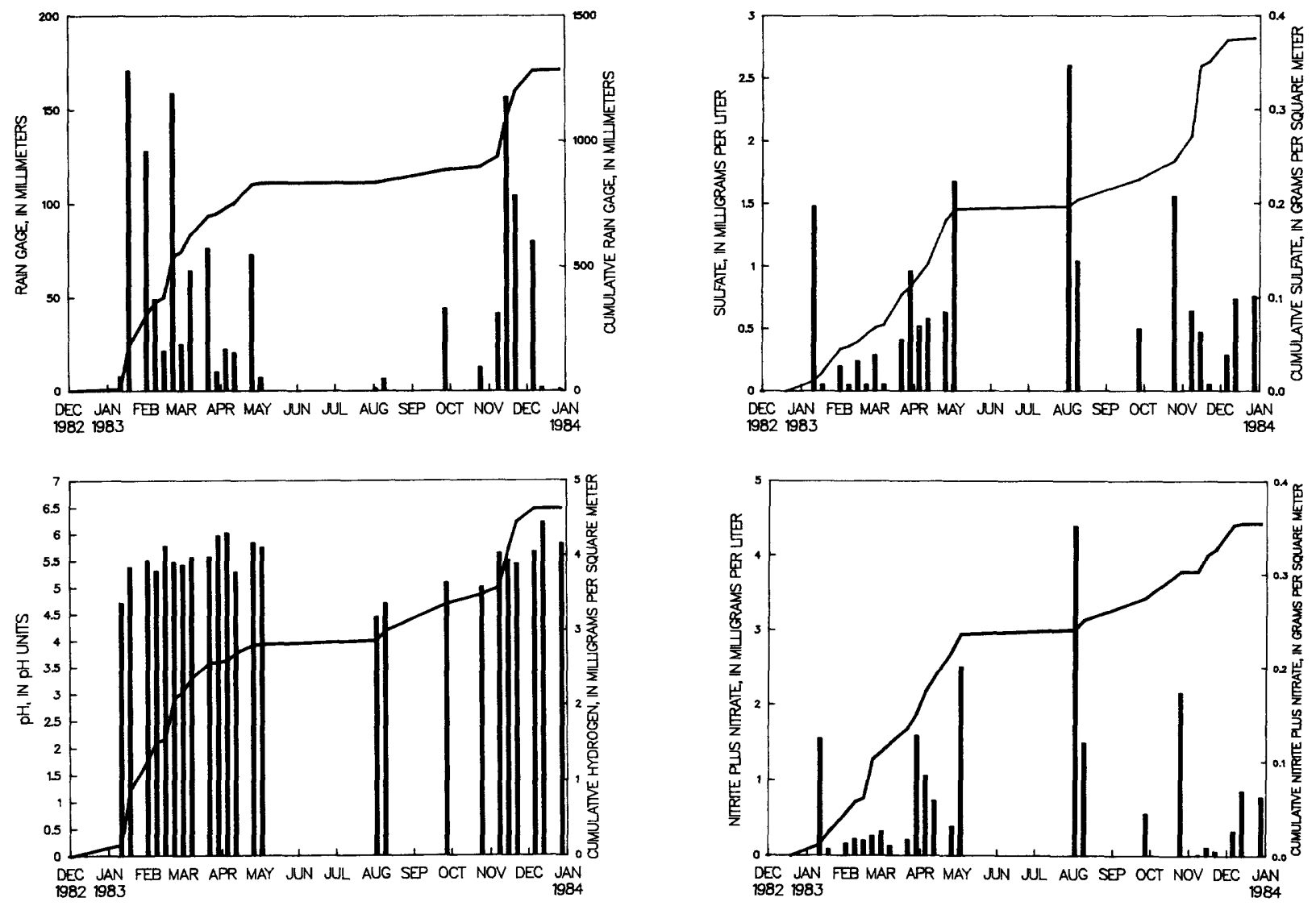

Bar plots of concentrations and cumulative line plots of loads for site CA75. Nitrite plus nitrate are reported as $\mathrm{NO}_{3}$ and sulfate as $\mathrm{SO}_{4}$.

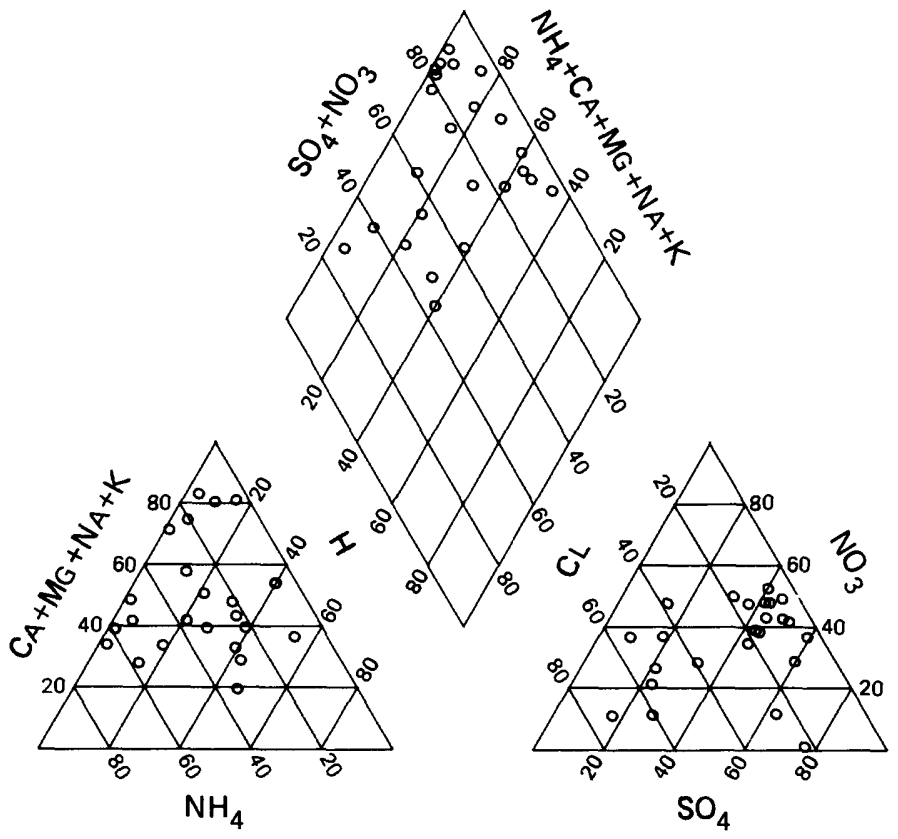

Percentage composition of major ions for site CA75. 


\section{NATIONAL TRENDS NETWORK - - 1983 CALENDER YEAR SUMMARY DATA}

lppt = precipitation; $\mathrm{mm}=$ millimeters; $\mathrm{cm}=$ centimeters; $\mathrm{mg}=$ milligrams; $\mathrm{L}=1$ iters; $\mathrm{g}=\mathrm{grams} ; \mathrm{m}=$ meter; $\mu \mathrm{s}=$ microsiemens; cond = specific conductance

STATION: Davis, California

CAL number: CA88

ADS number: $009 \mathrm{a} 00$

Station altitude above mean sea level, in meters: 18 Number of sampling intervals (days in parenthesis):

-- With ppt measurements: 53 (371)

-- When ppt occurred: $33 \quad$ (231)

-- When ppt did not occur: $20 \quad$ (140)

-- When sample volume was substituted for missing rain gage: 0 ( 0 )

-- With chemical samples: 21 (147)
Latitude: $38^{\circ} 32^{\prime} 07^{\prime \prime}$ Longitude: $121^{\circ} 46^{\prime} 30^{\prime \prime}$

Station summary period: $12 / 28 / 1982$ to $01 / 03 / 1984$

Length of summary period: 53 sampling intervals ( 371 days)

Percent summary period with ppt measurements: $\quad 100.0$

Percent summary period with chemical samples or no ppt: 77.4

Percent of total measured ppt with chemical samples: 89.9

Percent of total measured ppt in raingage that was

collected in the wet-sample bucket:

97.3

Total measured ppt, in m: 918.1

\begin{tabular}{|c|c|c|c|c|c|c|c|c|c|c|c|c|}
\hline $\begin{array}{l}\text { Statistical } \\
\text { measures }\end{array}$ & $\begin{array}{l}\text { Mea- } \\
\text { sured } \\
\text { ppt, } \\
\text { mm }\end{array}$ & $\begin{array}{l}\text { Lab } \\
\text { specific } \\
\text { conduc- } \\
\text { tance, } \\
\mu \mathrm{S} / \mathrm{cm}\end{array}$ & $\begin{array}{r}\text { Lab } \\
\mathrm{pH}\end{array}$ & $\begin{array}{l}\text { Calcium } \\
\text { as Ca, } \\
\mathrm{mg} / \mathrm{L}\end{array}$ & $\begin{array}{l}\text { Magne- } \\
\text { sium } \\
\text { as Ms, } \\
\mathrm{mg} / \mathrm{L}\end{array}$ & $\begin{array}{l}\text { Sodium } \\
\text { as } \mathrm{Na} \text {, } \\
\mathrm{mg} / \mathrm{L}\end{array}$ & $\begin{array}{l}\text { Potas } \\
\text { sium } \\
\text { as K, } \\
\mathrm{mg} / \mathrm{L}\end{array}$ & $\begin{array}{l}\text { Ammonia } \\
\text { as } \mathrm{NH}^{-} / \mathrm{L}^{\prime}\end{array}$ & $\begin{array}{c}\text { Chlor- } \\
\text { ide } \\
\text { as Cl, } \\
\mathrm{mg} / \mathrm{L}\end{array}$ & $\begin{array}{l}\text { Nitrite } \\
\text { plus } \\
\text { nitrate } \\
\text { as } \mathrm{NO}_{3} \text {, } \\
\mathrm{mg} / \mathrm{L}^{\circ}\end{array}$ & $\begin{array}{l}\text { Sulfate } \\
\text { as } \mathrm{SO}_{4} \text {, } \\
\mathrm{mg} / \mathrm{L}^{\circ}\end{array}$ & $\begin{array}{l}\text { Hydrogen } \\
\text { ion } \\
\text { as } \mathrm{H}, \\
\mathrm{mg} / \mathrm{L}\end{array}$ \\
\hline Minimum value & 0.00 & 3.1 & 5.23 & 0.02 & 0.011 & 0.041 & 0.006 & 0.03 & 0.06 & 0.32 & 0.19 & $3.98 E-04$ \\
\hline 10 percentile & .00 & 4.0 & 5.37 & .03 & .012 & .049 & .010 & .18 & .09 & .36 & .35 & $8.55 E-04$ \\
\hline 25 percentile & .00 & 5.4 & 5.69 & .04 & .021 & .103 & .012 & .31 & .15 & .50 & .42 & $1.08 E-03$ \\
\hline 50 percentile & .30 & 7.2 & 5.85 & .05 & .036 & .208 & .020 & .35 & .34 & .73 & .63 & $1.41 E-03$ \\
\hline 75 percentile & 27.30 & 10.8 & 5.96 & .11 & .061 & .327 & .034 & .56 & .59 & 1.01 & .82 & $2.05 E-03$ \\
\hline 90 percentile & 60.08 & 13.0 & 6.07 & .25 & .306 & .923 & .087 & .72 & 1.70 & 1.40 & 1.20 & $4.29 E-03$ \\
\hline Maximum value & 111.80 & 30.6 & 6.40 & .84 & .442 & 3.510 & .149 & .77 & 6.63 & 1.70 & 1.44 & $5.89 E-03$ \\
\hline Volume-weighted mean & NA & 6.6 & 5.82 & .06 & .045 & .310 & .025 & .37 & .56 & .64 & .53 & $1.53 E-03$ \\
\hline Arithmetic mean & 17.32 & 8.5 & 5.81 & .11 & .073 & .402 & .031 & .41 & .72 & .78 & .65 & $1.85 E-03$ \\
\hline $\begin{array}{l}\text { No. of samples } \\
\text { Total load, g/m2 } \\
\text { Maximum interval }\end{array}$ & $\begin{array}{c}53 \\
\text { NA }\end{array}$ & $\begin{array}{l}21 \\
\text { NA }\end{array}$ & $\begin{array}{l}21 \\
\text { NA }\end{array}$ & $\begin{array}{l}21 \\
0.048\end{array}$ & $\begin{array}{l}21 \\
0.037\end{array}$ & $\begin{array}{l}21 \\
0.256\end{array}$ & $\begin{array}{l}21 \\
0.020\end{array}$ & $\begin{array}{l}21 \\
0.302\end{array}$ & $\begin{array}{l}21 \\
0.465\end{array}$ & $\begin{array}{l}21 \\
0.528\end{array}$ & $\begin{array}{l}21 \\
0.435\end{array}$ & $\begin{array}{l}21 \\
1.3 E-03\end{array}$ \\
\hline $\begin{array}{l}\text { load, } 8 / \mathrm{m} 2 \\
\text { Correlation with ppt } \\
\text { Kendall tau }\end{array}$ & $\begin{array}{c}\text { NA } \\
\text { volume: }\end{array}$ & $\begin{array}{l}\text { NA } \\
\text { Cond } \\
-0.48\end{array}$ & $\begin{array}{l}\text { NA } \\
\text { pH } \\
0.17\end{array}$ & $\begin{array}{l}.006 \\
\mathrm{Ca} \\
-.45\end{array}$ & $\begin{array}{l}.007 \\
M g \\
-.24\end{array}$ & $\begin{array}{l}.058 \\
\mathrm{Na} \\
-.04\end{array}$ & $\begin{array}{l}.005 \\
\mathrm{~K} \\
-.26\end{array}$ & $\begin{array}{c}.037 \\
\mathrm{NH} \\
-.26\end{array}$ & $\begin{array}{l}.109 \\
\mathrm{cl} \\
.00\end{array}$ & $\begin{array}{l}.078 \\
\mathrm{NO}_{3} \\
-.42\end{array}$ & $\begin{array}{l}.055 \\
\mathrm{SO}_{4}^{4} \\
-.45\end{array}$ & $\begin{array}{c}1.5 \mathrm{E}-04 \\
\mathrm{H} \\
-0.17\end{array}$ \\
\hline P-level & & .003 & .290 & .006 & .131 & .809 & .102 & .096 & 1.000 & .009 & .004 & .290 \\
\hline
\end{tabular}

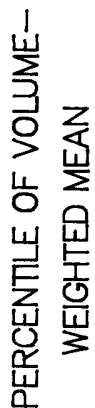

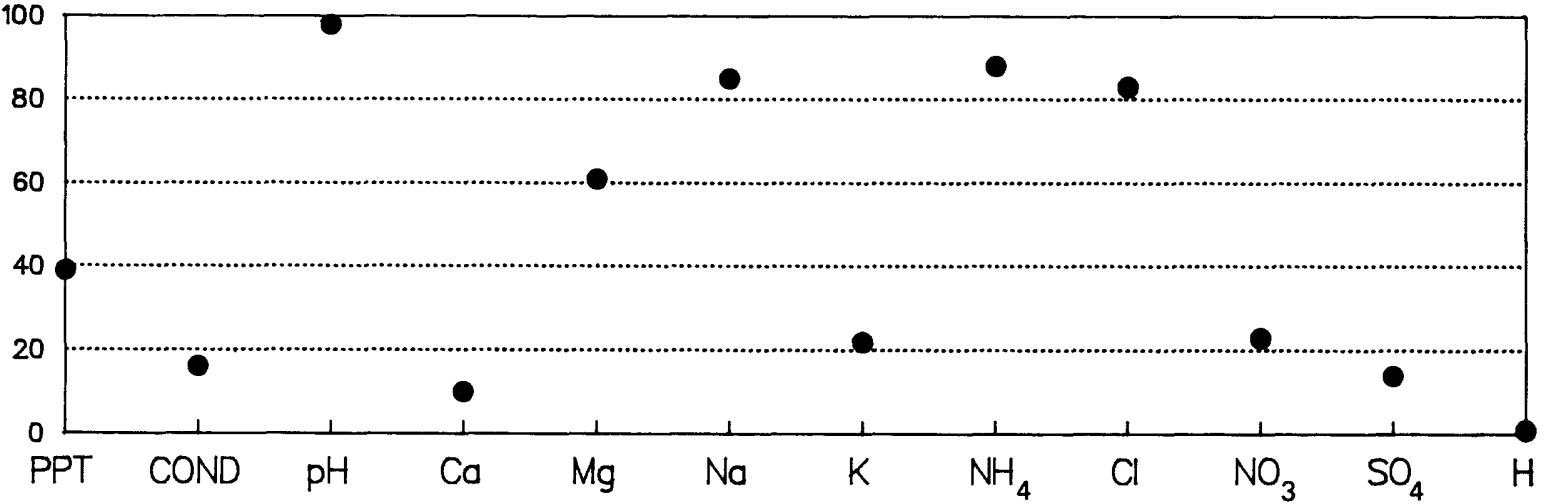

Percentiles of volume-weighted mean concentrations for site CA88, based on frequency distributions of data from 55 National Trends Network sites. 

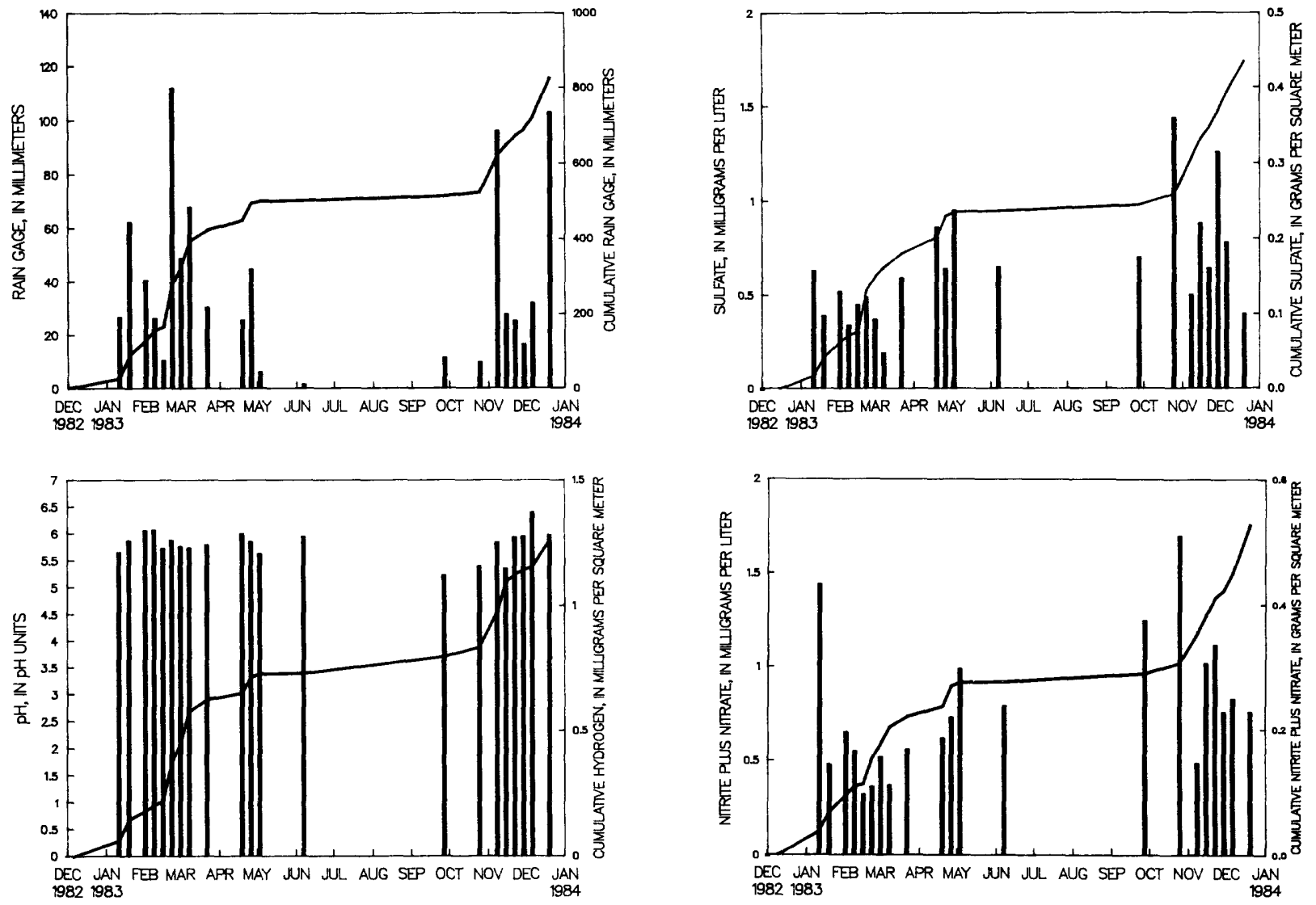

Bar plots of concentrations and cumulative line plots of loads for site CA88. Nitrite plus nitrate are reported as $\mathrm{NO}_{3}$ and sulfate as $\mathrm{SO}_{4}$.

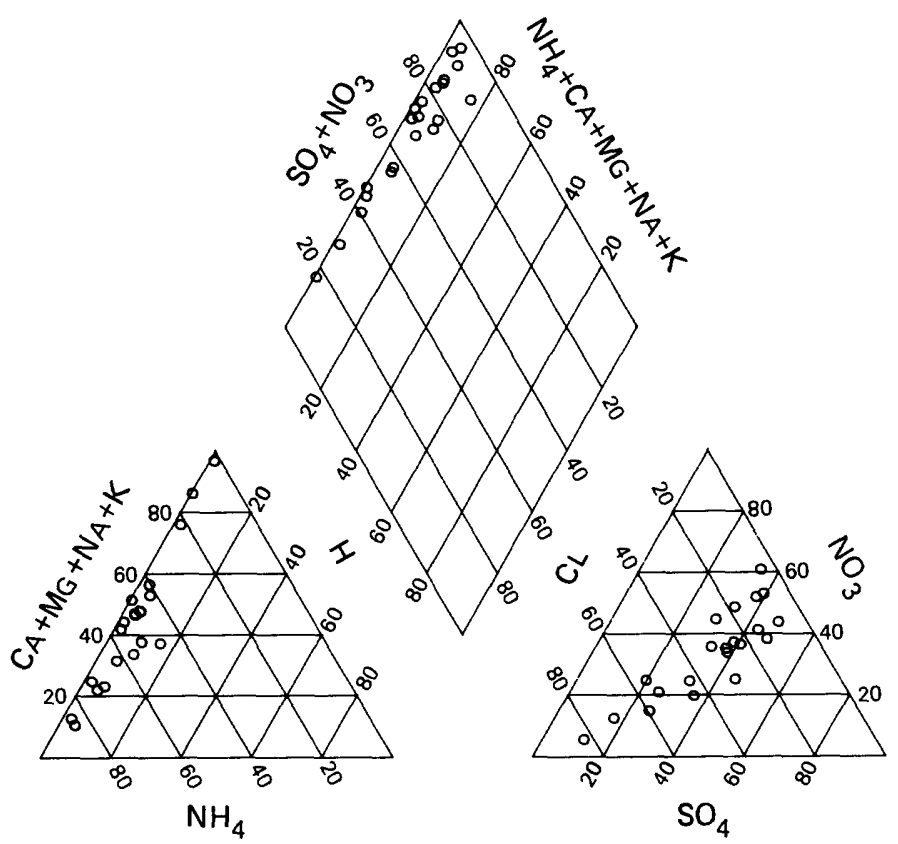

Percentage composition of major ions for site CA88. 


\section{NATIONAL TRENDS NETWORK -- 1983 CALENDER YEAR SUMMARY DATA}

Ippt = precipitation; $\mathrm{mm}=$ millimeters; $\mathrm{cm}=$ centimeters; $\mathrm{mg}=$ milligrams; $\mathrm{L}=1$ iters;

$\mathrm{g}=\mathrm{grams} ; \mathrm{m}=$ meter; $\mu \mathrm{s}=\mathrm{micros} 1 \mathrm{emens} ;$ cond $=$ specific conductance

STATION: Yosemite National Park, California

Latitude: $37^{\circ} 47^{\prime} 49^{\prime \prime}$ Longitude: $119^{\circ} 51^{\prime} 30^{\prime \prime}$
CAL number: CA99
Map ID number: 13

ADS number: $157 \mathrm{a} 00$

Station altitude above mean sea level, in meters: 1408

Number of sampling intervals (days in parenthesis):

-- With ppt measurements: $54 \quad$ (371)

-- When ppt occurred: $41 \quad$ (280)

-- When ppt did not occur: 13 (91)

-- When sample volume was substituted for missing rain gage: 3 ( 20)

-- With chemical samples: $31 \quad$ (210)
Station summary period: $12 / 28 / 1982$ to $01 / 03 / 1984$

Length of summary period: 54 sampling intervals ( 371 days)

Percent summary period with ppt measurements:

100.0

Percent summary period with chemical samples or no ppt: 81.1

Percent of total measured ppt with chemical samples: 87.0

Percent of total measured ppt in raingage that was

collected in the wet-sample bucket:

100.2

Total measured ppt, in m: 2322.2

\begin{tabular}{|c|c|c|c|c|c|c|c|c|c|c|c|c|}
\hline $\begin{array}{l}\text { Statistical } \\
\text { measures }\end{array}$ & $\begin{array}{l}\text { Mea- } \\
\text { sured } \\
\text { ppt, } \\
\text { mm }\end{array}$ & $\begin{array}{c}\text { Lab } \\
\text { specific } \\
\text { conduc- } \\
\text { tance, } \\
\mu \mathrm{S} / \mathrm{cm}\end{array}$ & $\begin{array}{r}\mathrm{Lab} \\
\mathrm{pH}\end{array}$ & $\begin{array}{c}\text { Calcium } \\
\text { as } \mathrm{Ca} \\
\mathrm{mg} / \mathrm{L}\end{array}$ & $\begin{array}{l}\text { Magne- } \\
\text { sium } \\
\text { as } \mathrm{Mg} \text {, } \\
\mathrm{mg} / \mathrm{L}\end{array}$ & $\begin{array}{c}\text { Sodium } \\
\text { as Na, } \\
\mathrm{mg} / \mathrm{L}\end{array}$ & $\begin{array}{c}\text { Potas- } \\
\text { sium } \\
\text { as } \mathrm{K} \text {, } \\
\mathrm{mg} / \mathrm{L}\end{array}$ & $\begin{array}{l}\text { Ammonia } \\
\text { as } \mathrm{NH}_{4} \text {, }\end{array}$ & $\begin{array}{l}\text { Chlor- } \\
\text { ide } \\
\text { as Cl, } \\
\mathrm{mg} / \mathrm{L}\end{array}$ & $\begin{array}{l}\text { Nitrite } \\
\text { plus } \\
\text { nitrate } \\
\text { as } \mathrm{NO}_{3} \text { ' } \\
\mathrm{mg} / \mathrm{L}\end{array}$ & $\begin{array}{l}\text { Sulfate } \\
\text { as } \mathrm{SO}_{4} \text { ' } \\
\mathrm{mg} / \mathrm{L}\end{array}$ & $\begin{array}{l}\text { Hydrogen } \\
\text { ion } \\
\text { as } \mathrm{H}, \\
\mathrm{mg} / \mathrm{L}\end{array}$ \\
\hline Minimum value & 0.00 & 1.8 & 4.55 & 0.00 & 0.001 & 0.015 & 0.003 & 0.01 & 0.01 & 0.01 & 0.05 & $1.45 \mathrm{E}-03$ \\
\hline 10 percentile & .00 & 2.1 & 4.68 & .01 & .004 & .022 & .004 & .01 & .05 & .08 & .05 & $2.00 E-03$ \\
\hline 25 percentile & .00 & 2.8 & 5.24 & .01 & .009 & .043 & .008 & .01 & .07 & .17 & .25 & $2.29 \mathrm{E}-03$ \\
\hline 50 percentile & 7.00 & 4.2 & 5.43 & .06 & .018 & .065 & .018 & .09 & .11 & .34 & .44 & $3.72 E-03$ \\
\hline 75 percentile & 82.50 & 8.8 & 5.64 & .12 & .038 & .214 & .045 & .29 & .22 & 1.49 & .99 & $5.75 E-03$ \\
\hline 90 percentile & 138.95 & 15.9 & 5.70 & .33 & .097 & .309 & .100 & .61 & .46 & 1.99 & 1.33 & $2.11 E-02$ \\
\hline Maximum value & 210.80 & 24.8 & 5.84 & .61 & .142 & .892 & .569 & .76 & 1.44 & 3.04 & 1.52 & 2. $82 \mathrm{E}-02$ \\
\hline Volume-weighted mean & NA & 3.7 & 5.46 & .04 & .015 & .078 & .014 & .08 & .14 & .29 & .28 & $3.43 E-03$ \\
\hline Arithmetic mean & 43.00 & 6.9 & 5.36 & .11 & .032 & .133 & .046 & .18 & .20 & .76 & .57 & $6.38 E-03$ \\
\hline $\begin{array}{l}\text { No. of samples } \\
\text { Total load, } 8 / \mathrm{m} 2 \\
\text { Maximum interval }\end{array}$ & $\begin{array}{l}54 \\
\text { NA }\end{array}$ & $\begin{array}{l}31 \\
\text { NA }\end{array}$ & $\begin{array}{l}31 \\
\text { NA }\end{array}$ & $\begin{array}{l}31 \\
0.085\end{array}$ & $\begin{array}{l}31 \\
0.030\end{array}$ & $\begin{array}{l}31 \\
0.159\end{array}$ & $\begin{array}{l}31 \\
0.028\end{array}$ & $\begin{array}{l}31 \\
0.163\end{array}$ & $\begin{array}{l}31 \\
0.275\end{array}$ & $\begin{array}{l}31 \\
0.584\end{array}$ & $\begin{array}{l}31 \\
0.560\end{array}$ & $\begin{array}{l}31 \\
6.9 E-03\end{array}$ \\
\hline $\begin{array}{l}\text { load, } 8 / \mathrm{m} 2 \\
\text { Correlation with ppt } \\
\text { Kendall tau }\end{array}$ & $\begin{array}{l}\text { NA } \\
\text { volume: }\end{array}$ & $\begin{array}{l}\text { NA } \\
\text { Cond } \\
-0.55\end{array}$ & $\begin{array}{c}\mathrm{NA} \\
\mathrm{pH} \\
0.35\end{array}$ & $\begin{array}{l}.022 \\
\mathrm{Ca} \\
-.49\end{array}$ & $\begin{array}{l}.004 \\
\mathrm{Mg} \\
-.53\end{array}$ & $\begin{array}{l}.029 \\
\mathrm{Na} \\
-.35\end{array}$ & $\begin{array}{l}.004 \\
\mathrm{~K} \\
-.53\end{array}$ & $\begin{array}{l}.029 \\
\mathrm{NH}_{4}^{4} \\
-.37\end{array}$ & $\begin{array}{l}.044 \\
C 1 \\
-.28\end{array}$ & $\begin{array}{l}.119 \\
\mathrm{NO}_{3}^{3} \\
-.54\end{array}$ & $\begin{array}{l}.072 \\
\mathrm{so}^{4} \\
-.52\end{array}$ & $\begin{array}{l}7.8 \mathrm{E}-04 \\
\mathrm{H} \\
-0.35\end{array}$ \\
\hline P-level & & .000 & .007 & .000 & .000 & .006 & .000 & .006 & .031 & .000 & .000 & 0.007 \\
\hline
\end{tabular}

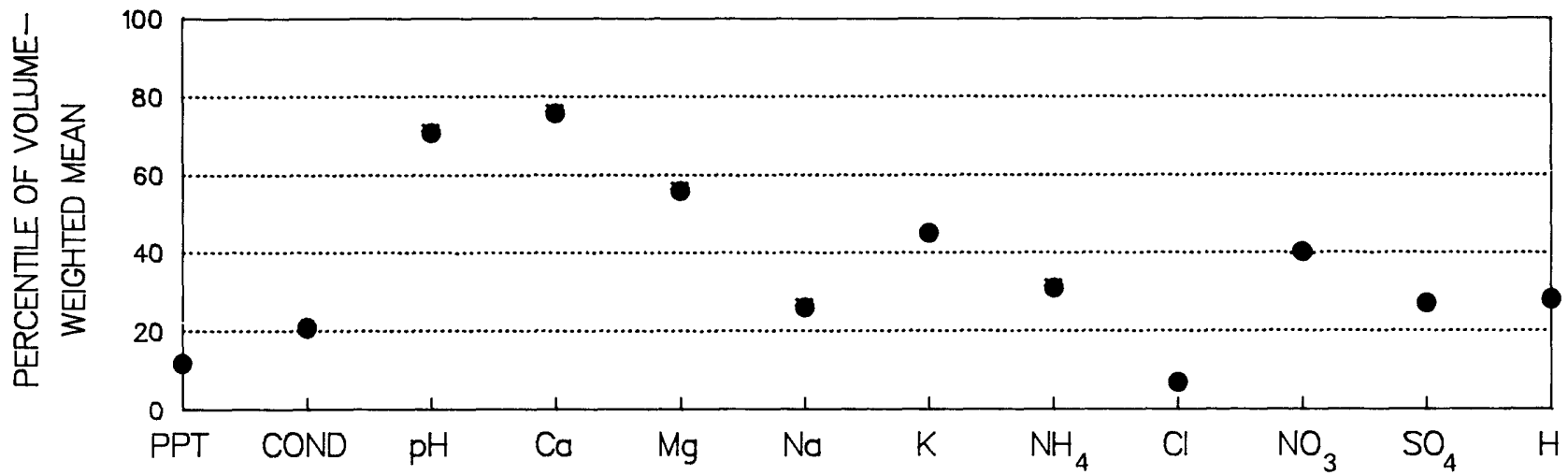

Percentiles of volume-weighted mean concentrations for site CO15, based on frequency distributions of data from 55 National Trends Network sites. 

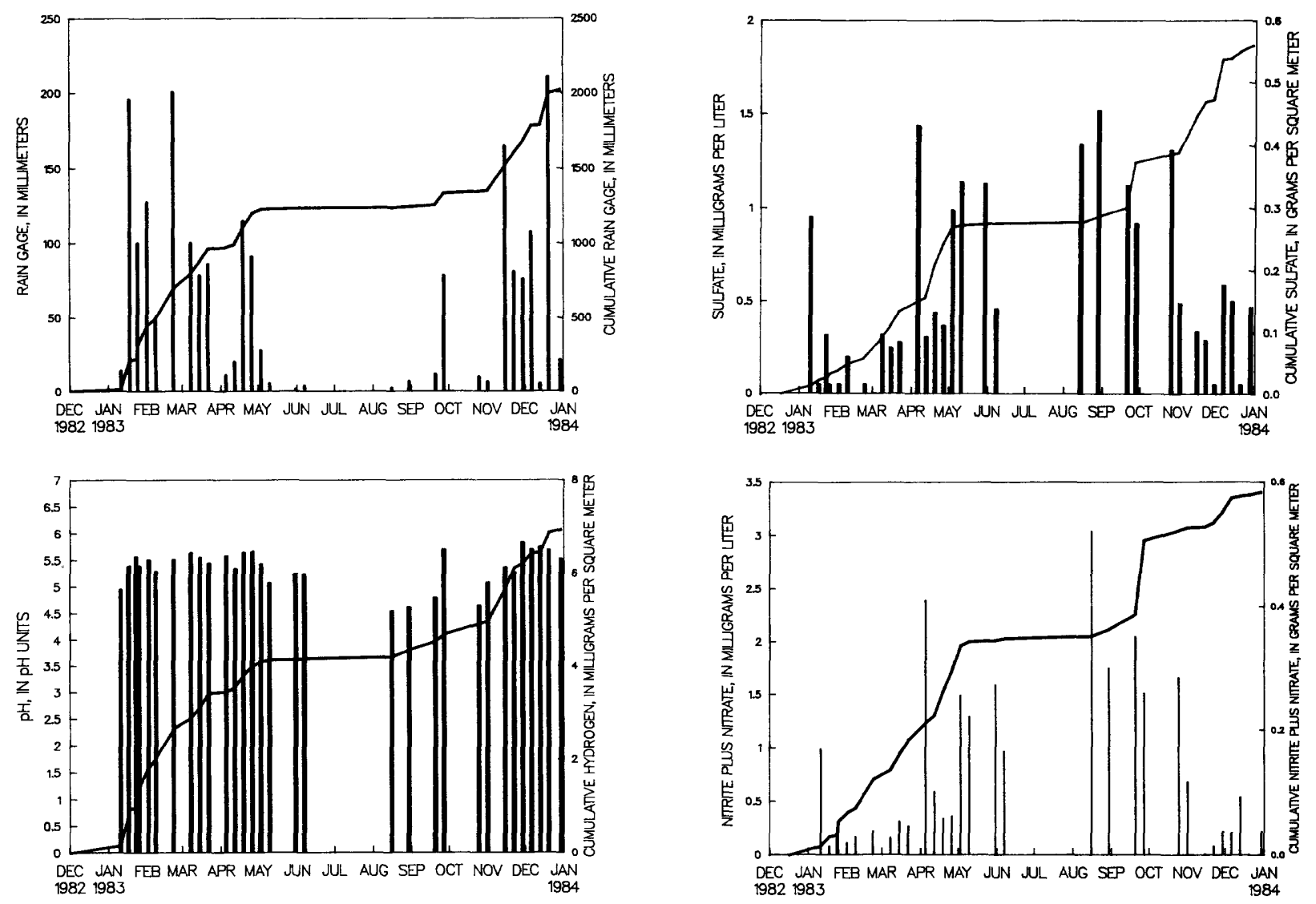

Bar plots of concentrations and cumulative line plots of loads for site CA99. Nitrite plus nitrate are reported as $\mathrm{NO}_{3}$ and sulfate as $\mathrm{SO}_{4}$.

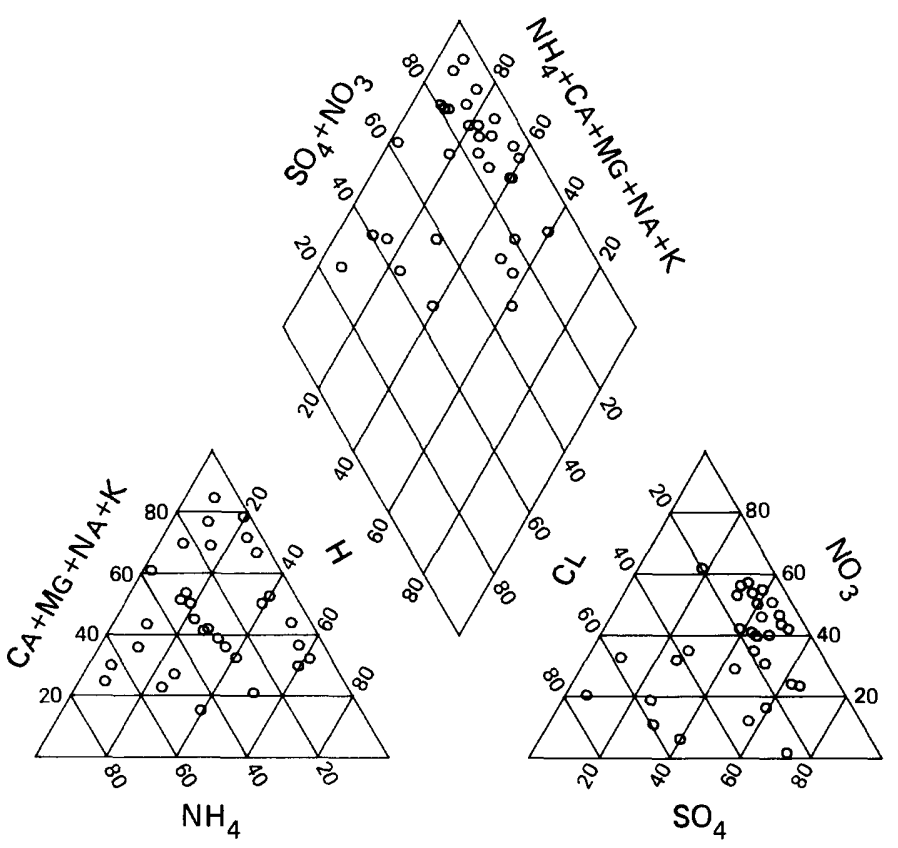

Percentage composition of major ions for site CA99. 


\section{NATIONAL TRENDS NETWORK -- 1983 CALENDER YEAR SUMMARY DATA}

$[\mathrm{ppt}=$ precipitation; $\mathrm{mm}=$ millimeters; $\mathrm{cm}=$ centimeters; $\mathrm{mg}=\mathrm{milligrams;} \mathrm{L=1iters;}$ $8=$ grams; $m=$ meter $; \mu s=$ microsiemens; cond = specific conductance $]$

STATION: Sand Spring, Colorado

CAL number: CO15

ADS number: $173 \mathrm{a} 00$

Station altitude above mean sea level, in meters: 1998

Number of sampling intervals (days in parenthesis):

-- With ppt measurements: 53 (371)

-- When ppt occurred: 51 (357)

-- When ppt did not occur: 2 ( 14)

-- When sample volume was substituted for missing rain gage: 0 ( 0$)$

-- With chemical samples: $39 \quad$ (273)
Latitude: $40^{\circ} 30^{\prime} 27^{\prime \prime}$ Longitude: $107^{\circ} 42^{\prime} 07^{\prime \prime}$

Station summary period: $12 / 28 / 1982$ to $01 / 03 / 1984$

Length of summary period: 53 sampling intervals ( 371 days)

Percent summary period with ppt measurements: $\quad 100.0$

Percent summary period with chemical samples or no ppt: 77.4

Percent of total measured ppt with chemical samples: $\quad 77.0$

Percent of total measured ppt in raingage that was

collected in the wet-sample bucket:

96.8

Total measured ppt, in m: 427.7

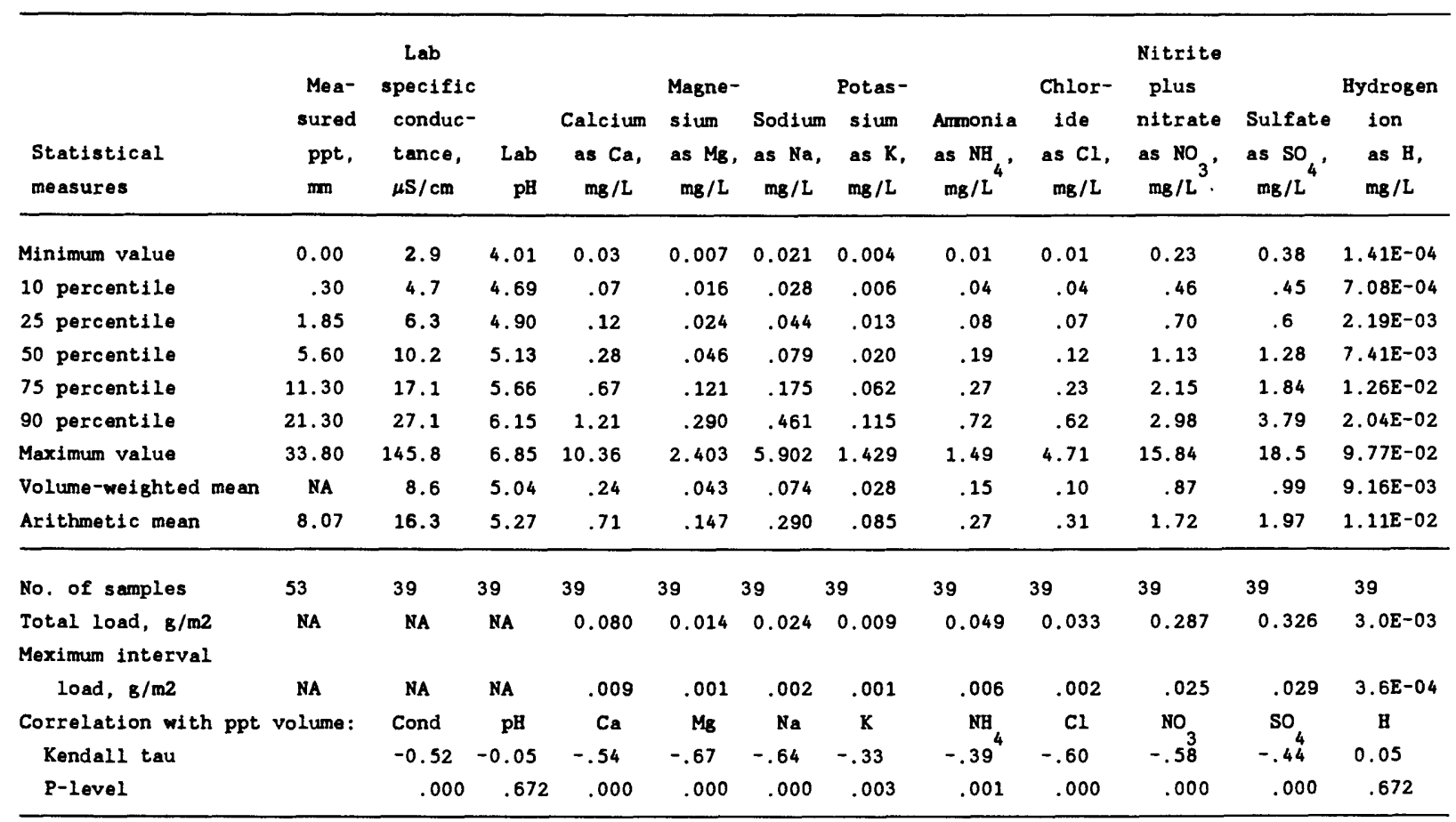

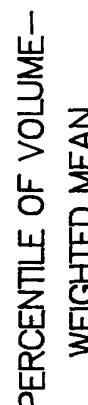

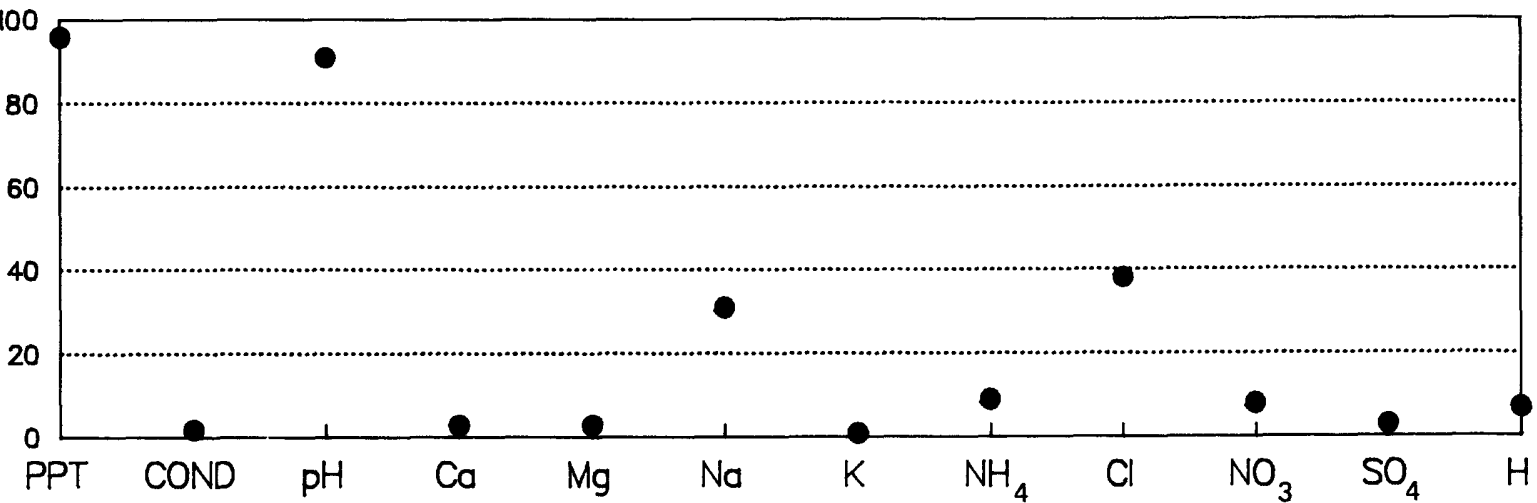

Percentiles of volume-weighted mean concentrations for site CA99, based on frequency distributions of data from 55 National Trends Network sites. 

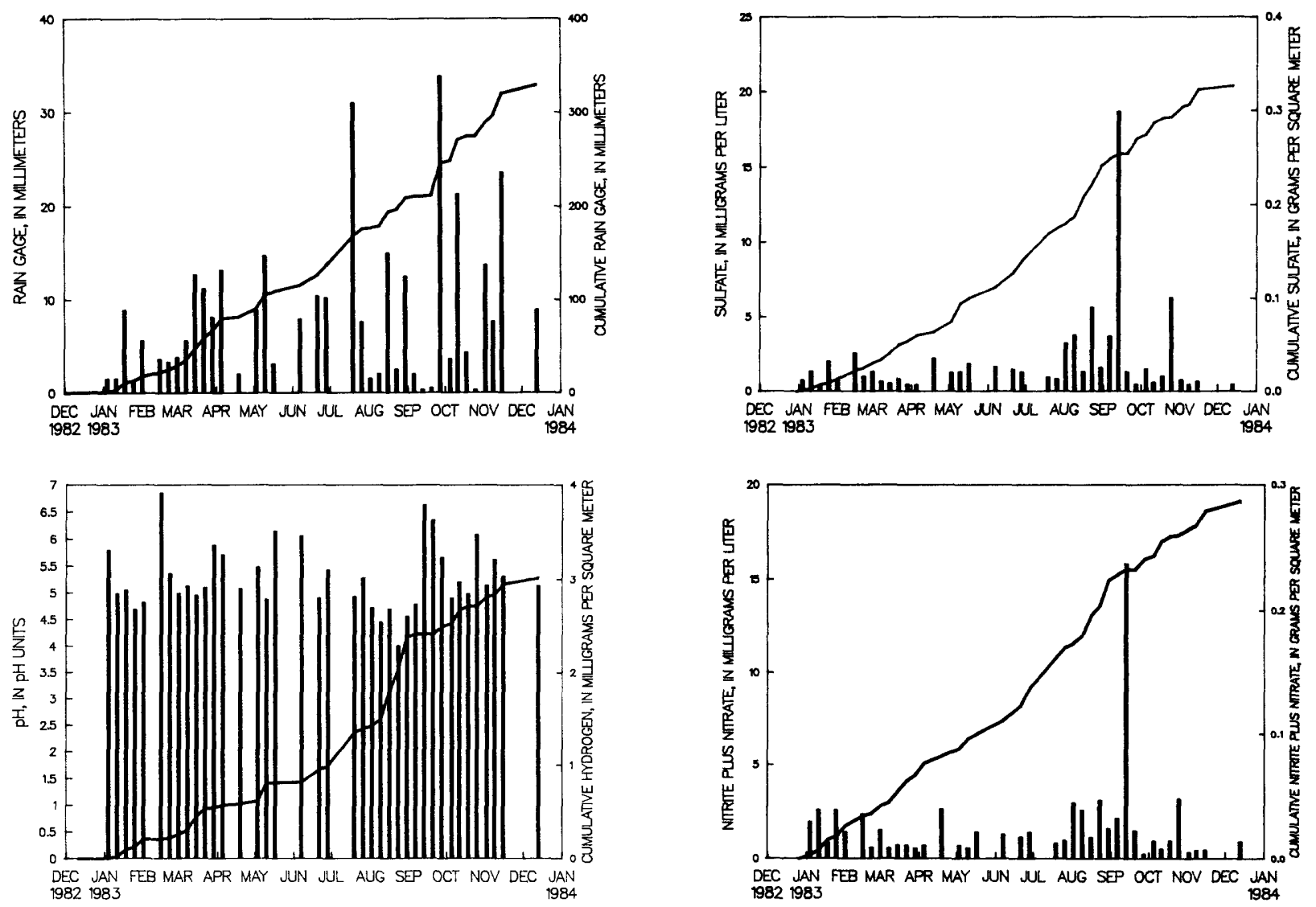

Bar plots of concentrations and cumulative line plots of loads for site CO15. Nitrite plus nitrate are reported as $\mathrm{NO}_{3}$ and sulfate as $\mathrm{SO}_{4}$.

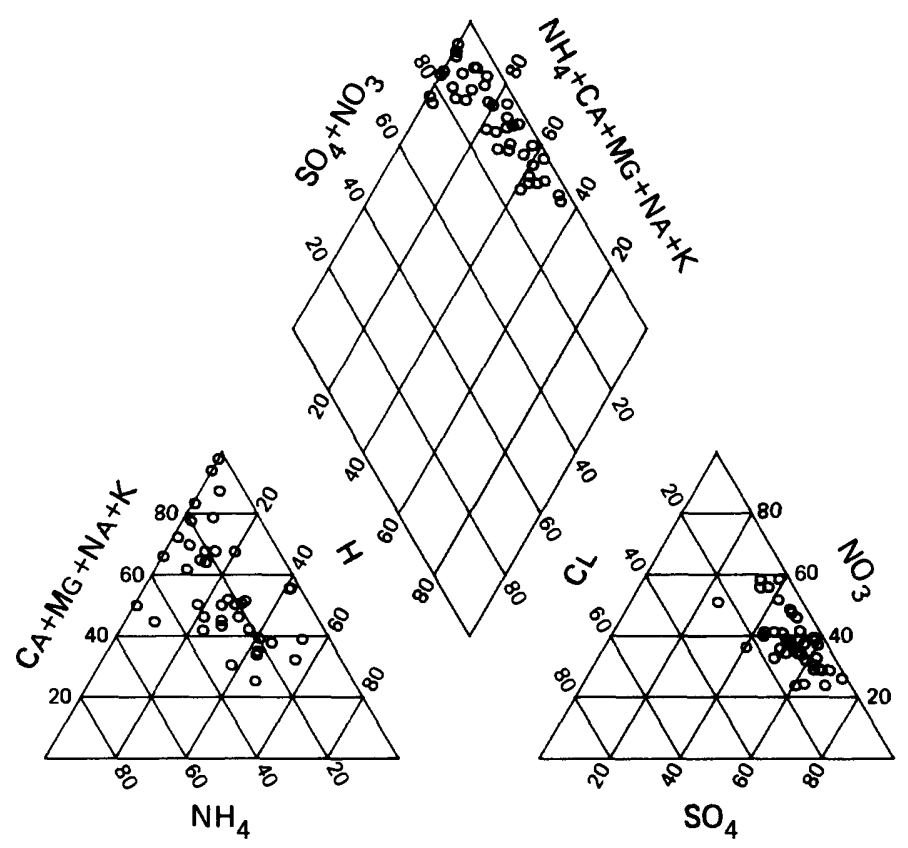

Percentage composition of major ions for site COIS. 


\section{NATIONAL TRENDS NETWORK - 1983 CALENDER YEAR SUMMARY DATA}

lppt $=$ precipitation; $\mathrm{mm}=$ millimeters; $\mathrm{cm}=$ centimeters; $\mathrm{mg}=\mathrm{milligrams;} \mathrm{L}=1$ iters; $\mathrm{g}=$ grams; $\mathrm{m}=$ meter; $\mu \mathrm{s}=$ microsiemens; cond = specific conductance $]$

STATION: Pawnee, Colorado

CAL number: $\operatorname{CO} 22$

ADS number: $012 \mathrm{a} 01$

Station altitude above mean sea level, in meters: 1641 Number of sampling intervals (days in parenthesis):

-- With ppt measurments:

-- When ppt occurred:

-- When ppt did not occur:

-- When sample volume was substituted for missing rain gage:

-- With chemical samples:
Map ID number: 18

Latitude: $40^{\circ} 48^{\prime} 23^{\prime \prime}$ Longitude: $104^{\circ} 45^{\prime} 15^{\prime \prime}$
Station summary period: $12 / 28 / 1982$ to $01 / 03 / 1984$

Length of summary period: 53 sampling intervals ( 371 days)

Percent summary period with ppt measurements :

100.0

Percent summary period with chemical samples or no ppt: 75.5

Percent of total measured ppt with chemical samples: 87.1

Percent of total measured ppt in raingage that was

collected in the wet-sample bucket:

89.5

Total measured ppt, in m: 374.0

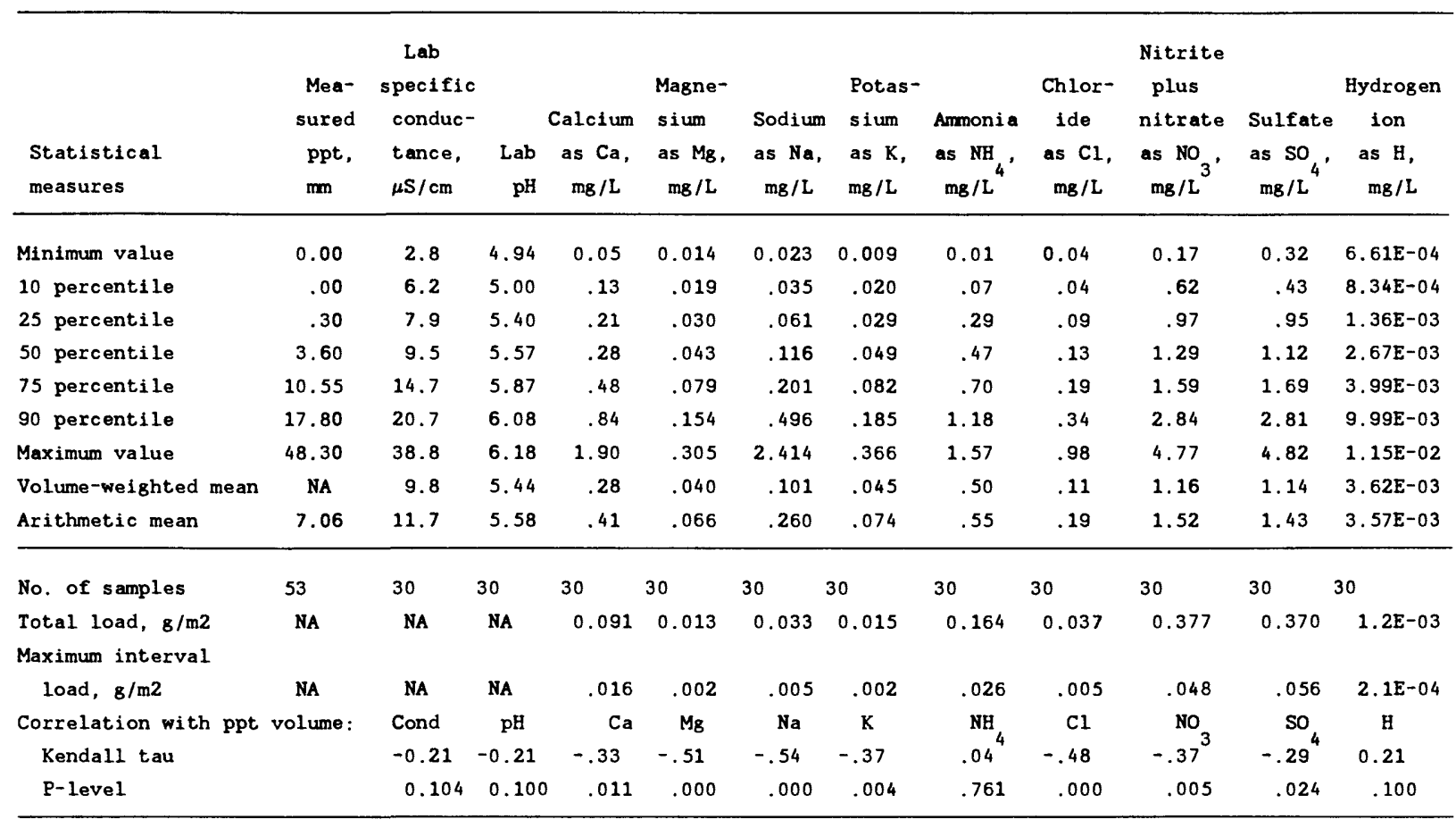

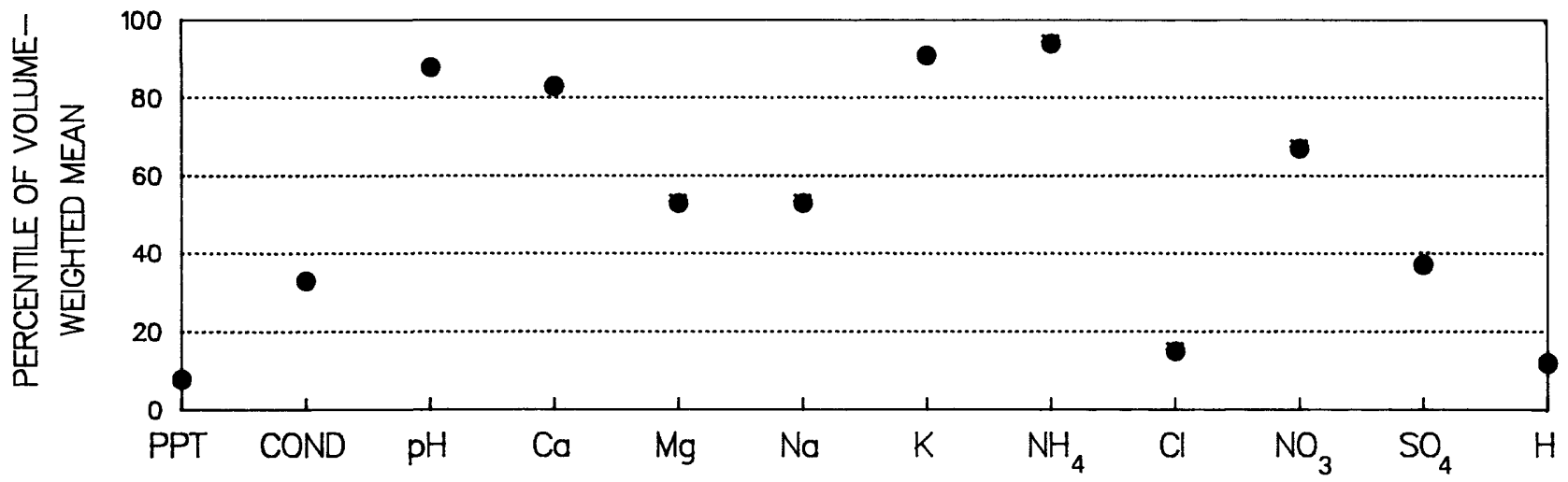

Percentiles of volume-weighted mean concentrations for site $\mathrm{CO} 22$, based on frequency distributions of data from 55 National Trends Network sites. 

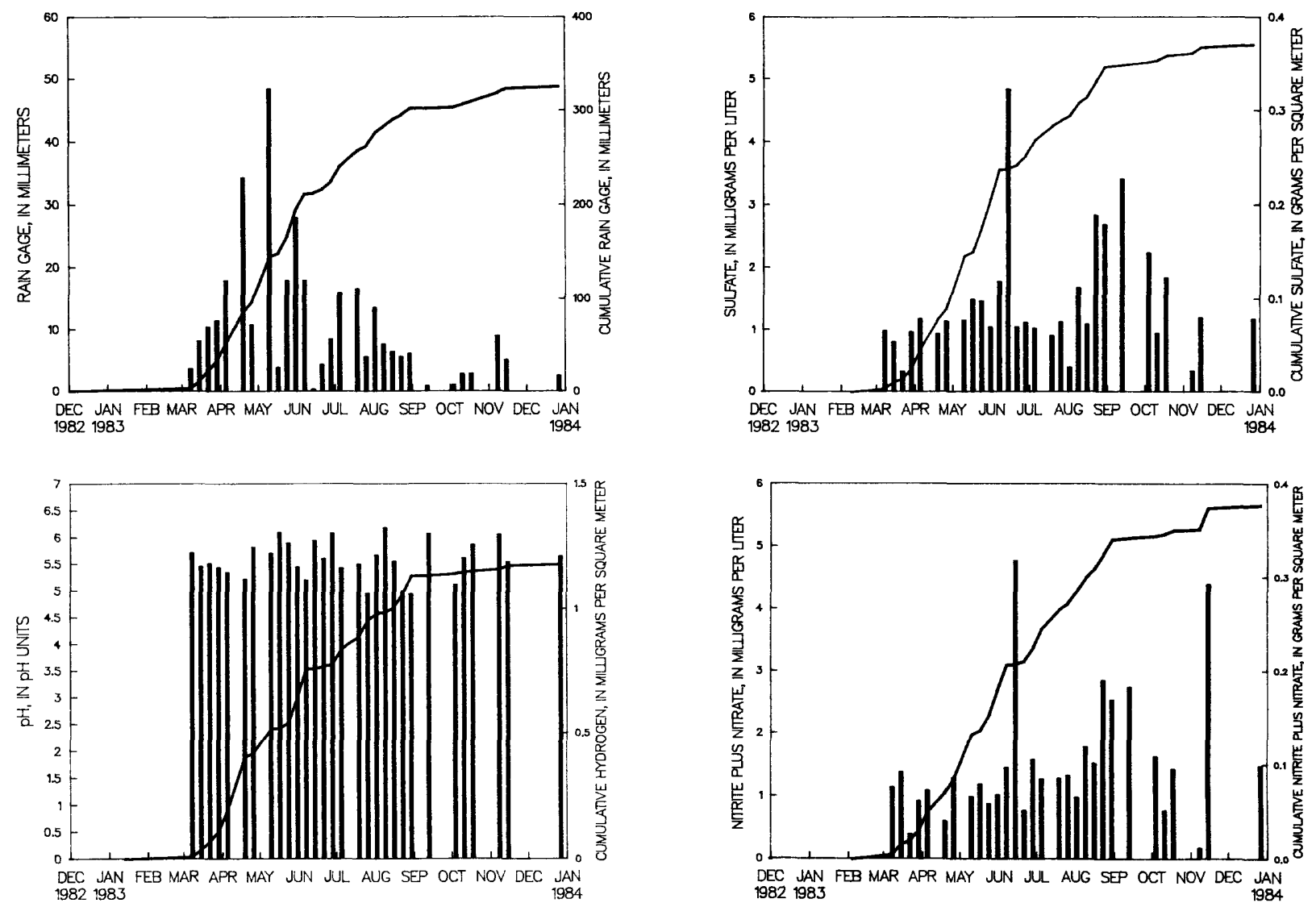

Bar plots of concentrations and cumulative line plots of loads for site $\mathrm{CO} 22$.

Nitrite plus nitrate are reported as $\mathrm{NO}_{3}$ and sulfate as $\mathrm{SO}_{4}$.

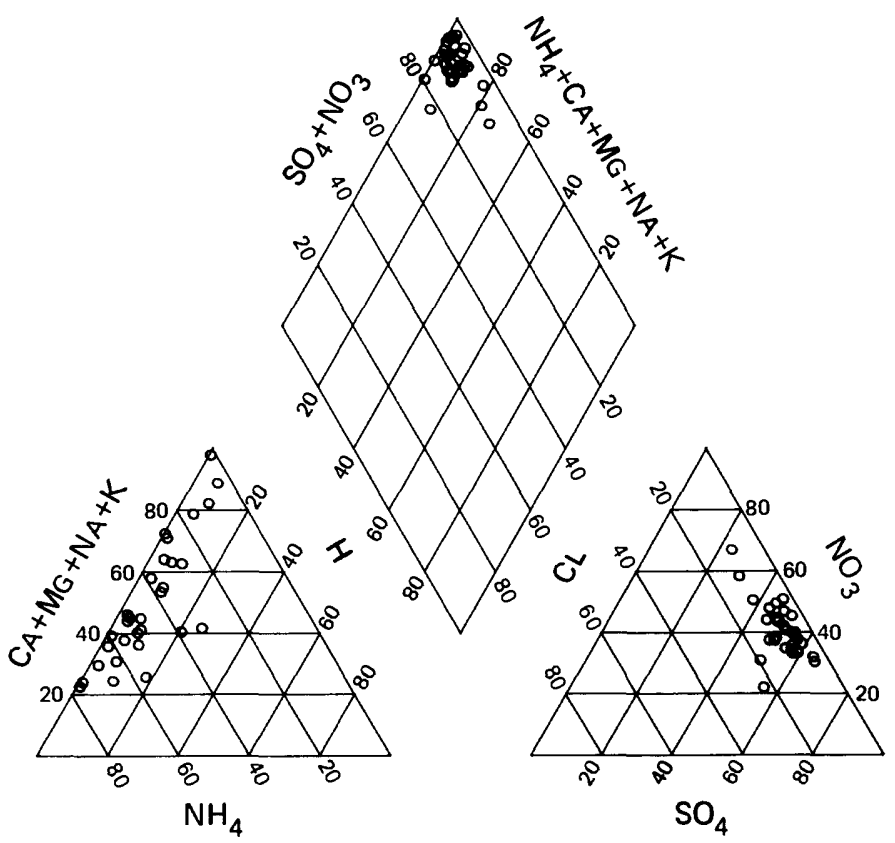

Percentage composition of major ions for site $\mathrm{CO} 22$. 


\section{NATIONAL TRENDS NETWORK -- 1983 CALENDER YEAR SUMMARY DATA}

lppt $=$ precipitation; $\mathrm{mm}=$ millimeters; $\mathrm{cm}=$ centimeters; $\mathrm{mg}=\mathrm{milligrams;} \mathrm{L}=11$ ters; $\mathrm{g}=\mathrm{grams} ; \mathrm{m}=$ meter $\boldsymbol{\mu \mathrm { s }}=\mathrm{microsiemens} ;$ cond $=$ specific conductance $]$

STATION: Bradford Forest, Florida

CAL number: FLO3

ADS number: $015 \mathrm{a} 00$

Station altitude above mean sea level, in meters: 44 Number of sampling intervals (days in parenthesis):

-- With ppt measurements: $52 \quad$ (364)

-- When ppt occurred: $49 \quad$ (343)

-- When ppt did not occur: $3 \quad$ ( 21)

-- When sample volume was substituted for missing rain gage: 0 ( 0 )

-- With chemical samples: 37 (256)
Latitude: $29^{\circ} 58^{\prime} 29^{\prime \prime}$ Longitude: $82^{\circ} 11^{\prime} 53^{\circ}$

Station summary period: $12 / 28 / 1982$ to $01 / 03 / 1984$

Length of summary period: 53 sampling intervals ( 371 days)

Percent summary period with ppt measurements:

98.1

Percent sumnary period with chemical samples or no ppt: 74.7

Percent of total measured ppt with chemical samples: 80.3

Percent of total measured ppt in raingage that was

collected in the wet-sample bucket:

93.8

Total measured ppt, in $\mathrm{mm}: 1619.5$

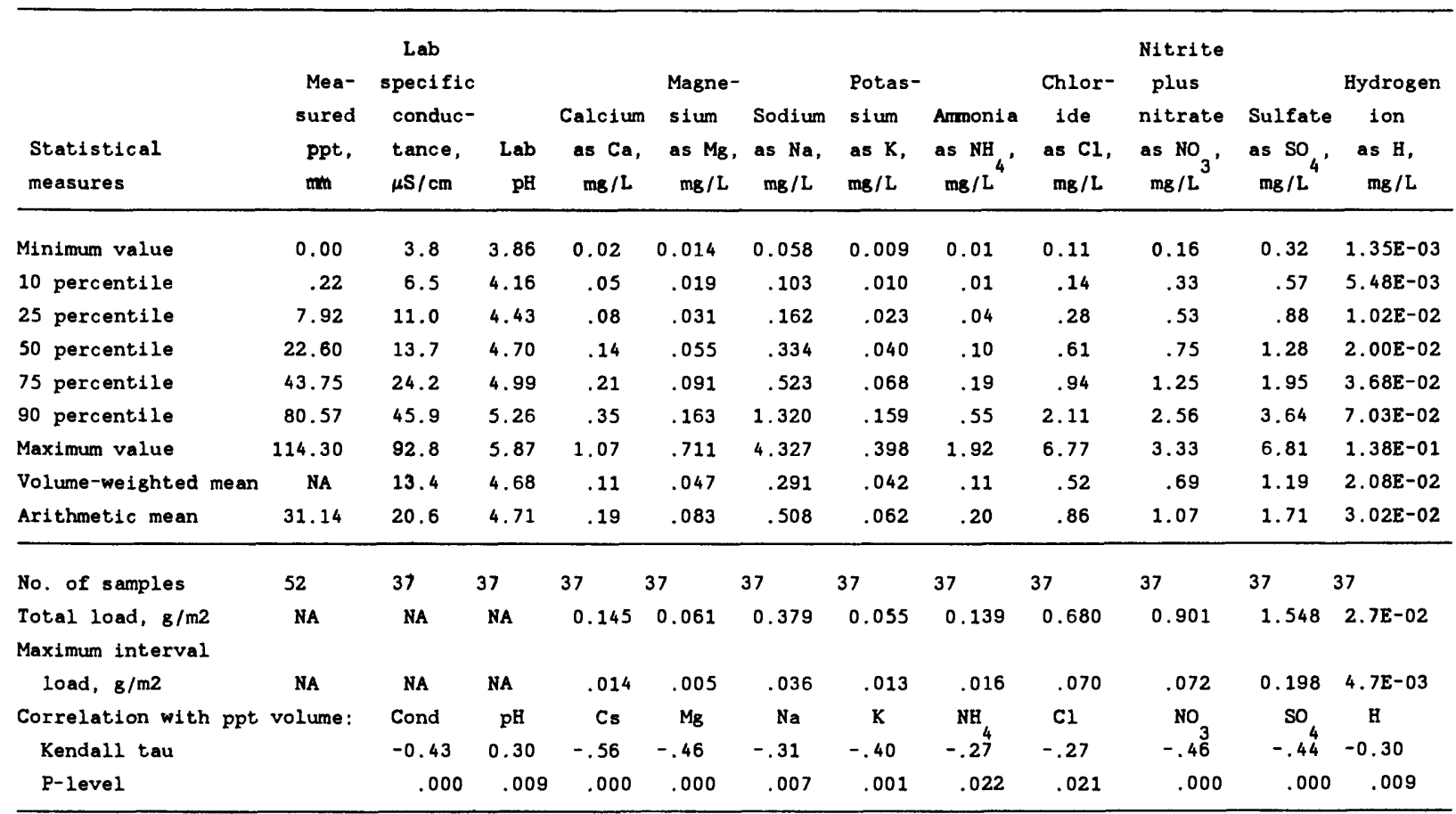

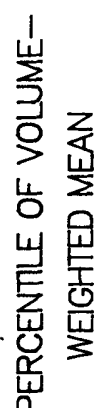

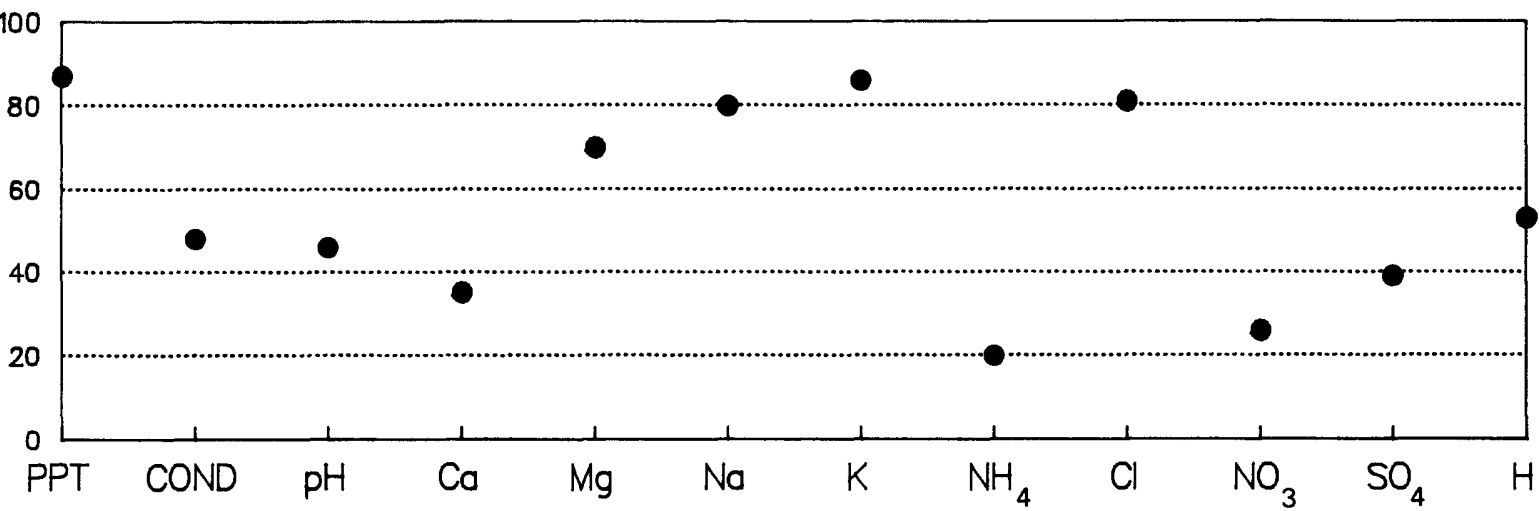

Percentiles of volume-weighted mean concentrations for site FL03, based on frequency distributions of data from 55 National Trends Network sites. 

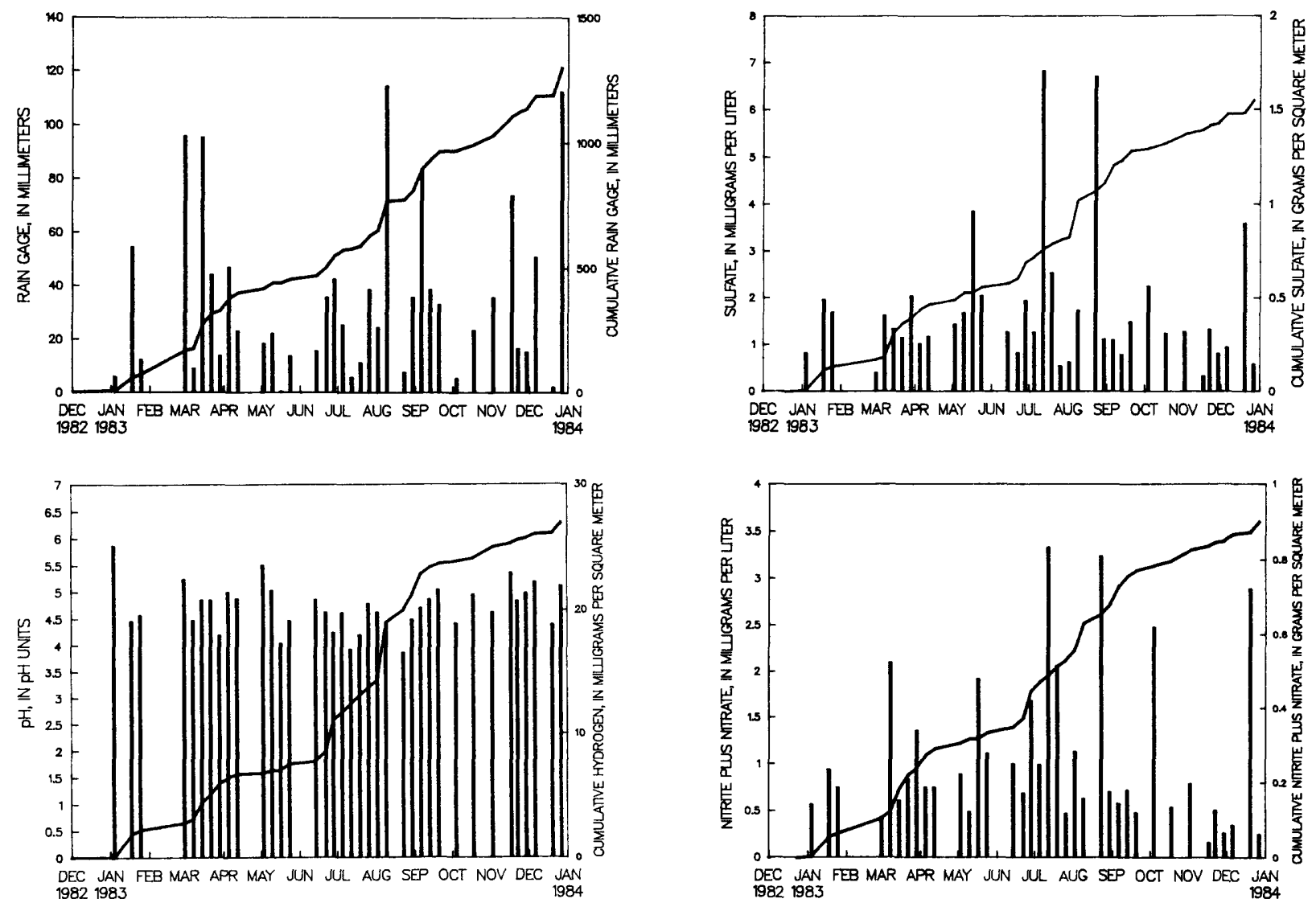

Bar plots of concentrations and cumulative line plots of loads for site FL03. Nitrite plus nitrate are reported as $\mathrm{NO}_{3}$ and sulfate as $\mathrm{SO}_{4}$.

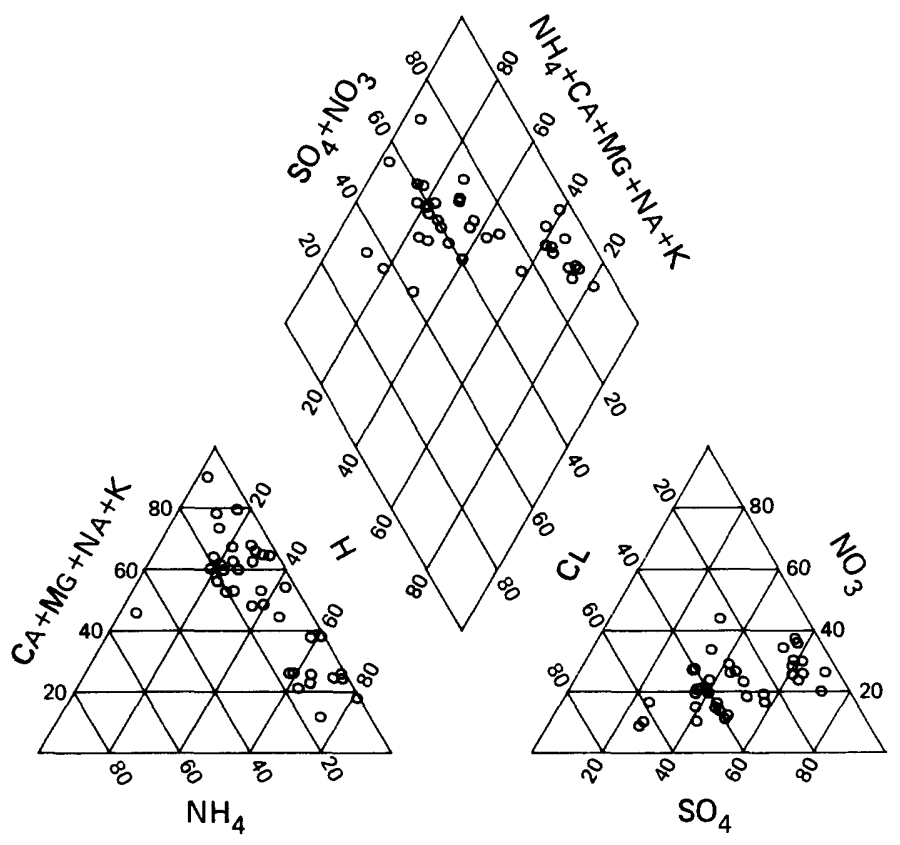

Percentage composition of major ions for site FL03. 


\section{NATIONAL TRENDS NETWORK -- 1983 CALENDER YEAR SUMMARY DATA}

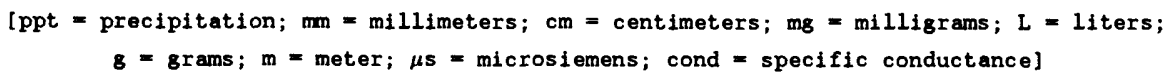

STATION: Everglades National Park, Florida

Latitude: $25^{\circ} 23^{\prime} 40^{\prime \prime}$ Longitude: $80^{\circ} 41^{\prime} 45^{\prime \prime}$
CAL number: FL11 Map ID number: 21

ADS number: $016 a 00$

Station altitude above mean sea level, in meters: 2

Number of sampling intervals (days in parenthesis):

-- With ppt measurements: $51 \quad$ (371)

-- When ppt occurred: 49 (357)

-- When ppt did not occur: 2 ( 14)

-- When sample volume was substituted for missing rain gage: $0 \quad(0)$

-- With chemical samples: $36 \quad$ (252)
Station summary period: $12 / 28 / 1982$ to $01 / 03 / 1984$

Length of summary period: 51 sampling intervals ( 371 days)

Percent sumary period with ppt measurements: $\quad 100.0$

Percent summary period with chemical samples or no ppt: 71.7

Percent of total measured ppt with chemical samples: $\quad 71.4$

Percent of total measured ppt in raingage that was

collected in the wet-sample bucket:

95.0

Total measured ppt, in m: 1645.3

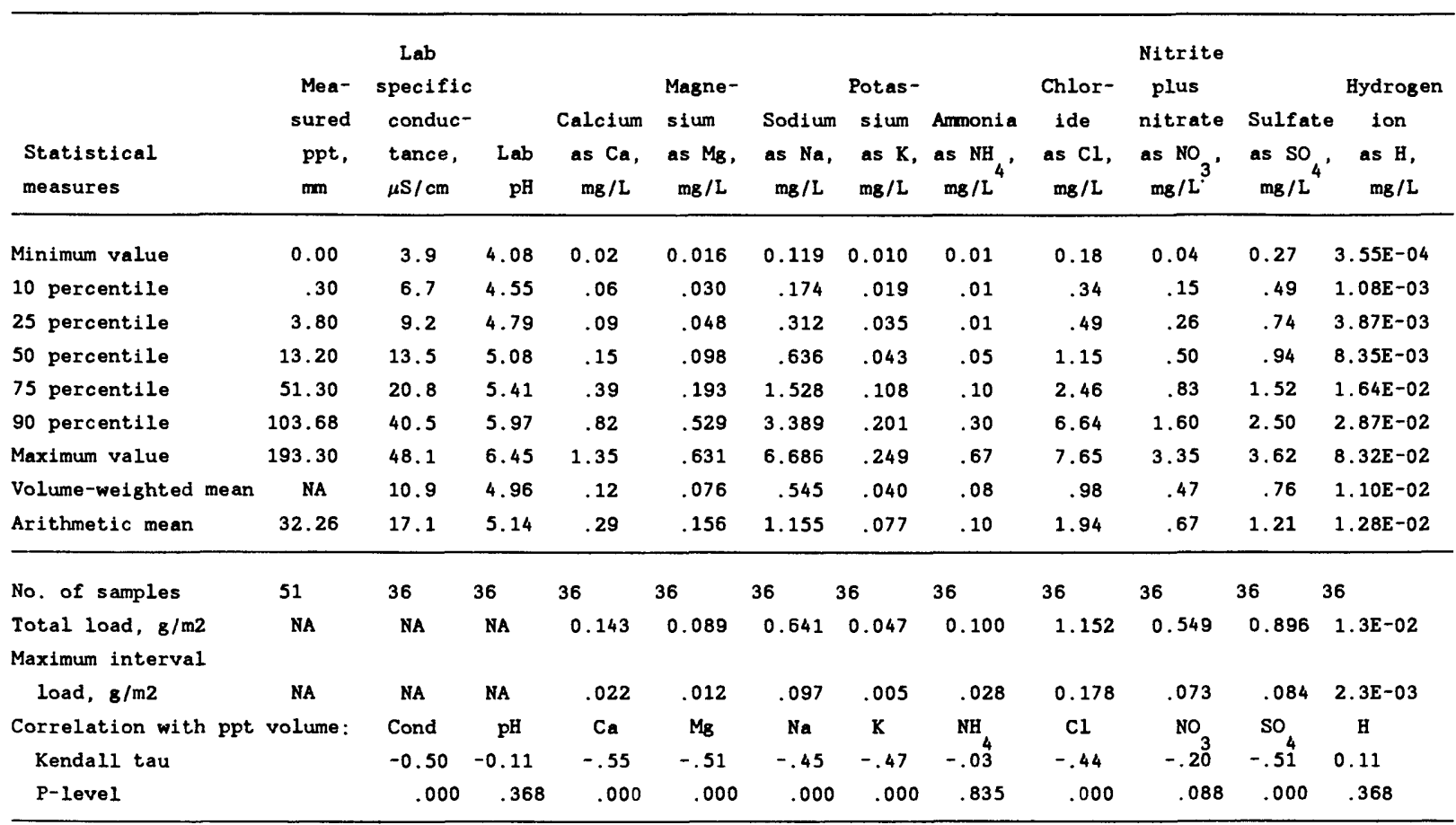

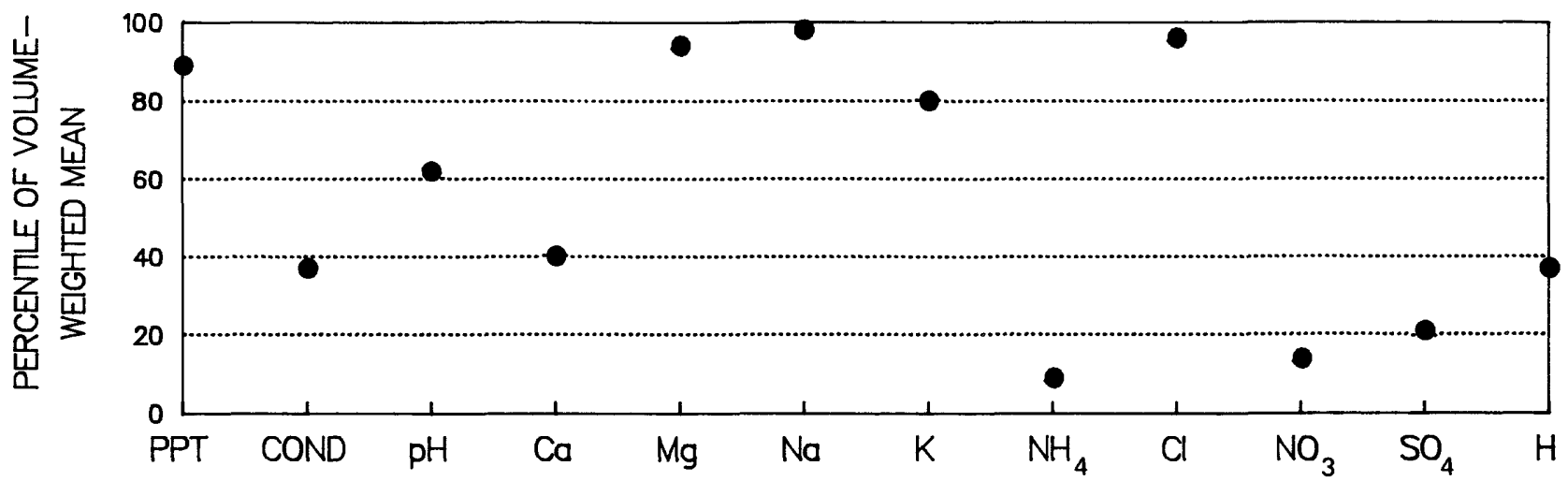

Percentiles of volume-weighted mean concentrations for site FL11, based on frequency distributions of data from 55 National Trends Network sites. 

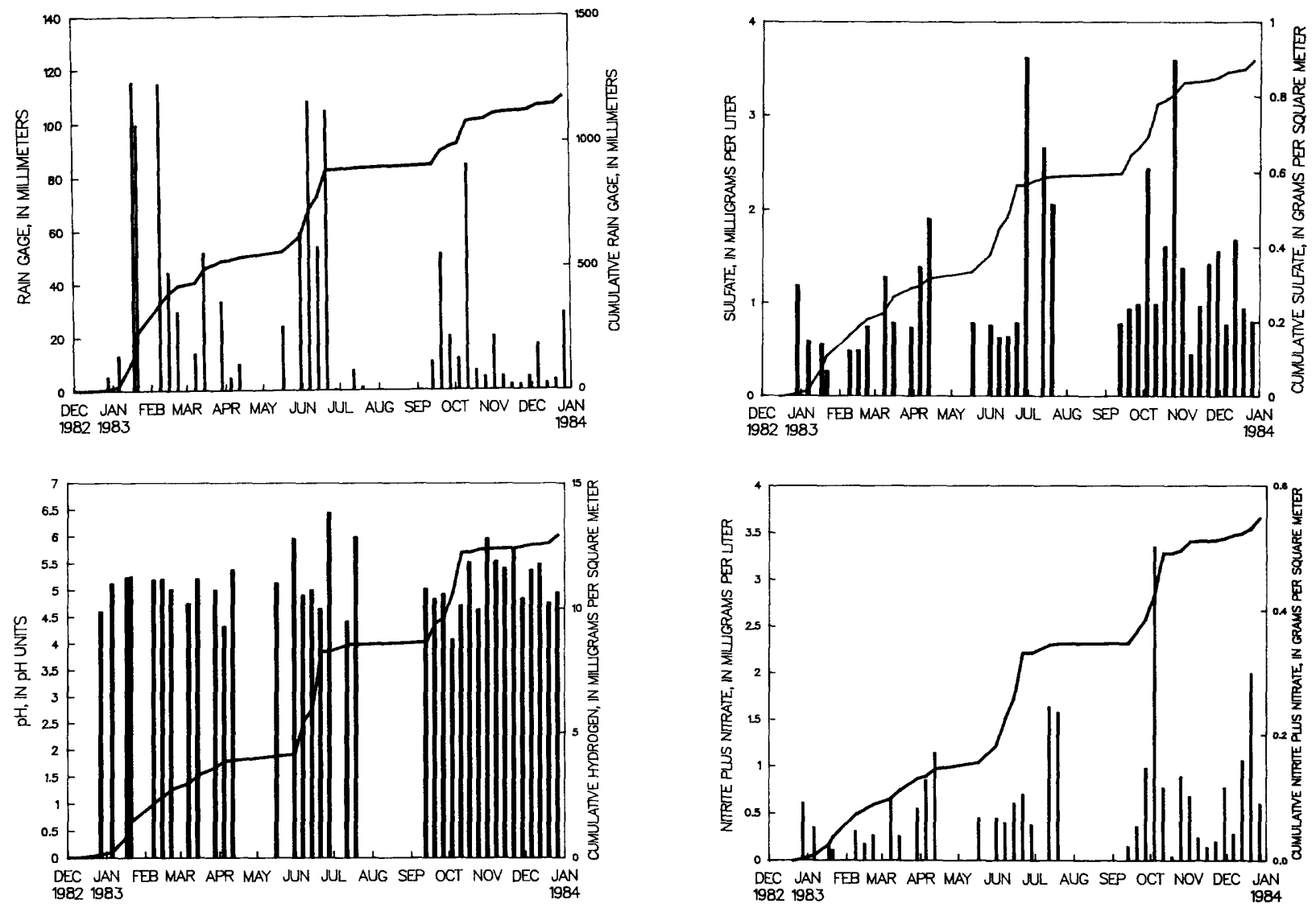

Bar plots of concentrations and cumulative line plots of loads for site FL11. Nitrite plus nitrate are reported as $\mathrm{NO}_{3}$ and sulfate as $\mathrm{SO}_{4}$.

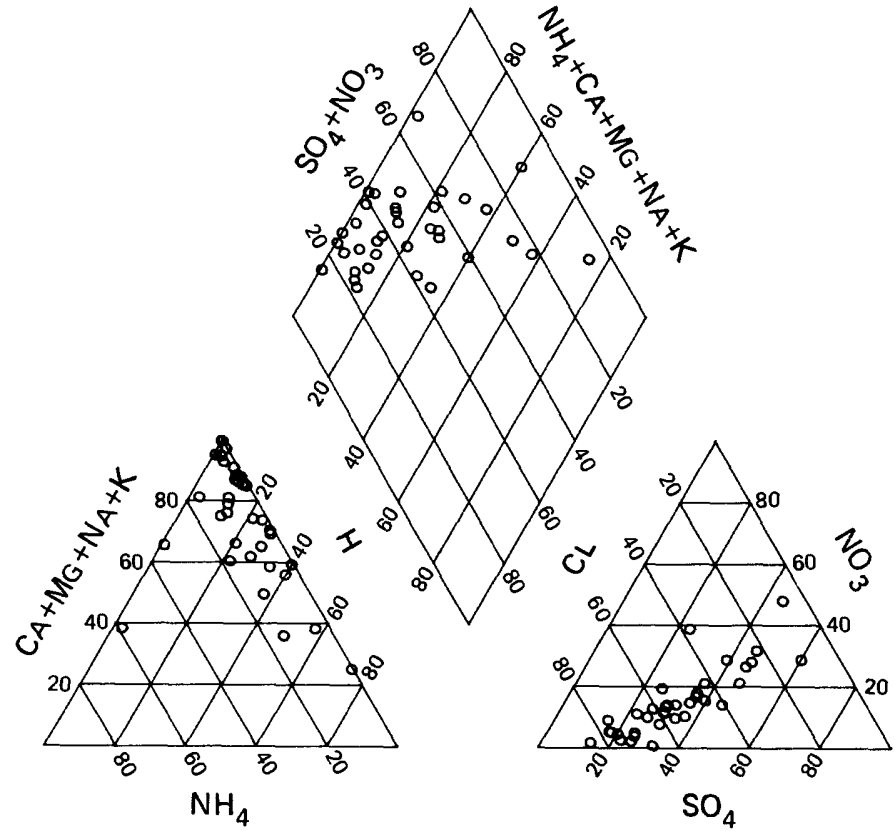

Percentage composition of major ions for site FL11. 


\section{NATIONAL TRENDS NETWORK -- 1983 CALENDER YEAR SUMMARY DATA}

Lppt = precipitation; $\mathrm{mm}=$ millimeters; $\mathrm{cm}=$ centimeters; $\mathrm{mg}=$ milligrams; L = 1iters; $8=$ grams; $m=$ meter $\mu \mathrm{s}=$ microsiemens; cond $=$ specific conductance $]$

STATION: Headquarters, Idaho

CAL number: ID04

ADS number: 271a00

Station altitude above mean sea level, in meters: 969 Number of sampling intervals (days in parenthesis):

-- With ppt measurements: $50 \quad$ (372)

-- When ppt occurred: $47 \quad$ (352)

-- When ppt did not occur: 3 ( 20)

-- When sample volume was substituted for missing rain gage: 5 ( 49)

-- With chemical samples: $32 \quad$ (239)
Latitude: $47^{\circ} 37^{\prime} 40^{\prime \prime}$ Longitude: $115^{\circ} 49^{\prime} 10^{\prime \prime}$

Station summary period: $12 / 28 / 1982$ to $01 / 04 / 1984$

Length of sumary period: 50 sampling intervals (372 days)

Percent summary period with ppt measurements:

100.3

Percent summary period with chemical samples or no ppt: 69.8

Percent of total measured ppt with chemical samples: 67.9

Percent of total measured ppt in raingage thst was

collected in the wet-sample bucket:

97.7

Total measured ppt, in mm: 1132.6

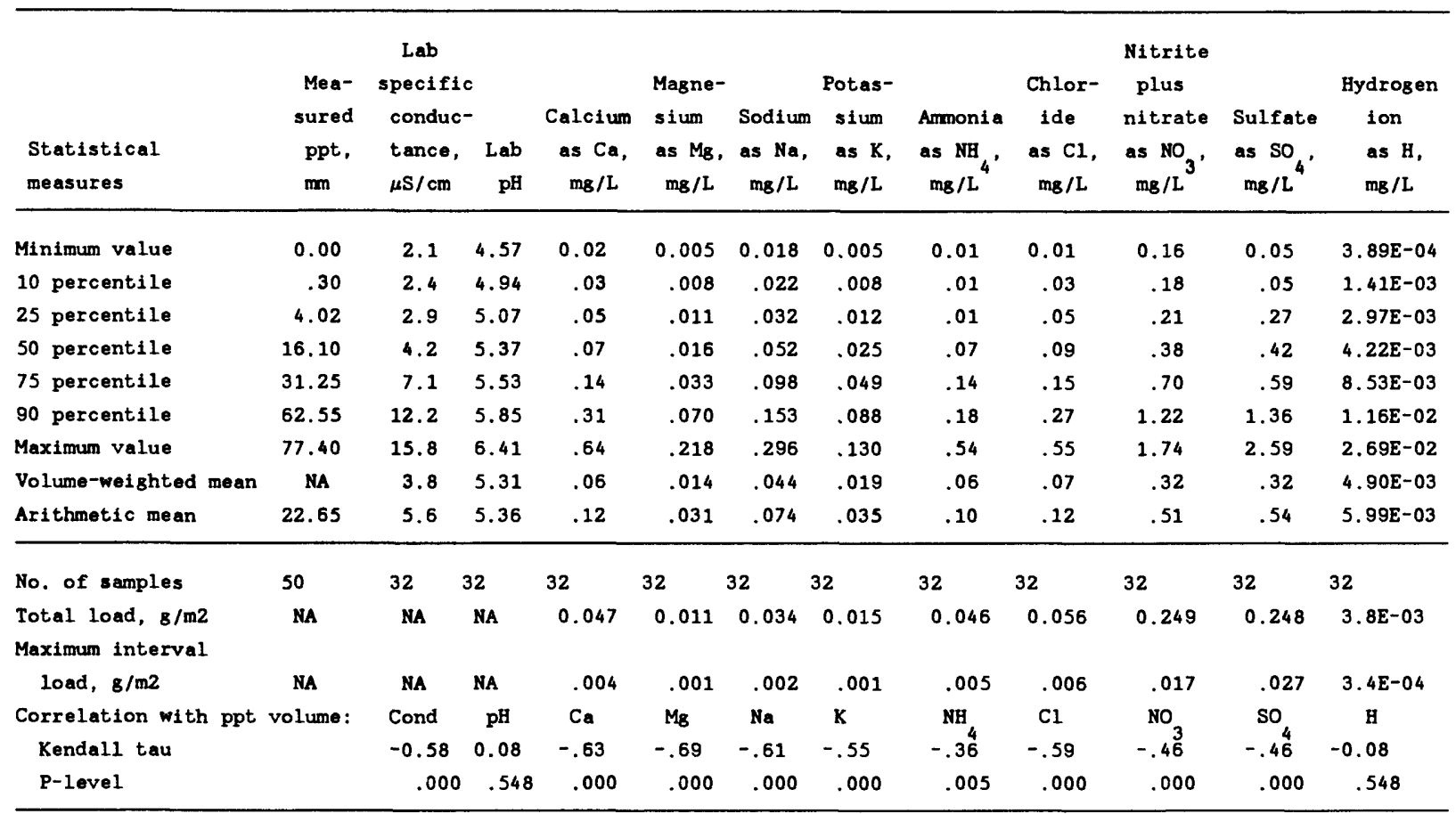

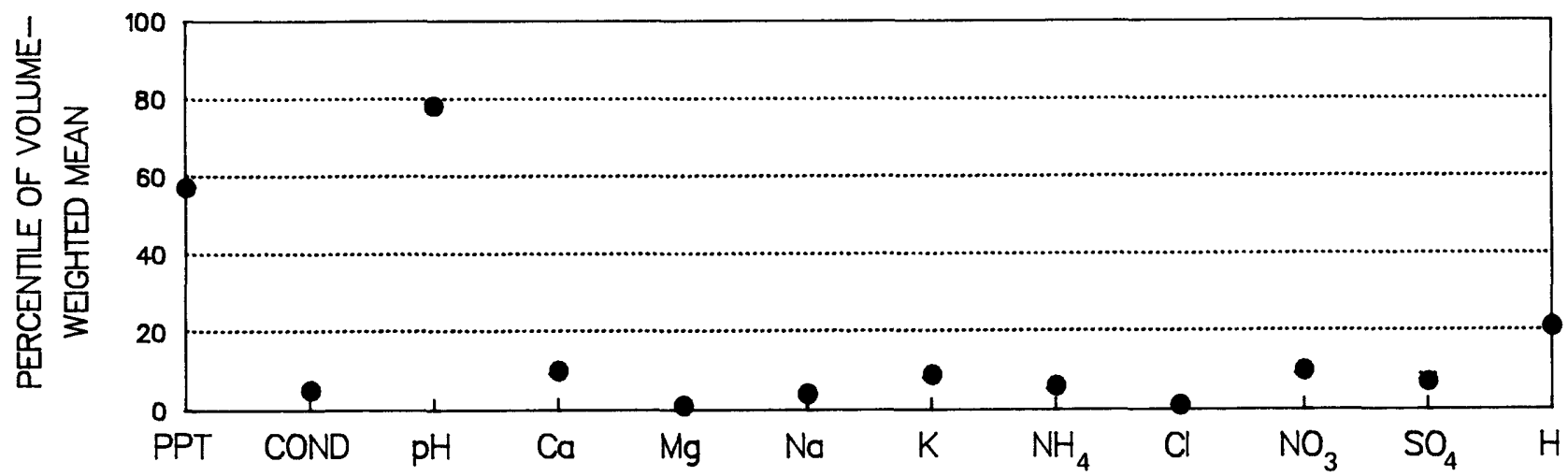

Percentiles of volume-weighted mean concentrations for site ID04, based on frequency distributions of data from 55 National Trends Network sites. 

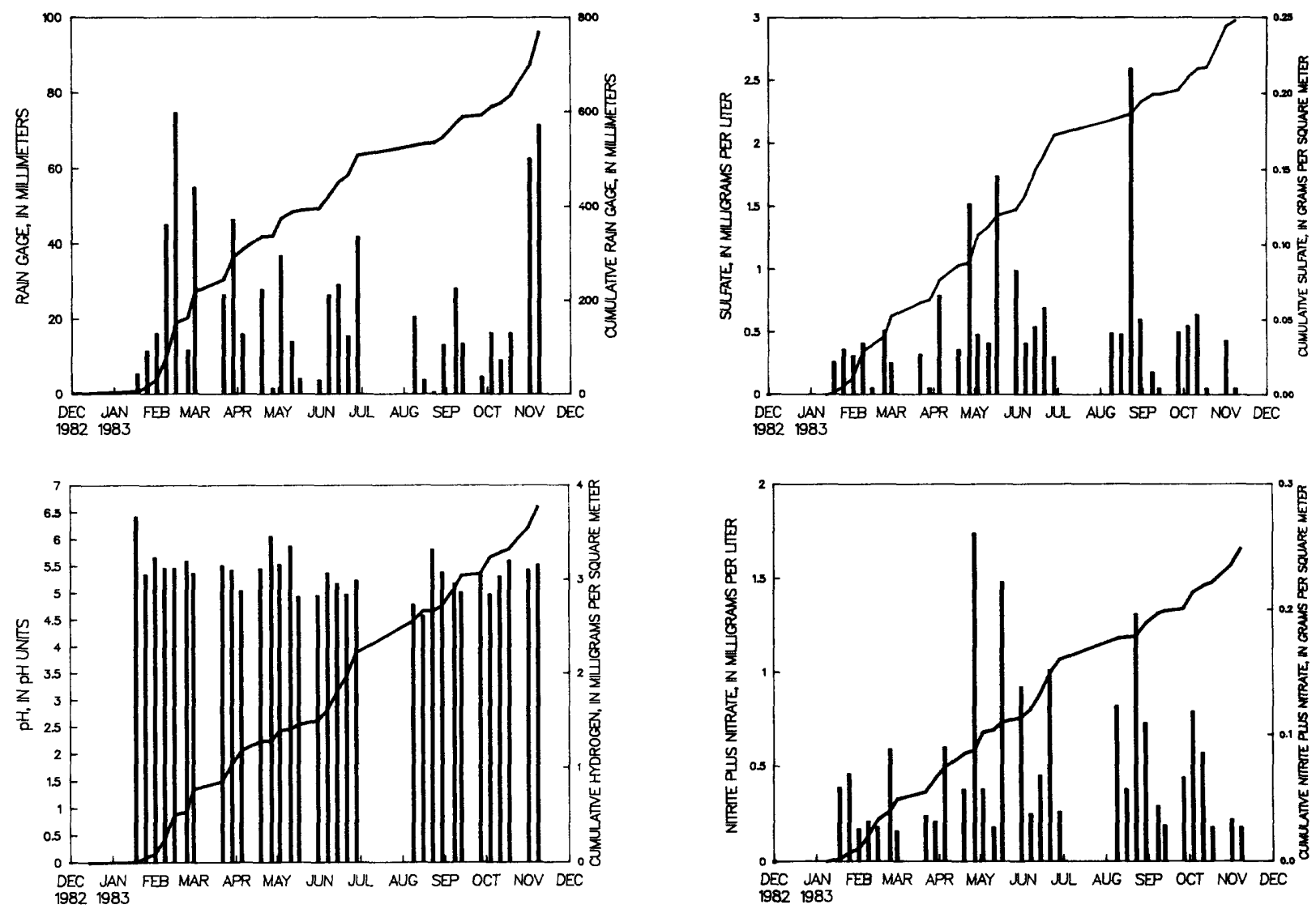

Bar plots of concentrations and cumulative line plots of loads for site ID04.

Nitrite plus nitrate are reported as $\mathrm{NO}_{3}$ and sulfate as $\mathrm{SO}_{4}$.

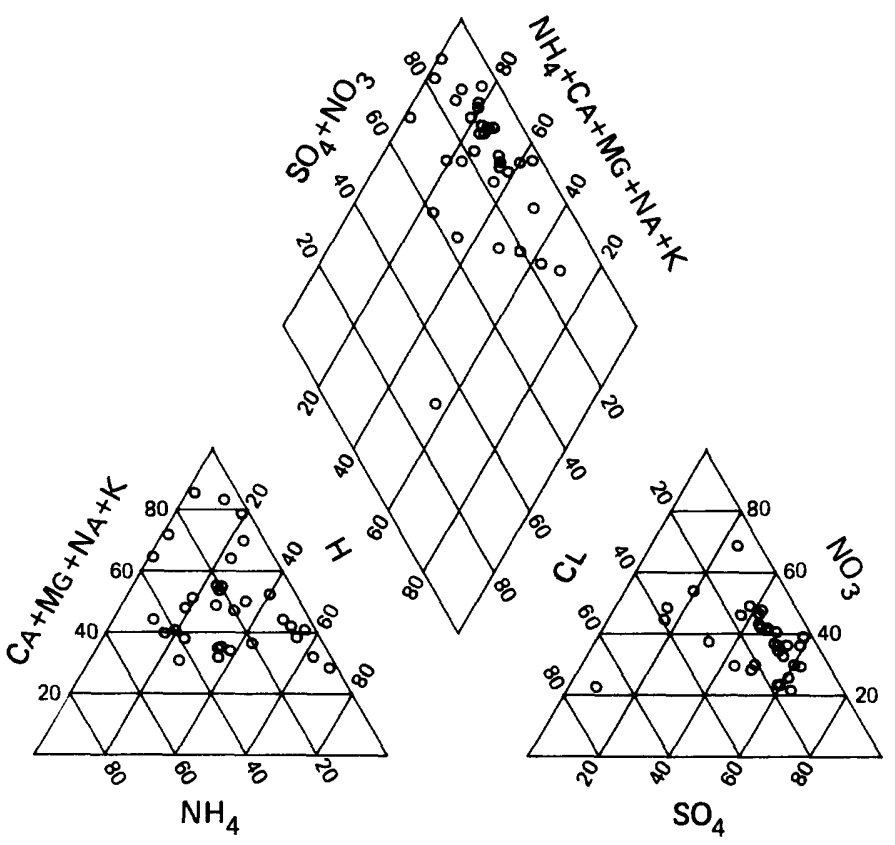

Percentage composition of major ions for site ID04. 


\section{NATIONAL TRENDS NETWORK -- 1983 CALENDER YEAR SUMMARY DATA}

[ppt = precipitation; $\mathrm{mm}=$ millimeters; $\mathrm{cm}=$ centimeters; $\mathrm{mg}=$ milligrams; L = liters;

$\mathbf{g}=\mathbf{g r a m s} ; \mathrm{m}=$ meter $; \mu \mathrm{s}=$ microsiemens; cond = specific conductance $]$

STATION: NIARC, Illinois

CAL number: IL1B

ADS number: $024 a 00$

Station altitude above mean sea level, in meters: 265

Number of sampling intervals (days in parenthesis):

-- With ppt measurements: $53 \quad$ (371)

-- When ppt occurred: 53 (371)

-- When ppt did not occur: 0 ( 0$)$

-- When sample volume was substituted for missing rain gage: 0 ( 0 )

-- With chemical samples: 39 (273)
Latitude: $41^{\circ} 50^{\prime} 29^{\prime \prime}$ Longitude: $88^{\circ} 51^{\prime} 04^{\prime \prime}$

Station summary period: $12 / 28 / 1982$ to $01 / 03 / 1984$

Length of summary period: 53 sampling intervals ( 371 days)

Percent summary period with ppt measurements: 100.0 Percent summary period with chemical samples or no ppt: 73.6 Percent of total measured ppt with chemical samples: 94.9 Percent of total measured ppt in raingage that was

collected in the wet-sample bucket:

97.9

Total measured ppt, in $\mathrm{mm}: 1001.3$

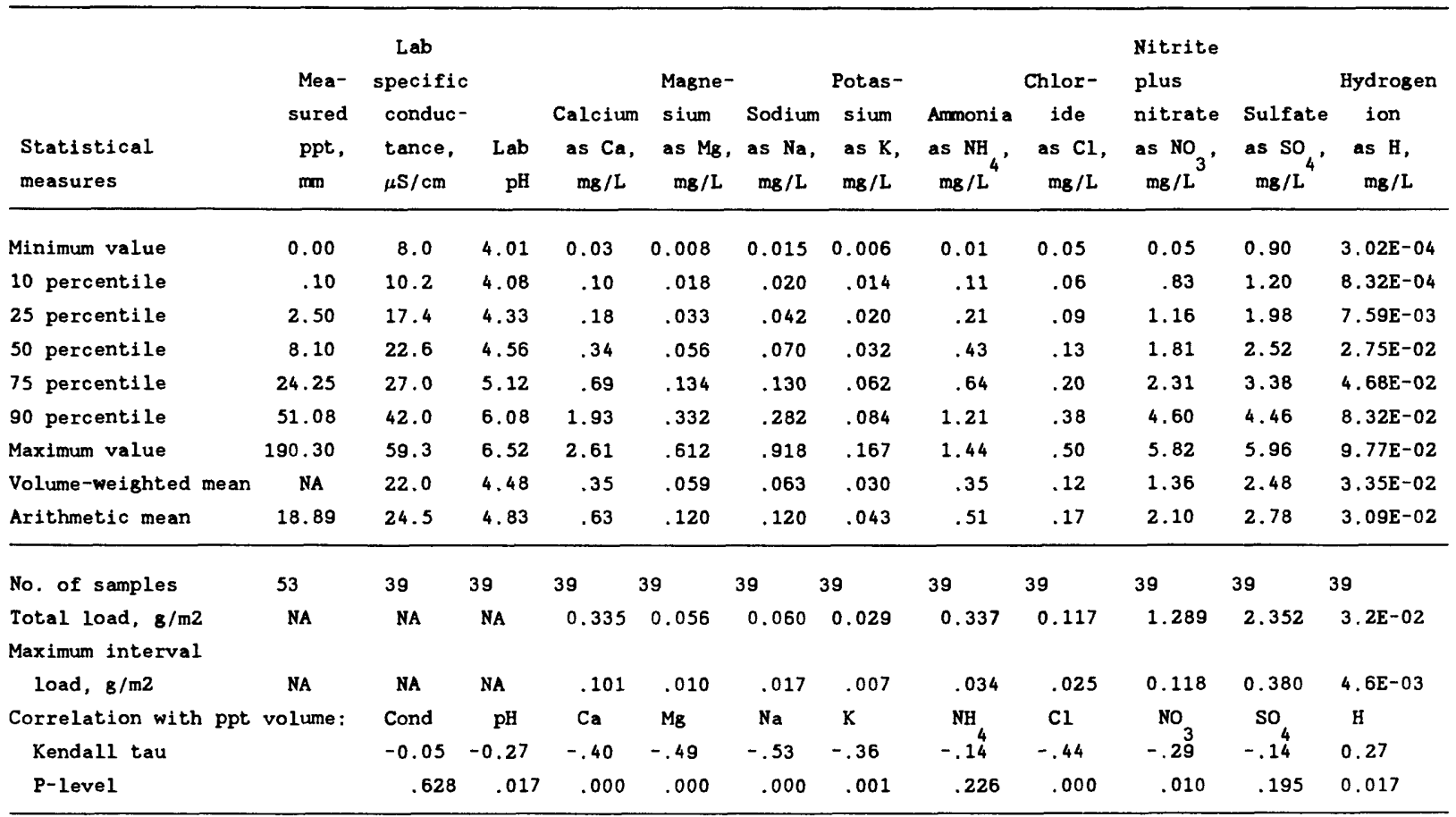

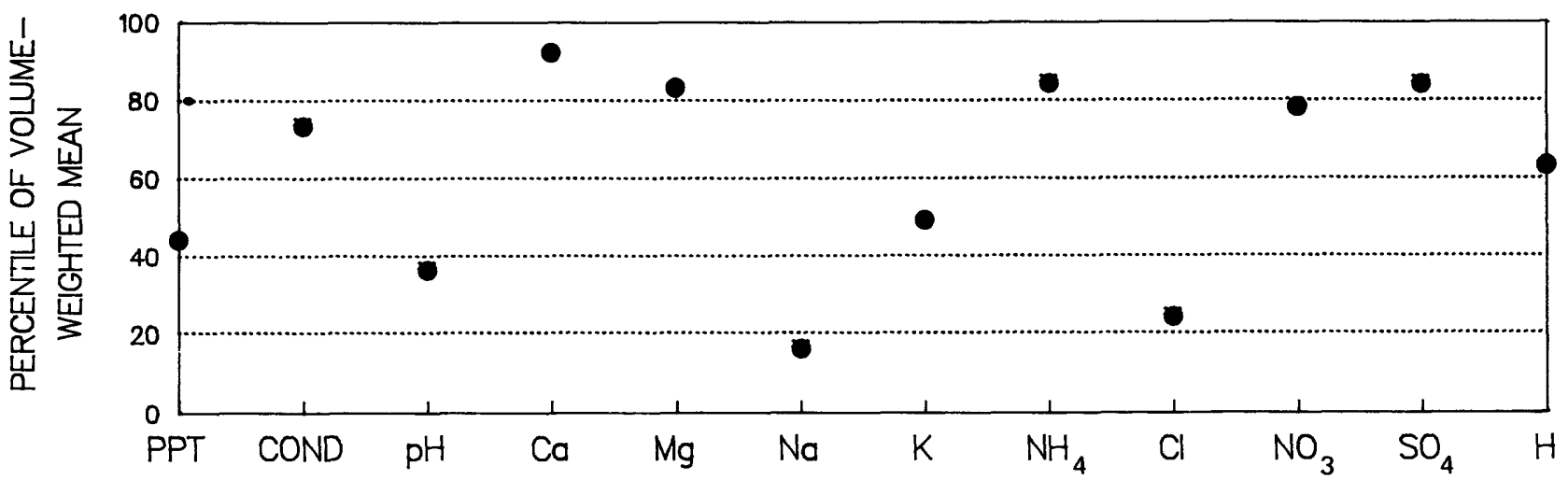

Percentiles of volume-weighted mean concentrations for site IL18, based on frequency distributions of data from 55 National Trends Network sites. 

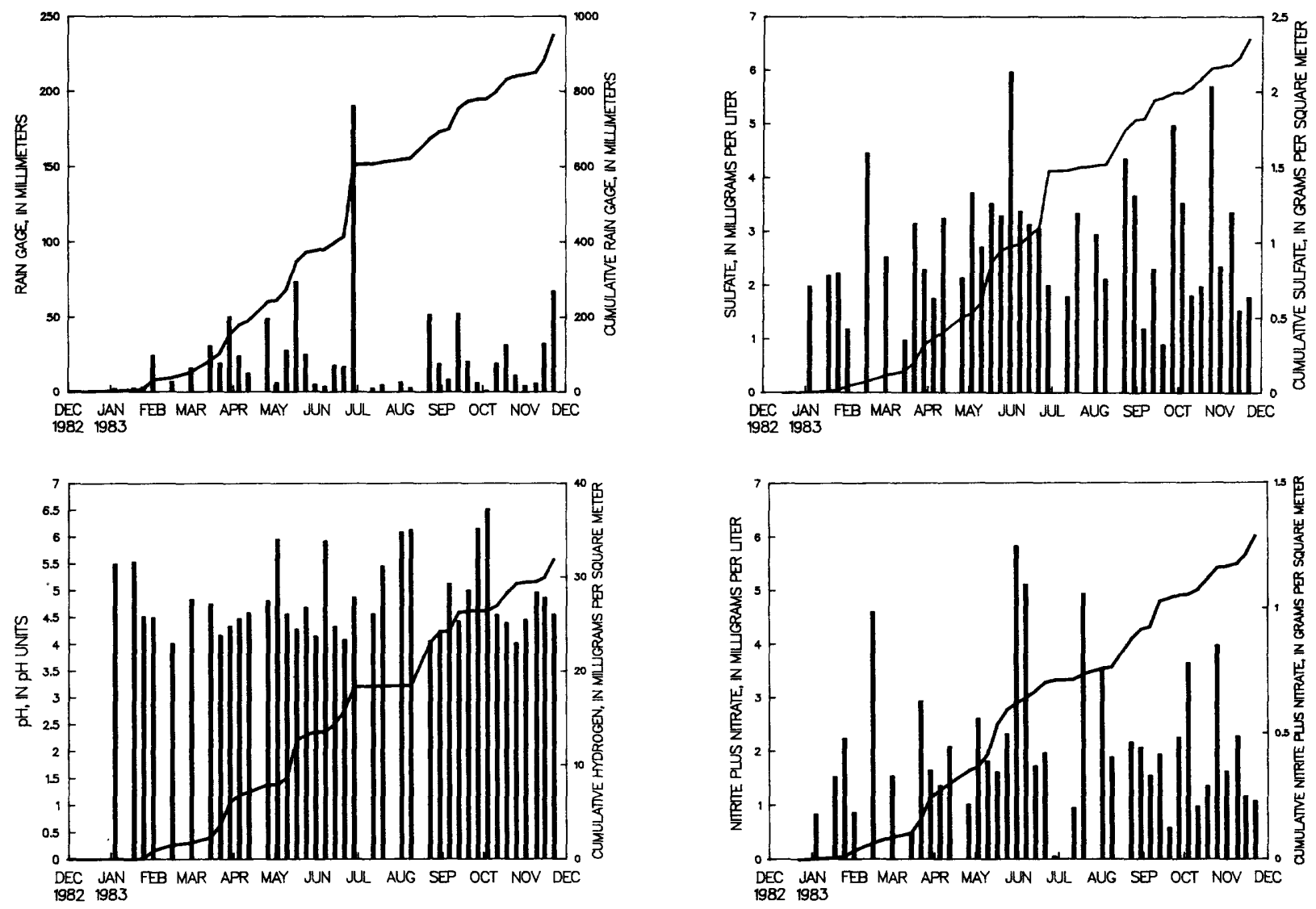

Bar plots of concentrations and cumulative line plots of loads for site IL18. Nitrite plus nitrate are reported as $\mathrm{NO}_{3}$ and sulfate as $\mathrm{SO}_{4}$.

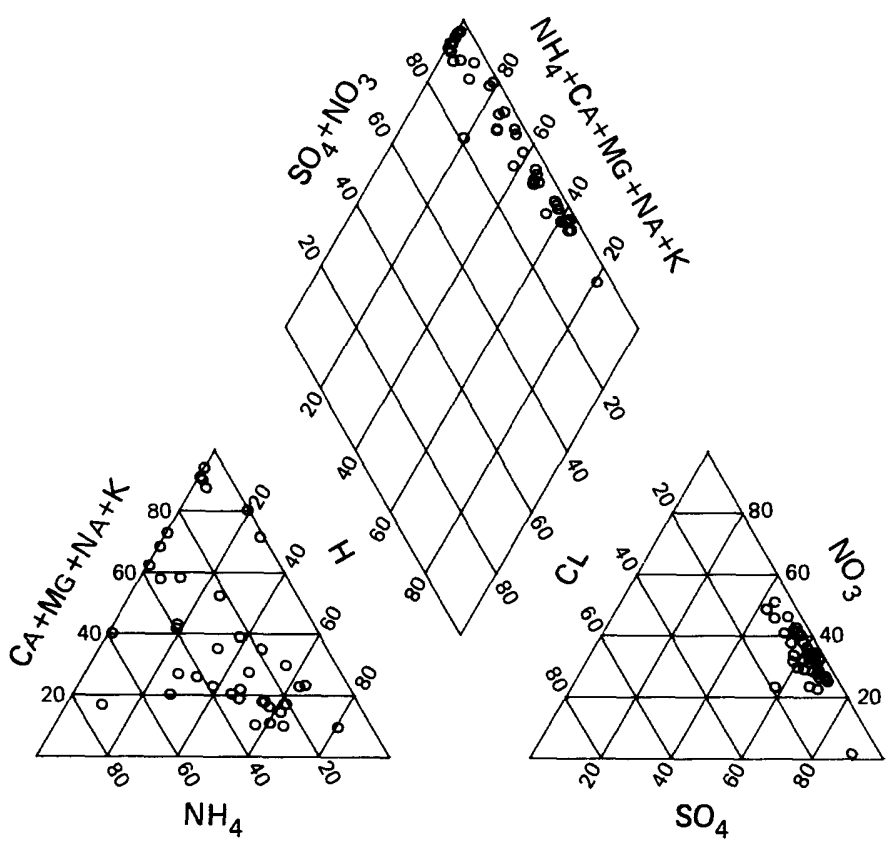

Percentage composition of major ions for site IL18. 


\section{NATIONAL TRENDS NETWORK -- 1983 CALENDER YEAR SUMMARY DATA}

lppt $=$ precipitation; $\mathrm{mm}=$ millimeters; $\mathrm{cm}=$ centimeters; $\mathrm{mg}=$ milligrams; L = liters ;

$\mathrm{g}=\mathrm{grams} ; \mathrm{m}=$ meter; $\mu \mathrm{s}=$ microsiemens; cond = specific conductance $]$

STATION: Dixon Springs, Illinois

CAL number: IL63

ADS number: 023 a00

Station altitude above mean sea level, in meters: 161

Number of sampling intervals (days in parenthesis):

-- With ppt measurements: $53 \quad$ (371)

-- When ppt occurred: $47 \quad$ (329)

-- When ppt did not occur: 6 ( 42)

-- When sample volume was substituted for missing rain gage: 0 ( 0$)$

-- With chemical samples: $37 \quad$ (259)
Latitude: $\quad 37^{\circ} 26^{\prime} 08^{\prime \prime}$ Longitude: $\quad 88^{\circ} 40^{\prime} 19^{\prime \prime}$

Station sumary period: $12 / 28 / 1982$ to $01 / 03 / 1984$

Length of summary period: 53 sampling intervals ( 371 days)

Percent summary period with ppt measurements: $\quad 100.0$

Percent sumary period with chemical samples or no ppt: 81.1

Percent of total measured ppt with chemical samples: 91.7

Percent of total measured ppt in raingage that was

collected in the wet-sample bucket:

88.8

Total measured ppt, in m: 1466.0

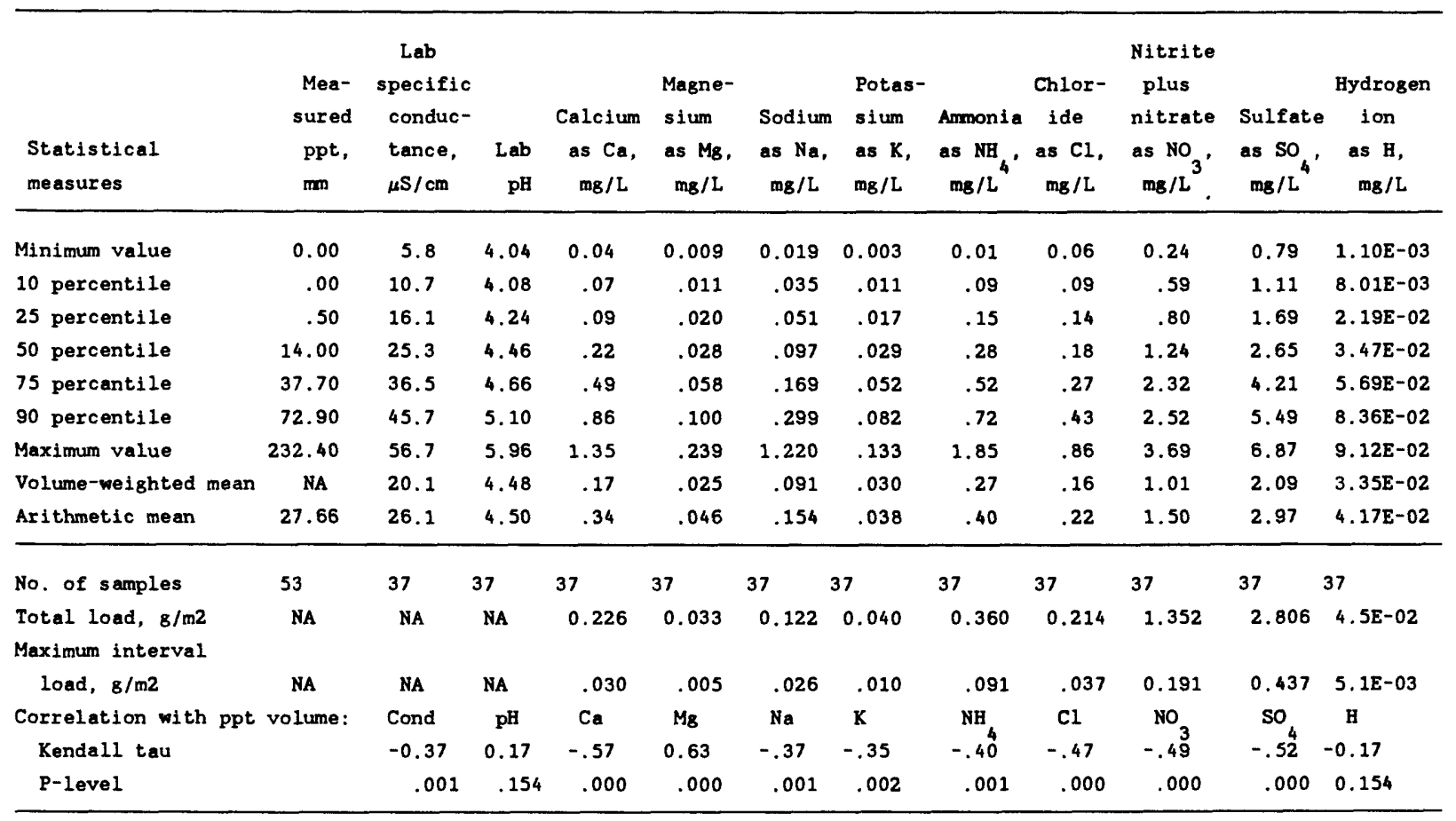

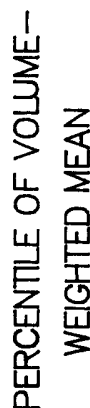

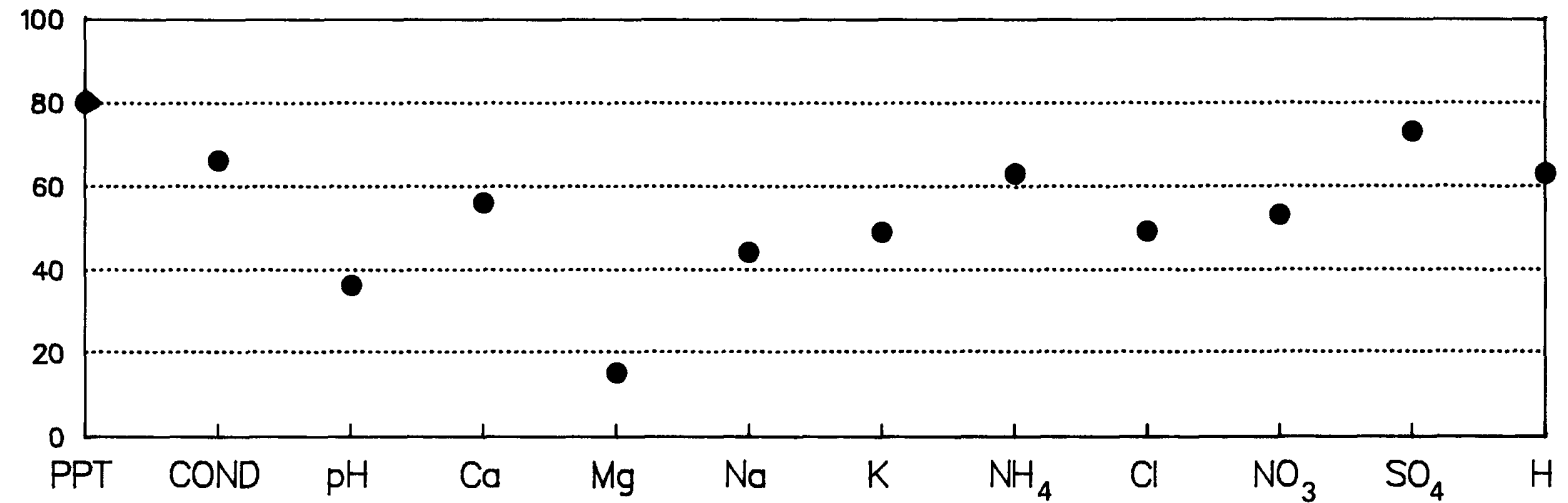

Percentiles of volume-weighted mean concentrations for site IL63, based on frequency distributions of data from 55 National Trends Network sites. 

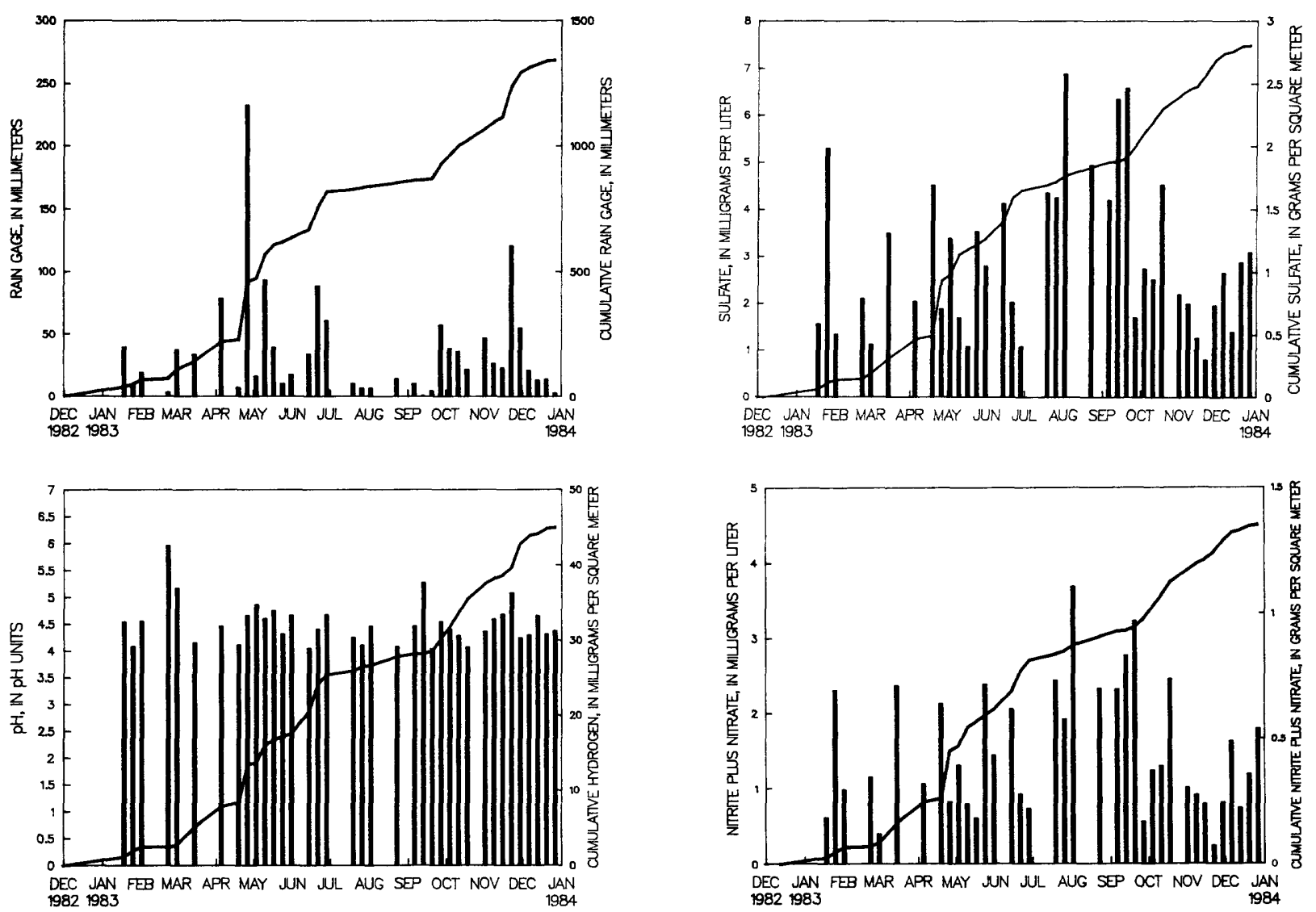

Bar plots of concentrations and cumulative line plots of loads for site IL63.

Nitrite plus nitrate are reported as $\mathrm{NO}_{3}$ and sulfate as $\mathrm{SO}_{4}$.

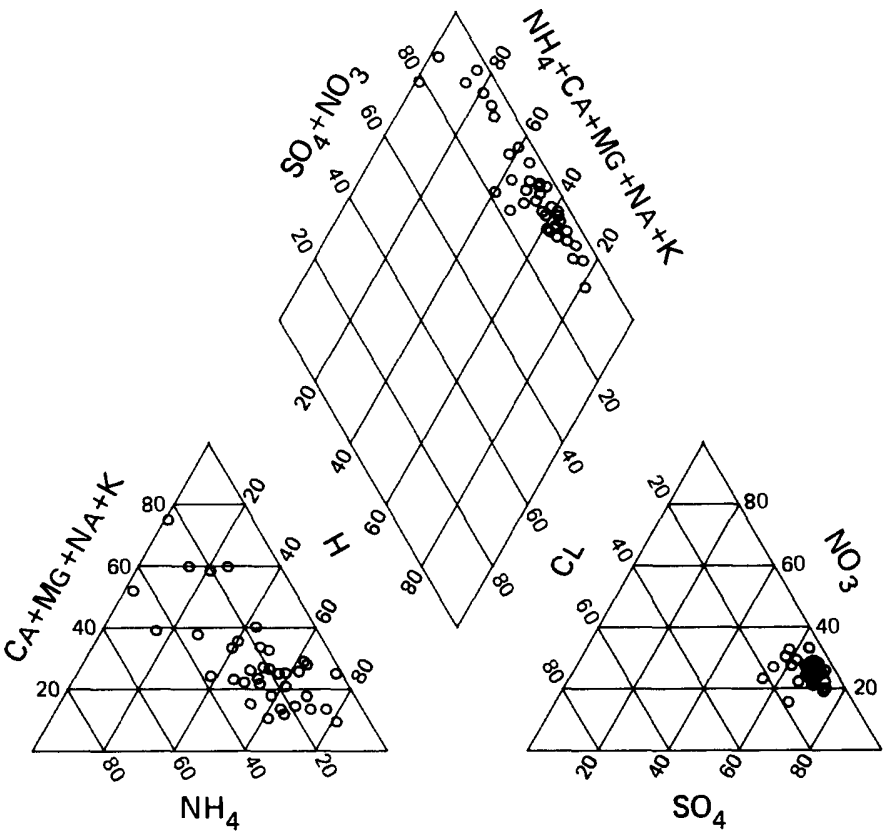

Percentage composition of major ions for site IL63. 


\section{NATIONAL TRENDS NETWORK - - 1983 CALENDER YEAR SUMMARY DATA}

$[$ ppt $=$ precipitation; $\mathrm{mm}=$ millimeters; $\mathrm{cm}=$ centimeters; $\mathrm{mg}=$ milligrams; $\mathrm{L}=1$ iters

$g=g$ rams; $m=$ meter $; \mu \mathrm{s}=$ microsiemens; cond = specific conductance $]$

STATION: Konza Prairie, Kansas

CAL number: KS31

ADS number: $273 \mathrm{a} 00$

Station altitude above mean sea level, in meters: 344

Number of sampling intervals (days in parenthesis):

-- With ppt measurements: $52 \quad$ (371)

-- When ppt occurred: $48 \quad$ (343)

-- When ppt did not occur: $4 \quad 4 \quad$ ( 28)

-- When sample volume was substituted for missing rain gage: 1 ( 7)

-- With chemical samples: 38 (273)
Latitude: $39^{\circ} 06^{\prime} 08^{\prime \prime}$ Long itude: $95^{\circ} 36^{\prime} 33^{\prime \prime}$

Station summary period: $12 / 28 / 1982$ to $01 / 03 / 1984$

Length of summary period: 52 sampling intervals ( 371 days)

$\begin{array}{ll}\text { Percent sumary period with ppt measurements: } & 100.0\end{array}$

Percent summary period with chemical samples or no ppt: 81.1

Percent of total measured ppt with chemical samples: 98.0

Percent of total measured ppt in raingage that was

collected in the wet-sample bucket:

97.3

Total measured ppt, in $\mathrm{mm}: \quad 760.2$

\begin{tabular}{|c|c|c|c|c|c|c|c|c|c|c|c|c|}
\hline $\begin{array}{l}\text { Statistical } \\
\text { measures }\end{array}$ & $\begin{array}{c}\text { Mea- } \\
\text { sured } \\
\text { ppt, } \\
\text { mm }\end{array}$ & $\begin{array}{c}\text { Lab } \\
\text { specific } \\
\text { conduc- } \\
\text { tance, } \\
\mu \mathrm{S} / \mathrm{cm}\end{array}$ & $\begin{array}{r}\text { Lab } \\
\text { pH }\end{array}$ & $\begin{array}{c}\text { Calcium } \\
\text { as Ca, } \\
\mathrm{mg} / \mathrm{L}\end{array}$ & $\begin{array}{l}\text { Magne- } \\
\text { sium } \\
\text { as } \mathrm{Mg} \text {, } \\
\mathrm{mg} / \mathrm{L}\end{array}$ & $\begin{array}{c}\text { Sodium } \\
\text { as } \mathrm{Na} \text {, } \\
\mathrm{mg} / \mathrm{L}\end{array}$ & $\begin{array}{l}\text { Potas- } \\
\text { sium } \\
\text { as K, } \\
\mathrm{mg} / \mathrm{L}\end{array}$ & $\begin{array}{l}\text { Ammonia } \\
\text { as } \mathrm{NH}{ }_{4}^{\prime} \\
\mathrm{mg} / \mathrm{L}^{\prime}\end{array}$ & $\begin{array}{c}\text { Chlor- } \\
\text { ide } \\
\text { as } \mathrm{Cl} \text {, } \\
\mathrm{mg} / \mathrm{L}\end{array}$ & $\begin{array}{l}\text { Nitrite } \\
\text { plus } \\
\text { nitrate } \\
\text { as } \mathrm{NO}_{3} \text { ' } \\
\mathrm{mg} / \mathrm{L}\end{array}$ & $\begin{array}{l}\text { Sulfate } \\
\text { as } \mathrm{SO}_{4} \\
\mathrm{mg} / \mathrm{L}^{\prime}\end{array}$ & $\begin{array}{l}\text { Hydrogen } \\
\text { ion } \\
\text { as } \mathrm{H}, \\
\text { mg } / \mathrm{L}\end{array}$ \\
\hline Minimum value & 0.00 & 4.0 & 4.38 & 0.05 & 0.009 & 0.024 & 0.008 & 0.06 & 0.01 & 0.42 & 0.05 & $1.58 \mathrm{E}-04$ \\
\hline 10 percentile & .00 & 6.4 & 4.61 & .10 & .013 & .032 & .011 & .11 & .05 & .73 & .43 & $8.75 E-04$ \\
\hline 25 percentile & .35 & 8.8 & 4.71 & .15 & .021 & .044 & .017 & .20 & .08 & 1.01 & .95 & $2.81 E-03$ \\
\hline 50 percentile & 6.25 & 13.3 & 5.12 & .32 & .035 & .080 & .045 & .38 & .11 & 1.44 & 1.45 & $7.50 \mathrm{E}-03$ \\
\hline 75 percentile & 20.75 & 16.6 & 5.55 & .81 & .073 & .168 & .062 & .59 & .20 & 2.00 & 2.06 & $1.95 \mathrm{E}-02$ \\
\hline 90 percentile & 47.36 & 22.7 & 6.06 & 1.38 & .138 & .477 & .146 & .81 & .48 & 3.51 & 4.12 & $2.49 \mathrm{E}-02$ \\
\hline Maximum value & 59.70 & 80.6 & 6.80 & 10.57 & .470 & 1.500 & .518 & 1.63 & 1.14 & 9.24 & 9.17 & $4.17 \mathrm{E}-02$ \\
\hline Volume-weighted mean & NA & 12.6 & 4.88 & .34 & .034 & .081 & .033 & .37 & .11 & 1.30 & 1.49 & $1.32 \mathrm{E}-02$ \\
\hline No. of samples & 52 & 38 & 38 & 38 & 38 & 38 & 38 & 38 & 38 & 38 & 38 & 38 \\
\hline $\begin{array}{l}\text { Total load, } 8 / \mathrm{m} 2 \\
\text { Maximum interva } 1\end{array}$ & NA & NA & NA & 0.251 & 0.025 & 0.060 & 0.024 & 0.276 & 0.083 & 0.968 & 1.108 & $9.9 \mathrm{E}-03$ \\
\hline load, $\mathrm{g} / \mathrm{m} 2$ & NA & NA & NA & .041 & .003 & .007 & .003 & .029 & .010 & .085 & 0.109 & $1.3 E-03$ \\
\hline $\begin{array}{l}\text { Correlation with ppt } \\
\text { Kendall tau }\end{array}$ & volume: & $\begin{array}{l}\text { Cond } \\
-0.14-\end{array}$ & $\begin{array}{c}\mathrm{pH} \\
-0.30\end{array}$ & $\begin{array}{c}\mathrm{Ca} \\
-.34\end{array}$ & $\begin{array}{l}\mathrm{Mg} \\
-.45\end{array}$ & $\begin{array}{c}\mathrm{Na} \\
-.42\end{array}$ & $\begin{array}{c}\mathrm{K} \\
-.43\end{array}$ & $\begin{array}{r}\mathrm{NH}_{4} \\
-.15\end{array}$ & $\begin{array}{l}C 1 \\
-.37\end{array}$ & $\begin{array}{l}\mathrm{NO}_{3} \\
-.36\end{array}$ & $\begin{array}{r}\mathrm{SO}_{4} \\
-.12\end{array}$ & $\begin{array}{l}\mathrm{H} \\
0.30\end{array}$ \\
\hline p-level & & .213 & .007 & .003 & .000 & .000 & .000 & .195 & .001 & .001 & .279 & .007 \\
\hline
\end{tabular}

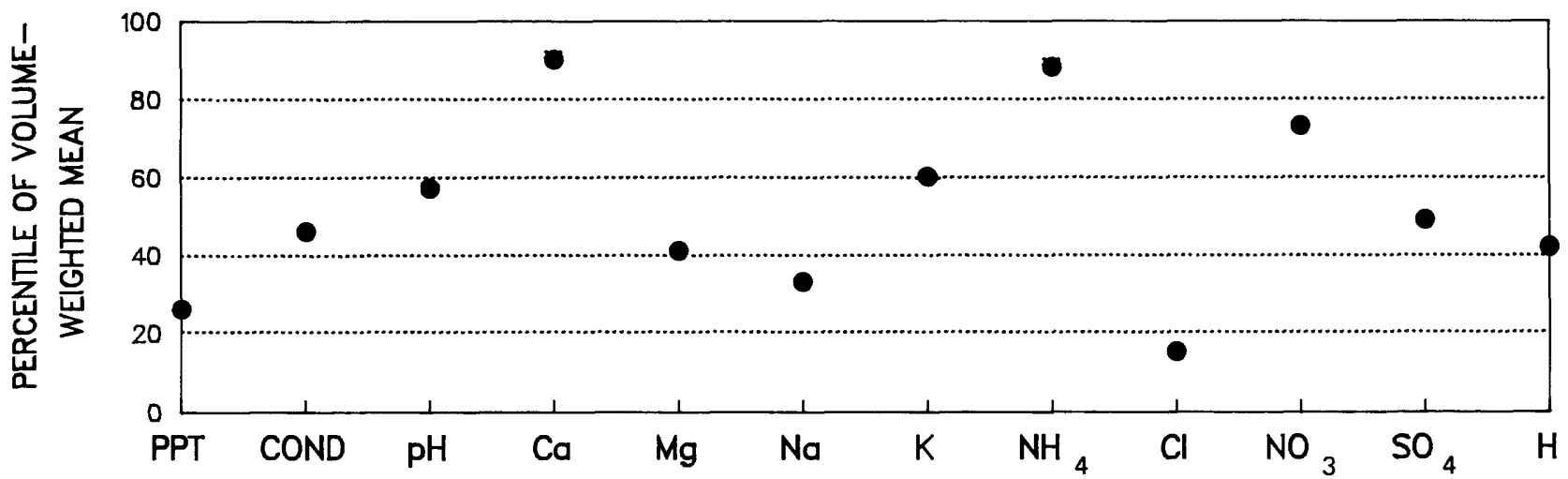

Percentiles of volume-weighted mean concentrations for site KS31, based on frequency distributions of data from 55 National Trends Network sites. 

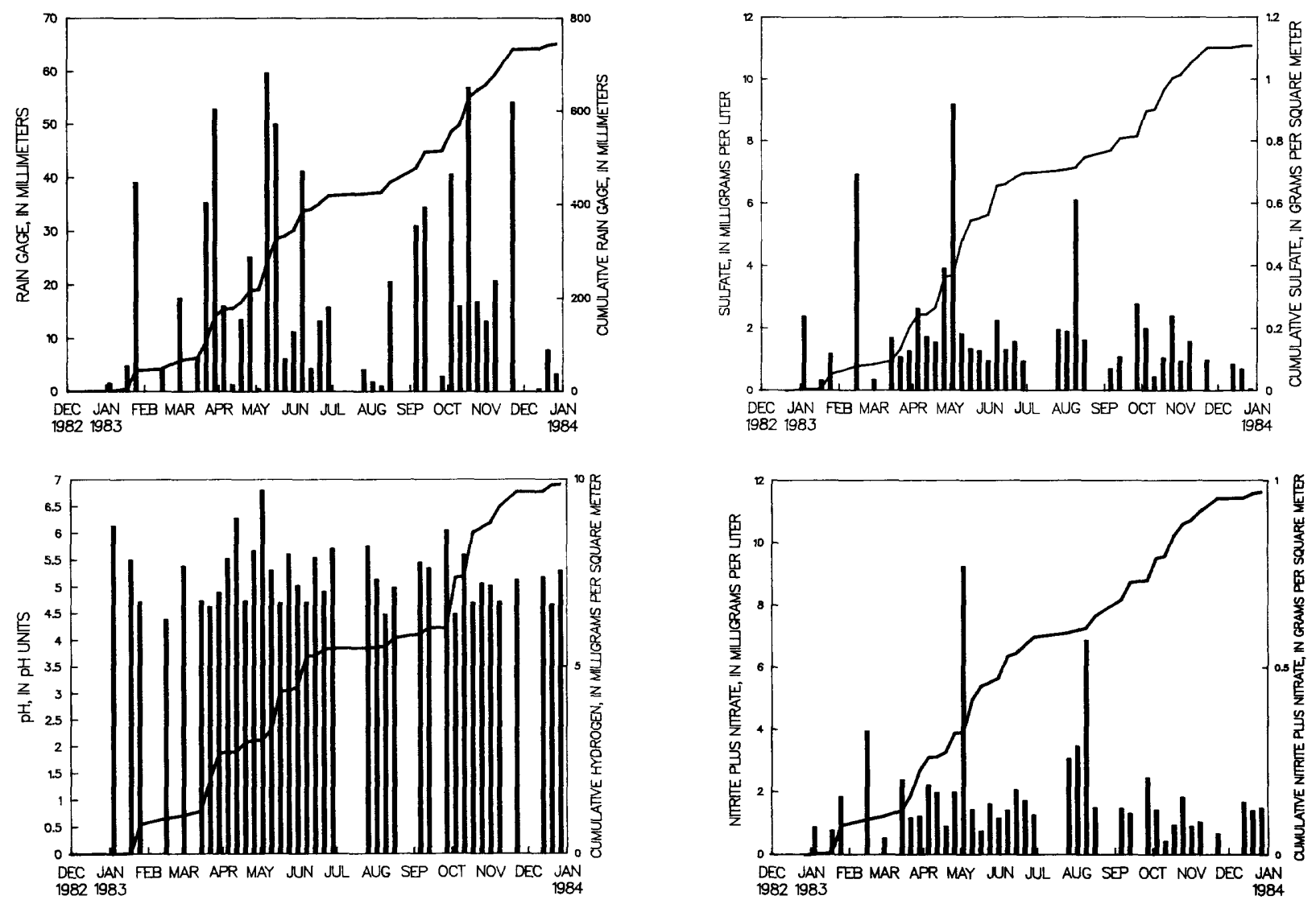

Bar plots of concentrations and cumulative line plots of loads for site KS31. Nitrite plus nitrate are reported as $\mathrm{NO}_{3}$ and sulfate as $\mathrm{SO}_{4}$.

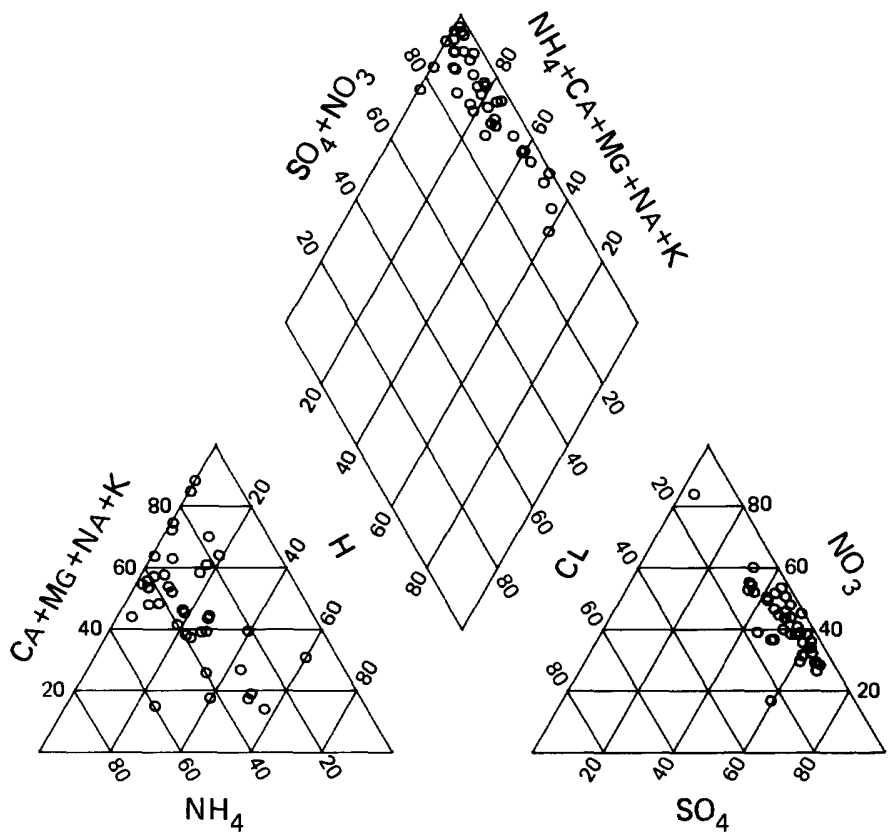

Percentage composition of major ions for site KS31. 


\section{NATIONAL TRENDS NETWORK -- 1983 CALENDER YEAR SUMMARY DATA}

[ppt = precipitation; $\mathrm{mm}=$ millimeters; $\mathrm{cm}=$ centimeters; $\mathrm{mg}=\mathrm{milligrams;} \mathrm{L=} \mathrm{liters;}$

$\mathrm{B}=\mathrm{grams} ; \mathrm{m}=$ meter $\boldsymbol{\mu s}=\mathrm{microsiemens;}$ cond $=$ specific conductance $]$

STATION: East, Massachusetts

CAL number: MA13

ADS number: $277 \mathrm{a} 00$

Station altitude above mean sea level, in meters: 20

Number of sampling intervals (days in parenthesis):

-- With ppt measurements: 53 (371)

-- When ppt occurred: 50 (350)

-- When ppt did not occur: 3 (21)

-- When sample volume was substituted for missing rain gage: 0 ( 0$)$

-- With chemical samples: 39 (273)
Latitude: $42^{\circ} 23^{\prime} 02^{\prime \prime}$ Longitude: $71^{\circ} 12^{\prime} 53^{\prime \prime}$

Station summary period: $12 / 28 / 1982$ to $01 / 03 / 1984$

Length of summary period: 53 sampling intervals ( 371 days)

Percent sumary period with ppt measurements: $\quad 100.0$

Percent summary period with chemical samples or no ppt: 79.2

Percent of total measured ppt with chemical samples: $\quad 82.7$

Percent of total measured ppt in raingage that was

collected in the wet-sample bucket:

96.7

Total measured ppt, in $\mathrm{mm}: 1337.2$

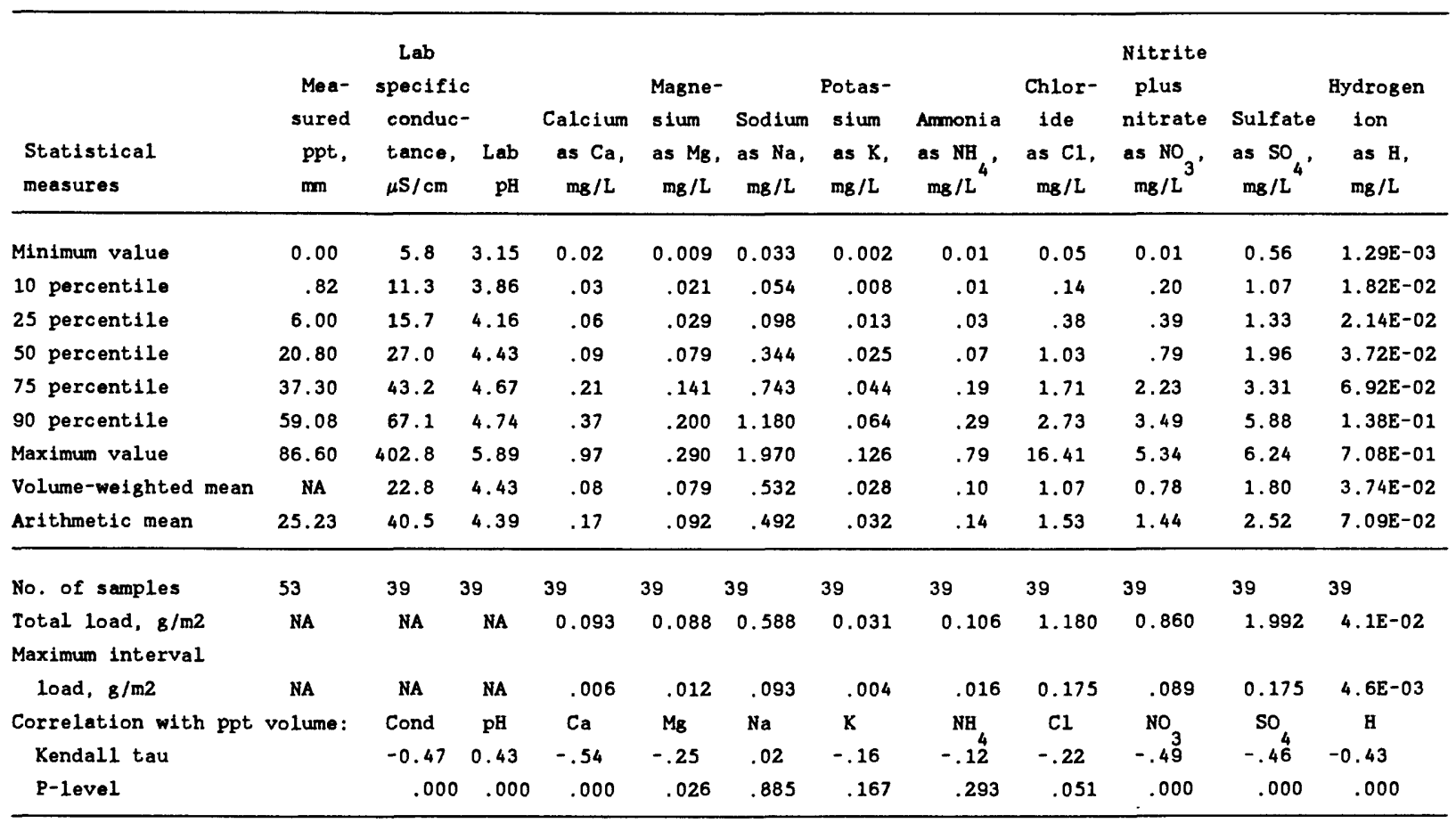

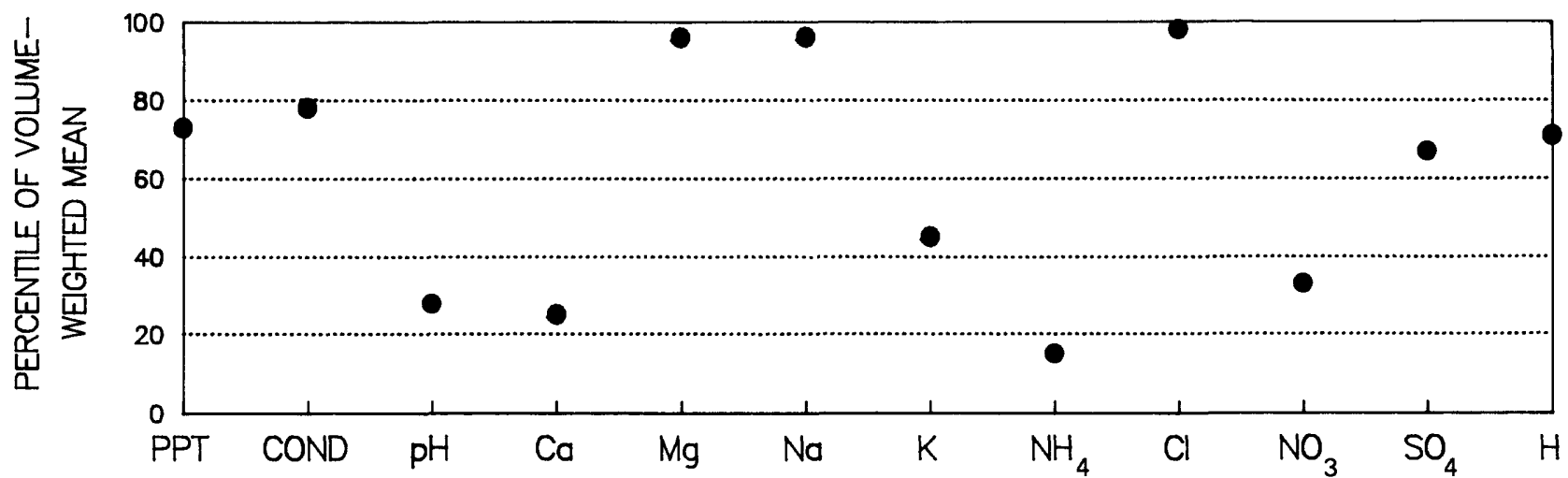

Percentiles of volume-weighted mean concentrations for site MA13, based on frequency distributions of data from 55 National Trends Network sites. 

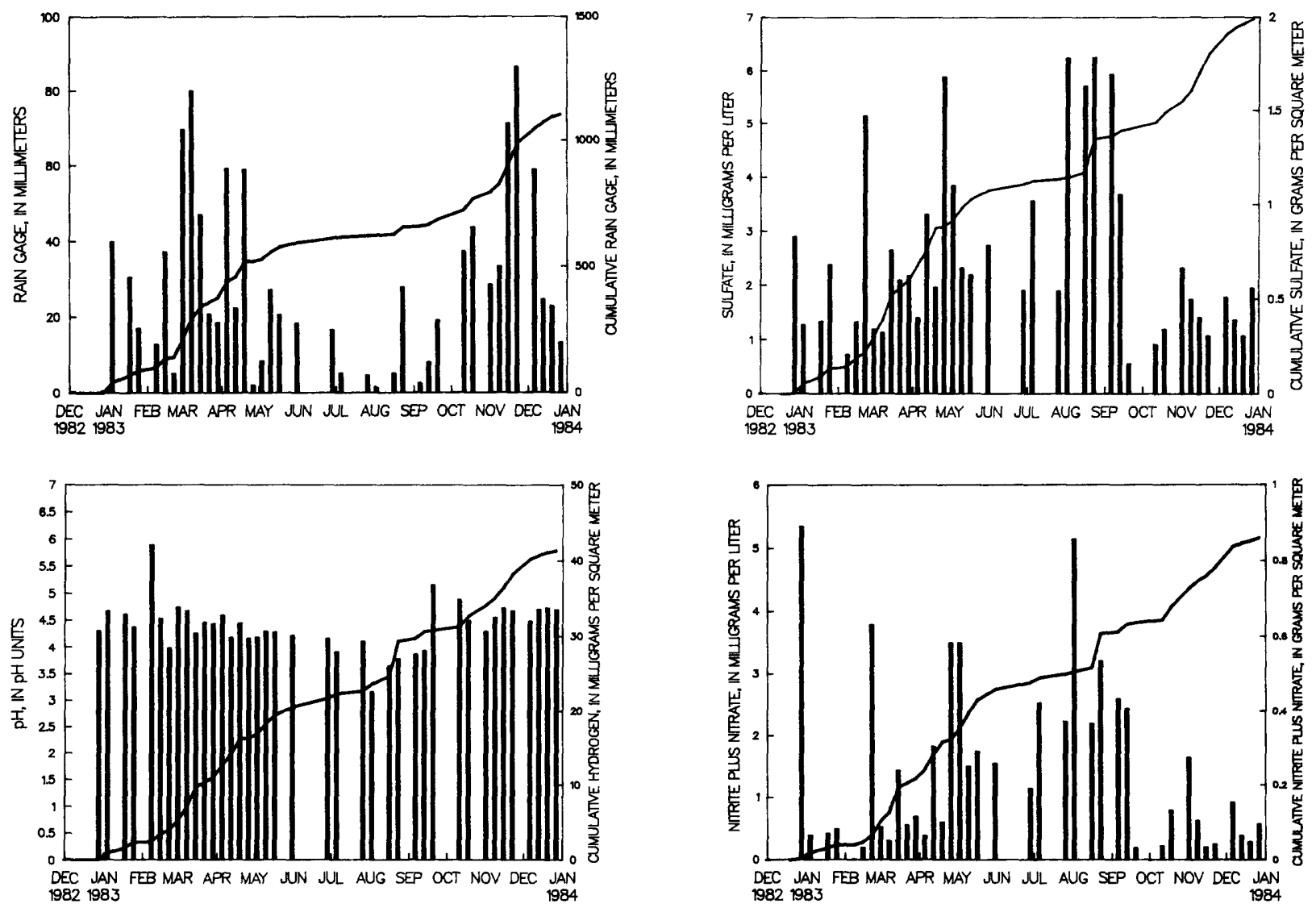

Bar plots of concentrations and cumulative line plots of loads for site MAl3. Nitrite plus nitrate are reported as $\mathrm{NO}_{3}$ and sulfate as $\mathrm{SO}_{4}$.

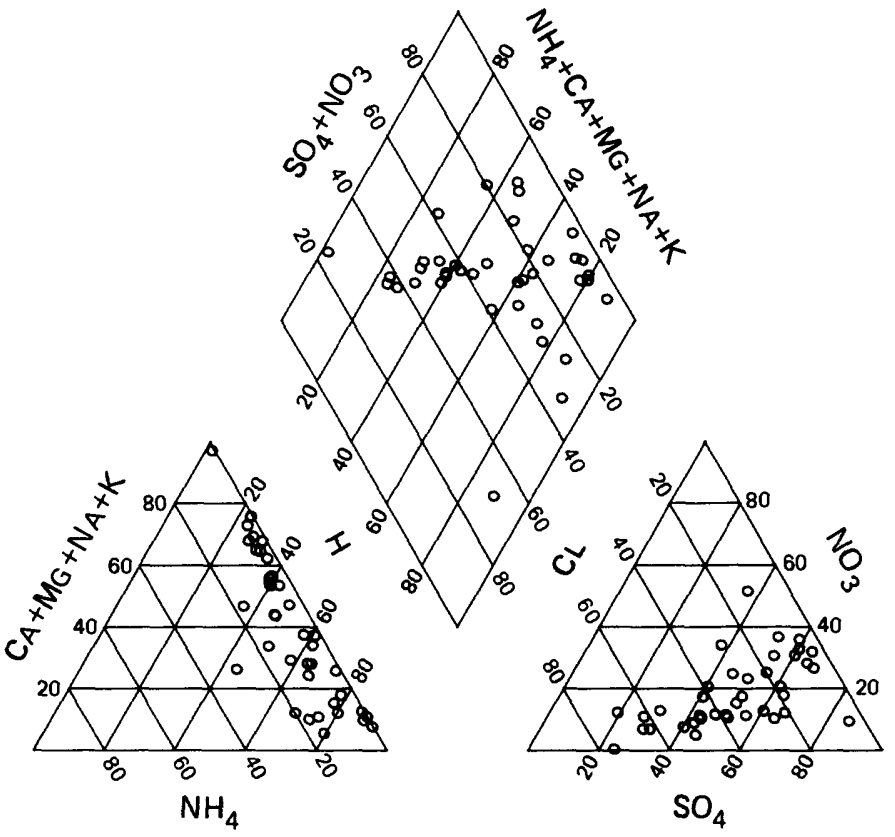

Percentage composition of major ions for site MA13. 


\section{NATIONAL TRENDS NETWORK -- 1983 CALENDER YEAR SUMMARY DATA}

[ppt = precipitation; $\mathrm{mm}=$ millimeters; $\mathrm{cm}=$ centimeters; $\mathrm{mg}=\operatorname{milligrams;~} \mathrm{L}=1$ iters; $\mathrm{g}=\mathrm{grams} ; \mathrm{m}=$ meter; $\mu \mathrm{s}=$ microsiemens; cond = specific conductance $]$

STATION: Bridgton, Maine

CAL number: MEO2

ADS number: $164 \mathrm{a} 00$

Station altitude above mean sea level, in meters: 222 Number of sampling intervals (days in parenthesis):

-- With ppt measurements: $46 \quad$ (322)

-- When ppt occurred: $46 \quad$ (322)

- When ppt did not occur:

-- When sample volume was substituted for missing rain gage: 0 ( 0 )

-- With chemical samples: $42 \quad$ (294)
Latitude: $44^{\circ} 06^{\prime} 27^{\prime \prime}$ Longitude: $70^{\circ} 43^{\prime} 44^{\prime \prime}$

Station summary period: $12 / 28 / 1982$ to $01 / 03 / 1984$

Length of summary period: 53 sampling intervals ( 371 days)

Percent summary period with ppt measurements: 86.8

Percent sumary period with chemical samples or no ppt: 79.2

Percent of total measured ppt with chemical samples: 94.3

Percent of total measured ppt in raingage that was

collected in the wet-sample bucket:

95.0

Total measured ppt, in $\mathrm{mm:} 1342.7$

\begin{tabular}{|c|c|c|c|c|c|c|c|c|c|c|c|c|}
\hline $\begin{array}{l}\text { Statistical } \\
\text { measures }\end{array}$ & $\begin{array}{c}\text { Mea- } \\
\text { sured } \\
\text { ppt, } \\
\text { mm }\end{array}$ & $\begin{array}{c}\text { Lab } \\
\text { specific } \\
\text { conduc- } \\
\text { tance, } \\
\mu \mathrm{S} / \mathrm{cm}\end{array}$ & $\begin{array}{r}\mathrm{Lab} \\
\mathrm{pH}\end{array}$ & $\begin{array}{c}\text { Calcium } \\
\text { as Ca, } \\
\mathrm{mg} / \mathrm{L}\end{array}$ & $\begin{array}{l}\text { Magne- } \\
\text { sium } \\
\text { as Mg, } \\
\mathrm{mg} / \mathrm{L}\end{array}$ & $\begin{array}{c}\text { Sodium } \\
\text { as } \mathrm{Na} \text {, } \\
\mathrm{mg} / \mathrm{L}\end{array}$ & $\begin{array}{l}\text { Potas- } \\
\text { sium } \\
\text { as } \mathrm{K} \text {, } \\
\mathrm{mg} / \mathrm{L}\end{array}$ & $\begin{array}{l}\text { Ammonia } \\
\text { as } \mathrm{NH}_{4} \text {, } \\
\mathrm{mg} / \mathrm{L}\end{array}$ & $\begin{array}{l}\text { Chlor- } \\
\text { ide } \\
\text { as } \mathrm{Cl} \text {, } \\
\mathrm{mg} / \mathrm{L}\end{array}$ & $\begin{array}{l}\text { Nitrite } \\
\text { plus } \\
\text { nitrate } \\
\text { as } \mathrm{NO}_{3} \text {, } \\
\mathrm{mg} / \mathrm{L}\end{array}$ & $\begin{array}{l}\text { Sulfate } \\
\text { as } \mathrm{So}^{\text {, }} \\
\mathrm{mg} / \mathrm{L}\end{array}$ & $\begin{array}{l}\text { Hydrogen } \\
\text { te ion } \\
\text { as } \mathrm{H}, \\
\mathrm{mg} / \mathrm{L}\end{array}$ \\
\hline Minimum value & 0.00 & 2.6 & 3.82 & 0.01 & 0.005 & 0.015 & 0.004 & 0.01 & 0.01 & 0.08 & 0.26 & $8.13 E-04$ \\
\hline 10 percentile & 1.15 & 5.2 & 4.09 & .02 & .008 & .025 & .005 & .01 & .04 & .18 & .44 & $4.96 E-03$ \\
\hline 25 percentile & 8.85 & 6.6 & 4.46 & .03 & .016 & .038 & .008 & .04 & .08 & .25 & .62 & $8.91 E-03$ \\
\hline 50 percentile & 21.70 & 12.3 & 4.77 & .06 & .024 & .089 & .013 & .06 & .17 & .58 & .91 & $1.70 \mathrm{E}-02$ \\
\hline 75 percentile & 46.32 & 23.7 & 5.05 & .13 & .038 & .203 & .023 & .14 & .25 & 1.10 & 2.25 & $3.43 E-02$ \\
\hline 90 percentile & 65.78 & 47.6 & 5.30 & .38 & .146 & .581 & .047 & .62 & .72 & 2.22 & 4.25 & $8.07 E-02$ \\
\hline Maximum value & 101.40 & 64.7 & 6.09 & 1.85 & .346 & .738 & .251 & .97 & 1.49 & 3.40 & 5.38 & $1.51 E-01$ \\
\hline Volume-weighted mean & NA & 13.6 & 4.63 & .06 & .029 & .159 & .015 & .11 & .29 & .62 & 1.20 & $2.32 E-02$ \\
\hline Arithmetic mean & 29.19 & 18.4 & 4.76 & .15 & .046 & .159 & .028 & .17 & .26 & .89 & 1.62 & $3.02 E-02$ \\
\hline No. of samples & 46 & 42 & 42 & 42 & 42 & 42 & 42 & 42 & 42 & 42 & 42 & 42 \\
\hline $\begin{array}{l}\text { Total load, } 8 / \mathrm{m} 2 \\
\text { Maximum interval }\end{array}$ & NA & $\mathrm{NA}$ & NA & 0.074 & 0.036 & 0.201 & 0.019 & 0.139 & 0.363 & 0.783 & 1.523 & 2.9E-02 \\
\hline load, $8 / \mathrm{m} 2$ & NA & NA & NA & .006 & .008 & .063 & .003 & .027 & .124 & .059 & 0.172 & $2.6 \mathrm{E}-03$ \\
\hline $\begin{array}{l}\text { Correlation with ppt } \\
\text { Kendall tau }\end{array}$ & volume: & $\begin{array}{l}\text { Cond } \\
-0.22\end{array}$ & $\begin{array}{c}\mathrm{pH} \\
0.07\end{array}$ & $\begin{array}{r}\mathrm{Ca} \\
-.52\end{array}$ & $\begin{array}{r}M g \\
-.37\end{array}$ & $\begin{array}{r}\mathrm{Na} \\
-.13\end{array}$ & $\begin{array}{c}\mathrm{K} \\
-.19\end{array}$ & $\begin{array}{l}\mathrm{NH}_{4} \\
-.19\end{array}$ & $\begin{array}{c}\mathrm{Cl} \\
-.15\end{array}$ & $\begin{array}{l}\mathrm{NO}_{3} \\
-.23\end{array}$ & $\begin{array}{c}\mathrm{SO}_{4} \\
-.24-\end{array}$ & $\begin{array}{c}\mathrm{H} \\
-0.07\end{array}$ \\
\hline P-level & & .042 & .530 & .000 & .001 & .233 & .075 & .093 & .165 & .035 & .029 & .530 \\
\hline
\end{tabular}

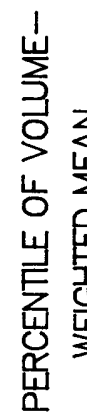

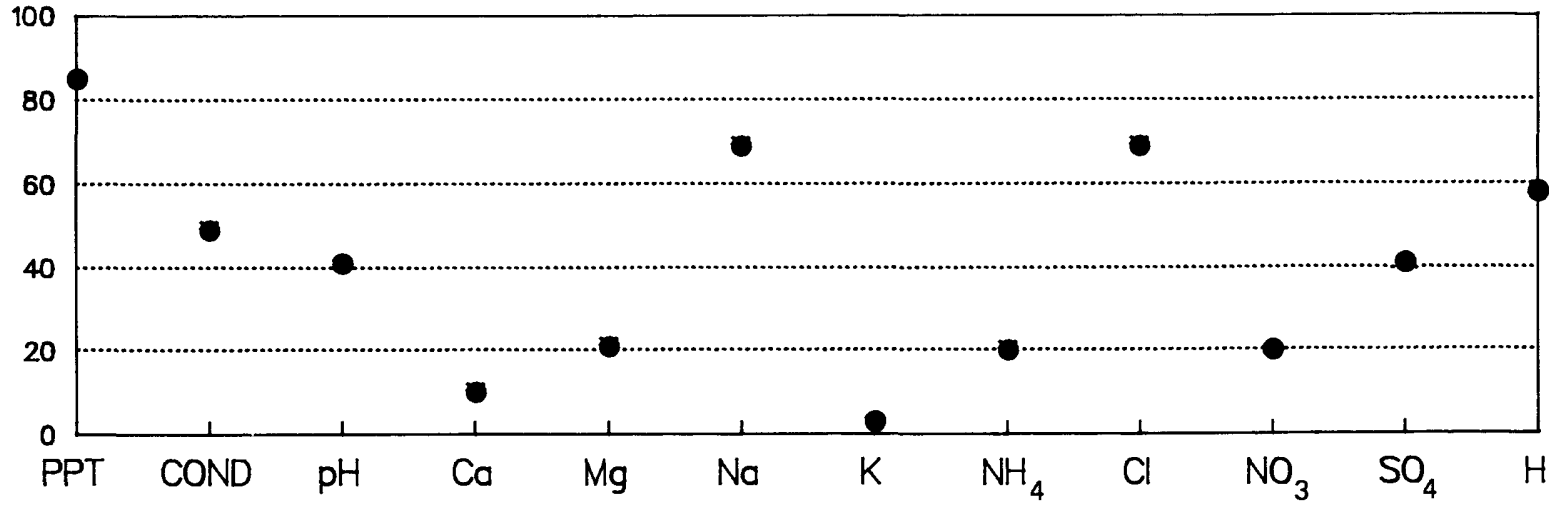

Percentiles of volume-weighted mean concentrations for site ME02, based on frequency distributions of data from 55 National Trends Network sites. 

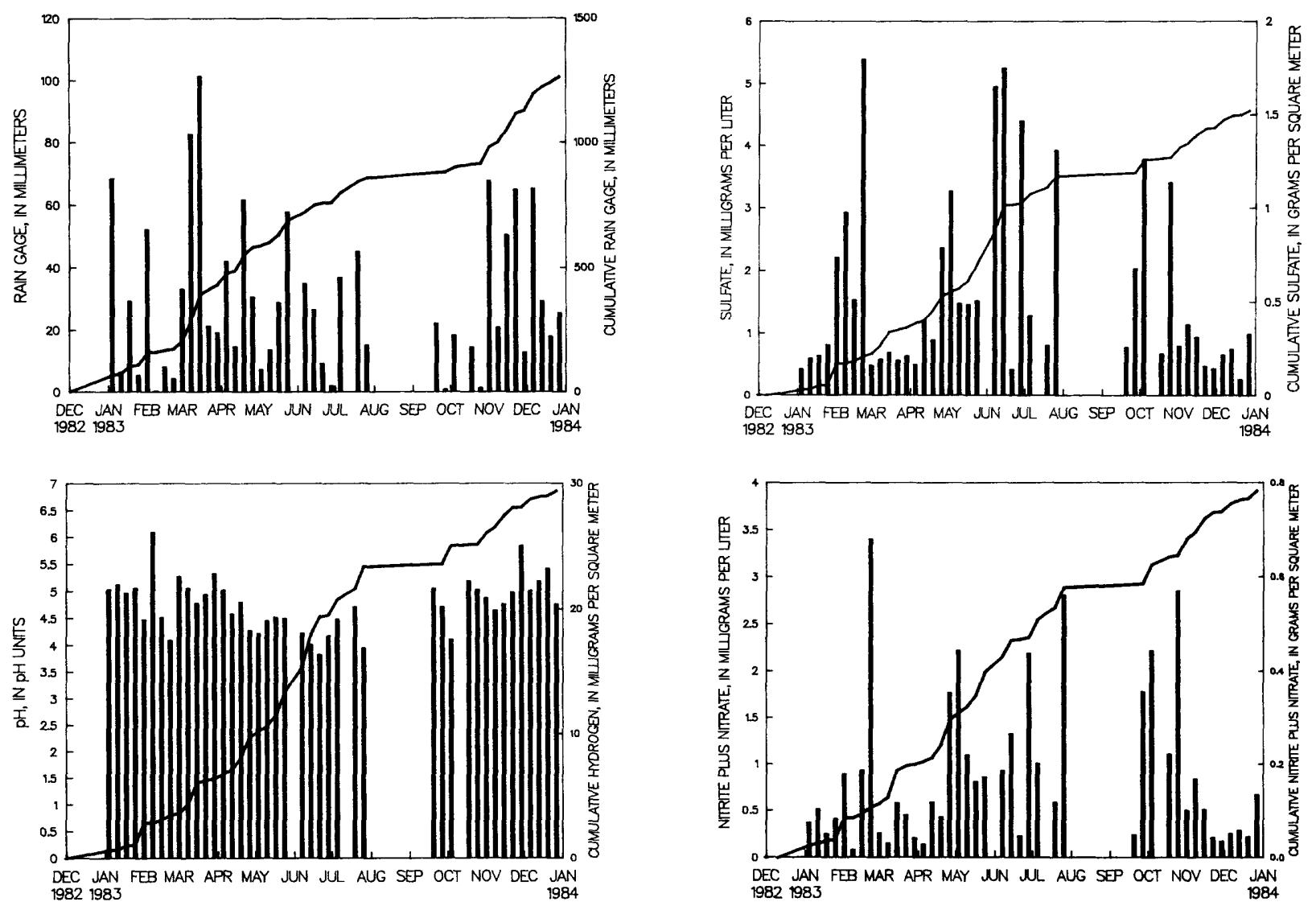

Bar plots of concentrations and cumulative line plots of loads for site ME02. Nitrite plus nitrate are reported as $\mathrm{NO}_{3}$ and sulfate as $\mathrm{SO}_{4}$.

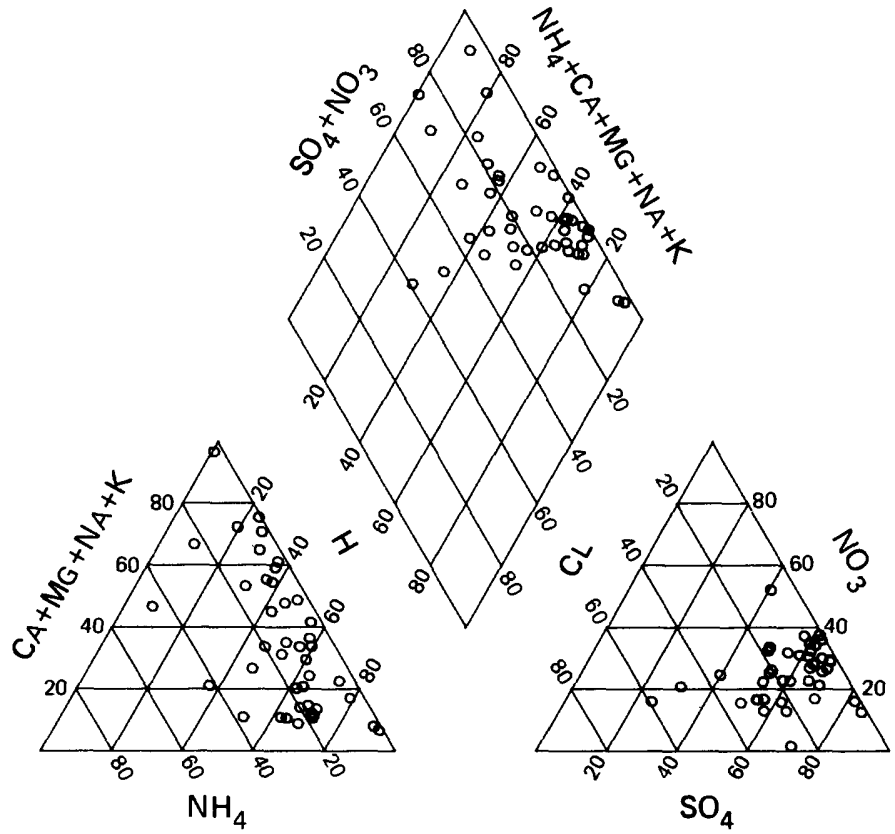

Percentage composition of major ions for site ME02. 


\section{NATIONAL TRENDS NETWORK - 1983 CALENDER YEAR SUMMARY DATA}

[ppt = precipitation; $\mathrm{mm}=$ millimeters; $\mathrm{cm}=$ centimeters; $\mathrm{mg}=\mathrm{milligrams;} \mathrm{L} \mathrm{=} \mathrm{1iters;}$

$\mathrm{g}=\mathrm{grams} ; \mathrm{m}=$ meter $\boldsymbol{\mu s}=$ microsiemens; cond = specific conductance $]$

STATION: Wellston, Michigan (composite data from sites 033 a00 and $033 \mathrm{a0}$ ) Latitude: $44^{\circ} 13^{\prime} 28^{\prime \prime}$ Longitude: $85^{\circ} 49^{\prime} 07^{\prime \prime}$ CAL number: MI53 Map ID number: 47 ADS number: 033a

Station altitude above mean sea level, in meters: 292 Number of sampling intervals (deys in parenthesis):

-- With ppt measurements: 53 (371)

-- When ppt occurred: 51 (357)

-- When ppt did not occur: 2 ( 14)

-- When sample volume was substituted for missing rain gage: 0 ( 0$)$

-- With chemicel samples: $46 \quad$ (322)

Station summary period: $12 / 28 / 1982$ to $01 / 03 / 1984$

Length of sumary period: 53 sampling intervals ( 371 days)

Percent sumary period with ppt measurements: 100.0

Percent surmary period with chemical samples or no ppt: 90.6

Percent of total measured ppt with chemical samples: 92.3

Percent of total measured ppt in raingage thet wes

collected in the wet-sample bucket:

87.8

Total measured ppt, in m: 980.7

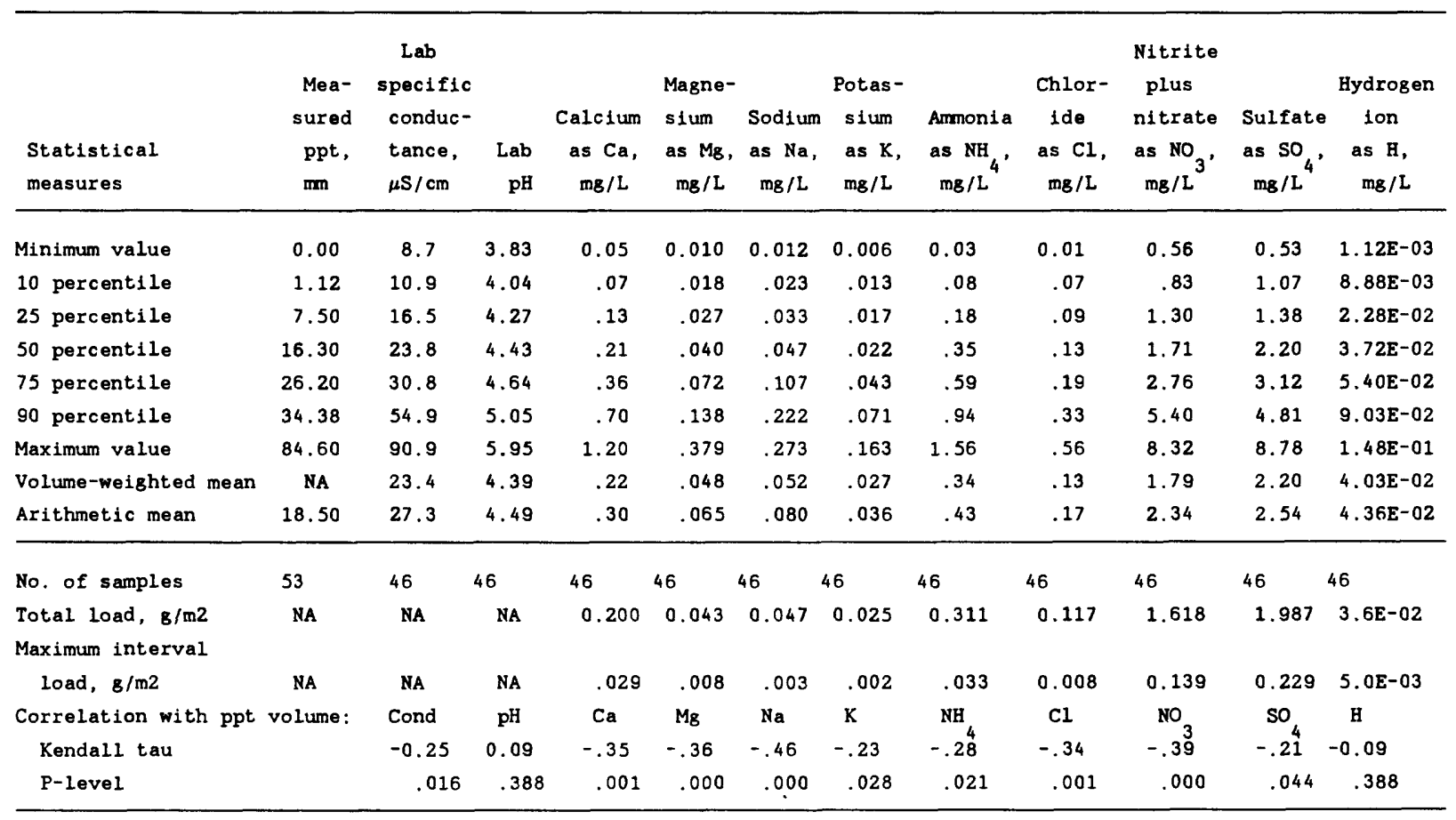

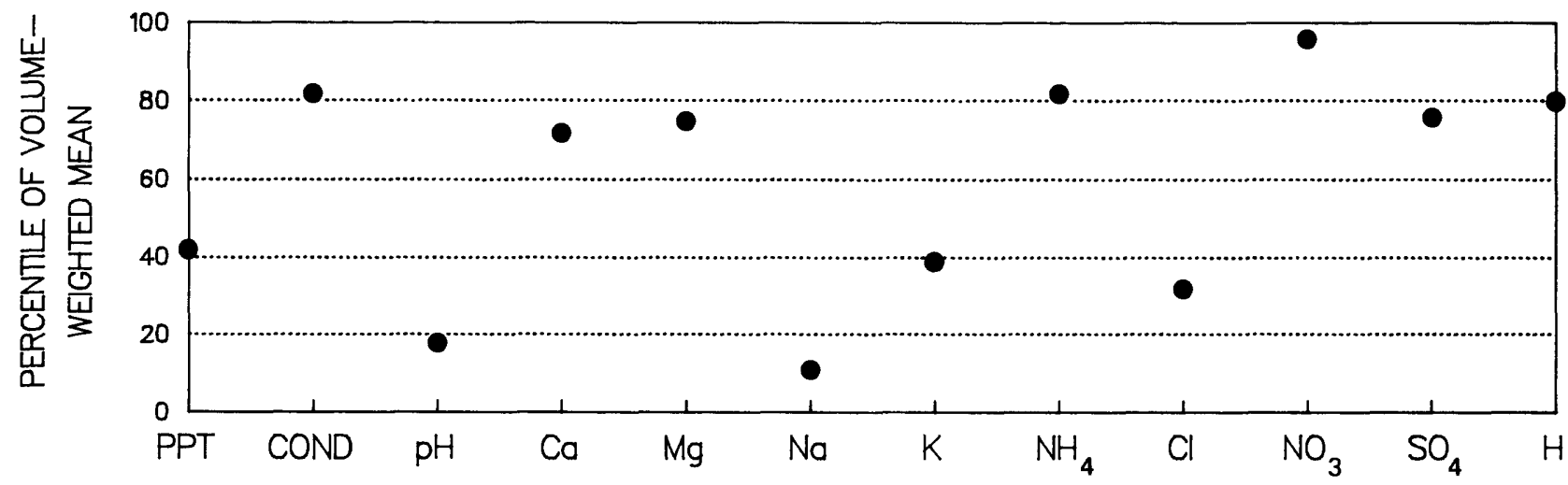

Percentiles of volume-weighted mean concentrations for site MI53, based on

frequency distributions of data from 55 National Trends Network sites. 

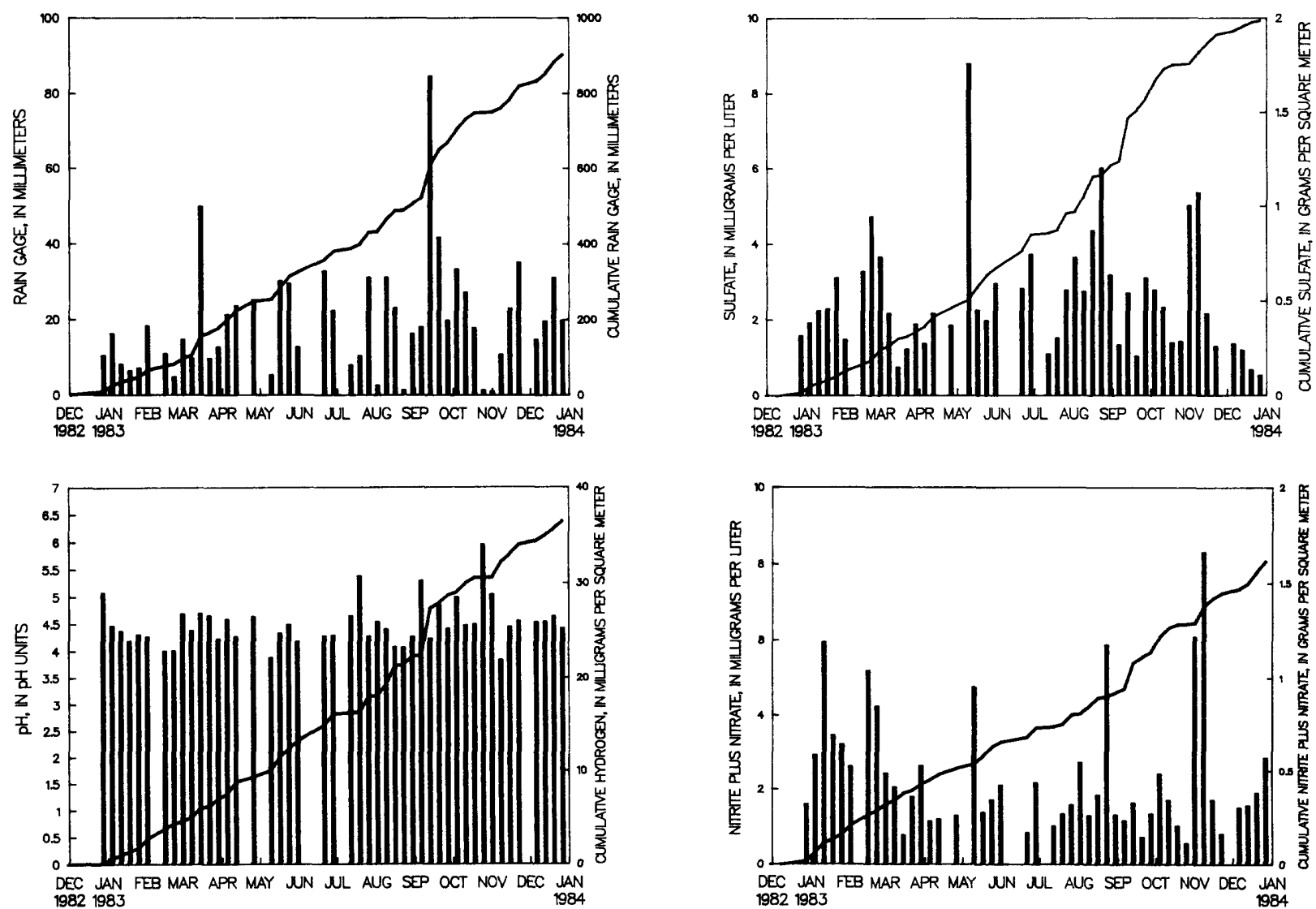

Bar plots of concentrations and cumulative line plots of loads for site MI53. Nitrite plus nitrate are reported as $\mathrm{NO}_{3}$ and sulfate as $\mathrm{SO}_{4}$.

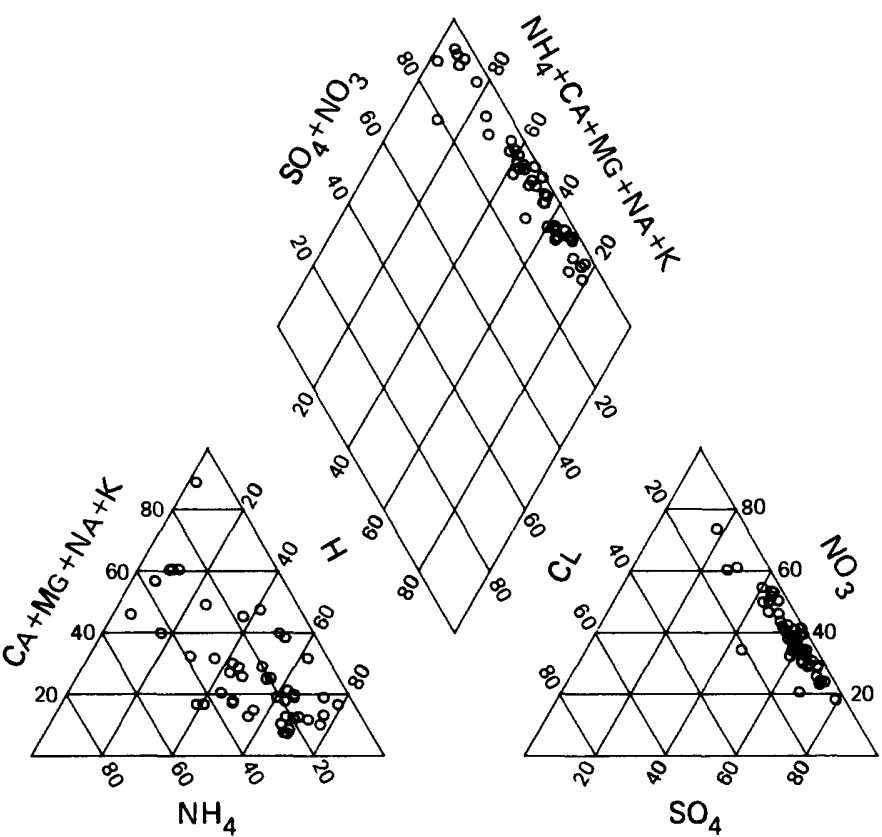

Percentage composition of major ions for site MI53. 


\section{NATIONAL TRENDS NETWORK -- 1983 CALENDER YEAR SUMMARY DATA}

โppt = precipitation; $\mathrm{mm}=$ millimeters; $\mathrm{cm}=$ centimeters; $\mathrm{mg}=$ milligrams; L = liters; $\mathrm{g}=\mathrm{grams} ; \mathrm{m}=$ meter; $\mu \mathrm{s}=$ microsiemens; cond = specific conductance $]$

STATION: Marcell, Minnesota

CAL number: MN16

ADS number: $034 \mathrm{a} 00$

Map ID number: 48

Station altitude above mean sea level, in meters: 431

Number of sampling intervals (days in parenthesis):

-- With ppt measurements: $53 \quad$ (371)

-- When ppt occurred: $50 \quad$ (350)

-- When ppt did not occur: 3 ( 21)

-- When sample volume was substituted for missing rain gage: 0 ( 0 )

-- With chemical samples: 32
Latitude: $47^{\circ} 31^{\prime} 52^{\prime \prime}$ Longitude: $93^{\circ} 28^{\prime} 07^{\prime \prime}$

Station summary period: $12 / 28 / 1982$ to $01 / 03 / 1984$

Length of sumary period: 53 sampling intervals ( 371 days)

Percent sumary period with ppt measurements: $\quad 100.0$

Percent sumary period with chemical samples or no ppt: 66.0

Percent of total measured ppt with chemical samples: $\quad 71.7$

Percent of total measured ppt in raingage that was

collected in the wet-sample bucket:

93.6

Total measured ppt, in mm: 704.1

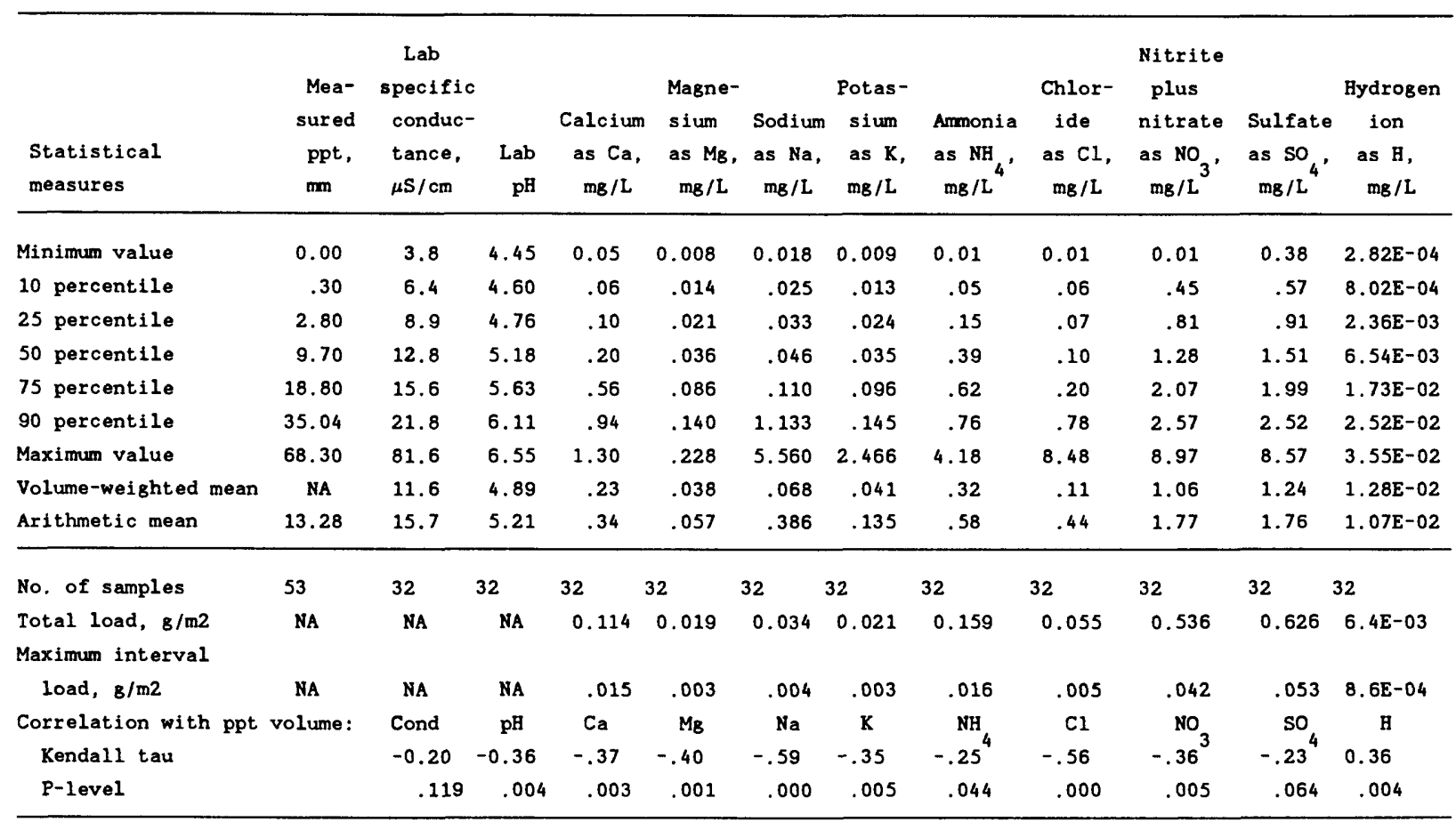

岁

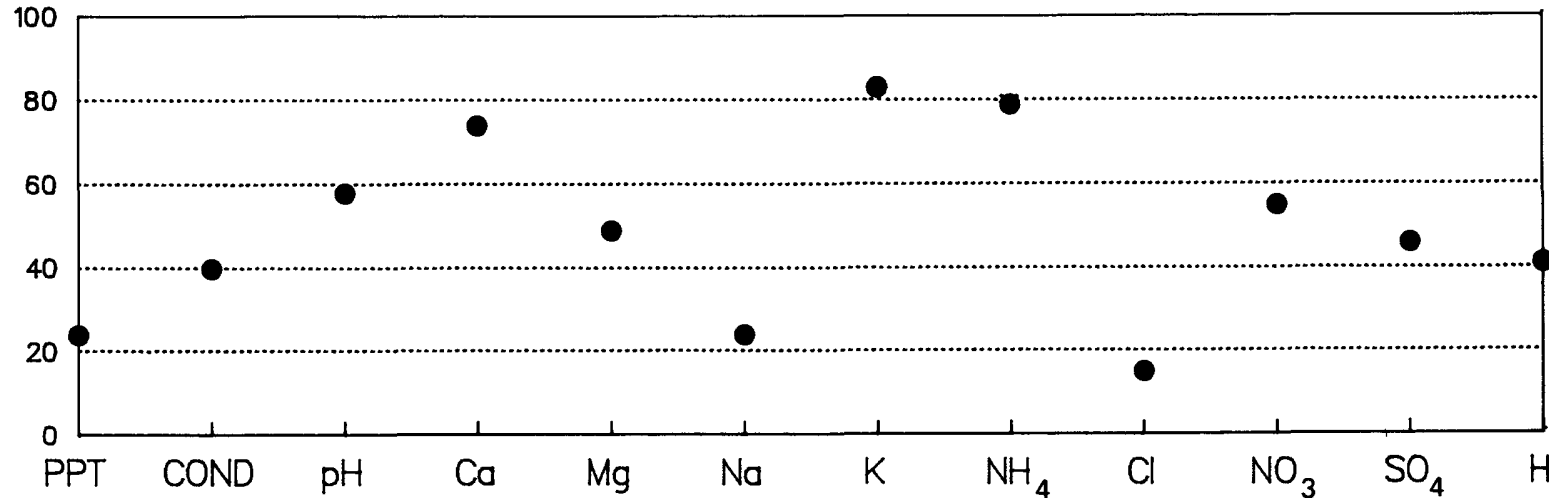

Percentiles of volume-weighted mean concentrations for site MN16, based on frequency distributions of data from 55 National Trends Network sites. 

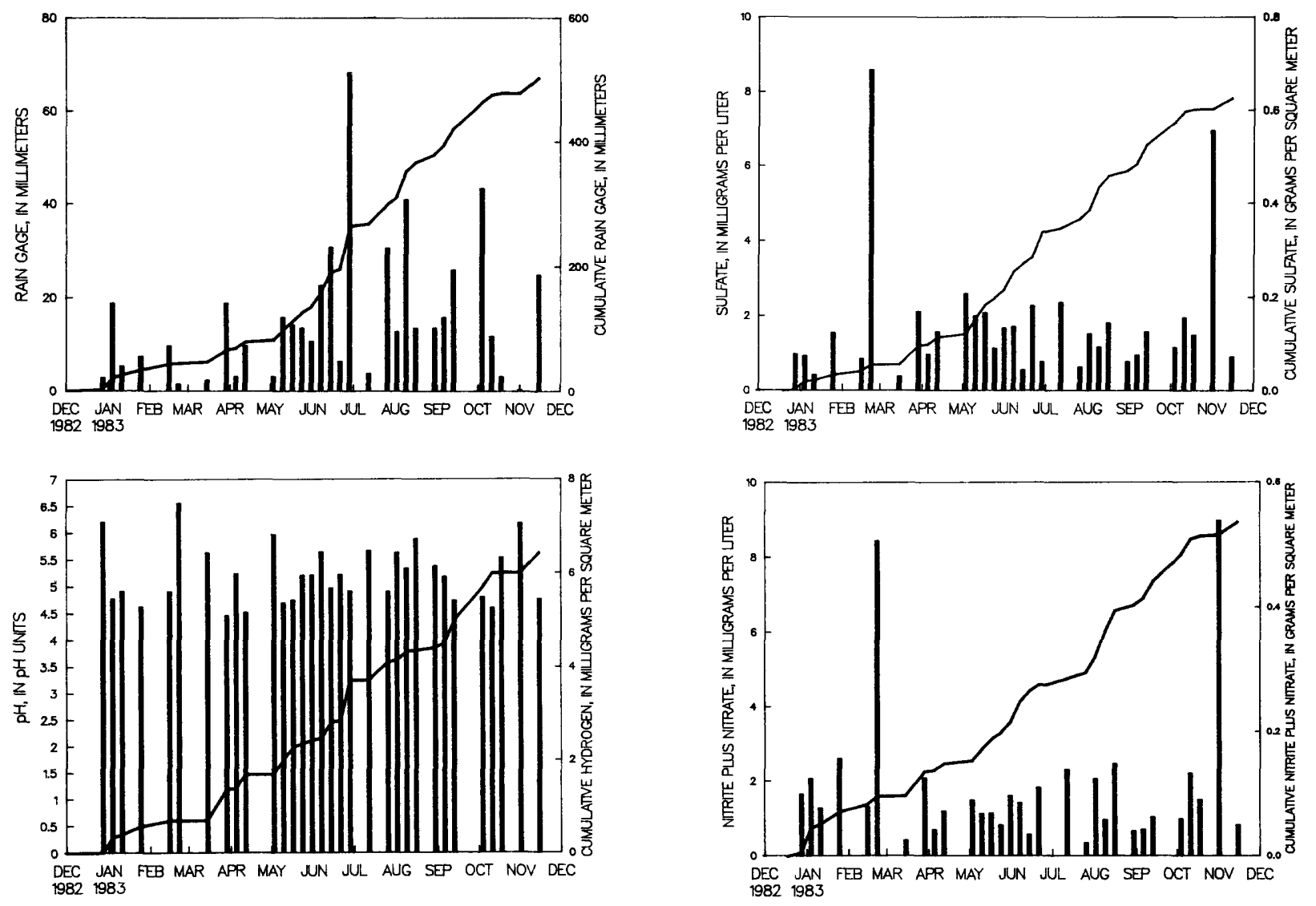

Bar plots of concentrations and cumulative line plots of loads for site MN16. Nitrite plus nitrate are reported as $\mathrm{NO}_{3}$ and sulfate as $\mathrm{SO}_{4}$.

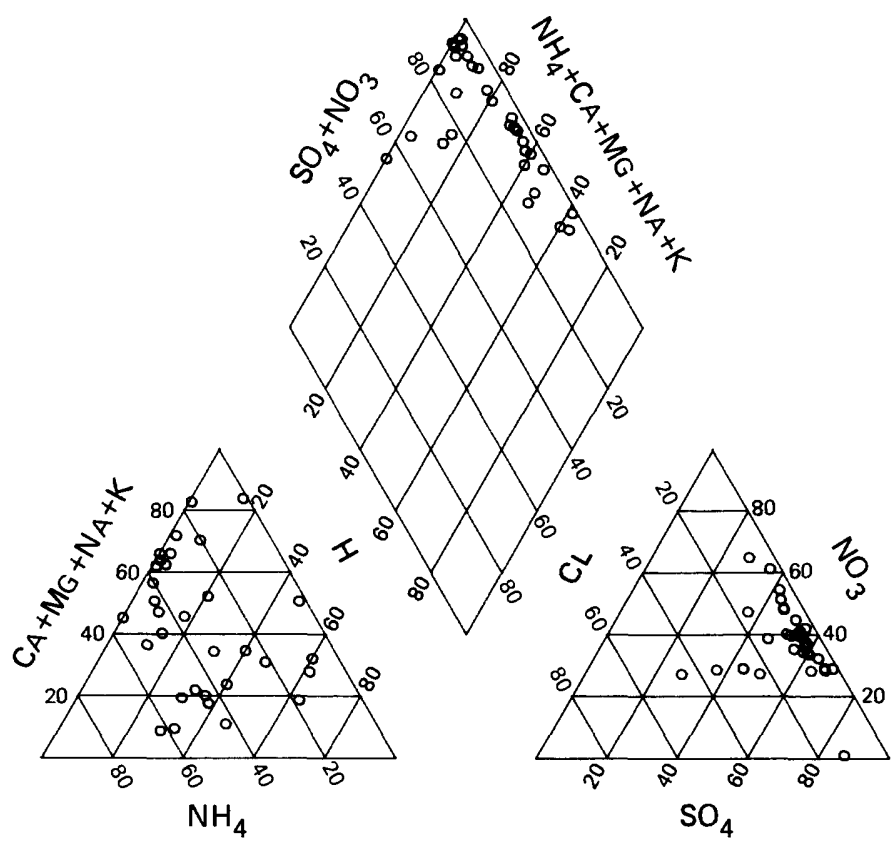

Percentage composition of major ions for site MN16. 


\section{NATIONAL TRENDS NETWORK - - 1983 CALENDER YEAR SUMMARY DATA}

lppt = precipitation; $\mathrm{mm}=$ millimeters; $\mathrm{cm}=$ centimeters; $\mathrm{mg}=$ milligrams; $\mathrm{L}=1$ iters; $\mathrm{g}=\mathrm{grams} ; \mathrm{m}=$ meter; $\mu \mathrm{s}=$ microsiemens; cond $=$ specific conductance $]$

STATION: Fernberg, Minnesota

CAL number: MN18

ADS number: $166 \mathrm{a02}$

Station altitude above mean sea level, in meters: 524

Number of sampling intervals (days in parenthesis):

-- With ppt measurements: 52 (371)

-- When ppt occurred: $48 \quad$ (343)

-- When ppt did not occur: 4 (28)

-- When sample volume was substituted for missing rain gage: 0 ( 0 )

-- With chemical samples: $38 \quad$ (286)
Latitude: $47^{\circ} 56^{\prime} 45^{\prime \prime}$ Longitude: $91^{\circ} 29^{\prime} 43^{\prime \prime}$

Station summary period: $12 / 28 / 1982$ to $01 / 03 / 1984$

Length of summary period: 52 sampling intervals ( 371 days)

Percent summary period with ppt measurements: $\quad 100.0$

Percent summary period with chemical samples or no ppt: 79.2

Percent of total measured ppt with chemical samples: $\quad 74.2$

Percent of total measured ppt in raingage that was

collected in the wet-sample bucket:

82.9

Total measured ppt, in mm: 890.1

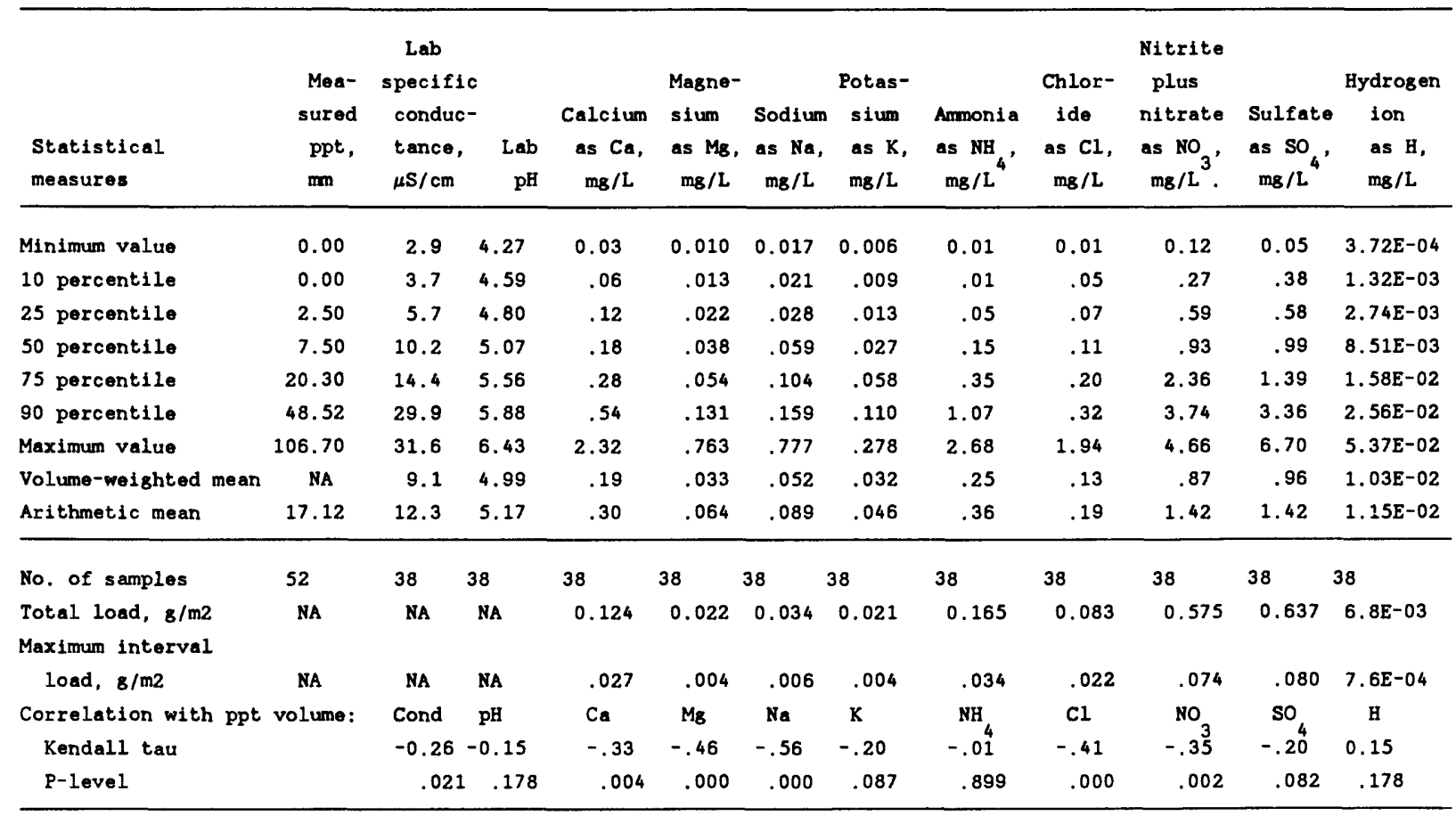

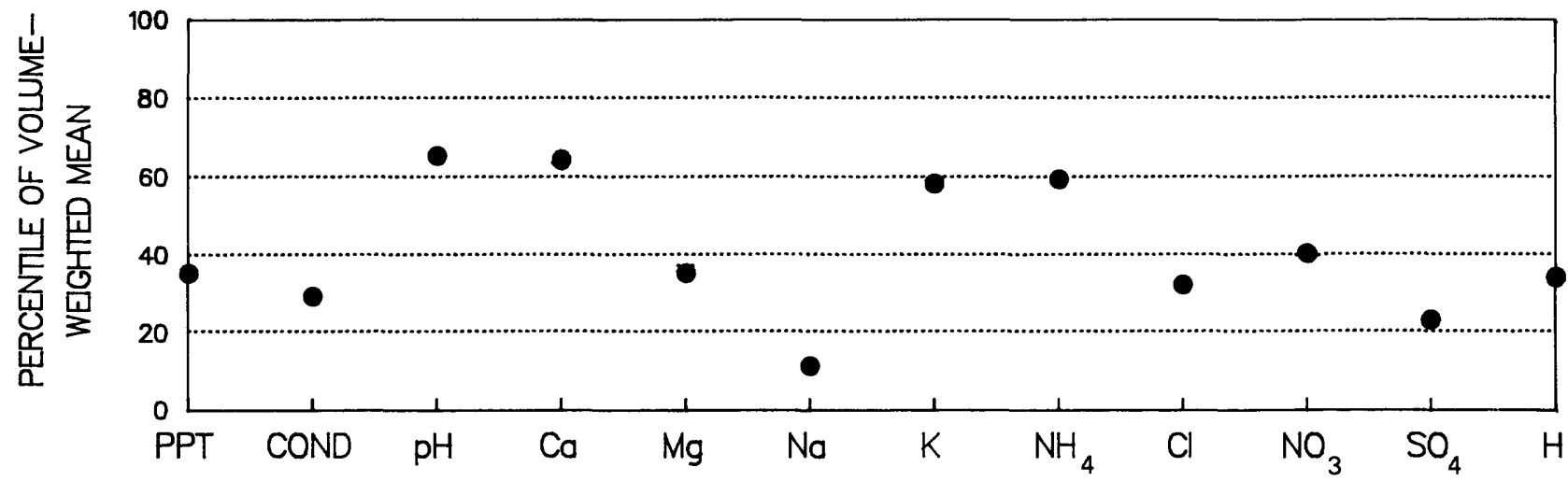

Percentiles of volume-weighted mean concentrations for site MN18, based on frequency distributions of data from 55 National Trends Network sites. 

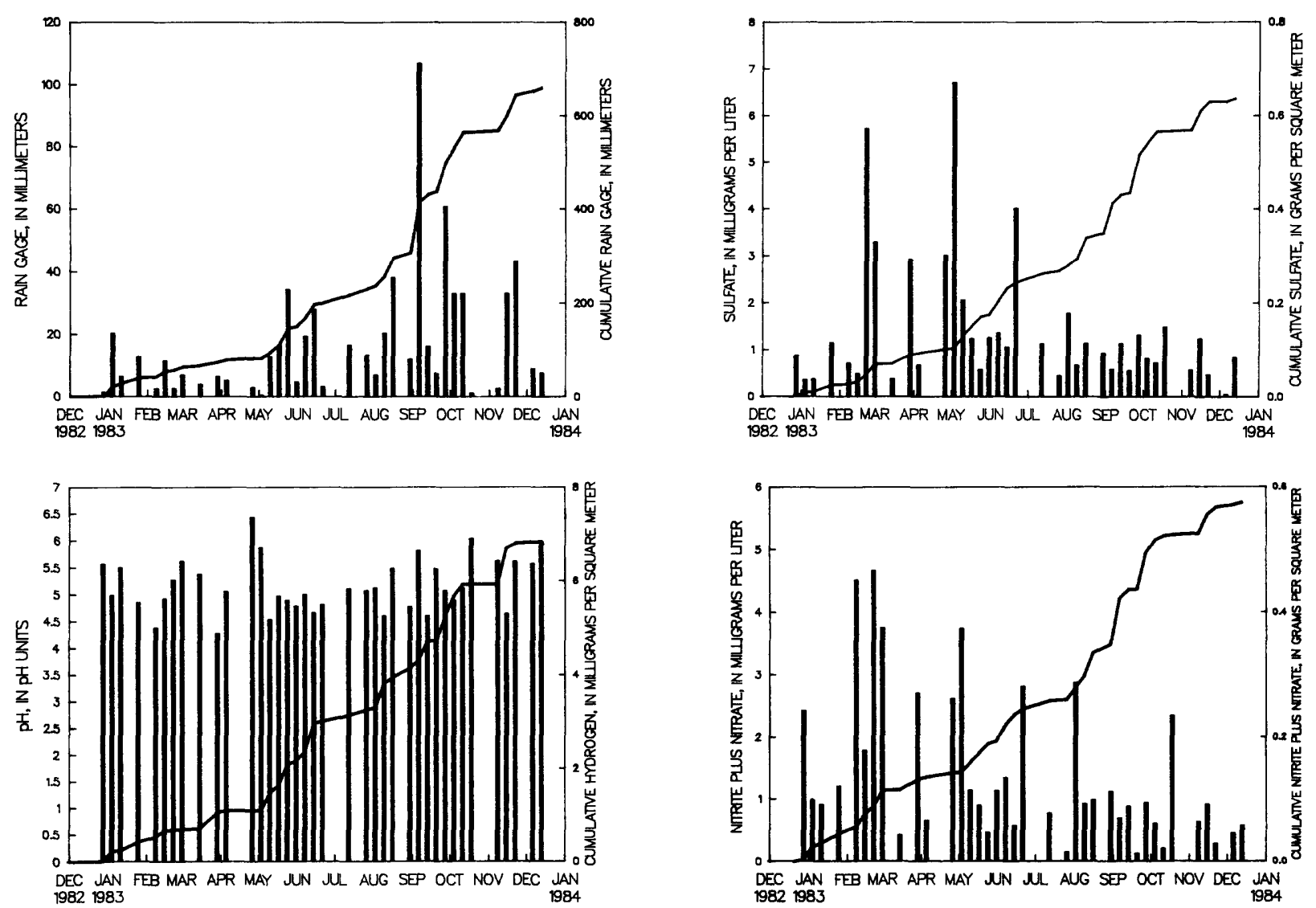

Bar plots of concentrations and cumulative line plots of loads for site MN18.

Nitrite plus nitrate are reported as $\mathrm{NO}_{3}$ and sulfate as $\mathrm{SO}_{4}$.

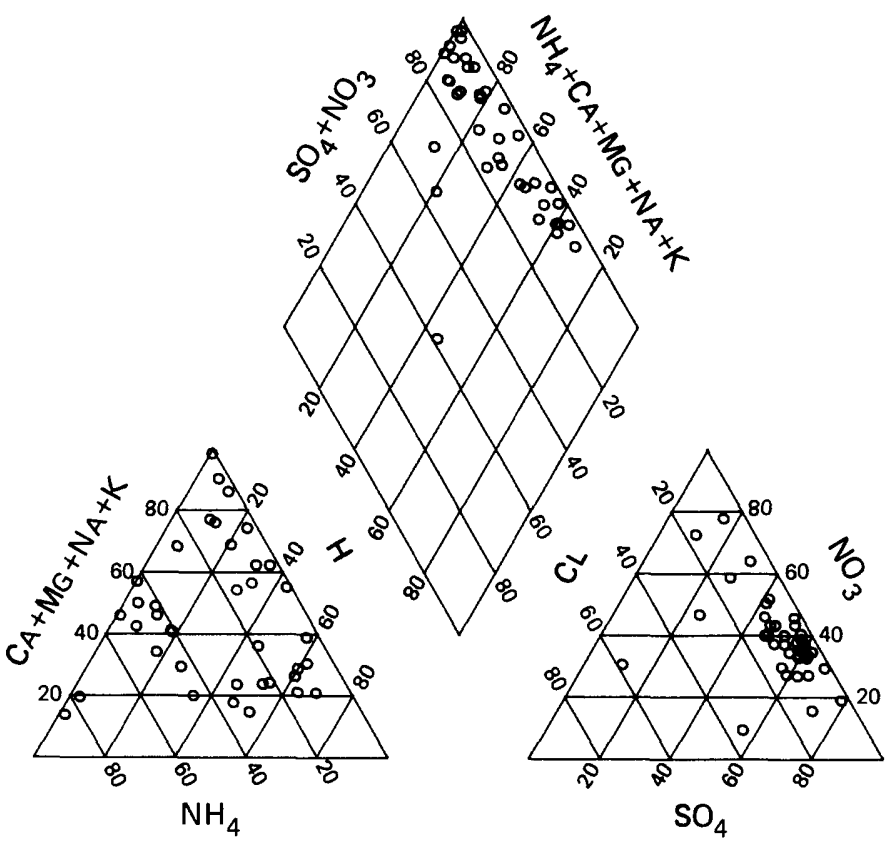

Percentage composition of major ions for site MN18. 


\section{NATIONAL TRENDS NETWORK - - 1983 CALENDER YEAR SUMMARY DATA}

[ppt = precipitation; $\mathrm{mm}=$ millimeters; $\mathrm{cm}=$ centimeters; $\mathrm{mg}=$ milligrams; L = liters; $\mathrm{g}=\mathrm{grams} ; \mathrm{m}=$ meter; $\mu \mathrm{s}=$ microsiemens; cond $=$ specific conductance $]$

STATION: University Forest, Missouri

\section{CAL number: MO05}

ADS number: $253 \mathrm{e} 00$

Station altitude above mean sea level, in meters: 154

Number of sampling intervals (days in parenthesis):

-- With ppt measurements: 53 (371)

-- When ppt occurred: $50 \quad$ (350)

-- When ppt did not occur: $3 \quad$ ( 21)

-- When sample volume was substituted for missing rain gage: 0 ( 0 )

-- With chemical samples: 37 (259)
Latitude: $36^{\circ} 54^{\prime} 39^{\prime \prime}$ Longitude: $90^{\circ} 19^{\prime} 06^{\prime \prime}$

Station sumary period: $12 / 28 / 1982$ to $01 / 03 / 1984$

Length of summary period: 53 sampling intervals ( 371 days)

Percent summary period with ppt measurements: $\quad 100.0$ Percent summary period with chemical samples or no ppt: 75.5 Percent of total measured ppt with chemical samples: 91.3 Percent of total measured ppt in raingage that was collected in the wet-sample bucket:

96.1

Total measured ppt, in $\mathrm{mm}: 1142.2$

\begin{tabular}{|c|c|c|c|c|c|c|c|c|c|c|c|c|}
\hline $\begin{array}{l}\text { Statistical } \\
\text { measures }\end{array}$ & $\begin{array}{c}\text { Mea- } \\
\text { sured } \\
\text { ppt, } \\
\text { mm }\end{array}$ & $\begin{array}{c}\text { Lab } \\
\text { specific } \\
\text { conduc- } \\
\text { tance, } \\
\mu \mathrm{S} / \mathrm{cm}\end{array}$ & $\begin{array}{r}\text { Lab } \\
\mathrm{pH}\end{array}$ & $\begin{array}{c}\text { Calcium } \\
\text { as Ca, } \\
\mathrm{mg} / \mathrm{L}\end{array}$ & $\begin{array}{l}\text { Magne- } \\
\text { sium } \\
\text { es Mg, } \\
\mathrm{mg} / \mathrm{L}\end{array}$ & $\begin{array}{c}\text { Sodium } \\
\text { as } \mathrm{Na} \text {, } \\
\mathrm{mg} / \mathrm{L}\end{array}$ & $\begin{array}{l}\text { Potas- } \\
\text { sium } \\
\text { as } \mathrm{K}, \\
\mathrm{mg} / \mathrm{L}\end{array}$ & $\begin{array}{l}\text { Ammonia } \\
\text { as } \mathrm{NH} \\
\mathrm{mg} / \mathrm{L}^{\prime}\end{array}$ & $\begin{array}{l}\text { Chlor- } \\
\text { ide } \\
\text { as } \mathrm{Cl} \text {, } \\
\mathrm{mg} / \mathrm{L}\end{array}$ & $\begin{array}{l}\text { Nitrite } \\
\text { plus } \\
\text { nitrate } \\
\text { as } \mathrm{NO}_{3} \text {, } \\
\mathrm{mg} / \mathrm{L}\end{array}$ & $\begin{array}{c}\text { Sulfate } \\
\text { as } \mathrm{SO}_{4}, \\
\mathrm{mg} / \mathrm{L}^{4}\end{array}$ & $\begin{array}{l}\text { Hydrogen } \\
\begin{array}{c}\text { ion } \\
\text { as } \mathrm{H}, \\
\mathrm{mg} / \mathrm{L}\end{array}\end{array}$ \\
\hline Minimum value & 0.00 & 3.3 & 3.91 & 0.03 & 0.007 & 0.019 & 0.010 & 0.01 & 0.03 & 0.32 & 0.55 & $1.48 \mathrm{E}-03$ \\
\hline 10 percentile & .00 & 8.5 & 4.23 & .06 & .012 & .031 & .014 & .04 & .06 & .51 & .81 & $8.93 E-03$ \\
\hline 25 percentile & 1.25 & 12.4 & 4.36 & .11 & .020 & .056 & .022 & .15 & .10 & .84 & 1.8 & $1.50 \mathrm{E}-02$ \\
\hline 50 percentile & 14.20 & 16.7 & 4.66 & .26 & .043 & .110 & .036 & .27 & .15 & 1.27 & 1.75 & $2.19 \mathrm{E}-02$ \\
\hline 75 percentile & 38.00 & 25.0 & 4.82 & .49 & .072 & .169 & .067 & .41 & .28 & 2.31 & 2.73 & $4.32 E-02$ \\
\hline 90 percentile & 50.58 & 36.1 & 5.05 & .77 & .118 & .244 & .092 & .69 & .39 & 2.80 & 3.97 & $5.89 \mathrm{E}-02$ \\
\hline Maximum value & 105.40 & 66.9 & 5.83 & 1.00 & .198 & 1.081 & .146 & 1.27 & .54 & 4.37 & 7.5 & $1.23 E-01$ \\
\hline Volume-weighted mean & NA & 14.8 & 4.67 & .21 & .036 & .111 & .038 & .28 & .18 & 1.07 & 1.63 & $2.15 E-02$ \\
\hline Arithmetic mean & 21.55 & 20.1 & 4.66 & .32 & .053 & .139 & .047 & .33 & .19 & 1.57 & 2.16 & $3.01 E-02$ \\
\hline No. of samples & 53 & 37 & 37 & 37 & 37 & 37 & 37 & 37 & 37 & 37 & 37 & 37 \\
\hline $\begin{array}{l}\text { Total load, } 8 / \mathrm{m} 2 \\
\text { Maximum interval }\end{array}$ & NA & NA & NA & 0.214 & 0.037 & 0.116 & 0.039 & 0.295 & 0.185 & 1.115 & 1.704 & 2. $2 E-02$ \\
\hline load, $8 / \mathrm{m} 2$ & $\mathrm{NA}$ & NA & NA & .030 & .006 & .025 & .007 & .058 & .031 & 0.118 & .208 & $2.2 \mathrm{E}-03$ \\
\hline $\begin{array}{l}\text { Correlation with ppt } \\
\text { Kendall tau }\end{array}$ & volume: & $\begin{array}{l}\text { Cond } \\
-0.39\end{array}$ & $\begin{array}{l}\mathrm{pH} \\
0.28\end{array}$ & $\begin{array}{l}\mathrm{Ca} \\
-.52\end{array}$ & $\begin{array}{l}\mathrm{Mg} \\
-.53\end{array}$ & $\begin{array}{l}\mathrm{Na} \\
-.28\end{array}$ & $\begin{array}{l}\mathrm{K} \\
-.33\end{array}$ & $\begin{array}{c}\mathrm{NH}_{4} \\
-.16\end{array}$ & $\begin{array}{l}C 1 \\
-.20\end{array}$ & $\begin{array}{l}\mathrm{NO}^{3} \\
-.51\end{array}$ & $\begin{array}{l}\mathrm{SO}_{4} \\
-.36\end{array}$ & $\begin{array}{c}\mathrm{H} \\
-0.28\end{array}$ \\
\hline P-level & & .001 & .014 & .000 & .000 & .014 & .005 & .173 & .091 & .000 & .002 & .014 \\
\hline
\end{tabular}

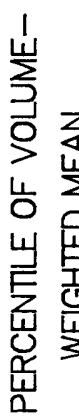

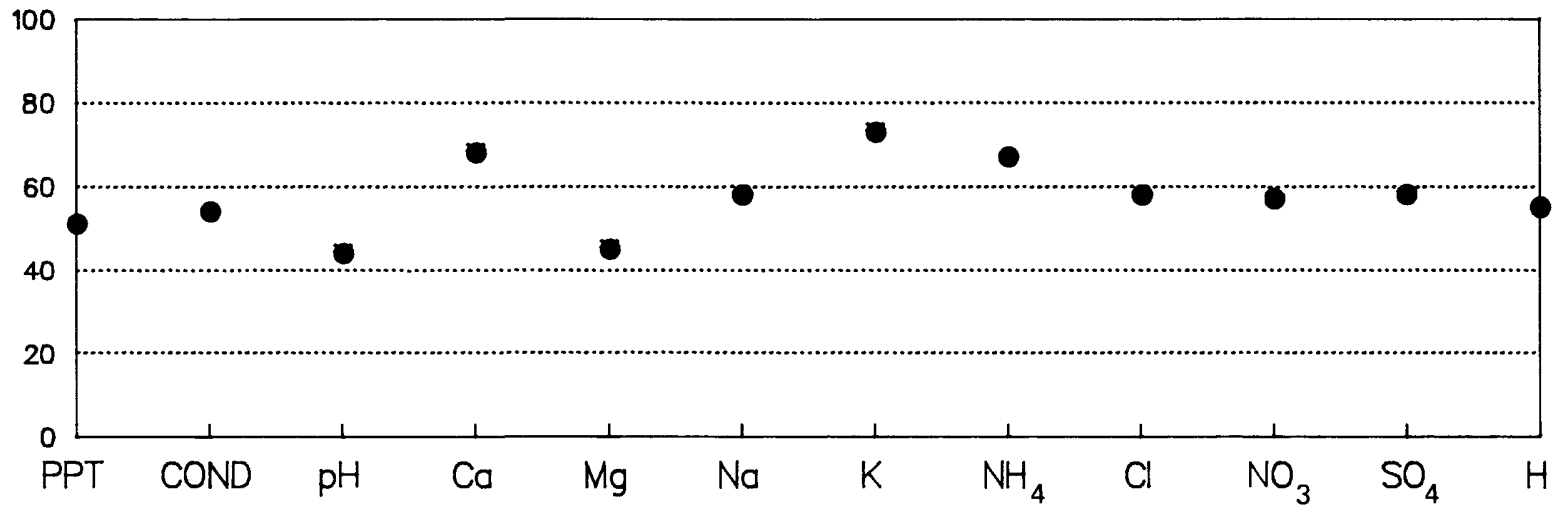

Percentiles of volume-weighted mean concentrations for site MO05, based on frequency distributions of data from 55 National Trends Network sites. 

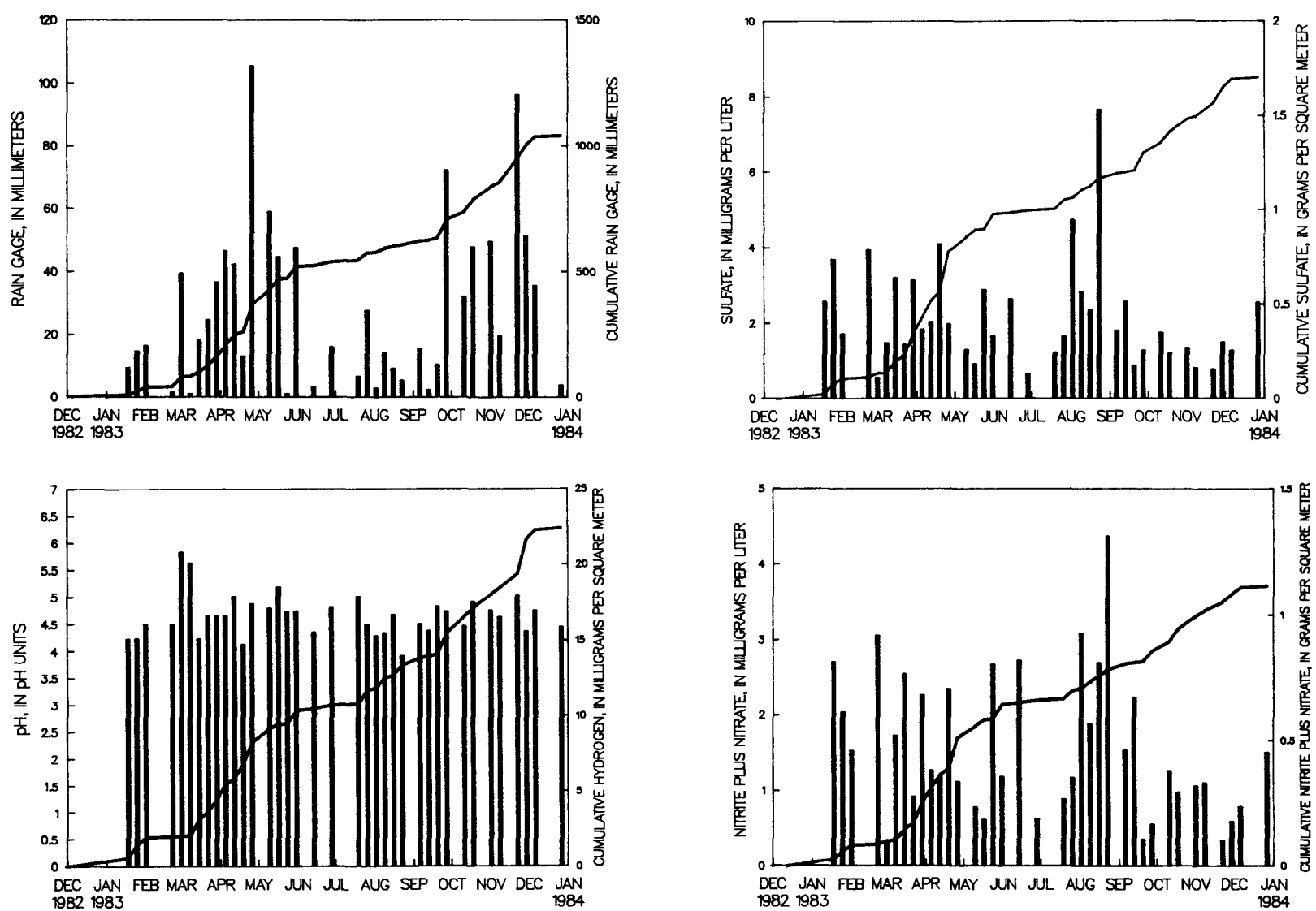

Bar plots of concentrations and cumulative line plots of loads for site MO05. Nitrite plus nitrate are reported as $\mathrm{NO}_{3}$ and sulfate as $\mathrm{SO}_{4}$.

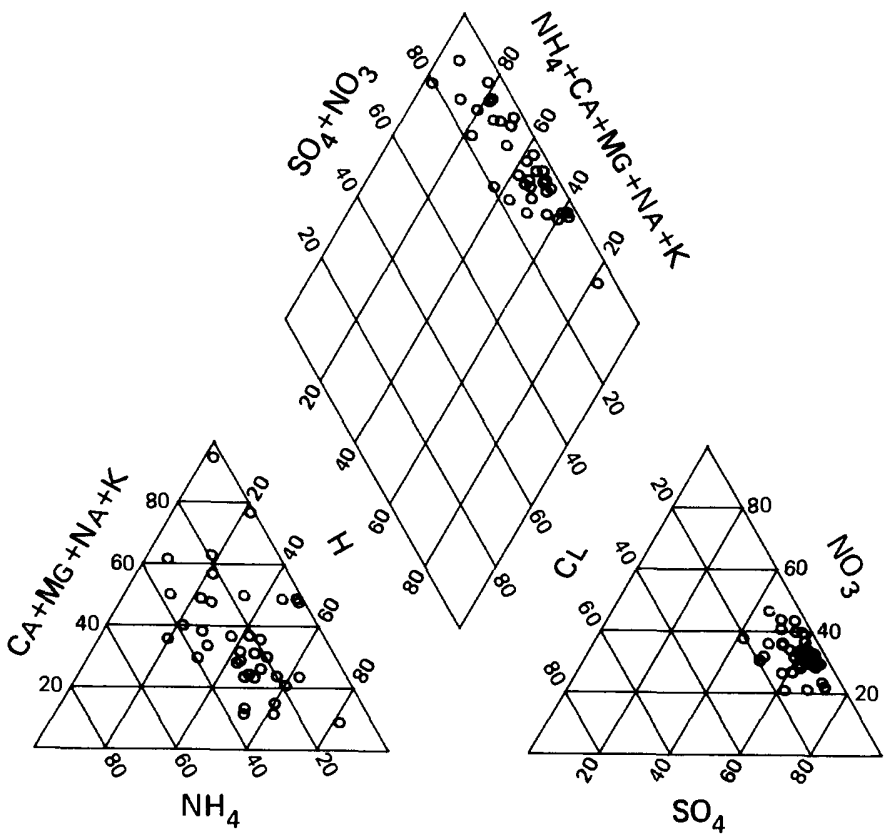

Percentage composition of major ions for site MO05. 


\section{NATIONAL TRENDS NETWORK -- 1983 CALENDER YEAR SUMMARY DATA}

lppt = precipitation; $\mathrm{mm}=$ millimeters; $\mathrm{cm}=$ centimeters; $\mathrm{mg}=$ milligrams; $\mathrm{L}=1 \mathrm{iters}$;

$8=$ grams; $\mathrm{m}=$ meter; $\mu \mathrm{s}=$ microsiemens; cond = specific conductance $]$

STATION: Lewiston, North Carolina

CAL number: $\mathrm{NCO} 3$

ADS number: 049a00

Station altitude above mean sea level, in meters: 26 Number of sampling intervals (days in parenthesis):

-- With ppt measurements: 53 (371)

-- When ppt occurred: $47 \quad$ (329)

-- When ppt did not occur: 6 (42)

-- When sample volume was substituted for missing rain gage: 0 ( 0$)$

-- With chemical samples: $33 \quad$ (232)
Latitude: $\quad 36^{\circ} 07^{\prime} 40^{\prime \prime}$ Longitude: $\quad 7^{\circ} 10^{\prime} 30^{\prime \prime}$

Station summary period: $12 / 28 / 1982$ to $01 / 03 / 1984$

Length of summary period: 53 sampling intervals ( 371 days)

Percent summary period with ppt measurements: 100.0

Percent surmary period with chemical samples or no ppt: 73.9

Percent of total measured ppt with chemical samples: 67.2

Percent of total measured ppt in raingage that was

collected in the wet-sample bucket:

98.5

Total measured ppt, in $\mathrm{mm}: 1097.5$

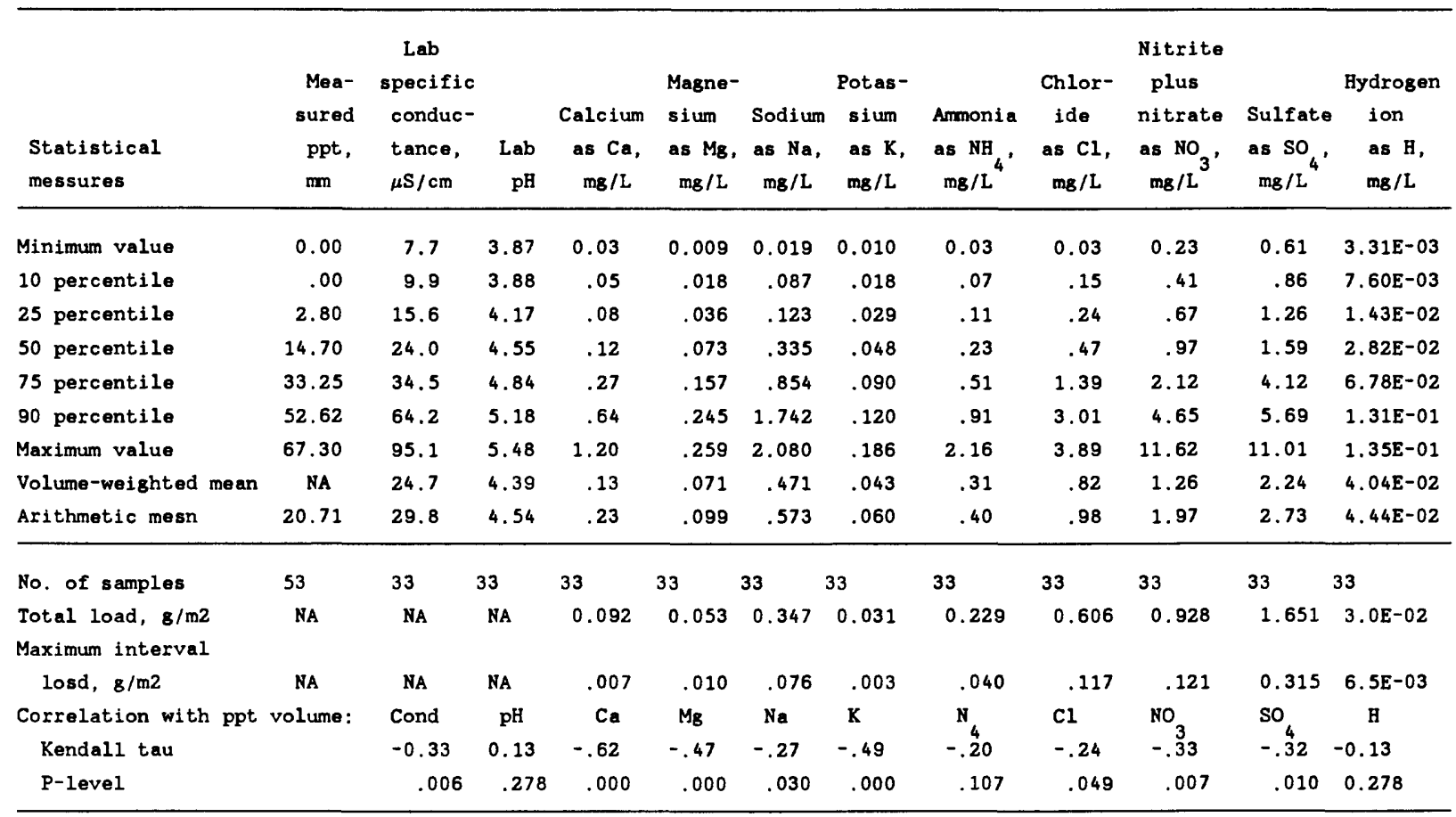

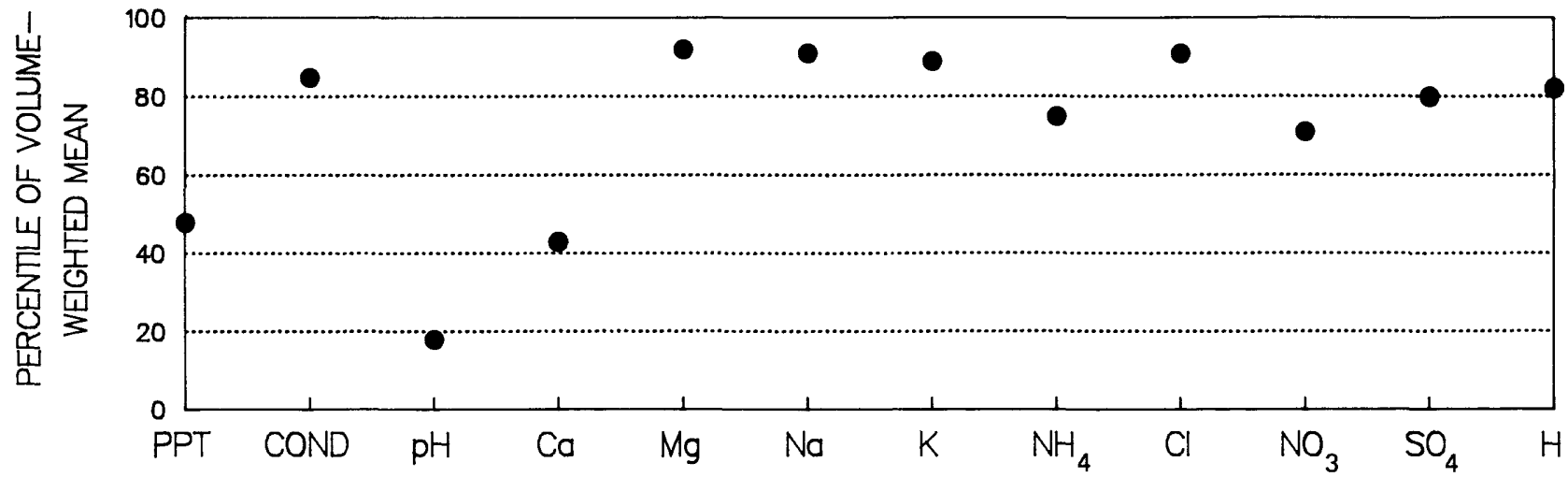

Percentiles of volume-weighted mean concentrations for site $\mathrm{NC03}$, based on frequency distributions of data from 55 National Trends Network sites. 

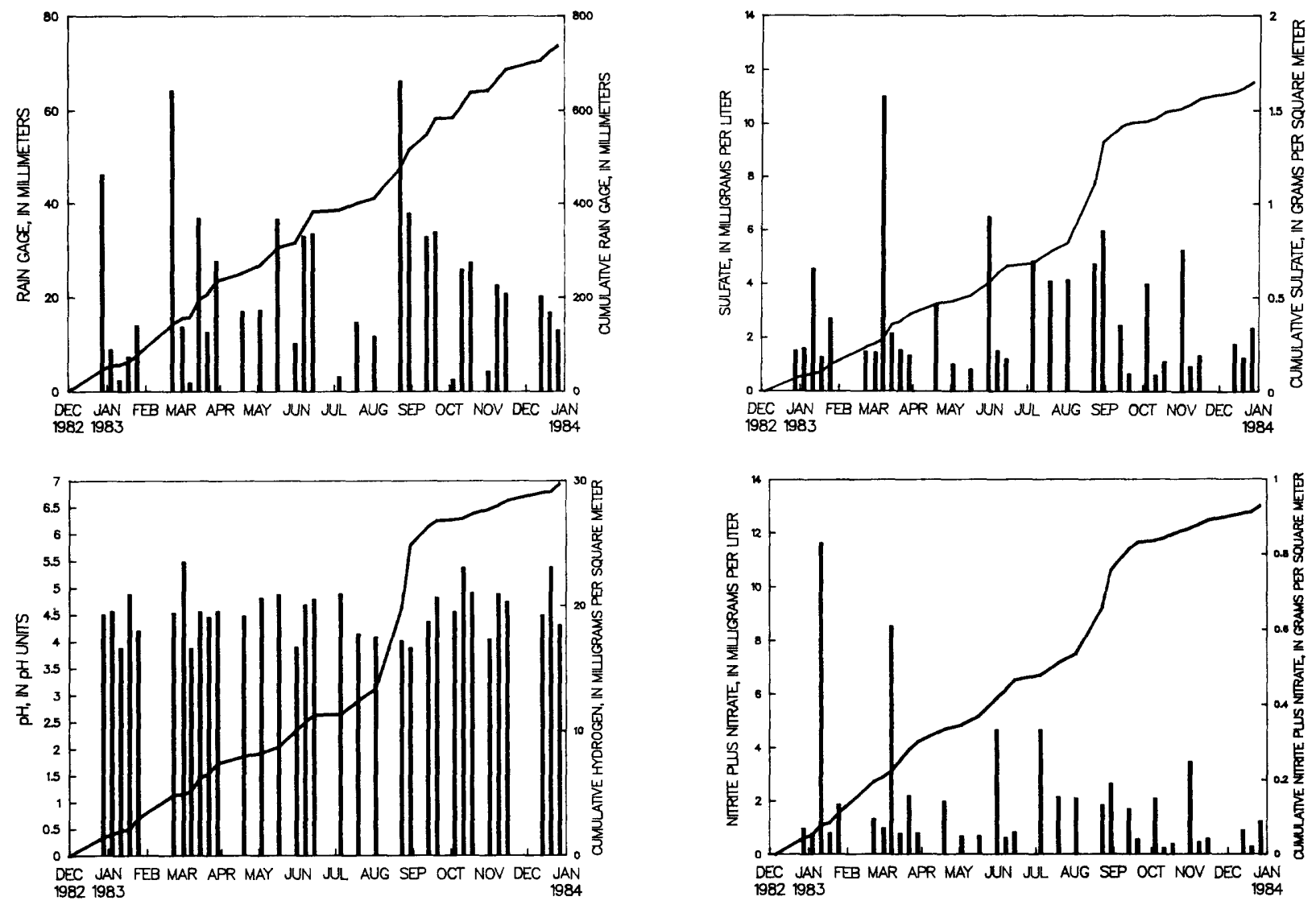

Bar plots of concentrations and cumulative line plots of loads for site NC03. Nitrite plus nitrate are reported as $\mathrm{NO}_{3}$ and sulfate as $\mathrm{SO}_{4}$.

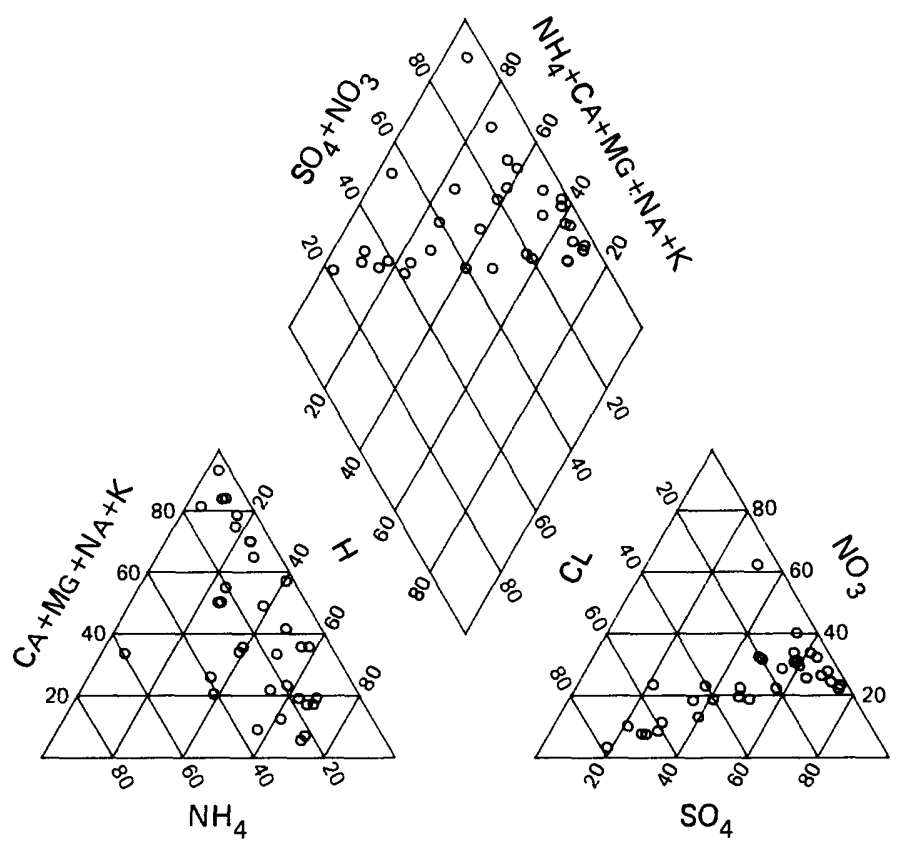

Percentage composition of major ions for site $\mathrm{NCO3}$. 


\section{NATIONAL TRENDS NETWORK - 1983 CALENDER YEAR SUMMARY DATA}

[ppt $=$ precipitation; $\mathrm{mm}=$ millimeters; $\mathrm{cm}=$ centimeters; $\mathrm{mg}=$ milligrams; $\mathrm{L}=1 \mathrm{iters} ;$

8 = $\mathrm{grams} ; m=$ meter $; \mu \mathrm{s}=$ microsiemens; cond $=$ specific conductance $]$

STATION: Coweeta, North Carolina

CAL number: NC25

ADS number: 050 a00

Station altitude above mean sea level, in meters: 686

Number of sampling intervals (days in parenthesis):

-- With ppt measurementa: 51 (371)

-- When ppt occurred: 49 (357)

-- When ppt did not occur: 2 (14)

-- When sample volume was substituted for missing rain gage: 0 ( 0$)$

-- With chemical samples: $36 \quad$ (259)
Latitude: $\quad 35^{\circ} 03^{\prime} 38^{\prime \prime}$ Longitude: $83^{\circ} 25^{\prime} 50^{\prime \prime}$

Station summary period: $12 / 28 / 1982$ to $01 / 03 / 1984$

Length of sumary period: 51 sampling intervals ( 371 days)

Percent summary period with ppt measurements: $\quad 100.0$

Percent summary period with chemical samples or no ppt: 73.6

Percent of total measured ppt with chemical samples: 86.5

Percent of total measured ppt in raingage that was

collected in the wet-sample bucket:

99.5

Total measured ppt, in $\mathrm{mm}: 2015.8$

\begin{tabular}{|c|c|c|c|c|c|c|c|c|c|c|c|c|}
\hline $\begin{array}{l}\text { Statistical } \\
\text { measures }\end{array}$ & $\begin{array}{l}\text { Mea- } \\
\text { sured } \\
\text { ppt, } \\
\text { mm }\end{array}$ & $\begin{array}{c}\text { Lab } \\
\text { specific } \\
\text { conduc- } \\
\text { tance, } \\
\mu \mathrm{S} / \mathrm{cm}\end{array}$ & $\begin{array}{r}\text { Lab } \\
\mathrm{pH}\end{array}$ & $\begin{array}{c}\text { Calcium } \\
\text { as Ca, } \\
\mathrm{mg} / \mathrm{L}\end{array}$ & $\begin{array}{l}\text { Magne- } \\
\text { sium } \\
\text { as } \mathrm{Mg} \text {, } \\
\mathrm{mg} / \mathrm{L}\end{array}$ & $\begin{array}{l}\text { Sodium } \\
\text { as } \mathrm{Na} \text {, } \\
\mathrm{mg} / \mathrm{L}\end{array}$ & $\begin{array}{l}\text { Potas- } \\
\text { sium } \\
\text { as } \mathrm{K} \text {, } \\
\mathrm{mg} / \mathrm{L}\end{array}$ & $\begin{array}{l}\text { Ammonia } \\
\text { as } \mathrm{NH}_{4} \text {, } \\
\mathrm{mg} / \mathrm{L}^{\circ}\end{array}$ & $\begin{array}{l}\text { Chlor- } \\
\text { ide } \\
\text { as } \mathrm{Cl} \text {, } \\
\mathrm{mg} / \mathrm{L}\end{array}$ & $\begin{array}{l}\text { Nitrite } \\
\text { plus } \\
\text { nitrate } \\
\text { as } \mathrm{NO}_{3} \text {, } \\
\mathrm{mg} / \mathrm{L}^{3}\end{array}$ & $\begin{array}{l}\text { Sulfate } \\
\text { as so } \\
\mathrm{mg} / \mathrm{L}^{4}\end{array}$ & $\begin{array}{l}\text { Hydrogen } \\
\text { ion } \\
\text { as } \mathrm{H}, \\
\mathrm{mg} / \mathrm{L}\end{array}$ \\
\hline 10 percentile & .70 & 4.1 & 4.25 & .02 & .006 & .020 & .007 & .01 & .05 & .22 & .46 & $5.51 E-03$ \\
\hline 25 percentile & 8.60 & 7.2 & 4.47 & .03 & .011 & .032 & .010 & .06 & .08 & .39 & .66 & $1.07 E-02$ \\
\hline 50 percentile & 28.70 & 11.1 & 4.76 & .07 & .017 & .059 & .018 & .14 & .12 & .59 & 1.18 & 1. $72 \mathrm{E}-02$ \\
\hline 75 percentile & 51.30 & 19.3 & 4.97 & .14 & .031 & .100 & .044 & .23 & .18 & 1.08 & 1.99 & $3.39 E-02$ \\
\hline 90 percentile & 116.22 & 28.7 & 5.26 & .23 & .064 & .224 & .064 & .34 & .35 & 1.54 & 2.55 & 5. $70 E-02$ \\
\hline Maximum value & 165.40 & 36.8 & 5.48 & .41 & .083 & .415 & .170 & .67 & .71 & 2.04 & 4.08 & $7.24 \mathrm{E}-02$ \\
\hline Arithmetic mean & 39.53 & 14.1 & 4.76 & .10 & .025 & .086 & .031 & .16 & .16 & .76 & 1.39 & $2.33 \mathrm{E}-02$ \\
\hline No. of samples & 51 & 36 & 36 & 36 & 36 & 36 & 36 & 36 & 36 & 36 & 36 & 36 \\
\hline $\begin{array}{l}\text { Total load, } 8 / \mathrm{m} 2 \\
\text { Maximum interval }\end{array}$ & NA & NA & NA & 0.141 & 0.034 & 0.163 & 0.047 & 0.288 & 0.314 & 1.088 & 2.115 & $3.4 \mathrm{E}-02$ \\
\hline load, $8 / m 2$ & NA & NA & NA & .023 & .007 & .051 & .006 & .039 & .087 & 0.128 & 0.271 & $5.3 \mathrm{E}-03$ \\
\hline $\begin{array}{l}\text { Correlation with ppt } \\
\text { Kendall tau }\end{array}$ & volume: & $\begin{array}{l}\text { Cond } \\
-0.21\end{array}$ & $\begin{array}{c}\mathrm{pH} \\
0.18\end{array}$ & $\begin{array}{c}\mathrm{Ca} \\
-.31\end{array}$ & $\begin{array}{c}M g \\
-.34\end{array}$ & $\begin{array}{l}\mathrm{Na} \\
-.02\end{array}$ & $\begin{array}{l}\mathbf{K} \\
-.08\end{array}$ & $\begin{array}{c}\mathrm{NH}_{4}^{4} \\
-.02\end{array}$ & $\begin{array}{c}C 1 \\
-.02\end{array}$ & $\begin{array}{l}\mathrm{NO}_{3} \\
-.30\end{array}$ & $\begin{array}{r}\text { so }_{4} \\
-.21\end{array}$ & $\begin{array}{c}\mathrm{H} \\
-0.18\end{array}$ \\
\hline P-level & & .077 & .127 & .008 & .004 & .849 & .513 & .848 & .848 & .010 & .070 & .127 \\
\hline
\end{tabular}

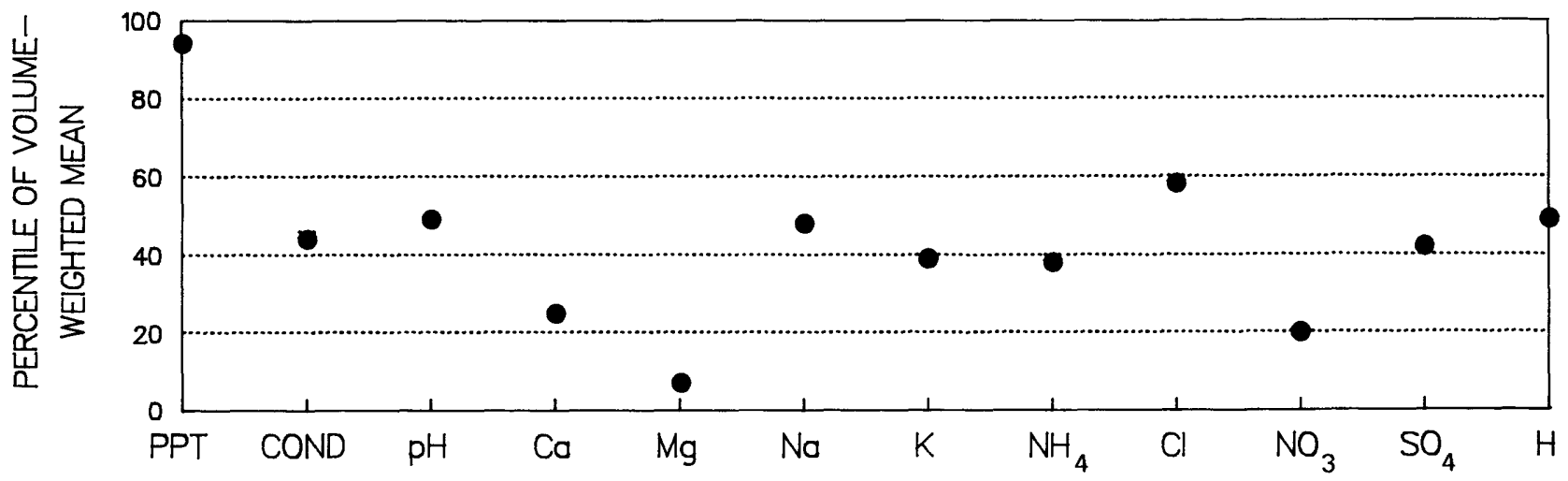

Percentiles of volume-weighted mean concentrations for site NC25, based on frequency distributions of data from 55 National Trends Network sites. 

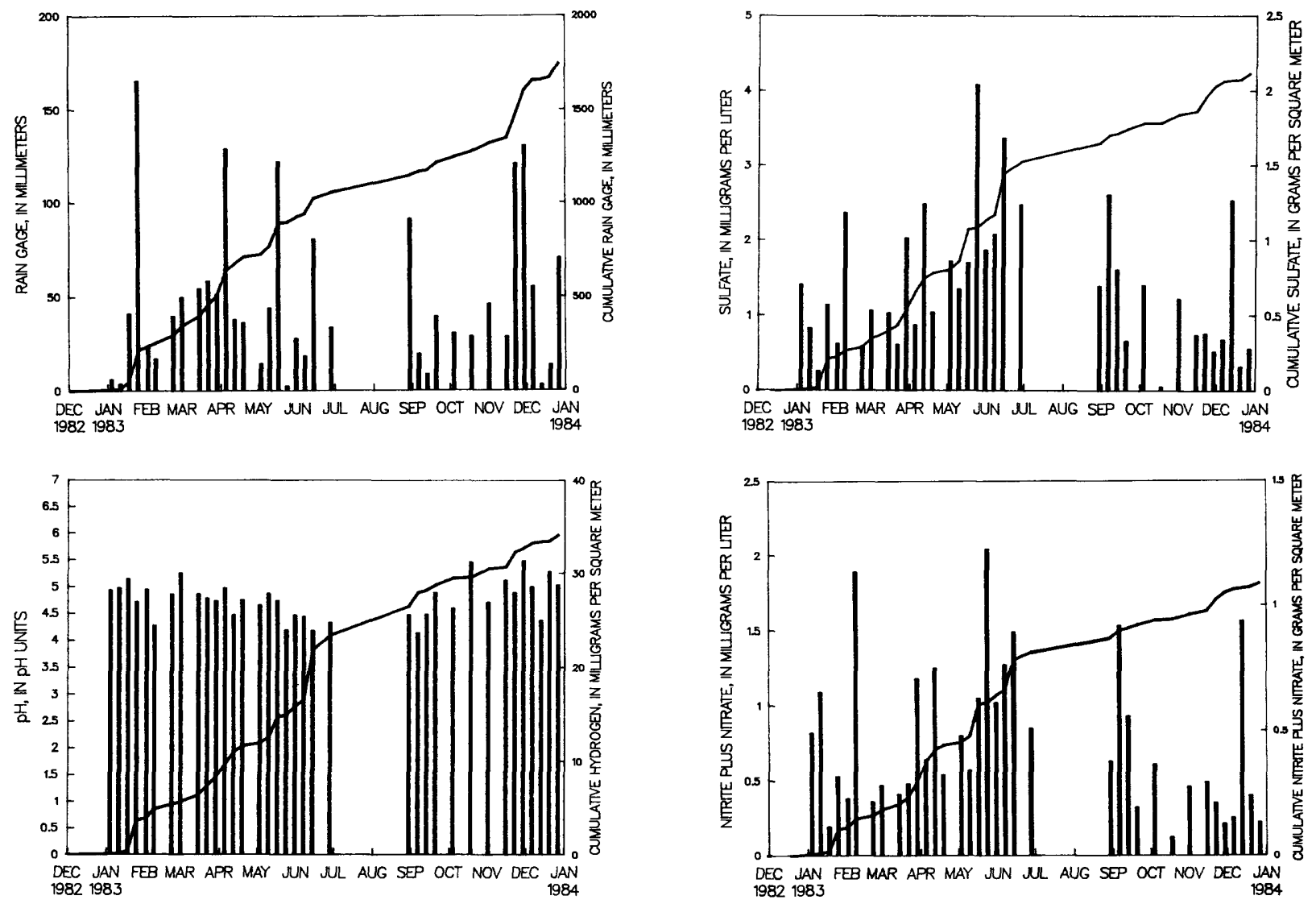

Bar plots of concentrations and cumulative line plots of loads for site NC25. Nitrite plus nitrate are reported as $\mathrm{NO}_{3}$ and sulfate as $\mathrm{SO}_{4}$.

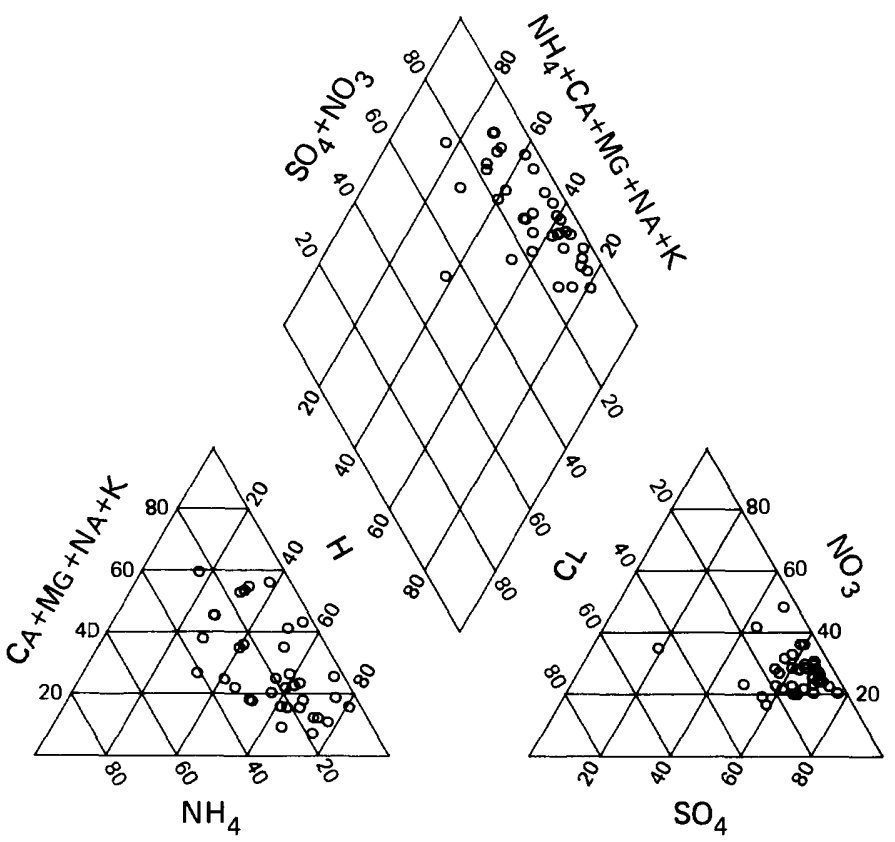

Percentage composition of major ions for site NC25. 


\section{NATIONAL TRENDS NETWORK - - 1983 CALENDER YEAR SUMMARY DATA}

Ippt = precipitation; $\mathrm{mm}=$ millimeters; $\mathrm{cm}=$ centimeters; $\mathrm{mg}=\mathrm{milligrams;} \mathrm{L} \mathrm{=} \mathrm{liters;}$

$\mathbf{g}=\mathrm{grams} ; \mathrm{m}=$ meter; $\mu \mathrm{s}=\mathrm{microsiemens;}$ cond = specific conductance]

STATION: Piedmont Station, North Carolina
CAL number: NC34
Map ID number: 57

ADS number: $051 \mathrm{a} 00$

Station altitude above mean sea level, in meters: 221

Number of sampling intervals (days in parenthesis):

-- With ppt measurements: $53 \quad$ (371)

-- When ppt occurred: $49 \quad$ (343)

- When ppt did not occur: $4 \quad 4$ ( 28)

-- When sample volume was substituted for missing rain gage: $0 \quad(0)$

-- With chemical samples: 37 (259)
Latitude: $\quad 35^{\circ} 41^{\prime} 48^{\prime \prime}$ Longitude: $80^{\circ} 37^{\prime} 22^{\prime \prime}$

Station summary period: $12 / 28 / 1982$ to $01 / 03 / 1984$

Length of summary period: 53 sampling intervals (371 days)

$\begin{array}{ll}\text { Percent summary period with ppt measurements : } & 100.0\end{array}$

Percent summary period with chemical samples or no ppt: 77.4

Percent of total measured ppt with chemical samples: 76.3

Percent of total measured ppt in raingage that was

collected in the wet-sample bucket:

96.3

Total measured ppt, in $\mathrm{mm}: 1116,1$

\begin{tabular}{|c|c|c|c|c|c|c|c|c|c|c|c|c|}
\hline $\begin{array}{l}\text { Statistical } \\
\text { measures }\end{array}$ & $\begin{array}{c}\text { Mea- } \\
\text { sured } \\
\text { ppt, } \\
\text { mm }\end{array}$ & $\begin{array}{l}\text { Lab } \\
\text { specific } \\
\text { conduc- } \\
\text { tance, } \\
\mu \mathrm{S} / \mathrm{cm}\end{array}$ & $\begin{array}{r}\text { Lab } \\
\text { pH }\end{array}$ & $\begin{array}{c}\text { Calcium } \\
\text { as } \mathrm{Ca}, \\
\mathrm{mg} / \mathrm{L}\end{array}$ & $\begin{array}{l}\text { Magne- } \\
\text { sium } \\
\text { as } \mathrm{Mg}_{\mathrm{B}} \\
\mathrm{mg} / \mathrm{L}\end{array}$ & $\begin{array}{l}\text { Sodium } \\
\text { as } \mathrm{Na} \text {, } \\
\mathrm{mg} / \mathrm{L}\end{array}$ & $\begin{array}{l}\text { Potas- } \\
\text { sium } \\
\text { as K, } \\
\mathrm{mg} / \mathrm{L}\end{array}$ & $\begin{array}{l}\text { Ammonia } \\
\text { as } \mathrm{NH}_{4} \text {, }\end{array}$ & $\begin{array}{c}\text { Chlor- } \\
\text { ide } \\
\text { as } \mathrm{Cl} \text {, } \\
\mathrm{mg} / \mathrm{L}\end{array}$ & $\begin{array}{l}\text { Nitrite } \\
\text { plus } \\
\text { nitrate } \\
\text { as } \mathrm{NO}_{3^{\prime}} \\
\mathrm{mg} / \mathrm{L}\end{array}$ & $\begin{array}{l}\text { Sulfate } \\
\text { as } \mathrm{SO}^{\text {. }} \\
\mathrm{mg} / \mathrm{L}^{\prime}\end{array}$ & $\begin{array}{l}\text { Hydrogen } \\
\text { ion } \\
\text { as } \mathrm{H}, \\
\mathrm{mg} / \mathrm{L}\end{array}$ \\
\hline Minimum value & 0.00 & 4.9 & 3.67 & 0.01 & 0.008 & 0.023 & 0.004 & 0.01 & 0.04 & 0.33 & 0.57 & 1. $35 \mathrm{E}-03$ \\
\hline 10 percentile & .04 & 11.6 & 3.92 & .04 & .012 & .041 & .010 & .05 & .09 & .48 & .90 & $1.51 E-02$ \\
\hline 25 percentile & 3.20 & 13.3 & 4.21 & .07 & .024 & .069 & .023 & .11 & .16 & .84 & 1.23 & $2.16 \mathrm{E}-02$ \\
\hline 50 percentile & 16.00 & 19.9 & 4.51 & .13 & .040 & .169 & .040 & .24 & .26 & 1.17 & 1.86 & $3.09 E-02$ \\
\hline 75 percentile & 34.90 & 33.7 & 4.66 & .19 & .068 & .289 & .060 & .44 & .48 & 2.20 & 3.17 & $6.11 E-02$ \\
\hline 90 percentile & 51.38 & 63.7 & 4.84 & .41 & .101 & .633 & .103 & .71 & .99 & 3.41 & 7.42 & $1.23 \mathrm{E}-01$ \\
\hline Maximum vslue & 67.60 & 98.4 & 5.87 & .56 & .103 & 1.420 & .176 & 1.39 & 1.46 & 4.28 & 11.55 & $2.14 E-01$ \\
\hline Volume-weighted mean & NA & 21.6 & 4.42 & .10 & .043 & .234 & .041 & .23 & .42 & 1.12 & 1.99 & $3.79 E-02$ \\
\hline Arithmetic mean & 21.06 & 28.7 & 4.48 & .16 & .048 & .247 & .049 & .31 & .37 & 1.58 & 2.78 & 5. $13 E-02$ \\
\hline No. of samples & 53 & 37 & 37 & 37 & 37 & 37 & 37 & 37 & 37 & 37 & 37 & 37 \\
\hline $\begin{array}{l}\text { Total load, } 8 / \mathrm{m} 2 \\
\text { Maximum interval }\end{array}$ & NA & NA & NA & 0.089 & 0.036 & 0.199 & 0.035 & 0.197 & 0.355 & 0.950 & 1.695 & $3.2 \mathrm{E}-02$ \\
\hline $\begin{array}{l}\text { load, } 8 / \mathrm{m} 2 \\
\text { Correlation with ppt } \\
\text { Kendall tau }\end{array}$ & $\begin{array}{c}\text { NA } \\
\text { volume: }\end{array}$ & $\begin{array}{l}\text { NA } \\
\text { Cond } \\
-0.29\end{array}$ & $\begin{array}{c}\mathrm{NA} \\
\mathrm{pH} \\
0.18\end{array}$ & $\begin{array}{l}.008 \\
\mathrm{Ca} \\
-.51\end{array}$ & $\begin{array}{l}.005 \\
\mathrm{Mg} \\
-.28\end{array}$ & $\begin{array}{l}.041 \\
\mathrm{Na} \\
-.12\end{array}$ & $\begin{array}{l}.006 \\
K \\
-.28\end{array}$ & $\begin{array}{l}.024 \\
\mathrm{NH}^{4} \\
-.23\end{array}$ & $\begin{array}{l}.073 \\
.11 \\
-.08\end{array}$ & $\begin{array}{l}.069 \\
\mathrm{NO}_{3} \\
-.37\end{array}$ & $\begin{array}{l}0.169 \\
\mathrm{so}^{4} \\
-.25\end{array}$ & $\begin{array}{c}3.1 \mathrm{E}-03 \\
\mathrm{H} \\
-0.18\end{array}$ \\
\hline P-level & & .013 & .126 & .000 & .016 & .283 & .016 & .045 & .504 & .001 & .030 & .126 \\
\hline
\end{tabular}

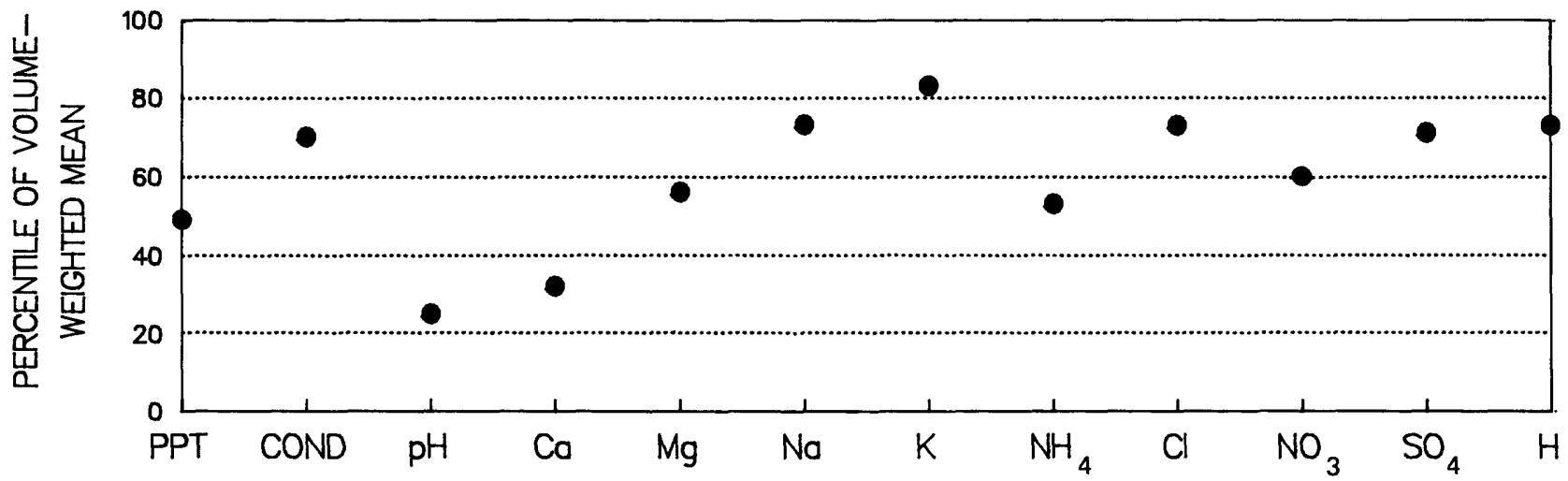

Percentiles of volume-weighted mean concentrations for site NC34, based on frequency distributions of data from 55 National Trends Network sites. 

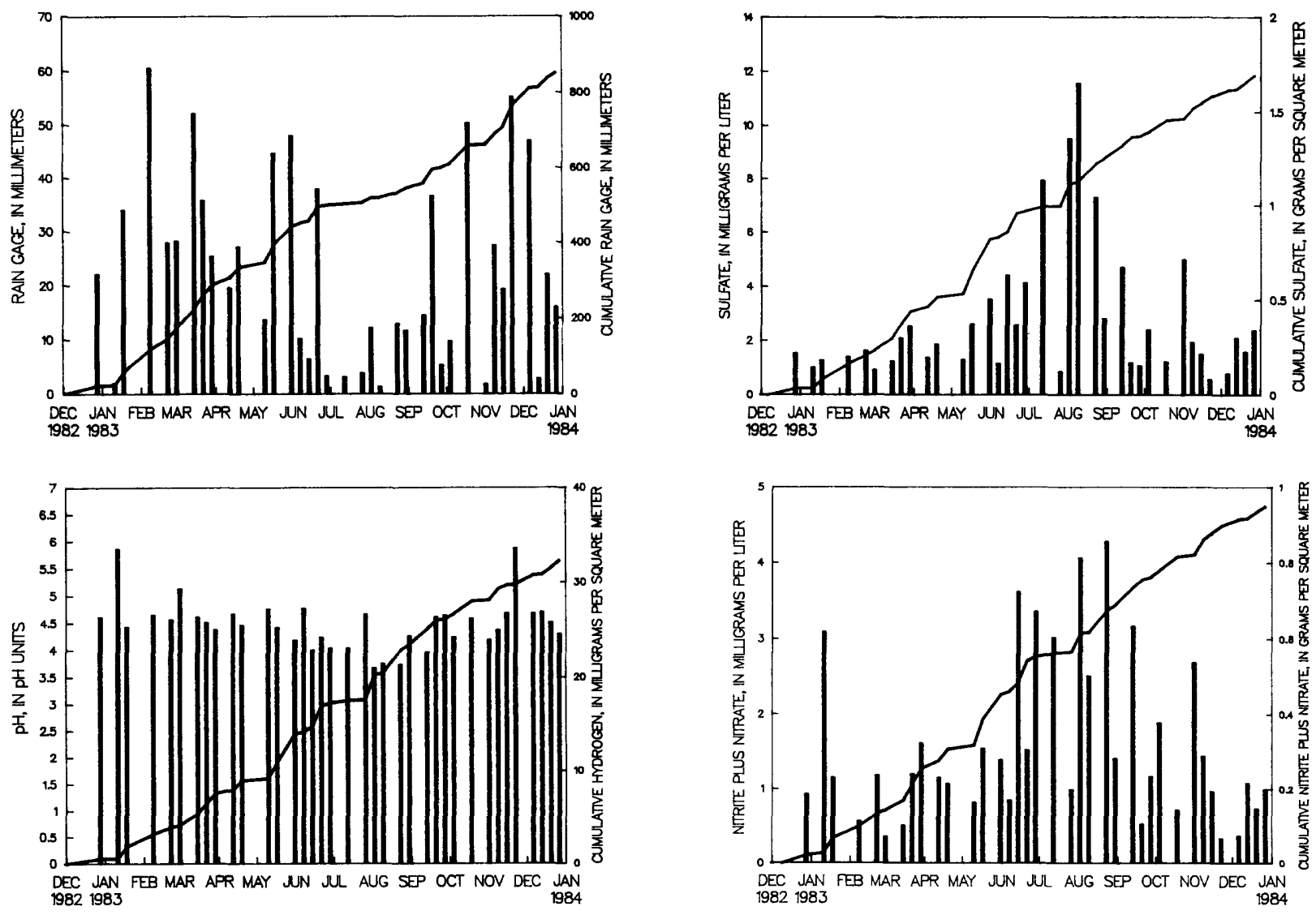

Bar plots of concentrations and cumulative line plots of loads for site NC34.

Nitrite plus nitrate are reported as $\mathrm{NO}_{3}$ and sulfate as $\mathrm{SO}_{4}$.

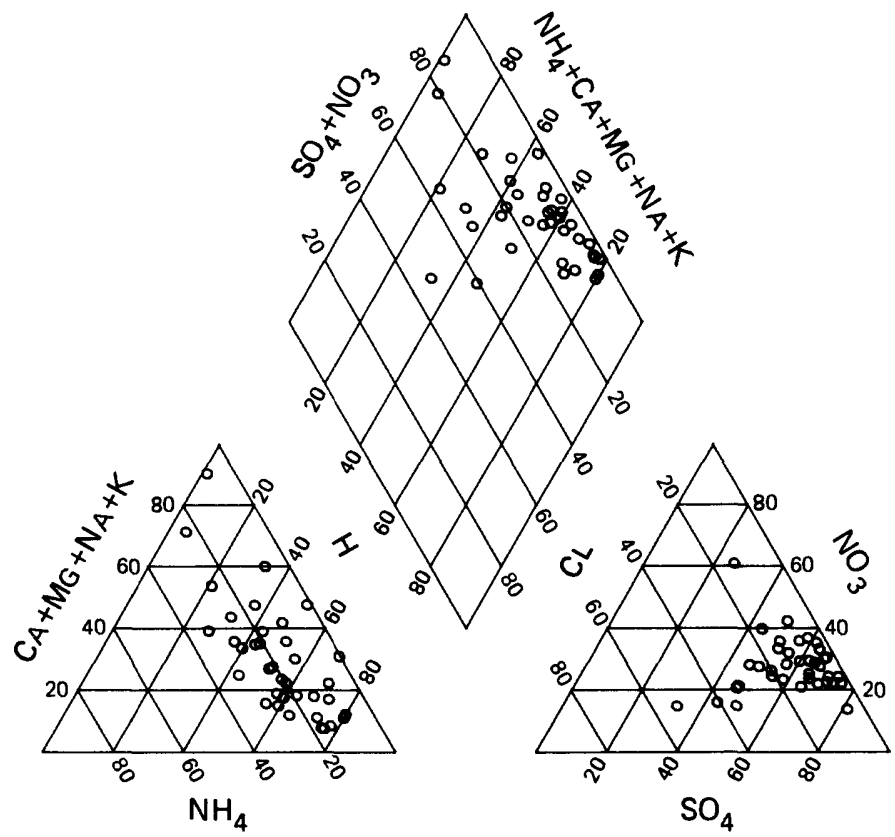

Percentage composition of major ions for site NC34. 


\section{NATIONAL TRENDS NETWORK - 1983 CALENDER YEAR SUMMARY DATA}

lppt $=$ precipitation; $\mathrm{mm}=$ millimeters; $\mathrm{cm}=$ centimeters; $\mathrm{mg}=$ milligrams; L = 1iters; $\mathrm{g}=$ grams; $\mathrm{m}=$ meter; $\mu \mathrm{s}=$ microsiemens; cond = specific conductance $]$

STATION: Clinton Station, North Carolina

CAL number: NC35

ADS number: $052 \mathrm{a00}$

Station eltitude above mean sea level, in meters: 47

Number of sampling intervals (days in parenthesis):

-- With ppt measurements: 52

-- When ppt occurred: 48 (336)

-- When ppt did not occur: 4 (28)

-- When sample volume was substituted for missing rain gage: 0 ( 0$)$

-- With chemical samples: 37
Letitude: $35^{\circ} 01^{\prime} 26^{\prime \prime}$ Longitude: $78^{\circ} 16^{\prime} 45^{\prime \prime}$

Station summary period: $12 / 28 / 1982$ to $01 / 03 / 1984$

Length of summary period: 53 sampling intervals ( 371 days)

Percent sumary period with ppt measurements: 98.1

Percent sumary period with chemical samples or no ppt: 77.4

Percent of total measured ppt with chemical samples: $\quad 88.4$

Percent of total measured ppt in raingage that was

collected in the wet-sample bucket:

97.6

Total measured ppt, in $\mathrm{mm}: 1316.2$

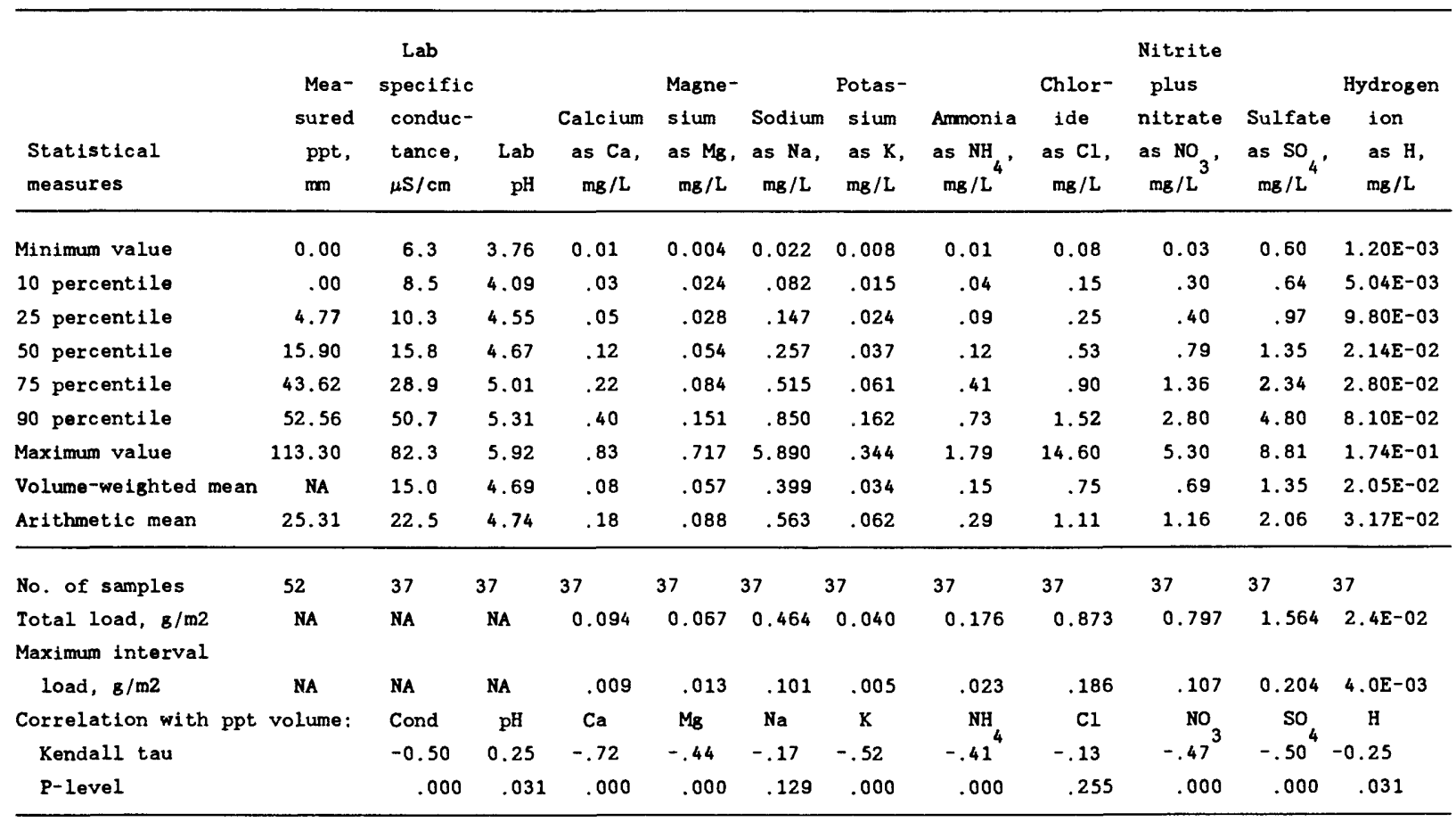

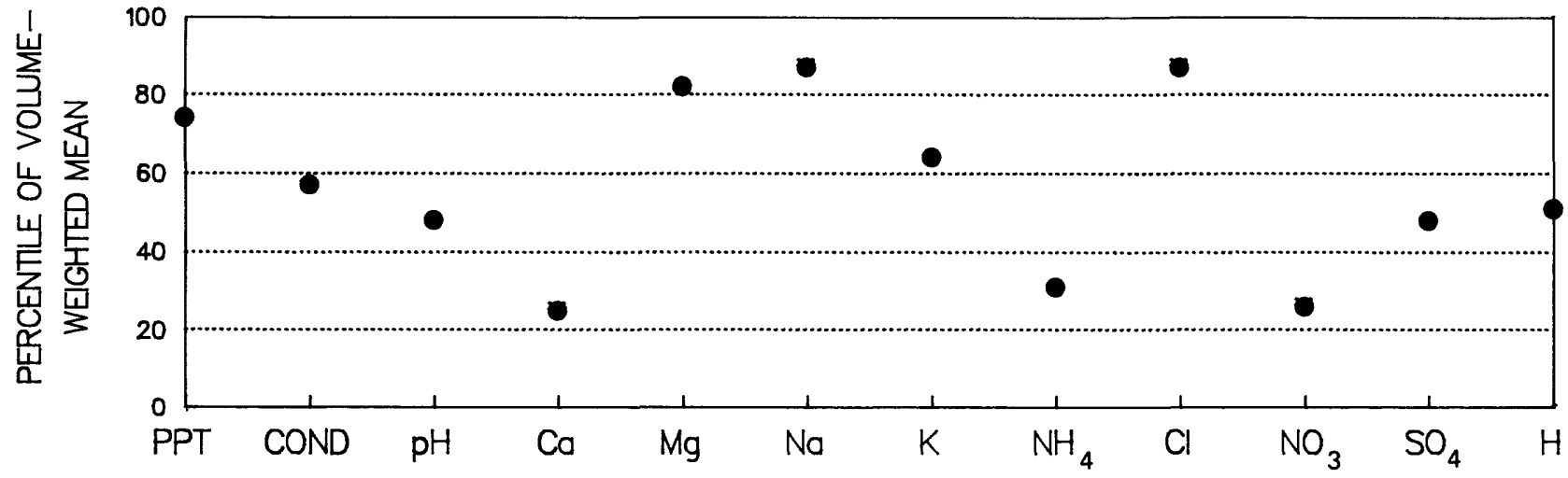

Percentiles of volume-weighted mean concentrations for site NC35, based on frequency distributions of data from 55 National Trends Network sites. 

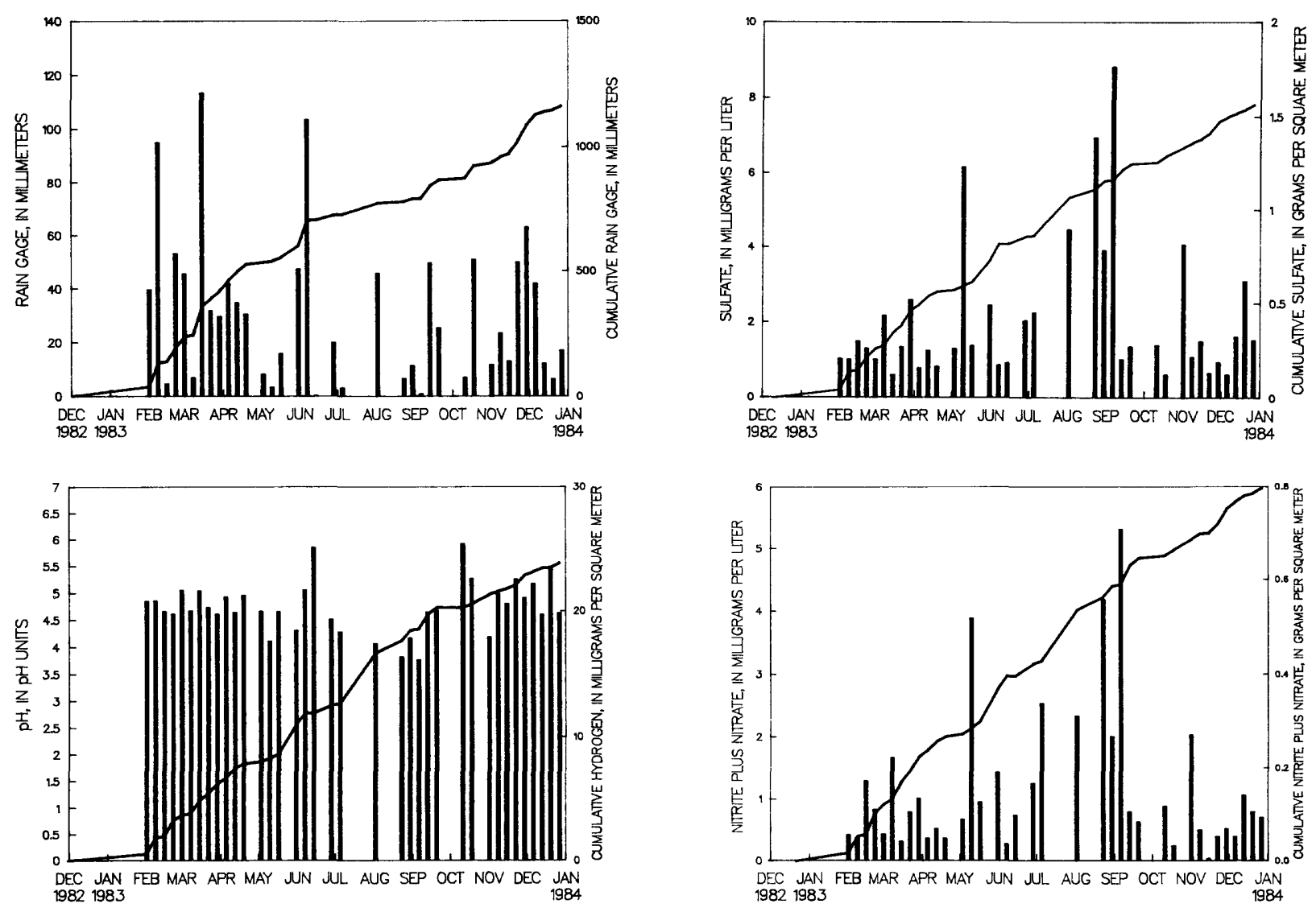

Bar plots of concentrations and cumulative line plots of loads for site NC35.

Nitrite plus nitrate are reported as $\mathrm{NO}_{3}$ and sulfate as $\mathrm{SO}_{4}$.

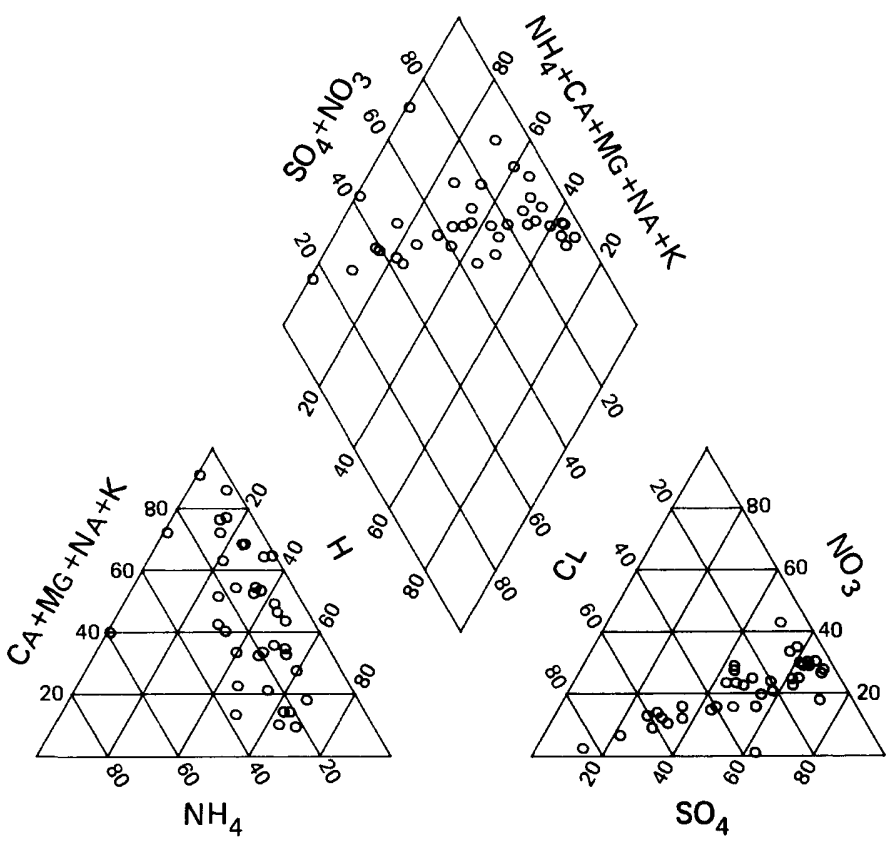

Percentage composition of major ions for site NC35. 


\section{NATIONAL TRENDS NETWORK - 1983 CALENDER YEAR SUMMARY DATA}

[ppt = precipitation; $\mathrm{mm}=$ millimeters; $\mathrm{cm}=$ centimeters; $\mathrm{mg}=$ milligrams; $\mathrm{L}=11$ ters;

$\mathrm{g}=\mathrm{grams} ; \mathrm{m}=$ meter; $\mu \mathrm{s}=$ microsiemens; cond = specific conductance $]$

STATION: Finley (A), North Carolina

Latitude: $35^{\circ} 43^{\prime} 43^{\prime \prime}$ Longitude: $78^{\circ} 40^{\prime} 52^{\prime \prime}$

(composite data from sites $053 \mathrm{aO2}$ and $053 \mathrm{a} 03$ )

CAL number: NC41 Map ID number: 60

ADS number: 053a

Station altitude above mean sea level, in meters: 119

Number of sampling intervals (days in parenthesis):

-- With ppt measurements: 53 (378)

-- When ppt occurred: 50 (357)

-- When ppt did not occur: $3 \quad$ (21)

- When sample volume was substituted for missing rain gage: 0 ( 0 )

-- With chemical samples: $38 \quad$ (273)

Station summary period: $12 / 21 / 1982$ to $01 / 03 / 1984$

Length of sumnary period: 53 sampling intervals (378 days)

Percent summary period with ppt measurements: 101.9

Percent summary period with chemical samples or no ppt: 79.2

Percent of total measured ppt with chemical samples: 66.1

Percent of total measured ppt in raingage that was

collected in the wet-sample bucket:

93.1

Total measured ppt, in m: 1230.4

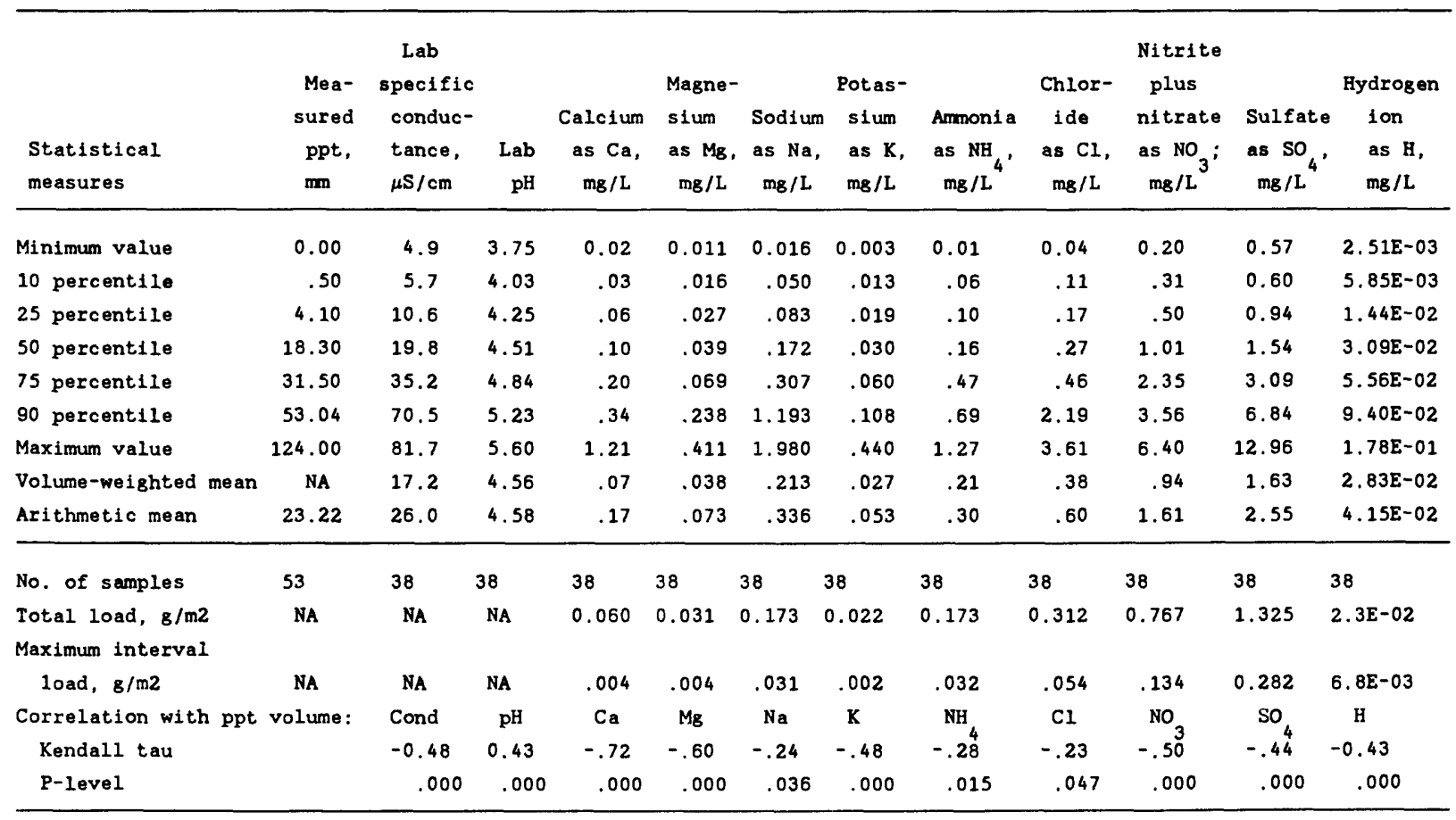

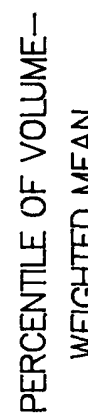

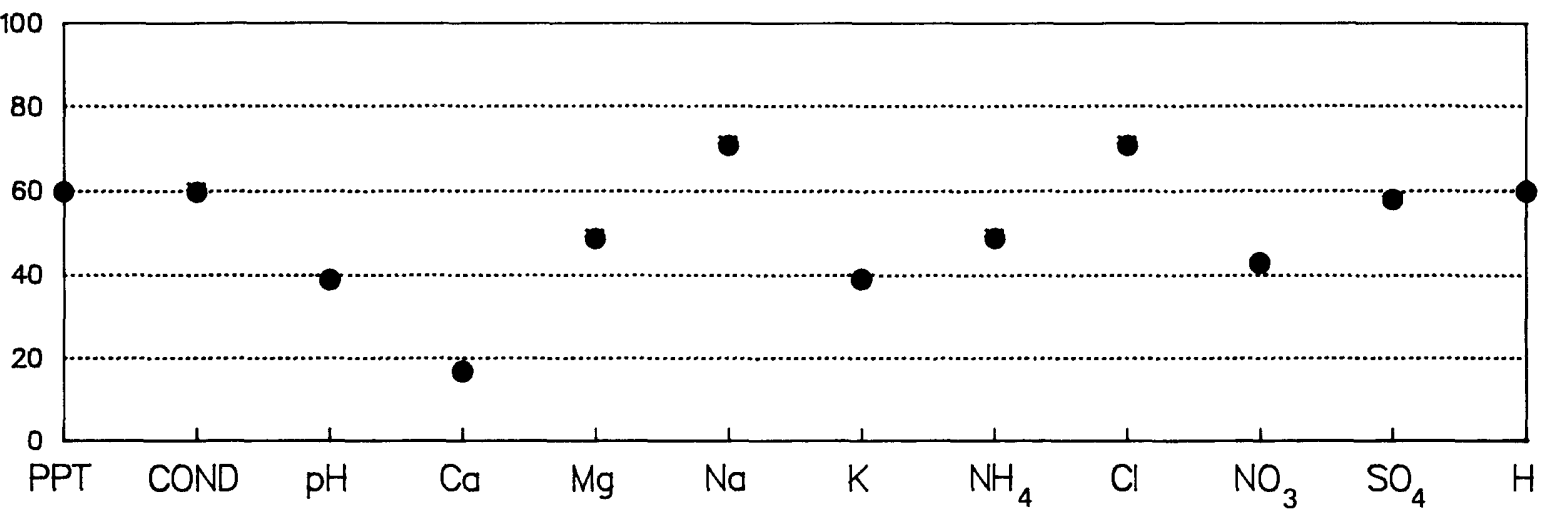

Percentiles of volume-weighted mean concentrations for site NC41, based on frequency distributions of data from 55 National Trends Network sites. 

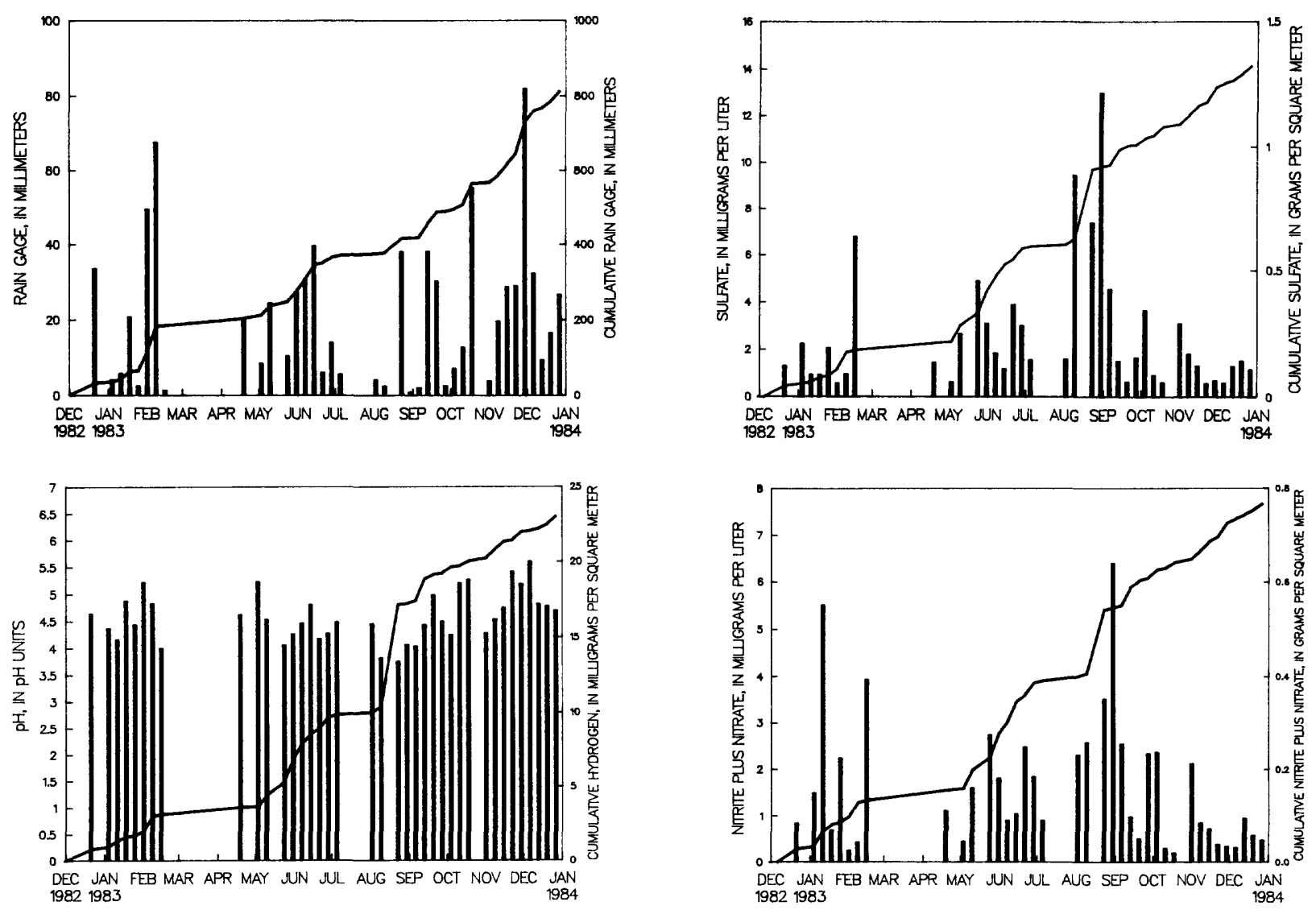

Bar plots of concentrations and cumulative line plots of loads for site NC41.

Nitrite plus nitrate are reported as $\mathrm{NO}_{3}$ and sulfate as $\mathrm{SO}_{4}$.

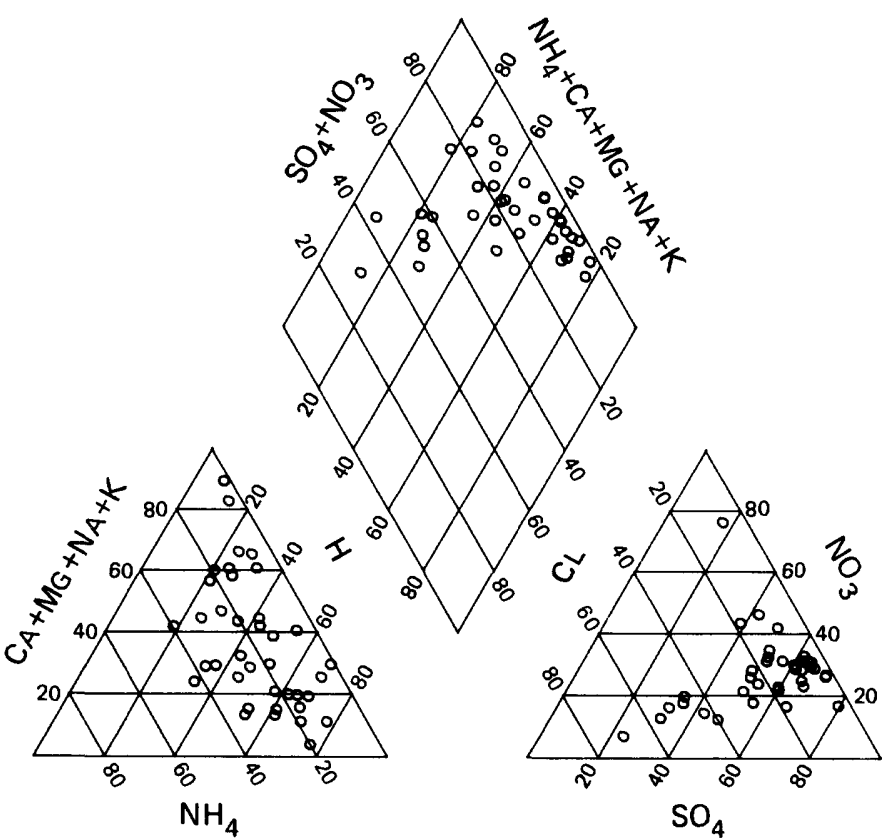

Percentage composition of major ions for site NC41. 


\section{NATIONAL TRENDS NETWORK -- 1983 CALENDER YEAR SUMMARY DATA}

[ppt $=$ precipitation; $\mathrm{mm}=$ millimeters; $\mathrm{cm}=$ centimeters; $\mathrm{mg}=$ milligrams; $\mathrm{L}=1 \mathrm{iters}$;

$\mathrm{g}=\mathrm{grams} ; \mathrm{m}=$ meter $\boldsymbol{\mu s}=\mathrm{microsiemens} ;$ cond = specific conductance $]$

STATION: Teddy Roosevelt NP, North Dakota

Latitude: $47^{\circ} 36^{\prime} 09^{\prime \prime}$ Longitude: $103^{\circ} 15^{\prime} 54^{\prime \prime}$

(composite data from $062 \mathrm{a} 00$ and $062 \mathrm{a} 01$ )

CAL number: NDO7

Map ID number: 61

ADS number: 062a

Station summary period: $12 / 21 / 1982$ to $01 / 03 / 1984$

Station altitude above mean sea level, in meters: 618

Number of sampling intervals (days in parenthesis):

-- With ppt measurements: $\quad 50 \quad$ (371)

-- When ppt occurred: $47 \quad$ (350)

-- When ppt did not occur: 3 ( 21)

-- When sample volume was substi-

tuted for missing rain gage: 5 ( 34 )

-- With chemical samples: $30 \quad$ (225)

Length of sumary period: 51 sampling intervals (378 days)

Percent sumary period with ppt measurements: $\quad 100.0$

Percent sumary period with chemical samples or no ppt: 66.3

Percent of total measured ppt with chemical samples: 85.3

Percent of total measured ppt in raingage that was

collected in the wet-sample bucket:

95.6

Total measured ppt, in m: 263.3

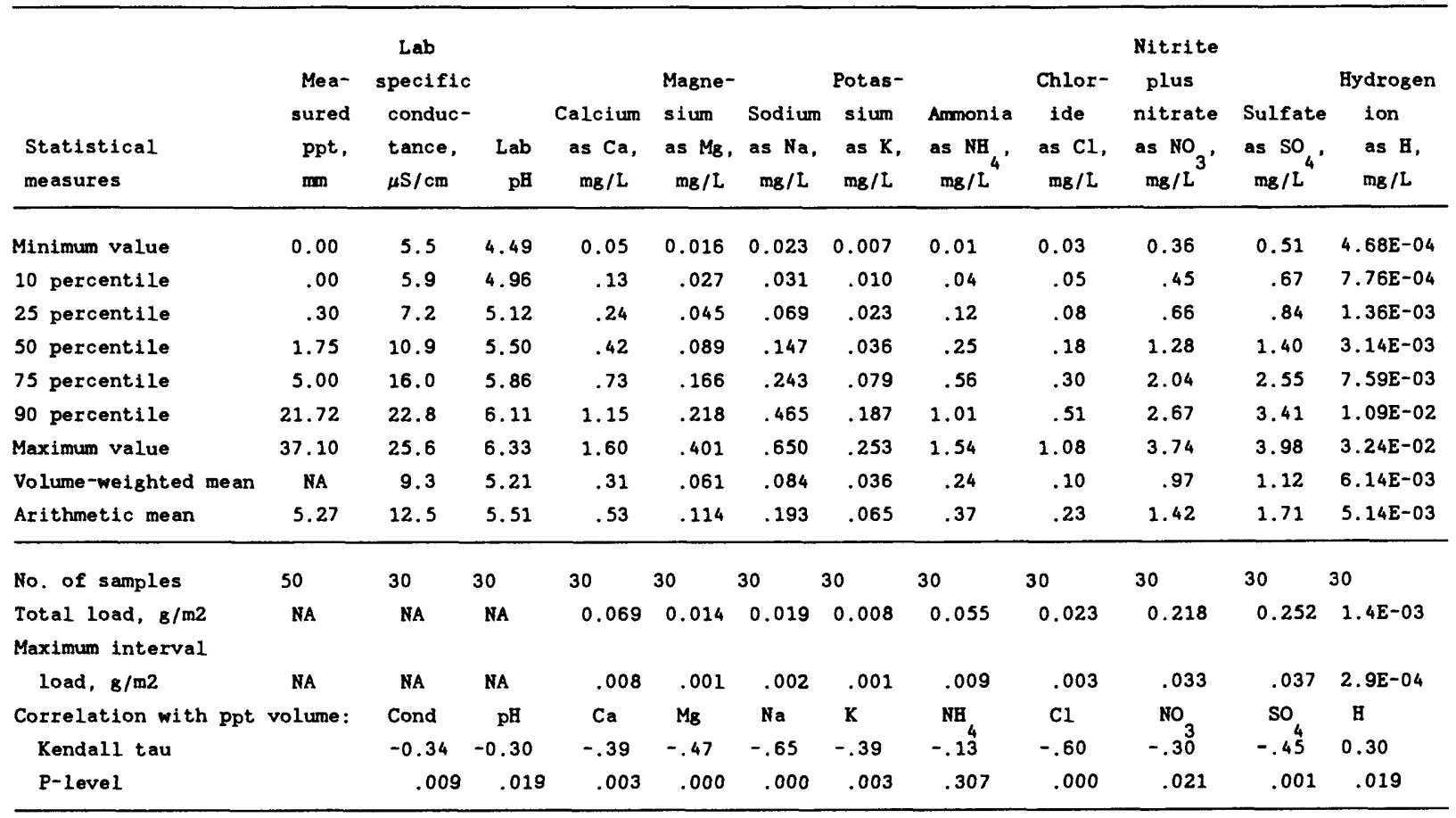

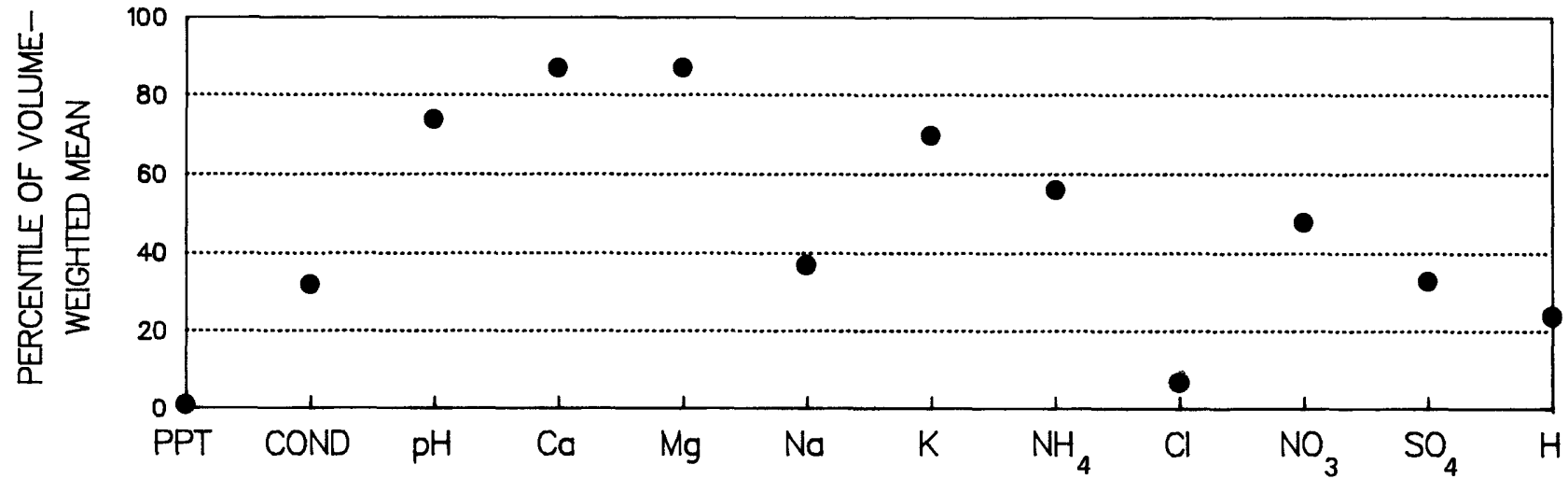

Percentiles of volume-weighted mean concentrations for site ND07, based on

frequency distributions of data from 55 National Trends Network sites. 

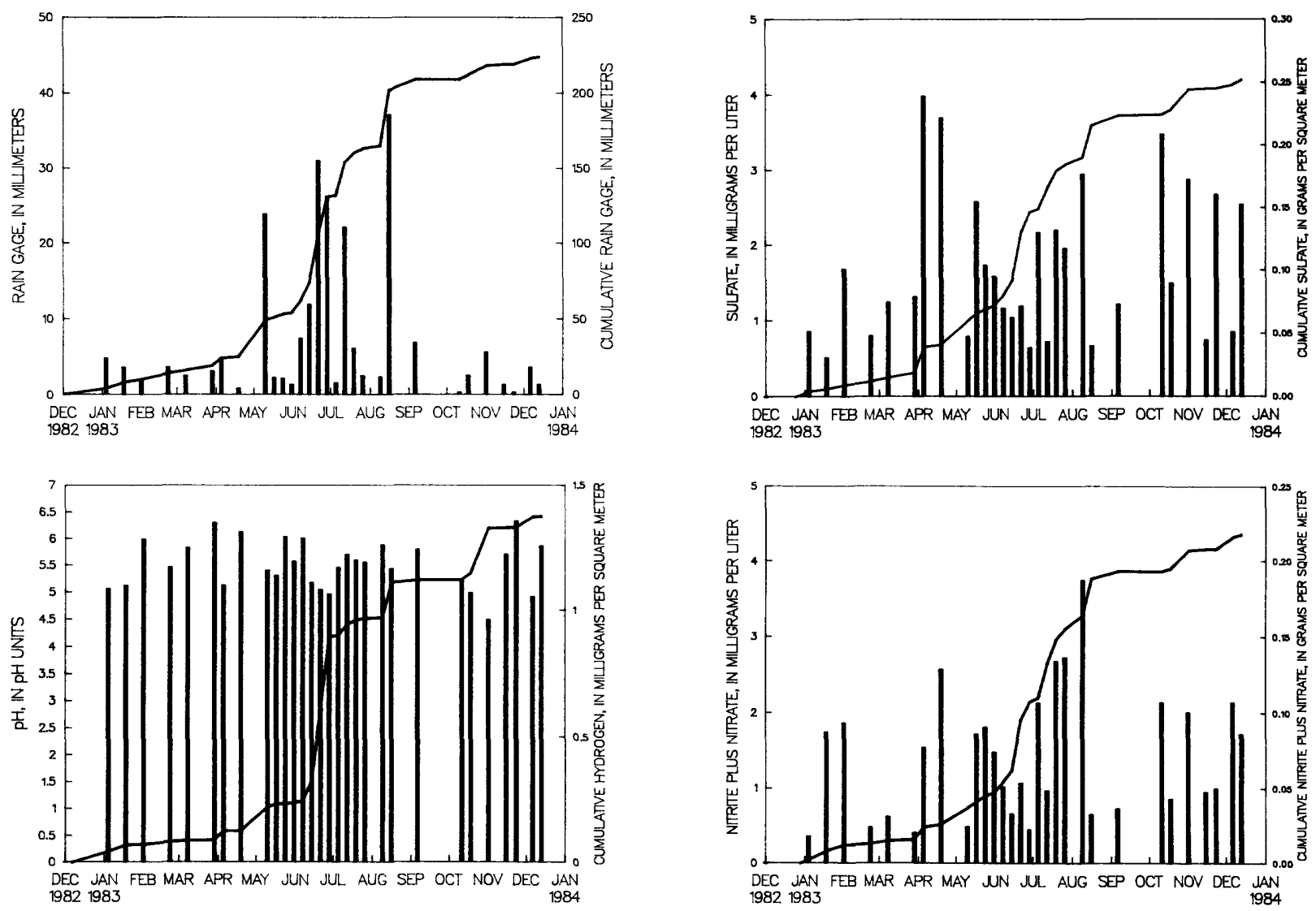

Bar plots of concentrations and cumulative line plots of loads for site ND07. Nitrite plus nitrate are reported as $\mathrm{NO}_{3}$ and sulfate as $\mathrm{SO}_{4}$.

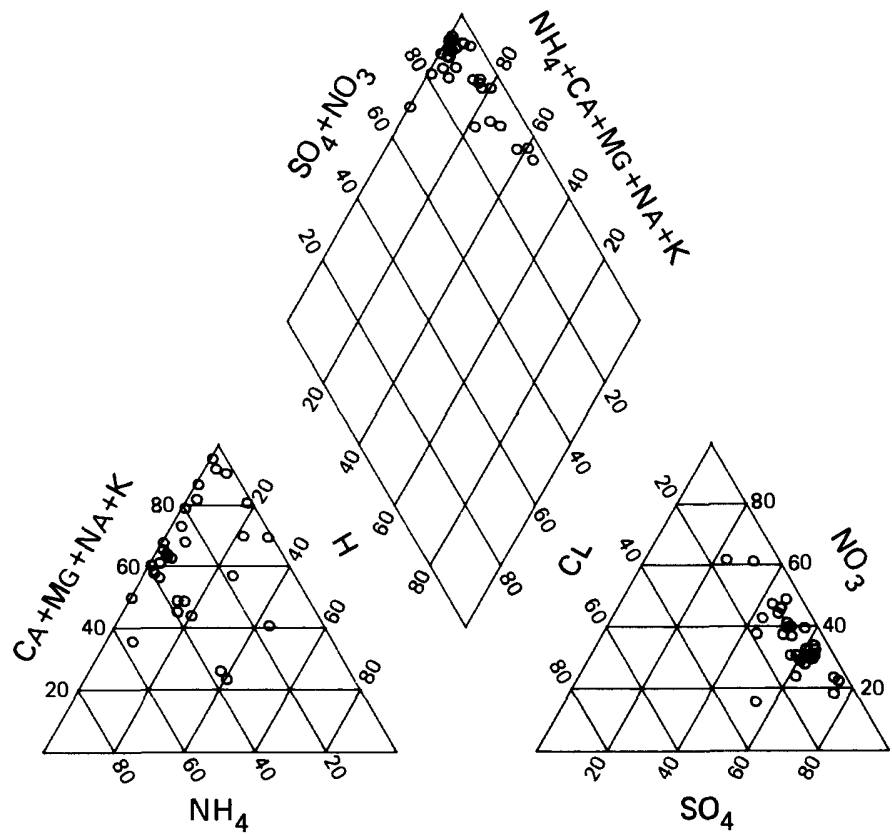

Percentage composition of major ions for site ND07. 


\section{NATIONAL TRENDS NETWORK -- 1983 CALENDER YEAR SUMMARY DATA}

[ppt = precipitation; $\mathrm{mm}=$ millimeters; $\mathrm{cm}=$ centimeters; $\mathrm{mg}=$ milligrams; L = 1iters;

$g$ = grams; $m=$ meter; $\mu s=$ microsiemens; cond = specific conductance

Latitude: $41^{\circ} 09^{\prime} 11^{\prime \prime}$ Longitude: $96^{\circ} 29^{\prime} 34^{\prime \prime}$

CAL number: NE15

Map ID number: 64

ADS number: $038 \mathrm{a}$

Station summary period: $12 / 29 / 1982$ to $01 / 03 / 1984$

Station altitude above mean sea level, in meters: 352

Length of summary period: 53 sampling intervals ( 370 days)

Number of sampling intervals (days in parenthesis):

-- With ppt measurements: $53 \quad$ (370)

-- When ppt occurred: $46 \quad$ (322)

-- When ppt did not occur: 7 (48)

-- When sample volume was substi-

(48) Percent of total measured ppt in raingage that was

collected in the wet-s ample bucket:

99.7

Percent summary period with chemical samples or no ppt: 79.0

Percent of total measured ppt with valid samples: 91.3

98.7

-- With chemical samples: 35 (245) Total measured ppt, in m: 660.9

\begin{tabular}{|c|c|c|c|c|c|c|c|c|c|c|c|c|}
\hline $\begin{array}{l}\text { Statistical } \\
\text { measures }\end{array}$ & $\begin{array}{l}\text { Mea- } \\
\text { sured } \\
\text { ppt, } \\
\text { mm }\end{array}$ & $\begin{array}{l}\text { Lab } \\
\text { specific } \\
\text { conduc- } \\
\text { tance, } \\
\mu \mathrm{S} / \mathrm{cm}\end{array}$ & $\begin{array}{r}\text { Lab } \\
\mathbf{p H}\end{array}$ & $\begin{array}{c}\text { Calcium } \\
\text { as } \mathrm{Ca}, \\
\mathrm{mg} / \mathrm{L}\end{array}$ & $\begin{array}{l}\text { Magne- } \\
\text { sium } \\
\text { as Ms, } \\
\mathrm{mg} / \mathrm{L}\end{array}$ & $\begin{array}{l}\text { Sodium } \\
\text { as } \mathrm{Na} \text {, } \\
\mathrm{mg} / \mathrm{L}\end{array}$ & $\begin{array}{l}\text { Potas- } \\
\text { sium } \\
\text { as } K \text {, } \\
\text { mB/L }\end{array}$ & $\begin{array}{l}\text { Ammonia } \\
\text { as } \mathrm{NH} \\
\mathrm{mg} / \mathrm{L}^{\circ}\end{array}$ & $\begin{array}{l}\text { Chlor- } \\
\text { ide } \\
\text { as } \mathrm{Cl} \text {, } \\
\mathrm{mg} / \mathrm{L}\end{array}$ & $\begin{array}{l}\text { Nitrite } \\
\text { plus } \\
\text { nitrate } \\
\text { as } \mathrm{NO}_{3} \text { ' } \\
\mathrm{mg} / \mathrm{L}\end{array}$ & $\begin{array}{l}\text { Sulfate } \\
\text { as } \mathrm{SO}_{4} \text {, } \\
\mathrm{mg} / \mathrm{L}^{\prime}\end{array}$ & $\begin{array}{l}\text { Hydrogen } \\
\text { Ion } \\
\text { as H, } \\
\text { mg / L }\end{array}$ \\
\hline Minimum value & 0.00 & 6.8 & 3.73 & 0.05 & 0.008 & 0.011 & 0.007 & 0.01 & 0.04 & 0.69 & 0.47 & $2.69 E-04$ \\
\hline 10 percentile & 0.00 & 7.9 & 4.44 & .07 & .011 & .025 & .013 & .17 & .07 & .88 & .59 & $4.71 E-04$ \\
\hline 25 percentile & 0.30 & 9.6 & 4.82 & .21 & .027 & .043 & .024 & .42 & .09 & 1.02 & 1.02 & $1.07 \mathrm{E}-03$ \\
\hline 50 percentile & 5.10 & 14.9 & 5.47 & .42 & .046 & .097 & .050 & .79 & .13 & 1.58 & 1.65 & $3.39 \mathrm{E}-03$ \\
\hline 75 percentile & 24.75 & 28.9 & 5.97 & .75 & .097 & .217 & .117 & 1.29 & .28 & 2.56 & 3.46 & $1.51 E-02$ \\
\hline 90 percentile & 33.98 & 43.5 & 6.33 & 1.87 & .191 & .365 & .179 & 2.08 & .47 & 4.82 & 4.75 & $3.65 \mathrm{E}-02$ \\
\hline Maximum value & 66.00 & 88.8 & 6.57 & 3.18 & .345 & .508 & .372 & 5.23 & .77 & 5.91 & 9.67 & $1.86 \mathrm{E}-01$ \\
\hline Volume-weighted mean & NA & 14.5 & 5.01 & .39 & .047 & .102 & .042 & .65 & .15 & 1.38 & 1.71 & $9.80 \mathrm{E}-03$ \\
\hline No. of samples & 53 & 35 & 35 & 35 & 35 & 35 & 35 & 35 & 35 & 35 & 35 & 35 \\
\hline $\begin{array}{l}\text { Total load, } 8 / \mathrm{m} 2 \\
\text { Maximum interval }\end{array}$ & NA & NA & NA & 0.238 & 0.028 & 0.061 & 0.025 & 0.394 & 0.090 & 0.830 & 1.032 & $5.9 E-03$ \\
\hline load, $8 / \mathrm{m} 2$ & NA & NA & NA & .036 & .007 & .020 & .003 & .056 & .021 & .099 & 0.193 & 1. $5 \mathrm{E}-03$ \\
\hline $\begin{array}{l}\text { Correlation with ppt } \\
\text { Kendall tau }\end{array}$ & volume: & $\begin{array}{l}\text { Cond } \\
-0.44\end{array}$ & $\begin{array}{c}\mathrm{pH} \\
-0.06\end{array}$ & $\begin{array}{r}\mathrm{Ca} \\
-.34\end{array}$ & $\begin{array}{r}M g \\
-.39\end{array}$ & $\begin{array}{r}\mathrm{Na} \\
-.43\end{array}$ & $\begin{array}{c}K \\
-.45\end{array}$ & $\begin{array}{r}\mathrm{NH}^{4} \\
-.42^{4}\end{array}$ & $\begin{array}{r}C 1 \\
-.46\end{array}$ & $\begin{array}{r}\mathrm{NO}_{3} \\
-.49\end{array}$ & $\begin{array}{l}\mathrm{SO}^{4} \\
-.25\end{array}$ & $\begin{array}{c}\mathrm{H} \\
0.06\end{array}$ \\
\hline P-level & & .000 & .588 & .005 & .001 & .000 & .000 & .000 & .000 & .000 & .035 & .588 \\
\hline
\end{tabular}

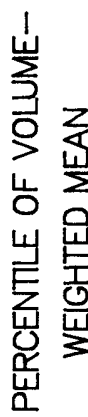

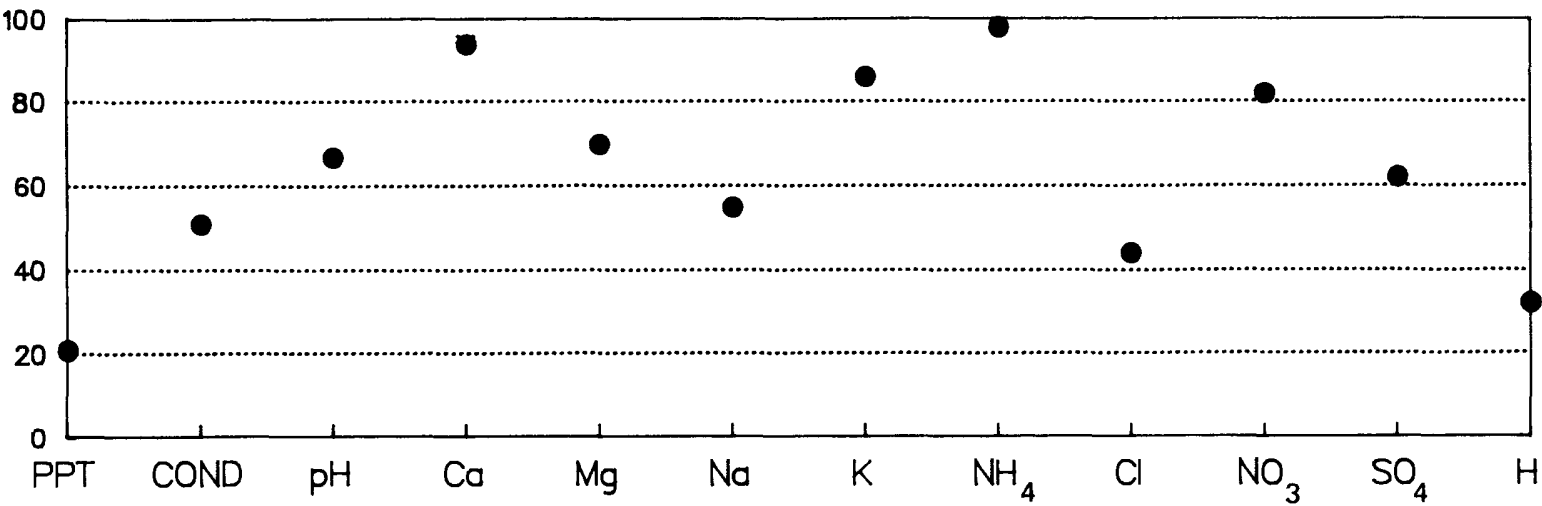

Percentiles of volume-weighted mean concentrations for site NE15, based on frequency distributions of data from 55 National Trends Network sites. 

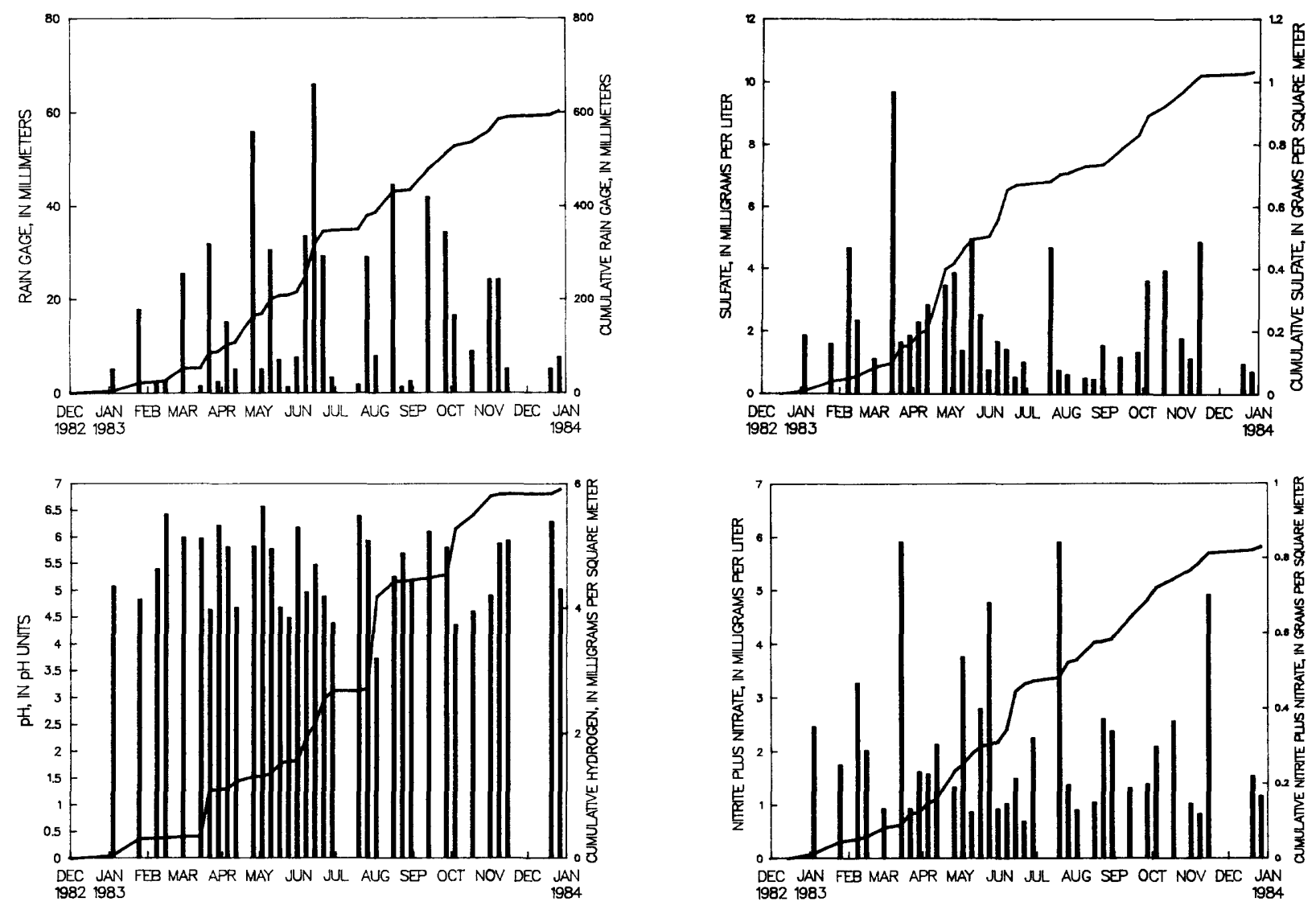

Bar plots of concentrations and cumulative line plots of loads for site NE15.

Nitrite plus nitrate are reported as $\mathrm{NO}_{3}$ and sulfate as $\mathrm{SO}_{4}$.

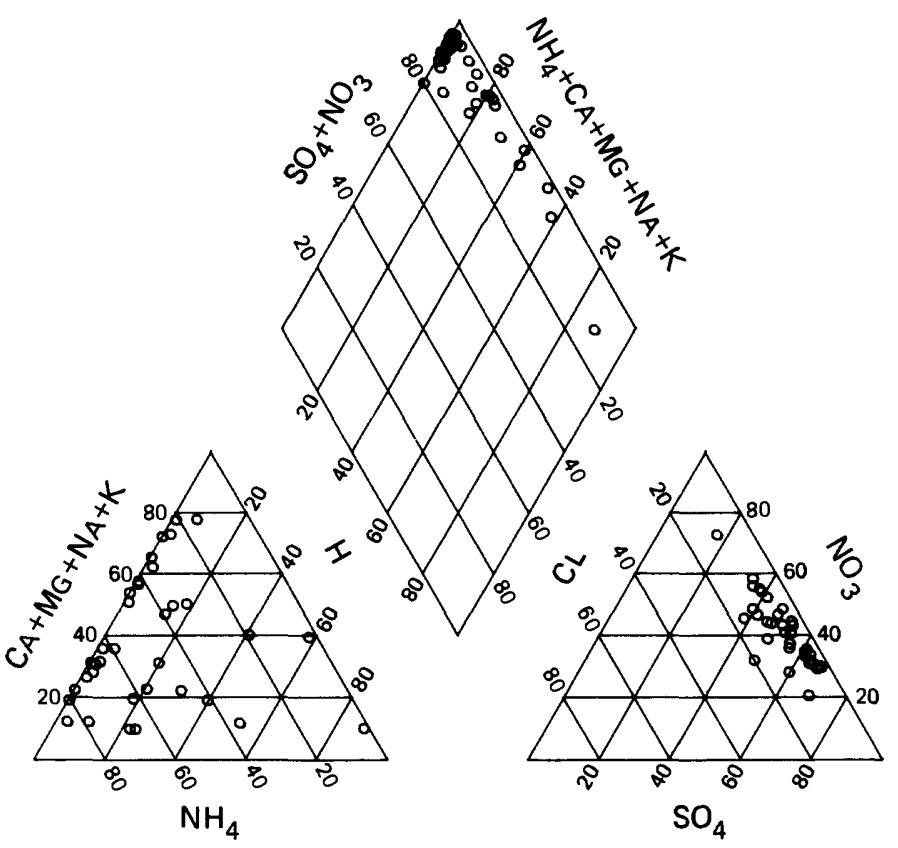

Percentage composition of major ions for site NE15. 


\section{NATIONAL TRENDS NETWORK -- 1983 CALENDER YEAR SUMMARY DATA}

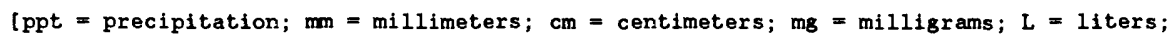

$\mathrm{g}=\mathrm{grams} ; \mathrm{m}=$ meter $\boldsymbol{\mu s}=$ microsiemens; cond = specific conductance $]$

STATION: Hubbard Brook, New Hampshire

Latitude: $43^{\circ} 56^{\prime} 35^{\prime \prime}$ Longitude: $\quad 71^{\circ} 42^{\prime} 12^{\prime \prime}$

CAL number: NHO2 Map ID number: 65

ADS number: $039 \mathrm{a} 00$

Station altitude above mean sea level, in meters: 250

Number of sampling intervals (days in parenthesis):

-- With ppt measurements: 53 (371)

-- When ppt occurred: $52 \quad$ (364)

-- When ppt did not occur: 1 ( 7)

-- When sample volume was substituted for missing rain gage: 0 ( 0$)$

-- With chemical samples: $36 \quad$ (252)
Station summary period: $12 / 28 / 1982$ to $01 / 03 / 1984$

Length of sumary period: 53 sampling intervals ( 371 days)

Percent summary period with ppt measurements: $\quad 100.0$

Percent sumary period with chemical samples or no ppt: 69.8

Percent of total measured ppt with chemical samples: 65.5

Percent of total measured ppt in raingage that was

collected in the wet-sample bucket:

97.1

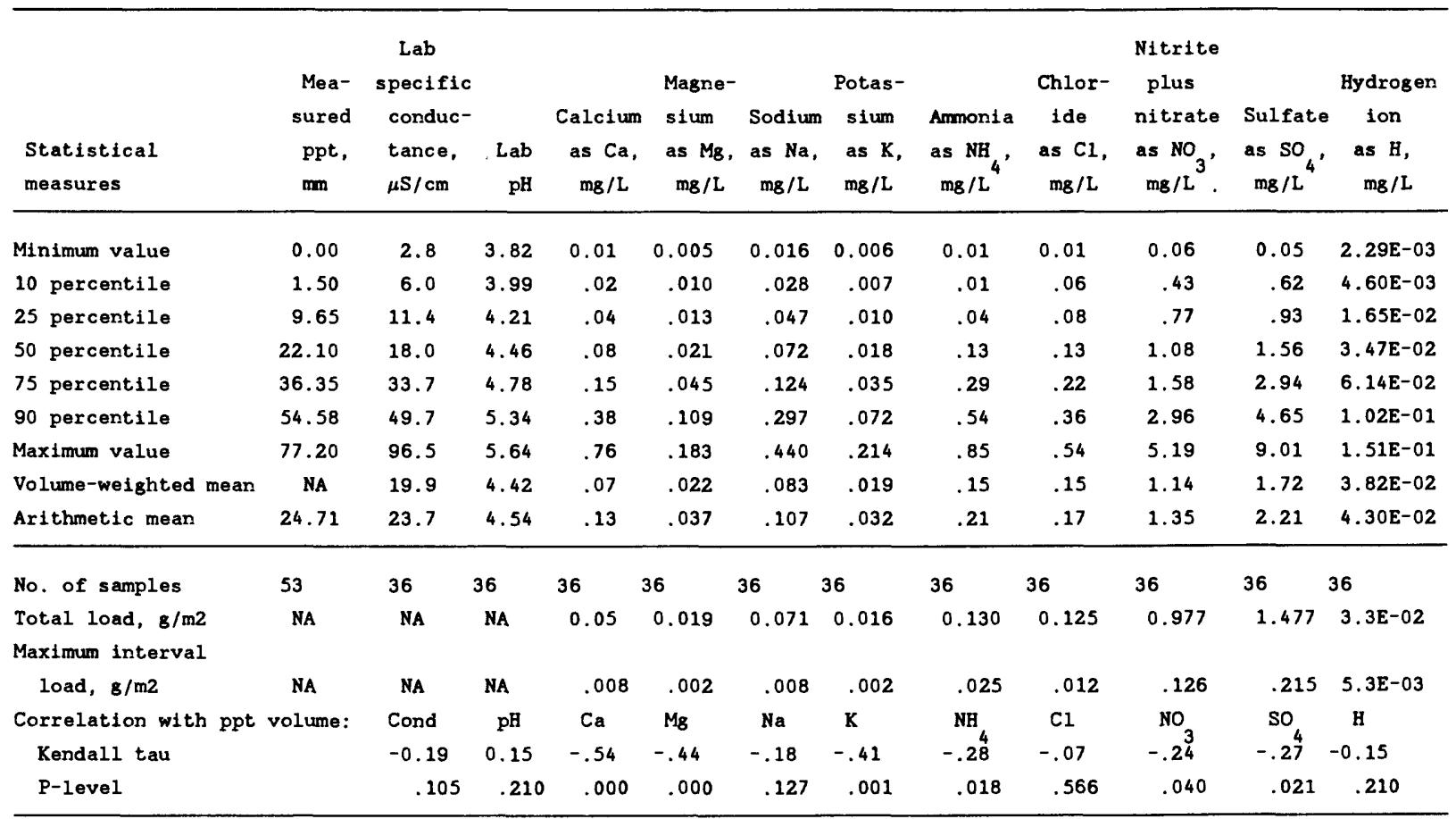

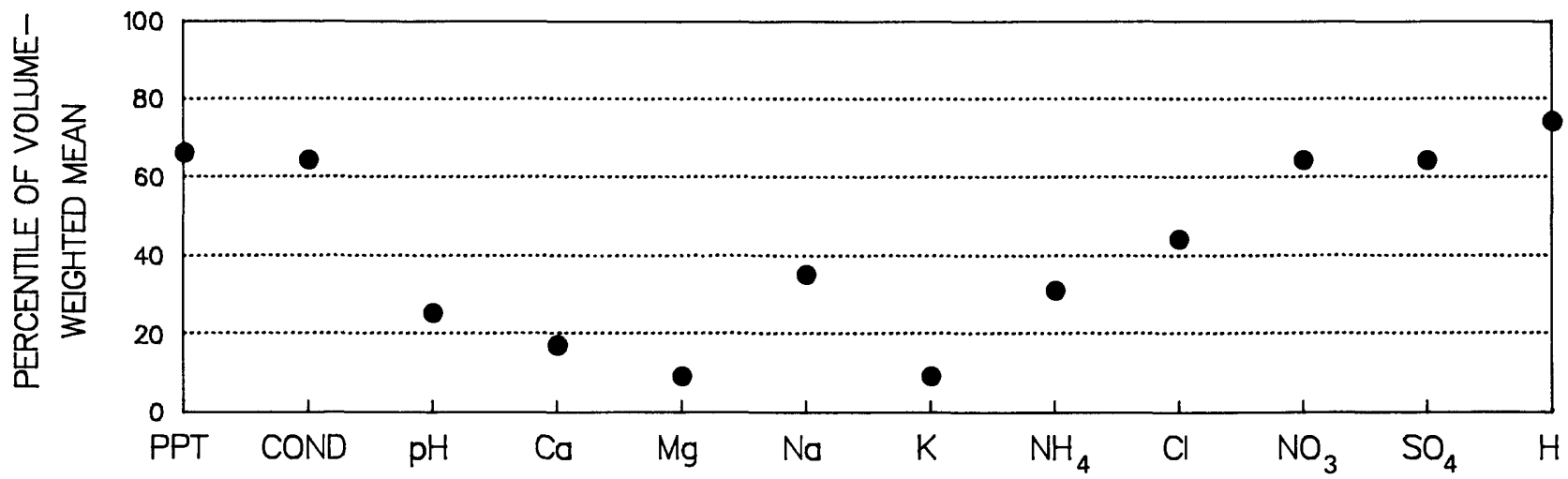

Percentiles of volume-weighted mean concentrations for site NH02, based on frequency distributions of data from 55 National Trends Network sites. 

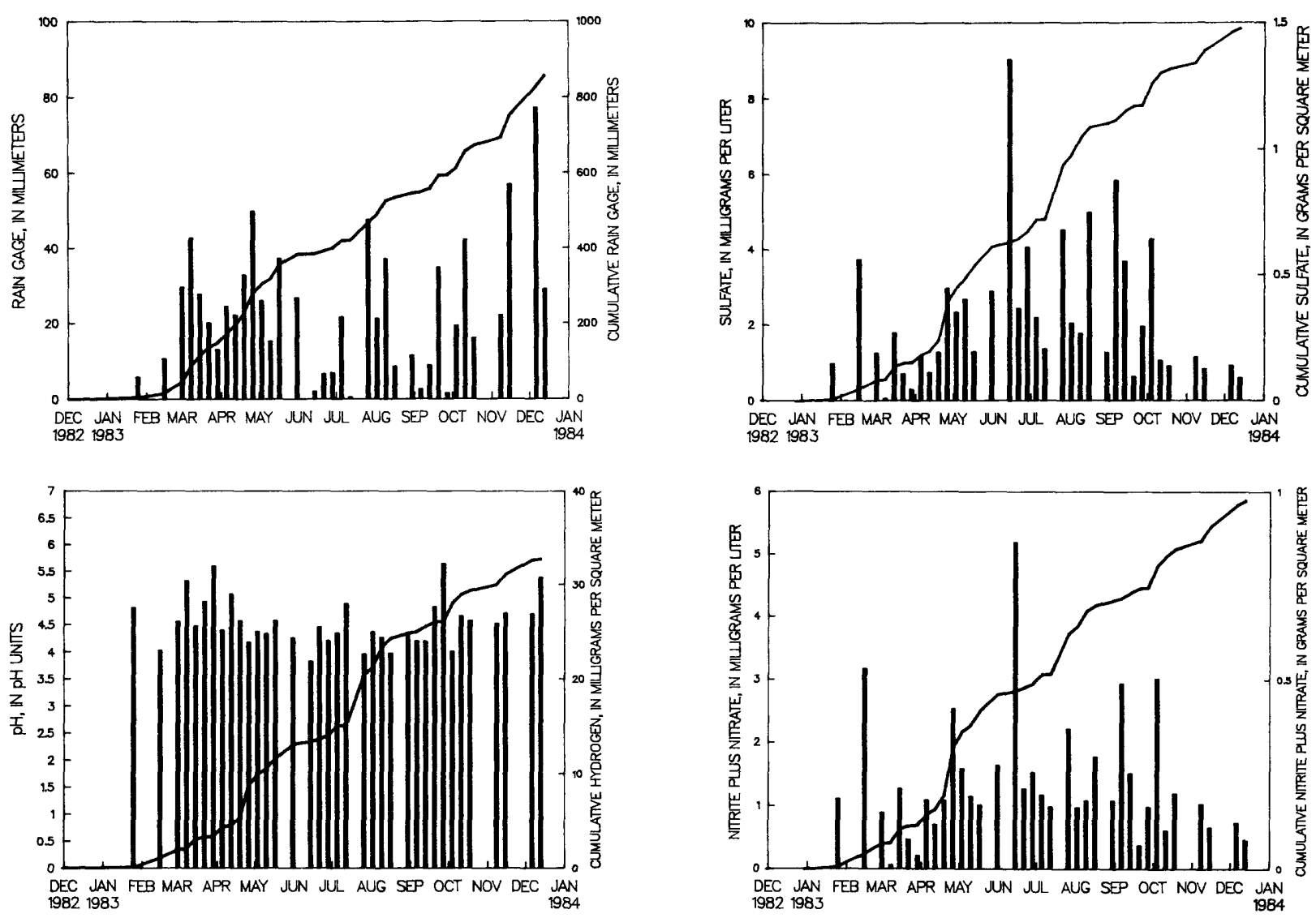

Bar plots of concentrations and cumulative line plots of loads for site NH02.

Nitrite plus nitrate are reported as $\mathrm{NO}_{3}$ and sulfate as $\mathrm{SO}_{4}$.

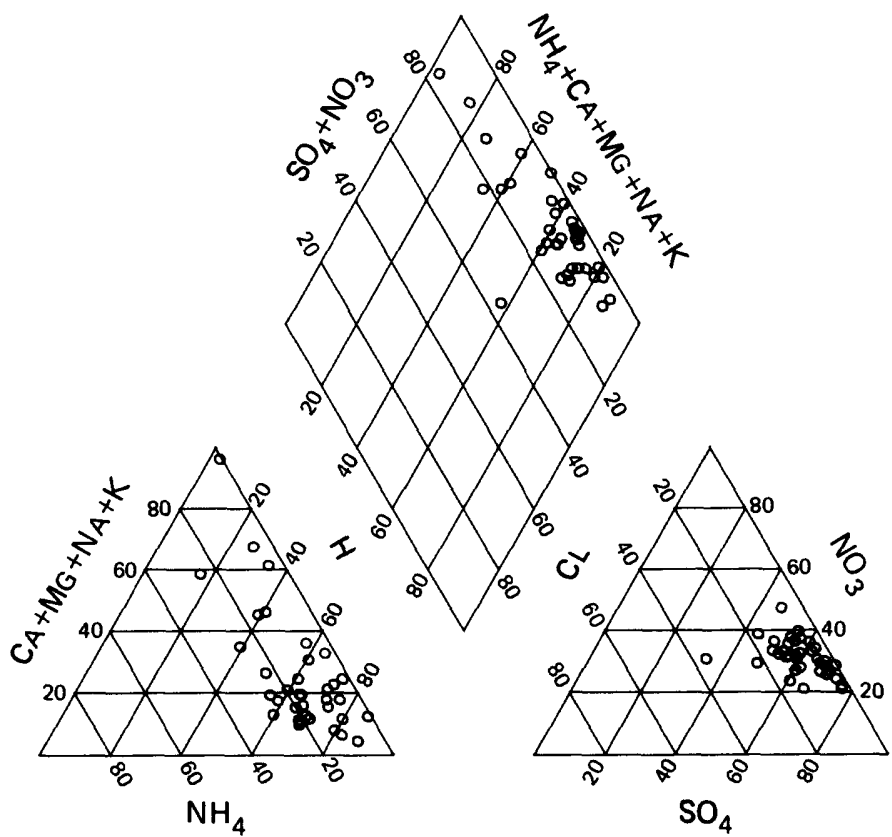

Percentage composition of major ions for site NH02. 


\section{NATIONAL TRENDS NETWORK - - 1983 CALENDER YEAR SUMMARY DATA}

lppt $=$ precipitation; $\mathrm{mm}=$ millimeters; $\mathrm{cm}=$ centimeters; $\mathrm{mg}=$ milligrams; L $=1$ liters;

$g=g r a m s ; m=$ meter; $\mu s=$ microsiemens; cond = specific conductance $]$

STATION: Washington Crossing, New Jersey

CAL number: NJ99

ADS number: 285a00

Map ID number: 66

Station elevation above mean sea level, in meters: 72 Number of sampling intervals (days in parenthesis):

-- With ppt measurments: $53 \quad$ (371)

-- When ppt occurred: $\quad 47 \quad(330)$

-- When ppt did not occur: 6 ( 41)

-- When sample volume was substituted for missing rain gage: 0 ( 0 )

-- With chemical samples: $31 \quad$ (220)
Latitude: $40^{\circ} 18^{\prime} 54^{\prime \prime}$ Longitude: $74^{\circ} 51^{\prime} 17^{\prime \prime}$

Station summary period: $12 / 28 / 1982$ to $01 / 03 / 1984$

Length of summary period: 53 sampling intervals ( 371 days)

Percent summary period with ppt measurments: $\quad 100.0$

Percent sumnary period with chemical samples or no ppt: 70.4

Percent of total measured ppt with chemical samples: 80.2

Percent of total measured ppt in raingage that was

collected in the wet-sample bucket:

97.1

Total measured ppt, in $\mathrm{mm}: 1422.2$

\begin{tabular}{|c|c|c|c|c|c|c|c|c|c|c|c|c|}
\hline $\begin{array}{l}\text { Statistical } \\
\text { measures }\end{array}$ & $\begin{array}{c}\text { Mea- } \\
\text { sured } \\
\text { ppt, } \\
\text { mn }\end{array}$ & $\begin{array}{c}\text { Lab } \\
\text { specific } \\
\text { conduc- } \\
\text { tance, } \\
\mu \mathrm{S} / \mathrm{cm}\end{array}$ & $\begin{array}{r}\text { Lab } \\
\mathrm{pH}\end{array}$ & $\begin{array}{c}\text { Calcium } \\
\text { as Ca, } \\
\text { mg/L }\end{array}$ & $\begin{array}{l}\text { Magne- } \\
\text { sium } \\
\text { as Mg, } \\
\mathrm{mg} / \mathrm{L}\end{array}$ & $\begin{array}{c}\text { Sodium } \\
\text { as } \mathrm{Na} \text {, } \\
\mathrm{mg} / \mathrm{L}\end{array}$ & $\begin{array}{c}\text { Potas- } \\
\text { sium } \\
\text { as } \mathrm{K} \text {, } \\
\mathrm{mg} / \mathrm{L}\end{array}$ & $\begin{array}{l}\text { Ammonia } \\
\text { as } \mathrm{NH} \\
\mathrm{mg} / \mathrm{L}^{\prime}\end{array}$ & $\begin{array}{c}\text { Chlor- } \\
\text { ide } \\
\text { as } \mathrm{Cl} \text {, } \\
\mathrm{mg} / \mathrm{L}\end{array}$ & $\begin{array}{l}\text { Nitrite } \\
\text { plus } \\
\text { nitrate } \\
\text { as } \mathrm{NO}_{3} \text { ' } \\
\mathrm{mg} / \mathrm{L}\end{array}$ & $\begin{array}{l}\text { Sulfate } \\
\text { as } \mathrm{SO}_{4} \\
\mathrm{mg} / \mathrm{L}^{\prime}\end{array}$ & $\begin{array}{l}\text { Hydrogen } \\
\text { ion } \\
\text { as } \mathrm{H}, \\
\mathrm{mg} / \mathrm{L}\end{array}$ \\
\hline Minimum value & 0.00 & 7.3 & 3.54 & 0.03 & 0.009 & 0.025 & 0.006 & 0.01 & 0.09 & 0.29 & 0.49 & 8. 32E-03 \\
\hline 10 percentile & .00 & 8.2 & 3.92 & .03 & .015 & .043 & .008 & .05 & .09 & .32 & .83 & $1.24 \mathrm{E}-02$ \\
\hline 25 percentile & 2.65 & 12.7 & 4.13 & .06 & .021 & .069 & .016 & .06 & .14 & .64 & 1.12 & $1.91 \mathrm{E}-02$ \\
\hline 50 percentile & 27.40 & 23.8 & 4.39 & .08 & .040 & .118 & .024 & .12 & .23 & 1.25 & 1.67 & $4.07 E-02$ \\
\hline 75 percentile & 40.80 & 38.0 & 4.72 & .18 & .098 & .305 & .048 & .40 & .56 & 2.28 & 3.59 & $7.41 \mathrm{E}-02$ \\
\hline 90 percentile & 62.10 & 60.6 & 4.91 & .47 & .156 & .530 & .087 & .65 & 1.02 & 4.26 & 5.62 & $1.22 \mathrm{E}-01$ \\
\hline Maximum value & 103.10 & 144.7 & 5.08 & .72 & .221 & 1.190 & .124 & 1.23 & 2.22 & 9.38 & 12.11 & $2.88 \mathrm{E}-01$ \\
\hline Volume-weighted mean & NA & 22.4 & 4.40 & .09 & .053 & .306 & .026 & .16 & .58 & 1.15 & 1.86 & $3.93 E-02$ \\
\hline Arithmetic mean & 26.83 & 31.3 & 4.41 & .16 & .062 & .225 & .035 & .26 & .43 & 1.82 & 2.82 & $5.78 E-02$ \\
\hline $\begin{array}{l}\text { No. of samples } \\
\text { Total load, } 8 / \mathrm{m} 2 \\
\text { Maximum interval }\end{array}$ & $\begin{array}{c}53 \\
\text { NA }\end{array}$ & $\begin{array}{l}31 \\
\text { NA }\end{array}$ & $\begin{array}{l}31 \\
\text { NA }\end{array}$ & $\begin{array}{l}31 \\
0.102\end{array}$ & $\begin{array}{l}31 \\
0.061\end{array}$ & $\begin{array}{l}31 \\
0.349\end{array}$ & $\begin{array}{l}31 \\
0.030\end{array}$ & $\begin{array}{l}31 \\
0.181\end{array}$ & $\begin{array}{l}31 \\
0.666\end{array}$ & $\begin{array}{l}31 \\
1.306\end{array}$ & $\begin{array}{l}31 \\
2.116\end{array}$ & $\begin{array}{l}31 \\
4.5 E-02\end{array}$ \\
\hline $\begin{array}{l}\text { load, } \mathrm{g} / \mathrm{m} 2 \\
\text { Correlation with ppt } \\
\text { Kendall tau }\end{array}$ & $\begin{array}{c}\text { NA } \\
\text { volume: }\end{array}$ & $\begin{array}{l}\text { NA } \\
\text { Cond } \\
-0.37\end{array}$ & $\begin{array}{l}\mathrm{NA} \\
\mathrm{pH} \\
0.45\end{array}$ & $\begin{array}{l}.009 \\
\mathrm{Ca} \\
-.36\end{array}$ & $\begin{array}{l}.015 \\
\mathrm{Mg} \\
-.17\end{array}$ & $\begin{array}{l}.123 \\
\mathrm{Na} \\
.12\end{array}$ & $\begin{array}{l}.005 \\
\mathrm{~K} \\
-.25\end{array}$ & $\begin{array}{c}.028 \\
\mathrm{NH}^{4} \\
-.40^{2}\end{array}$ & $\begin{array}{l}.229 \\
\mathrm{Cl} \\
.10\end{array}$ & $\begin{array}{l}.170 \\
\mathrm{NO}_{3} \\
-.46\end{array}$ & $\begin{array}{l}0.228 \\
\mathrm{so}_{4} \\
-.43\end{array}$ & $\begin{array}{c}5.5 E-03 \\
H \\
-0.45\end{array}$ \\
\hline P-level & & .004 & .000 & .005 & .174 & .359 & .052 & .002 & .424 & .000 & .001 & .000 \\
\hline
\end{tabular}

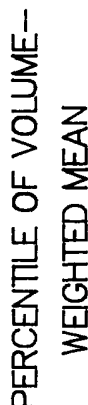

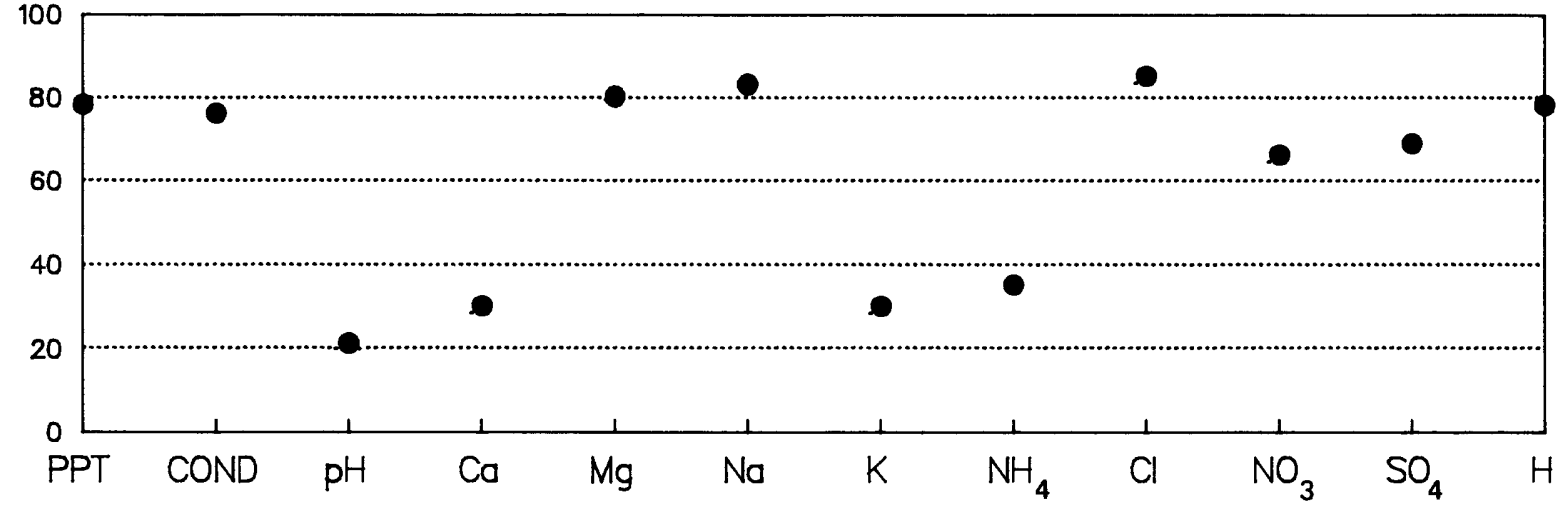

Percentiles of volume-weighted mean concentrations for site NJ99, based on

frequency distributions of data from 55 National Trends Network sites. 

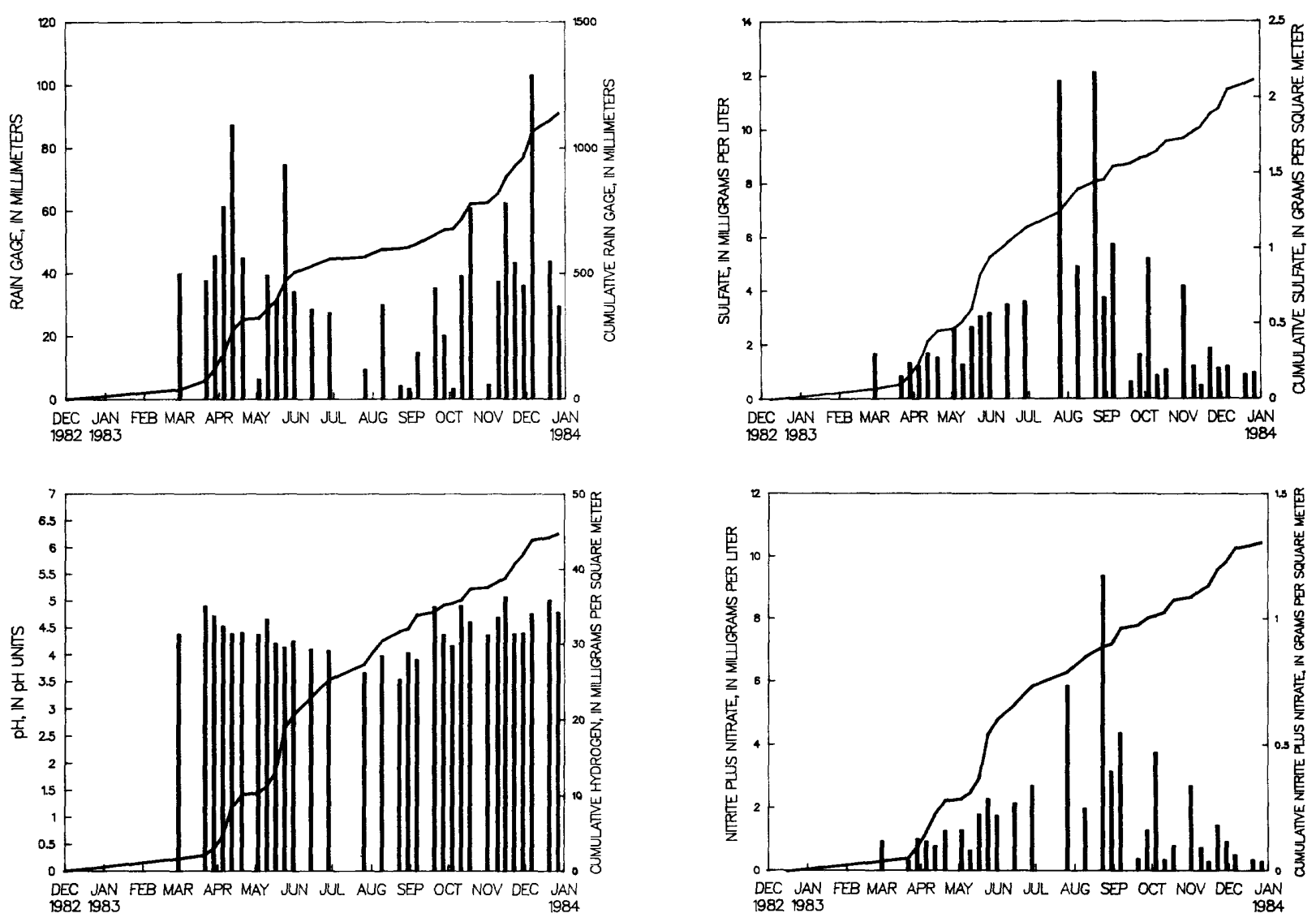

Bar plots of concentrations and cumulative line plots of loads for site NJ99. Nitrite plus nitrate are reported as $\mathrm{NO}_{3}$ and sulfate as $\mathrm{SO}_{4}$.

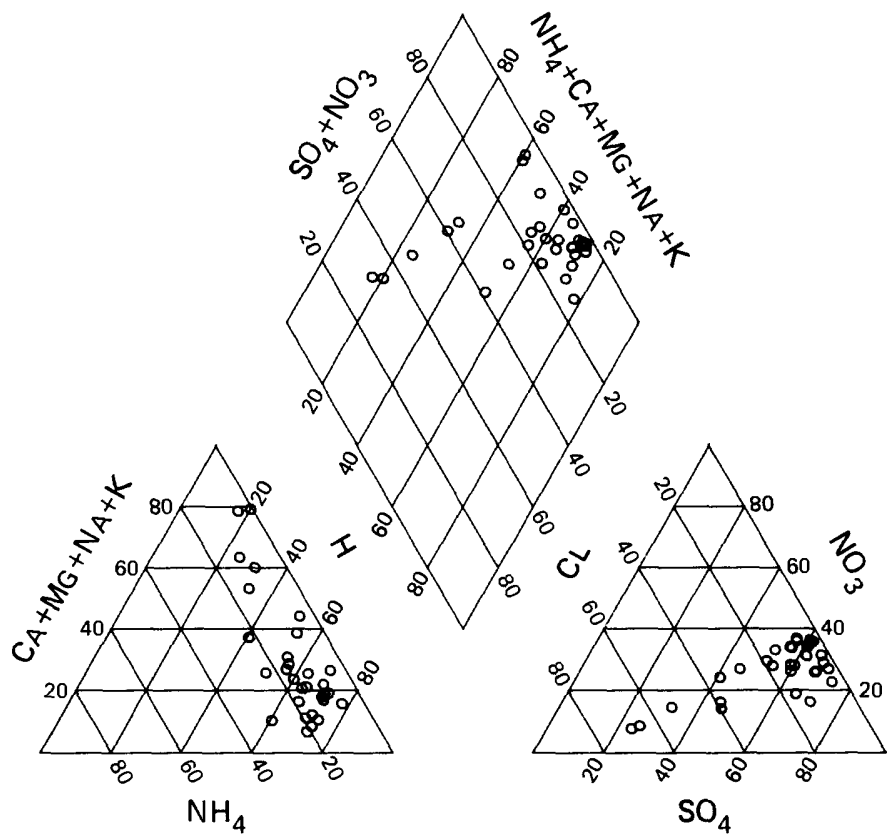

Percentage composition of major ions for site NJ99. 


\section{NATIONAL TRENDS NETWORK -- 1983 CALENDER YEAR SUMMARY DATA}

lppt = precipitation; $\mathrm{mm}=$ millimeters; $\mathrm{cm}=$ centimeters; $\mathrm{mg}=\mathrm{milligrams;} \mathrm{L}=1$ iters;

$8=\mathrm{grams} ; \mathrm{m}=$ meter $; \mu \mathrm{s}=$ microsiemens; cond $=$ specific conductance $]$

STATION: CUBA, New Mexico

CAL number: NMO9

ADS number: 280a00

Map ID number: 67

Station altitude above mean sea level, in meters: 2124

Number of sampling intervals (days in parenthesis):

-- With ppt measurements: $52 \quad$ (371)

-- When ppt occurred: 46 (329)

-- When ppt did not occur: 6 (42)

-- When sample volume was substituted for missing rain gage: 0 ( 0 )

-- With chemical samples: 33
Latitude: $36^{\circ} 02^{\prime} 27^{\prime \prime}$ Longitude: $106^{\circ} 58^{\prime} 17^{\prime \prime}$

Station summary period: $12 / 28 / 1982$ to $01 / 03 / 1984$

Length of summary period: 52 sampling intervals ( 371 days)

$\begin{array}{ll}\text { Percent summary period with ppt measurements: } & 100.0\end{array}$

Percent summary period with chemical samples or no ppt: 75.5

Percent of total measured ppt with chemical samples: 83.0

Percent of total measured ppt in raingage that was

collected in the wet-sample bucket:

90.9

Total measured ppt, in $\mathrm{mm}: 361.8$

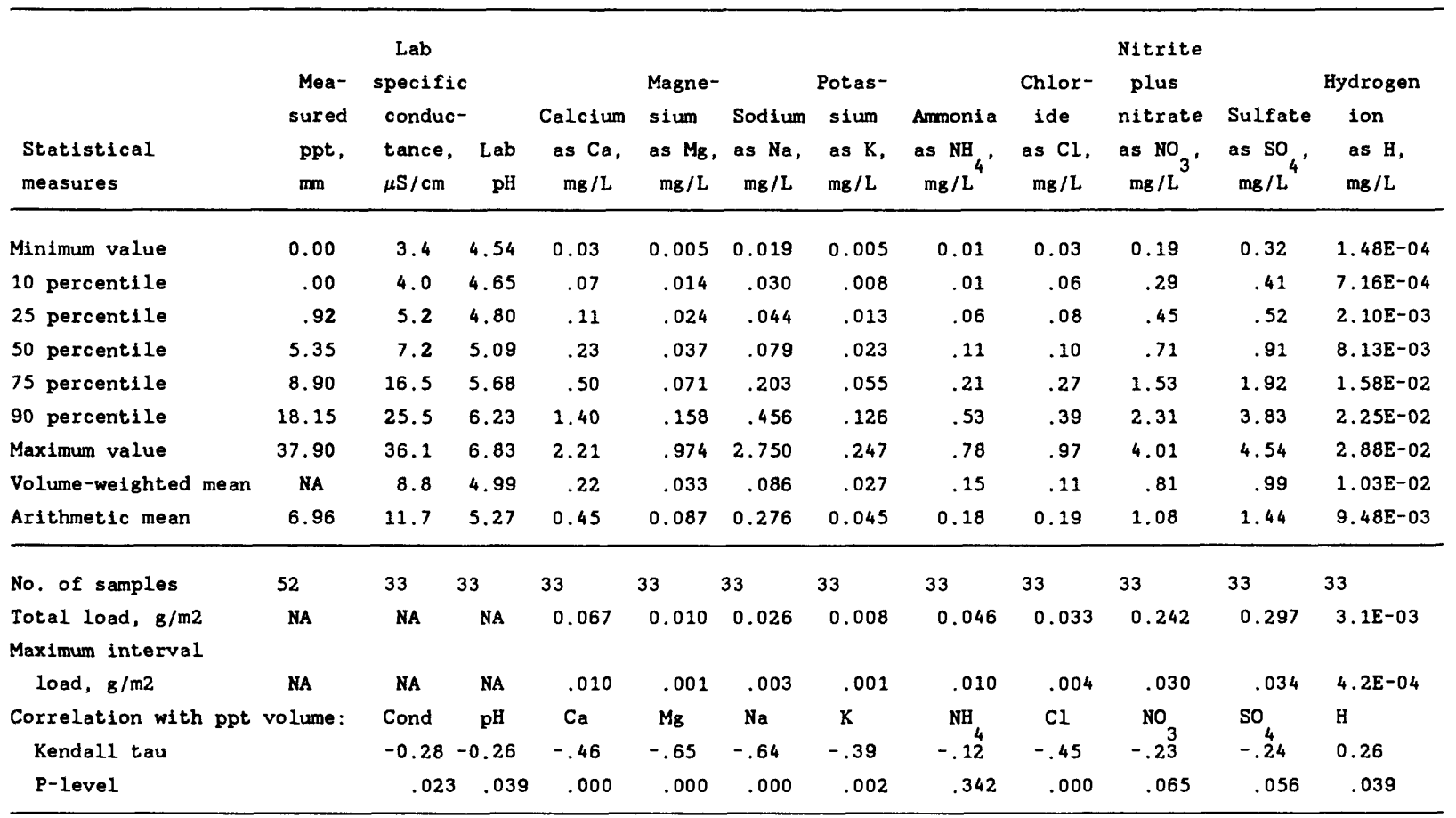

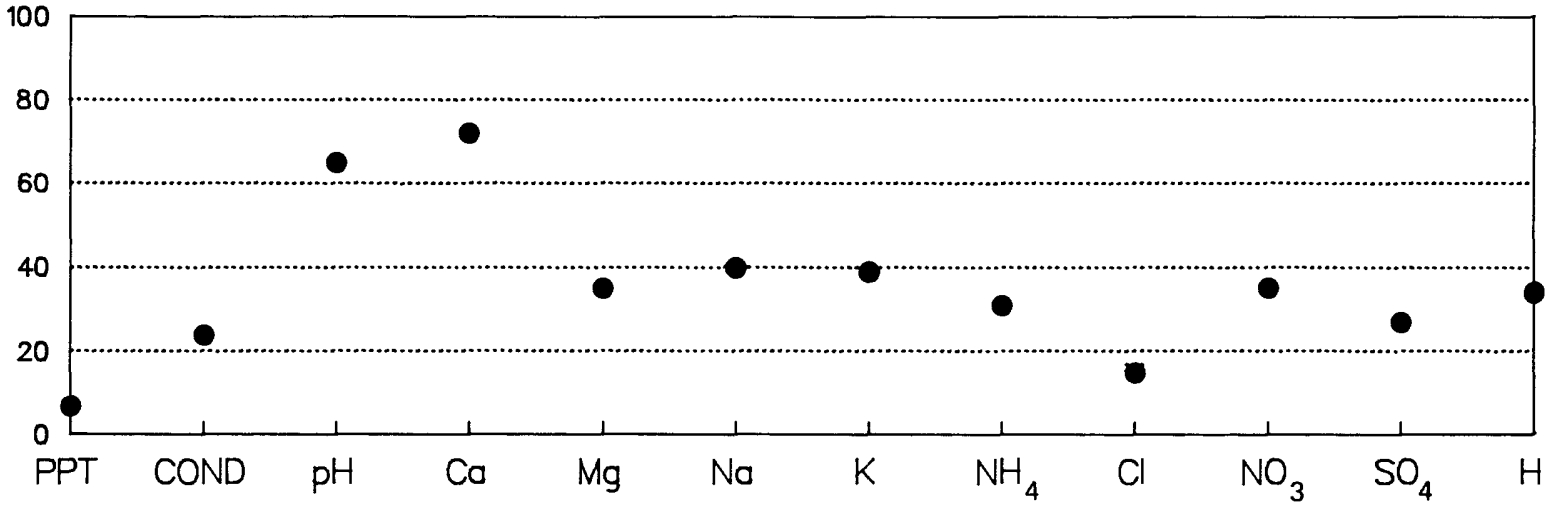

Percentiles of volume-weighted mean concentrations for site NM09, based on frequency distributions of data from 55 National Trends Network sites. 

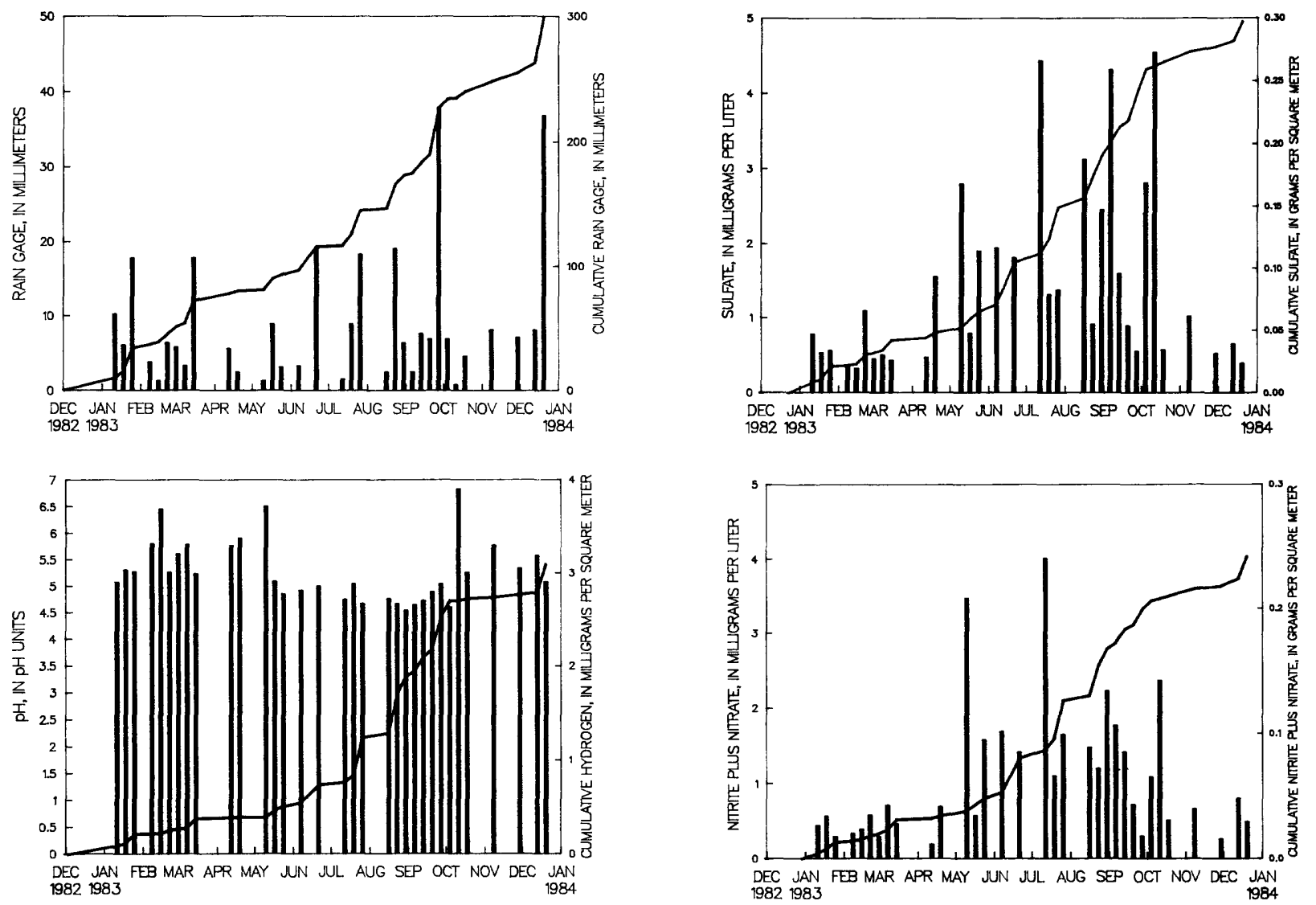

Bar plots of concentrations and cumulative line plots of loads for site NM09. Nitrite plus nitrate are reported as $\mathrm{NO}_{3}$ and sulfate as $\mathrm{SO}_{4}$.

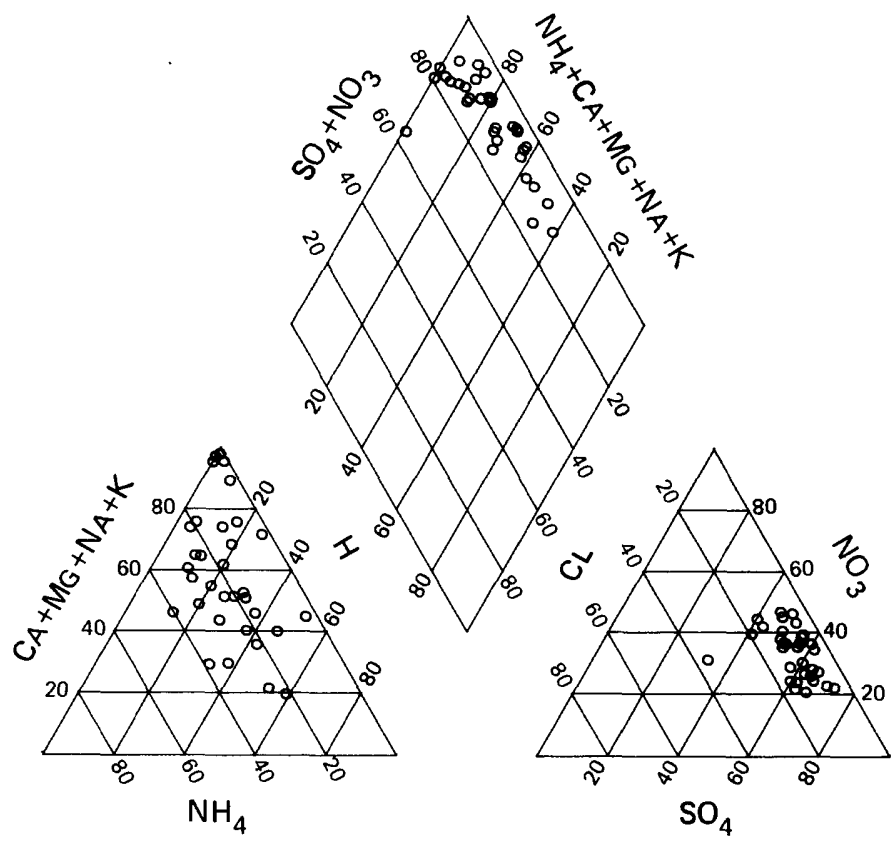

Percentage composition of major ions for site NM09. 


\section{NATIONAL TRENDS NETWORK -- 1983 CALENDER YEAR SUMMARY DATA}

lppt = precipitation; $\mathrm{mm}=$ millimeters; $\mathrm{cm}=$ centimeters; $\mathrm{mg}=$ milligrams; L $=1$ iters;

$g=8 \mathrm{rams} ; \mathrm{m}=$ meter; $\mu \mathrm{s}=$ microsiemens; cond = specific conductance $]$

STATION: Aurora, New York

CAL number: NY08

ADS number: $040 \mathrm{a} 00$

Station altitude above mean sea level, in meters: 249

Number of sampling intervals (days in parenthesis):

-- With ppt measurements: $53 \quad$ (370)

-- When ppt occurred: 50 (349)

-- When ppt did not occur: 3 ( 21)

-- When sample volume was substituted for missing rain gage: 0 ( 0 )

-- With chemical samples: $40 \quad$ (279)
Latitude: $42^{\circ} 44^{\prime} 02^{\prime \prime}$ Longitude: $76^{\circ} 39^{\prime} 35^{\prime \prime}$

Station summary period: $12 / 29 / 1982$ to $01 / 03 / 1984$

Length of summary period: 53 sampling intervals ( 370 days)

Percent sumary period with ppt measurements :

99.7

Percent sumary period with chemical samples or no ppt: 80.9

Percent of total measured ppt with chemical samples: $\quad 90.4$

Percent of total measured ppt in raingage that was

collected in the wet-sample bucket:

91.2

Total measured ppt, in m: 793.5

\begin{tabular}{|c|c|c|c|c|c|c|c|c|c|c|c|c|}
\hline $\begin{array}{l}\text { Statistical } \\
\text { measures }\end{array}$ & $\begin{array}{l}\text { Mea- } \\
\text { sured } \\
\text { ppt, } \\
\text { mm }\end{array}$ & $\begin{array}{c}\text { Lab } \\
\text { specific } \\
\text { conduc- } \\
\text { tance, } \\
\mu \mathrm{S} / \mathrm{cm}\end{array}$ & $\begin{array}{r}\text { Lab } \\
\mathrm{pH}\end{array}$ & $\begin{array}{c}\text { Calcium } \\
\text { as } \mathrm{Ca}, \\
\mathrm{mg} / \mathrm{L}\end{array}$ & $\begin{array}{l}\text { Magne- } \\
\text { sium } \\
\text { as Mg, } \\
\mathrm{mg} / \mathrm{L}\end{array}$ & $\begin{array}{l}\text { Sodium } \\
\text { as Na, } \\
\text { mg/L }\end{array}$ & $\begin{array}{l}\text { Potas- } \\
\text { sium } \\
\text { as } \mathrm{K} \text {, } \\
\mathrm{mg} / \mathrm{L}\end{array}$ & $\begin{array}{l}\text { Ammonia } \\
\text { as } \mathrm{NH}_{4} \text {. } \\
\mathrm{mg} / \mathrm{L}^{\circ}\end{array}$ & $\begin{array}{l}\text { Chlor- } \\
\text { ide } \\
\text { as Cl, } \\
\mathrm{mg} / \mathrm{L}\end{array}$ & $\begin{array}{l}\text { Nitrite } \\
\text { plus } \\
\text { nitrate } \\
\text { as } \mathrm{NO}_{3} \text { ' } \\
\mathrm{mg} / \mathrm{L}\end{array}$ & $\begin{array}{l}\text { Sulfate } \\
\text { as } \mathrm{SO}_{4^{\prime}} \\
\mathrm{mg} / \mathrm{L}\end{array}$ & $\begin{array}{c}\text { Hydrogen } \\
\text { ion } \\
\text { as } \mathrm{H}, \\
\mathrm{mg} / \mathrm{L}\end{array}$ \\
\hline Minimun value & 0.00 & 7.9 & 3.72 & 0.02 & 0.006 & 0.017 & 0.003 & 0.01 & 0.01 & 0.47 & 0.68 & $1.35 \mathrm{E}-03$ \\
\hline 10 percentile & .82 & 12.9 & 3.86 & .04 & .008 & .023 & .008 & .07 & .07 & .59 & .88 & $2.07 E-02$ \\
\hline 25 percentile & 4.60 & 21.3 & 3.99 & .07 & .016 & .040 & .010 & .14 & .10 & 1.24 & 1.67 & $3.43 \mathrm{E}-02$ \\
\hline 50 percentile & 11.90 & 30.9 & 4.26 & .14 & .028 & .057 & .021 & .29 & .16 & 1.86 & 2.84 & $5.44 E-02$ \\
\hline 75 percentile & 22.10 & 62.8 & 4.46 & .42 & .084 & .147 & .058 & .57 & .29 & 3.24 & 6.42 & $1.02 E-01$ \\
\hline 90 percentile & 33.80 & 76.7 & 4.68 & .79 & .160 & .256 & .128 & .86 & .51 & 4.69 & 8.91 & 1. $39 \mathrm{E}-01$ \\
\hline Maximum value & 51.10 & 101.0 & 5.87 & 7.34 & 1.481 & 7.520 & .491 & 1.62 & 6.23 & 7.13 & 14.64 & $1.91 \mathrm{E}-01$ \\
\hline Volume-weighted mean & NA & 32.3 & 4.22 & .21 & .045 & .118 & .031 & .29 & .20 & 1.78 & 3.01 & $5.98 \mathrm{E}-02$ \\
\hline No. of samples & 53 & 40 & 40 & 40 & 40 & 40 & 40 & 40 & 40 & 40 & 40 & 40 \\
\hline $\begin{array}{l}\text { Total load, } 8 / \mathrm{m} 2 \\
\text { Maximum interval }\end{array}$ & NA & NA & NA & 0.148 & 0.032 & 0.084 & 0.023 & 0.209 & 0.142 & 1.273 & 2.155 & $4.3 E-02$ \\
\hline $\begin{array}{l}\text { load, } 8 / \mathrm{m} 2 \\
\text { Correlation with ppt } \\
\text { Kendall tau }\end{array}$ & $\begin{array}{l}\text { NA } \\
\text { volume: }\end{array}$ & $\begin{array}{l}\text { NA } \\
\text { Cond } \\
-0.38\end{array}$ & $\begin{array}{l}\mathrm{NA} \\
\mathrm{pH} \\
0.24\end{array}$ & $\begin{array}{r}.034 \\
\mathrm{Ca} \\
-.50\end{array}$ & $\begin{array}{r}.007 \\
M_{8} \\
-.57\end{array}$ & $\begin{array}{c}.034 \\
\mathrm{Na} \\
-.50\end{array}$ & $\begin{array}{c}.005 \\
-.51\end{array}$ & $\begin{array}{c}.023 \\
-.27^{4}\end{array}$ & $\begin{array}{c}.028 \\
.11 \\
-.50\end{array}$ & $\begin{array}{l}0.149 \\
\mathrm{NO}_{3} \\
-.40^{3}\end{array}$ & $\begin{array}{c}0.341 \\
\text { so } \\
-0.41\end{array}$ & $\begin{array}{l}6.6 E-03 \\
H \\
-0.24\end{array}$ \\
\hline P-level & & .001 & .031 & .000 & .000 & .000 & .000 & .014 & .000 & .000 & .000 & .031 \\
\hline
\end{tabular}

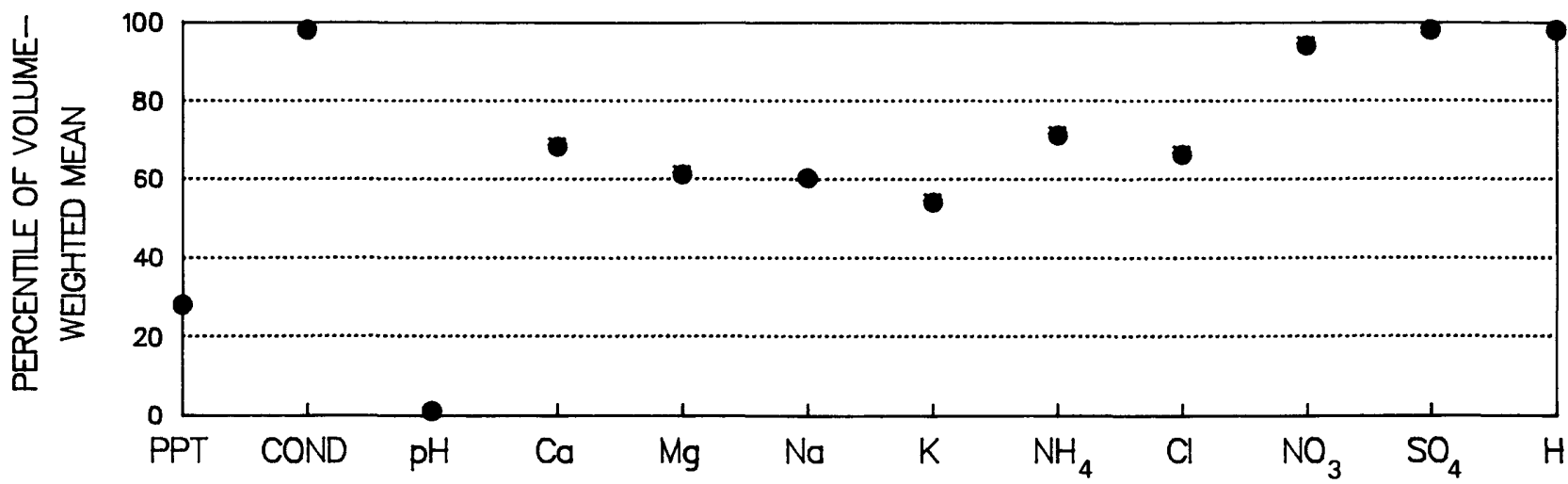

Percentiles of volume-weighted mean concentrations for site NY08, based on frequency distributions of data from 55 National Trends Network sites. 

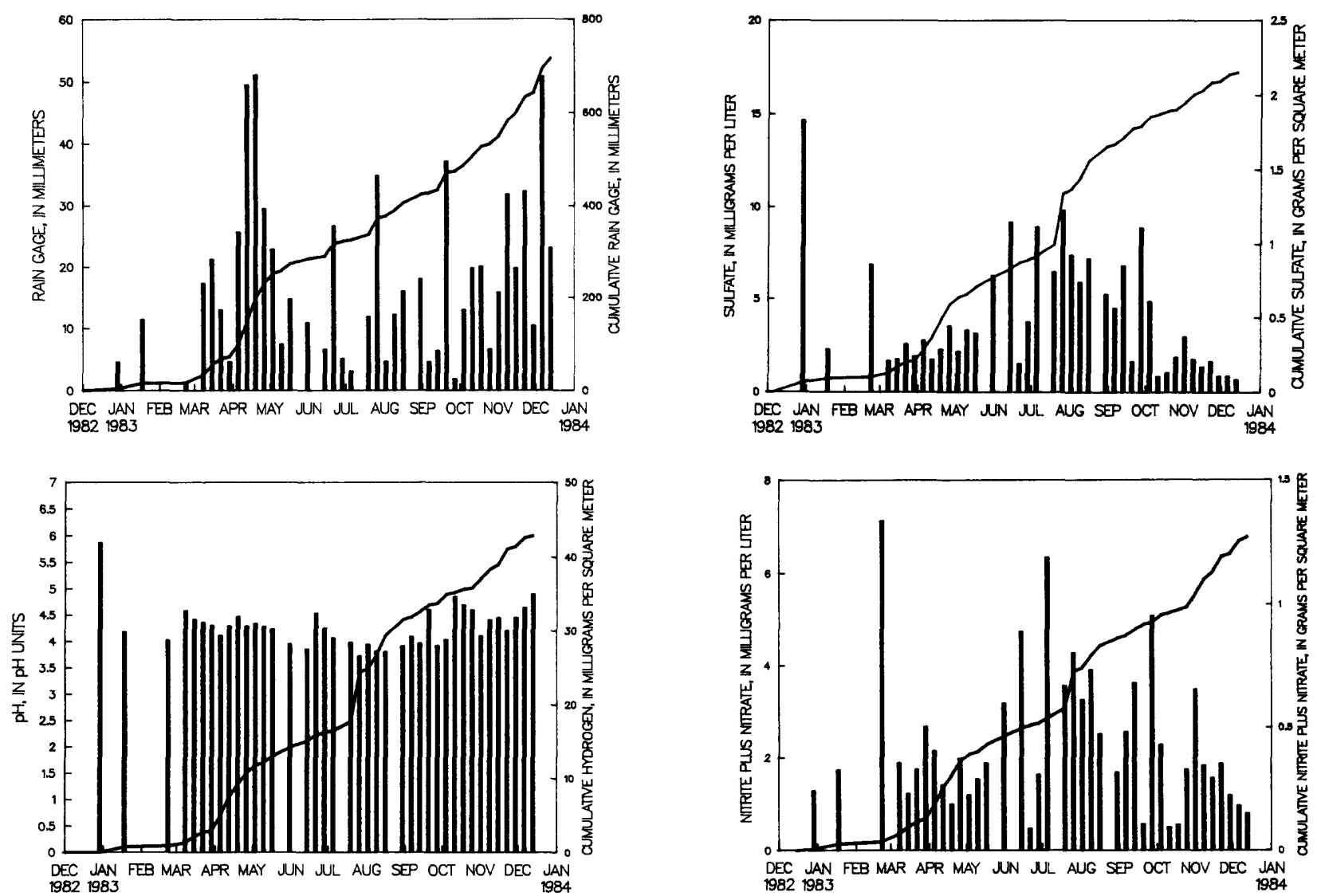

Bar plots of concentrations and cumulative line plots of loads for site NY08. Nitrite plus nitrate are reported as $\mathrm{NO}_{3}$ and sulfate as $\mathrm{SO}_{4}$.

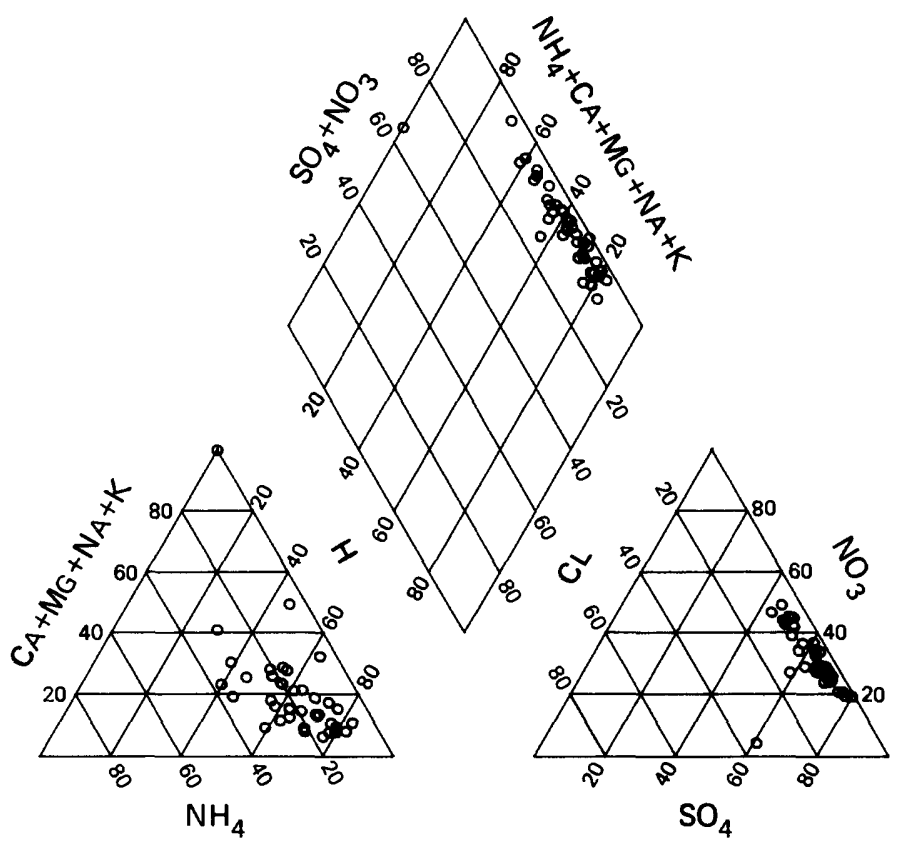

Percentage composition of major ions for site NY08. 


\section{NATIONAL TRENDS NETWORK -- 1983 CALENDER YEAR SUMMARY DATA}

lppt $=$ precipitation; $\mathrm{mm}=$ millimeters; $\mathrm{cm}=$ centimeters; $\mathrm{mg}=\mathrm{mllligrams;} \mathrm{L}=11$ ters; $\mathrm{g}=\mathrm{grams} ; \mathrm{m}=$ meter; $\mu \mathrm{s}=$ microsiemens; cond $=$ specific conductance $]$

STATION: Chautauqua, New York

CAL number: NY10

ADS number: $041 \mathrm{a} 00$

Station altitude above mean sea level, in meters: 488 Number of sampling intervals (days in parenthesis):

-- With ppt measurements: $53 \quad$ (371)

-- When ppt occurred: $52 \quad$ (364)

-- When ppt did not occur: 1 ( 7)

-- When sample volume was substituted for missing rain gage: 0 ( 0 )

-- With chemical samples: 39 (273)
Latitude: $\quad 42^{\circ} 17^{\prime} 58^{\prime \prime}$ Longitude: $79^{\circ} 23^{\prime} 47^{\prime \prime}$

Station summary period: $12 / 28 / 1982$ to $01 / 03 / 1984$

Length of summary period: 53 sampling intervals ( 371 days)

Percent summary period with ppt measurements: $\quad 100.0$

Percent summary period with chemical samples or no ppt: 75.5

Percent of total measured ppt with chemical samples: 82.2

Percent of total measured ppt in raingage that was

collected in the wet-sample bucket:

97.0

Total measured ppt, in mm: 1046.2

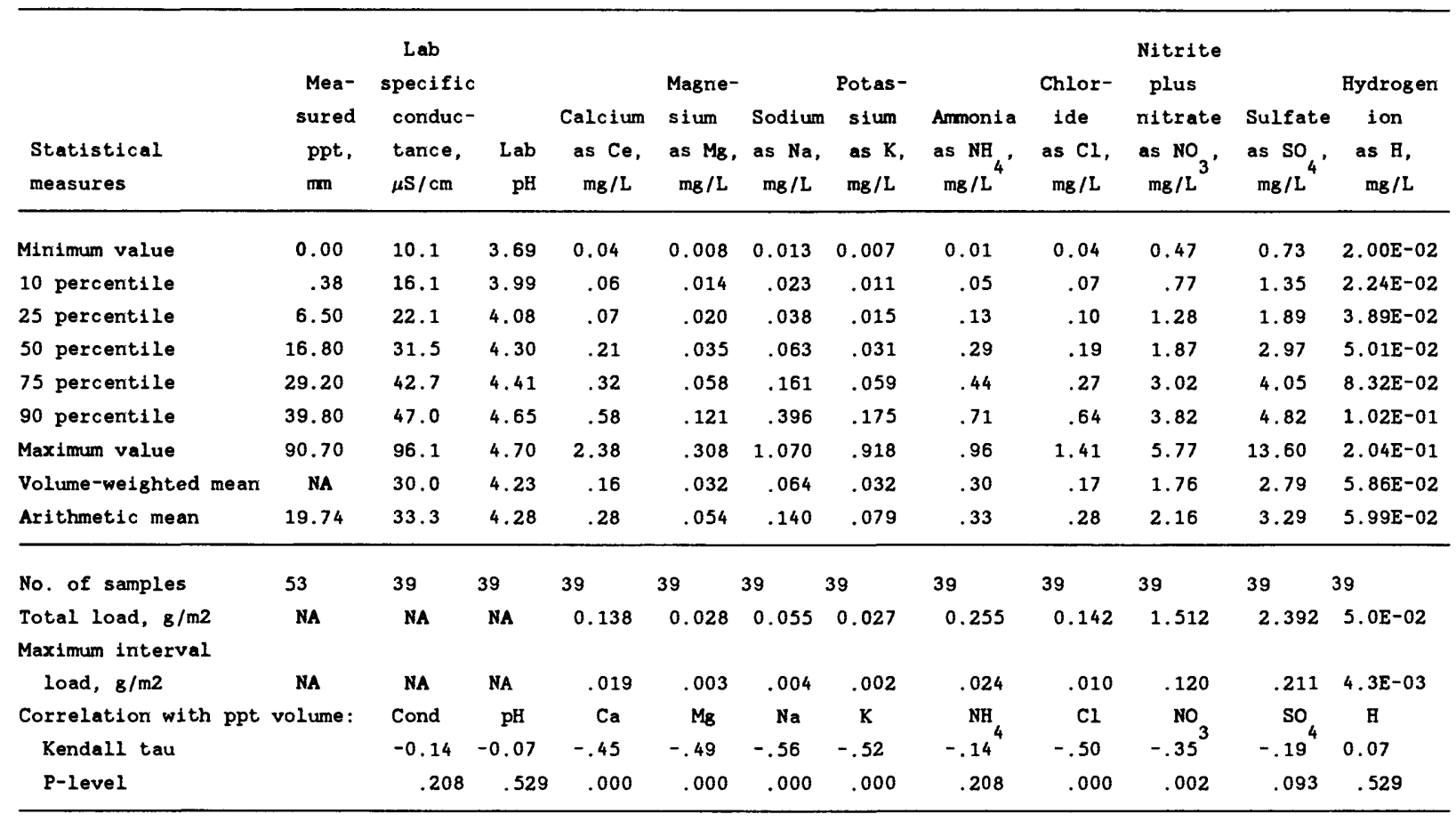

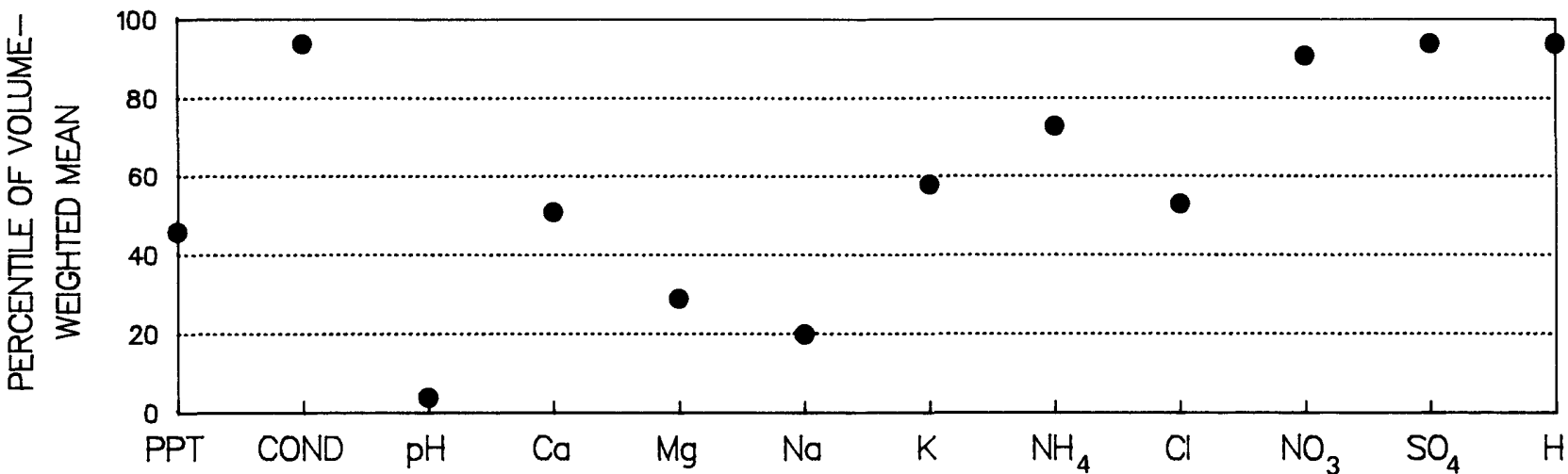

Percentiles of volume-weighted mean concentrations for site NY10, based on frequency distributions of data from 55 National Trends Network sites. 

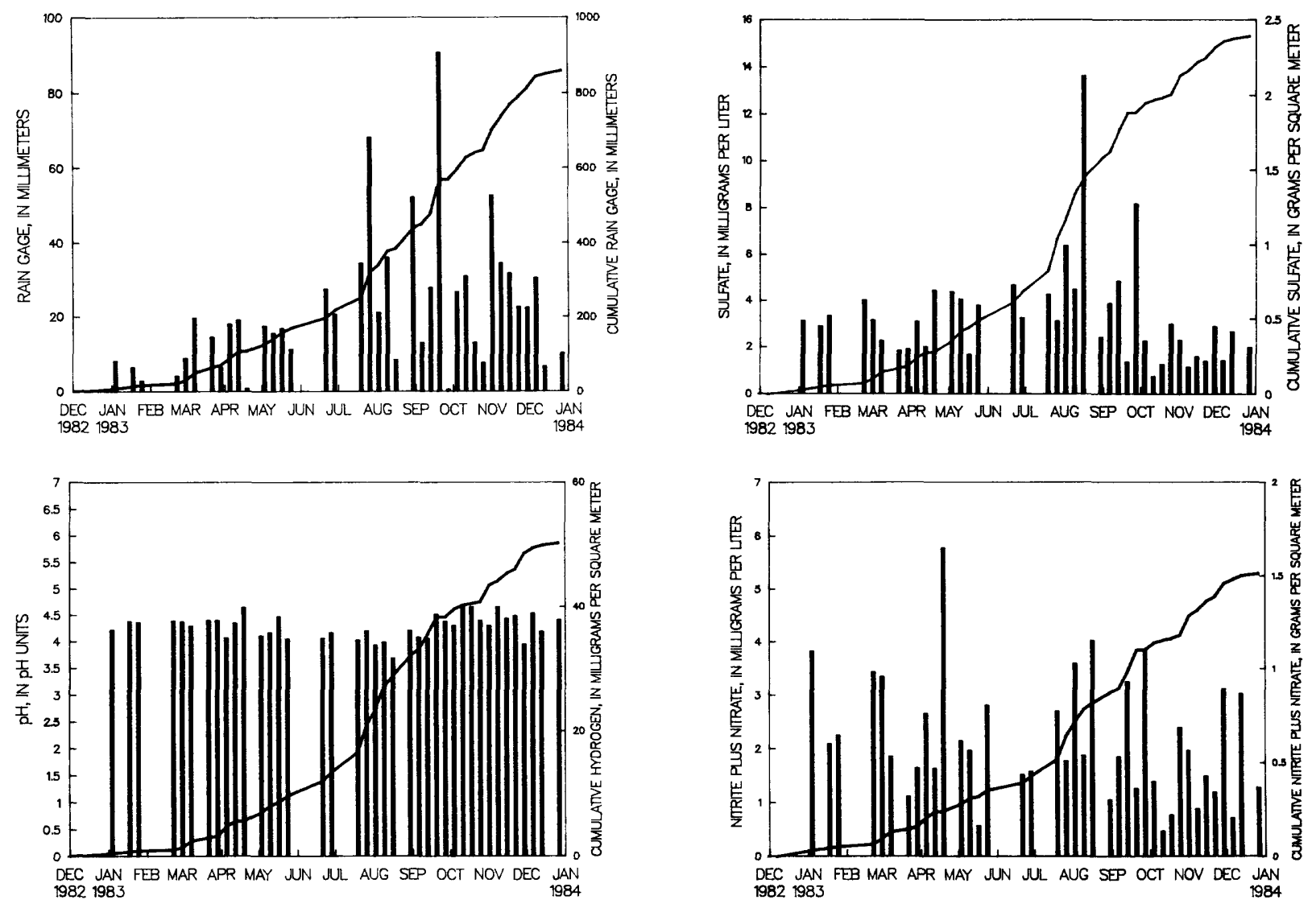

Bar plots of concentrations and cumulative line plots of loads for site NY10. Nitrite plus nitrate are reported as $\mathrm{NO}_{3}$ and sulfate as $\mathrm{SO}_{4}$.

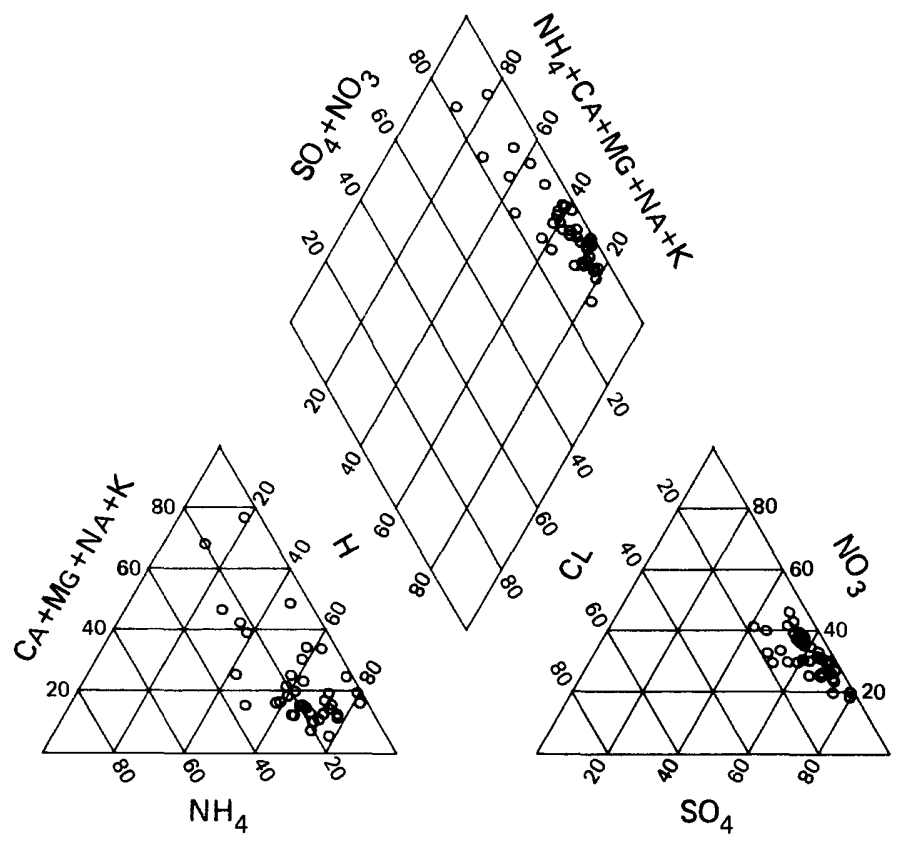

Percentage composition of major ions for site NY10. 


\section{NATIONAL TRENDS NETWORK -- 1983 CALENDER YEAR SUMMARY DATA}

[ppt $=$ precipitation; $\mathrm{mm}=$ millimeters; $\mathrm{cm}=$ centimeters; $\mathrm{mg}=$ milligrams; $\mathrm{L}=1$ liters $;$ $\mathrm{g}=\mathrm{grans} ; \mathrm{m}=$ meter $\boldsymbol{\mu s}=$ microsiemens; cond $=$ specific conductance $]$

STATION: Knobit, New York

CAL number: NY12

ADS number: 042a00

Station altitude above mean sea level, in meters: 406 Number of sampling intervals (days in parenthesis):

-- With ppt measurements: $49 \quad$ (371)

-- When ppt occurred: 47

-- When ppt did not occur: 2 ( 14)

-- When sample volume was substituted for missing rain gage: 0 ( 0 )

-- With chemical samples: 41 (316)
Latitude: $\quad 42^{\circ} 22^{\prime} 41^{\prime \prime}$ Longitude: $73^{\circ} 30^{\prime} 10^{\prime \prime}$

Station summary period: $12 / 28 / 1982$ to $01 / 03 / 1984$

Length of summary period: 49 sampling intervals ( 371 days)

Percent summary period with ppt measurements: $\quad 100.0$

Percent summary period with chemical samples or no ppt: 88.9

Percent of total measured ppt with chemical samples: 94.5

Percent of total measured ppt in raingage that was

collected in the wet-sample bucket:

93.8

Total measured ppt, in m: 1214.5

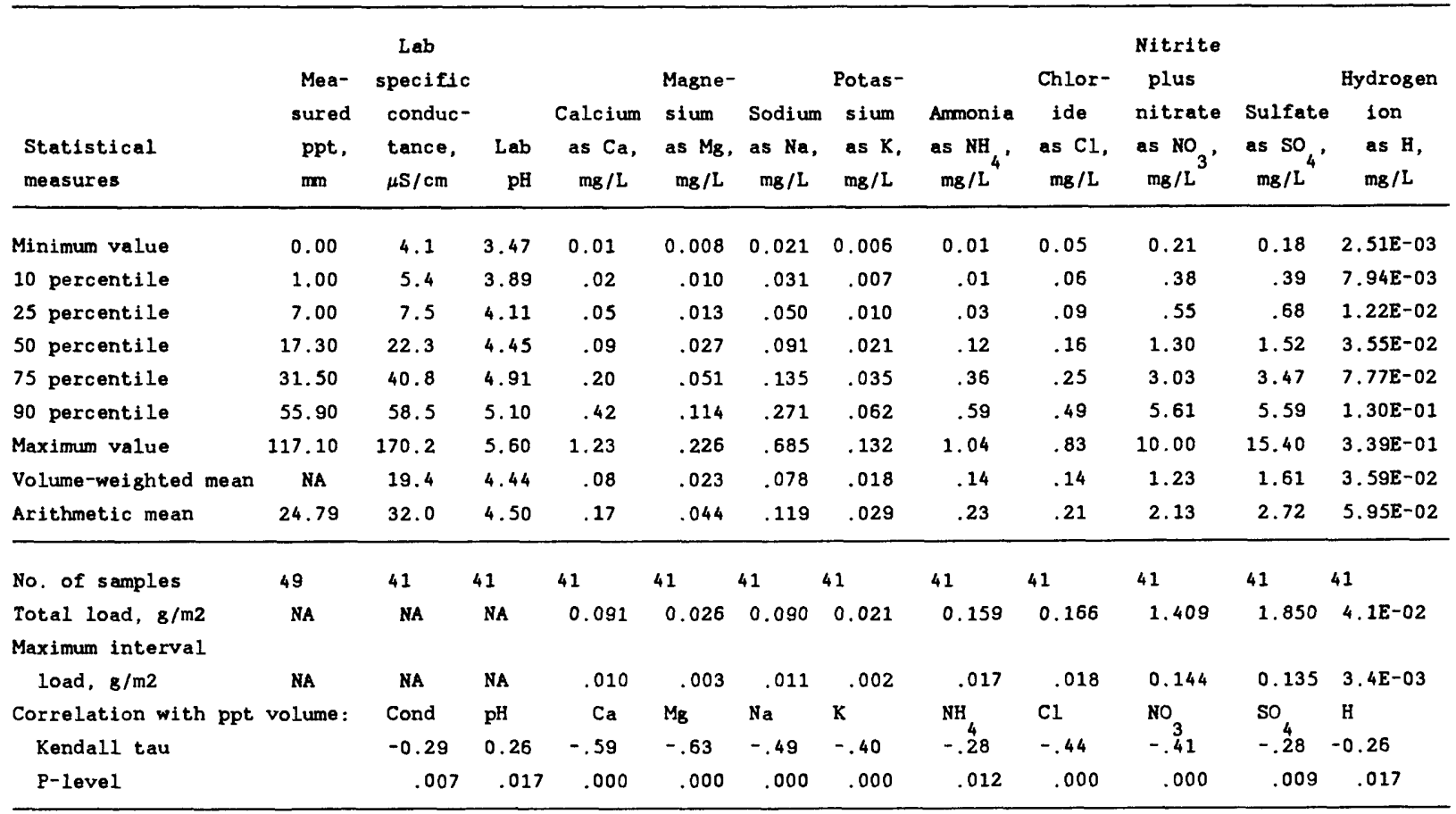

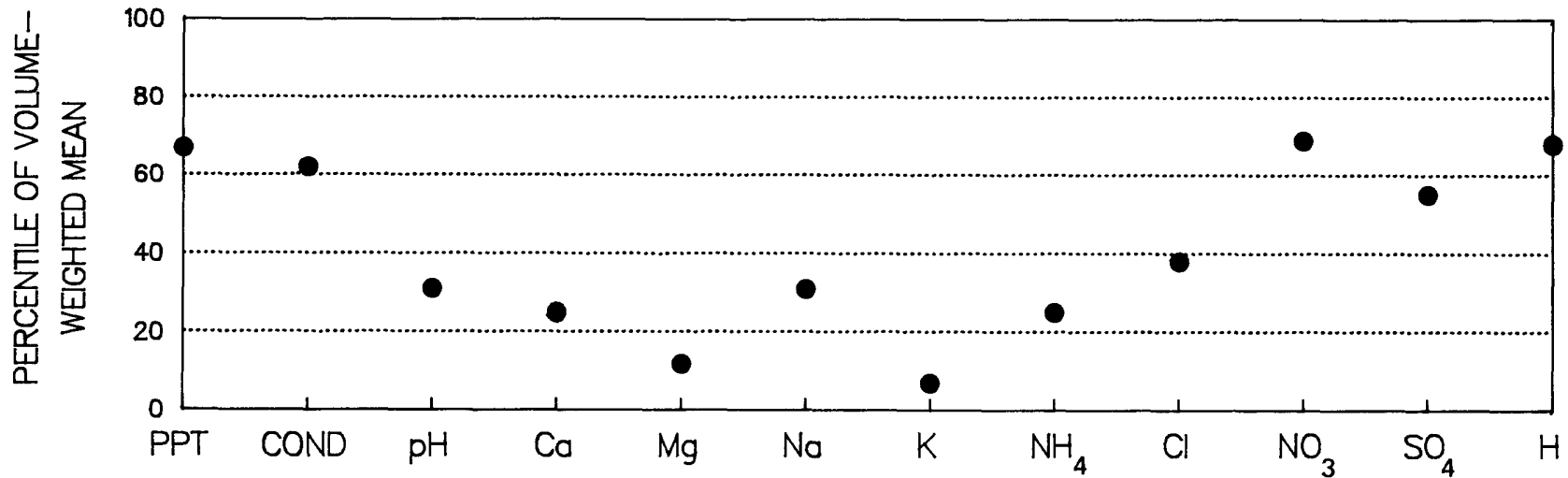

Percentiles of volume-weighted mean concentrations for site NY12, based on

frequency distributions of data from 55 National Trends Network sites. 

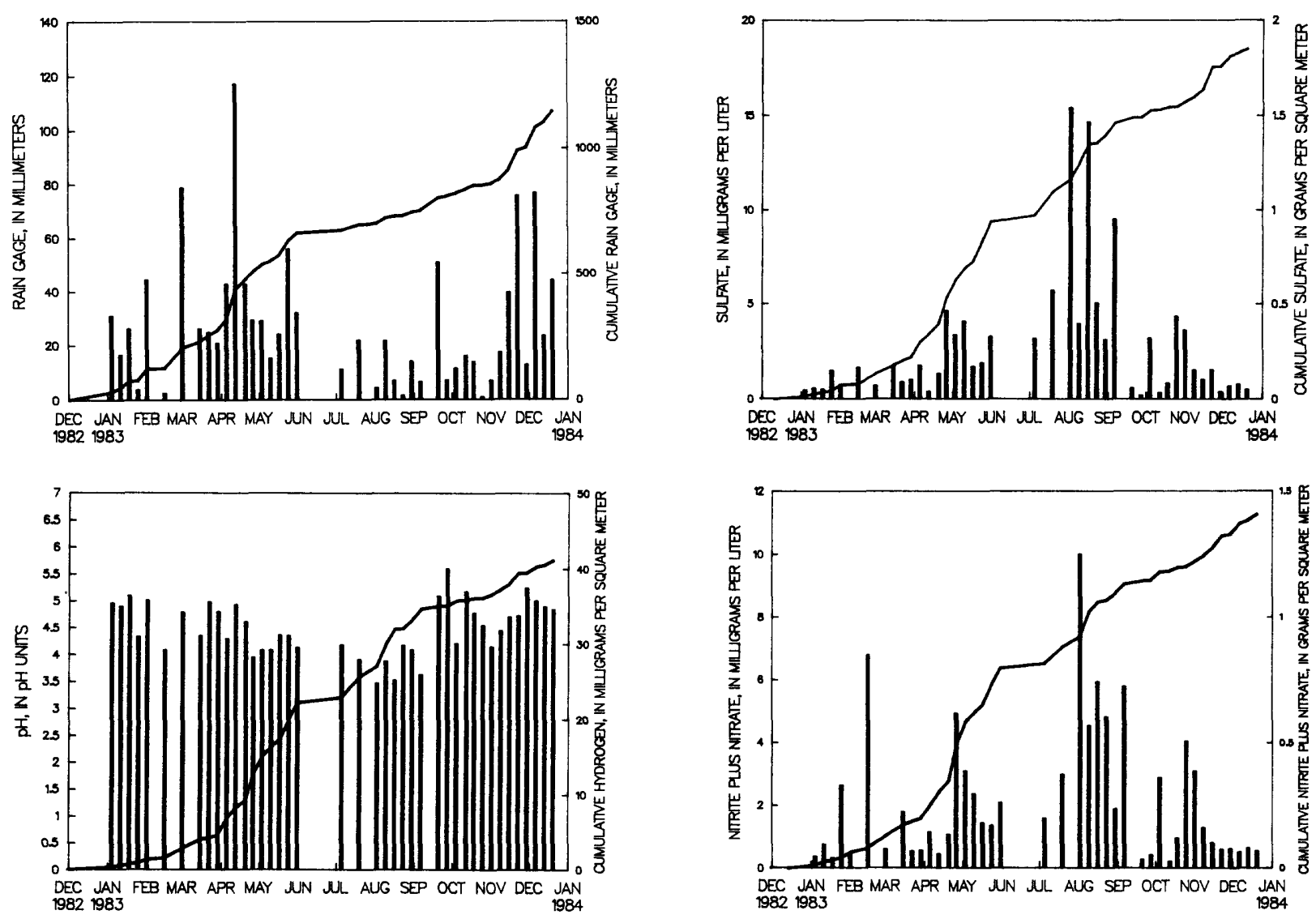

Bar plots of concentrations and cumulative line plots of loads for site NY12.

Nitrite plus nitrate are reported as $\mathrm{NO}_{3}$ and sulfate as $\mathrm{SO}_{4}$.

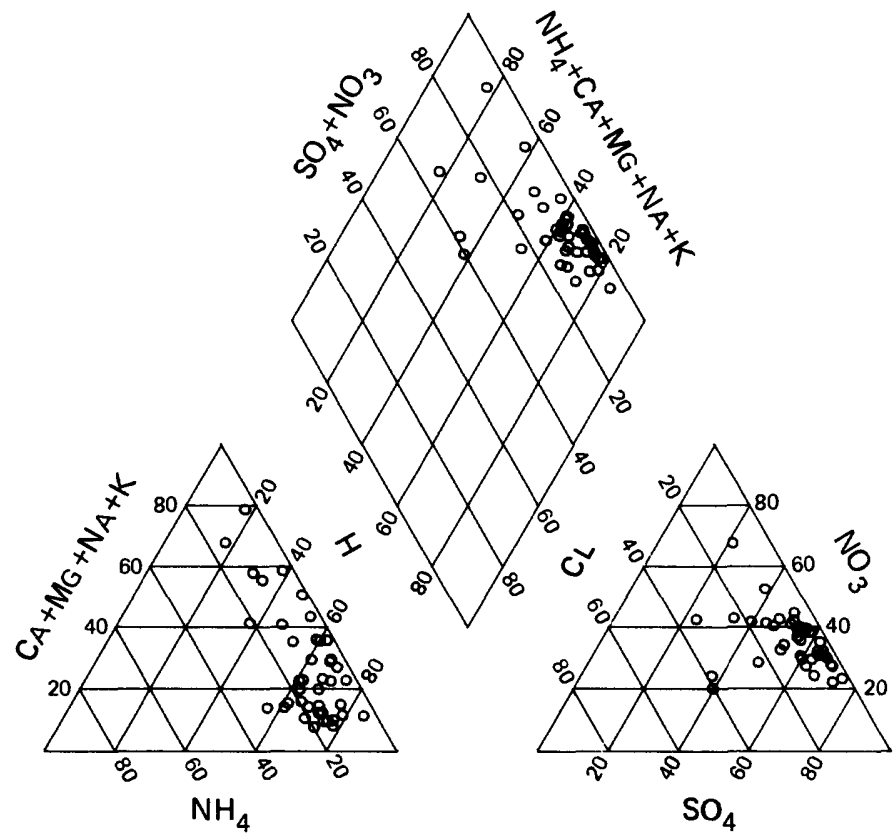

Percentage composition of major ions for site NY12. 


\section{NATIONAL TRENDS NETWORK -- 1983 CALENDER YEAR SUMMARY DATA}

[ppt $=$ precipitation; $\mathrm{mm}=$ millimeters $; \mathrm{cm}=$ centimeters; $\mathrm{mg}=$ milligrams; $\mathrm{L}=1$ iters; $\mathbf{g}=\mathbf{g r a m s} ; \mathrm{m}=$ meter $; \mu \mathrm{s}=$ microsiemens; cond = specific conductance $]$

STATION: Stilwell Lake, New York

CAL number: NY51

ADS number: $045 a 00$

Station eltitude above mean sea level, in meters: 186

Number of sampling intervals (days in parenthesis):

-- With ppt measurements: $53 \quad$ (371)

-- When ppt occurred: 51 (357)

-- When ppt did not occur: 2 ( 14)

-- When sample volume was substituted for missing rain gage: $0(0)$

-- With chemical samples: 41 (287)
Latitude: $41^{\circ} 21^{\prime} 00^{\prime \prime}$ Longitude: $\quad 74^{\circ} 02^{\prime} 22^{\prime \prime}$

Station summary period: $12 / 28 / 1982$ to $01 / 03 / 1984$

Length of summery period: 53 sampling intervals ( 371 days)

Percent summary period with ppt measurements: 100.0

Percent summary period with chemical samples or no ppt: 81.1

Percent of total measured ppt with chemical samples: 88.5

Percent of total measured ppt in raingage that was

collected in the wet-sample bucket:

93.7

Total measured ppt, in m: 1851.2

\begin{tabular}{|c|c|c|c|c|c|c|c|c|c|c|c|c|}
\hline $\begin{array}{l}\text { Statistical } \\
\text { measures }\end{array}$ & $\begin{array}{l}\text { Mea- } \\
\text { sured } \\
\text { ppt, } \\
\text { mm }\end{array}$ & $\begin{array}{c}\text { Lab } \\
\text { specific } \\
\text { conduc- } \\
\text { tance, } \\
\mu S / c m\end{array}$ & $\begin{array}{r}\text { Lab } \\
\mathrm{pH}\end{array}$ & $\begin{array}{c}\text { Calcium } \\
\text { as Ca, } \\
\mathrm{ms} / \mathrm{L}\end{array}$ & $\begin{array}{c}\text { Magne- } \\
\text { sium } \\
\text { as Mg, } \\
\mathrm{mg} / \mathrm{L}\end{array}$ & $\begin{array}{c}\text { Sodium } \\
\text { as } \mathrm{Na} \text {, } \\
\mathrm{mg} / \mathrm{L}\end{array}$ & $\begin{array}{l}\text { Potas- } \\
\text { sium } \\
\text { as } \mathrm{K} \text {, } \\
\mathrm{mg} / \mathrm{L}\end{array}$ & $\begin{array}{l}\text { Ammonia } \\
\text { as } \mathrm{NH}_{\mathrm{mg}} \mathrm{L}^{\circ}\end{array}$ & $\begin{array}{c}\text { Chlor- } \\
\text { ide } \\
\text { as } \mathrm{Cl} \text {, } \\
\mathrm{mg} / \mathrm{L}\end{array}$ & $\begin{array}{l}\text { Nitrite } \\
\text { plus } \\
\text { nitrate } \\
\text { as } \mathrm{NO}_{3} \\
\mathrm{mg} / \mathrm{L}\end{array}$ & $\begin{array}{l}\text { Sulfate } \\
\text { as } \mathrm{SO}_{4} \text {, } \\
\mathrm{mg} / \mathrm{L}\end{array}$ & $\begin{array}{l}\text { Hydrogen } \\
\text { ion } \\
\text { as } \mathrm{H}, \\
\mathrm{mg} / \mathrm{L}\end{array}$ \\
\hline 10 percentile & .50 & 11.2 & 3.90 & .03 & .018 & .056 & .007 & .01 & .11 & .48 & .91 & $1.57 \varepsilon-02$ \\
\hline 25 percentile & 2.65 & 13.8 & 4.08 & .05 & .025 & .096 & .015 & .06 & .16 & .75 & 1.16 & $2.16 \mathrm{E}-02$ \\
\hline 50 percentile & 26.90 & 26.9 & 4.35 & .08 & .049 & .167 & .023 & .14 & .27 & 1.34 & 2.11 & $4.47 E-02$ \\
\hline 75 percentile & 54.10 & 41.9 & 4.66 & .21 & .112 & .448 & .043 & .33 & .77 & 2.84 & 3.62 & $8.32 E-02$ \\
\hline 90 percentile & 84.18 & 83.2 & 4.80 & 1.68 & .340 & 1.058 & .179 & .68 & 1.70 & 6.14 & 8.97 & $1.25 \mathrm{E}-01$ \\
\hline Maximum value & 174.80 & 180.7 & 5.86 & 2.39 & 1.849 & 11.888 & .921 & 1.67 & 20.95 & 12.55 & 20.68 & $2.75 E-01$ \\
\hline Arithmetic mean & 34.93 & 38.2 & 4.38 & .36 & .135 & .629 & .080 & .25 & 1.03 & 2.46 & 3.48 & $6.08 \mathrm{E}-02$ \\
\hline No. of samples & 53 & 41 & 41 & 41 & 41 & 41 & 41 & 41 & 41 & 41 & 41 & 41 \\
\hline $\begin{array}{l}\text { Total load, } 8 / \mathrm{m} 2 \\
\text { Maximum interval }\end{array}$ & NA & NA & NA & 0.120 & 0.075 & 0.447 & 0.035 & 0.181 & 0.788 & 1.793 & 2.824 & $6.2 E-02$ \\
\hline $10 \mathrm{ad}, \mathrm{g} / \mathrm{m} 2$ & NA & NA & NA & .008 & .016 & .127 & .005 & .018 & .226 & 0.130 & 0.206 & $5.1 E-03$ \\
\hline $\begin{array}{l}\text { Correlation with ppt } \\
\text { Kendall tau }\end{array}$ & volume: & $\begin{array}{l}\text { Cond } \\
-0.42\end{array}$ & $\begin{array}{c}\mathrm{pH} \\
0.33\end{array}$ & $\begin{array}{c}\mathrm{Ca} \\
-.48\end{array}$ & $\begin{array}{l}\mathrm{Mg} \\
-.43\end{array}$ & $\begin{array}{c}\mathrm{Na} \\
-.24\end{array}$ & $\begin{array}{c}K \\
-.48\end{array}$ & $\begin{array}{r}\mathrm{NH}_{4} \\
-.40\end{array}$ & $\begin{array}{c}\mathrm{Cl} \\
-.22\end{array}$ & $\begin{array}{l}\mathrm{NO}_{3} \\
-.51\end{array}$ & $\begin{array}{c}\mathrm{SO}_{4} \\
-.41-\end{array}$ & $\begin{array}{c}\text { H } \\
-0.33\end{array}$ \\
\hline P-level & & .000 & .003 & .000 & .000 & .028 & .000 & .000 & .049 & .000 & .000 & .003 \\
\hline
\end{tabular}

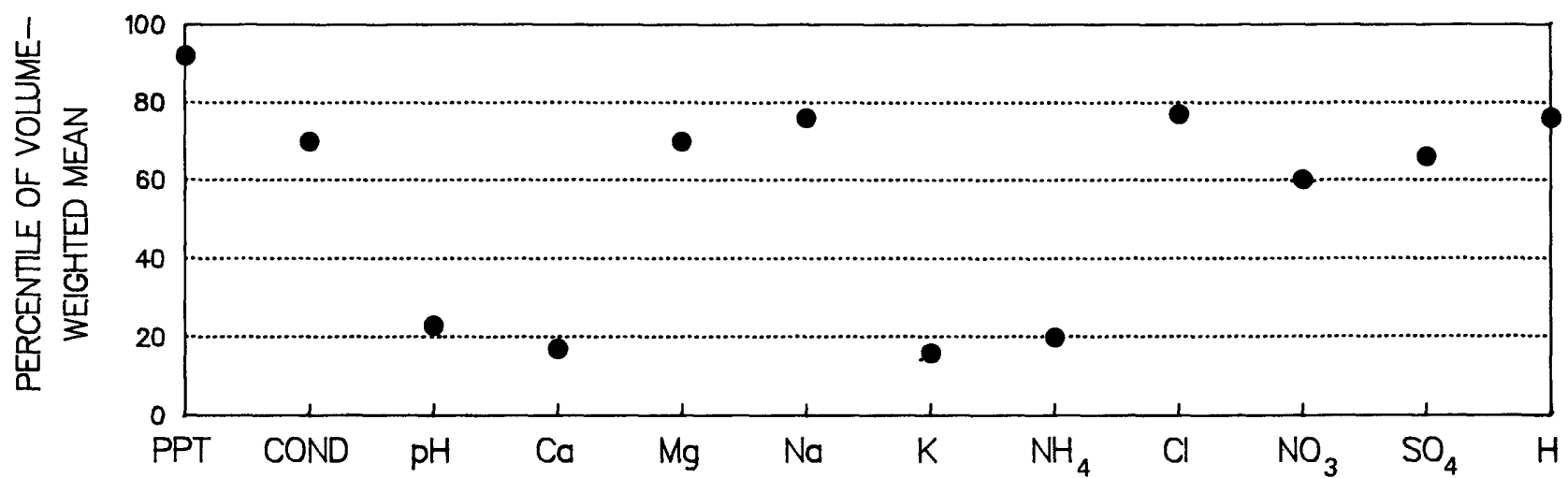

Percentiles of volume-weighted mean concentrations for site NY51, based on frequency distributions of data from 55 National Trends Network sites. 

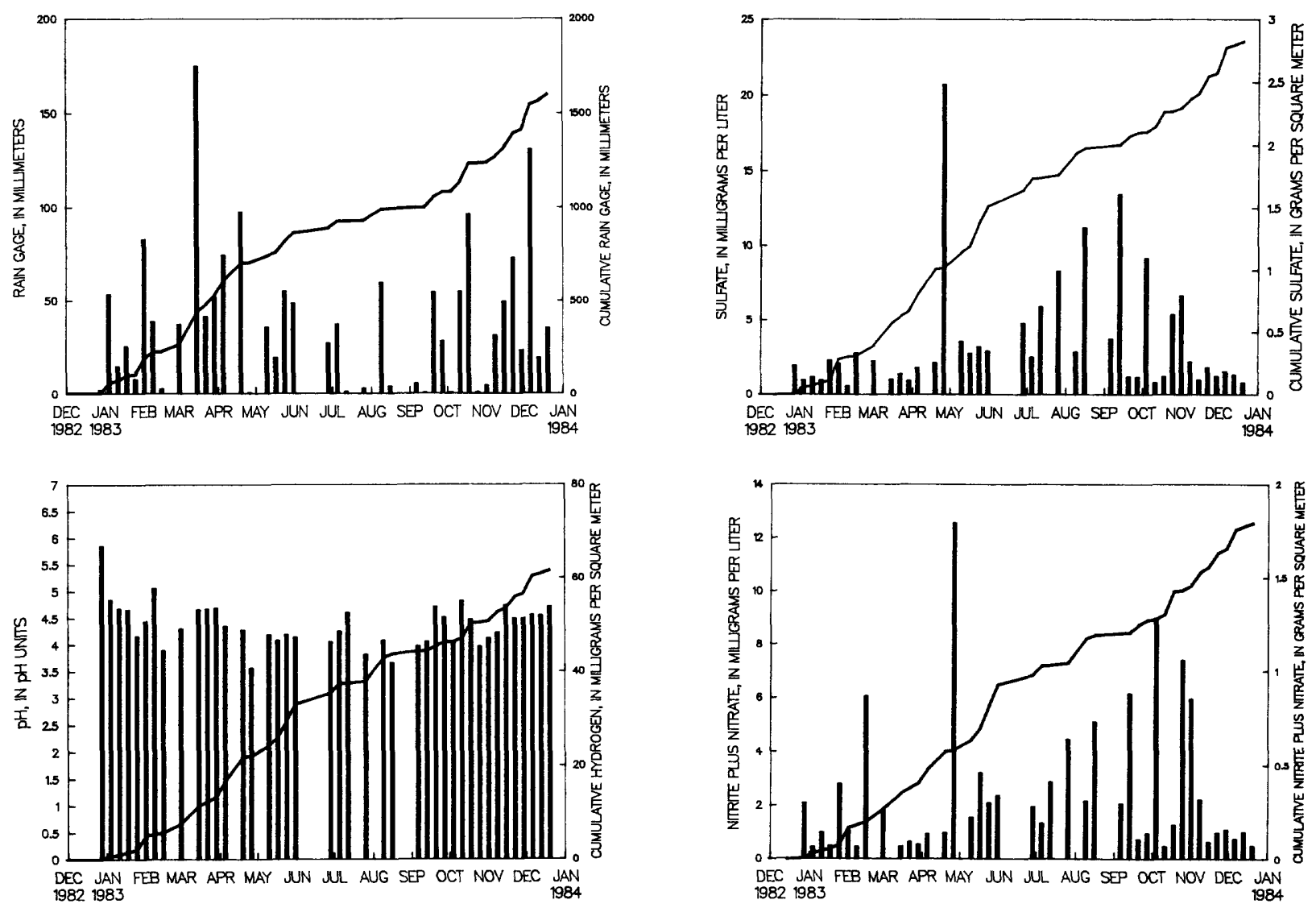

Bar plots of concentrations and cumulative line plots of loads for site NY51. Nitrite plus nitrate are reported as $\mathrm{NO}_{3}$ and sulfate as $\mathrm{SO}_{4}$.

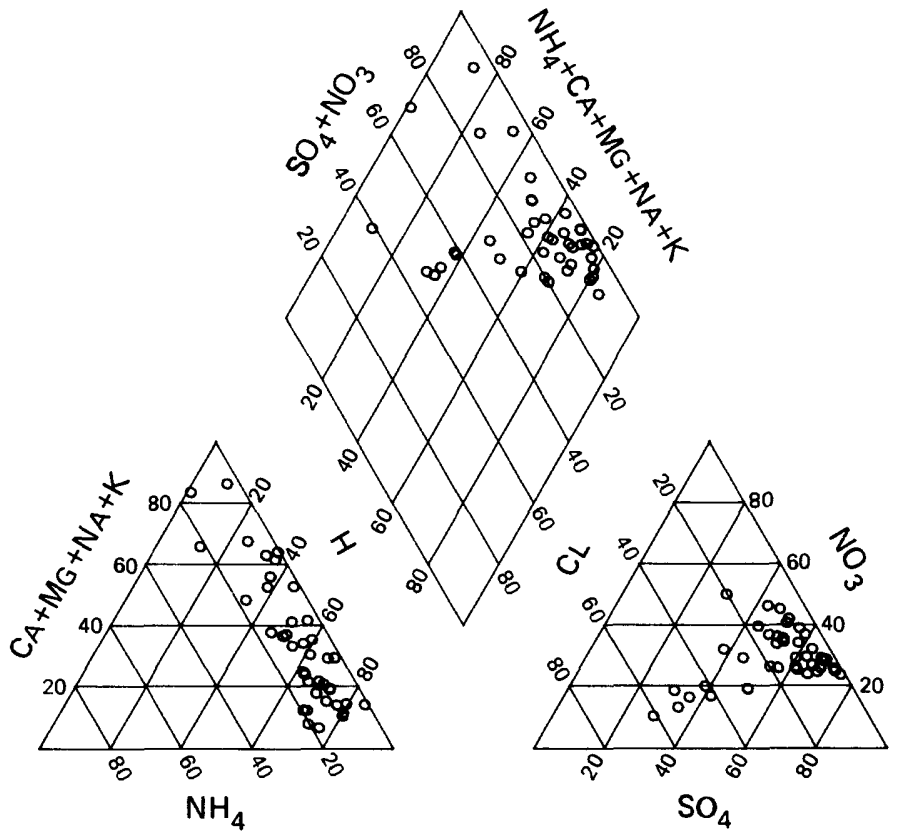

Percentage composition of major ions for site NY51. 


\section{NATIONAL TRENDS NETWORK -- 1983 CALENDER YEAR SUMMARY DATA}

[ppt = precipitation; $\mathrm{mm}=$ millimeters; $\mathrm{cm}=$ centimeters; $\mathrm{mg}=$ milligrams; $\mathrm{L}=1$ iters;

$8=8 \mathrm{rams} ; \mathrm{m}=$ meter; $\mu \mathrm{s}=$ microsiemens; cond = specific conductance $]$

STATION: Bennett Bridge, New York

CAL number: NY52

ADS number: $046 a 00$

Station altitude above mean sea level, in meters: 245

Number of sampling intervals (days in parenthesis):

-- With ppt measurements: $51 \quad$ (364)

-- When ppt occurred: 49 (351)

-- When ppt did not occur: 2 ( 13)

-- When sample volume was substituted for missing rain gage: 0 ( 0$)$

-- With chemical samples: 44 (317)
Latitude: $43^{\circ} 31^{\prime} 34^{\prime \prime}$ Longitude: $75^{\circ} 56^{\prime} 50^{\prime \prime}$

Station summary period: $12 / 28 / 1982$ to $01 / 03 / 1984$

Length of summary period: 52 sampling intervals ( 371 days)

Percent summary period with ppt measurements: 98.1

Percent summary period with chemical samples or no ppt: 88.9

Percent of total measured ppt with chemical samples: 88.0

Percent of total measured ppt in raingage that was

collected in the wet-sample bucket:

94.2

Total measured ppt, in mm: 1458.4

\begin{tabular}{|c|c|c|c|c|c|c|c|c|c|c|c|c|}
\hline $\begin{array}{l}\text { Statistical } \\
\text { measures }\end{array}$ & $\begin{array}{c}\text { Mea- } \\
\text { sured } \\
\text { ppt, } \\
\text { mm }\end{array}$ & $\begin{array}{l}\text { Lab } \\
\text { specific } \\
\text { conduc- } \\
\text { tance, } \\
\mu \mathrm{S} / \mathrm{cm}\end{array}$ & $\begin{array}{r}\mathrm{Lab} \\
\mathrm{pH}\end{array}$ & $\begin{array}{c}\text { Calcium } \\
\text { as Ca, } \\
\mathrm{mg} / \mathrm{L}\end{array}$ & $\begin{array}{l}\text { Magne- } \\
\text { sium } \\
\text { as Mg, } \\
\mathrm{mg} / \mathrm{L}\end{array}$ & $\begin{array}{l}\text { Sodium } \\
\text { as } \mathrm{Na} \text {, } \\
\mathrm{mg} / \mathrm{L}\end{array}$ & $\begin{array}{l}\text { Potas- } \\
\text { sium } \\
\text { as } K \text {, } \\
\text { mg/L }\end{array}$ & $\begin{array}{l}\text { Ammonia } \\
\text { as } \mathrm{NH}_{4} \text {, } \\
\mathrm{mg} / \mathrm{L}\end{array}$ & $\begin{array}{l}\text { Chlor- } \\
\text { ide } \\
\text { as } \mathrm{Cl} \text {, } \\
\mathrm{mg} / \mathrm{L}\end{array}$ & $\begin{array}{l}\text { Nitrite } \\
\text { plus } \\
\text { nitrate } \\
\text { as } \mathrm{NO}_{3} \text {. } \\
\mathrm{mg} / \mathrm{L}\end{array}$ & $\begin{array}{l}\text { Sulfate } \\
\text { as } \mathrm{SO}_{4} \\
\mathrm{mg} / \mathrm{L}^{\prime}\end{array}$ & $\begin{array}{l}\text { Hydrogen } \\
\text { ion } \\
\text { as } \mathrm{H} \\
\mathrm{mg} / \mathrm{L}\end{array}$ \\
\hline Minimum value & 0.00 & 8.0 & 3.44 & 0.03 & 0.009 & 0.015 & 0.008 & 0.01 & 0.07 & 0.59 & 0.71 & $5.89 E-03$ \\
\hline 10 percentile & 1.20 & 11.9 & 3.87 & .05 & .013 & .024 & .011 & .07 & .09 & .87 & .95 & $1.85 \mathrm{E}-02$ \\
\hline 25 percentile & 12.20 & 17.0 & 4.03 & .09 & .020 & .040 & .014 & .16 & .11 & 1.51 & 1.32 & 2. $82 \mathrm{E}-02$ \\
\hline 50 percentile & 22.90 & 28.9 & 4.30 & .15 & .030 & .068 & .031 & .31 & .17 & 2.03 & 2.77 & $4.96 \mathrm{E}-02$ \\
\hline 75 percentile & 39.40 & 52.4 & 4.55 & .35 & .066 & .136 & .049 & .58 & .24 & 2.87 & 4.70 & $9.28 \mathrm{E}-02$ \\
\hline 90 percentile & 62.10 & 71.1 & 4.73 & .91 & .204 & .386 & .138 & .85 & .66 & 5.34 & 6.71 & $1.34 \mathrm{E}-01$ \\
\hline Maximum value & 73.70 & 203.7 & 5.23 & 1.62 & .283 & .753 & .495 & 2.30 & 2.03 & 28.44 & 12.02 & $3.63 \mathrm{E}-01$ \\
\hline Volume-weighted mean & NA & 31.2 & 4.23 & .15 & .030 & .075 & .031 & .32 & .17 & 2.04 & 2.72 & $5.89 \mathrm{E}-02$ \\
\hline Arithmetic mean & 28.60 & 40.2 & 4.29 & .29 & .059 & .131 & .058 & .43 & .28 & 3.24 & 3.29 & $7.09 \mathrm{E}-02$ \\
\hline No. of samples & 51 & 44 & 44 & 44 & 44 & 44 & 44 & 44 & 44 & 44 & 44 & 44 \\
\hline $\begin{array}{l}\text { Total load, } 8 / \mathrm{m} 2 \\
\text { Maximum interval }\end{array}$ & NA & NA & NA & 0.186 & 0.039 & 0.096 & 0.039 & 0.413 & 0.220 & 2.625 & 3.494 & $7.6 \mathrm{E}-02$ \\
\hline load, $8 / \mathrm{m} 2$ & NA & NA & NA & .010 & .002 & .015 & .008 & .034 & .022 & 0.192 & 0.390 & $9.3 E-03$ \\
\hline $\begin{array}{l}\text { Correlation with ppt } \\
\text { Kendall tau }\end{array}$ & volume: & $\begin{array}{l}\text { Cond } \\
-0.26\end{array}$ & $\begin{array}{c}\mathrm{pH} \\
0.18\end{array}$ & $\begin{array}{c}C a \\
-.51\end{array}$ & $\begin{array}{l}M B \\
-.55\end{array}$ & $\begin{array}{l}\mathrm{Na} \\
-.46\end{array}$ & $\begin{array}{c}K \\
-.53\end{array}$ & $\begin{array}{l}\mathrm{NH}_{4} \\
-.25\end{array}$ & $\begin{array}{l}\mathrm{Cl} \\
-.37\end{array}$ & $\mathrm{NO}_{3}$ & $\begin{array}{l}\mathrm{SO}_{4} \\
-.26\end{array}$ & $\begin{array}{l}\mathrm{B} \\
-0.18\end{array}$ \\
\hline P-level & & .014 & .085 & .000 & .000 & .000 & .000 & .019 & .001 & .001 & .012 & .085 \\
\hline
\end{tabular}

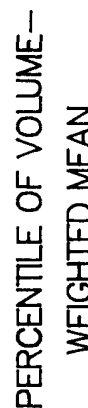

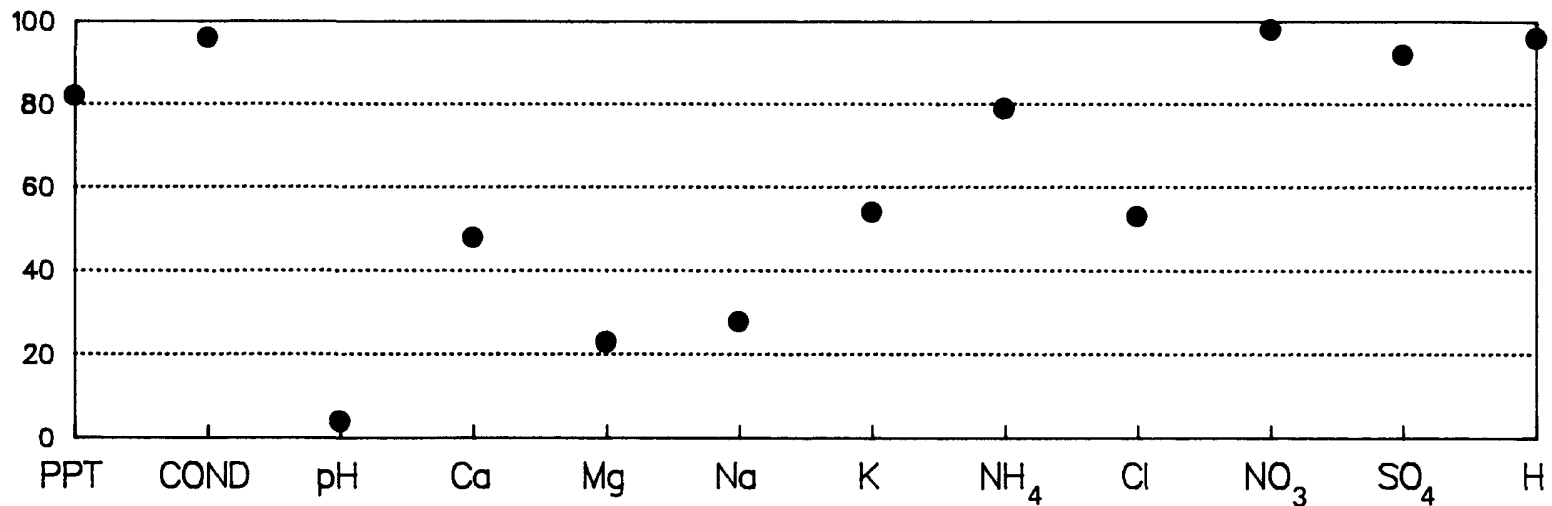

Percentiles of volume-weighted mean concentrations for site NY52, based on

frequency distributions of data from 55 National Trends Network sites. 

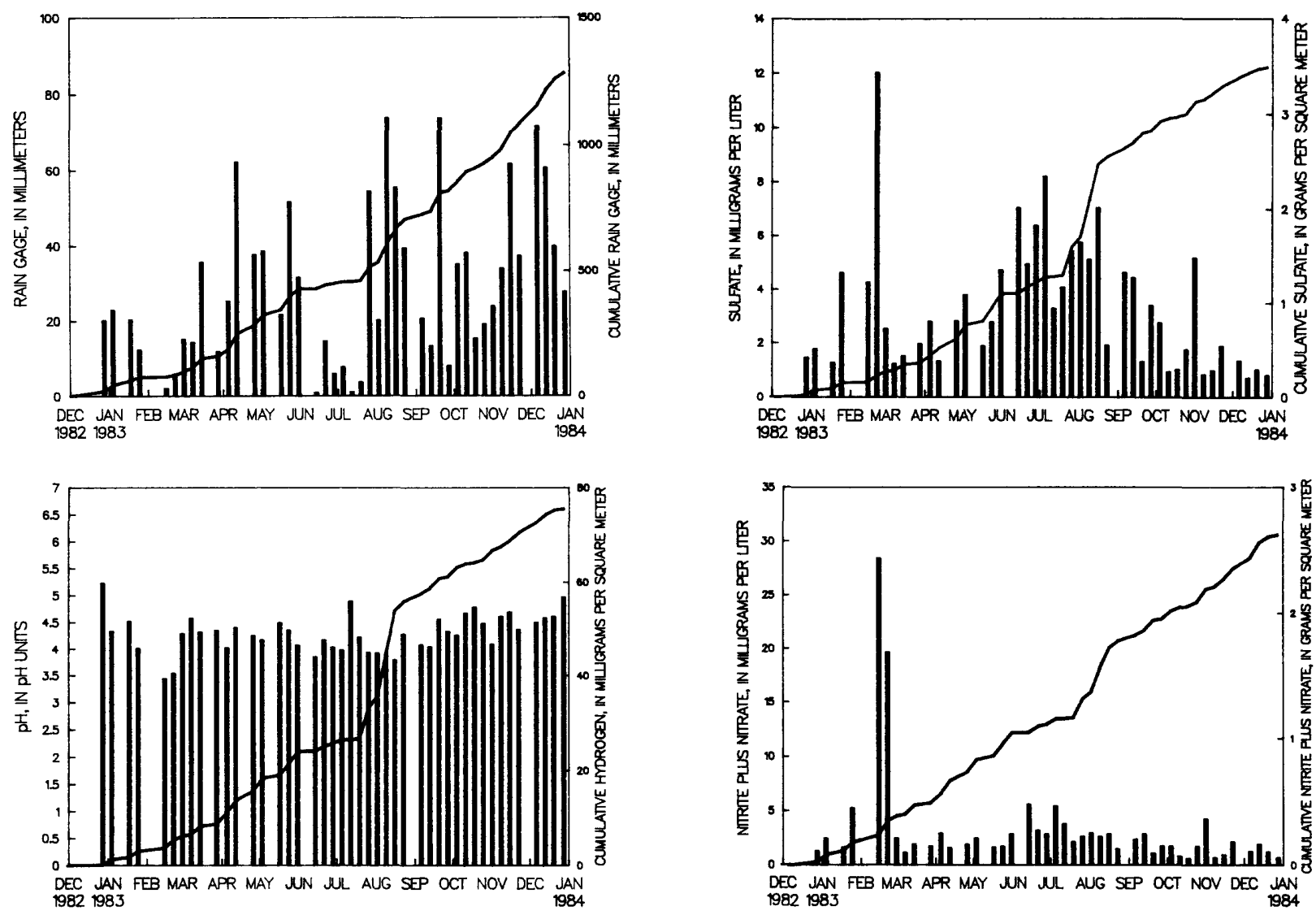

Bar plots of concentrations and cumulative line plots of loads for site NY52. Nitrite plus nitrate are reported as $\mathrm{NO}_{3}$ and sulfate as $\mathrm{SO}_{4}$.

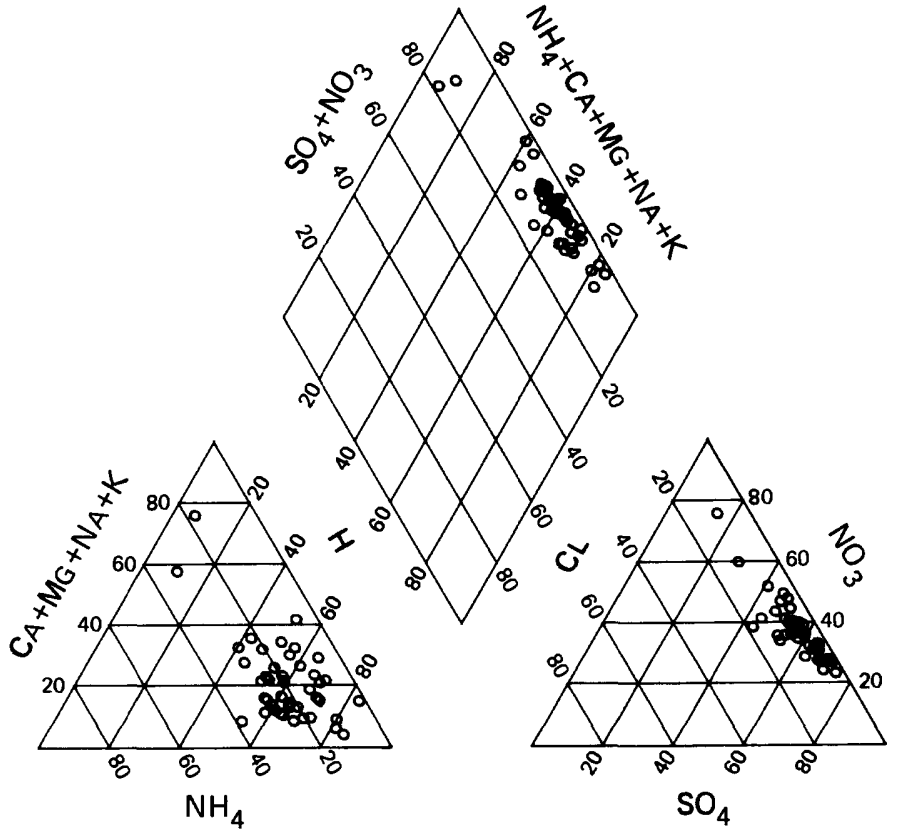

Percentage composition of major ions for site NY52. 


\section{NATIONAL TRENDS NETWORK -- 1983 CALENDER YEAR SUMMARY DATA}

lppt $=$ precipitation; $\mathrm{mm}=$ millimeters; $\mathrm{cm}=$ centimeters; $\mathrm{mg}=$ milligrams; $\mathrm{L}=1 \mathrm{iters}$;

$\mathrm{B}=\mathrm{Brams} ; \mathrm{m}=$ meter; $\mu \mathrm{s}=$ microsiemens; cond = specific conductance $]$

STATION: Jasper, New York

CAL number: NY65

ADS number: $047 \mathrm{a} 00$

Station altitude above mean sea level, in meters: 634 Number of sampling intervals (days in parenthesis):

-- With ppt measurements: $52 \quad$ (371)

-- When ppt occurred: 50 (357)

-- When ppt did not occur: 2 ( 14)

- When sample volume was substituted for missing rain gage: 6 ( 43 )

-- With chemical samples: $44 \quad$ (308)
Latitude: $42^{\circ} 06^{\prime} 22^{\prime \prime}$ Longitude: $77^{\circ} 32^{\prime} 08^{\prime \prime}$

Station summary period: $12 / 28 / 1982$ to $01 / 03 / 1984$

Length of sumary period: 52 sampling intervals ( 371 days)

$\begin{array}{ll}\text { Percent summary period with ppt measurements: } & 100.0\end{array}$

Percent summary period with chemical samples or no ppt: 86.8

Percent of total measured ppt with chemical samples: 96.2

Percent of total measured ppt in raingage that was

collected in the wet-sample bucket:

95.8

Total measured ppt, in mm: 672.1

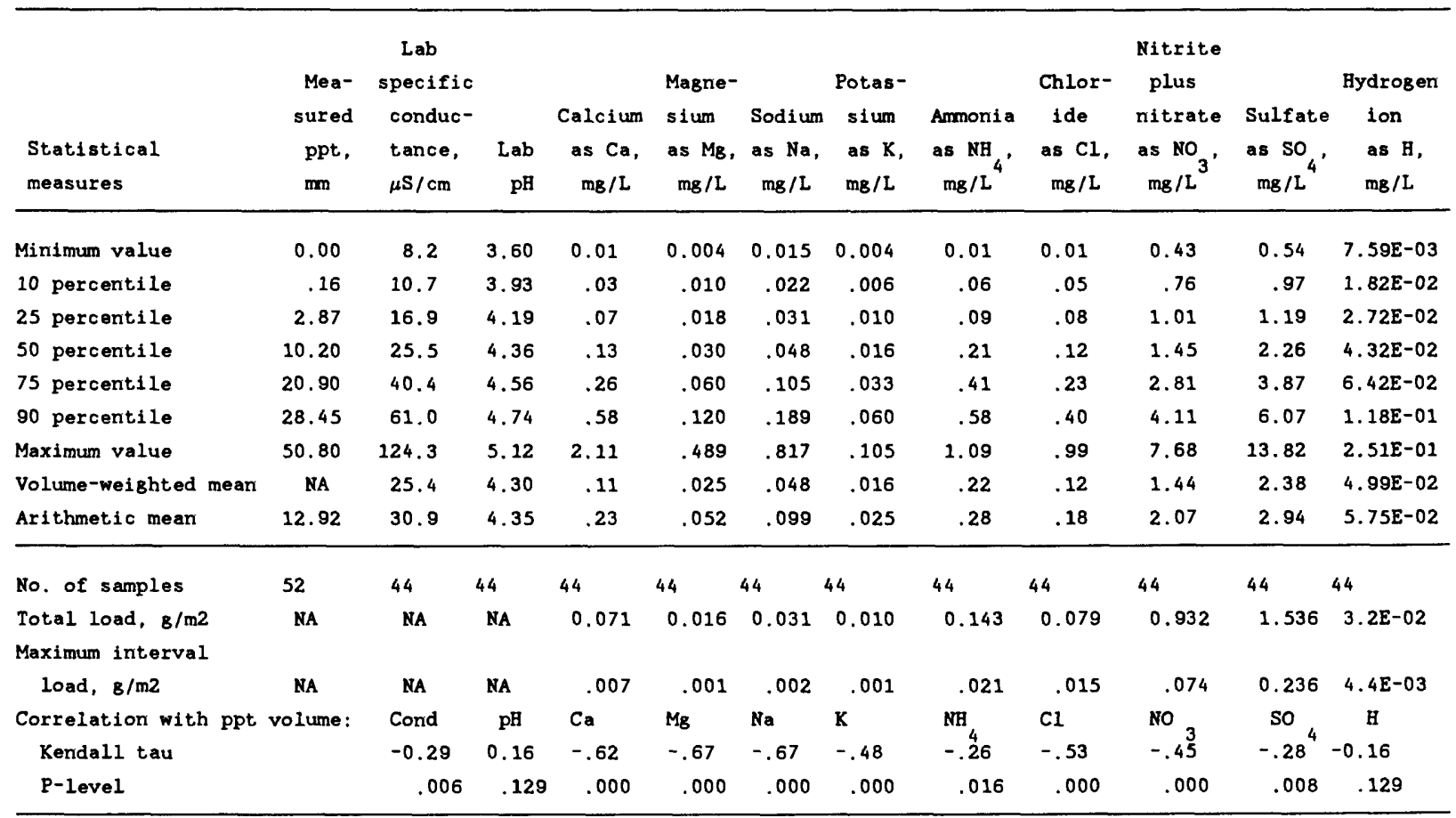

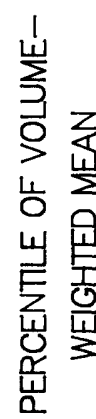

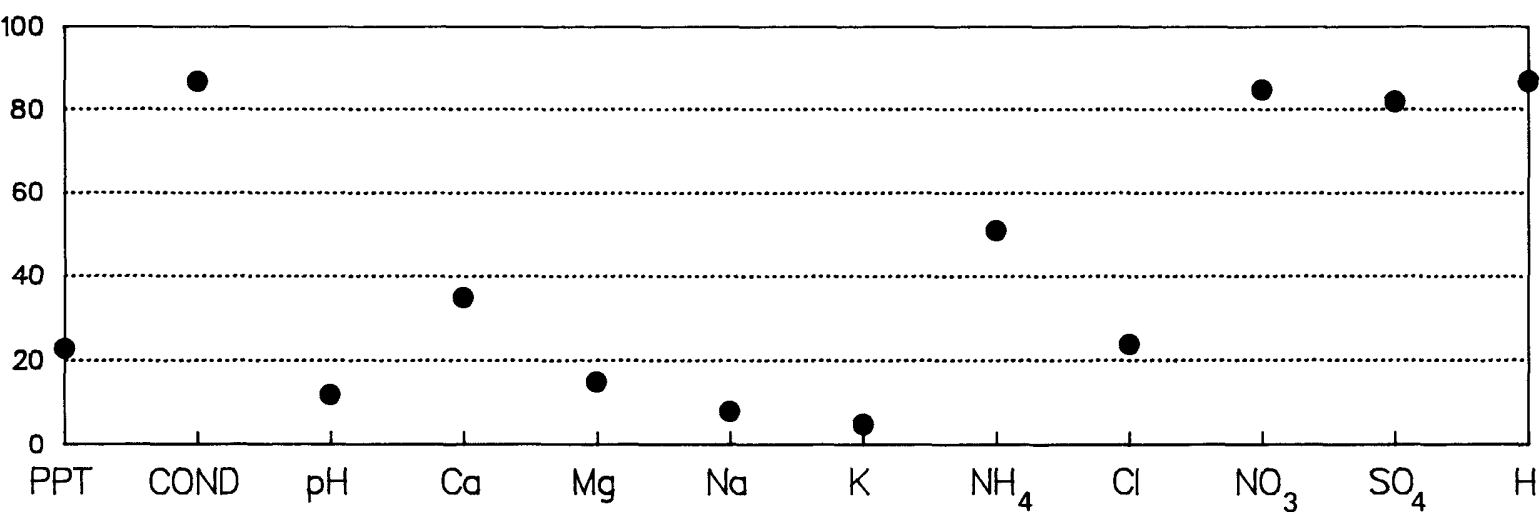

Percentiles of volume-weighted mean concentrations for site NY65, based on frequency distributions of data from 55 National Trends Network sites. 

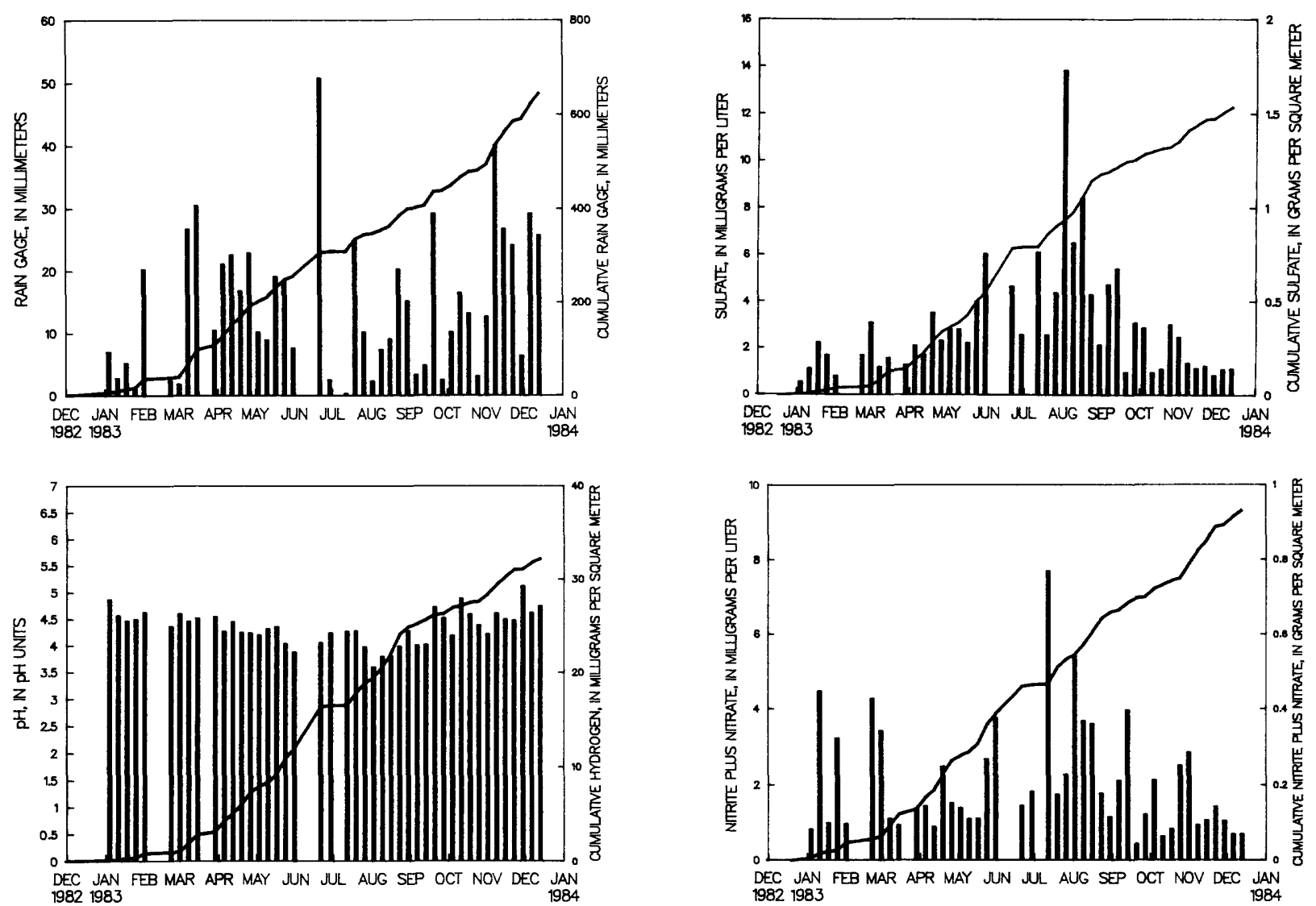

Bar plots of concentrations and cumulative line plots of loads for site NY65. Nitrite plus nitrate are reported as $\mathrm{NO}_{3}$ and sulfate as $\mathrm{SO}_{4}$.

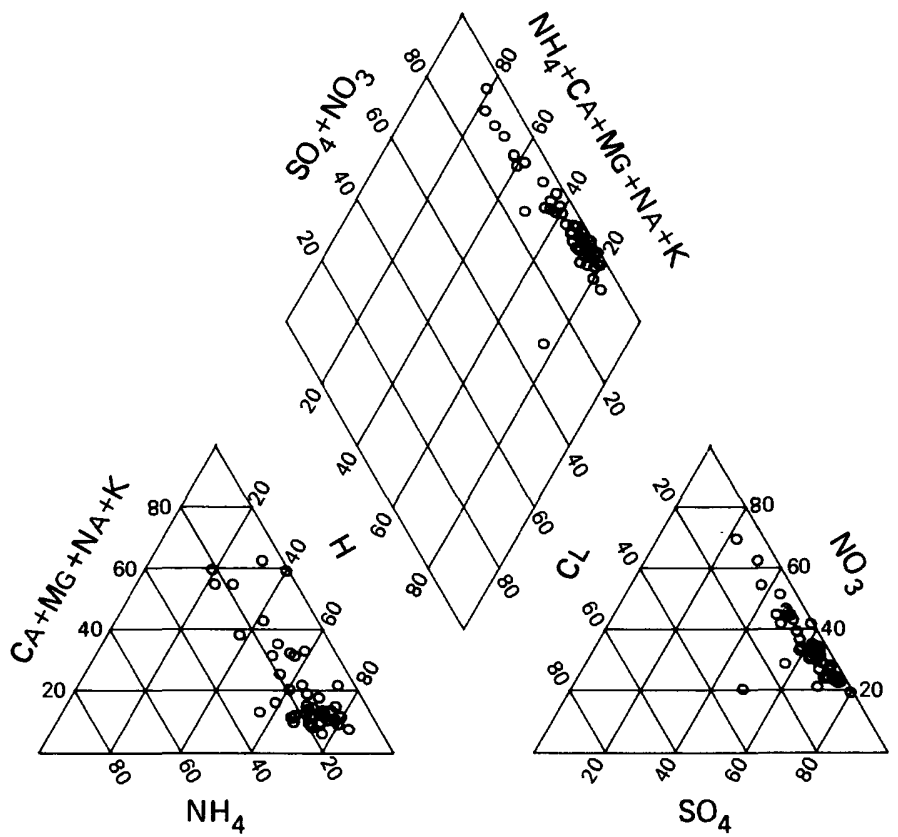

Percentage composition of major ions for site NY65. 


\section{NATIONAL TRENDS NETWORK - 1983 CALENDER YEAR SUMMARY DATA}

lppt = precipitation; $\mathrm{mm}=$ millimeters; $\mathrm{cm}=$ centimeters; $\mathrm{mg}=$ milligrams; $\mathrm{L}=11$ ters;

$8=\operatorname{grams} ; \mathrm{m}=$ meter $\boldsymbol{\mu s}=$ microsiemens; cond = specific conductance $]$

STATION: Delaware, Ohio

CAL number: $\mathrm{OH} 17$

ADS number: $055 \mathrm{a00}$

Station altitude above mean sea level, in meters: 285

Number of sampling intervals (days in parenthesis):

-- With ppt measurements: 53 (371)

-- When ppt occurred: $52 \quad$ (364)

-- When ppt did not occur: 11 ( 7)

-- When sample volume was substi-

tuted for missing rain gage: 0 ( 0 )

-- With chemical samples: $40 \quad$ (280)
Latitude: $40^{\circ} 21^{\prime} 19^{\prime \prime}$ Longitude: $83^{\circ} 03^{\prime} 58^{\prime \prime}$

Station summary period: $12 / 28 / 1982$ to $01 / 03 / 1984$

Length of summary period: 53 sampling intervals ( 371 days)

Percent sumary period with ppt measurements:

100.0

Percent summary period with chemical samples or no ppt: 77.4

Percent of total measured ppt with chemical samples: 83.5

Percent of total measured ppt in raingage that was

collected in the wet-sample bucket:

100.2

Total measured ppt, in $\mathrm{mm}: \mathbf{8 7 2 . 8}$

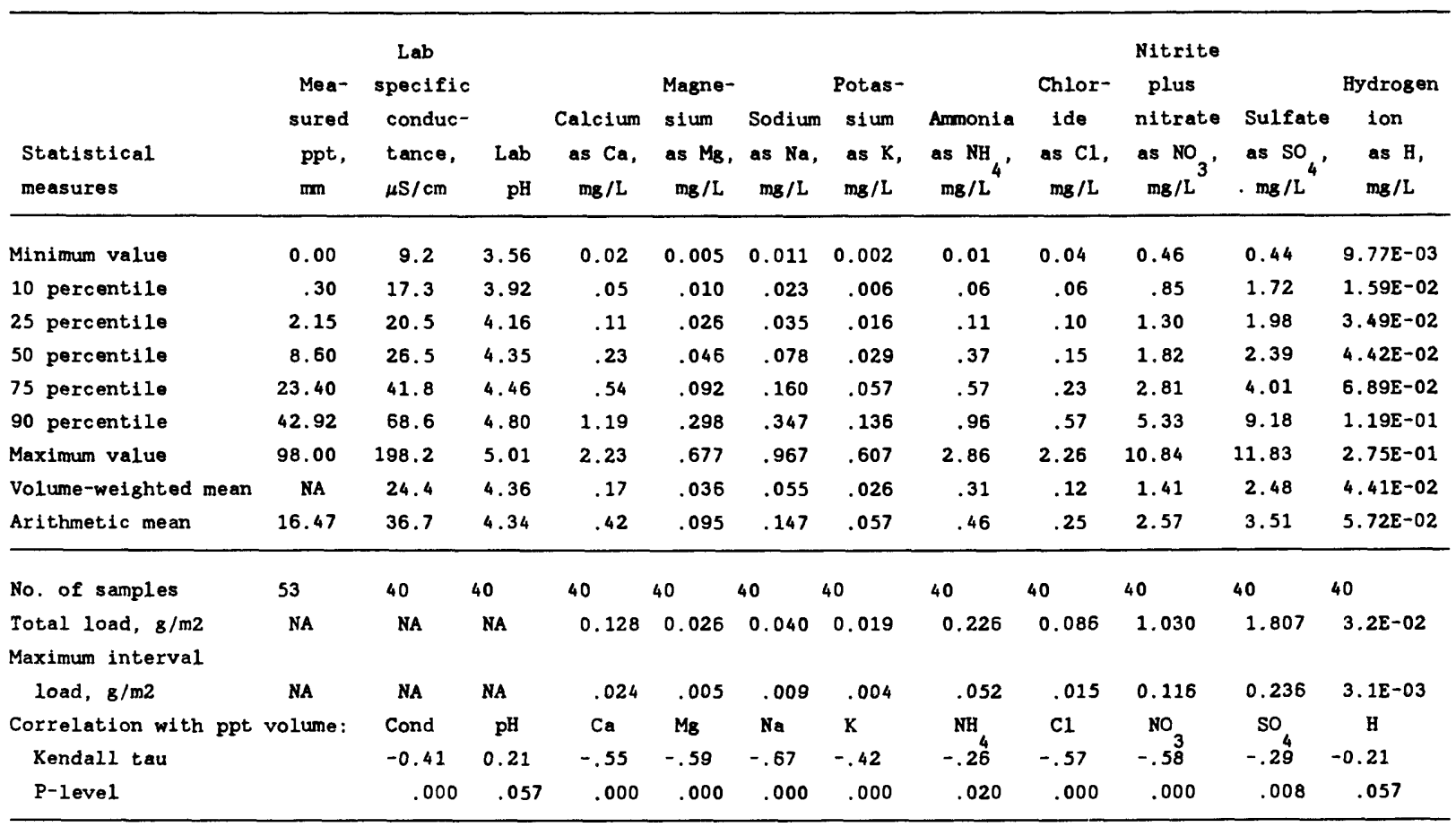

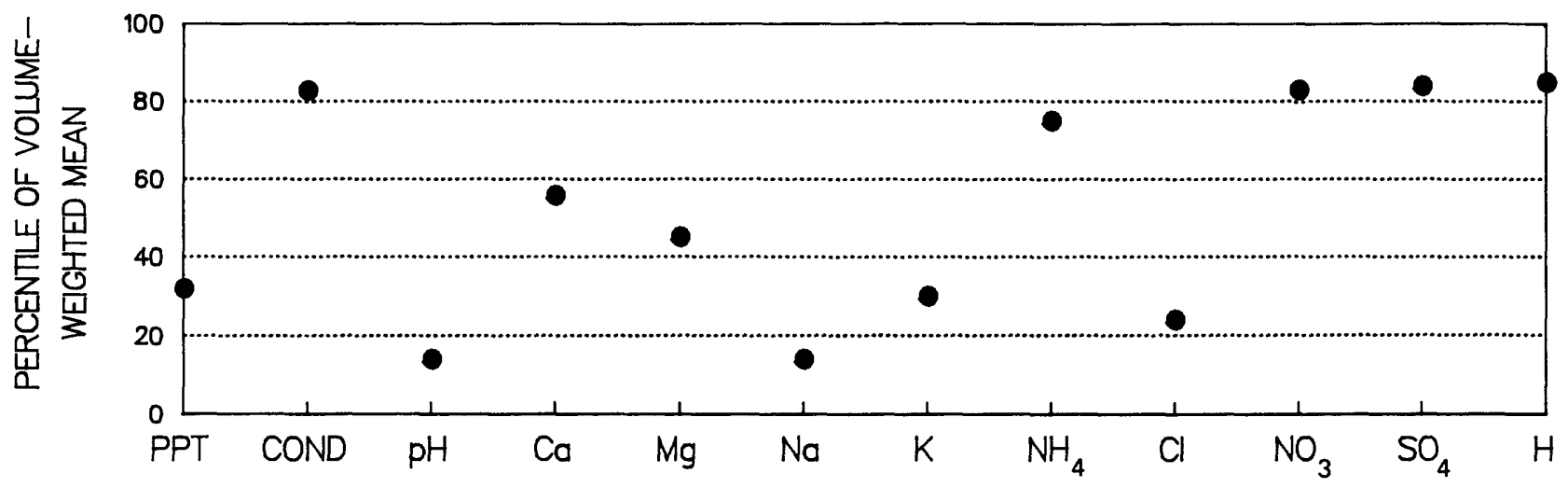

Percentiles of volume-weighted mean concentrations for site OH17, based on frequency distributions of data from 55 National Trends Network sites. 

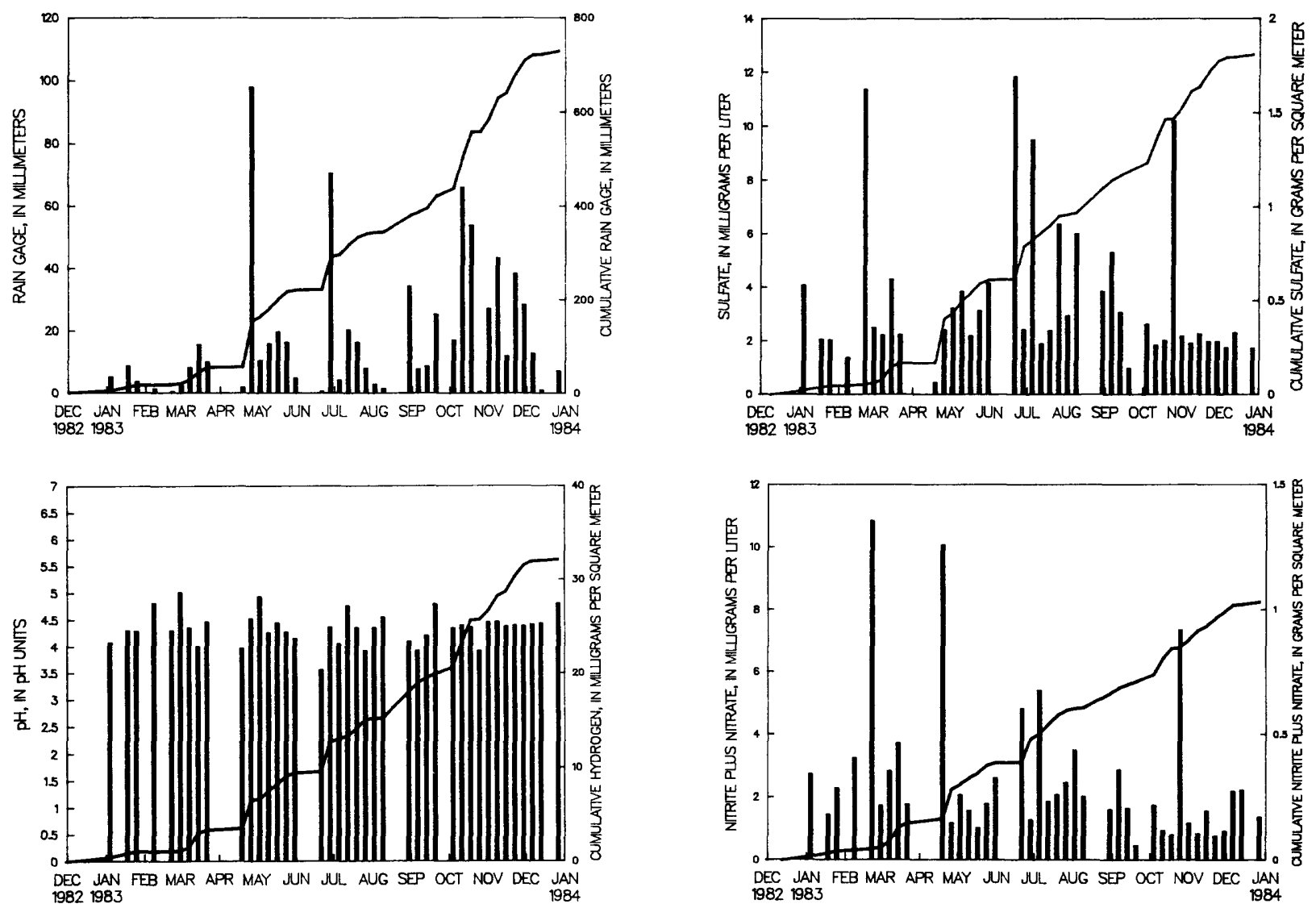

Bar plots of concentrations and cumulative line plots of loads for site OH17. Nitrite plus nitrate are reported as $\mathrm{NO}_{3}$ and sulfate as $\mathrm{SO}_{4}$

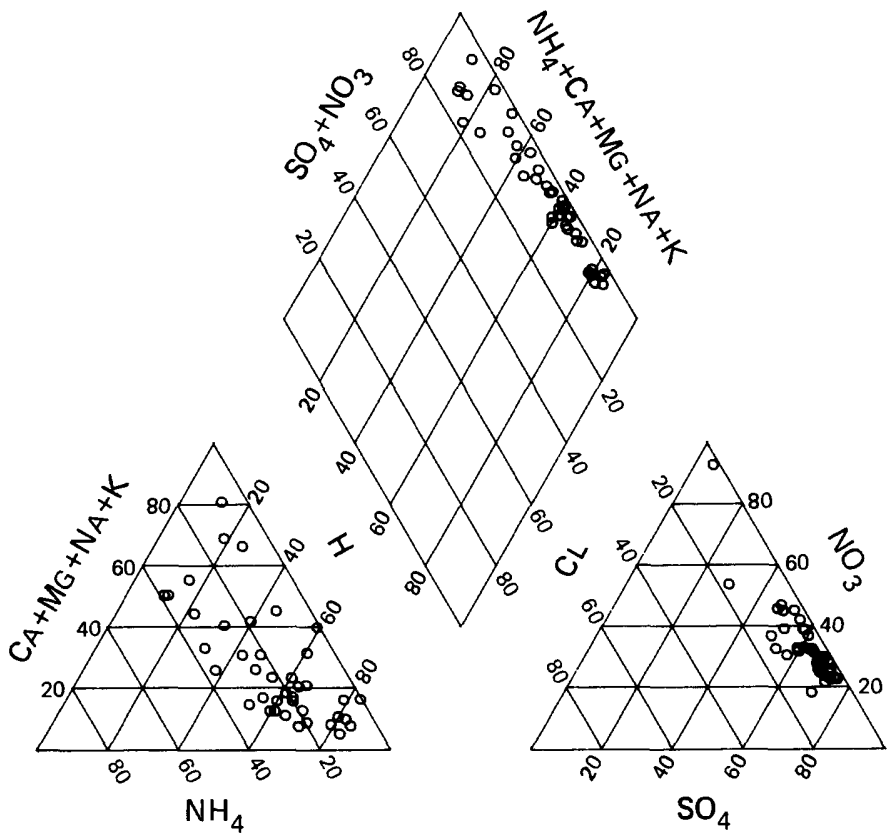

Percentage composition of major ions for site $\mathrm{OH} 17$. 


\section{NATIONAL TRENDS NETWORK -- 1983 CALENDER YEAR SUMMARY DATA}

[ppt $=$ precipitation; $\mathrm{mm}=$ millimeters $; \mathrm{cm}=$ centimeters; $\mathrm{mg}=\operatorname{milligrams;~L=~liters;~}$

$\mathrm{g}=\mathrm{grams} ; \mathrm{m}=$ meter $; \mu \mathrm{s}=$ microsiemens; cond = specific conductance $]$

STATION: Wooster, Ohio

CAL number: $\mathrm{OH} 71$

ADS number: $058 \mathrm{a} 00$

Station altitude above mean sea level, in meters: 315 Number of sampling intervals (days in parenthesis):

-- With ppt measurements: $\quad 53 \quad$ (371)

-- When ppt occurred: $52 \quad(364)$

-- When ppt did not occur: $11(7)$

-- When sample volume was substituted for missing rain gage:
Latitude: $40^{\circ} 46^{\circ} 48^{\prime \prime}$ Longitude: $81^{\circ} 55^{\prime} 31^{\prime \prime}$

Station sumary period: $12 / 28 / 1982$ to $01 / 03 / 1984$

Length of sumary period: 53 sampling intervals ( 371 days)

Percent sumary period with ppt measurements: $\quad 100.0$

Percent surmary period with chemical samples or no ppt: 67.9

Percent of total measured ppt with chemical samples: 70.5

Percent of total measured ppt in raingage that was

collected in the wet-sample bucket:

98.9

Total measured ppt, in m: 860.1

\begin{tabular}{|c|c|c|c|c|c|c|c|c|c|c|c|c|}
\hline $\begin{array}{l}\text { Statistical } \\
\text { measures }\end{array}$ & $\begin{array}{l}\text { Mea- } \\
\text { sured } \\
\text { ppt, } \\
\text { mm }\end{array}$ & $\begin{array}{l}\text { Lab } \\
\text { specific } \\
\text { conduc- } \\
\text { tance, } \\
\mu \mathrm{S} / \mathrm{cm}\end{array}$ & $\begin{array}{r}\mathrm{Lab} \\
\mathrm{pH}\end{array}$ & $\begin{array}{c}\text { Calcium } \\
\text { as Ca, } \\
\text { mg/L }\end{array}$ & $\begin{array}{l}\text { Magne- } \\
\text { sium } \\
\text { as } \mathrm{Mg}, \\
\mathrm{mg} / \mathrm{L}\end{array}$ & $\begin{array}{l}\text { Sodium } \\
\text { as } \mathrm{Na} \text {, } \\
\mathrm{mg} / \mathrm{L}\end{array}$ & $\begin{array}{l}\text { Potas- } \\
\text { sium } \\
\text { as } \mathrm{K}, \\
\mathrm{mg} / \mathrm{L}\end{array}$ & $\begin{array}{l}\text { Ammonia } \\
\text { as } \mathrm{NH}_{\mathrm{mg}} / \mathrm{L}^{\prime}\end{array}$ & $\begin{array}{c}\text { Chlor- } \\
\text { ide } \\
\text { as } \mathrm{Cl} \text {, } \\
\mathrm{mg} / \mathrm{L}\end{array}$ & $\begin{array}{l}\text { Nitrite } \\
\text { plus } \\
\text { nitrate } \\
\text { as } \mathrm{NO}_{3} \text { ' } \\
\mathrm{mg} / \mathrm{L}\end{array}$ & $\begin{array}{l}\text { Sulfate } \\
\text { as so } \\
\mathrm{mg} / \mathrm{L}^{\prime}\end{array}$ & $\begin{array}{l}\text { Hydrogen } \\
\text { ion } \\
\text { as } \mathrm{H} \\
\mathrm{mg} / \mathrm{L}\end{array}$ \\
\hline Minimum value & 0.00 & 11.7 & 3.69 & 0.04 & 0.012 & 0.017 & 0.005 & 0.06 & 0.01 & 0.59 & 1.03 & $8.91 E-03$ \\
\hline 10 percentile & .24 & 15.1 & 3.98 & .06 & .013 & .023 & .008 & .08 & .06 & .69 & 1.53 & $2.19 \mathrm{E}-02$ \\
\hline 25 percentile & 2.90 & 20.1 & 4.21 & .11 & .020 & .030 & .012 & .13 & .10 & .92 & 1.76 & $2.82 \mathrm{E}-02$ \\
\hline 50 percentile & 16.50 & 25.0 & 4.37 & .20 & .037 & .054 & .027 & .37 & .14 & 1.64 & 2.69 & $4.27 E-02$ \\
\hline 75 percentile & 24.00 & 31.0 & 4.55 & .26 & .057 & .150 & .039 & .59 & .22 & 2.96 & 3.48 & $6.17 \mathrm{E}-02$ \\
\hline 90 percentile & 32.82 & 66.9 & 4.66 & .53 & .116 & .293 & .082 & 1.02 & .46 & 4.12 & 6.29 & $1.05 E-01$ \\
\hline Maximum value & 66.80 & 90.9 & 5.05 & 1.23 & .241 & .332 & .176 & 1.45 & .87 & 7.59 & 7.57 & $2.04 \mathrm{E}-01$ \\
\hline Volume-weighted mean & NA & 29.1 & 4.28 & .17 & .033 & .064 & .025 & .35 & .16 & 1.61 & 2.81 & $5.24 \mathrm{E}-02$ \\
\hline Arithmetic mean & 16.23 & 30.9 & 4.36 & .26 & .053 & .101 & .035 & .43 & .20 & 2.10 & 3.08 & $5.29 \mathrm{E}-02$ \\
\hline No. of samples & 53 & 35 & 35 & 35 & 35 & 35 & 35 & 35 & 35 & 35 & 35 & 35 \\
\hline $\begin{array}{l}\text { Total load, } \mathrm{g} / \mathrm{m} 2 \\
\text { Maximum interval }\end{array}$ & NA & NA & NA & 0.100 & 0.020 & 0.039 & 0.015 & 0.211 & 0.095 & 0.973 & 1.706 & $3.2 \mathrm{E}-02$ \\
\hline load, $\mathrm{g} / \mathrm{m} 2$ & NA & NA & NA & .010 & .002 & .006 & .003 & .026 & .020 & .094 & 0.238 & $4.8 E-03$ \\
\hline $\begin{array}{l}\text { Correlation with ppt } \\
\text { Kenda1l tau }\end{array}$ & volume: & $\begin{array}{l}\text { Cond } \\
-0.11\end{array}$ & $\begin{array}{c}\mathrm{pH} \\
-0.03\end{array}$ & $\begin{array}{c}\mathrm{Ca} \\
-.48\end{array}$ & $\begin{array}{l}\mathrm{Mg} \\
-.51\end{array}$ & $\begin{array}{l}\mathrm{Na} \\
-.43\end{array}$ & $\begin{array}{l}K \\
-.35\end{array}$ & $\begin{array}{l}\mathrm{NH}_{4} \\
-.19\end{array}$ & $\begin{array}{c}C 1 \\
-.42\end{array}$ & $\begin{array}{l}\text { No } \\
-.38\end{array}$ & $\begin{array}{l}\text { So } \\
-.20\end{array}$ & $\begin{array}{c}\mathrm{H} \\
0.03\end{array}$ \\
\hline P-level & & .349 & .776 & .000 & .000 & .000 & .003 & .105 & .000 & .001 & .091 & .776 \\
\hline
\end{tabular}

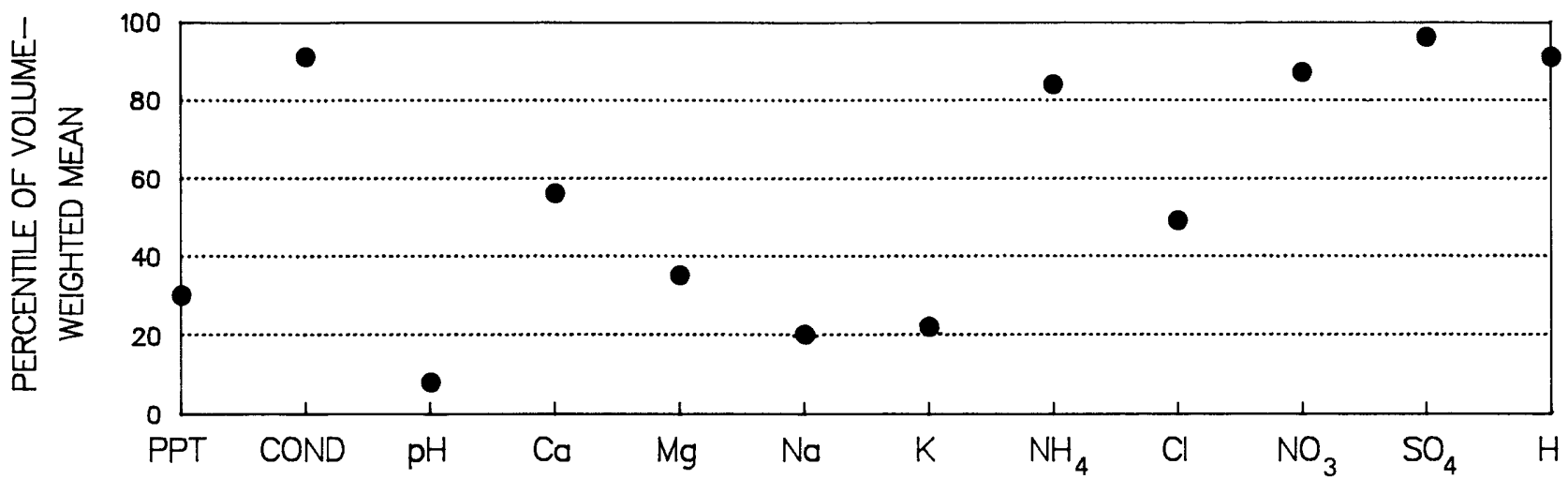

Percentiles of volume-weighted mean concentrations for site OH71, based on

frequency distributions of data from 55 National Trends Network sites. 

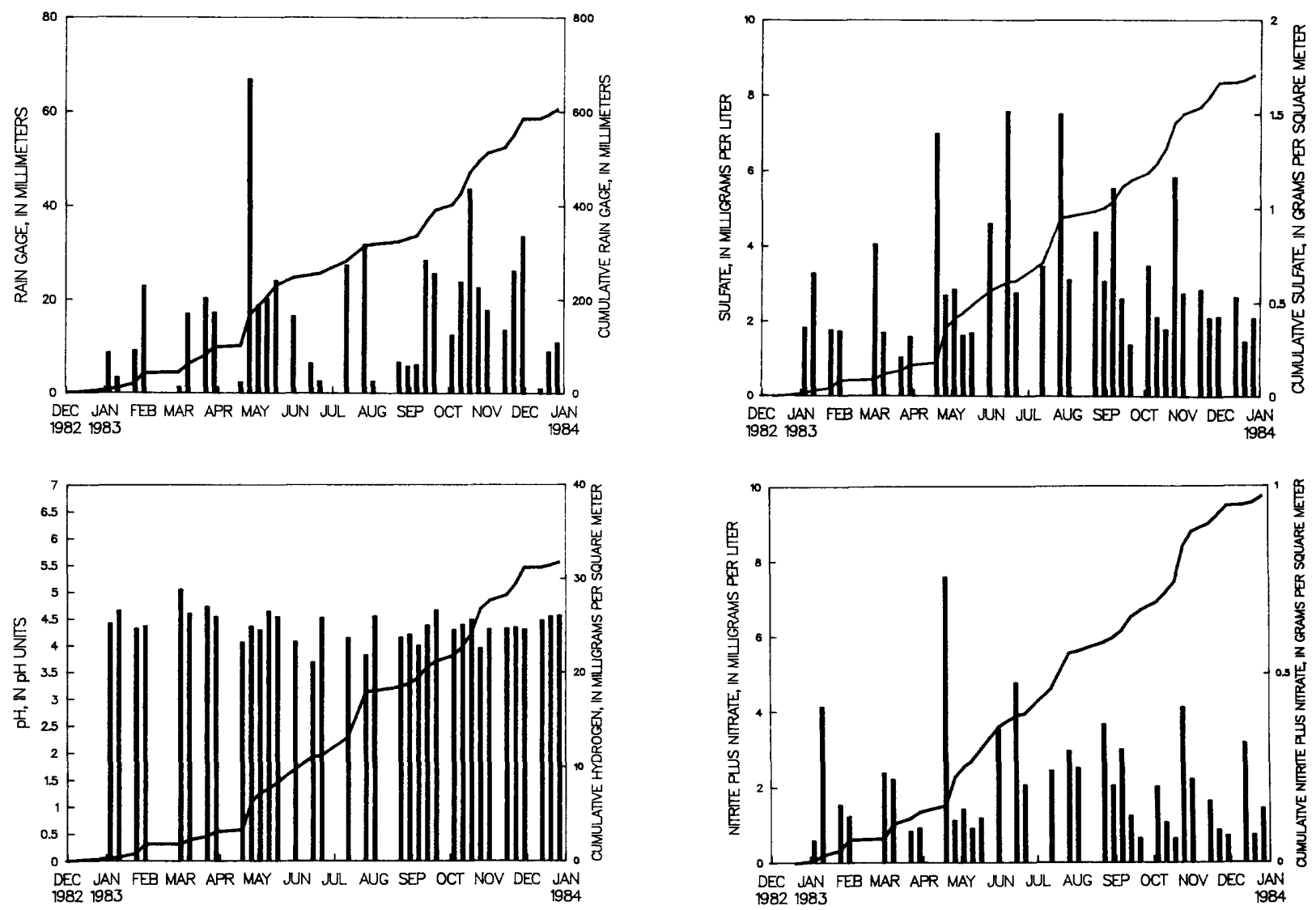

Bar plots of concentrations and cumulative line plots of loads for site $\mathrm{OH} 71$. Nitrite plus nitrate are reported as $\mathrm{NO}_{3}$ and sulfate as $\mathrm{SO}_{4}$.

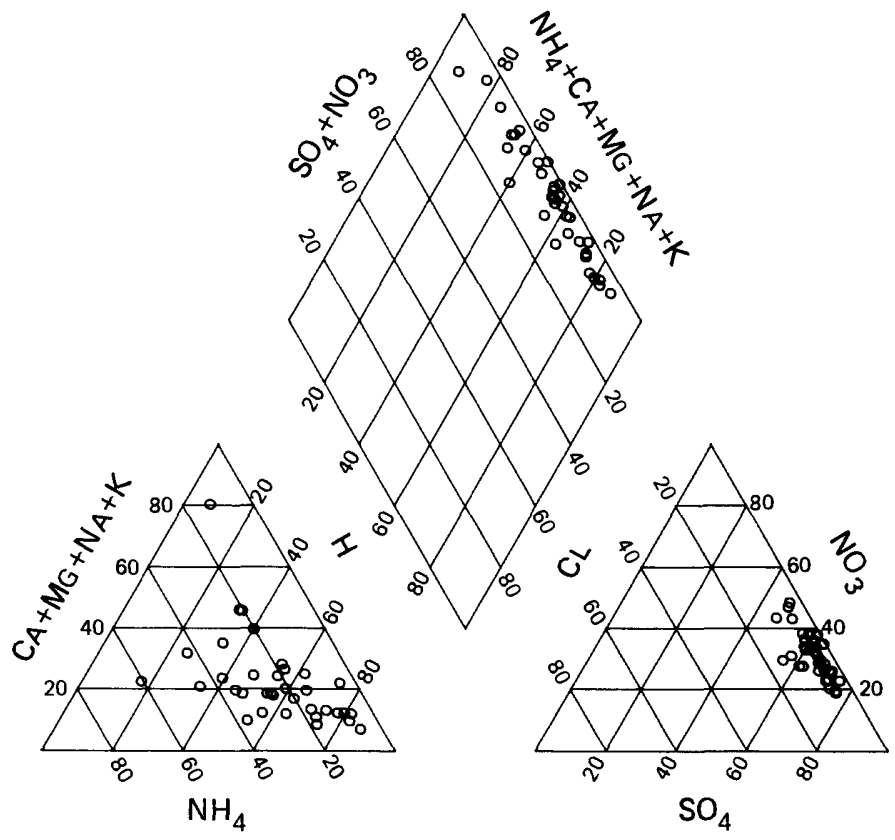

Percentage composition of major ions for site $\mathrm{OH} 71$. 


\section{NATIONAL TRENDS NETWORK - 1983 CALENDER YEAR SUMMARY DATA}

lppt = precipitation; $\mathrm{mm}=$ millimeters; $\mathrm{cm}=$ centimeters; $\mathrm{mg}=$ milligrams; L $=$ liters;

8 = grams; $m=$ meter; $\mu s=$ microsiemens; cond = specific conductance

STATION: Vines Hill, Oregon

CAL number: OR11

ADS number: 027 a00

Station altitude above mean sea level, in meters: 904 Number of sampling intervals (days in parenthesis):

-- With ppt measurements: 49 (378)

-- When ppt occurred: $44 \quad$ (343)

-- When ppt did not occur: 5 ( 35)

- When sample volume was substituted for missing rain gage: 2 ( 14)

-- With chemical samples: $30 \quad$ (241)
Latitude: $43^{\circ} 53^{\prime} 57^{\prime \prime}$ Longitude: $117^{\circ} 25^{\prime} 37^{\prime \prime}$

Station summary period: $12 / 28 / 1982$ to $01 / 10 / 1984$

Length of summary period: 49 sampling intervals ( 378 days)

Percent summary period with ppt measurements: 101.9

Percent summary period with chemical samples or no ppt: 74.4

Percent of total measured ppt with chemical samples: 81.0

Percent of total measured ppt in raingage that was

collected in the wet-sample bucket:

95.9

Total measured ppt, in mm: 386.8

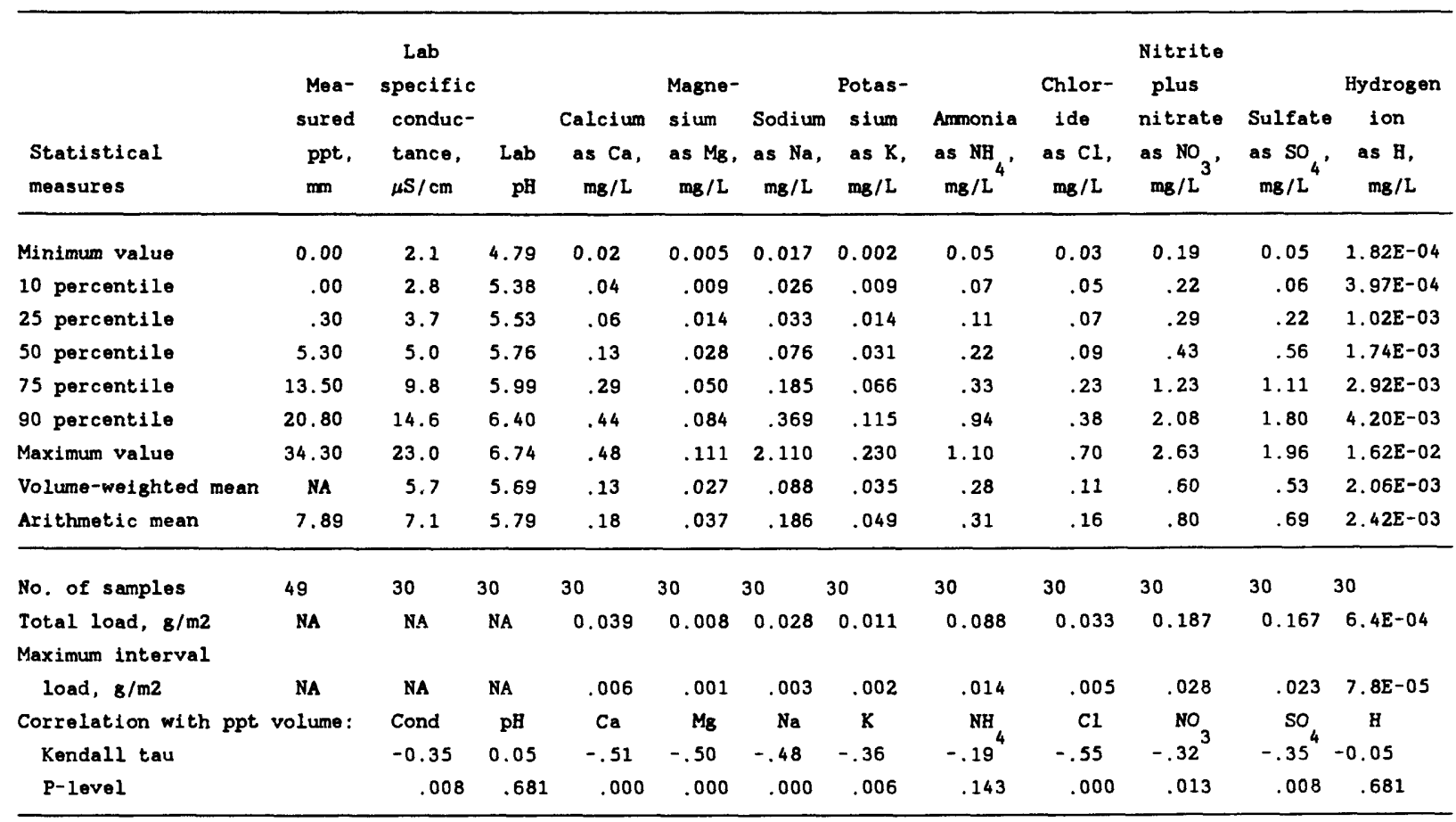

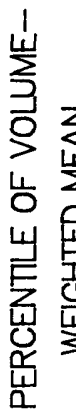

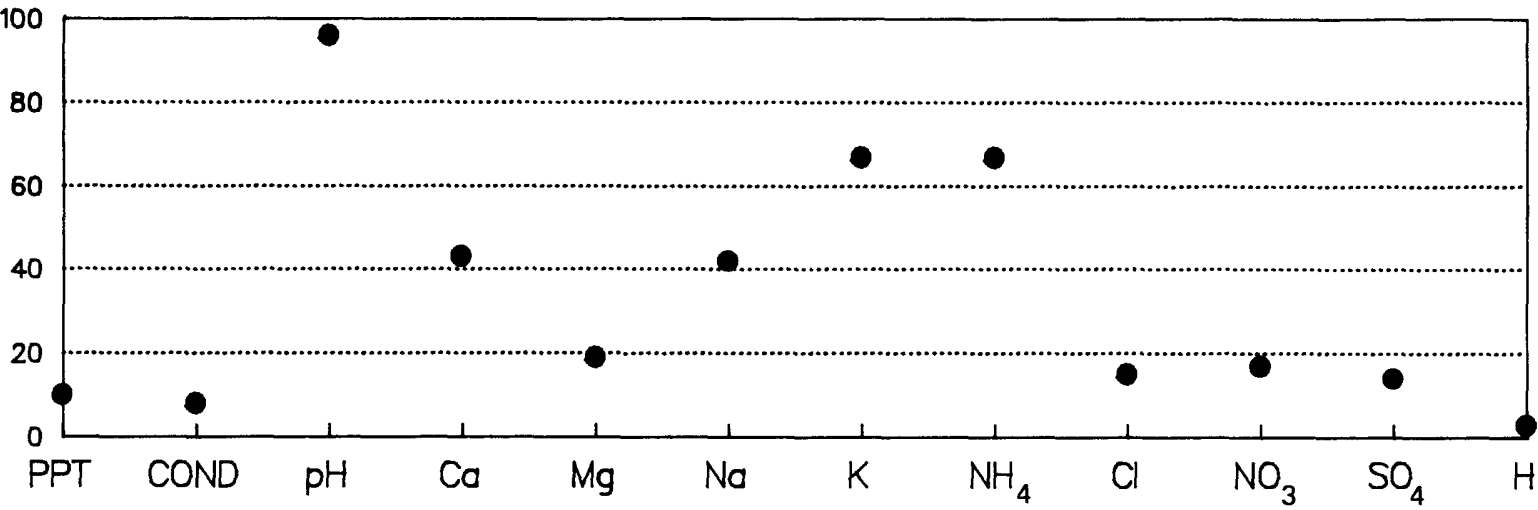

Percentiles of volume-weighted mean concentrations for site OR 11 , based on frequency distributions of data from 55 National Trends Network sites. 

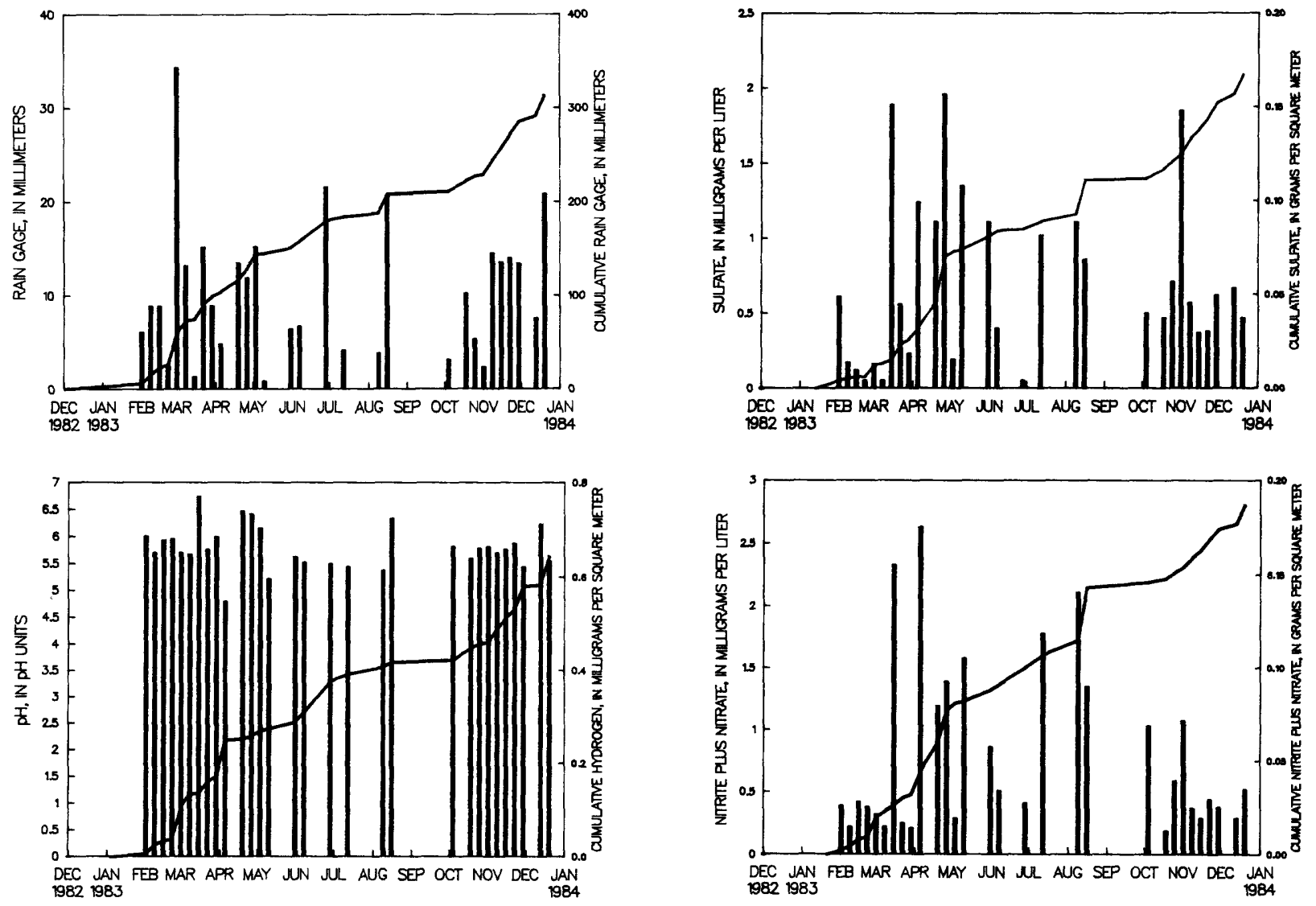

Bar plots of concentrations and cumulative line plots of loads for site OR 11 . Nitrite plus nitrate are reported as $\mathrm{NO}_{3}$ and sulfate as $\mathrm{SO}_{4}$.

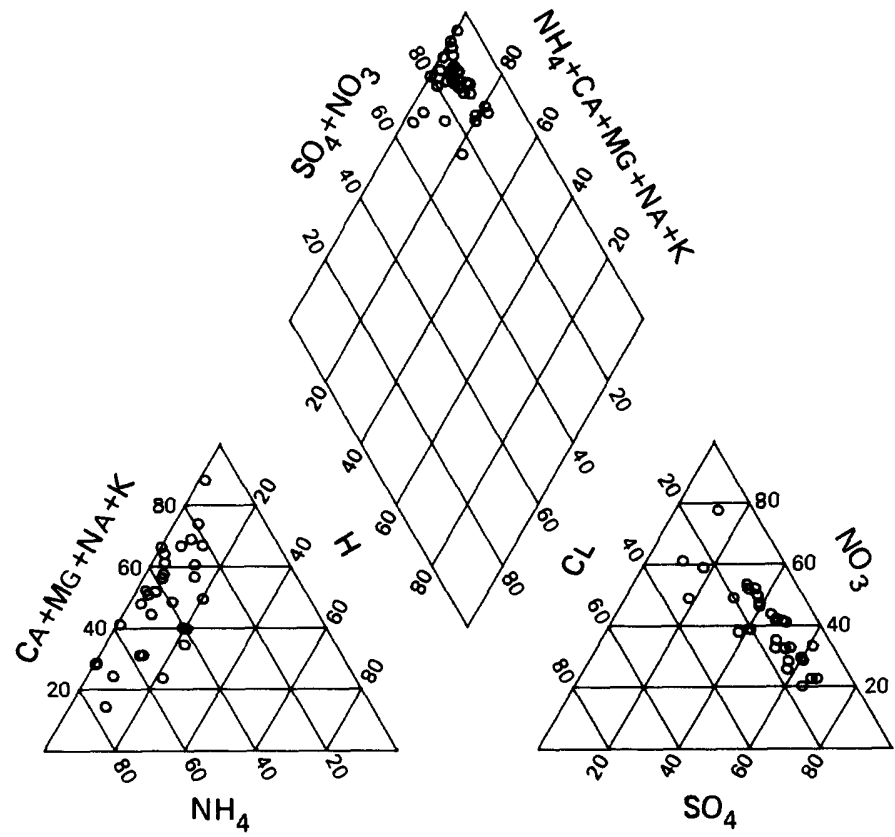

Percentage composition of major ions for site OR11. 


\section{NATIONAL TRENDS NETWORK -- 1983 CALENDER YEAR SUMMARY DATA}

lppt $=$ precipitation; $\mathrm{mm}=$ millimeters $; \mathrm{cm}=$ centimeters; $\mathrm{mg}=\operatorname{milligrams;~L~}=$ liters; $\mathbf{g}=\mathrm{grams} ; \mathrm{m}=$ meter $; \boldsymbol{\mu s}=$ microsiemens; cond = specific conductance $]$

STATION: Composited from stations $060 \mathrm{a} 00$ and $366 \mathrm{a} 00$ CAL number: OR97+OR99 Map ID number: 84 ADS numbers: $060 \mathrm{a} 00$ and $366 \mathrm{a} 00$

Station altitude above mean sea level, in meters: 69 Number of sampling intervals (days in parenthesis):

-- With ppt measurements: 53 (371)

-- When ppt occurred: $50 \quad$ (350)

-- When ppt did not occur: 3 ( 21)

-- When sample volume was substituted for missing rain gage: 16 (112)

-- With chemical samples: $42 \quad$ (294)
Latitude: $\quad 44^{\circ} 38^{\prime}$ Longitude: $123^{\circ} 12^{\prime}$

Station sumary period: $12 / 28 / 1982$ to $01 / 03 / 1984$

Length of sumary period: 53 sampling intervals (371 days)

Percent summary period with ppt measurements: 100.0

Percent sumary period with chemical samples or no ppt: 84.9

Percent of total measured ppt with chemical samples: 95.0

Percent of total measured ppt in raingage that was

collected in the wet-sample bucket:

91.8

Total measured ppt, in $\mathrm{mm}: 1235.4$

\begin{tabular}{|c|c|c|c|c|c|c|c|c|c|c|c|c|}
\hline $\begin{array}{l}\text { Statistical } \\
\text { measures }\end{array}$ & $\begin{array}{l}\text { Mea- } \\
\text { sured } \\
\text { ppt, } \\
\text { mm }\end{array}$ & $\begin{array}{c}\text { Lab } \\
\text { specific } \\
\text { conduc- } \\
\text { tance, } \\
\mu \mathrm{S} / \mathrm{cm}\end{array}$ & $\begin{array}{r}\text { Lab } \\
\text { pH }\end{array}$ & $\begin{array}{c}\text { Calcium } \\
\text { as Ca, } \\
\mathrm{mg} / \mathrm{L}\end{array}$ & $\begin{array}{l}\text { Magne- } \\
\text { sium } \\
\text { as Mg, } \\
\mathrm{mg} / \mathrm{L}\end{array}$ & $\begin{array}{l}\text { Sodium } \\
\text { as } \mathrm{Na} \text {, } \\
\mathrm{mg} / \mathrm{L}\end{array}$ & $\begin{array}{l}\text { Potas- } \\
\text { sium } \\
\text { as K, } \\
\mathrm{mg} / \mathrm{L}\end{array}$ & $\begin{array}{l}\text { Ammonia } \\
\text { as } \mathrm{NH}_{\mathrm{mg}} / \mathrm{L}^{\circ}\end{array}$ & $\begin{array}{l}\text { Chlor- } \\
\text { ide } \\
\text { as } C l \text {, } \\
\mathrm{mg} / \mathrm{L}\end{array}$ & $\begin{array}{l}\text { Nitrite } \\
\text { plus } \\
\text { nitrate } \\
\text { as } \mathrm{NO}_{3} \text {, } \\
\mathrm{mg} / \mathrm{L}^{\circ}\end{array}$ & $\begin{array}{l}\text { Sulfate } \\
\text { as } \mathrm{SO}_{4} \text {, } \\
\mathrm{mg} / \mathrm{L}\end{array}$ & $\begin{array}{l}\text { Hydrogen } \\
\text { ion } \\
\text { as } \mathrm{H}, \\
\mathrm{mg} / \mathrm{L}\end{array}$ \\
\hline Minimum value & 0.00 & 2.4 & 4.63 & 0.01 & 0.004 & 0.026 & 0.003 & 0.01 & 0.07 & 0.01 & 0.05 & 3. $31 E-04$ \\
\hline 10 percentile & .30 & 3.0 & 4.95 & .03 & .013 & .054 & .009 & .01 & .11 & .12 & .08 & $1.13 E-03$ \\
\hline 25 percentile & 2.80 & 4.8 & 5.30 & .06 & .025 & .110 & .021 & .01 & .18 & .16 & .39 & $2.13 E-03$ \\
\hline 50 percentile & 16.00 & 6.7 & 5.47 & .09 & .059 & .320 & .031 & .05 & .41 & .23 & .49 & $3.35 E-03$ \\
\hline 75 percentile & 36.90 & 8.8 & 5.67 & .15 & .089 & .564 & .054 & .10 & 1.03 & .46 & .76 & $5.02 E-03$ \\
\hline 90 percentile & 62.22 & 12.6 & 5.95 & .28 & .120 & .780 & .107 & .30 & 1.39 & 1.03 & 1.29 & $1.12 \mathrm{E}-02$ \\
\hline Maximum value & 88.60 & 20.7 & 6.48 & .86 & .252 & 2.100 & .150 & .87 & 3.85 & 1.98 & 1.85 & $2.34 E-02$ \\
\hline Volume-weighted mean & NA & 6.7 & 5.42 & .07 & .069 & .522 & .030 & .06 & .95 & .22 & .44 & $3.78 \mathrm{E}-03$ \\
\hline No. of samples & 53 & 42 & 42 & 42 & 42 & 42 & 42 & 42 & 42 & 42 & 42 & 42 \\
\hline $\begin{array}{l}\text { Total load, } 8 / \mathrm{m} 2 \\
\text { Maximum interval }\end{array}$ & NA & NA & NA & 0.083 & 0.081 & 0.613 & 0.035 & 0.065 & 1.113 & 0.261 & 0.515 & $4.4 E-03$ \\
\hline load, $8 / \mathrm{m} 2$ & NA & NA & NA & .009 & .021 & .174 & .007 & .008 & .320 & .017 & .065 & $4.8 E-04$ \\
\hline $\begin{array}{l}\text { Correlation with ppt } \\
\text { Kendall tau }\end{array}$ & volume: & $\begin{array}{l}\text { Cond } \\
-0.21\end{array}$ & $\begin{array}{r}\mathrm{pH} \\
0.00\end{array}$ & $\begin{array}{r}\mathrm{Ca} \\
-.61\end{array}$ & $\begin{array}{r}\mathrm{Mg} \\
-.12\end{array}$ & $\begin{array}{l}\mathrm{Na} \\
.09\end{array}$ & $\begin{array}{c}K \\
-.37\end{array}$ & $\begin{array}{r}\mathrm{NH}^{4} \\
-.21^{4}\end{array}$ & $\begin{array}{l}\mathrm{Cl} \\
.14\end{array}$ & $\begin{array}{l}\mathrm{NO}^{3} \\
-.46^{3}\end{array}$ & $\begin{array}{l}\text { So } \\
-.40\end{array}$ & $\begin{array}{r}\mathrm{H} \\
0.00\end{array}$ \\
\hline P-level & & .046 & .982 & .000 & .255 & .416 & .001 & .062 & .201 & .000 & .000 & .982 \\
\hline
\end{tabular}
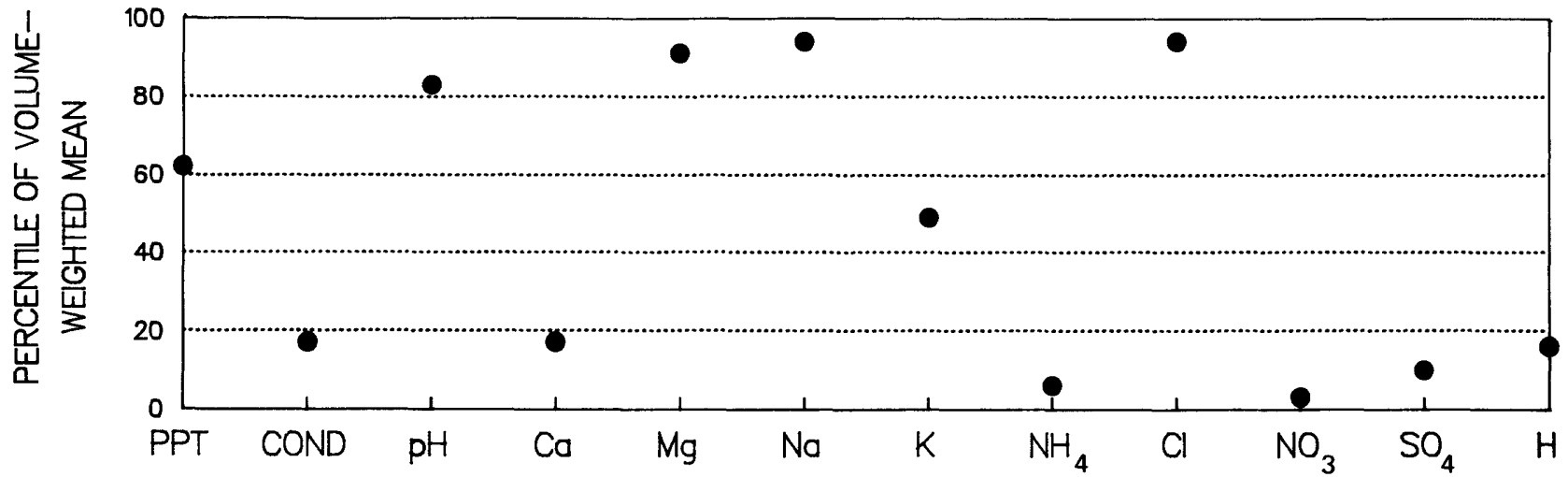

Percentiles of volume-weighted mean concentrations for site OR97, based on

frequency distributions of data from 55 National Trends Network sites. 

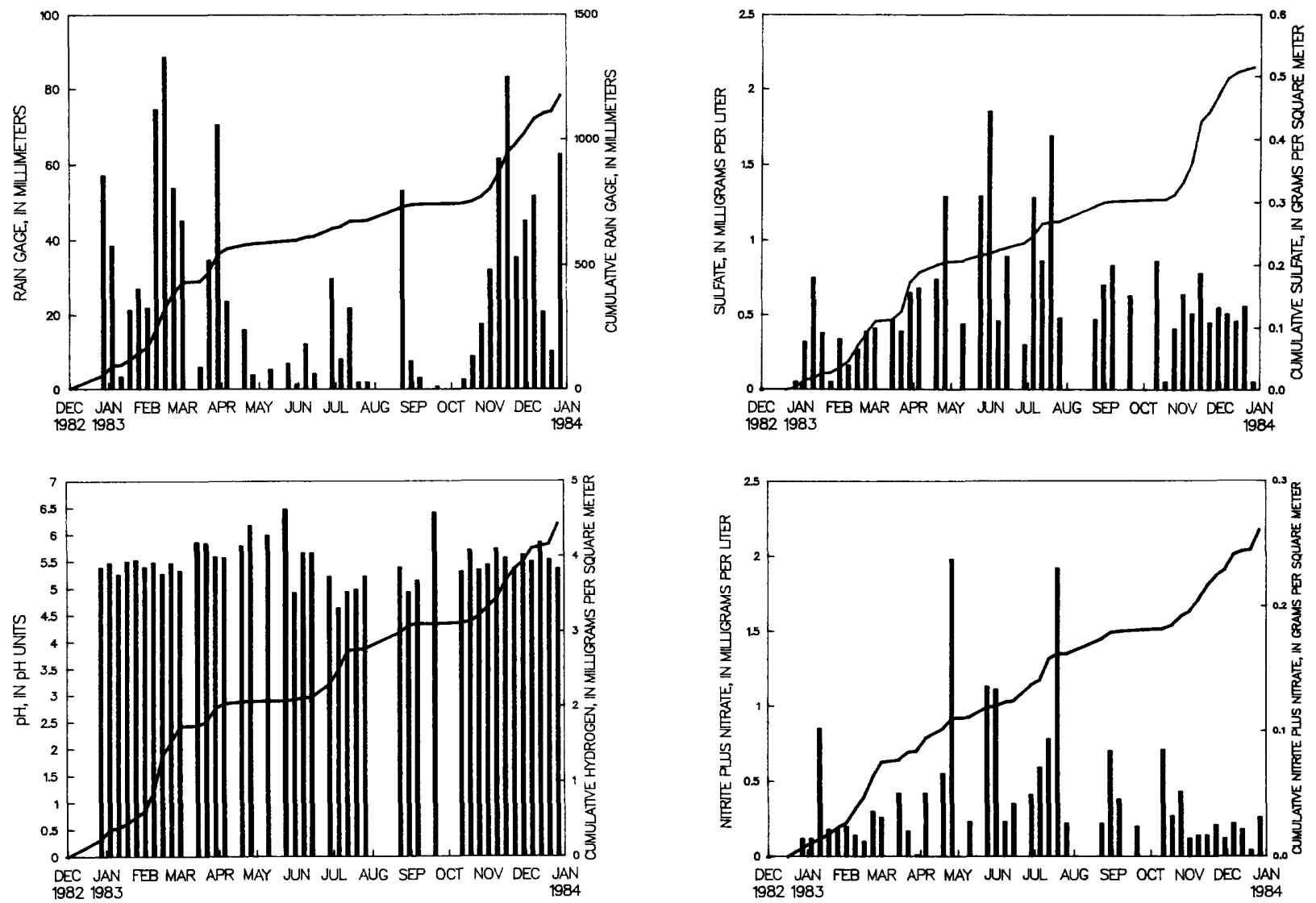

Bar plots of concentrations and cumulative line plots of loads for site OR97. Nitrite plus nitrate are reported as $\mathrm{NO}_{3}$ and sulfate as $\mathrm{SO}_{4}$.

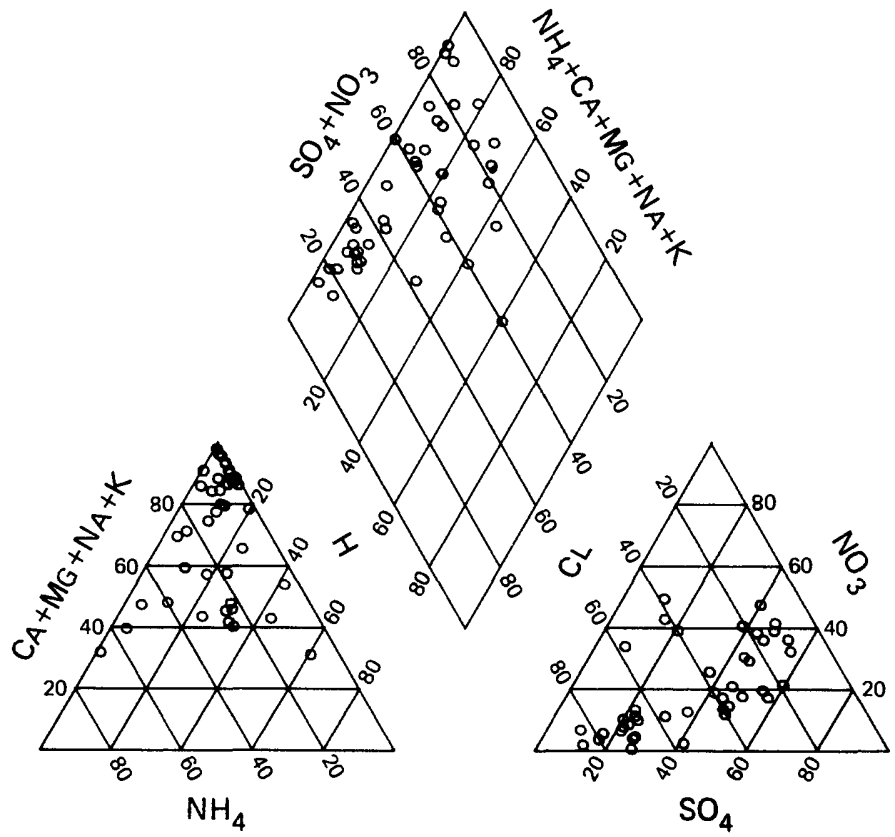

Percentage composition of major ions for site OR97. 


\section{NATIONAL TRENDS NETWORK -- 1983 CALENDER YEAR SUMMARY DATA}

lppt = precipitation; $\mathrm{mm}=$ millimeters; $\mathrm{cm}=$ centimeters; $\mathrm{mg}=$ milligrams; $\mathrm{L}=1$ iters; $8=g r a m s ; m=$ meter; $\mu s=$ microsiemens; cond = specific conductance $]$

STATION: Leading Ridge, Pennsylvania

CAL number: PA42

ADS number: $064 \mathrm{a} 00$

Station altitude above mean sea level, in meters: 282 Number of sampling intervals (days in parenthesis):

-- With ppt measurements: 53

-- When ppt occurred: 50 (350)

-- When ppt did not occur: 3 (21)

-- When sample volume was substituted for missing rain gage: 0 ( 0 )

-- With chemical samples: $46 \quad$ (322)
Latitude: $40^{\circ} 39^{\prime} 32^{\prime \prime}$ Longitude: $77^{\circ} 56^{\prime} 10^{\prime \prime}$

Station summary period: $12 / 28 / 1982$ to $01 / 03 / 1984$

Length of sumary period: 53 sampling intervals ( 371 days)

Percent sumary period with ppt measurements: $\quad 100.0$

Percent summary period with chemical samples or no ppt: 92.4

Percent of total measured ppt with chemical samples: 96.0

Percent of total measured ppt in raingage that was

collected in the wet-sample bucket:

90.3

Total measured ppt, in m: 1159.9

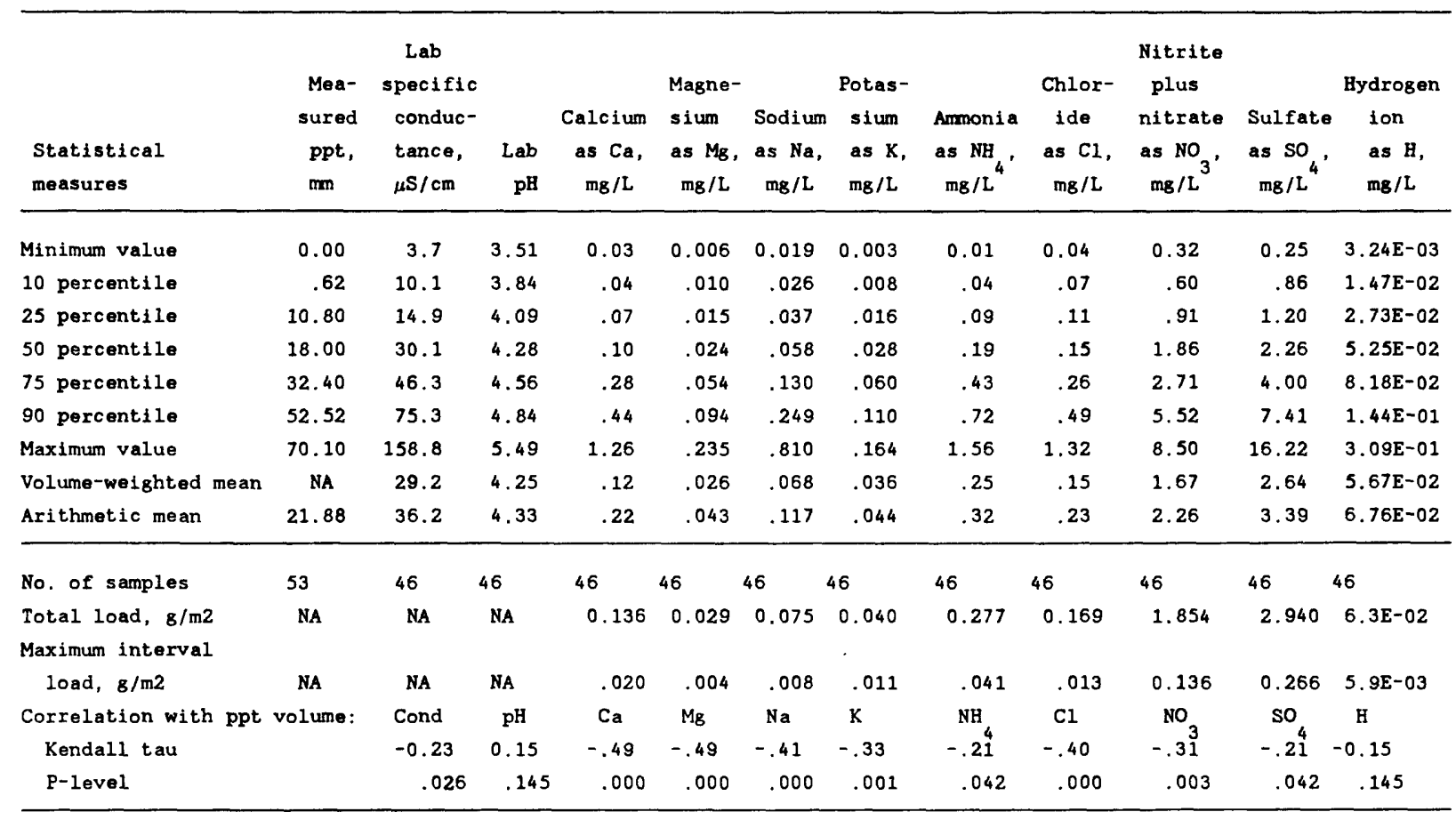

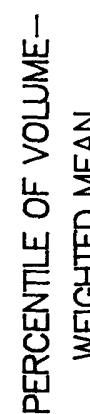

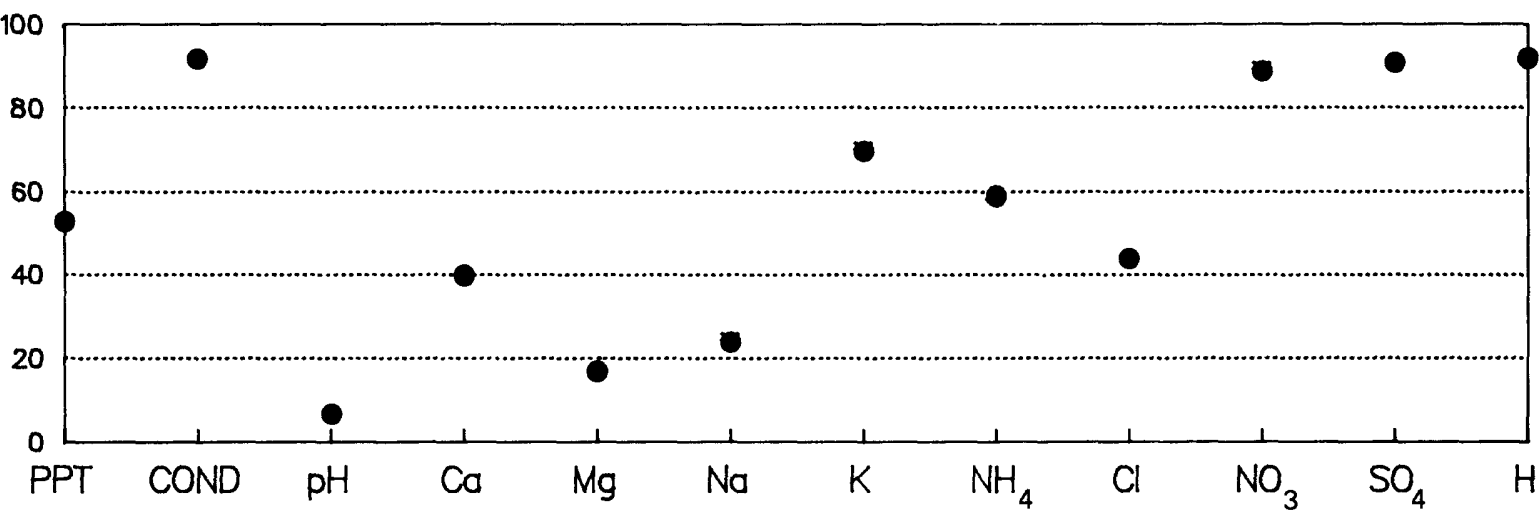

Percentiles of volume-weighted mean concentrations for site PA42, based on frequency distributions of data from 55 National Trends Network sites. 

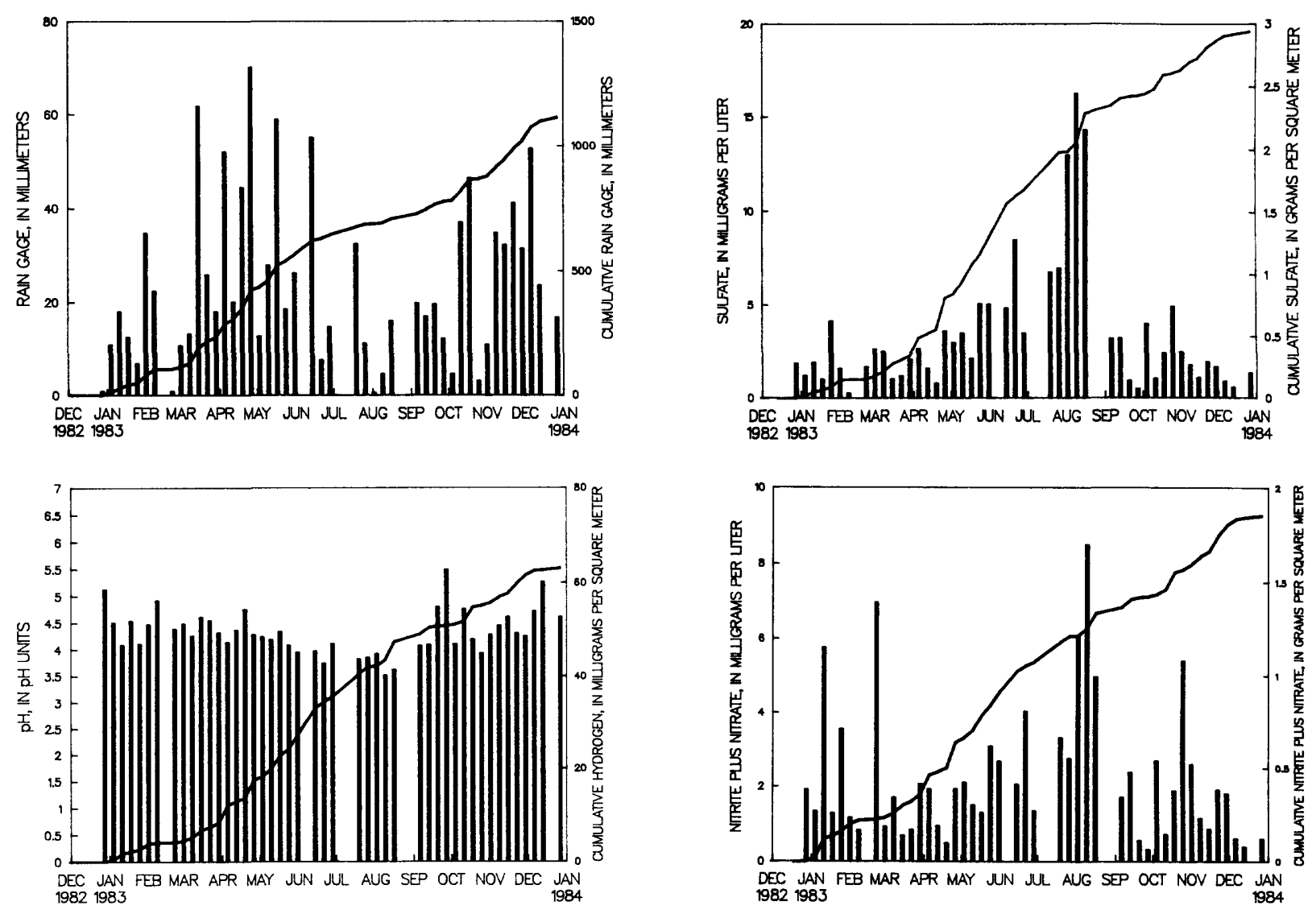

Bar plots of concentrations and cumulative line plots of loads for site PA42.

Nitrite plus nitrate are reported as $\mathrm{NO}_{3}$ and sulfate as $\mathrm{SO}_{4}$.

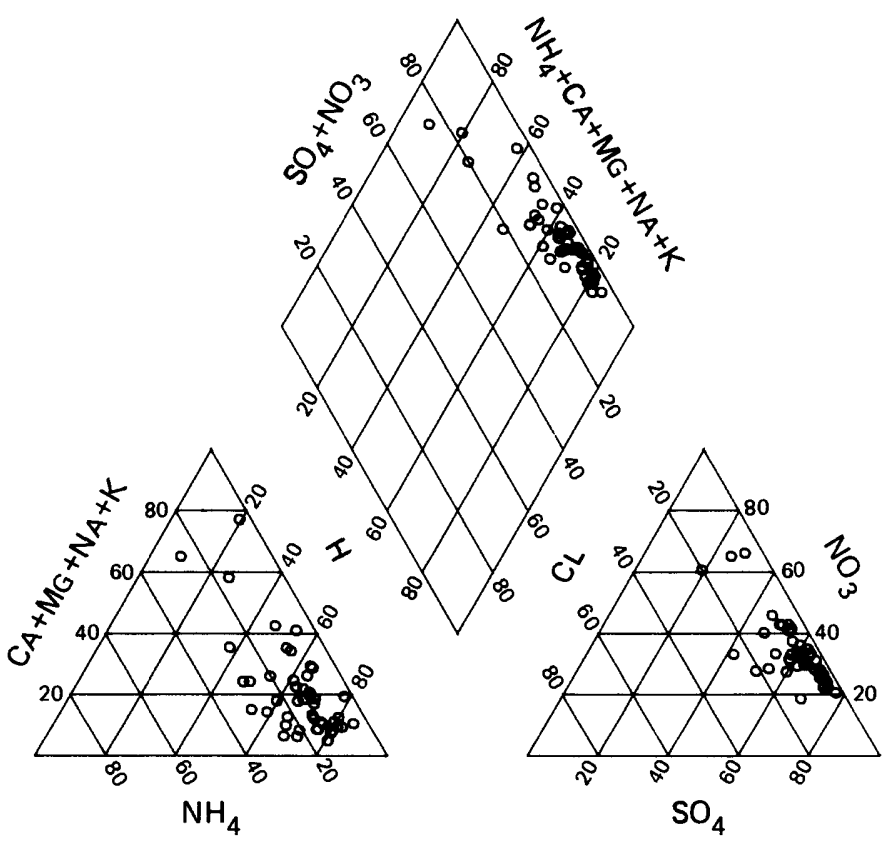

Percentage composition of major ions for site PA42. 


\section{NATIONAL TRENDS NETWORK -- 1983 CALENDER YEAR SUMMARY DATA}

lppt $=$ precipitation; $\mathrm{mm}=$ millimeters $\mathrm{cm}=$ centimeters; $\mathrm{mg}=$ milligrams; $\mathrm{L}=11$ ters $;$ $\mathbf{g}=$ grams; $\mathrm{m}=$ meter; $\mu \mathrm{s}=$ microsiemens; cond = specific conductance $]$

STATION: Walker Branch Watershed, Tennessee

CAL number: TNOO

Map ID number: 92

ADS number: $171 \mathrm{a} 00$

Station altitude above mean sea level, in meters: 341 Number of sampling intervals (days in parenthesis):

-- With ppt measurements: $53 \quad$ (371)

-- When ppt occurred: 49 (343)

-- When ppt did not occur: 4 (28)

-- When sample volume was substituted for missing rain gage: 0 ( 0$)$

-- With chemical samples: $40 \quad$ (280)
Latitude: $35^{\circ} 57^{\prime} 41^{\prime \prime}$ Longitude:

$84^{\circ} 17^{\prime} 14^{\prime \prime}$

Station summary period: $12 / 28 / 1982$ to $01 / 03 / 1984$

Length of summary period: 53 sampling intervals (371 days)

Percent summary period with ppt measurements:

100.0

Percent sumary period with chemical samples or no ppt: 83.0

Percent of total measured ppt with chemical samples: $\quad 80.0$

Percent of total measured ppt in raingage that was

collected in the wet-sample bucket:

102.0

Total measured ppt, in m: 1161.0

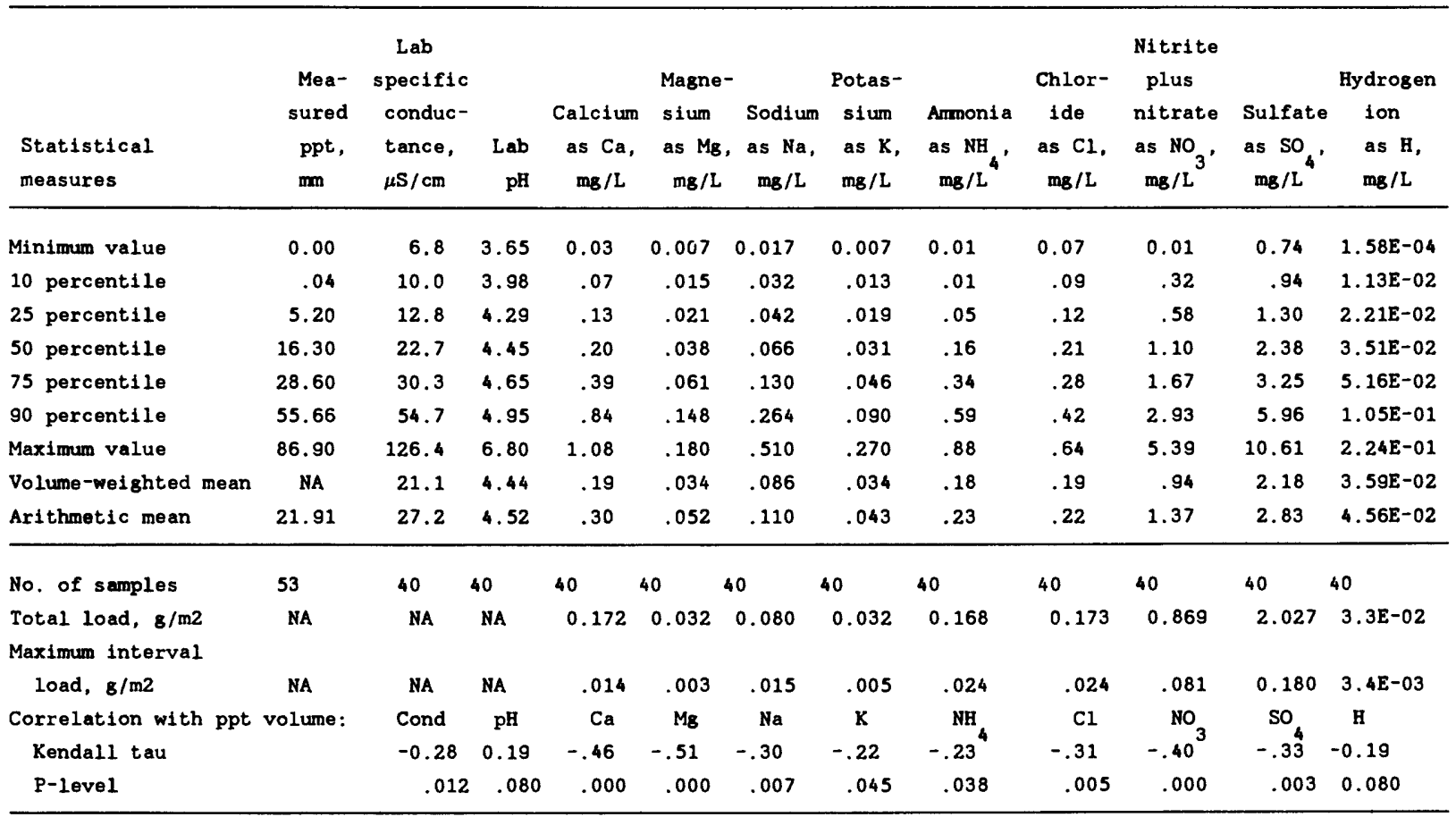

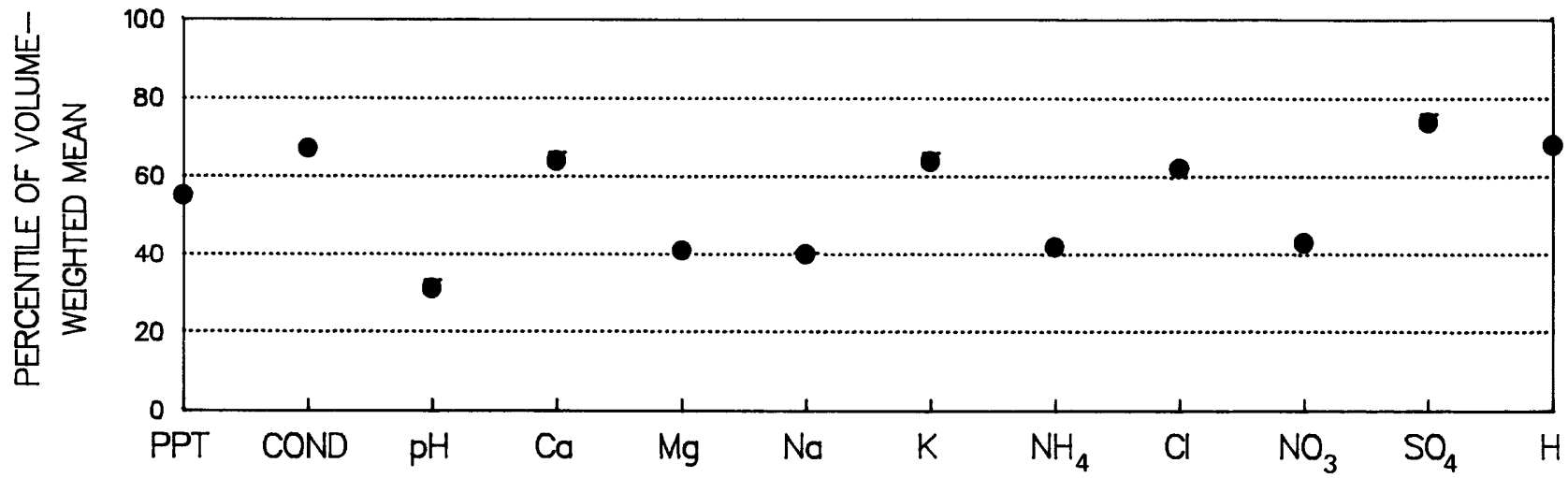

Percentiles of volume-weighted mean concentrations for site TN00, based on frequency distributions of data from 55 National Trends Network sites. 

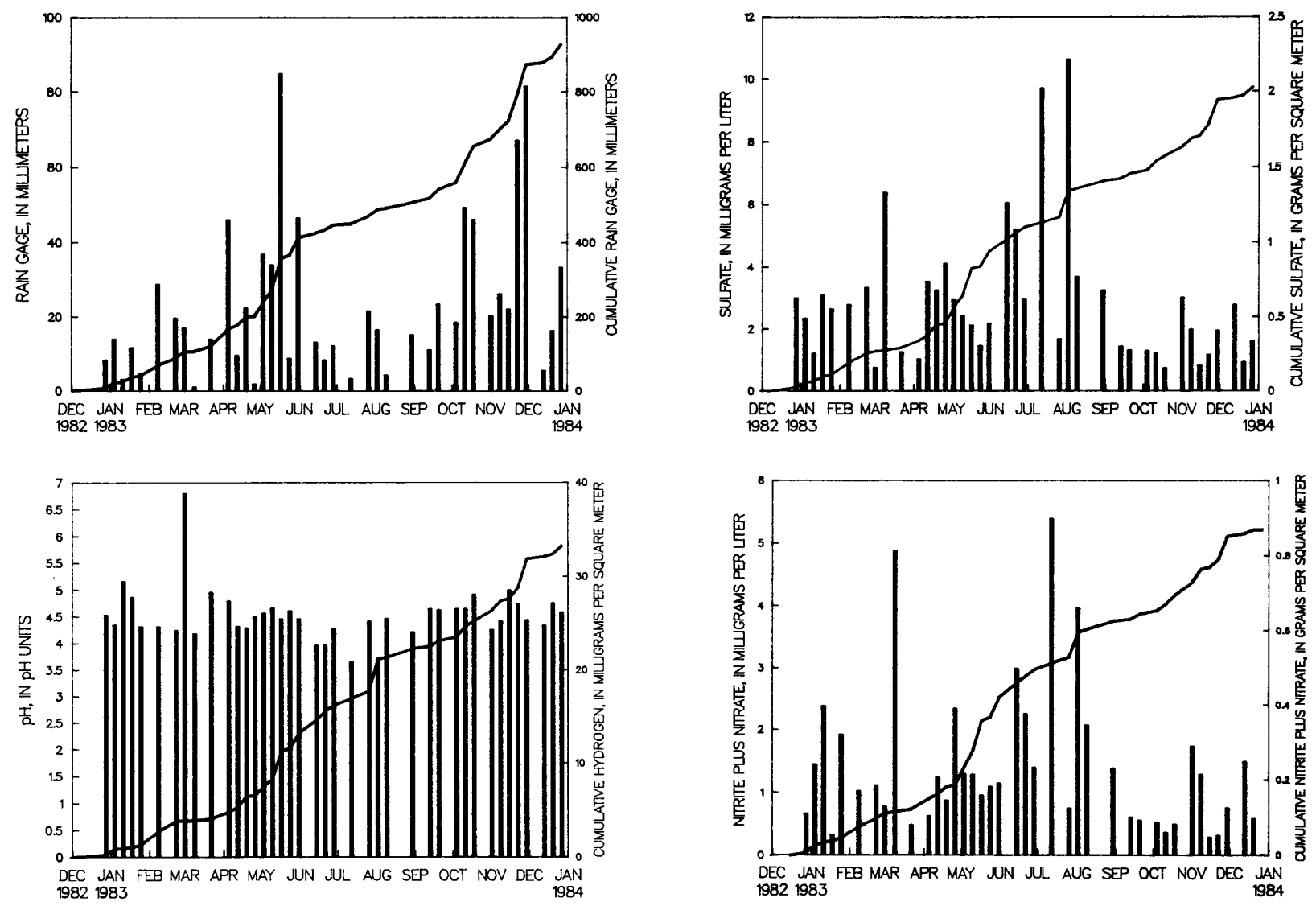

Bar plots of concentrations and cumulative line plots of loads for site TN00. Nitrite plus nitrate are reported as $\mathrm{NO}_{3}$ and sulfate as $\mathrm{SO}_{4}$.

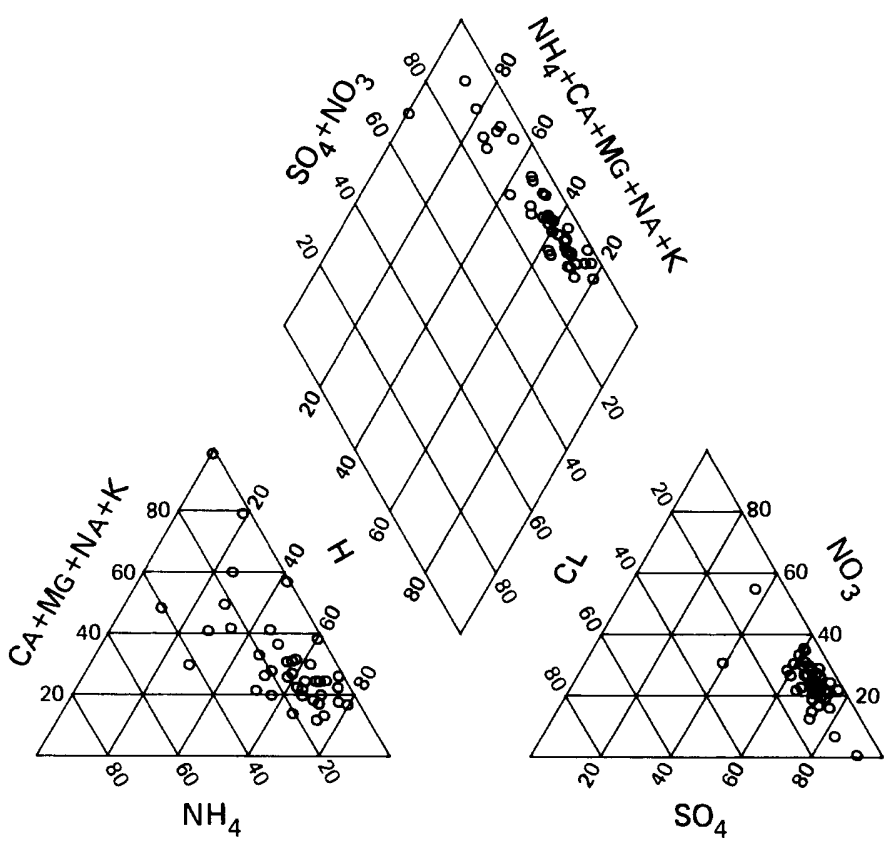

Percentage composition of major ions for site TN0O. 


\section{NATIONAL TRENDS NETWORK -- 1983 CALENDER YEAR SUMMARY DATA}

[ppt $=$ precipitation; $\mathrm{mm}=$ millimeters; $\mathrm{cm}=$ centimeters; $\mathrm{mg}=$ milligrams; $\mathrm{L}=11$ ters;

$\mathbf{g}=\mathrm{grams} ; \mathrm{m}=$ meter $; \mu \mathrm{s}=$ microsiemens; cond = specific conductance $]$

STATION: K-Bar, Texas

CAL number: TX04

ADS number: $070 \mathrm{a00}$

Station altitude above mean sea level, in meters: 1056

Number of sampling intervals (days in parenthesis):

-- With ppt measurements: 53 (371)

-- When ppt occurred: $36 \quad$ (252)

-- When ppt did not occur: 17 (119)

-- When sample volume was substituted for missing rain gage: 0 ( 0 )

-- With chemical samples: 27 (189)
Latitude: $29^{\circ} 18^{\circ} 07^{\prime \prime}$ Longitude: $103^{\circ} 10^{\prime} 38^{\prime \prime}$

Station summary period: $12 / 28 / 1982$ to $01 / 03 / 1984$

Length of summary period: 53 sampling intervals ( 371 days)

Percent summary period with ppt measurements: $\quad 100.0$

Percent summary period with chemical samples or no ppt: 83.0

Percent of total measured ppt with chemical samples: $\quad 88.2$

Percent of total measured ppt in raingage that was

collected in the wet-sample bucket:

101.5

Total measured ppt, in m: 287.0

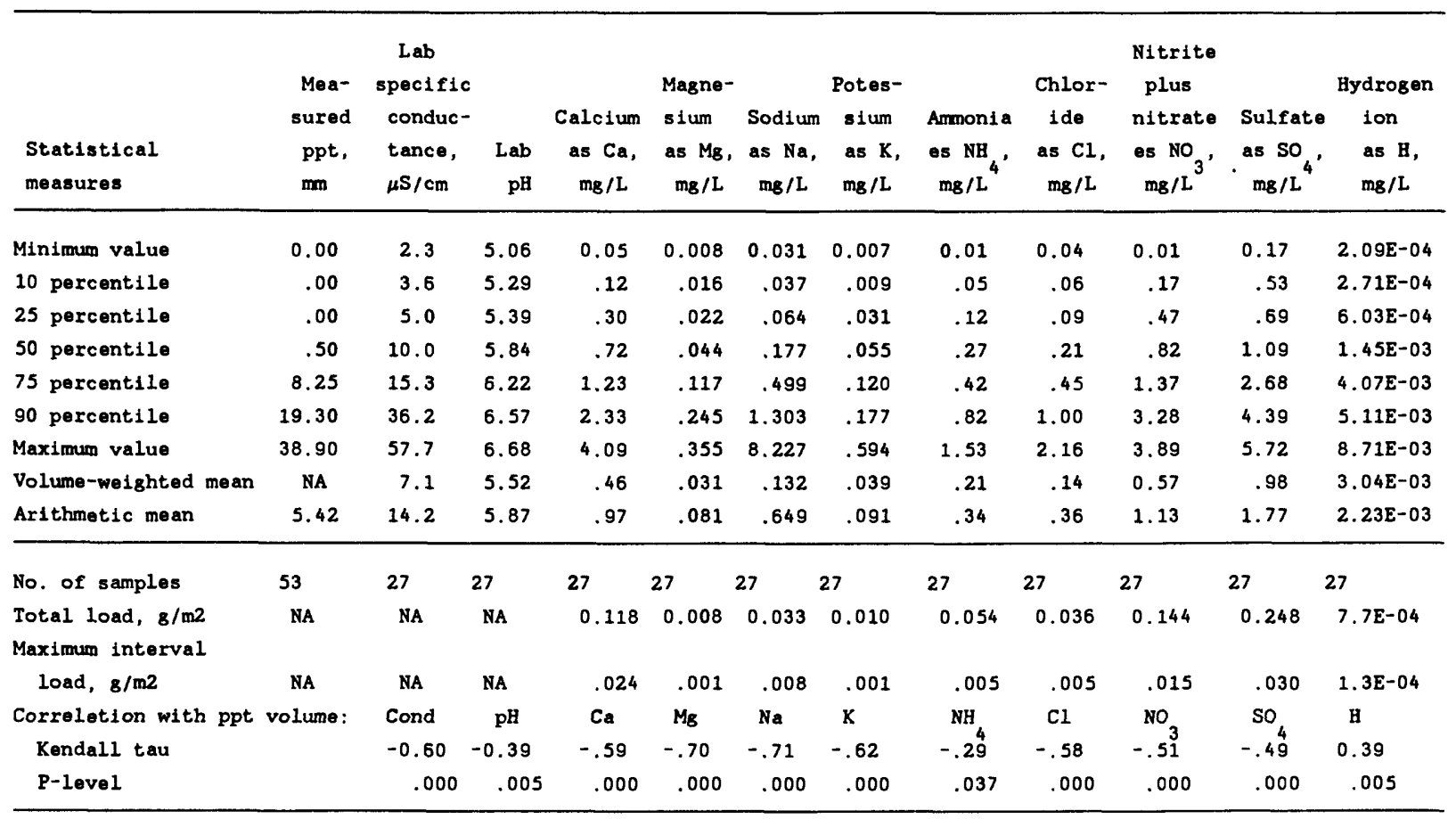

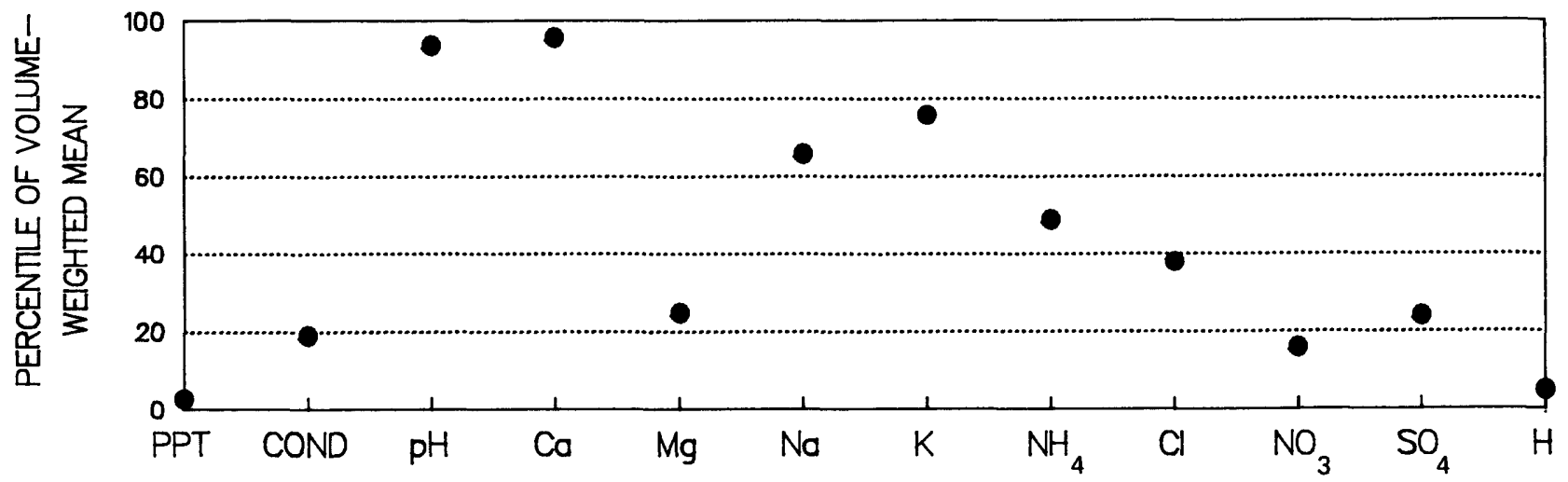

Percentiles of volume-weighted mean concentrations for site TX04, based on frequency distributions of data from 55 National Trends Network sites. 

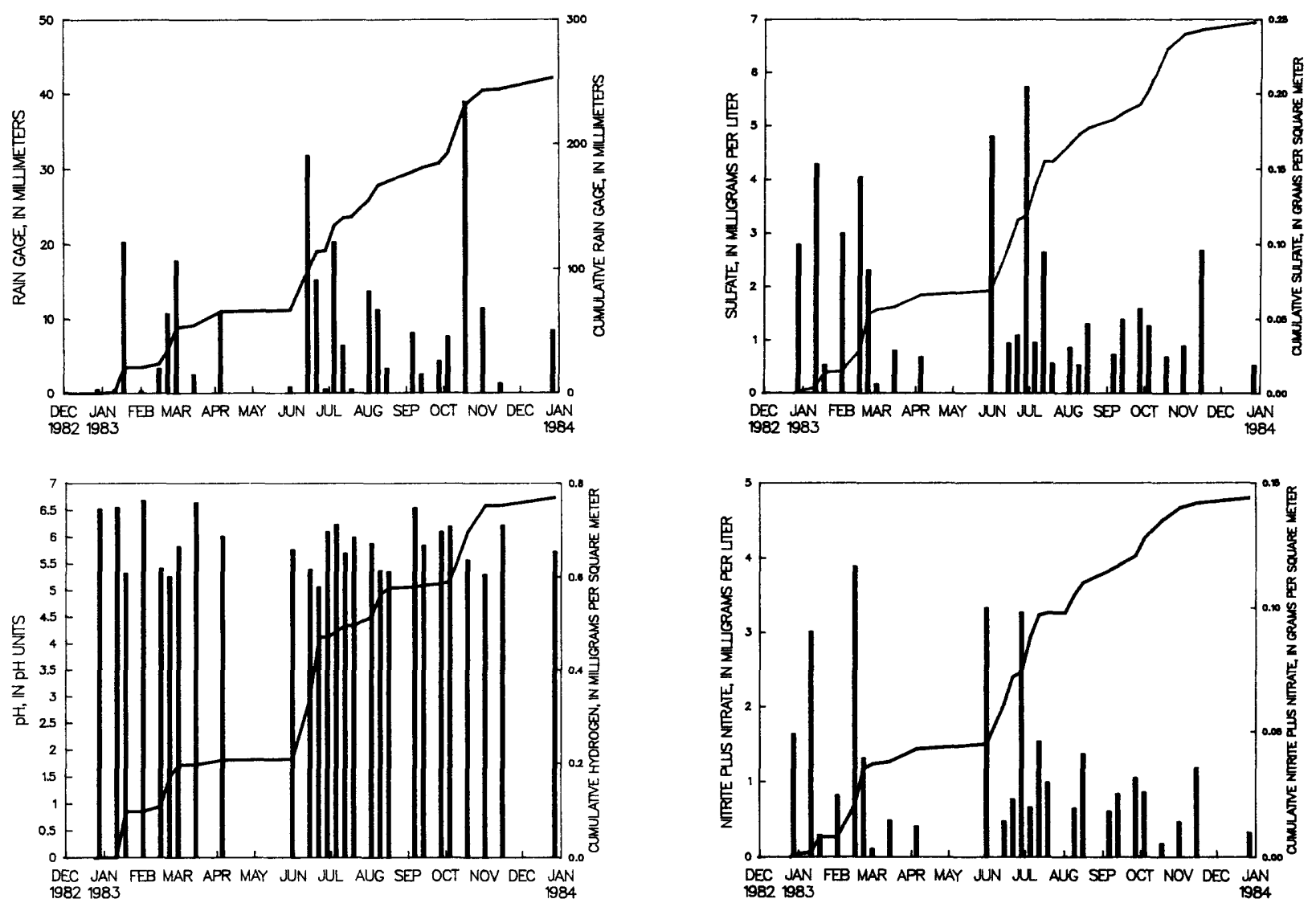

Bar plots of concentrations and cumulative line piots of loads for site TX04.

Nitrite plus nitrate are reported as $\mathrm{NO}_{3}$ and sulfate as $\mathrm{SO}_{4}$.

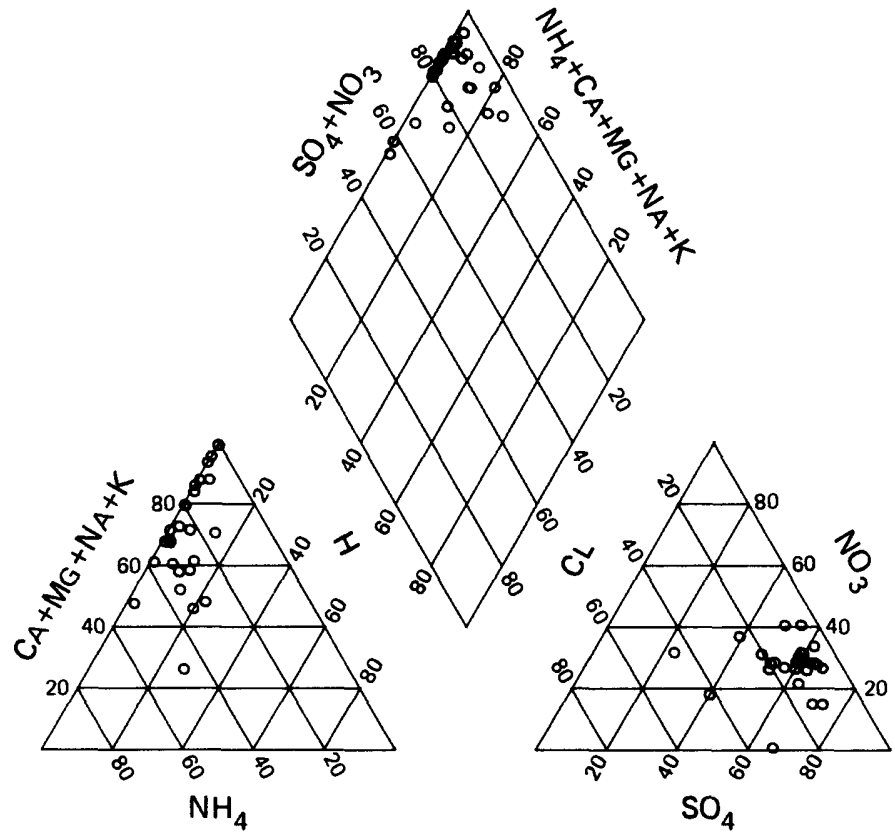

Percentage composition of major ions for site TX04. 


\section{NATIONAL TRENDS NETWORK -- 1983 CALENDER YEAR SUMMARY DATA}

[ppt $=$ precipitation; $\mathrm{mm}=$ millimeters; $\mathrm{cm}=$ centimeters; $\mathrm{mg}=\mathrm{milligrams;} \mathrm{L=11ters;}$

$\mathbf{g}=\mathbf{g r a m s} ; \mathrm{m}=$ meter $\boldsymbol{\mu s}=$ microsiemens $;$ cond = specific conductance $]$

STATION: Forest Seed Center, Texas

Latitude: $31^{\circ} 33^{\prime} 38^{\prime \prime}$ Longitude:

$94^{\circ} 51^{\prime} 39^{\prime \prime}$

CAL number: TX38

ADS number: $254 \mathrm{a} 00$

Station altitude above mean sea level, in meters: 84

Number of sampling intervals (days in parenthesis):

-- With ppt measurements: $54 \quad$ (371)

-- When ppt occurred: $48 \quad$ (329)

-- When ppt did not occur: 6 ( 42)

-- When sample volume was substi-

tuted for missing rain gage: 1 ( 7)

-- With chemical samples: 37 (259)
Station summary period: $12 / 28 / 1982$ to $01 / 03 / 1984$

Length of summary period: 54 sampling intervals ( 371 days)

$\begin{array}{ll}\text { Percent summary period with ppt measurements: } & 100.0\end{array}$

Percent summary period with chemical samples or no ppt: 81.1

Percent of total measured ppt with chemical samples: $\quad 71.8$

Percent of total measured ppt in raingage that was

collected in the wet-sample bucket:

99.1

\begin{tabular}{|c|c|c|c|c|c|c|c|c|c|c|c|c|}
\hline $\begin{array}{l}\text { Statistical } \\
\text { measures }\end{array}$ & $\begin{array}{l}\text { Mea- } \\
\text { sured } \\
\text { ppt, } \\
\text { mm }\end{array}$ & $\begin{array}{c}\text { Lab } \\
\text { specific } \\
\text { conduc- } \\
\text { tance, } \\
\mu S / \mathrm{cm}\end{array}$ & Lab & $\begin{array}{c}\text { Calcium } \\
\text { as Ca, } \\
\mathrm{mg} / \mathrm{L}\end{array}$ & $\begin{array}{l}\text { Magne- } \\
\text { sium } \\
\text { as Mg, } \\
\mathrm{mg} / \mathrm{L}\end{array}$ & $\begin{array}{l}\text { Sodium } \\
\text { as } \mathrm{Na} \text {, } \\
\mathrm{mg} / \mathrm{L}\end{array}$ & $\begin{array}{l}\text { Potas- } \\
\text { sium } \\
\text { as } \mathrm{K} \text {, } \\
\mathrm{mg} / \mathrm{L}\end{array}$ & $\begin{array}{l}\text { Ammonia } \\
\text { as } \mathrm{NH}_{4}{ }^{\circ}\end{array}$ & $\begin{array}{l}\text { Chlor- } \\
\text { ide } \\
\text { as } \mathrm{Cl} \text {, } \\
\mathrm{mg} / \mathrm{L}\end{array}$ & $\begin{array}{l}\text { Nitrite } \\
\text { plus } \\
\text { nitrate } \\
\text { as } \mathrm{NO}_{3} \text {. } \\
\mathrm{mg} / \mathrm{L}^{\circ}\end{array}$ & $\begin{array}{l}\text { Sulfate } \\
\text { as so } \\
\mathrm{mg}_{4} / \mathrm{L}\end{array}$ & $\begin{array}{l}\text { Hydrogen } \\
\text { ion } \\
\text { as H, } \\
\text { mg/L }\end{array}$ \\
\hline Minimum value & 0.00 & 4.6 & 4.24 & 0.02 & 0.006 & 0.017 & 0.005 & 0.01 & 0.05 & 0.01 & 0.58 & $3.63 \mathrm{E}-04$ \\
\hline 10 percentile & .00 & 7.7 & 4.49 & .06 & .016 & .071 & .019 & .04 & .09 & .32 & .62 & $1.82 \mathrm{E}-03$ \\
\hline 25 percentile & .88 & 10.3 & 4.56 & .09 & .032 & .178 & .030 & .10 & .29 & .47 & .97 & $6.61 \mathrm{E}-03$ \\
\hline 50 percentile & 19.30 & 15.5 & 4.86 & .20 & .058 & .344 & .049 & .19 & .44 & 1.08 & 1.41 & $1.38 \mathrm{E}-02$ \\
\hline 75 percentile & 37.62 & 22.6 & 5.18 & .44 & .101 & .591 & .118 & .36 & 1.03 & 1.77 & 2.72 & $2.75 E-02$ \\
\hline 90 percentile & 69.00 & 38.7 & 5.75 & 1.03 & .332 & 1.694 & .348 & 1.31 & 2.43 & 3.90 & 5.48 & $3.31 \mathrm{E}-02$ \\
\hline Maximum value & 99.80 & 70.6 & 6.44 & 4.40 & .385 & 2.537 & 1.157 & 1.76 & 5.27 & 6.44 & 9.36 & $5.75 E-02$ \\
\hline Volume-weighted mean & NA & 12.0 & 4.82 & .18 & .047 & .297 & .047 & .18 & .49 & .70 & 1.22 & $1.50 \mathrm{E}-02$ \\
\hline Arithmetic mean & 24.84 & 19.3 & 4.97 & .49 & .099 & .533 & .135 & .36 & .88 & 1.46 & 2.17 & $1.72 E-02$ \\
\hline $\begin{array}{l}\text { No. of samples } \\
\text { Total load, } \mathrm{g} / \mathrm{m} 2 \\
\text { Maximum interval }\end{array}$ & $\begin{array}{l}54 \\
\text { NA }\end{array}$ & $\begin{array}{l}37 \\
\text { NA }\end{array}$ & NA & $\begin{array}{l}37 \\
0.177\end{array}$ & $\begin{array}{l}37 \\
0.045\end{array}$ & $\begin{array}{l}37 \\
0.286\end{array}$ & $\begin{array}{l}37 \\
0.045\end{array}$ & $\begin{array}{l}37 \\
0.175\end{array}$ & $\begin{array}{l}37 \\
0.474\end{array}$ & $\begin{array}{l}37 \\
0.673\end{array}$ & $\begin{array}{l}37 \\
1.171\end{array}$ & $\begin{array}{l}37 \\
1.4 \mathrm{E}-02\end{array}$ \\
\hline $\begin{array}{l}\text { load, } 8 / \mathrm{m} 2 \\
\text { Correlation with ppt } \\
\text { Kendall tau }\end{array}$ & $\begin{array}{c}\text { NA } \\
\text { volume: }\end{array}$ & $\begin{array}{l}\text { NA } \\
\text { Cond } \\
-0.62\end{array}$ & $\begin{array}{l}\text { NA } \\
\text { pH } \\
0.07\end{array}$ & $\begin{array}{c}.022 \\
C a \\
-.53\end{array}$ & $\begin{array}{r}.004 \\
\mathrm{Mg} \\
-.52\end{array}$ & $\begin{array}{r}.028 \\
\mathrm{Na} \\
-.32\end{array}$ & $\begin{array}{c}.005 \\
K \\
-.57\end{array}$ & $\begin{array}{l}.018 \\
\mathrm{NH} \\
-.30\end{array}$ & $\begin{array}{l}.044 \\
C 1 \\
-.29\end{array}$ & $\begin{array}{l}.066 \\
\mathrm{NO}_{3} \\
-.62\end{array}$ & $\begin{array}{l}.096 \\
\mathrm{SO}_{4} \\
-.55\end{array}$ & $\begin{array}{l}1.8 E-03 \\
H \\
-0.07\end{array}$ \\
\hline P-level & & .000 & .530 & .000 & .000 & .006 & .000 & .009 & .012 & .000 & .000 & .530 \\
\hline
\end{tabular}

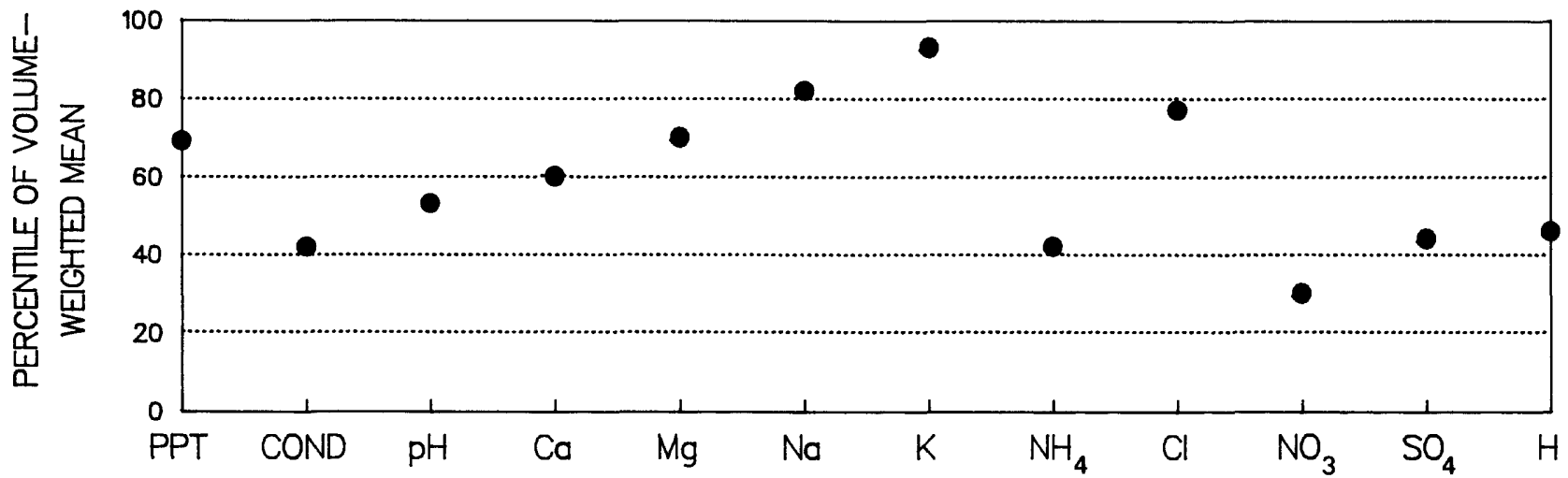

Percentiles of volume-weighted mean concentrations for site TX38, based on frequency distributions of data from 55 National Trends Network sites. 

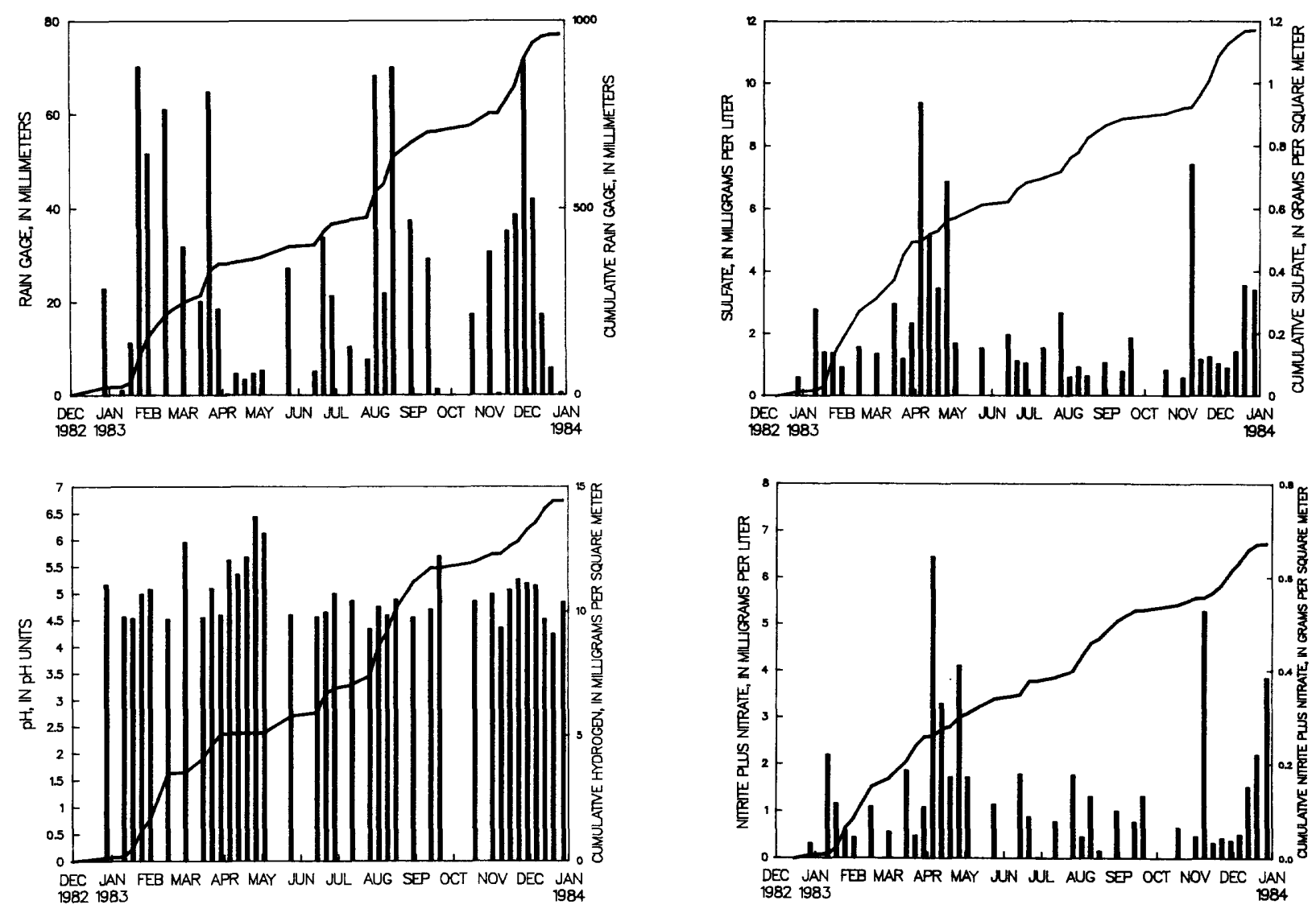

Bar plots of concentrations and cumulative line plots of loads for site TX38.

Nitrite plus nitrate are reported as $\mathrm{NO}_{3}$ and sulfate as $\mathrm{SO}_{4}$.

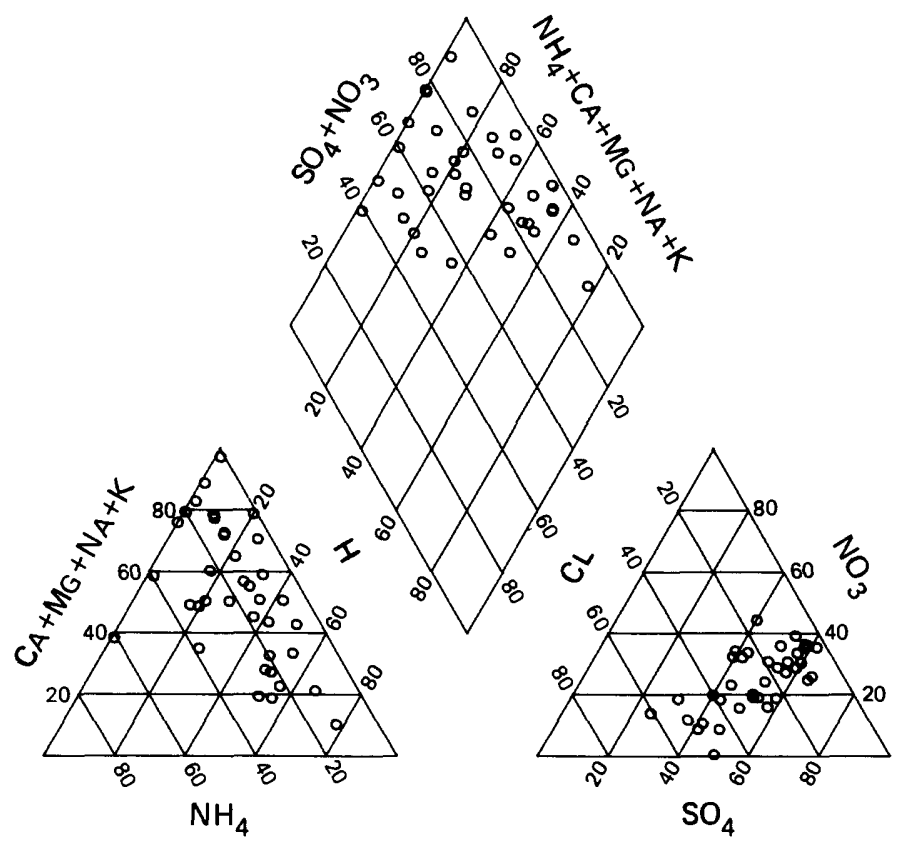

Percentage composition of major ions for site TX38. 


\section{NATIONAL TRENDS NETWORK -- 1983 CALENDER YEAR SUMMARY DATA}

[ppt = precipitation; $\mathrm{mm}=$ millimeters; $\mathrm{cm}=$ centimeters; $\mathrm{mg}=$ milligrams; $\mathrm{L}=1$ iters; $g=$ grams; $m=$ meter; $\mu \mathrm{s}=$ microsiemens; cond = specific conductance $]$

STATION: Cedar Mountain, Utah

CAL number: UTO2

ADS number: $069 \mathrm{a} 00$

Station altitude above mean sea level, in meters: 2356

Number of sampling intervals (days in parenthesis):

-- With ppt measurements: $33 \quad$ (384)

-- When ppt occurred: $31 \quad$ (370)

-- When ppt did not occur: 2 ( 14 )

-- When sample volume was substituted for missing rain gage: 3 ( 34 )

-- With chemical samples: 23 (265)
Latitude: $39^{\circ} 10^{\prime} 15^{\prime \prime}$ Longitude: $110^{\circ} 37^{\prime} 05^{\prime \prime}$

Station summary period: $12 / 21 / 1982$ to $01 / 17 / 1984$

Length of sumary period: 35 sampling intervals ( 392 days)

Percent sumary period with ppt measurements: 103.5

Percent summary period with chemical samples or no ppt: 75.2

Percent of total measured ppt with chemical samples: 72.2

Percent of total measured ppt in raingage that was

collected in the wet-sample bucket:

82.4

Total measured ppt, in $\mathrm{mm}: 277.4$

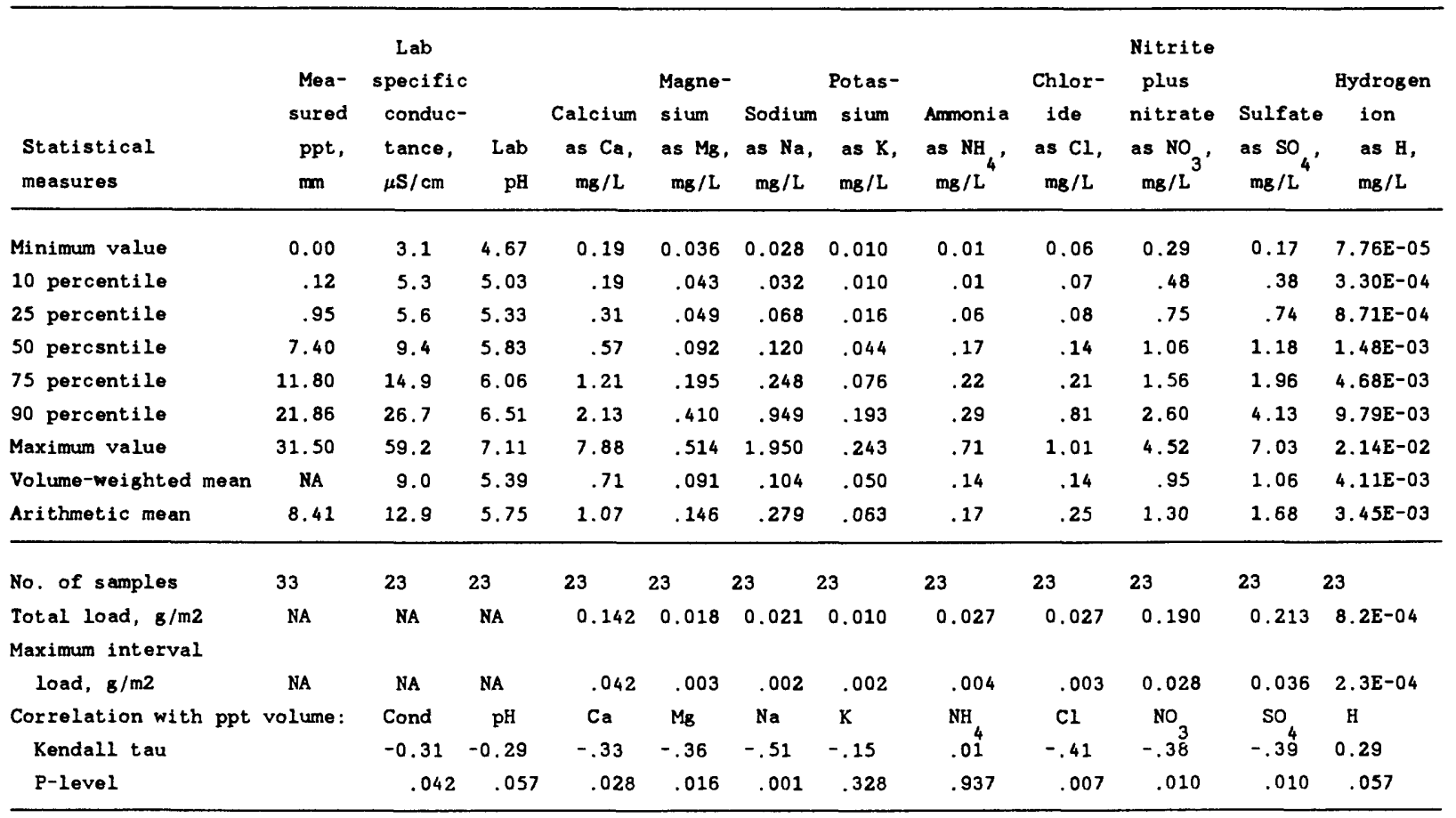

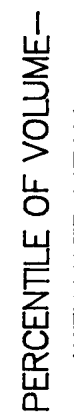

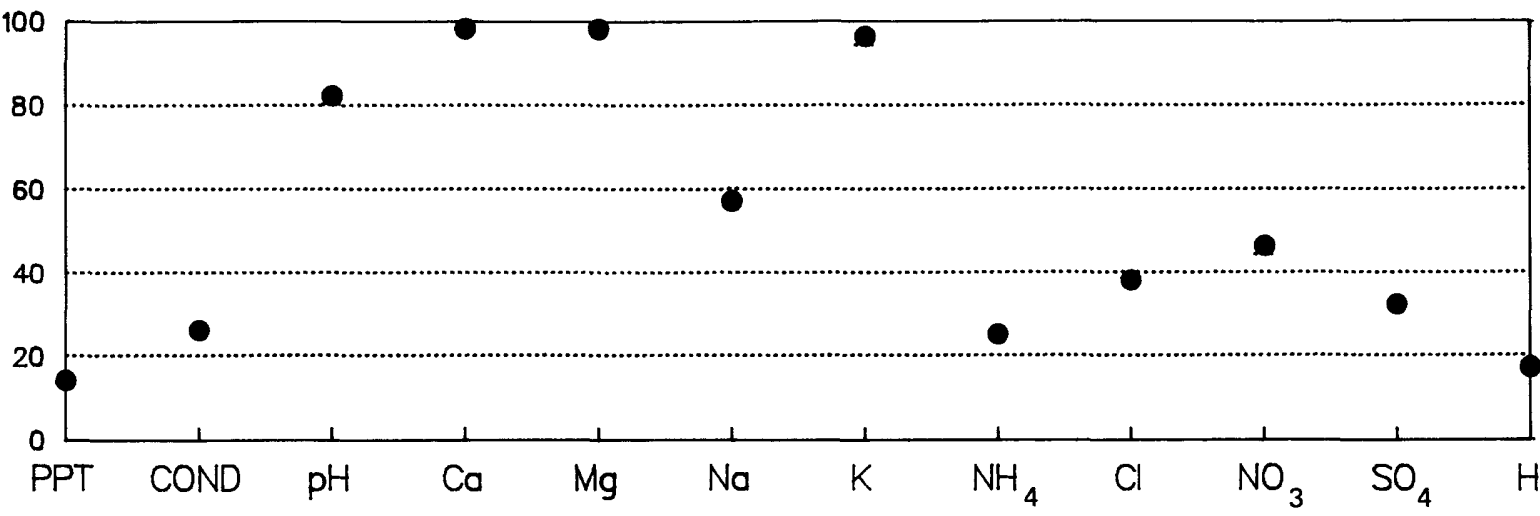

Percentiles of volume-weighted mean concentrations for site UT02, based on frequency distributions of data from 55 National Trends Network sites. 

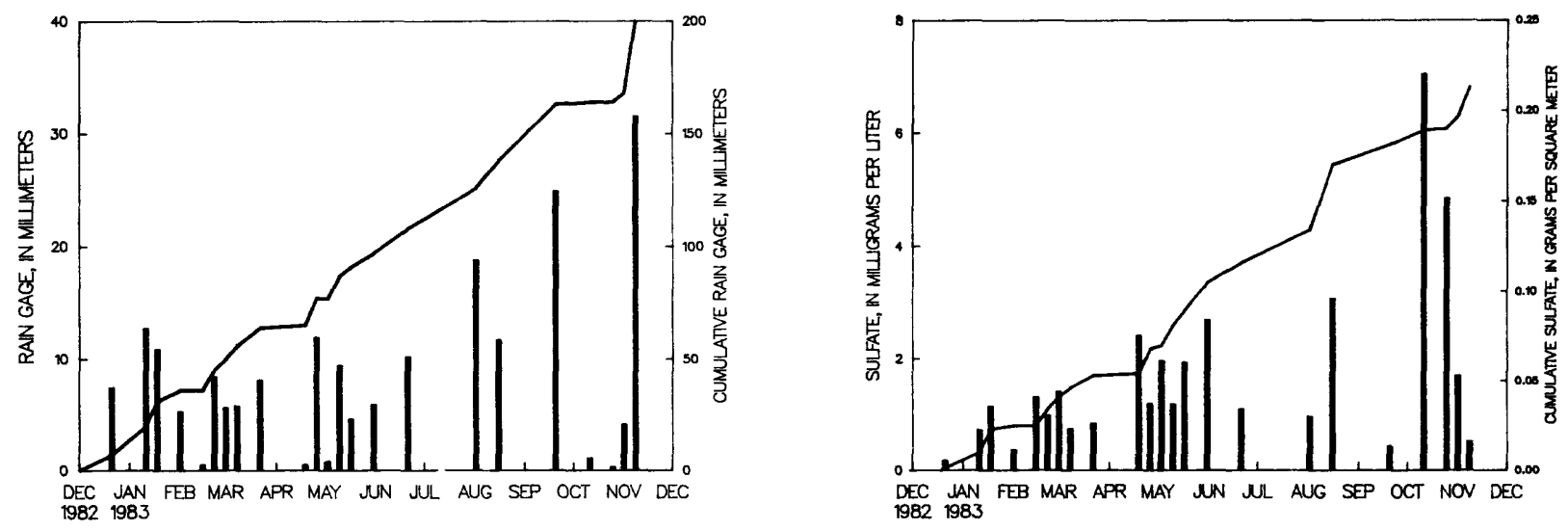

DEC JAN FEB MAR APR MAY JN UL AUG SEP OCT NOV DEC
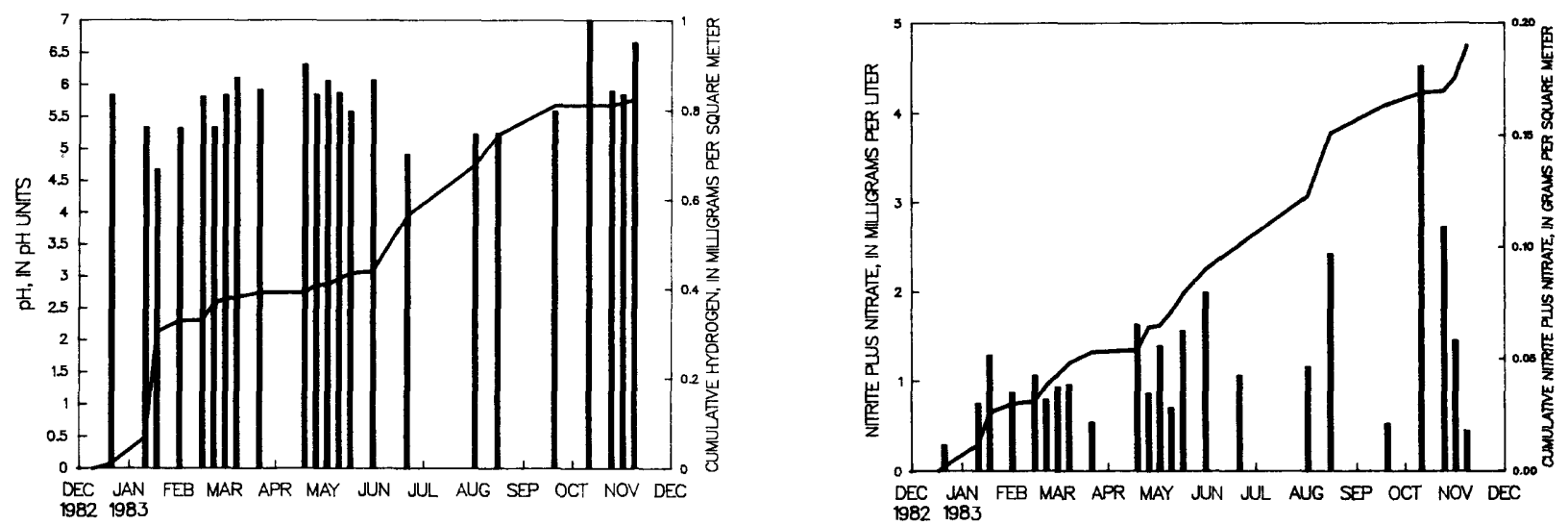

Bar plots of concentrations and cumulative line plots of loads for site UT02. Nitrite plus nitrate are reported as $\mathrm{NO}_{3}$ and sulfate as $\mathrm{SO}_{4}$.

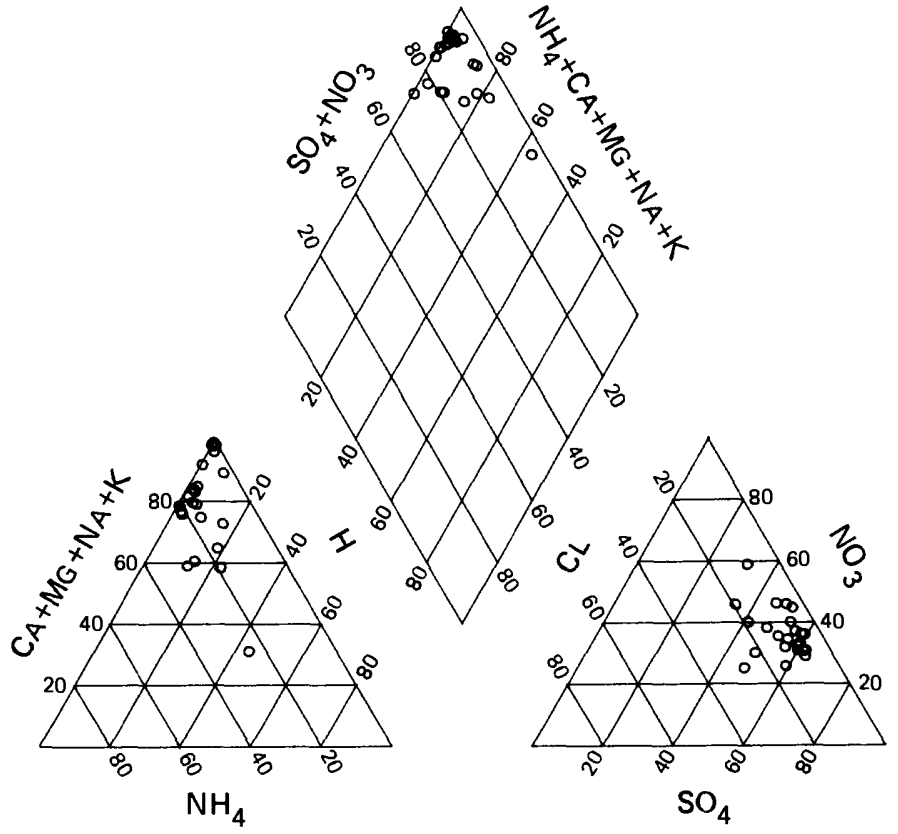

Percentage composition of major ions for site UT02. 


\section{NATIONAL TRENDS NETWORK -- 1983 CALENDER YEAR SUMMARY DATA}

lppt = precipitation; $\mathrm{mm}=$ millimeters; $\mathrm{cm}=$ centimeters; $\mathrm{mg}=\mathrm{milligrams;} \mathrm{L}=1 \mathrm{liters} ;$ $\mathrm{g}=$ grams; $\mathrm{m}=$ meter $\boldsymbol{\mu s}=$ microsiemens ; cond = specific conductance $]$

STATION: Bennington, Vermont

CAL number: vT01

ADS number: $249 a 00$

Station altitude above mean sea level, in meters: 305

Number of sampling intervals (days in parenthesis):

-- With ppt measurements: 52 (378)

-- When ppt occurred: 51 (371)

-- When ppt did not occur: 1 ( 7)

-- When sample volume was substituted for missing rain gage: 5 (35)

-- With chemical samples: $36 \quad$ (266)
Latitude: $42^{\circ} 52^{\prime} 34^{\prime \prime}$ Longitude: $73^{\circ} 09^{\prime} 48^{\prime \prime}$

Station summary period: $12 / 21 / 1982$ to $01 / 03 / 1984$

Length of summary period: 52 sampling intervals ( 378 days)

Percent summary period with ppt measurements: 101.9

Percent summary period with chemical samples or no ppt: 73.6

Percent of total measured ppt with chemical samples: 77.3

Percent of total measured ppt in raingage that was

collected in the wet-sample bucket:

92.0

Total measured ppt, in m: 1215.9

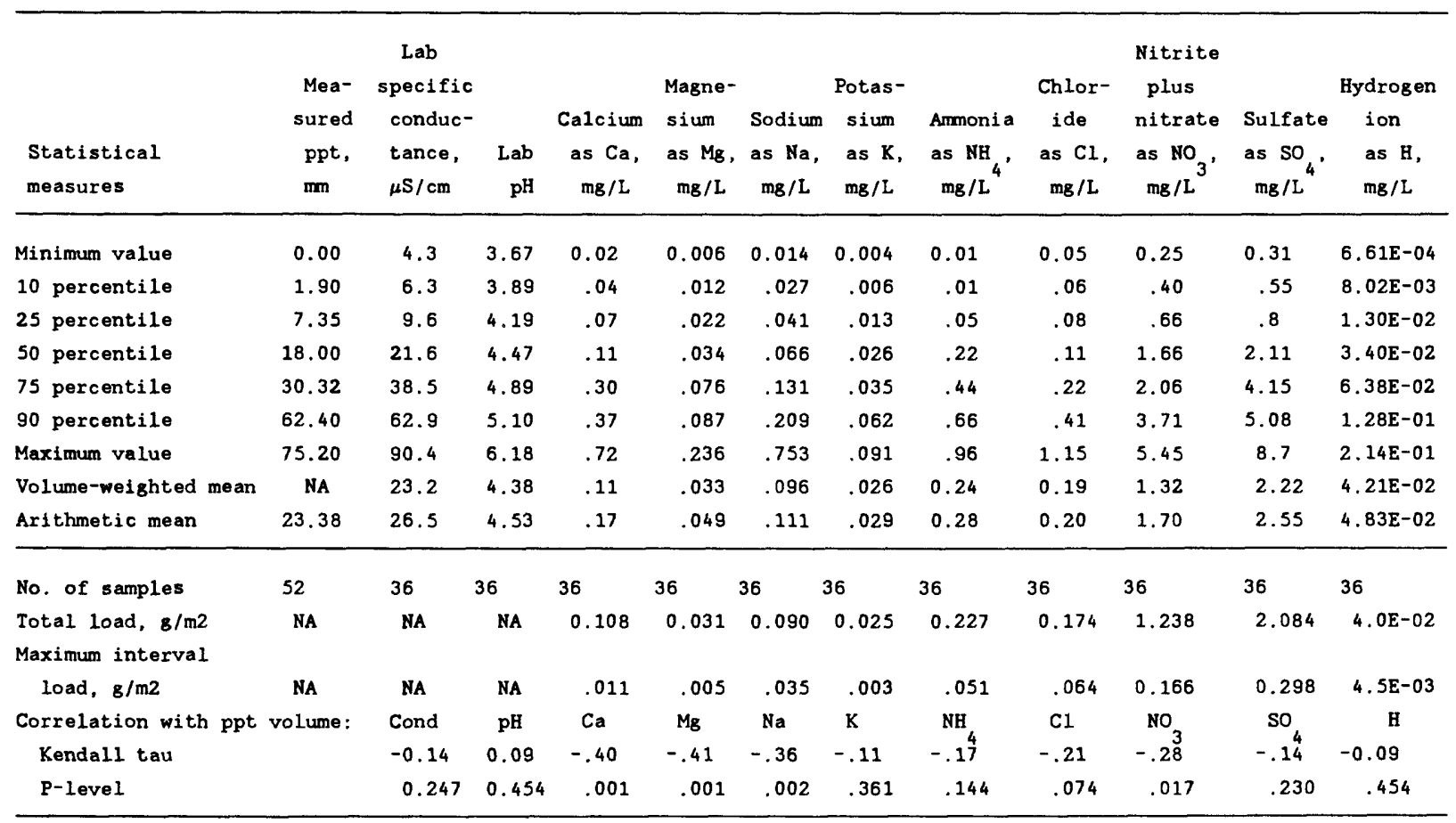

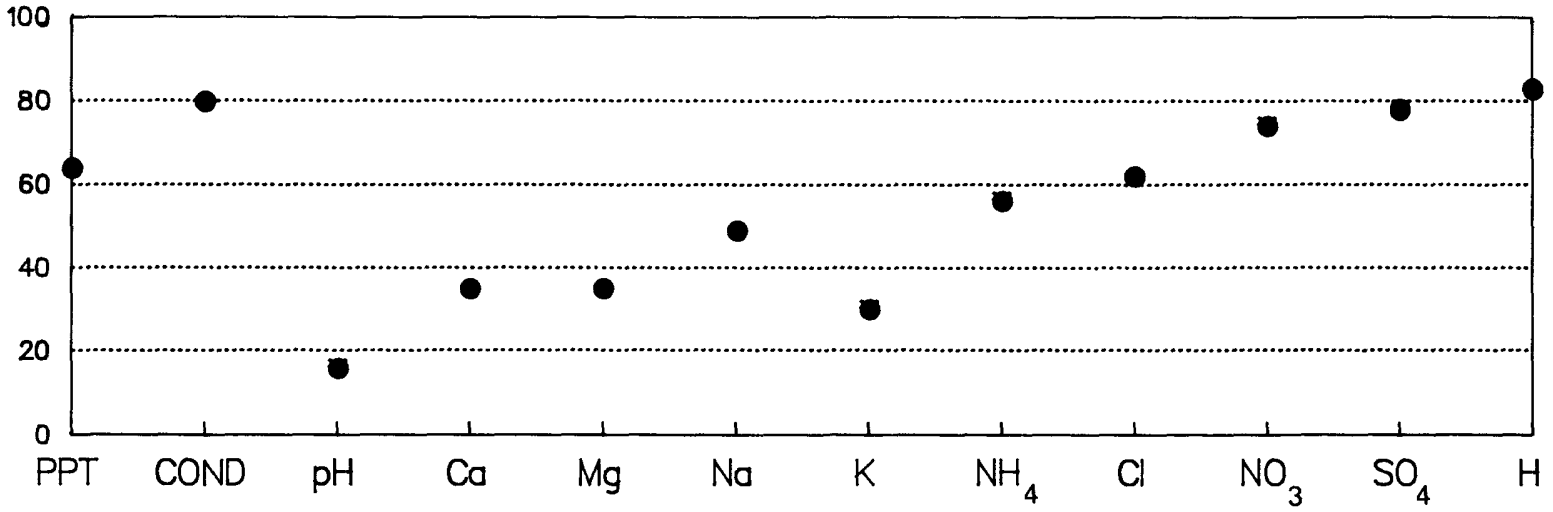

Percentiles of volume-weighted mean concentrations for site VT01, based on

frequency distributions of data from 55 National Trends Network sites. 

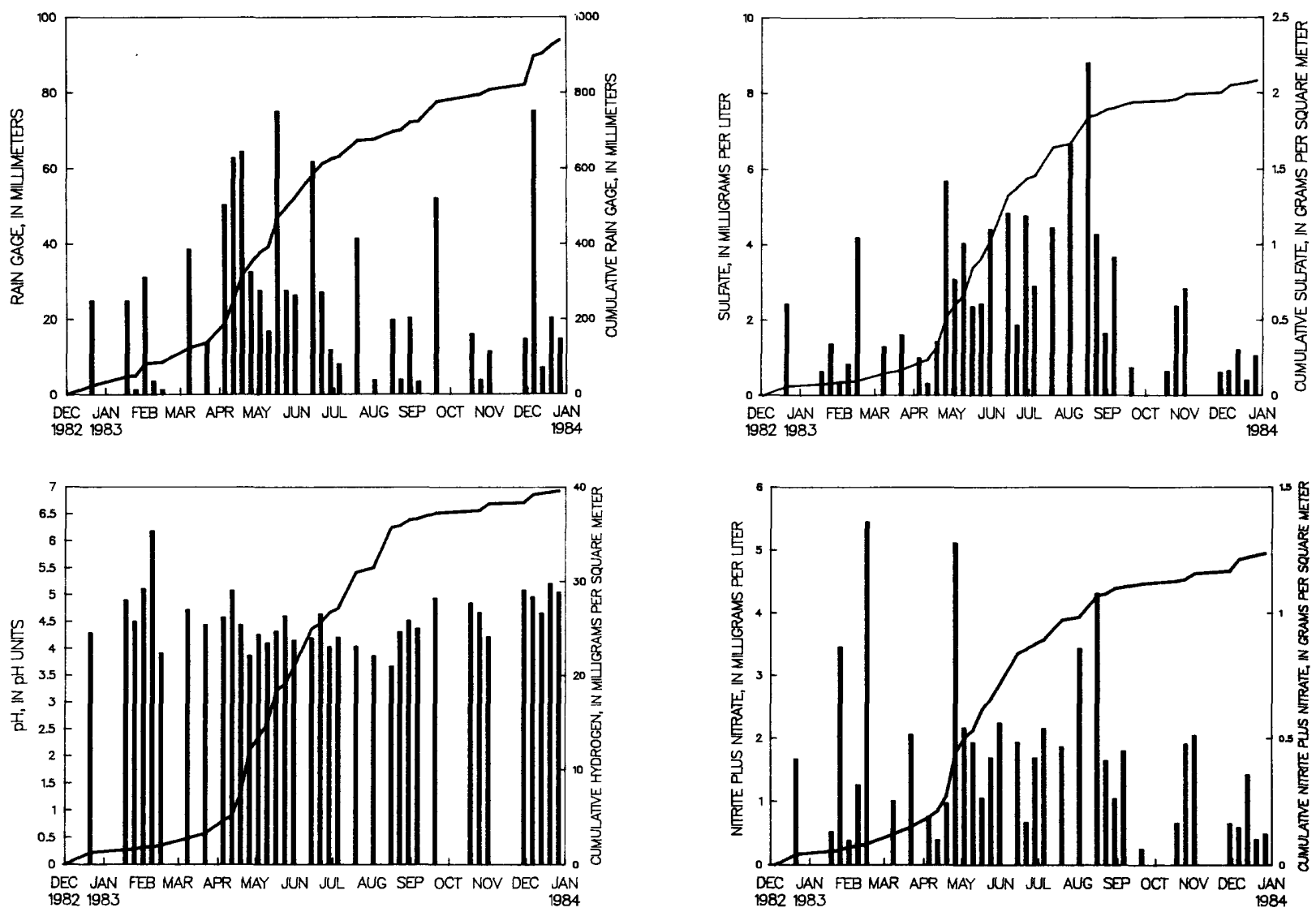

Bar plots of concentrations and cumulative line plots of loads for site VT01. Nitrite plus nitrate are reported as $\mathrm{NO}_{3}$ and sulfate as $\mathrm{SO}_{4}$.

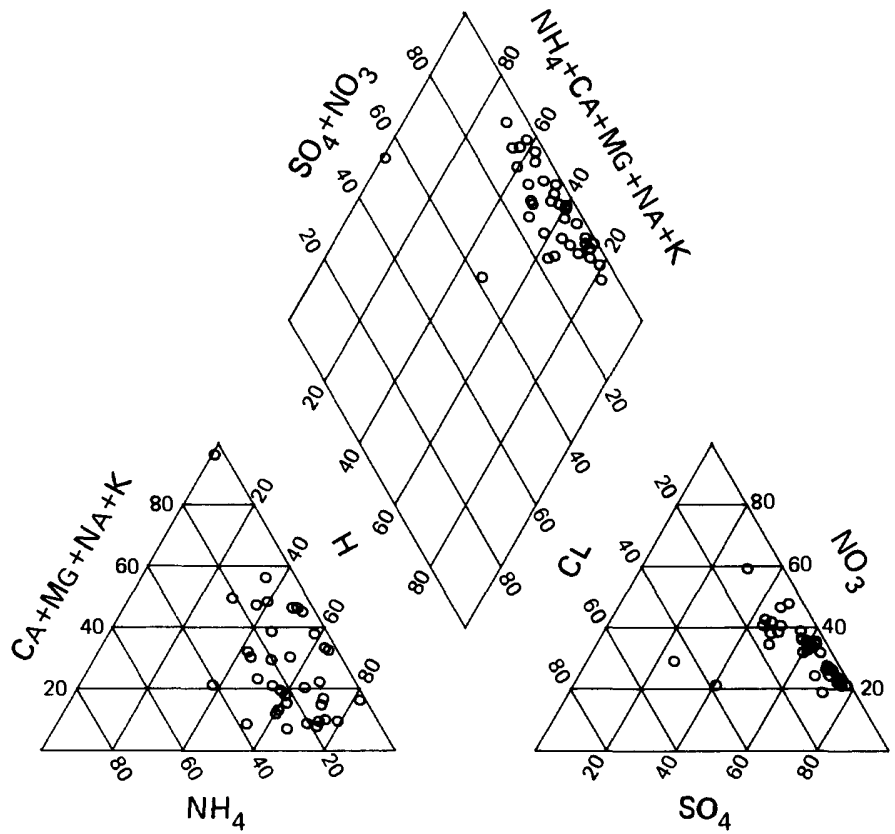

Percentage composition of major ions for site VT01. 


\section{NATIONAL TRENDS NETWORK -- 1983 CALENDER YEAR SUMMARY DATA}

[ppt = precipitation; $\mathrm{mm}=$ millimeters; $\mathrm{cm}=$ centimeters; $\mathrm{mg}=\mathrm{milligrams;} \mathrm{L}=11$ ters; $g=g r a m s ; m=$ meter $\mu \mathrm{s}=$ microsiemens; cond $=$ specific conductance $]$

STATION: Olympic National Park, Washington

CAL number: WA14

Map ID number: 101

\begin{abstract}
ADS number: $074 \mathrm{a} 00$
\end{abstract}
Station altitude above mean sea level, in meters: 176 Number of sampling intervals (days in parenthesis):

-- With ppt measurements: $58 \quad$ (371)

-- When ppt occurred: 57 (364)

-- When ppt did not occur: 1 ( 7)

-- When sample volume was substituted for missing rain gage:

-- With chemical samples:
Latitude: $47^{\circ} 51^{\prime} 36^{\prime \prime}$ Longitude: $123^{\circ} 55^{\prime} 57^{\prime \prime}$

Station summary period: $12 / 28 / 1982$ to $01 / 03 / 1984$

Length of sumary period: 58 sampling intervals ( 371 days)

Percent summary period with ppt measurements: $\quad 100.0$

Percent summary period with chemical samples or no ppt: 80.6

Percent of total measured ppt with chemical samples: 80.2

Percent of total measured ppt in raingage that was

collected in the wet-sample bucket:

97.0

Total measured ppt, in m: 4057.2

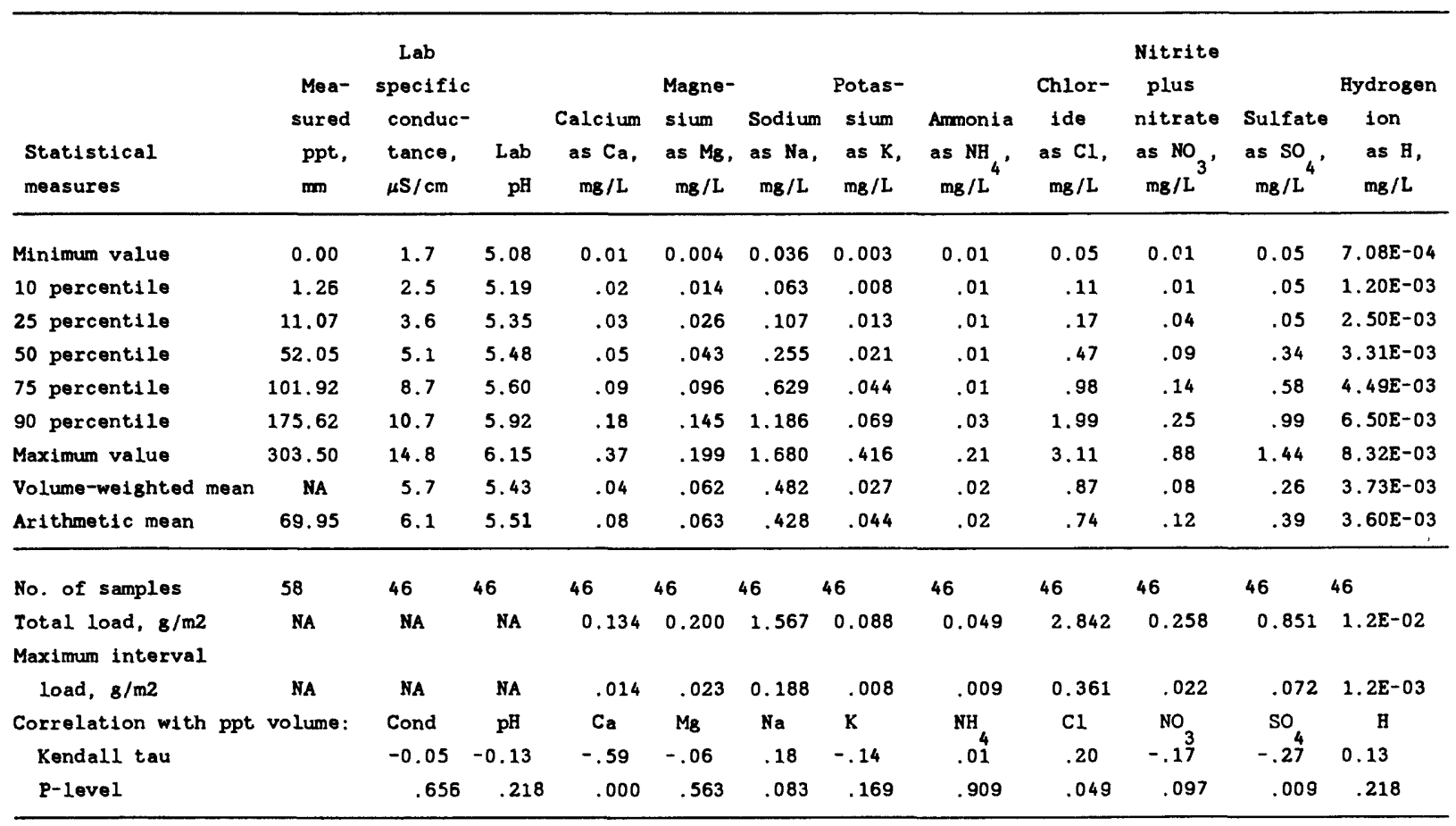

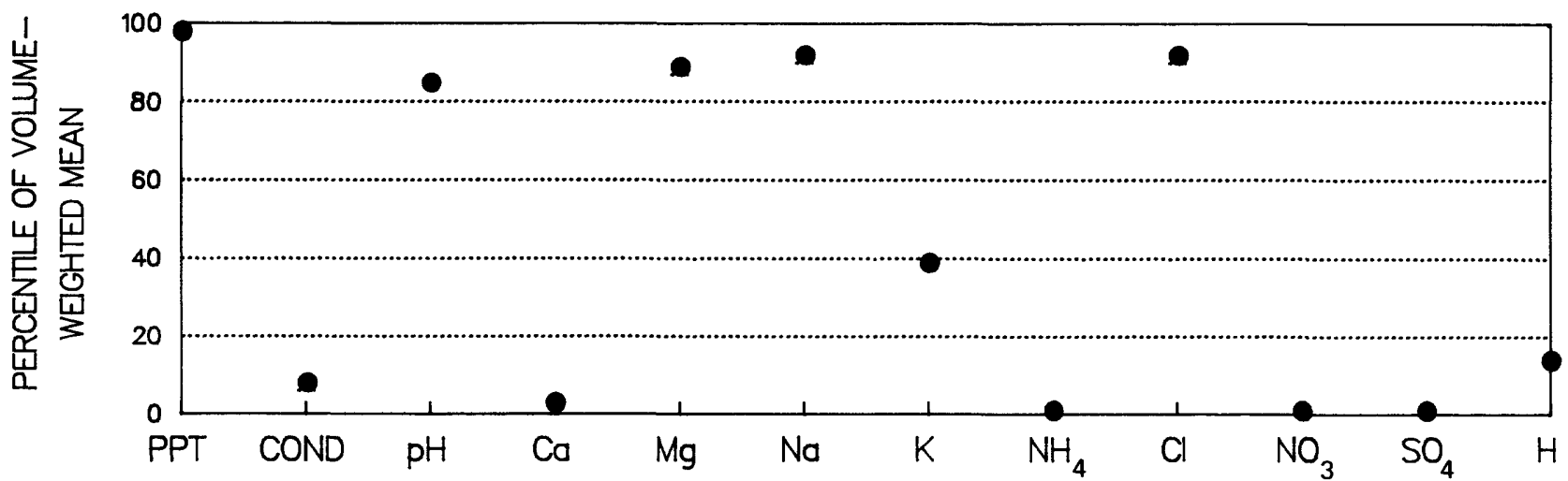

Percentiles of volume-weighted mean concentrations for site WA14, based on frequency distributions of data from 55 National Trends Network sites. 

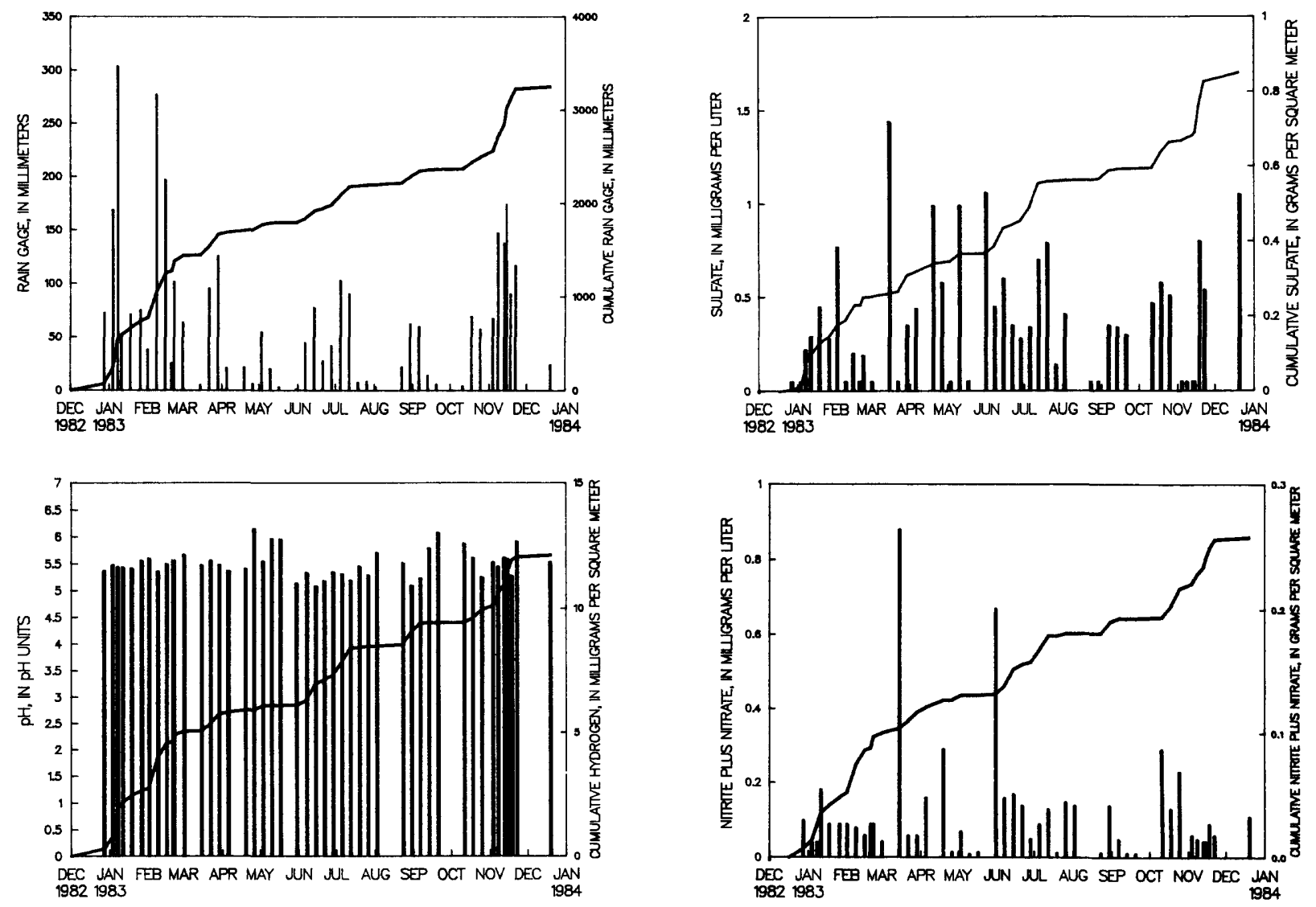

Bar plots of concentrations and cumulative line plots of loads for site WA14. Nitrite plus nitrate are reported as $\mathrm{NO}_{3}$ and sulfate as $\mathrm{SO}_{4}$.

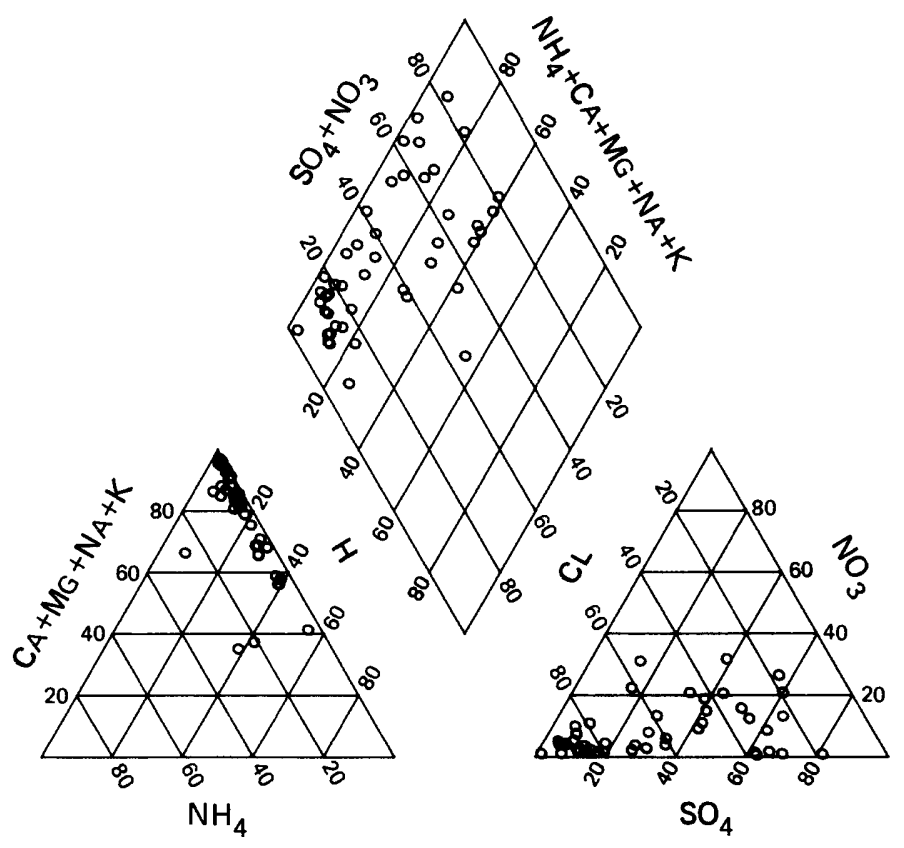

Percentage composition of major ions for site WA14. 


\section{NATIONAL TRENDS NETWORK -- 1983 CALENDER YEAR SUMMARY DATA}

lppt = precipitation; $\mathrm{mm}=$ millimeters $; \mathrm{cm}=$ centimeters; $\mathrm{mg}=$ milligrams; L = liters;

$\mathrm{g}=\mathrm{grams} ; \mathrm{m}=$ meter; $\mu \mathrm{s}=$ microsiemens; cond = specific conductance $]$

STATION: Lake Dubay, Wisconsin

CAL number: WI28

ADS number: $283 \mathrm{a} 00$

Map ID number: 102

Station altitude above mean sea level, in meters: 2113

Number of sampling intervals (days in parenthesis):

-- With ppt measurements: 53 (369)

-- When ppt occurred: $49 \quad$ (341)

-- When ppt did not occur: $4 \quad$ (28)

-- When sample volume was substituted for missing rain gage: 2 ( 14)

-- With chemical samples: 41 (285)
Latitude: $\quad 44^{\circ} 39^{\prime} 53^{\prime \prime}$ Longitude: $89^{\circ} 39^{\prime} 08^{\prime \prime}$

Station summary period: $12 / 28 / 1982$ to $01 / 03 / 1984$

Length of summary period: 54 sampling intervals ( 371 days)

Percent summary period with ppt measurements: 99.5

Percent summary period with chemical samples or no ppt: 84.4

Percent of total measured ppt with chemical samples: $\quad 90.0$

Percent of total measured ppt in raingage that was

collected in the wet-sample bucket:

95.5

Total measured ppt, in $\mathrm{mm}: 641.5$

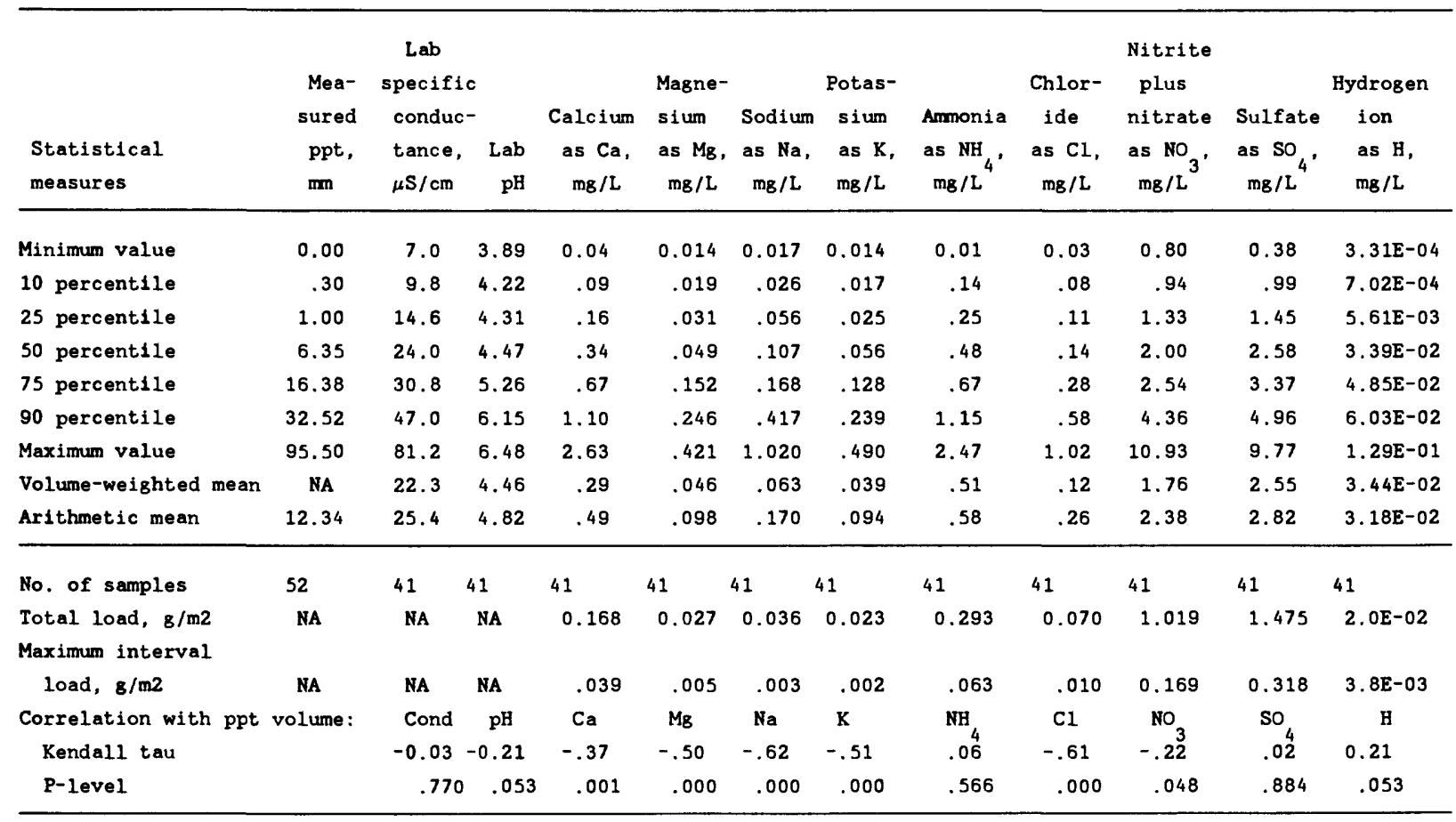

岁

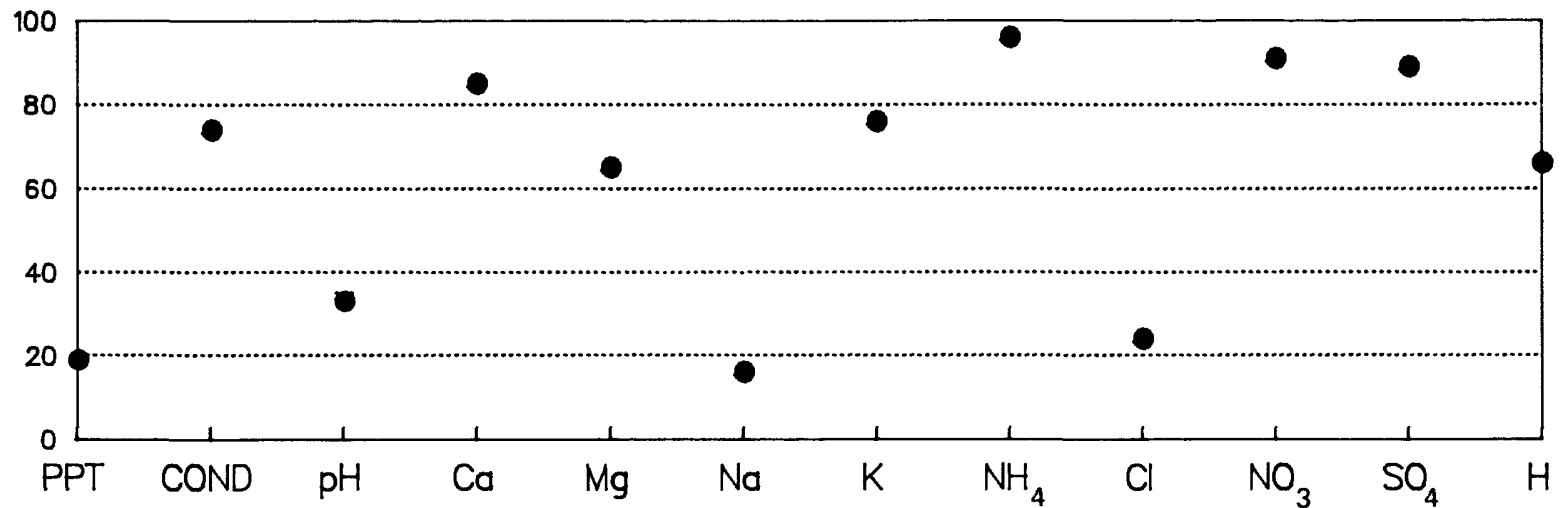

Percentiles of volume-weighted mean concentrations for site WI28, based on frequency distributions of data from 55 National Trends Network sites. 

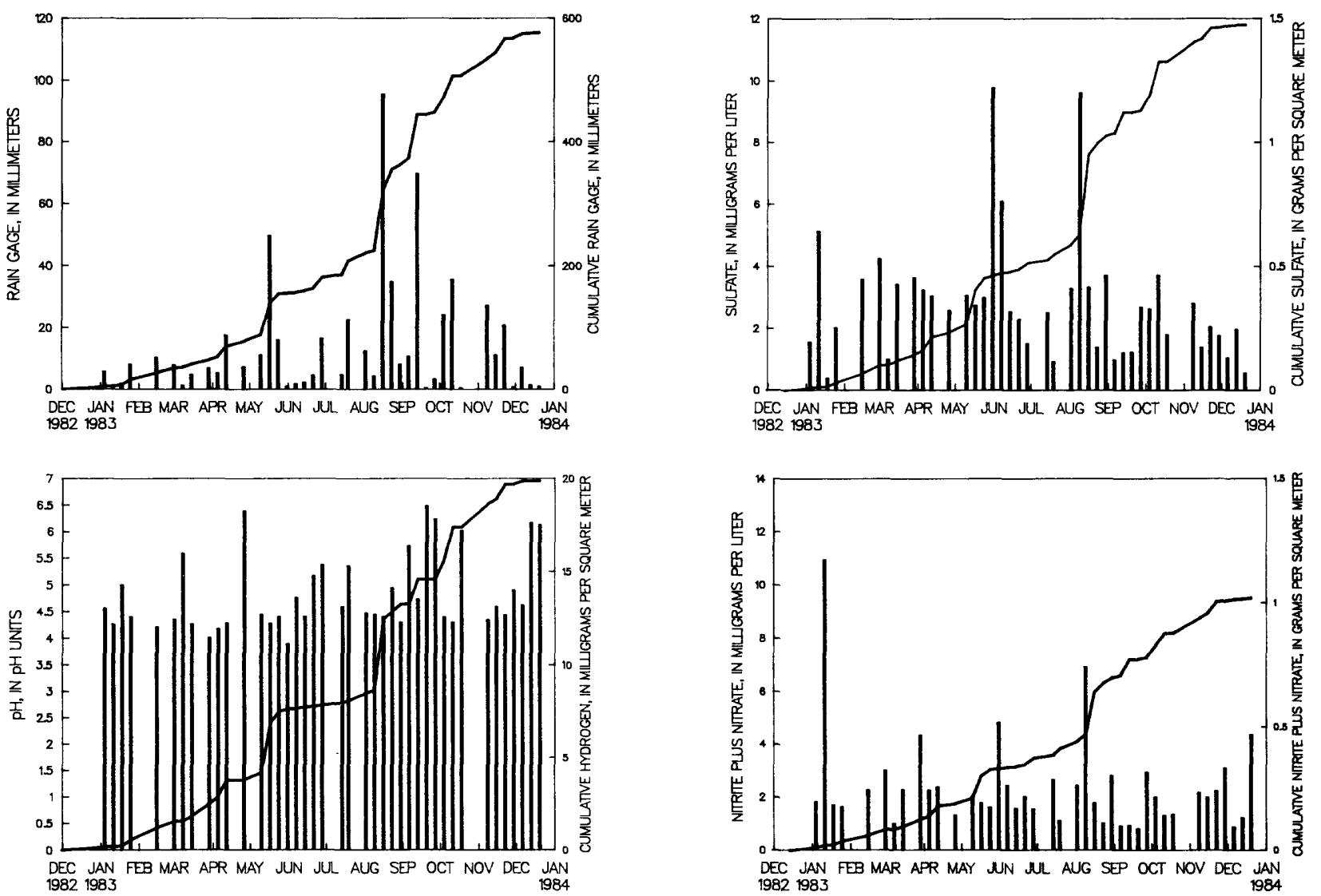

Bar plots of concentrations and cumulative line plots of loads for site WI28. Nitrite plus nitrate are reported as $\mathrm{NO}_{3}$ and sulfate as $\mathrm{SO}_{4}$.

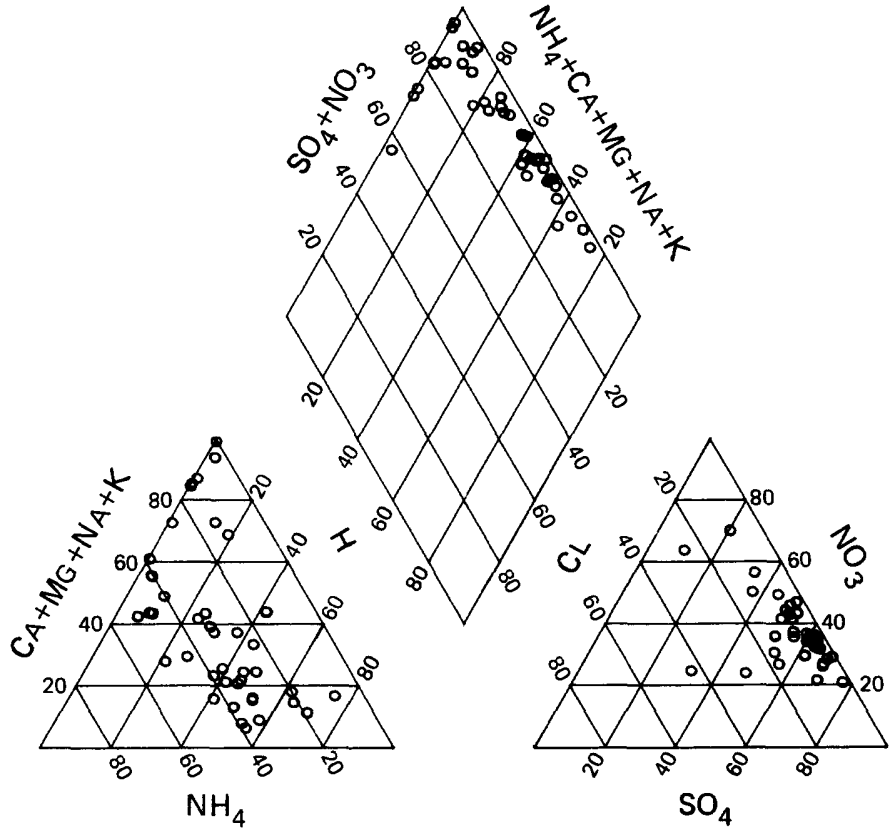

Percentage composition of major ions for site WI28. 


\section{NATIONAL TRENDS NETWORK -- 1983 CALENDER YEAR SUMMARY DATA}

lppt = precipitation; $\mathrm{mm}=$ millimeters; $\mathrm{cm}=$ centimeters; $\mathrm{mg}=$ milligrams; $\mathrm{L}=1 \mathrm{liters}$;

$\mathrm{g}=\mathrm{grams} ; \mathrm{m}=$ meter $; \mu \mathrm{s}=$ microsiemens; cond = specific conductance]

STATION: Trout Lake, Wisconsin

CAL number: WI36

ADS number: $076 a 00$

Station altitude above mean sea level, in meters: 501

Number of sampling intervals (days in parenthesis):

-- With ppt measurements: $52 \quad$ (372)

-- When ppt occurred: 51 (365)

-- When ppt did not occur: 11 ( 7)

-- When sample volume was substituted for missing rain gage: 3 ( 21 )

-- With chemical samplee: 34 (238)
Latitude: $46^{\circ} 03^{\prime} 09^{\prime \prime}$ Longitude: $89^{\circ} 39^{\prime} 11^{\prime \prime}$

Station summary period: $12 / 27 / 1982$ to $01 / 03 / 1984$

Length of summary period: 52 sampling intervels ( 372 days)

$\begin{array}{ll}\text { Percent summary period with ppt measurements: } & 100.3\end{array}$

Percent summary period with chemical samples or no ppt: 66.0

Percent of total measured ppt with chemical samples: 76.1

Percent of total measured ppt in raingage that was

collected in the wet-sample bucket:

96.4

Total measured ppt, in m: 859.9

\begin{tabular}{|c|c|c|c|c|c|c|c|c|c|c|c|c|}
\hline $\begin{array}{l}\text { Statistical } \\
\text { measures }\end{array}$ & $\begin{array}{c}\text { Mea- } \\
\text { sured } \\
\text { ppt, } \\
\text { mm }\end{array}$ & $\begin{array}{l}\text { Lab } \\
\text { specific } \\
\text { conduc- } \\
\text { tance, } \\
\mu \mathrm{S} / \mathrm{cm}\end{array}$ & $\begin{array}{r}\text { Lab } \\
\text { pH }\end{array}$ & $\begin{array}{c}\text { Calcium } \\
\text { as Ca, } \\
\mathrm{mg} / \mathrm{L}\end{array}$ & $\begin{array}{l}\text { Magne- } \\
\text { sium } \\
\text { as } \mathrm{Mg}, \\
\mathrm{mg} / \mathrm{L}\end{array}$ & $\begin{array}{c}\text { Sodium } \\
\text { as } \mathrm{Na} \text {, } \\
\mathrm{mg} / \mathrm{L}\end{array}$ & $\begin{array}{l}\text { Potas- } \\
\text { sium } \\
\text { as } \mathrm{K} \text {, } \\
\mathrm{mg} / \mathrm{L}\end{array}$ & $\begin{array}{l}\text { Ammonia } \\
\text { as } \mathrm{NH}_{4} \\
\mathrm{mg} / \mathrm{L}^{\prime}\end{array}$ & $\begin{array}{l}\text { Chlor- } \\
\text { ide } \\
\text { as } \mathrm{Cl} \text {, } \\
\mathrm{mg} / \mathrm{L}\end{array}$ & $\begin{array}{l}\text { Nitrite } \\
\text { plus } \\
\text { nitrate } \\
\text { as } \mathrm{NO}^{\prime} \\
\mathrm{mg} / \mathrm{L}\end{array}$ & $\begin{array}{l}\text { Sulfate } \\
\text { as so } \\
\text {. } \mathrm{mg} / \mathrm{L}^{4}\end{array}$ & $\begin{array}{l}\text { Hydrogen } \\
\text { ion } \\
\text { as } \mathrm{H}, \\
\mathrm{mg} / \mathrm{L}\end{array}$ \\
\hline Minimum value & 0.00 & 3.6 & 3.86 & 0.03 & 0.007 & 0.010 & 0.002 & 0.01 & 0.01 & 0.25 & 0.35 & $4.07 E-04$ \\
\hline 10 percentile & .36 & 7.0 & 4.32 & .04 & .011 & .015 & .006 & .01 & .02 & .58 & .48 & $2.48 \mathrm{E}-03$ \\
\hline 25 percentile & 2.70 & 10.0 & 4.55 & .09 & .016 & .023 & .012 & .09 & .07 & .89 & .9 & $7.30 \mathrm{E}-03$ \\
\hline 50 percentile & 10.70 & 15.5 & 4.70 & .19 & .030 & .044 & .019 & .26 & .11 & 1.22 & 1.68 & $1.97 \mathrm{E}-02$ \\
\hline 75 percentile & 21.90 & 22.4 & 5.14 & .38 & .057 & .088 & .035 & .48 & .14 & 2.05 & 2.36 & $2.82 E-02$ \\
\hline 90 percentile & 43.75 & 30.7 & 5.60 & .64 & .122 & .241 & .064 & 1.04 & .21 & 3.06 & 3.9 & $4.79 E-02$ \\
\hline Maximum value & 71.90 & 69.5 & 6.39 & 1.61 & .350 & .640 & .139 & 2.02 & .34 & 5.81 & 5.80 & $1.38 \mathrm{E}-01$ \\
\hline Volume-weighted mean & NA & 15.2 & 4.64 & .19 & .033 & .044 & .021 & .28 & .08 & 1.12 & 1.58 & 2. $28 \mathrm{E}-02$ \\
\hline Arithmetic mean & 16.54 & 17.5 & 4.84 & .27 & .052 & .088 & .027 & .38 & .11 & 1.62 & 1.87 & 2. $37 E-02$ \\
\hline No. of samples & 52 & 34 & 34 & 34 & 34 & 34 & 34 & 34 & 34 & 34 & 34 & 34 \\
\hline $\begin{array}{l}\text { Total load, } 8 / \mathrm{m} 2 \\
\text { Msximum interval }\end{array}$ & NA & NA & NA & 0.122 & 0.022 & 0.029 & 0.014 & 0.181 & 0.054 & 0.734 & 1.035 & 1. $5 E-02$ \\
\hline load, $g / m 2$ & NA & NA & NA & .020 & .005 & .004 & .003 & .043 & .005 & .101 & 0.183 & 1. $9 \mathrm{E}-03$ \\
\hline $\begin{array}{l}\text { Correlation with ppt } \\
\text { Kendall tau }\end{array}$ & volume: & $\begin{array}{l}\text { Cond } \\
-0.13-\end{array}$ & $\begin{array}{c}\mathrm{pH} \\
-0.14\end{array}$ & $\begin{array}{c}\mathrm{Ca} \\
-.29\end{array}$ & $\begin{array}{l}\mathrm{Mg} \\
-.33\end{array}$ & $\begin{array}{l}\mathrm{Na} \\
-.52\end{array}$ & $\begin{array}{l}\mathrm{K} \\
-.25\end{array}$ & $\begin{aligned} \mathrm{NH} \\
-.19\end{aligned}$ & $\begin{array}{c}C 1 \\
-.42\end{array}$ & $\begin{array}{l}\mathrm{NO}_{3} \\
-.39\end{array}$ & $\begin{array}{l}\text { So } \\
-.16\end{array}$ & $\begin{array}{c}\mathrm{H} \\
0.14\end{array}$ \\
\hline P-level & & .279 & .260 & .018 & .007 & .000 & .036 & .122 & .001 & .001 & .192 & .260 \\
\hline
\end{tabular}

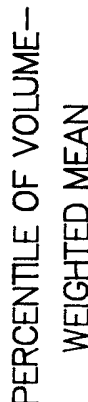

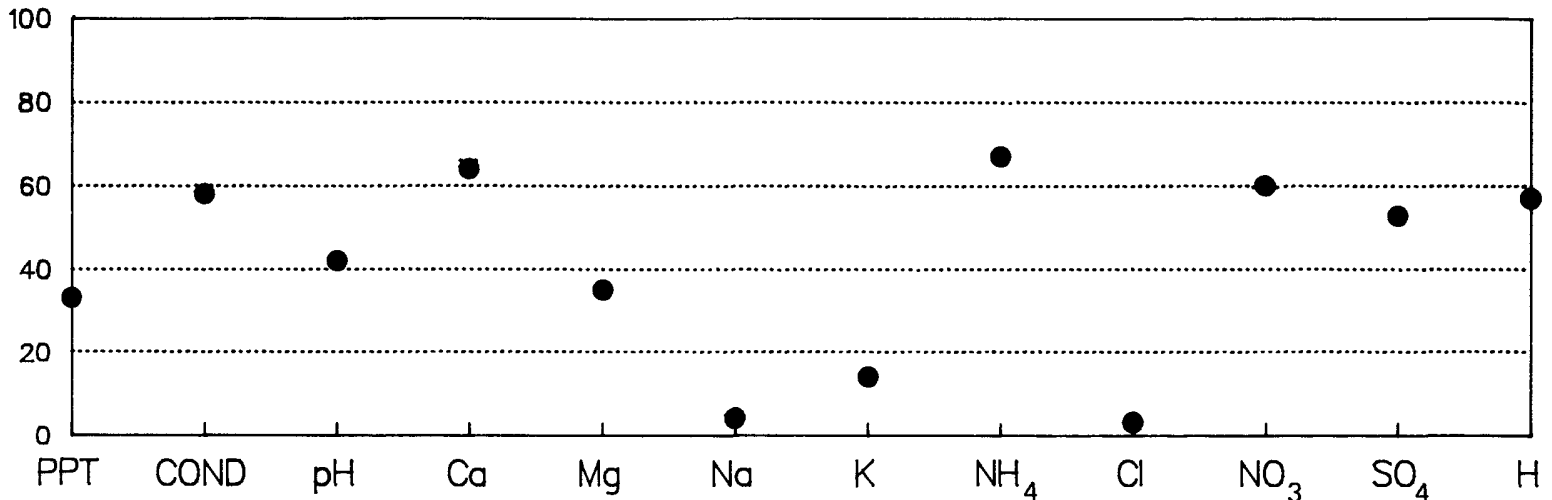

Percentiles of volume-weighted mean concentrations for site WI36, based on

frequency distributions of data from 55 National Trends Network sites. 

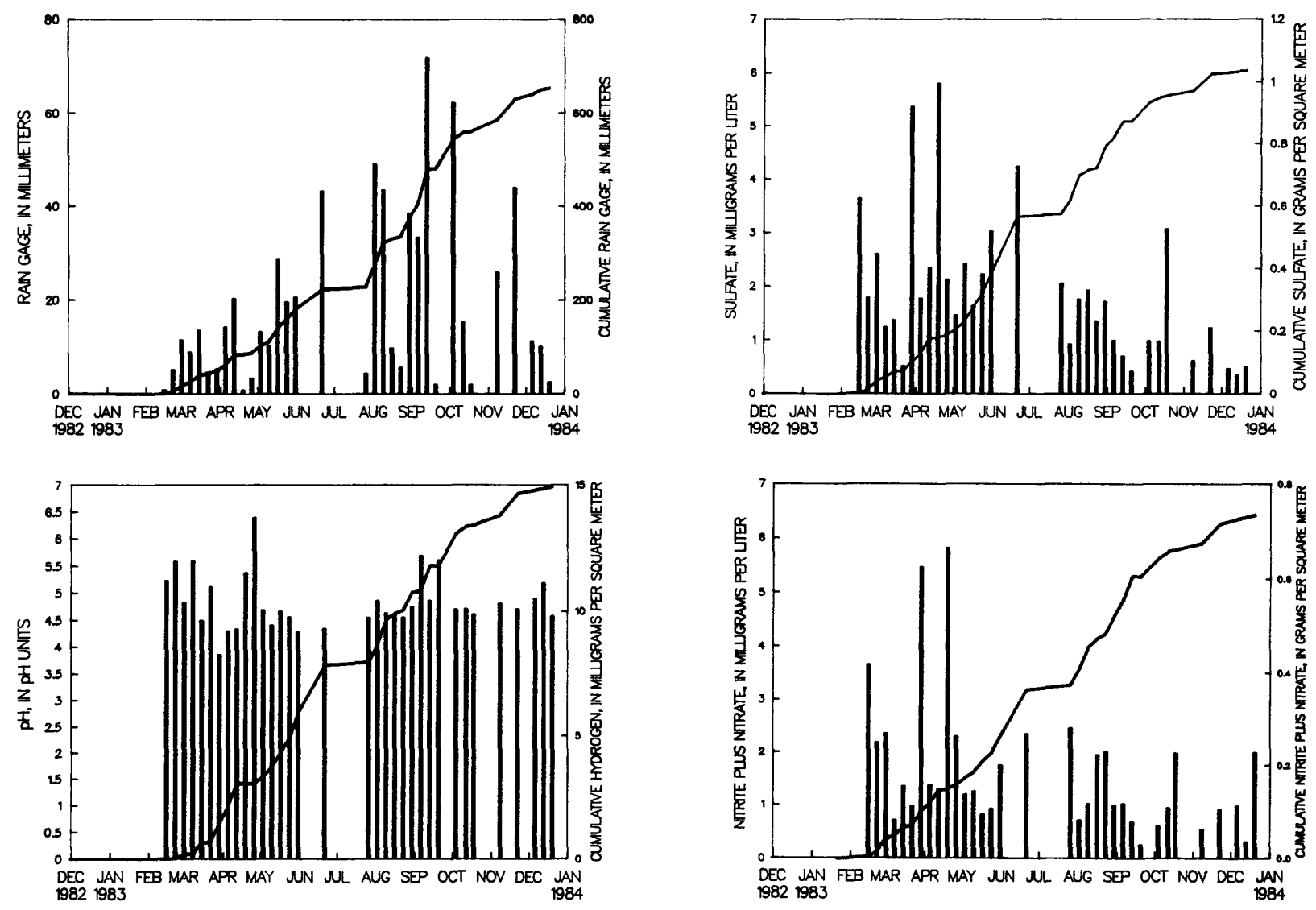

Bar plots of concentrations and cumulative line plots of loads for site WI36.

Nitrite plus nitrate are reported as $\mathrm{NO}_{3}$ and sulfate as $\mathrm{SO}_{4}$.

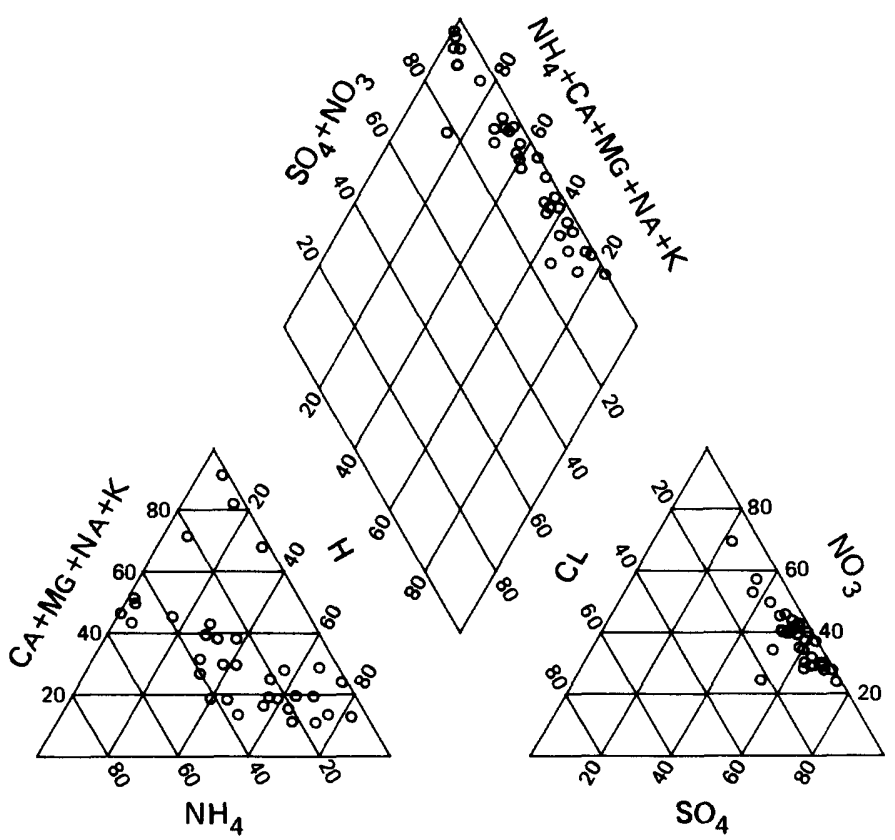

Percentage composition of major ions for site WI36. 


\section{NATIONAL TRENDS NETWORK - 1983 CALENDER YEAR SUMMARY DATA}

$[$ ppt $=$ precipitation; $\mathrm{mm}=$ millimeters; $\mathrm{cm}=$ centimeters; $\mathrm{mg}=\mathrm{milligrams;} \mathrm{L} \mathrm{=} \mathrm{liters;}$

$\mathbf{8}=\mathrm{grams} ; \mathrm{m}=$ meter $\boldsymbol{\mu s}=\mathrm{microsiemens}$; cond = specific conductance $]$

STATION: Spooner, Wisconsin

CAL number: WI37

ADS number: $077 \mathrm{a00}$

Station altitude above mean sea leve1, in meters: 331

Number of sampling intervals (days in parenthesis):

-- With ppt measurements: 53 (371)

-- When ppt occurred: 51 (357)

-- When ppt did not occur: 2 ( 14)

-- When sample volume mas substituted for missing rain gage: $0 \quad(0)$

-- With chemical samples: 33 (231)

Latitude: $45^{\circ} 49^{\prime} 21^{\prime \prime}$ Longitude: $91^{\circ} 52^{\prime} 30^{\prime \prime}$

Station summary period: $12 / 28 / 1982$ to $01 / 03 / 1984$

Length of summary period: 53 sampling intervals ( 371 days)

Percent summary period with ppt measurements: 100.0 Percent summary period with chemical samples or no ppt: 66.0 Percent of total measured ppt with chemical samples: $\quad 74.3$ Percent of total measured ppt in raingage that was

collected in the wet-sample bucket:

92.8

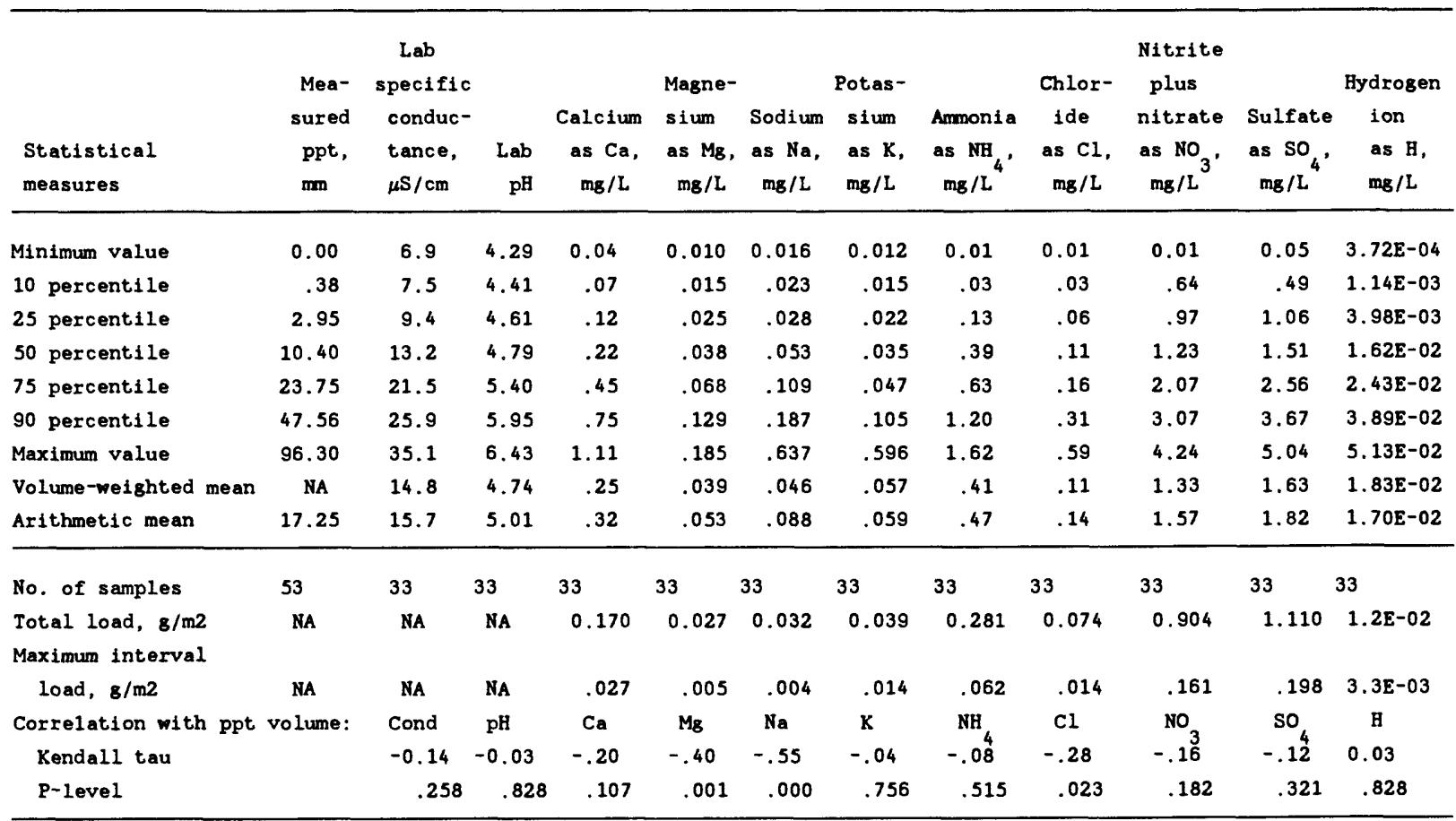

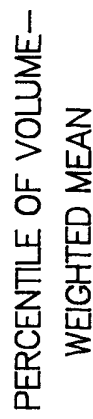

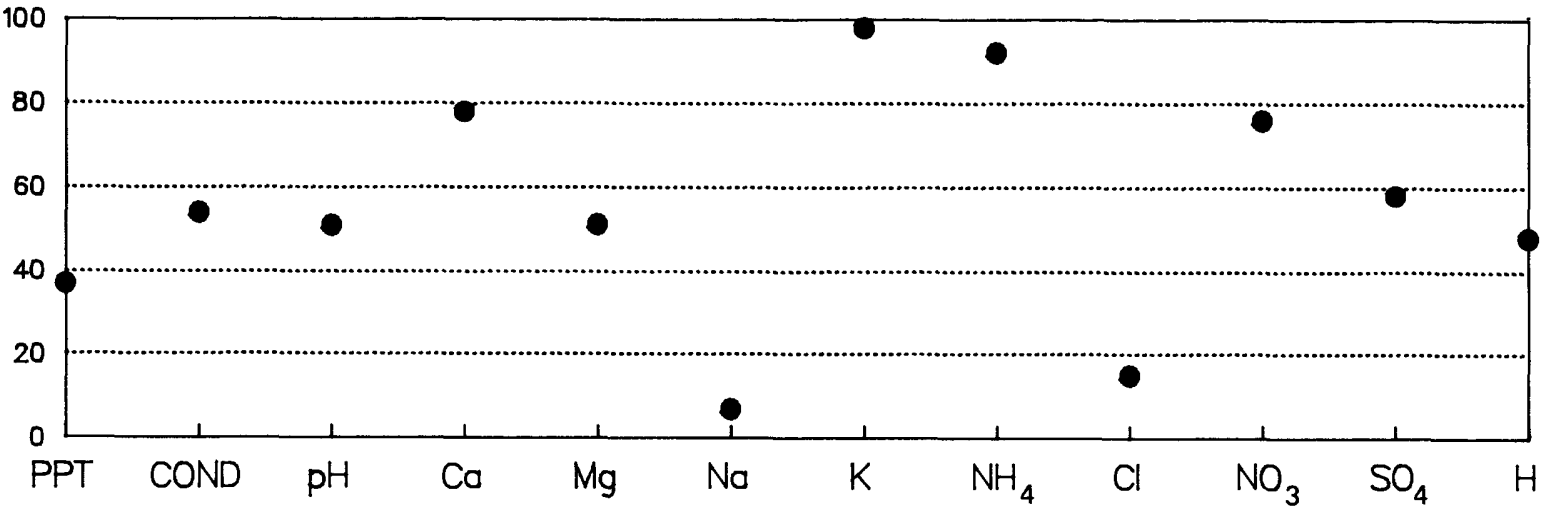

Percentiles of volume-weighted mean concentrations for site W137, based on frequency distributions of data from 55 National Trends Network sites. 

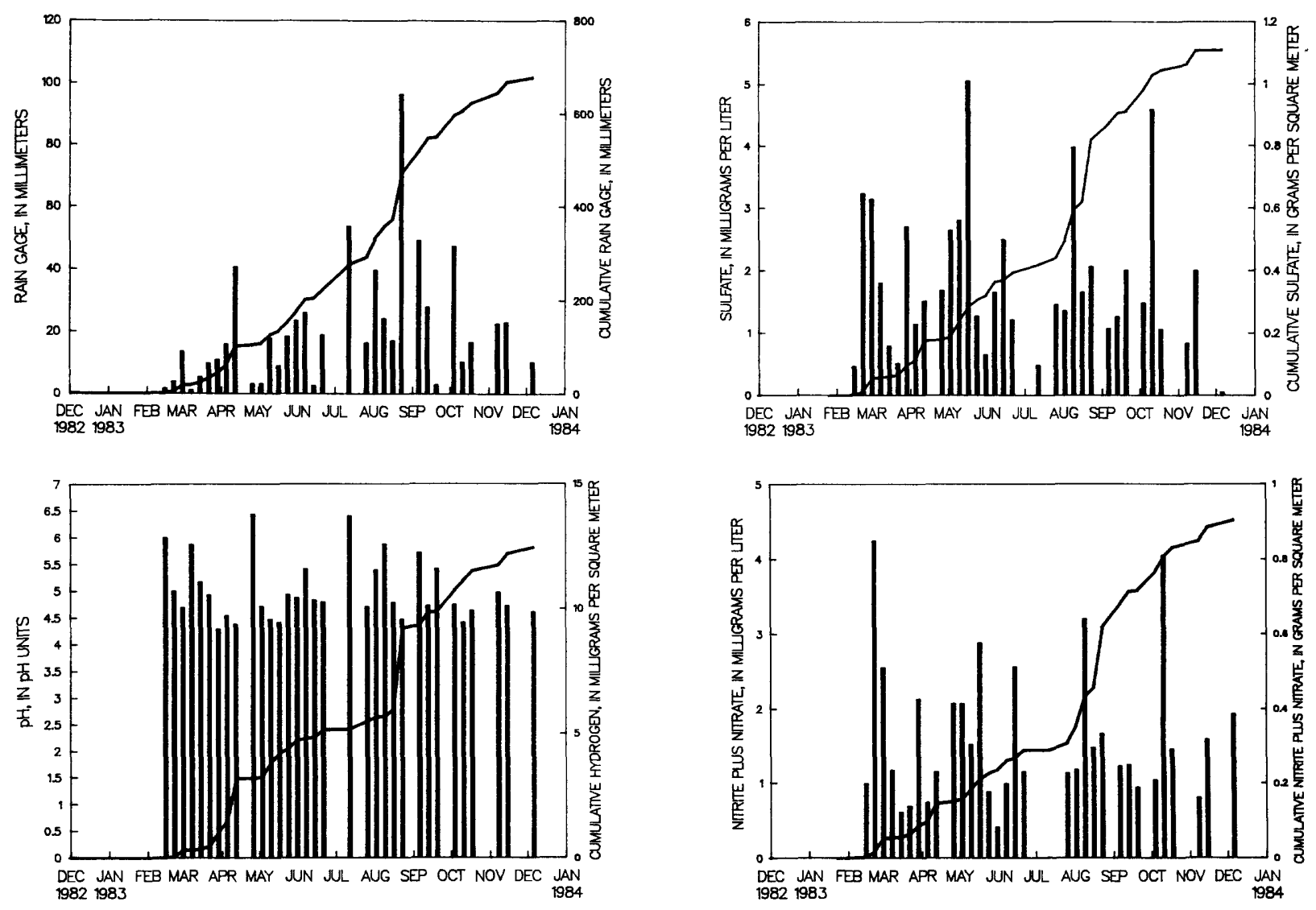

Bar plots of concentrations and cumulative line plots of loads for site WI37. Nitrite plus nitrate are reported as $\mathrm{NO}_{3}$ and sulfate as $\mathrm{SO}_{4}$.

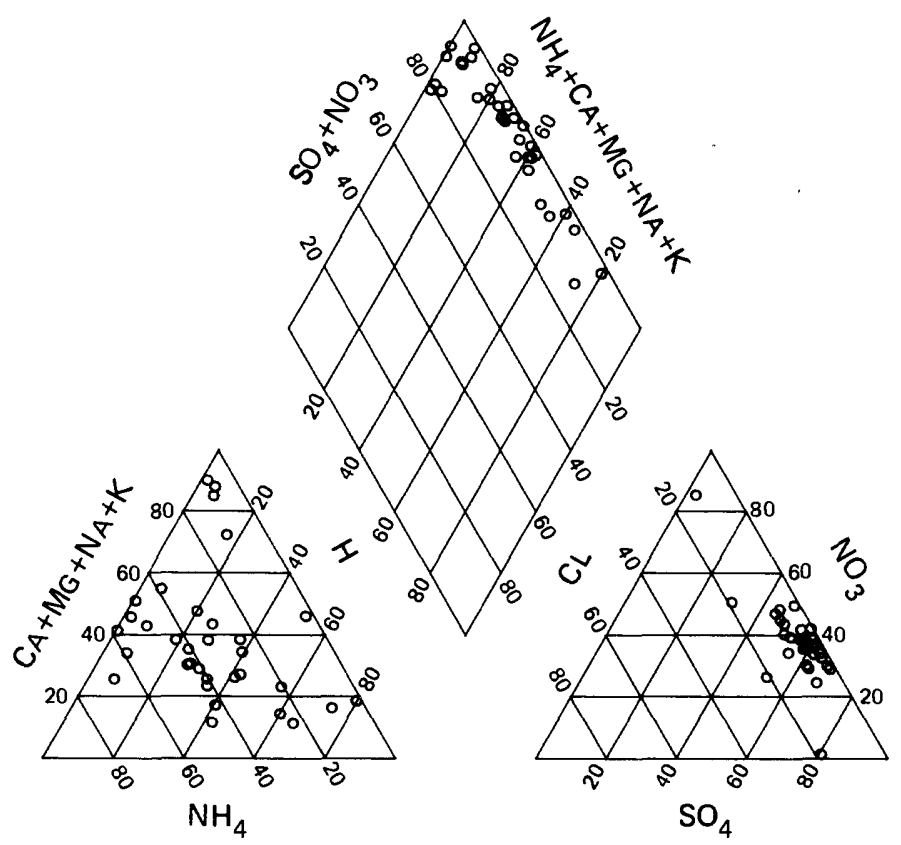

Percentage composition of major ions for site WI37. 


\section{NATIONAL TRENDS NETWORK - - 1983 CALENDER YEAR SUMMARY DATA}

lppt = precipitation; $\mathrm{mm}=$ millimeters; $\mathrm{cm}=$ centimeters; $\mathrm{mg}=$ milligrams; L $=1$ liters; $\mathrm{g}=\mathrm{grams} ; \mathrm{m}=$ meter; $\mu \mathrm{s}=$ microsiemens; cond = specific conductance $]$

STATION: Psrsons, West Virginia

CAL number: WV18

ADS number: 075 a00

Map ID number: 106

Station altitude above mean sea level, in meters: 305 Number of sampling intervals (days in parenthesis):

-- With ppt measurements: $53 \quad$ (371)

-- When ppt occurred: 52 (364)

-- When ppt did not occur:

-- When sample volume was subst1tuted for missing rain gage: 0 ( 0$)$

-- With chemical samples: 45 (315)
Latitude: $39^{\circ} 05^{\prime} 23^{\prime \prime}$ Longitude: $79^{\circ} 39^{\prime} 44^{\prime \prime}$

Stetion sumnary period: $12 / 28 / 1982$ to $01 / 03 / 1984$

Length of summary period: 53 sampling intervals ( 371 days)

Percent summary period with ppt measurements: $\quad 100.0$

Percent summary period with chemical samples or no ppt: 86.8

Percent of total measured ppt with chemical samples: 80.8

Percent of total measured ppt in raingage thet was

collected in the wet-sample bucket:

91.2

Total measured ppt, in $\mathrm{mm}: 1230.3$

\begin{tabular}{|c|c|c|c|c|c|c|c|c|c|c|c|c|}
\hline $\begin{array}{l}\text { Statistical } \\
\text { measures }\end{array}$ & $\begin{array}{c}\text { Mea- } \\
\text { sured } \\
\text { ppt, } \\
\text { mm }\end{array}$ & $\begin{array}{l}\text { Lab } \\
\text { specific } \\
\text { conduc- } \\
\text { tance, } \\
\mu S / c m\end{array}$ & $\begin{array}{r}\text { Lab } \\
\text { pH }\end{array}$ & $\begin{array}{c}\text { Calcium } \\
\text { es } \mathrm{Ca}, \\
\mathrm{ms} / \mathrm{L}\end{array}$ & $\begin{array}{l}\text { Magne- } \\
\text { sium } \\
\text { as } \mathrm{Mg} \text {, } \\
\mathrm{mg} / \mathrm{L}\end{array}$ & $\begin{array}{c}\text { Sodium } \\
\text { as } \mathrm{Na} \text {, } \\
\mathrm{mg} / \mathrm{L}\end{array}$ & $\begin{array}{l}\text { Potas- } \\
\text { sium } \\
\text { as } \mathrm{K} \text {, } \\
\mathrm{mg} / \mathrm{L}\end{array}$ & $\begin{array}{l}\text { Ammonia } \\
\text { as } \mathrm{NH}_{\mathrm{mg}} / \mathrm{L}^{\text {' }}\end{array}$ & $\begin{array}{l}\text { Chlor- } \\
\text { Ide } \\
\text { as } \mathrm{Cl} \text {, } \\
\mathrm{mg} / \mathrm{L}\end{array}$ & $\begin{array}{l}\text { Nitrite } \\
\text { plus } \\
\text { nitrate } \\
\text { as } \mathrm{NO}_{3} \text { ' } \\
\mathrm{mg} / \mathrm{L}\end{array}$ & $\begin{array}{l}\text { Sulfate } \\
\text { as so } \\
\mathrm{mg} / \mathrm{L}^{\circ}\end{array}$ & $\begin{array}{l}\text { Hydrogen } \\
\text { ion } \\
\text { as } \mathrm{H}, \\
\mathrm{mg} / \mathrm{L}\end{array}$ \\
\hline Minimum value & 0.00 & 3.6 & 3.71 & 0.03 & 0.004 & 0.010 & 0.004 & 0.01 & 0.01 & 0.26 & 0.33 & $1.26 \mathrm{E}-03$ \\
\hline 10 percentile & 3.92 & 7.2 & 3.82 & .05 & .010 & .020 & .009 & .01 & .04 & .41 & .75 & $9.77 \mathrm{E}-03$ \\
\hline 25 percentile & 7.75 & 13.2 & 4.05 & .10 & .015 & .030 & .014 & .06 & .08 & .70 & 1.11 & $2.21 \mathrm{E}-02$ \\
\hline 50 percentile & 20.30 & 19.8 & 4.44 & .16 & .025 & .042 & .030 & .14 & .11 & 1.17 & 1.94 & 3. $63 \mathrm{E}-02$ \\
\hline 75 percentile & 36.35 & 45.0 & 4.65 & .28 & .037 & .077 & .046 & .31 & .17 & 2.53 & 4.24 & $8.81 E-02$ \\
\hline 90 percentile & 58.28 & 75.3 & 5.01 & .54 & .080 & .149 & .086 & .49 & .27 & 3.79 & 6.99 & $1.51 \mathrm{E}-01$ \\
\hline Maximum value & 65.30 & 93.1 & 5.90 & 2.53 & .315 & .351 & .129 & 1.60 & .51 & 5.82 & 13.93 & $1.95 \mathrm{E}-01$ \\
\hline Volume-weighted mean & NA & 26.4 & 4.29 & .15 & .022 & .041 & .026 & .18 & .10 & 1.37 & 2.50 & $5.17 \mathrm{E}-02$ \\
\hline Arithmetic mean & 23.21 & 30.4 & 4.43 & .26 & .038 & .067 & .037 & .22 & .14 & 1.75 & 3.08 & $5.69 \mathrm{E}-02$ \\
\hline No. of samples & 53 & 45 & 45 & 45 & 45 & 45 & 45 & 45 & 45 & 45 & 45 & 45 \\
\hline $\begin{array}{l}\text { Total load, } 8 / \mathrm{m} 2 \\
\text { Maximum interval }\end{array}$ & NA & $\mathrm{NA}$ & NA & 0.151 & 0.022 & 0.041 & 0.026 & 0.174 & 0.103 & 1.358 & 2.485 & $5.1 E-02$ \\
\hline load, $\mathrm{g} / \mathrm{m} 2$ & NA & NA & NA & .013 & .002 & .002 & .002 & .029 & .008 & 0.135 & 0.393 & $8.9 E-03$ \\
\hline $\begin{array}{l}\text { Correlation with ppt } \\
\text { Kendall tau }\end{array}$ & volume: & $\begin{array}{l}\text { Cond } \\
-0.19\end{array}$ & $\begin{array}{c}\mathrm{pH} \\
0.13\end{array}$ & $\begin{array}{c}\mathrm{Ca} \\
-.49\end{array}$ & $\begin{array}{l}\mathrm{Mg} \\
-.62\end{array}$ & $\begin{array}{l}\mathrm{Na} \\
-.54\end{array}$ & $\begin{array}{l}\mathrm{K} \\
-.39\end{array}$ & $\begin{array}{l}\mathrm{NH} \\
-.10^{4}\end{array}$ & $\begin{array}{c}\mathrm{Cl} \\
-.35\end{array}$ & $\begin{array}{l}\mathrm{NO}_{3} \\
-.23\end{array}$ & $\begin{array}{l}\mathrm{SO}_{4} \\
-.20\end{array}$ & $\begin{array}{c}\mathrm{H} \\
-0.13\end{array}$ \\
\hline P-level & & .069 & .221 & .000 & .000 & .000 & .000 & .356 & .001 & .025 & .054 & .221 \\
\hline
\end{tabular}

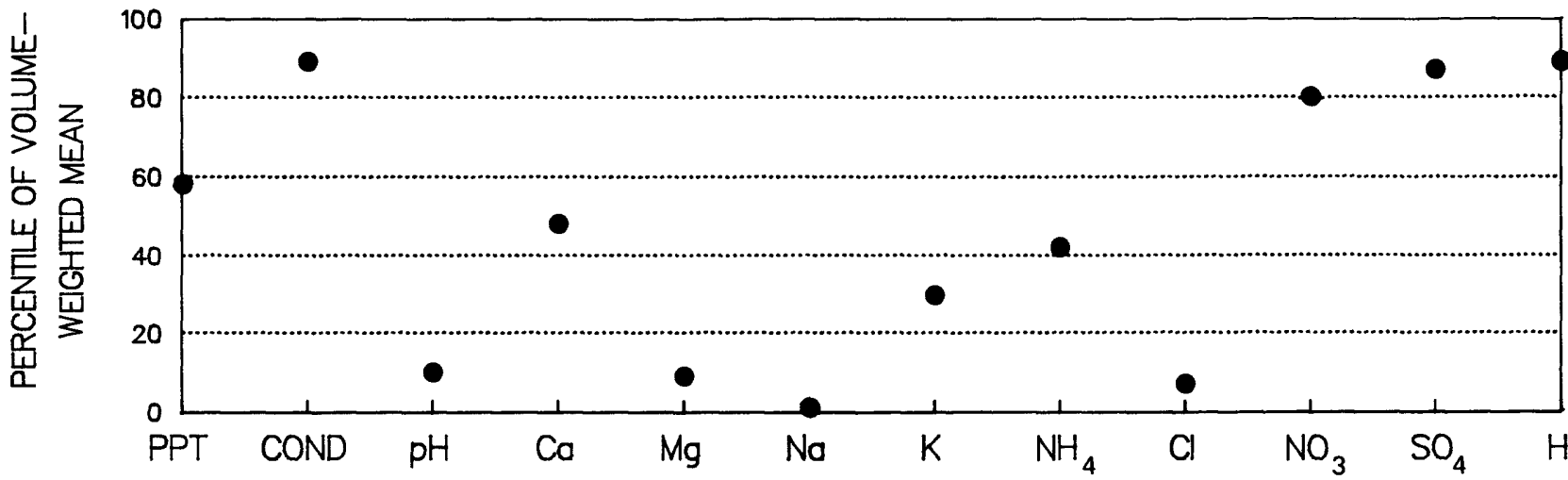

Percentiles of volume-weighted mean concentrations for site WV18, based on frequency distributions of data from 55 National Trends Network sites. 

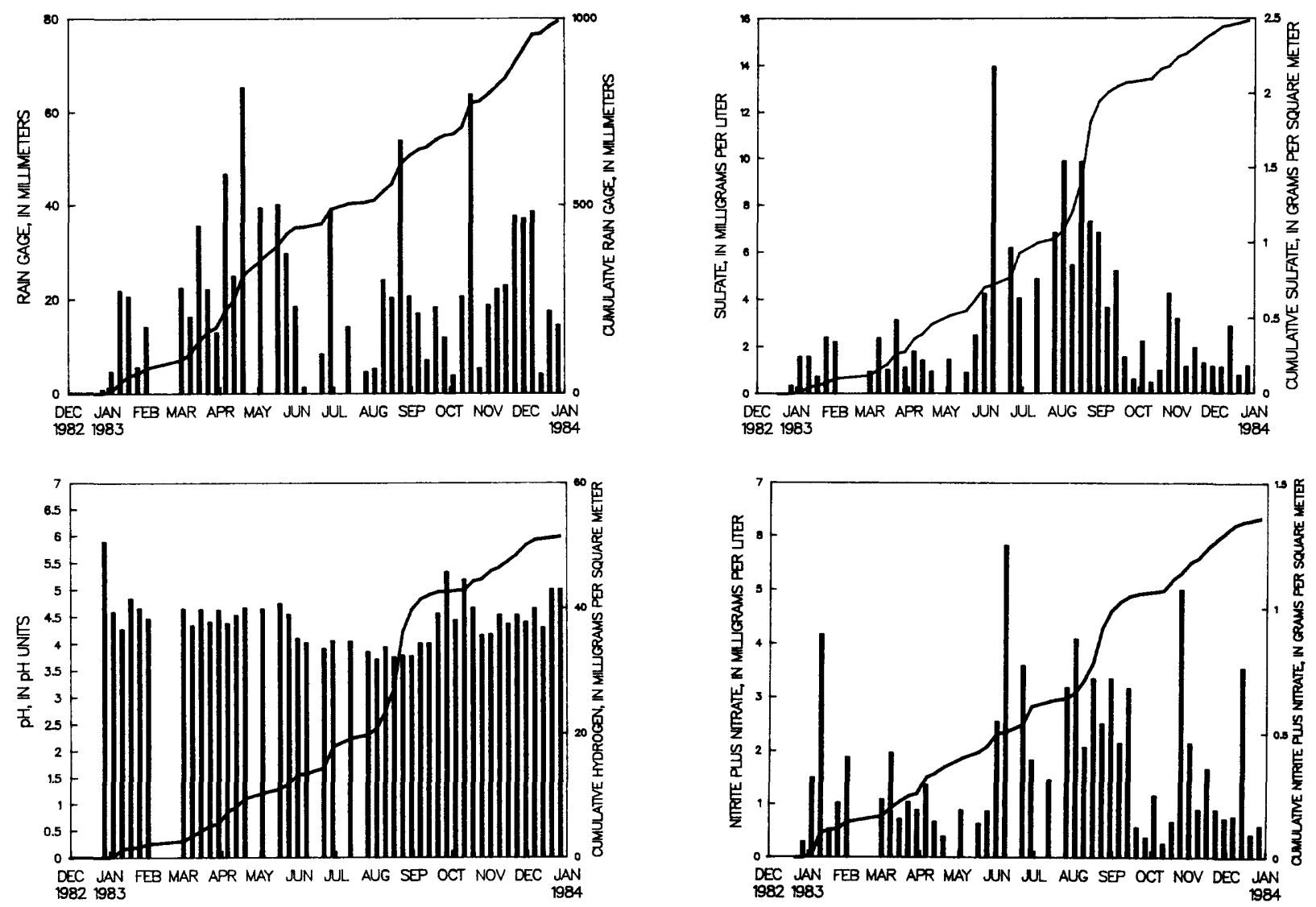

Bar plots of concentrations and cumulative line plots of loads for site WV18. Nitrite plus nitrate are reported as $\mathrm{NO}_{3}$ and sulfate as $\mathrm{SO}_{4}$.

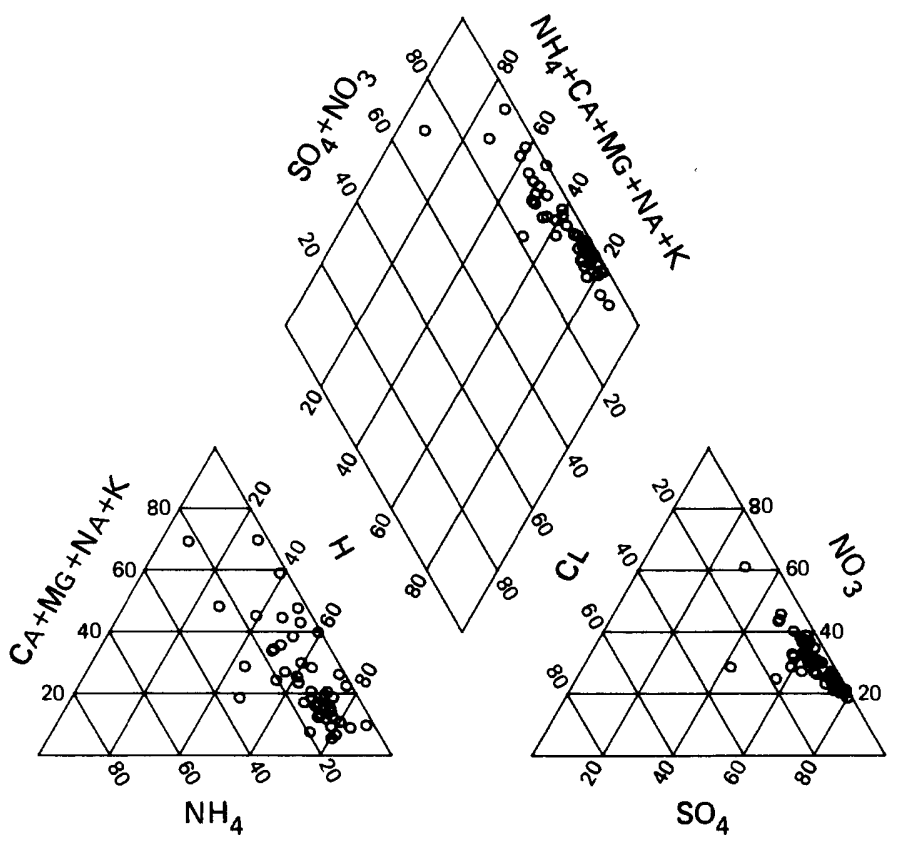

Percentage composition of major ions for site WV 18. 
lppt $=$ precipitation; $\mathrm{mm}=$ millimeters; $\mathrm{cm}=$ centimeters; $\mathrm{mg}=$ milligrams; L = liters;

$\mathrm{g}=\mathrm{grams} ; \mathrm{m}=$ meter $; \mu \mathrm{s}=$ microsiemens; cond $=$ specific conductance $]$

STATION: Newcastle, Wyoming

CAL number: WY99

ADS number: 255a00

Station altitude above mean sea level, in meters: 1466

Number of sampling intervals (days in parenthesis):

-- With ppt measurements:

-- When ppt occurred:

-- When ppt did not occur:

-- When sample volume was substituted for missing rain gage:

-- With chemical samples:
54 (371)

47 (322)

$7 \quad(49)$

$12(84)$

39 (272)
Latitude: $43^{\circ} 52^{\prime} 24^{\prime \prime}$ Longitude: $104^{\circ} 11^{\prime} 32^{\prime \prime}$

Station summary period: $12 / 28 / 1982$ to $01 / 03 / 1984$

Length of summary period: 54 sampling intervals ( 371 days)

Fercent summary period with ppt measurements: $\quad 100.0$

Percent summary period with chemical samples or no ppt: 86.5

Percent of total measured ppt with chemical samples: 81.9

Percent of total measured ppt in raingage that was

collected in the wet-sample bucket:

84.8

Total measured ppt, in m: 346.5

\begin{tabular}{|c|c|c|c|c|c|c|c|c|c|c|c|c|}
\hline $\begin{array}{l}\text { Statistical } \\
\text { measures }\end{array}$ & $\begin{array}{l}\text { Mea- } \\
\text { sured } \\
\text { ppt, } \\
\text { mm }\end{array}$ & $\begin{array}{c}\text { Lab } \\
\text { specific } \\
\text { conduc- } \\
\text { tance, } \\
\mu \mathrm{S} / \mathrm{cm}\end{array}$ & $\begin{array}{r}\text { Lab } \\
\text { pH }\end{array}$ & $\begin{array}{c}\text { Calcium } \\
\text { as Ca, } \\
\mathrm{mg} / \mathrm{L}\end{array}$ & $\begin{array}{c}\text { Magne- } \\
\text { sium } \\
\text { as } \mathrm{Mg}, \\
\mathrm{mg} / \mathrm{L}\end{array}$ & $\begin{array}{c}\text { Sodium } \\
\text { as } \mathrm{Na} \text {, } \\
\mathrm{mg} / \mathrm{L}\end{array}$ & $\begin{array}{l}\text { Potas- } \\
\text { sium } \\
\text { as } K \text {, } \\
\text { mg/L }\end{array}$ & $\begin{array}{l}\text { Ammonia } \\
\text { as } \mathrm{NH}_{\mathrm{mg}} / \mathrm{L}^{\circ}\end{array}$ & $\begin{array}{c}\text { Chlor- } \\
\text { ide } \\
\text { as } \mathrm{Cl} \text {, } \\
\mathrm{mg} / \mathrm{L}\end{array}$ & $\begin{array}{l}\text { Nitrite } \\
\text { plus } \\
\text { nitrate } \\
\text { as } \mathrm{NO}_{3} \\
\mathrm{mg} / \mathrm{L}\end{array}$ & $\begin{array}{l}\text { Sulfate } \\
\text { as } \mathrm{SO}_{\mathrm{mg}} \text {, }\end{array}$ & $\begin{array}{c}\text { Hydrogen } \\
\text { ion } \\
\text { as } \mathrm{H}, \\
\mathrm{mg} / \mathrm{L}\end{array}$ \\
\hline Minimum value & 0.00 & 2.8 & 4.85 & 0.05 & 0.011 & 0.020 & 0.002 & 0.01 & 0.01 & 0.01 & 0.05 & $5.62 \mathrm{E}-05$ \\
\hline 10 percentile & .00 & 4.2 & 4.93 & .10 & .015 & .027 & .008 & .01 & .07 & .36 & .37 & $5.01 E-04$ \\
\hline 25 percentile & .60 & 6.8 & 5.23 & .19 & .025 & .043 & .015 & .06 & .09 & .53 & .56 & $7.76 E-04$ \\
\hline 50 percentile & 3.80 & 10.7 & 5.82 & .38 & .070 & .149 & .038 & .17 & .18 & .98 & 1.16 & $1.51 \mathrm{E}-03$ \\
\hline 75 percentile & 10.75 & 13.5 & 6.11 & .85 & .144 & .273 & .114 & .49 & .26 & 1.63 & 1.63 & $5.89 E-03$ \\
\hline 90 percentile & 16.26 & 26.3 & 6.30 & 1.35 & .196 & .751 & .134 & .68 & .58 & 3.36 & 4.18 & $1.17 \mathrm{E}-02$ \\
\hline Maximum value & 34.50 & 143.7 & 7.25 & 8.04 & .505 & 21.733 & .387 & 1.93 & 4.71 & 6.45 & 7.81 & $1.41 E-02$ \\
\hline Volume-weighted mean & NA & 9.1 & 5.21 & .34 & .048 & .123 & .039 & .27 & .12 & .98 & 1.05 & $6.15 E-03$ \\
\hline No. of samples & 53 & 39 & 39 & 39 & 39 & 39 & 39 & 39 & 39 & 39 & 39 & 39 \\
\hline $\begin{array}{l}\text { Total load, } 8 / \mathrm{m} 2 \\
\text { Maximum interval }\end{array}$ & NA & NA & NA & 0.096 & 0.013 & 0.035 & 0.011 & 0.076 & 0.035 & 0.279 & 0.298 & $1.7 E-03$ \\
\hline load, $\mathrm{g} / \mathrm{m} 2$ & NA & NA & NA & .008 & .001 & .007 & .001 & .009 & .003 & .025 & .029 & $3.9 E-04$ \\
\hline $\begin{array}{l}\text { Correlation with ppt } \\
\text { Kendall tau }\end{array}$ & volume: & $\begin{array}{l}\text { Cond } \\
-0.33\end{array}$ & $\begin{array}{c}\mathrm{pH} \\
-0.47\end{array}$ & $\begin{array}{c}\mathrm{Ca} \\
-.48\end{array}$ & $\begin{array}{l}M g \\
-.62\end{array}$ & $\begin{array}{c}\mathrm{Na} \\
-.59\end{array}$ & $\begin{array}{l}K \\
-.37\end{array}$ & $\begin{array}{r}\mathrm{NH}^{4} \\
-.01^{4}\end{array}$ & $\begin{array}{r}C 1 \\
-.52\end{array}$ & $\begin{array}{l}\mathrm{NO}^{3} \\
-.23^{3}\end{array}$ & $\begin{array}{l}\mathrm{SO}_{4} \\
-.27\end{array}$ & $\begin{array}{c}\mathrm{H} \\
0.47\end{array}$ \\
\hline P-level & & .003 & .000 & .000 & .000 & .000 & .001 & .932 & .000 & .036 & .016 & .000 \\
\hline
\end{tabular}

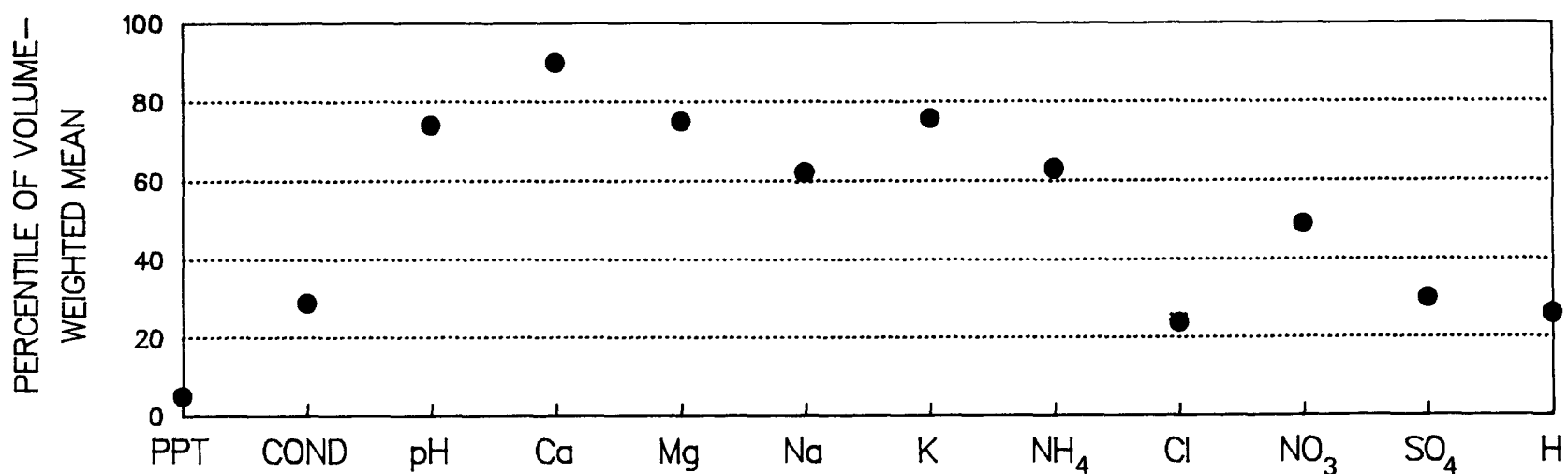

Percentiles of volume-weighted mean concentrations for site WY99, based on frequency distributions of data from 55 National Trends Network sites. 

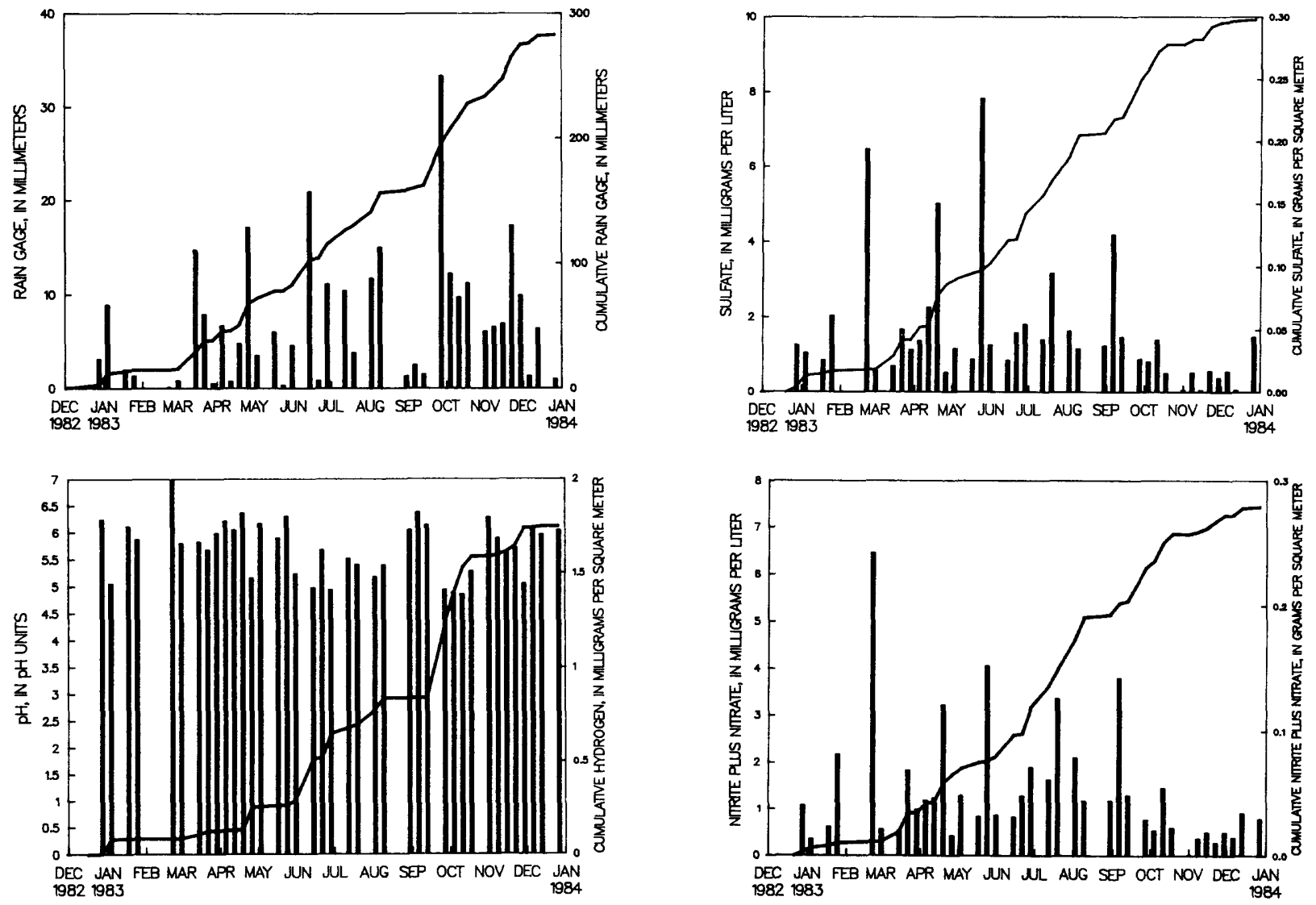

Bar plots of concentrations and cumulative line plots of loads for site WY99. Nitrite plus nitrate are reported as $\mathrm{NO}_{3}$ and sulfate as $\mathrm{SO}_{4}$.

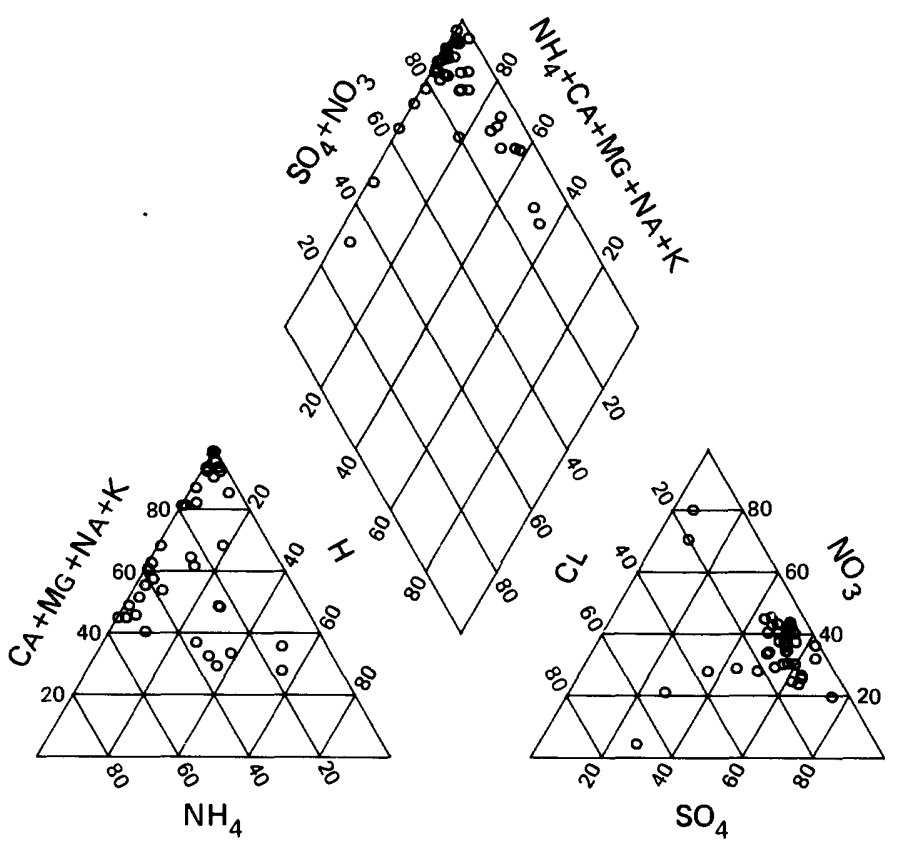

Percentage composition of major ions for site WY99. 
APPENDIX III:

Statistical Summaries for

Stations with Partial Records of

Precipitation-chemistry Data in 1983

(Station summaries are ordered numberically by Map ID numbers listed in table 1) 
[ppt = precipitation; $\mathrm{mm}=$ millimeters; $\mathrm{cm}=$ centimeters; $\mathrm{mg}=$ milligrams; L = liters;

$8=g r a m s ; m=$ meter; $\mu s=$ microsiemens; cond = specific conductance $]$

STATION: Blackbelt, Alabama

CAL number: AL10

ADS number: $329 \mathrm{a} 00$

Map ID number: 1

Station altitude above mean sea level, in meters: 58

Number of sampling intervals (days in parenthesis):

-- With ppt measurements : 18 (125)

-- When ppt occurred: $16 \quad$ (111)

-- When ppt did not occur: 2 ( 14)

-- When sample volume was substituted for missing rain gage: 0 ( 0$)$

-- With chemical samples: 16 (111)
Latitude: $32^{\circ} 27^{\prime} 30^{\prime \prime}$ Longitude:

$87^{\circ} 14^{\prime} 31^{\prime \prime}$

Station summary period: $08 / 31 / 1983$ to $01 / 03 / 1984$

Length of sumary period: 18 sampling intervals (125 days)

Percent summary period with ppt measurements:

33.7 Percent summary period with chemical samples or no ppt: 33.7

Percent of total measured ppt with chemical samples: 100.0 Percent of total measured ppt in raingage that was

collected in the wet-sample bucket:

99.6

Total measured ppt, in $\mathrm{mm}: 500.6$

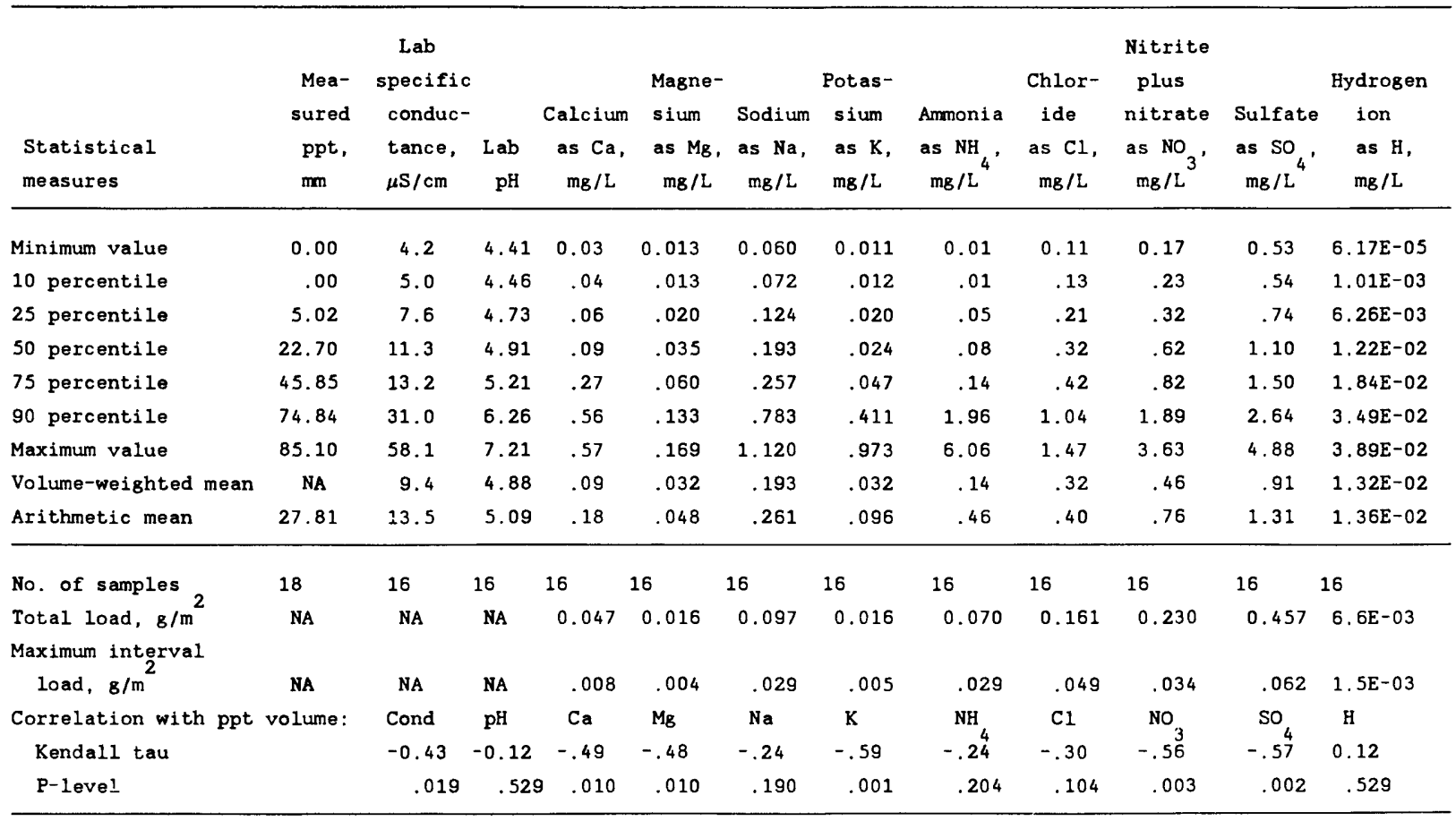

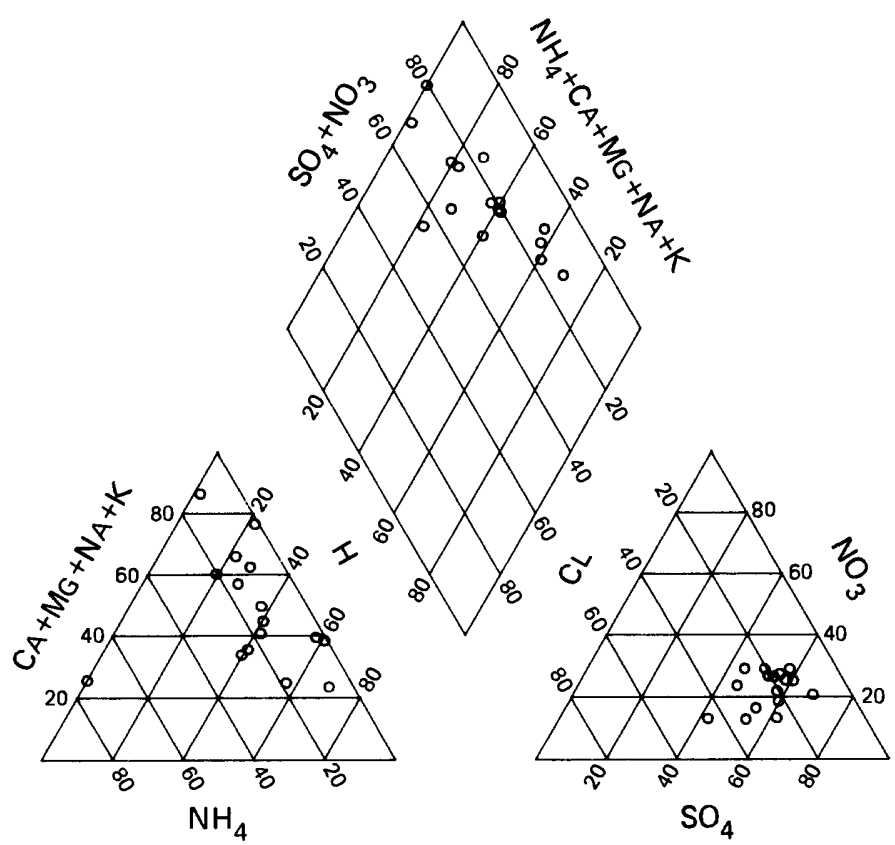

Percentage composition of major ions for site AL10. 
NATIONAL TRENDS NETWORK - 1983 CALENDER YEAR SUMMARY DATA

$[\mathrm{ppt}=$ precipitation; $\mathrm{mm}=$ millimeters; $\mathrm{cm}=$ centimeters; $\mathrm{mg}=$ milligrams; $\mathrm{L}=1 \mathrm{iters}$; $\mathbf{g}=\mathrm{grams} ; \mathrm{m}=$ meter; $\mu \mathrm{s}=$ microsiemens; cond = specific conductance $]$

STATION: Caddo Valley, Arkansas

CAL number: AR03

ADS number: $330 \mathrm{a00}$

Station altitude above mean sea level, in meters: 71

Number of sampling intervals (days in parenthesis):

-- With ppt measurements:

-- When ppt occurred:

-- When ppt did not occur:

-- When sample volume was substituted for missing rain gage:

-- With chemical samples:

Map ID number: 3

$0 \quad(0)$

( )
Latitude: $34^{\circ} 10^{\prime} 46^{\prime \prime}$ Longitude:

$93^{\circ} 05^{\prime} 55^{\prime \prime}$

Station surmary period: $12 / 30 / 1983$ to $01 / 03 / 1984$

Length of summary period: 1 sampling intervals ( 4 days)

Percent summary period with ppt measurements:

1.1

Percent summary period with chemical samples or no ppt:

Percent of total measured ppt with valid samples:

Percent of total measured ppt in raingage that was

collected in the wet-sample bucket:

Total measured ppt, in m:

0.3

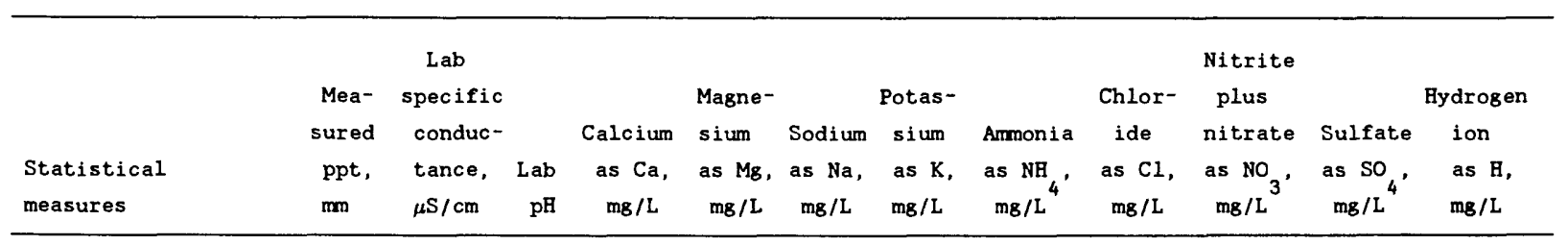

$\begin{array}{lr}\text { Minimum value } & 0.30 \\ 10 \text { percentile } & .30 \\ 25 \text { percentile } & .30 \\ 50 \text { percentile } & .30 \\ 75 \text { percentile } & .30 \\ 90 \text { percentile } & .30 \\ \text { Maximum value } & .30 \\ \text { Volume-weighted mean } & \text { NA } \\ \text { Arithmetic mean } & .30\end{array}$

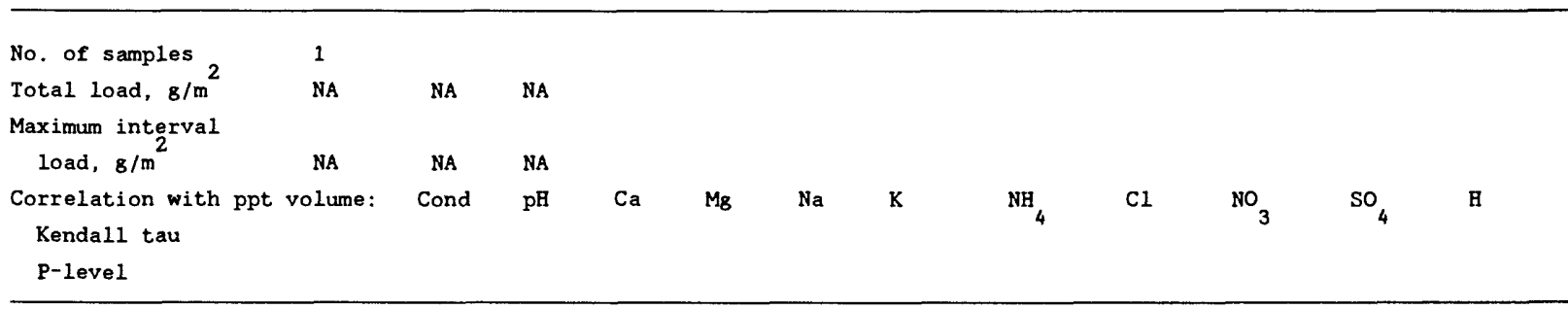




\section{NATIONAL TRENDS NETWORK -- 1983 CALENDER YEAR SUMMARY DATA}

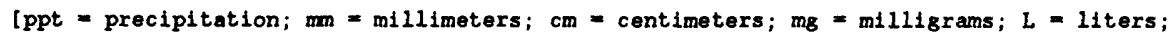

$g=8 \mathrm{rams} ; \mathrm{m}=$ meter; $\mu \mathrm{s}=$ microsiemens; cond = specific conductance $]$

STATION: Oliver Knoll, Arizona

CAL number: AZ99

ADS number: $054 \mathrm{a00}$

Station altitude above mean sea level, in meters: 1173

Number of sampling intervals (days in parenthesis):

-- With ppt measurements: 53

-- When ppt occurred: $41 \quad$ (294)

-- When ppt did not occur: $12 \quad(84)$

-- When sample volume was substituted for missing rain gage: 0 ( 0$)$

-- With chemical samples: 19 (138)
Latitude: $33^{\circ} 04^{\prime} 17^{\prime \prime}$ Longitude: $109^{\circ} 51^{\prime} 53^{\prime \prime}$

Station summary period: $12 / 28 / 1982$ to $01 / 10 / 1984$

Length of sumnary period: 53 sampling intervals ( 378 days)

Percent summary period with ppt measurements: 101.9

Percent summary period with chemical samples or no ppt: 59.8

Percent of total measured ppt with chemical samples: $\quad 70.1$

Percent of total measured ppt in raingage that was

collected in the wet-sample bucket:

97.8

Total measured ppt, in m: 476.2

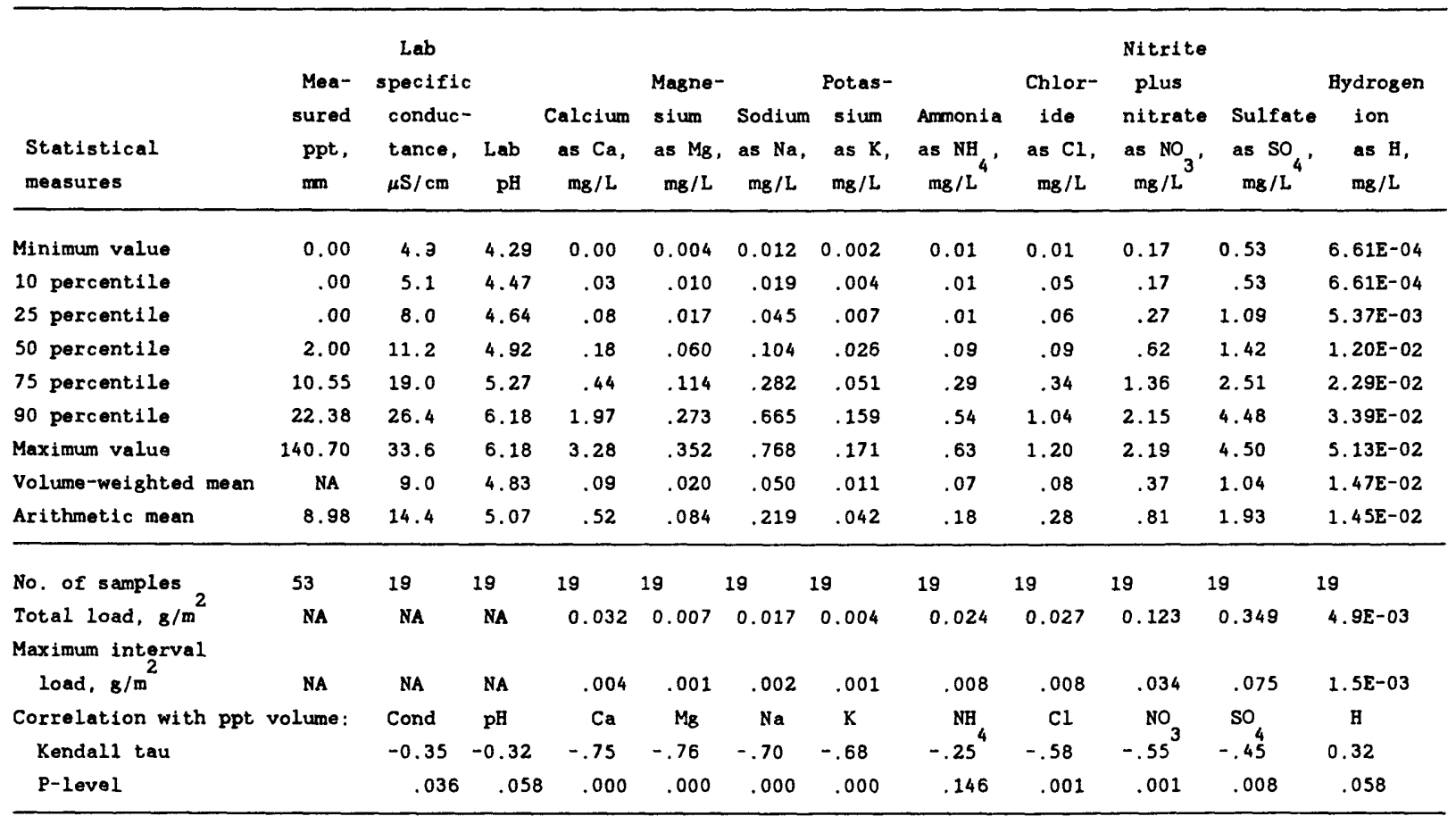

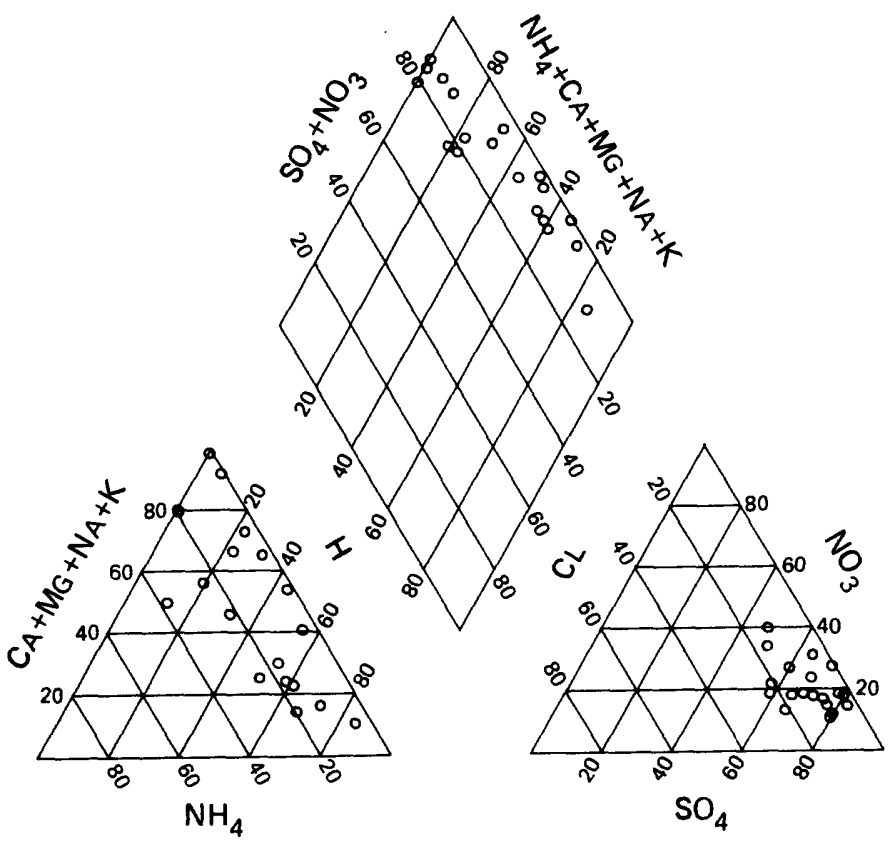

Percentage composition of major ions for site AZ99. 


\section{NATIONAL TRENDS NETWORK - 1983 CALENDER YEAR SUMMARY DATA}

$[\mathrm{ppt}=$ precipitation; $\mathrm{mm}=$ millimeters; $\mathrm{cm}=$ centimeters; $\mathrm{mg}=$ milligrams; $\mathrm{L}=11 \mathrm{ters}$;

$\mathbf{g}=\mathrm{grams} ; \mathrm{m}=$ meter; $\mu \mathrm{s}=$ microsiemens; cond = specific conductance $]$

STATION: Chuchupate Ranger Station, California

Latitude: $34^{\circ} 48^{\prime} 22^{\prime \prime}$ Longitude: $119^{\circ} 00^{\prime} 38^{\prime \prime}$

CAL number: CA98

ADS number: $332 \mathrm{a} 00$

Map ID number: 12

Station altitude above mean sea level, in meters:

Number of sampling intervals (days in parenthesis):

-- With ppt measurements: 22 (154)

-- When ppt occurred: 15 (105)

-- When ppt did not occur: 7 (49)

- When sample volume was substi-

tuted for missing rain gage: 0 ( 0 )

-- With chemical samples: 8 (56)
Station summary period: $08 / 02 / 1983$ to $01 / 03 / 1984$

Length of summary period: 22 sampling intervals (154 days)

Percent summary period with ppt measurements:

41.5

Percent summary period with chemical samples or no ppt: 28.3

Percent of total measured ppt with chemical samples: 82.3

Percent of total measured ppt in raingage that was

collected in the wet-sample bucket:

87.7

Total measured ppt, in mm: 214.7

\begin{tabular}{|c|c|c|c|c|c|c|c|c|c|c|c|c|}
\hline $\begin{array}{l}\text { Statistical } \\
\text { measures }\end{array}$ & $\begin{array}{l}\text { Mea- } \\
\text { sured } \\
\text { ppt, } \\
\text { mm }\end{array}$ & $\begin{array}{l}\text { Lab } \\
\text { specific } \\
\text { conduc- } \\
\text { tance, } \\
\mu \mathrm{S} / \mathrm{cm}\end{array}$ & Lab & $\begin{array}{c}\text { Calcium } \\
\text { as Ca, } \\
\text { mg/L }\end{array}$ & $\begin{array}{l}\text { Magne- } \\
\text { sium } \\
\text { as Mg, } \\
\mathrm{mg} / \mathrm{L}\end{array}$ & $\begin{array}{l}\text { Sodium } \\
\text { as } \mathrm{Na} \text {, } \\
\mathrm{mg} / \mathrm{L}\end{array}$ & $\begin{array}{l}\text { Potas- } \\
\text { sium } \\
\text { as } \mathrm{K} \text {, } \\
\mathrm{mg} / \mathrm{L}\end{array}$ & $\begin{array}{l}\text { Ammonia } \\
\text { as } \mathrm{NH} \\
\mathrm{mg} / \mathrm{L}^{\circ}\end{array}$ & $\begin{array}{l}\text { Chlor- } \\
\text { Ide } \\
\text { as } \mathrm{Cl} \text {, } \\
\mathrm{mg} / \mathrm{L}\end{array}$ & $\begin{array}{l}\text { Nitrite } \\
\text { plus } \\
\text { nitrate } \\
\text { as NO }{ }^{\prime} \\
\mathrm{mg}^{\prime} / \mathrm{L}^{3}\end{array}$ & $\begin{array}{l}\text { Sulfate } \\
\text { as so } \\
\mathrm{mg} / \mathrm{L}^{\prime}\end{array}$ & $\begin{array}{l}\text { Hydrogen } \\
\text { ion } \\
\text { as } \mathrm{H}, \\
\mathrm{mg} / \mathrm{L}\end{array}$ \\
\hline Minimum value & 0.00 & 1.9 & 5.01 & 0.00 & 0.003 & 0.017 & 0.002 & 0.01 & 0.01 & 0.01 & 0.05 & $2.63 E-04$ \\
\hline 10 percentile & .00 & 1.9 & 5.01 & .00 & .003 & .017 & .002 & .01 & .01 & .01 & .05 & $2.63 E-04$ \\
\hline 25 percentile & .00 & 2.1 & 5.34 & .01 & .004 & .019 & .004 & .01 & .06 & .08 & .12 & $2.06 E-03$ \\
\hline 50 percentile & .30 & 2.7 & 5.50 & .03 & .016 & .044 & .010 & .01 & .09 & .16 & .52 & $3.16 E-03$ \\
\hline 75 percentile & 15.52 & 6.3 & 5.70 & .10 & .026 & .101 & .026 & .04 & .17 & .26 & .76 & $4.55 E-03$ \\
\hline 90 percentile & 40.67 & 24.0 & 6.58 & .53 & .287 & 1.147 & .886 & .65 & 1.62 & .93 & 8.87 & $9.77 E-03$ \\
\hline Maximum value & 57.20 & 24.0 & 6.58 & .53 & .287 & 1.147 & .886 & .65 & 1.62 & .93 & 8.87 & $9.77 E-03$ \\
\hline Volume-weighted mean & NA & 2.7 & 5.46 & .02 & .009 & .037 & .007 & .01 & .08 & .16 & .34 & $3.49 E-03$ \\
\hline Arithmetic mean & 9.76 & 5.8 & 5.57 & .10 & .048 & .185 & .120 & .10 & .28 & .24 & 1.47 & $3.76 E-03$ \\
\hline $\begin{array}{l}\text { No. of samples } \\
\text { Total load, } \mathrm{B} / \mathrm{m}^{2}\end{array}$ & $\begin{array}{l}22 \\
\mathrm{NA}\end{array}$ & $\begin{array}{l}8 \\
\mathrm{NA}\end{array}$ & $\begin{array}{l}8 \\
\mathrm{NA}\end{array}$ & $\begin{array}{l}8 \\
0.004\end{array}$ & $\begin{array}{l}8 \\
0.002\end{array}$ & $\begin{array}{l}8 \\
0.007\end{array}$ & $\begin{array}{l}8 \\
0.001\end{array}$ & $\begin{array}{l}8 \\
0.003\end{array}$ & $\begin{array}{l}8 \\
0.014\end{array}$ & $\begin{array}{l}8 \\
0.029\end{array}$ & $\begin{array}{l}8 \\
0.059\end{array}$ & $\begin{array}{l}8 \\
6.2 E-04\end{array}$ \\
\hline \multicolumn{13}{|l|}{ Maximum interval } \\
\hline load, $\mathrm{B} / \mathrm{m}^{2}$ & NA & NA & NA & .001 & .000 & .003 & .000 & .001 & .005 & .011 & .024 & $2.4 E-04$ \\
\hline $\begin{array}{l}\text { Correlation with ppt } \\
\text { Kendall tau }\end{array}$ & volume: & $\begin{array}{l}\text { Cond } \\
-0.47\end{array}$ & $\begin{array}{c}\mathrm{pH} \\
-0.08\end{array}$ & $\begin{array}{l}\mathrm{Ca} \\
-.76\end{array}$ & $\begin{array}{l}\mathrm{Mg} \\
-.69\end{array}$ & $\begin{array}{l}\mathrm{Na} \\
-.47\end{array}$ & $\begin{array}{l}K \\
-.72\end{array}$ & $\begin{array}{l}\mathrm{NH}^{4} \\
-.50\end{array}$ & $\begin{array}{c}C 1 \\
-.52\end{array}$ & $\begin{array}{l}\mathrm{NO}_{3} \\
-.15\end{array}$ & $\begin{aligned} & \text { SO } \\
&-.44\end{aligned}$ & $\begin{array}{c}\text { H } \\
0.08\end{array}$ \\
\hline P-level & & .105 & .798 & .009 & .018 & .105 & .016 & .112 & .079 & .615 & .132 & .798 \\
\hline
\end{tabular}

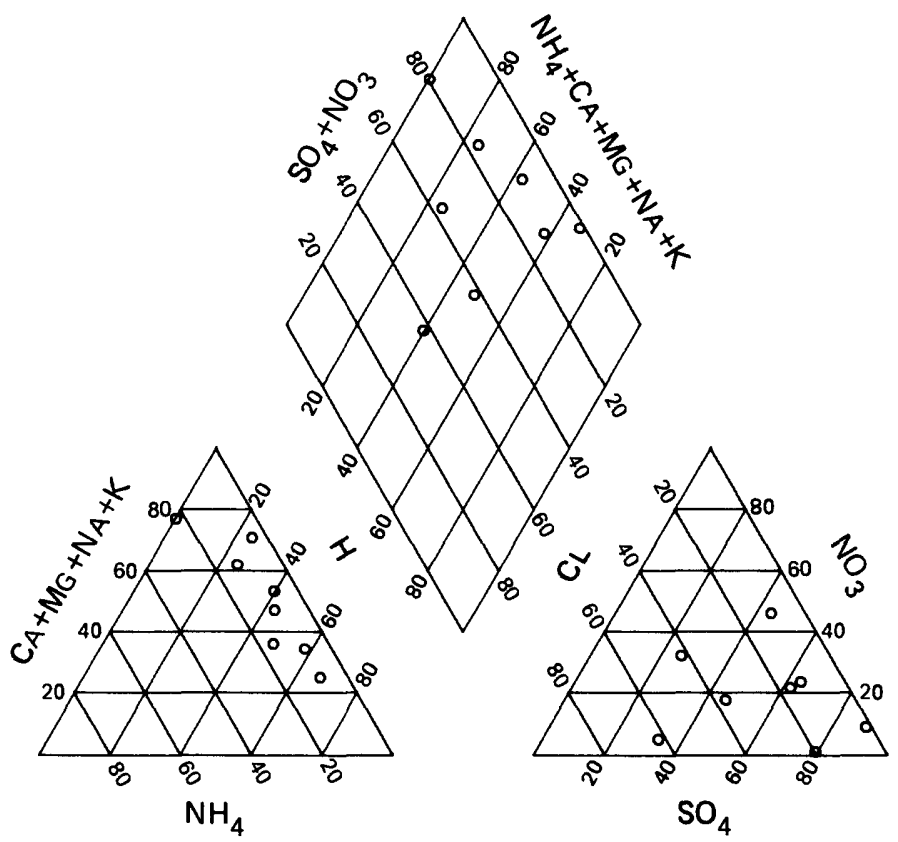

Percentage composition of major ions for site CA98. 


\section{NATIONAL TRENDS NETWORK - - 1983 CALENDER YEAR SUMMARY DATA}

[ppt $=$ precipitation; $\mathrm{mm}=$ millimeters; $\mathrm{cm}=$ centimeters; $\mathrm{mg}=$ milligrams; $\mathrm{L}=1 \mathrm{iters}$;

$\mathrm{g}=\mathrm{grams} ; \mathrm{m}=$ meter $\boldsymbol{\mu \mathrm { s }}=$ microsiemens; cond $=$ specific conductance $]$

STATION: Alamosa, Colorado

CAL number: $C O 00$

ADS number: $160 \mathrm{a} 03$

Map ID number: 14
Latitude: $37^{\circ} 26^{\prime} 36^{\prime \prime}$ Longitude: $105^{\circ} 51^{\prime} 55^{\prime \prime}$

Station altitude above mean sea level, in meters: 2298 Length of summary period: 11 sampling intervals (77 days) Number of sampling intervals (days in parenthesis):

-- With ppt measurements:

11 ( 77)

-- When ppt occurred:

(63)

Percent sumary period with chemical samples or no ppt:

-- When ppt did not occur:

$2(14)$

Percent of total measured ppt with chemical samples:

-- When sample volume was substi-

Percent of total measured ppt in raingage that was

collected in the wet-sample bucket:

tuted for missing rain gage: 0 ( 0 )

-- With chemical samples: 2 ( 14)

Total measured ppt, in $\mathrm{mm}: 44.3$

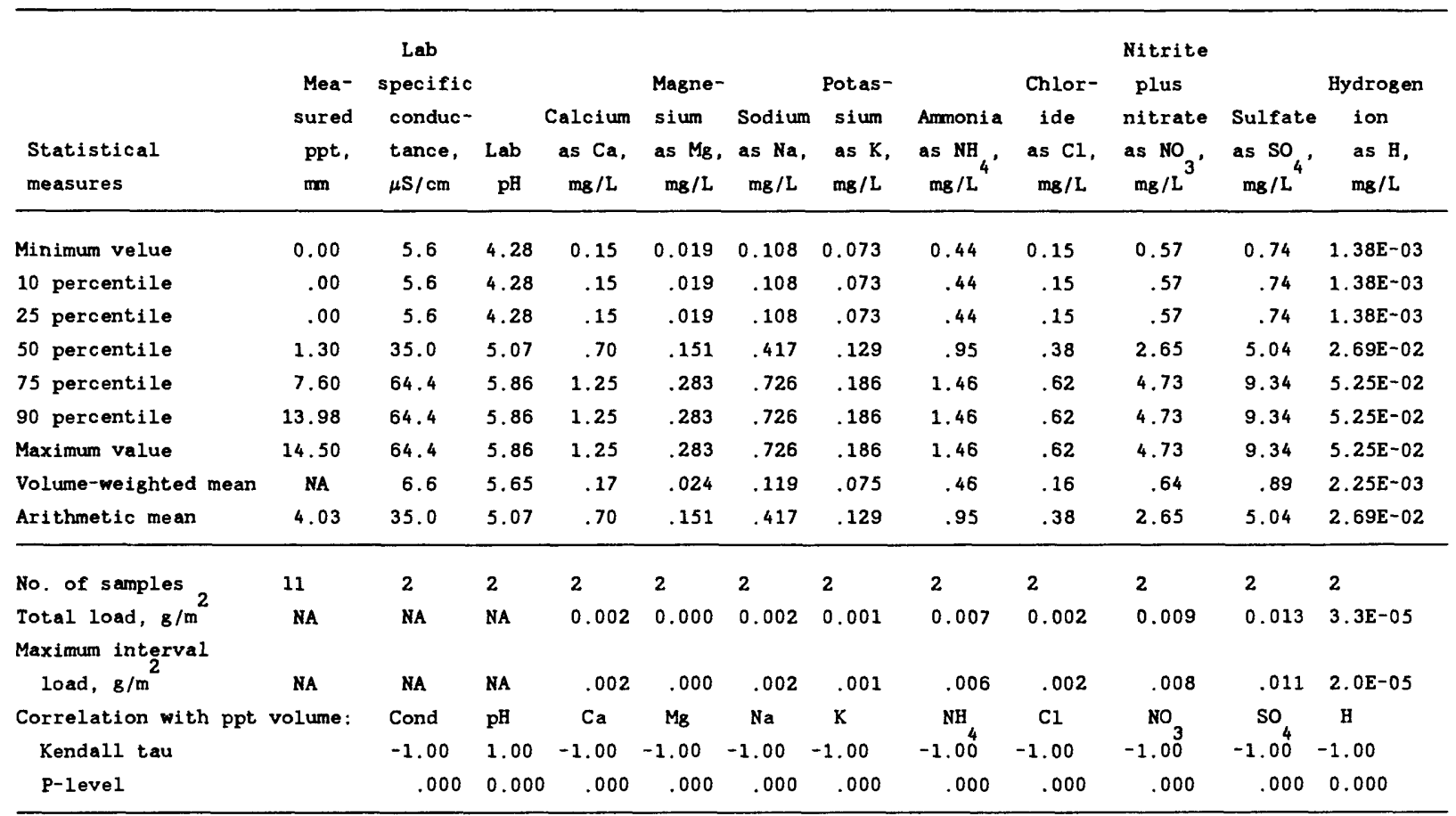




\section{NATIONAL TRENDS NETWORK -- 1983 CALENDER YEAR SUMMARY DATA}

$[\mathrm{ppt}=$ precipitation; $\mathrm{mm}=$ millimeters $\mathrm{cm}=$ centimeters; $\mathrm{mg}=$ milligrams; $\mathrm{L}=1$ iters;

$\mathrm{g}=\mathrm{grams} ; \mathrm{m}=$ meter; $\mu \mathrm{s}=$ microsiemens; cond = specific conductance $]$

STATION: Alamosa, Colorado

CAL number: COOO

ADS number: $160 \mathrm{a02}$

Station altitude above mean sea level, in meters: 2298

Number of sampling intervals (days in parenthesis):

-- With ppt measurements:

-- When ppt occurred:

-- When ppt did not occur:

-- When sample volume was subst1tuted for missing rain gage:

-- With chemical samples:
Latitude: $37^{\circ} 26^{\prime} 36^{\prime \prime}$ Longitude: $105^{\circ} 51^{\prime} 55^{\prime \prime}$

Station summary period: $12 / 28 / 1982$ to $10 / 18 / 1983$

Length of sumnary period: 42 sampling intervals (294 days)

Percent sumary period with ppt measurements:

79.2

Percent summary period with chemical samples or no ppt: 54.7

Percent of total measured ppt with chemical samples: $\quad 75.5$

Percent of total measured ppt in raingage that was

collected in the wet-sample bucket:

93.2

Total measured ppt, in m: 142.1

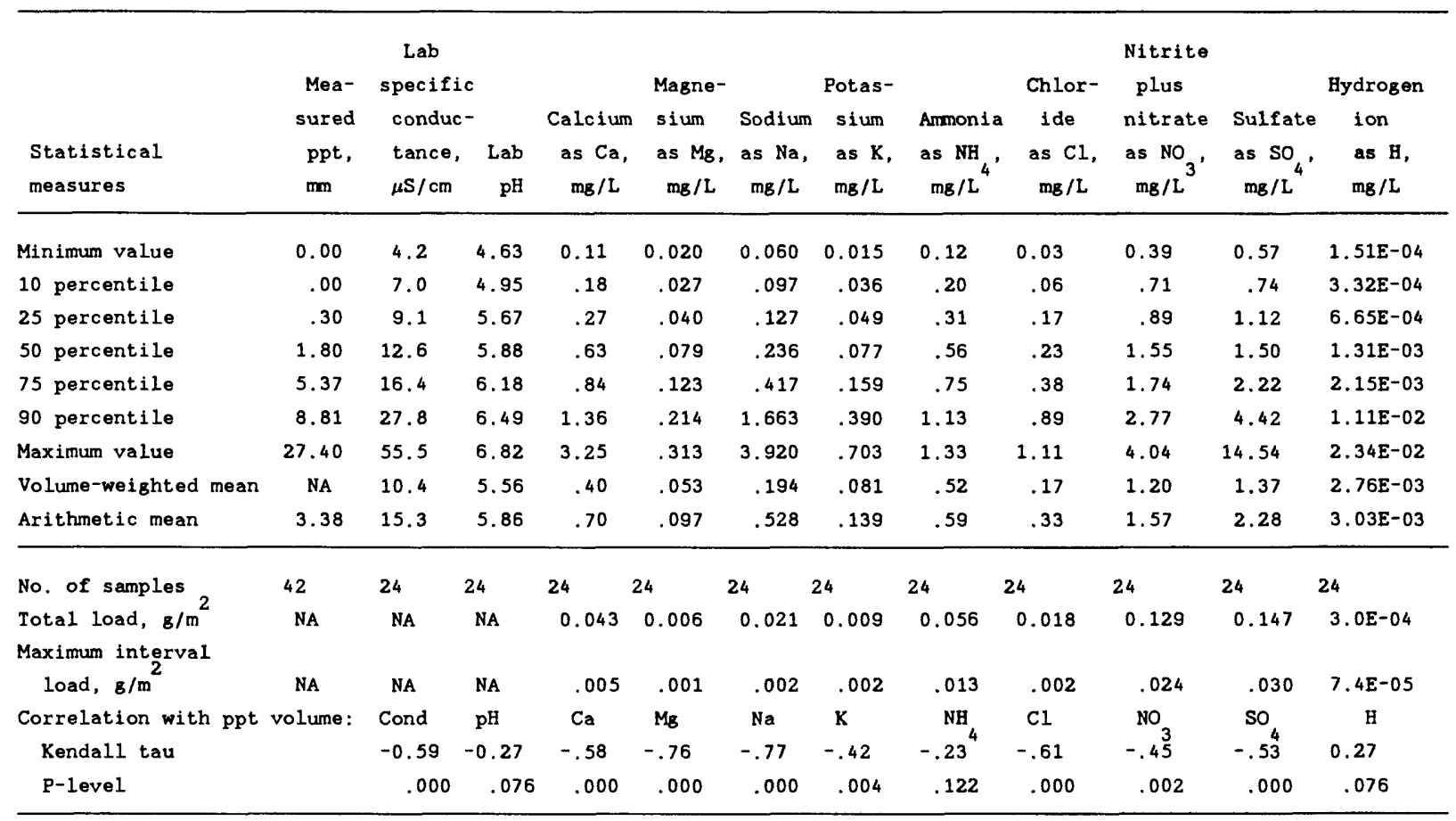


[ppt = precipitation; m = millimeters; $\mathrm{cm}=$ centimeters; $\mathrm{mg}=$ milligrams; $\mathrm{L}=11$ ters; $\mathbf{g}=\mathrm{grams} ; \mathrm{m}=$ meter; $\mu \mathrm{s}=$ microsiemens; cond = specific conductance $]$

STATION: Alamosa, Colorado (composite data from sites $160 \mathrm{a} 02$ and 160a03) Latitude: $37^{\circ} 26^{\prime} 36^{\prime \prime}$ Longitude: $105^{\circ} 51^{\prime} 55^{\prime \prime}$ CAL number: COOO Map ID number: 14 ADS number: 160a Station summary period: $12 / 28 / 1982$ to $01 / 03 / 1984$ Station altitude above mean sea level, in meters: 2298 Length of sumary period: 53 sampling intervals (371 days) Number of sampling intervals (days in parenthesis): Percent summary period with ppt measurements:

-- With ppt measurements:

(371) Percent summary period with chemical samples or no ppt:

-- When ppt occurred: Percent of total measured ppt with chemical samples:

-- When ppt did not occur: Percent of total measured ppt in raingage that was collected in the wet-sample bucket: tuted for missing rain gage: 0 ( 0 )

-- With chemical samples: 26 (182) Total measured ppt, in m: 186.4

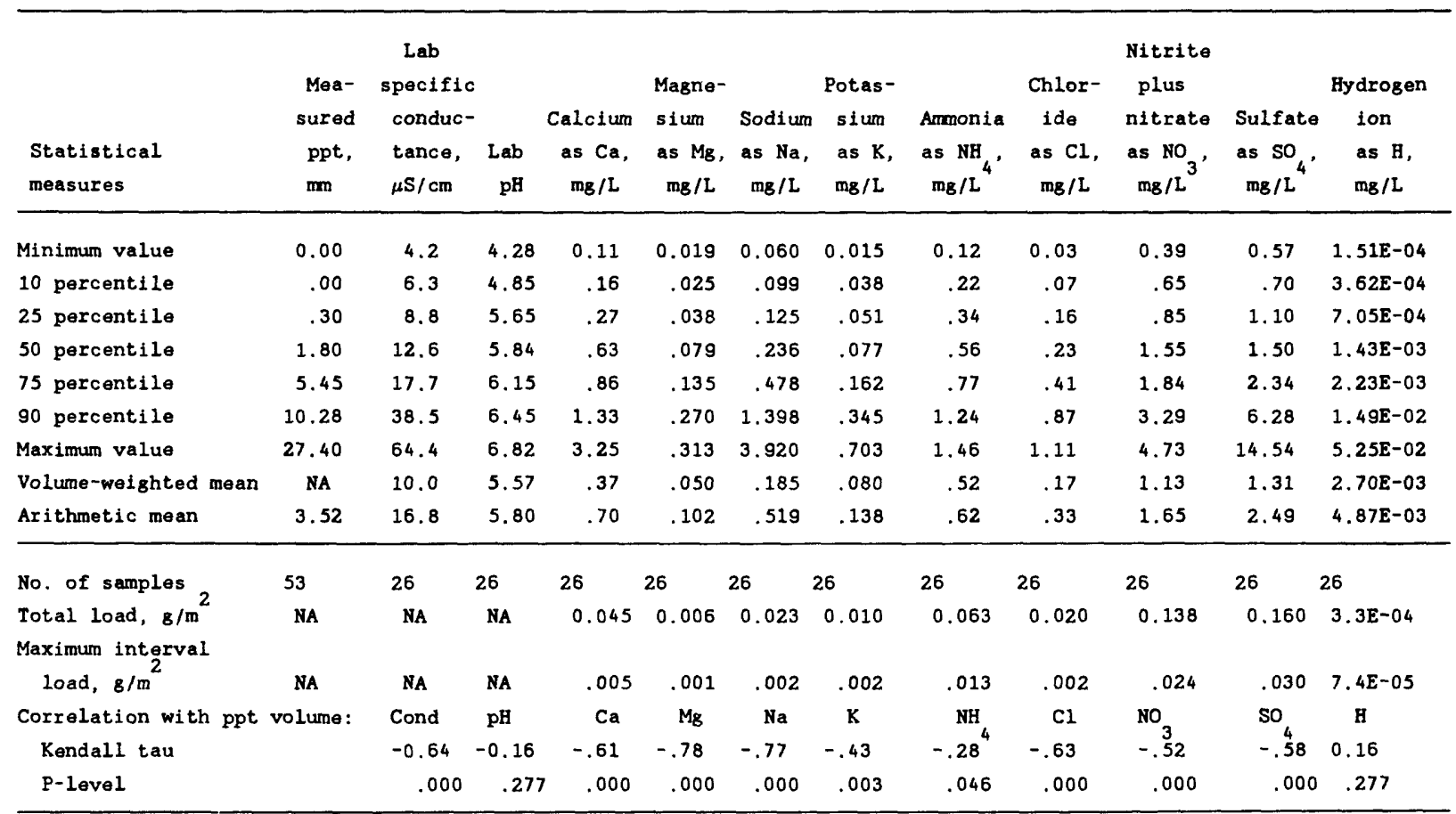

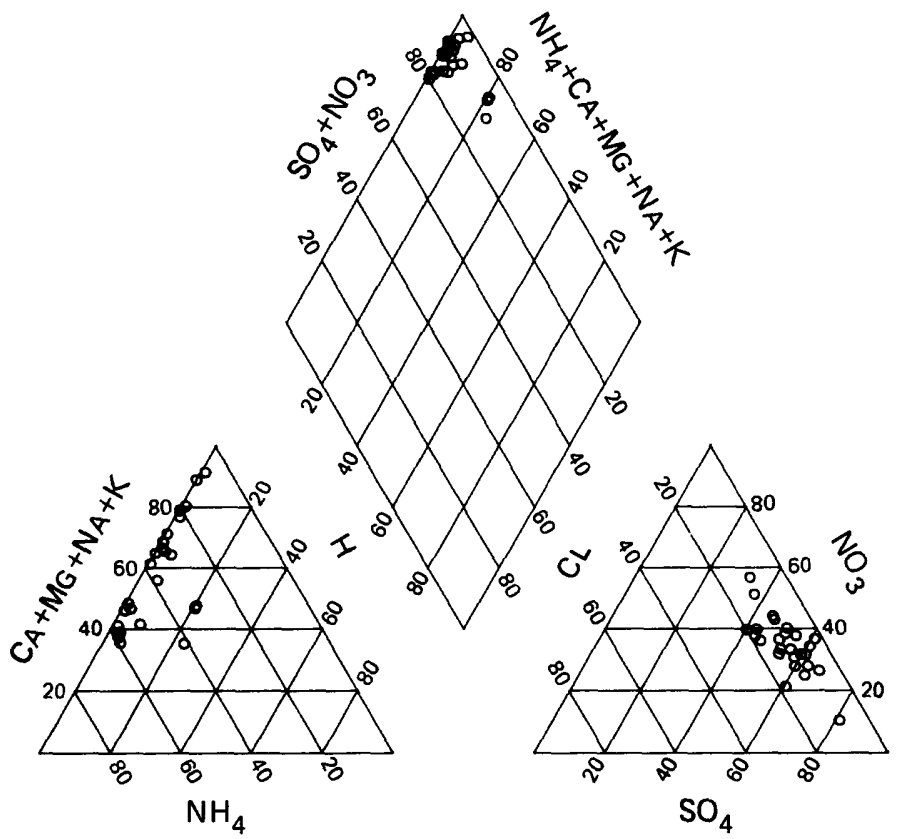

Percentage composition of major ions for site $\mathrm{COOO}$. 
[ppt = precipitation; $\mathrm{mn}=$ millimeters; $\mathrm{cm}=$ centimeters; $\mathrm{mg}=$ milligrams; L = 1iters;

$\mathrm{g}=\mathrm{grams} ; \mathrm{m}=$ meter; $\mu \mathrm{s}=$ microsiemens; cond = specific conductance

STATION: Las Animas, Colorado

CAL number: $\operatorname{COO1}$

ADS number: $333 \mathrm{a} 00$

Map ID number: 15

Station altitude above mean sea level, in meters: 1212 Number of sampling intervals (days in parenthesis):

-- With ppt measurements:

-- When ppt occurred:

13 (91)

-- When ppt did not occur:

$9(63)$

- When sample volume was subst1tuted for missing rain gage:

-- With chemical samples:
Latitude: $38^{\circ} 07^{\prime} 04^{\prime \prime}$ Longitude: $103^{\circ} 18^{\prime} 7^{\prime \prime}$

Station summary period: $10 / 04 / 1983$ to $01 / 03 / 1984$

length of summary period: 13 sampling intervals ( 91 days) Percent summary period with ppt measurements:

Percent sumary period with chemical samples or no ppt: 13.2 Percent of total measured ppt with chemical samples: 37.1

Percent of total measured ppt in raingage that was collected in the wet-sample bucket:

Total measured ppt, in mm: 19.7

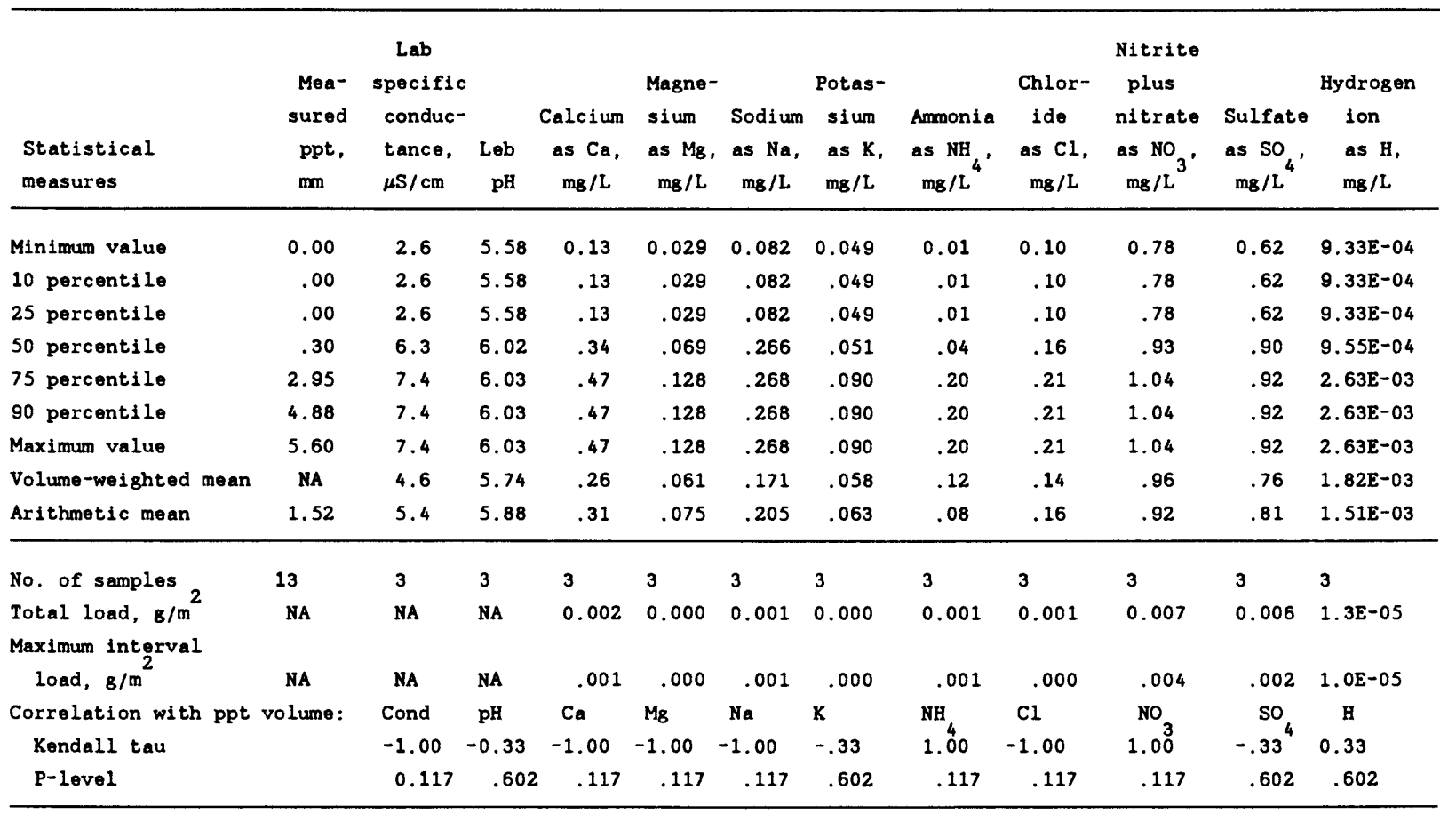

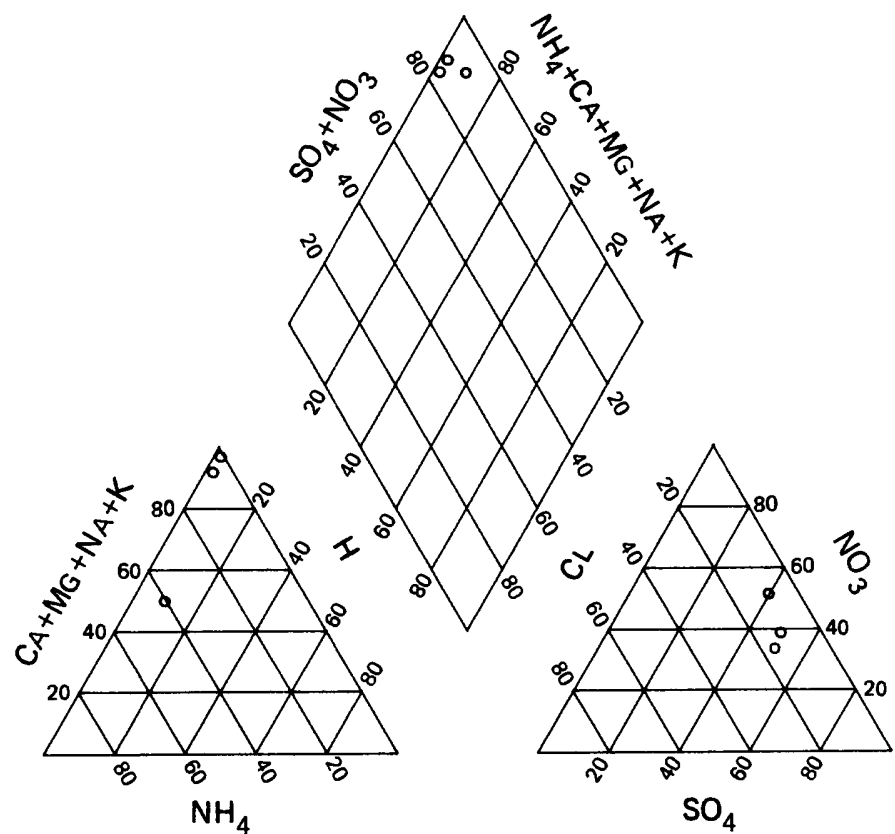

Percentage composition of major ions for site $\mathrm{COOI}$. 
$[$ ppt $=$ precipitation; $\mathrm{mm}=$ millimeters; $\mathrm{cm}=$ centimeters; $\mathrm{mg}=\mathrm{milligrams;} \mathrm{L} \mathrm{=} \mathrm{11ters;}$

$B=g r a m s ; m=$ meter; $\mu \mathrm{s}=$ microsiemens; cond = specific conductance $]$

STATION: Manitou, Colorado

CAL number: $\mathrm{CO} 1$

ADS number: $011 a 00$

Map ID number: 17

Station altitude above mean sea level, in meters: 2362 Number of sampling intervals (days in parenthesis):

-- With ppt measurments:

53 (371)

-- When ppt occurred:

-- When ppt did not occur:

46 (322)

-- When sample volume was substituted for missing rain gage:

-- With chemical samples:
Latitude: $39^{\circ} 06^{\prime} 04^{\prime \prime}$ Longitude: $105^{\circ} 05^{\prime} 31^{\prime \prime}$

Station sumary period: $12 / 28 / 1982$ to $01 / 03 / 1984$

Length of summary period: 53 sampling intervals ( 371 days) Percent summary period with ppt measurments:

100.0 Percent sumary period with chemical samples or no ppt: 60.4 Percent of total measured ppt with chemical samples: 46.0

Percent of total measured ppt in raingage that was collected in wet-sample bucket:

Total measured ppt, in mm: 488.3

\begin{tabular}{|c|c|c|c|c|c|c|c|c|c|c|c|c|}
\hline $\begin{array}{l}\text { Statistical } \\
\text { measures }\end{array}$ & $\begin{array}{l}\text { Mea- } \\
\text { sured } \\
\text { ppt, } \\
\text { mm }\end{array}$ & $\begin{array}{c}\text { Lab } \\
\text { spectfic } \\
\text { conduc- } \\
\text { tance, } \\
\mu S / \mathrm{cm}\end{array}$ & $\begin{array}{rr}c & \\
- & \\
\text { Lab } & \text { pH }\end{array}$ & $\begin{array}{c}\text { Calcium } \\
\text { as Ca, } \\
\mathrm{mg} / \mathrm{L}\end{array}$ & $\begin{array}{l}\text { Magne- } \\
\text { sium } \\
\text { as } \mathrm{Mg} \text {, } \\
\mathrm{mg} / \mathrm{L}\end{array}$ & $\begin{array}{l}\text { Sodium } \\
\text { as } \mathrm{Na} \text {, } \\
\mathrm{mg} / \mathrm{L}\end{array}$ & $\begin{array}{c}\text { Potas- } \\
\text { sium } \\
\text { as } K \\
\text { mg/L }\end{array}$ & $\begin{array}{l}\text { Ammonia } \\
\text { as } \mathrm{NH}_{\mathrm{mg} / \mathrm{L}^{\circ}}\end{array}$ & $\begin{array}{c}\text { Chlor- } \\
\text { Ide } \\
\text { as } \mathrm{Cl} \text {, } \\
\mathrm{mg} / \mathrm{L}\end{array}$ & $\begin{array}{l}\text { Nitrite } \\
\text { plus } \\
\text { nitrate } \\
\text { as } \mathrm{NO}_{3} \text { ' } \\
\mathrm{mg} / \mathrm{L}^{3}\end{array}$ & $\begin{array}{l}\text { Sulfate } \\
\text { as } \mathrm{SO}_{4} \text {, } \\
\mathrm{mg} / \mathrm{L}\end{array}$ & $\begin{array}{l}\text { Hydrogen } \\
\text { Ion } \\
\text { as } \mathrm{H}, \\
\mathrm{mg} / \mathrm{L}\end{array}$ \\
\hline Minimum value & 0.00 & 2.9 & 4.18 & 0.06 & 0.014 & 0.020 & 0.010 & 0.01 & 0.01 & 0.15 & 0.34 & $7.08 \mathrm{E}-04$ \\
\hline 10 percentile & .00 & 4.3 & 4.50 & .09 & .016 & .026 & .017 & .04 & .03 & .32 & .42 & $1.63 E-03$ \\
\hline 25 percentile & .30 & 8.3 & 4.79 & .15 & .030 & .045 & .026 & .08 & .07 & .95 & .64 & $3.94 E-03$ \\
\hline 50 percentile & 5.30 & 9.8 & 5.17 & .27 & .054 & .094 & .047 & .18 & .12 & 1.32 & 1.00 & $6.76 E-03$ \\
\hline 75 percentile & 14.90 & 15.8 & 5.40 & .59 & .137 & .165 & .077 & .26 & .17 & 2.42 & 1.83 & $1.62 \mathrm{E}-02$ \\
\hline 90 percentile & 22.46 & 22.5 & 5.84 & .84 & .150 & .350 & .262 & .48 & .35 & 3.45 & 2.77 & $3.19 E-02$ \\
\hline Maximum value & 60.20 & 40.0 & 6.15 & 1.08 & .351 & 1.032 & .363 & .54 & 1.10 & 4.45 & 3.91 & $6.61 E-02$ \\
\hline Volume-weighted mean & NA & 9.8 & 4.94 & .22 & .041 & .056 & .063 & .14 & .08 & 1.13 & .91 & $1.15 E-02$ \\
\hline No. of samples & 53 & 25 & 25 & 25 & 25 & 25 & 25 & 25 & 25 & 25 & 25 & 25 \\
\hline $\begin{array}{l}\text { Total load, } \mathrm{g} / \mathrm{m} 2 \\
\text { Maximum interval }\end{array}$ & NA & NA & NA & 0.048 & 0.009 & 0.012 & 0.014 & 0.031 & 0.017 & 0.254 & 0.206 & $2.6 E-03$ \\
\hline load, $8 / \mathrm{m} 2$ & NA & NA & NA & .007 & .002 & .001 & .006 & .004 & .002 & .027 & .032 & $3.7 E-04$ \\
\hline $\begin{array}{l}\text { Correlation with ppt } \\
\text { Kendall tau }\end{array}$ & volume: & $\begin{array}{l}\text { Cond } \\
-0.20\end{array}$ & $\begin{array}{c}\mathrm{pH} \\
-0.27\end{array}$ & $\begin{array}{c}\mathrm{Ca} \\
-.52\end{array}$ & $\begin{array}{l}\mathrm{Mg} \\
-.67\end{array}$ & $\begin{array}{c}\mathrm{Na} \\
-.77\end{array}$ & $\begin{array}{c}\mathrm{K} \\
-.20\end{array}$ & $\begin{array}{r}\mathrm{NH}_{4} \\
-.23\end{array}$ & $\begin{array}{c}C 1 \\
-.63\end{array}$ & $\begin{array}{l}\text { NO }_{3} \\
-.35\end{array}$ & $\begin{array}{r}\mathrm{SO}_{4} \\
-.32\end{array}$ & $\begin{array}{r}\mathrm{H} \\
0.27\end{array}$ \\
\hline P-level & & .175 & .065 & .000 & .000 & .000 & .175 & .116 & .000 & .015 & .028 & .065 \\
\hline
\end{tabular}

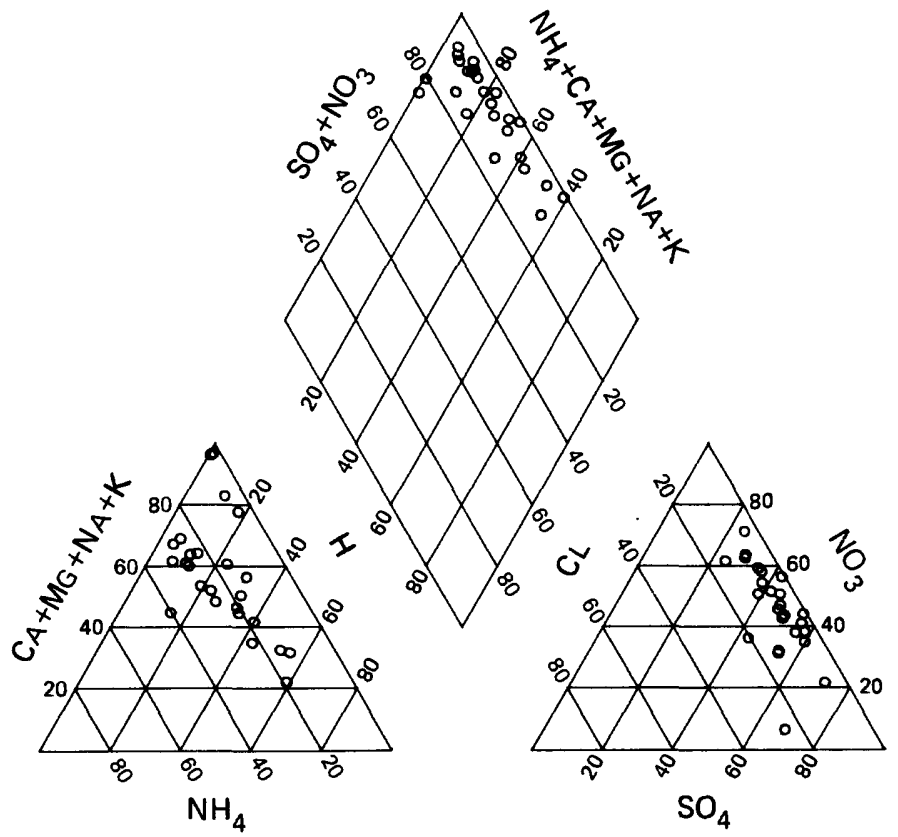

Percentage composition of major ions for site $\mathrm{CO} 21$. 
[ppt $=$ precipitation; $\mathrm{mm}=$ millimeters $; \mathrm{cm}=$ centimeters $; \mathrm{mg}=\mathrm{milligrams;} \mathrm{L}=1$ iters ;

$\mathrm{g}=\mathrm{grams} ; \mathrm{m}=$ meter $\boldsymbol{\mu s}=$ microsiemens; cond = specific conductance $]$

STATION: Mesa Verde, Colorado

CAL number: Cog9

ADS number: $029 a 00$

Station altitude above mean sea level, in meters: 217

Number of sampling intervals (days in parenthesis):

-- With ppt measurements:

$53 \quad(371)$

-- When ppt occurred.

-- When ppt did not occur:

49 (343)

-- When sample volume was substituted for missing rain gage:

-- With chemical samples:
Latitude: $37^{\circ} 11^{\prime} 56^{\prime \prime}$ Longitude: $108^{\circ} 29^{\prime} 26^{\prime \prime}$

Station summary period: $12 / 28 / 1982$ to $01 / 03 / 1984$

Length of summary period: 53 sampling intervals ( 371 days) Percent summary period with ppt measurements: 100.0 Percent summary period with chemical samples or no ppt: 58.5 Percent of total measured ppt with chemical samples: 56.5 Percent of total measured ppt in raingage that was collected in the wet-sample bucket:

Total measured ppt, in $\mathrm{mm}: 573.8$

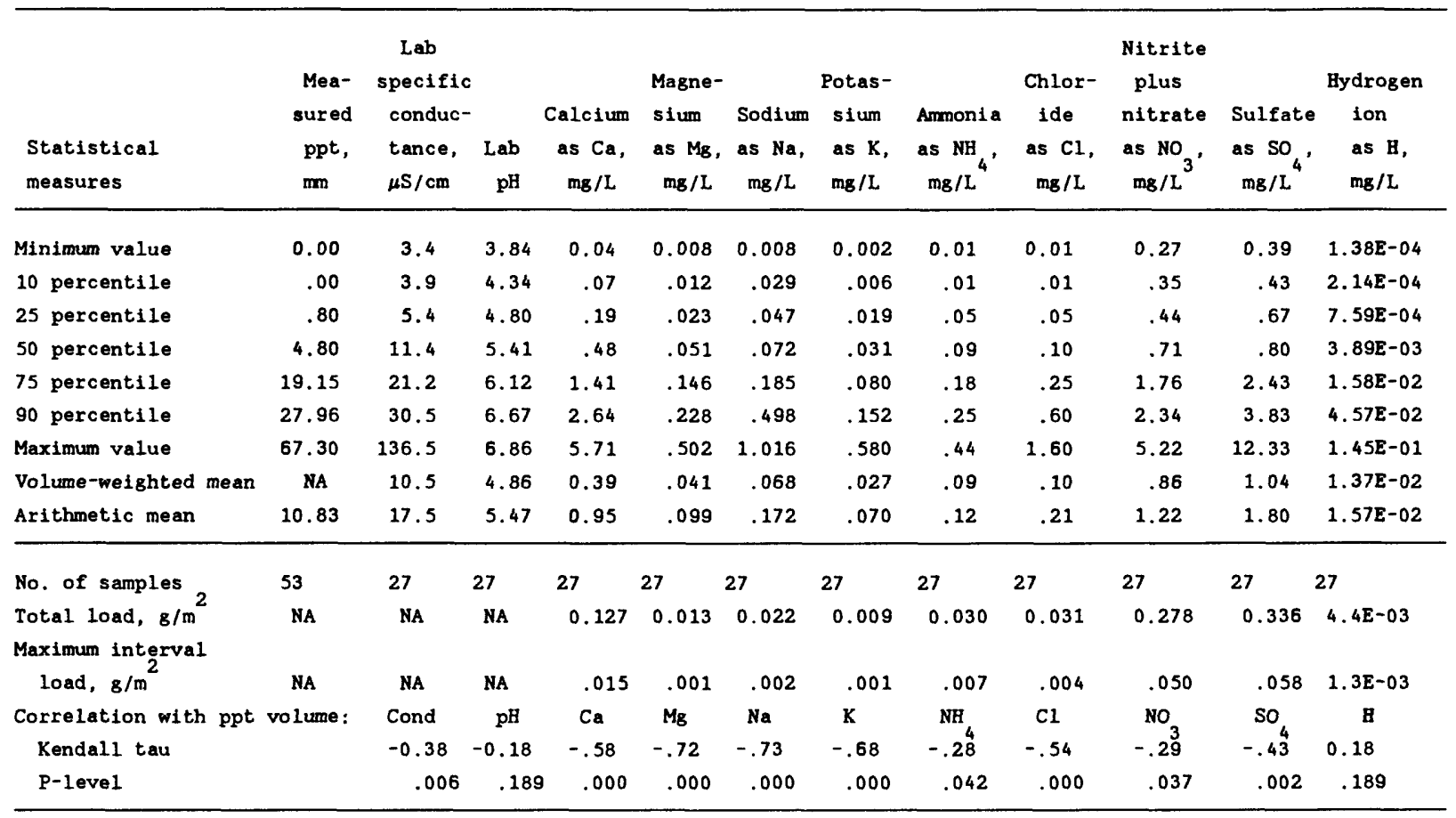

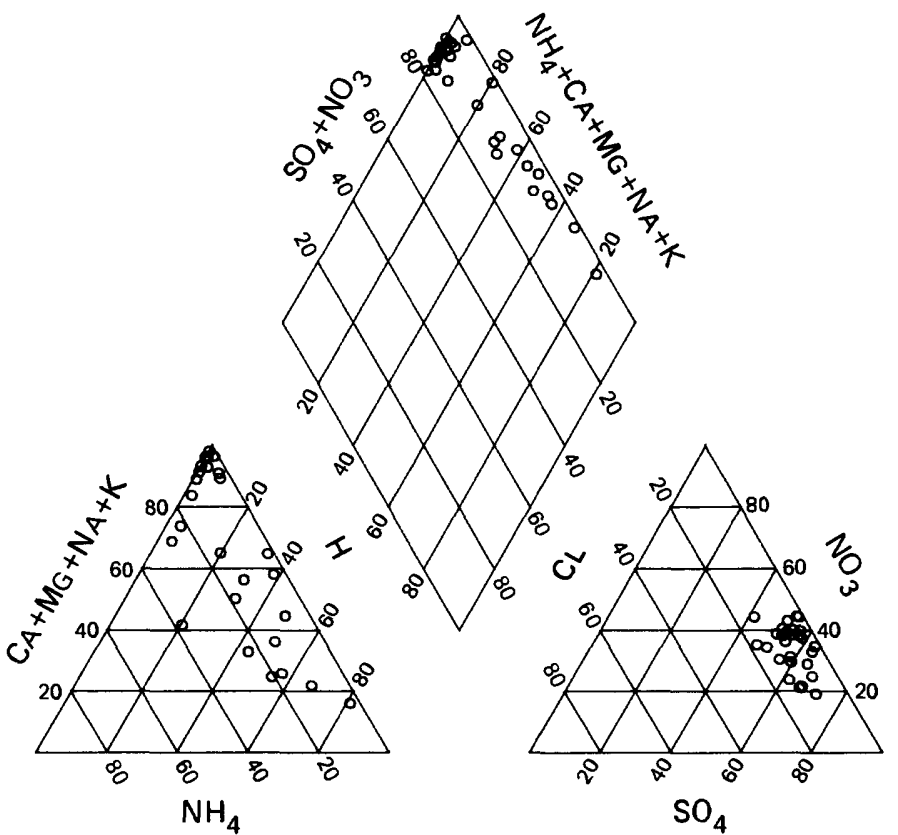

Percentage composition of major ions for site CO99. 


\section{NATIONAL TRENDS NETWORK -- 1983 CALENDER YEAR SUMMARY DATA}

lppt = precipitation; $\mathrm{mm}=$ millimeters; $\mathrm{cm}=$ centimeters; $\mathrm{mg}=$ milligrams; L = 1iters;

$\mathbf{g}=\mathrm{grams} ; \mathrm{m}=$ meter $\boldsymbol{\mu s}=$ microsiemens; cond = specific conductance $]$

STATION: Verna Well Field, Florida

CAL number: FL41

ADS number: $338 \mathrm{a} 00$

Station altitude above mean sea level, in meters: 25 Number of sampling intervals (days in parenthesis):

-- With ppt measuraments: 19 (133)

-- When ppt occurred: 19 (133)

-- When ppt did not occur:

-- When sample volume was substituted for missing rain gage: 0 ( 0$)$

-- With chamical samples: 5 (33)
Latitude: $27^{\circ} 22^{\prime} 48^{\prime \prime}$ Longitude: $82^{\circ} 17^{\prime} 02^{\prime \prime}$

Station summary period: $08 / 25 / 1983$ to $01 / 03 / 1984$

Length of summary period: 19 sampling intervals (131 days)

Percent summary period with ppt measurements: 35.8

Percent summary period with chemical samples or no ppt: 8.9

Percent of total measured ppt with chemical samples: 30.3

Percent of total measured ppt in raingage that was

collected in the wet-sample bucket:

100.4

Total measured ppt, in mm: 524.1

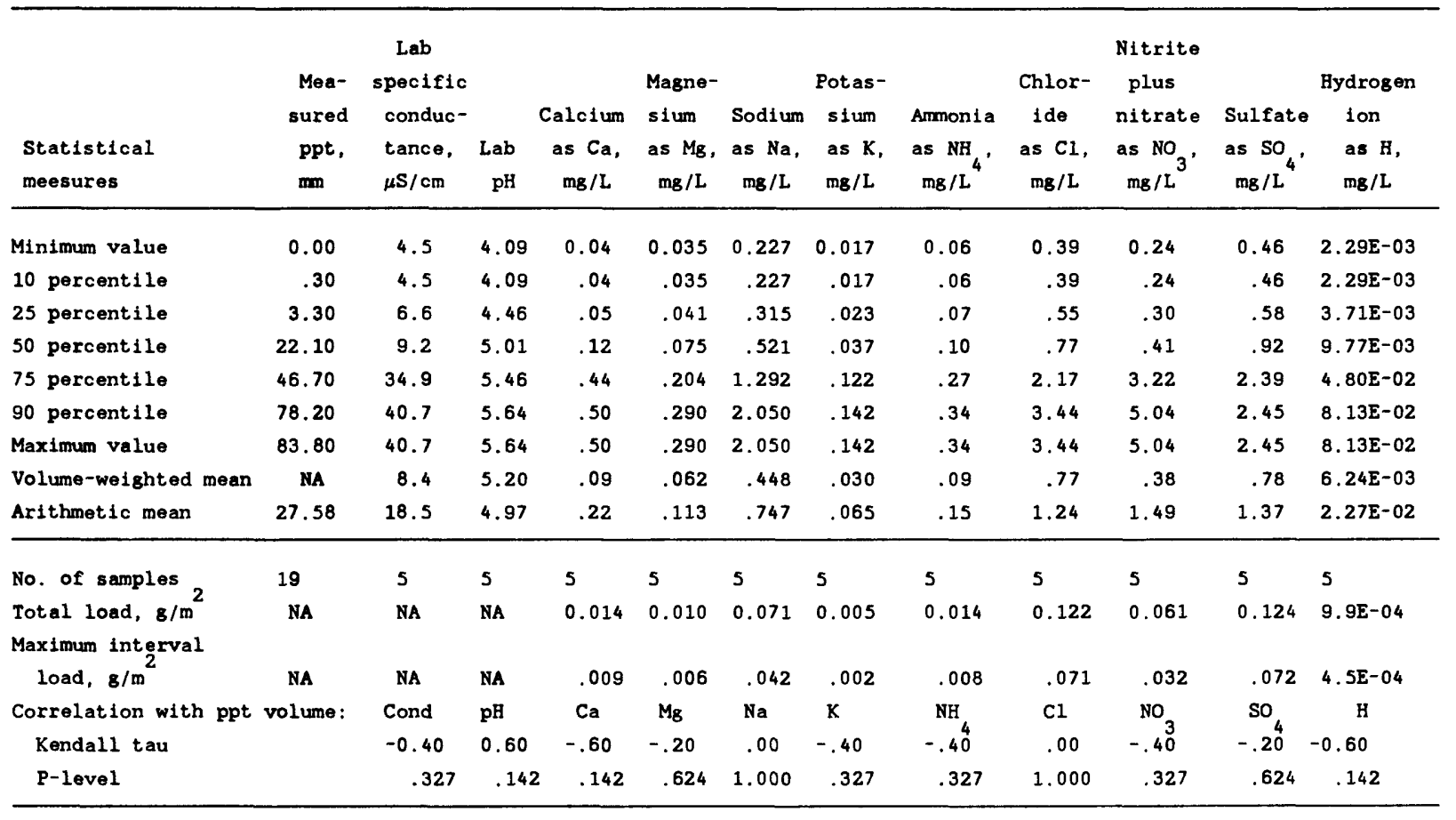

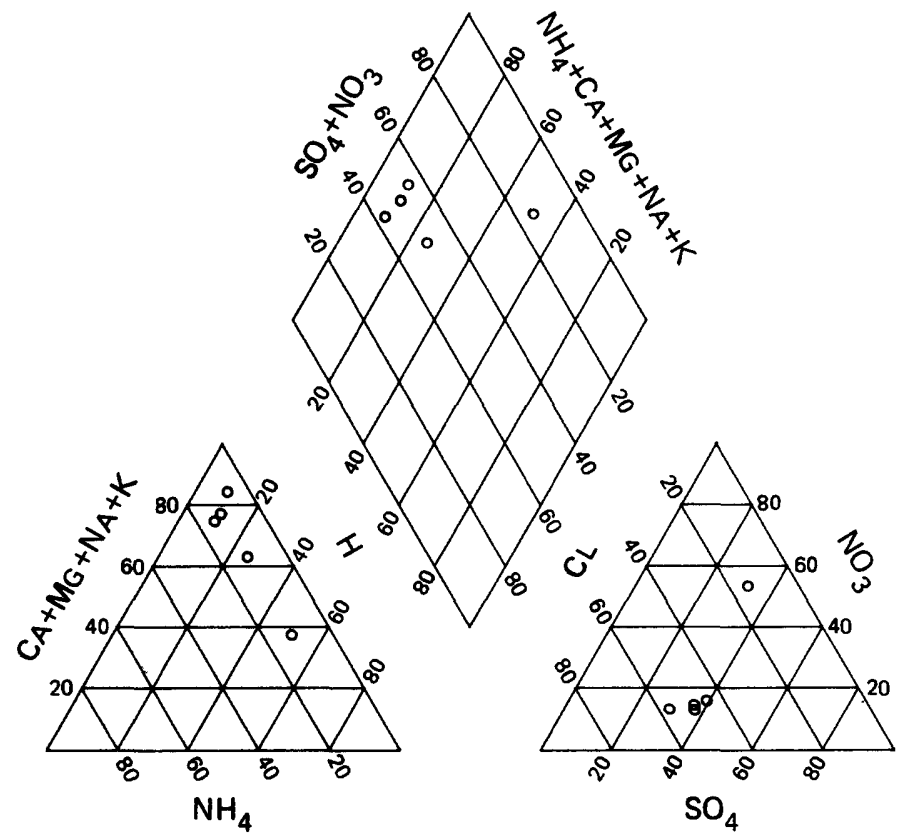

Percentage composition of major ions for site FL41. 


\section{NATIONAL TRENDS NETWORK -- 1983 CALENDER YEAR SUMMARY DATA}

[ppt = precipitation; $\mathrm{mn}=$ millimeters; $\mathrm{cm}=$ centimeters; $\mathrm{mg}=$ milligrams; L $=11$ ters;

$\mathrm{B}=$ grams; $\mathrm{m}=$ meter; $\mu \mathrm{s}=$ microsiemens; cond = specific conductance $]$

STATION: Georgia Station, Georgia

CAL number: GA41

ADS number: $017 \mathrm{a} 00$

Station altitude above mean sea level, in meters: 270

Number of sampling intervals (days in parenthesis):

-- With ppt measurements: 53

-- When ppt occurred: $52 \quad$ (364)

-- When ppt did not occur: 1 ( 7)

- When sample volume was substi-

tuted for missing rain gage: 0 ( 0$)$

-- With chemical samples: 33 (231)
Latitude: $33^{\circ} 10^{\prime} 40^{\prime \prime}$ Longitude: $84^{\circ} 24^{\prime} 22^{\prime \prime}$

Station summary period: $12 / 28 / 1982$ to $02 / 03 / 1984$

Length of summary period: 53 sampling intervals ( 371 days)

Percent summary period with ppt measurements: 100.0

Percent sumary period with chemical samples or no ppt: 64.2

Percent of total measured ppt with chemical samples: $\quad 76.7$

Percent of total measured ppt in raingage that was

collected in the wet-sample bucket:

95.4

Total measured ppt, in $\mathrm{mm}: 1281.6$

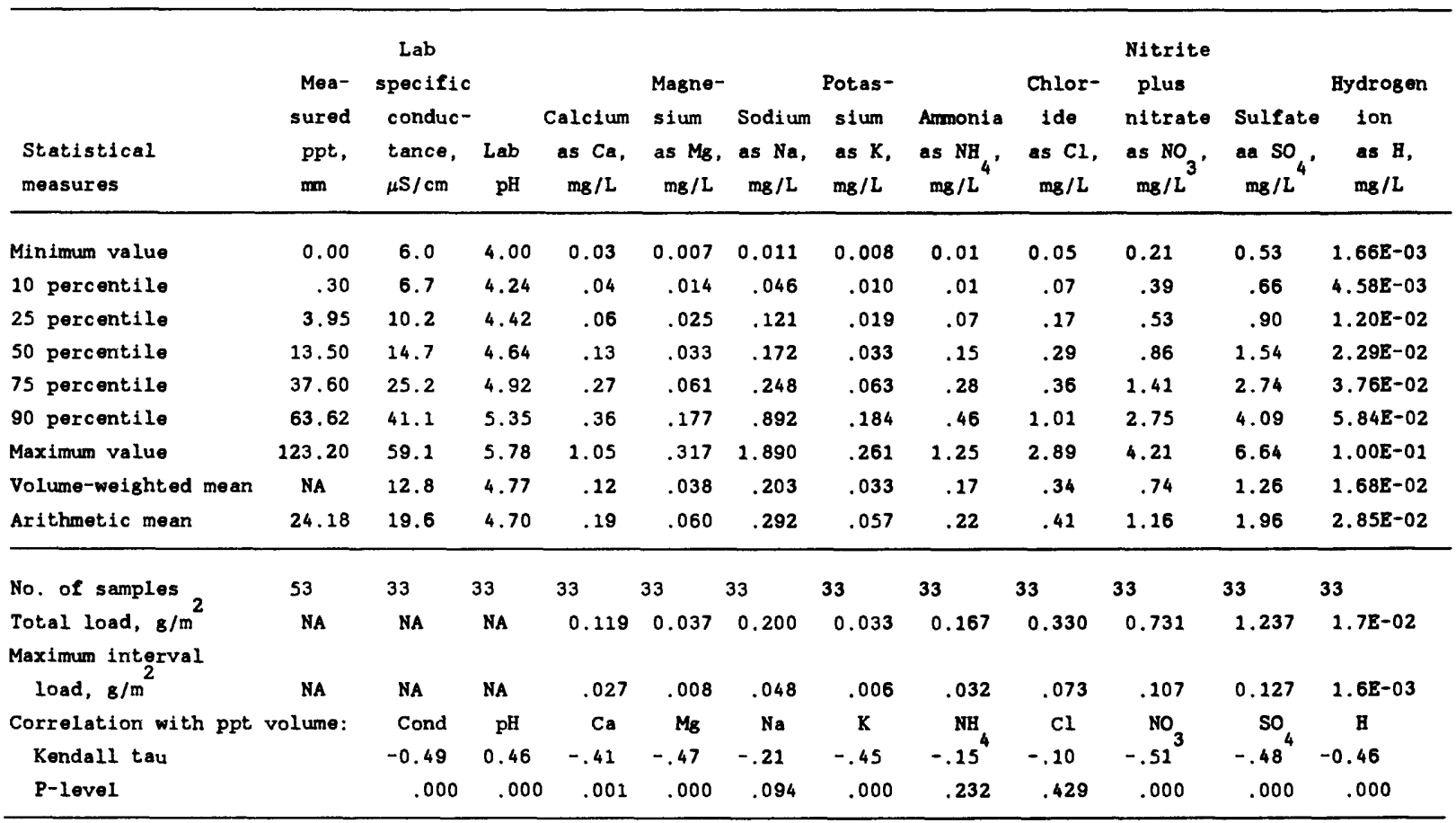

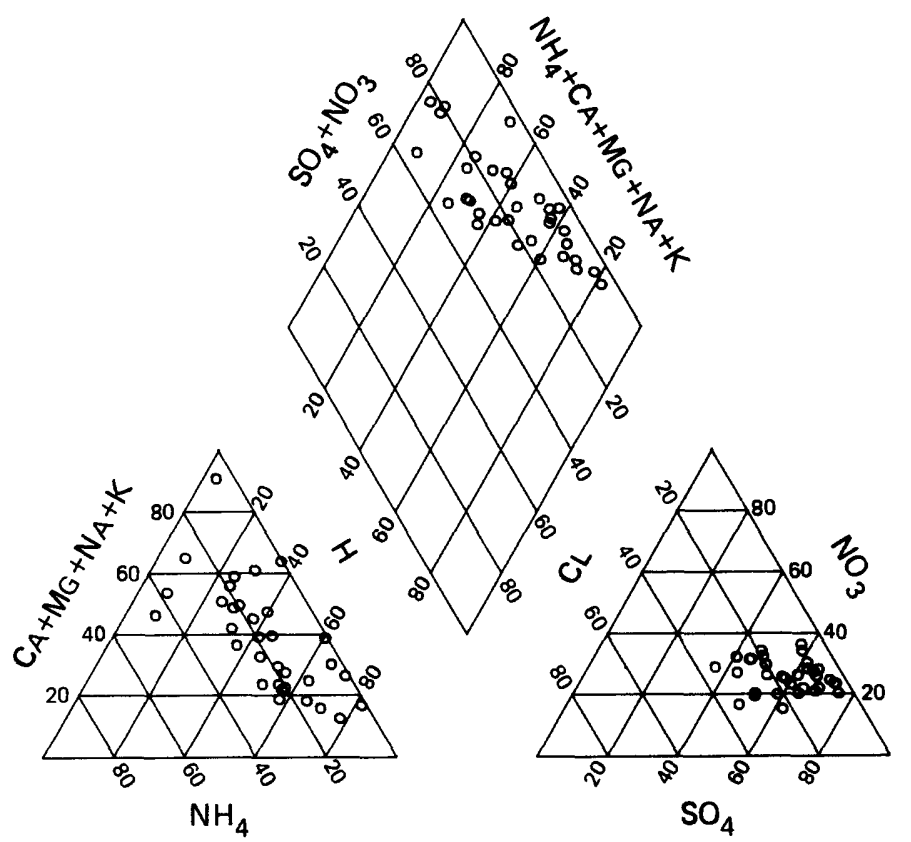

Percentage composition of major ions for site GA41. 
lppt $=$ precipitation; $\mathrm{mm}=$ millimeters; $\mathrm{cm}=$ centimeters; $\mathrm{mg}=$ milligrams; L = liters;

$\mathrm{g}=\mathrm{grams} ; \mathrm{m}=$ meter $\boldsymbol{\mu \mathrm { s }}=$ microsiemens; cond $=$ specific conductance $]$

STATION: Tifton, ARS, Georgia

CAL number: GA50

ADS number: $340 a 00$

Map ID number: 24

Station altitude above mean sea level, in meters: 104 Number of sampling intervals (days in parenthesis):

-- With ppt measurements:

-- When ppt occurred:

13 (91)

-- When ppt did not occur:

13 (91)

-- When sample volume was substituted for missing rain gage:

-- With chemical samples:
Latitude: $31^{*} 28^{\prime} 25^{\prime \prime}$ Longitude:

$83^{\circ} 31^{\prime} 59^{\prime \prime}$

Station summary period: $10 / 04 / 1983$ to $01 / 03 / 1984$

Length of summary period: 13 sampling intervals (91 days)

Percent summary period with ppt measurements:

24.5

Percent summary period with chemical samples or no ppt: 20.8

Percent of total measured ppt with chemical samples: $\quad 97.0$

Percent of total measured ppt in raingage that was

collected in the wet-sample bucket:

90.2

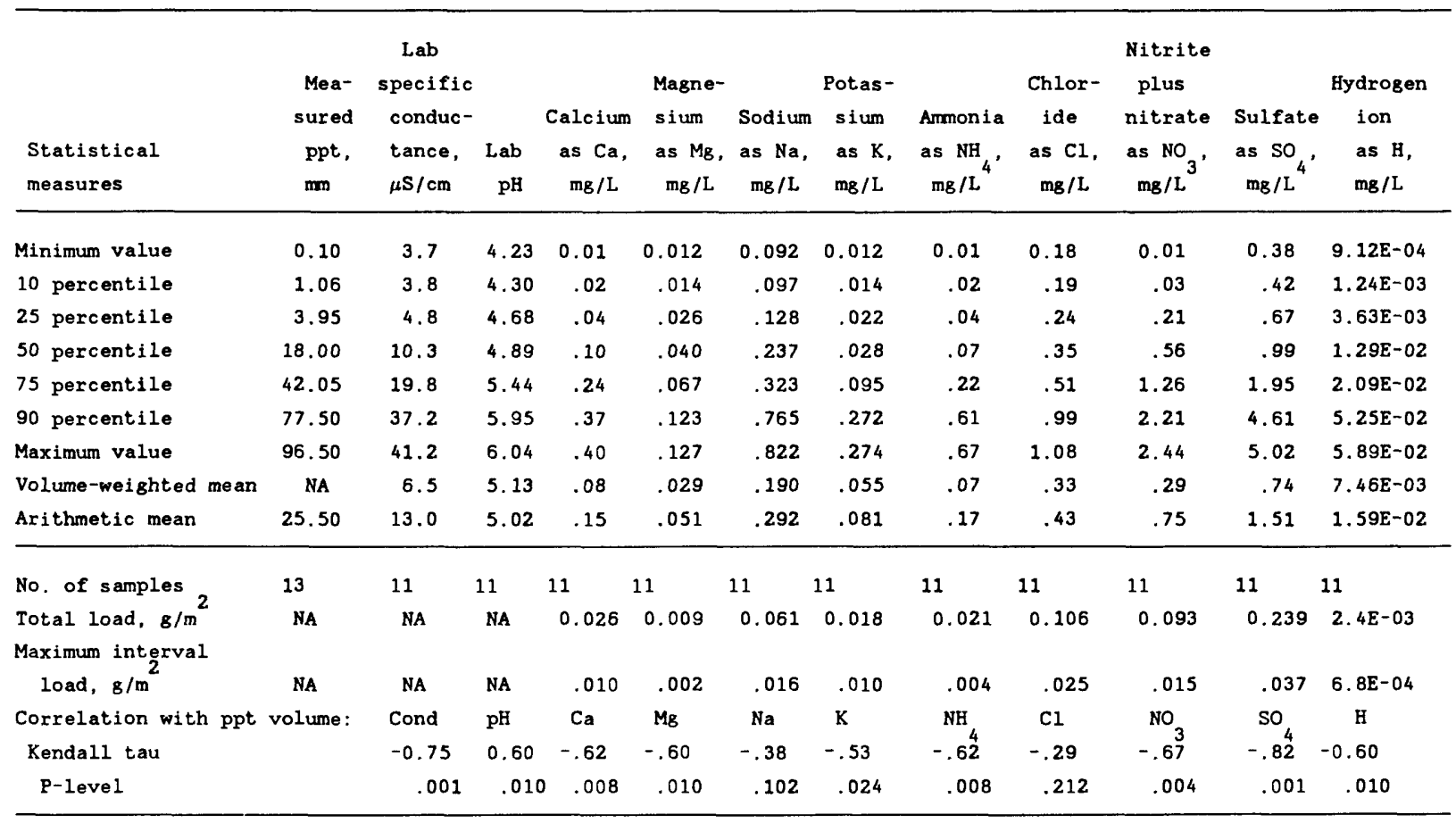

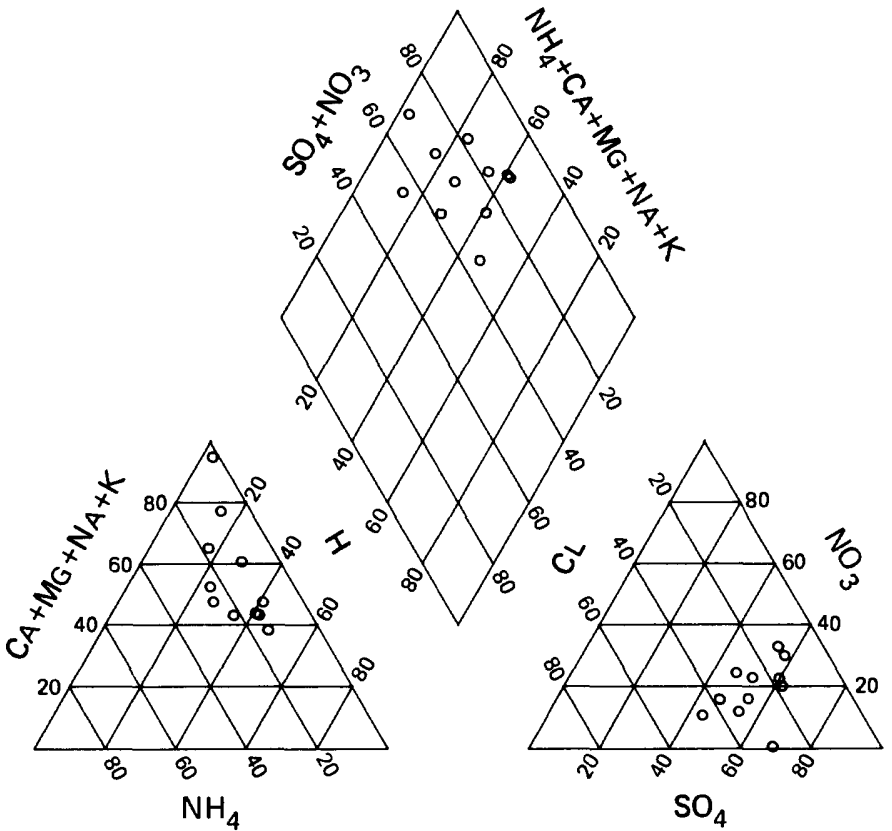

Percentage composition of major ions for site GA50. 


\section{NATIONAL TRENDS NETWORK - - 1983 CALENDER YEAR SUMMARY DATA}

lppt = precipitation; $\mathrm{mm}=$ millimeters; $\mathrm{cm}=$ centimeters; $\mathrm{mg}=$ milligrams; L = liters;

$g=g r a m s ; m=$ meter $; \mu s=$ microsiemens; cond = specific conductance $]$

STATION: Craters of Moon, Idaho

CAL number: ID03

ADS number: $019 a 00$

Map ID number 25:

Latitude: $43^{\circ} 27^{\prime} 48^{\prime \prime}$ Longitude: $113^{\circ} 33^{\prime} 31^{\prime \prime}$

umber of sampling intervala (days in parenthesis):

-- With ppt masurements: $50 \quad$ (371)

-- When ppt occurred: $46 \quad$ (343)

-- When ppt did not occur: $4 \quad 4$ ( 28)

-- When sampla volume was substituted for missing rain gage: 2 ( 14 )

-- With chemical samples: 23
Station summary period: $12 / 28 / 1982$ to $01 / 03 / 1984$

Length of summary period: 50 sampling intervals (371 days)

Percent summary period with ppt measurements: 100.0

Percent sumnary period with chemical samples or no ppt: 50.9

Percent of total measured ppt with chemical samples: $\quad 57.8$

Percent of total measured ppt in raingage that was

collected in the wet-sample bucket:

90.5

Total measured ppt, in $\mathrm{mm}: 493.9$

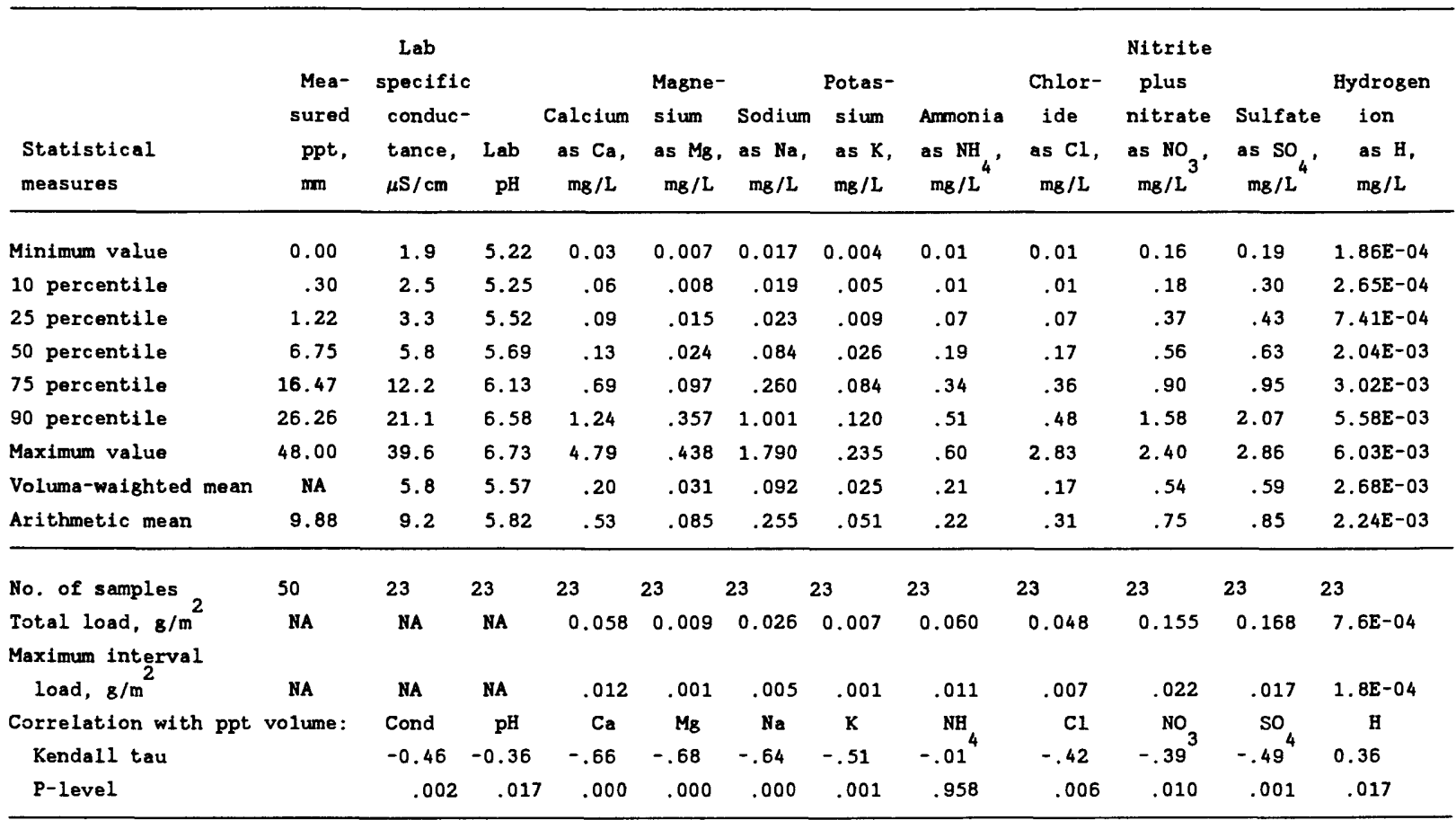

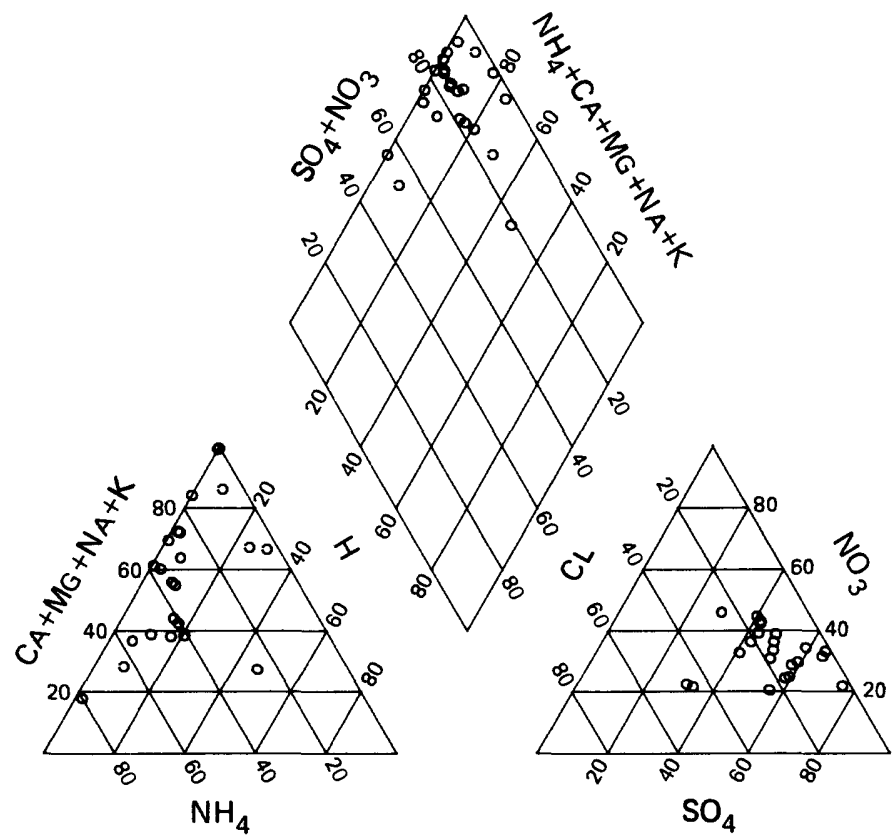

Percentage composition of major ions for site ID03. 


\section{NATIONAL TRENDS NETWORK - - 1983 CALENDER YEAR SUMMARY DATA}

lppt = precipitation; $\mathrm{mm}=$ millimeters; $\mathrm{cm}=$ cantimeters; $\mathrm{mg}=$ mill1grams; L $=$ liters;

$8=8 \mathrm{rams} ; \mathrm{m}=$ meter $; \mu \mathrm{s}=\mathrm{microsiemens} ;$ cond $=$ specific conductance $]$

STATION: Bondville, Illinois

CAL number: IL11

ADS number: 020200

Station altitude above maan sea level, in moters: 212

Number of sampling intervals (days in parenthesis):

-- With ppt measurements: $53 \quad$ (371)

-- When ppt occurred:

- When ppt did not occur:

$\begin{array}{rr}49 & (343) \\ 4 & (28)\end{array}$

-- When sample volume was substituted for missing rain gage:
Latitude: $40^{\circ} 03^{\prime} 12^{\prime \prime}$ Longitude: $88^{\circ} 22^{\prime} 19^{\prime \prime}$

Station summary period: $12 / 28 / 1982$ to $01 / 03 / 1984$

Length of summary period: 53 sampling intervals ( 371 days)

Percent summary period with ppt measuremants:

100.0

Percant summary pariod with chemical samples or no ppt: 47.2

Percant of total measured ppt with chemical samples: 51.3

Percent of total measured ppt in raingage that was

collactad in the wot-sampla bucket:

95.7

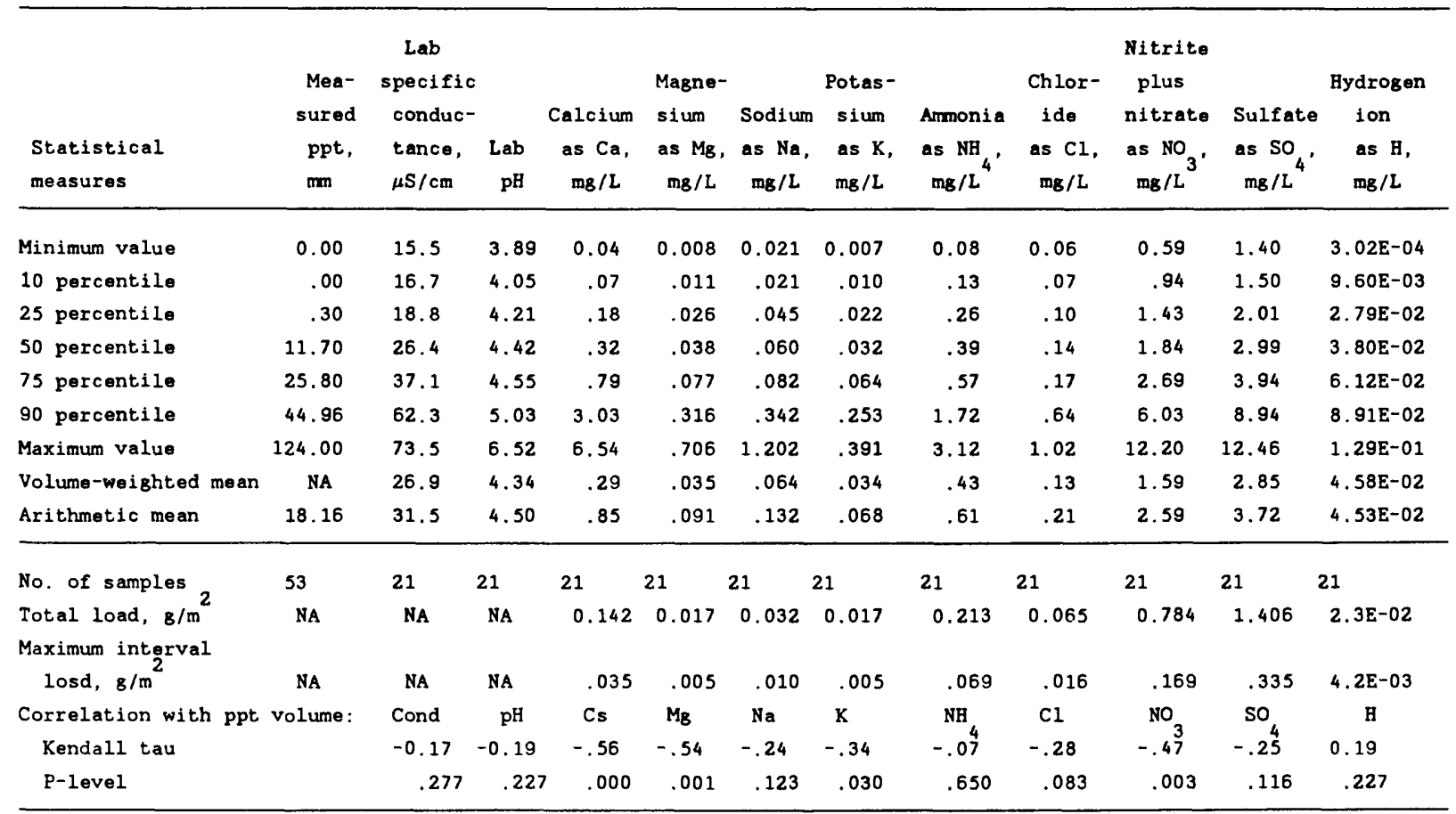

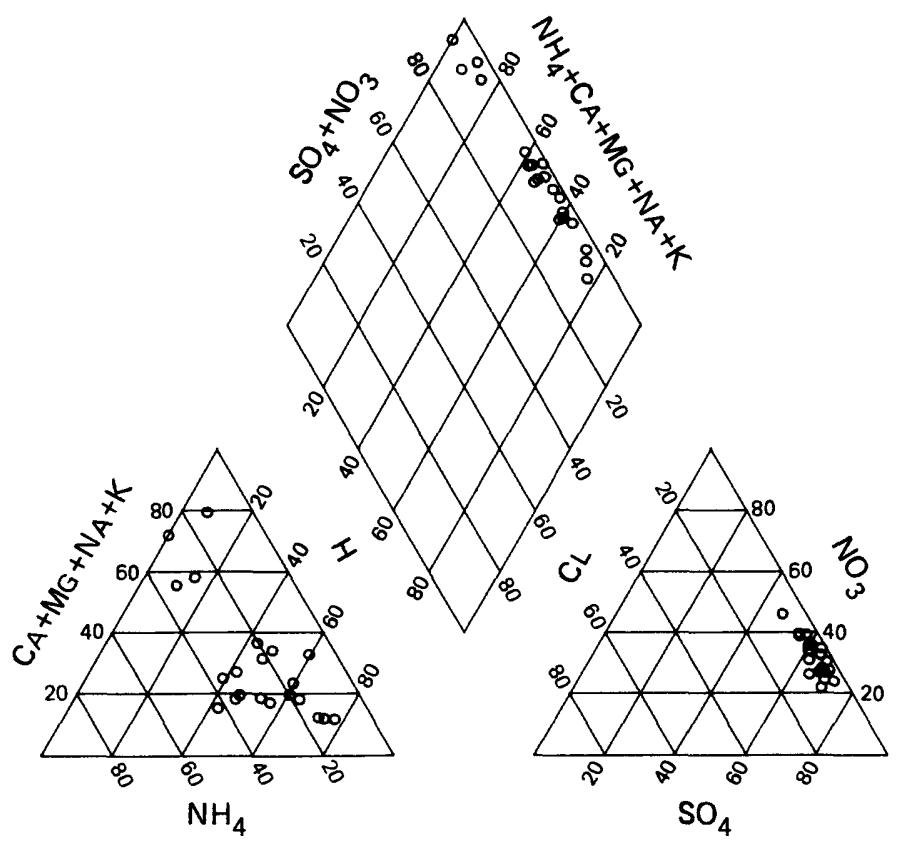

Percentage composition of major ions for site IL11. 


\section{NATIONAL TRENDS NETWORK -- 1983 CALENDER YEAR SUMMARY DATA}

[ppt $=$ precipitation; $\mathrm{mm}=$ millimeters; $\mathrm{cm}=$ centimeters; $\mathrm{mg}=$ milligrams; $\mathrm{L}=1$ liters;

$8=\mathrm{grams} ; \mathrm{m}=$ meter $; \mathrm{s}=$ microsiemens; cond = specific conductance $]$

STATION: Bondville, Illinols

CAL number: $11 \mathrm{IL}$

ADS number: $020 \mathrm{c00}$

Station altitude above mean sea level, in meters: 212

Number of sampling intervals (days in parenthesis):

-- With ppt measurements:

-- When ppt occurred:

-- When ppt did not occur:

-- When sample volume was substituted for missing rain gage:

-- With chemical samples:

$\begin{array}{rr}15 & (105) \\ 14 & (98) \\ 1 & (7) \\ 0 & \left(\begin{array}{r}0 \\ 6\end{array}\right. \\ & (42)\end{array}$

Latitude: $40^{\circ} 03^{\prime} 12^{\prime \prime}$ Longitude: $88^{\circ} 22^{\prime} 19^{\prime \prime}$

Station summary period: $09 / 20 / 1983$ to $01 / 03 / 1984$

Length of summary period: 15 sampling intervals ( 105 days)

Percent summary period with ppt measurements:

28.3

Percent summary period with chemical samples or no ppt: 13.2

Percent of total measured ppt with chemical samples: $\quad 34.4$

Percent of total measured ppt in raingage that was

collected in the wet-sample bucket:

82.6

Total measured ppt, in $\mathrm{mm}: 364.2$

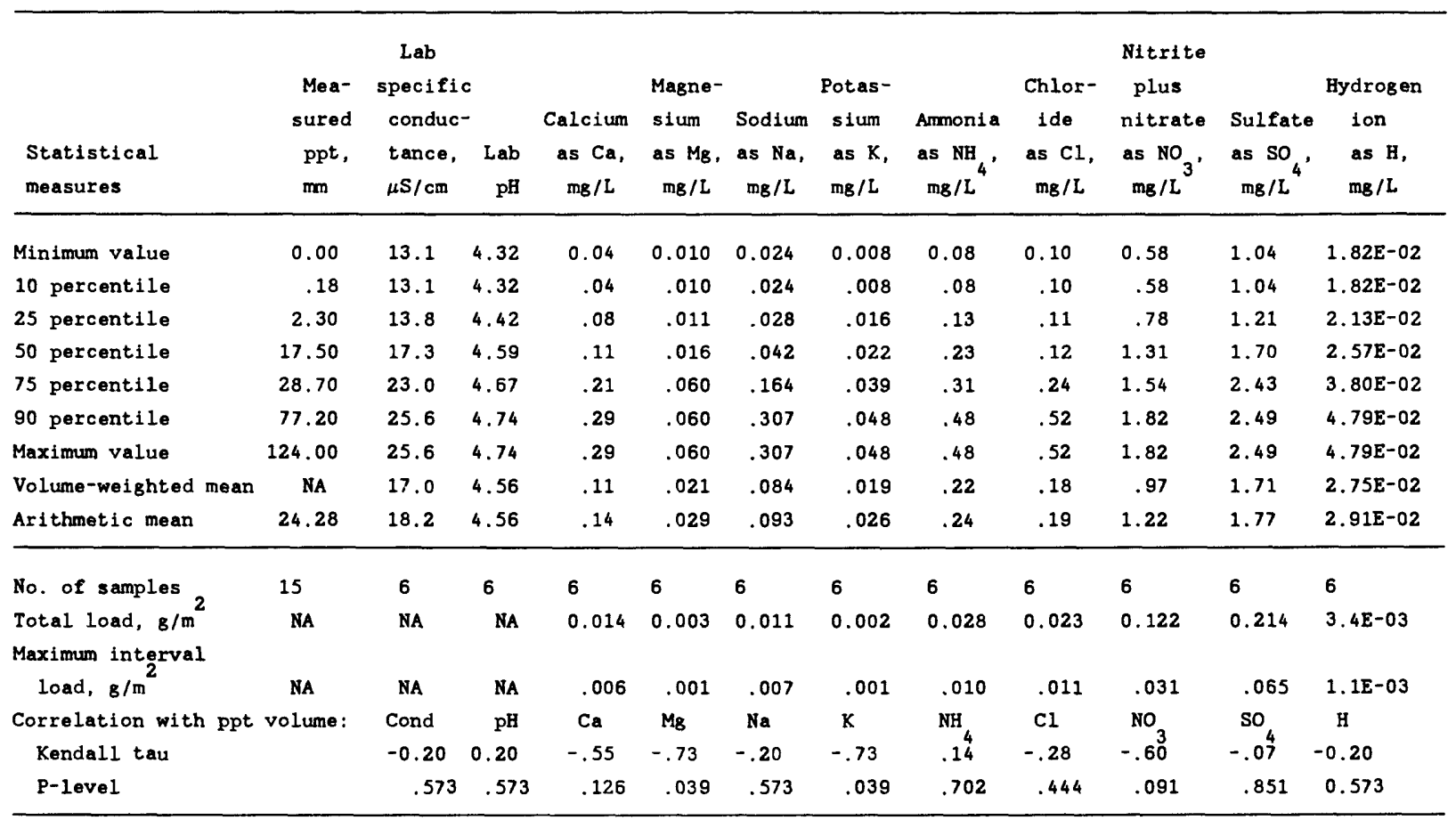

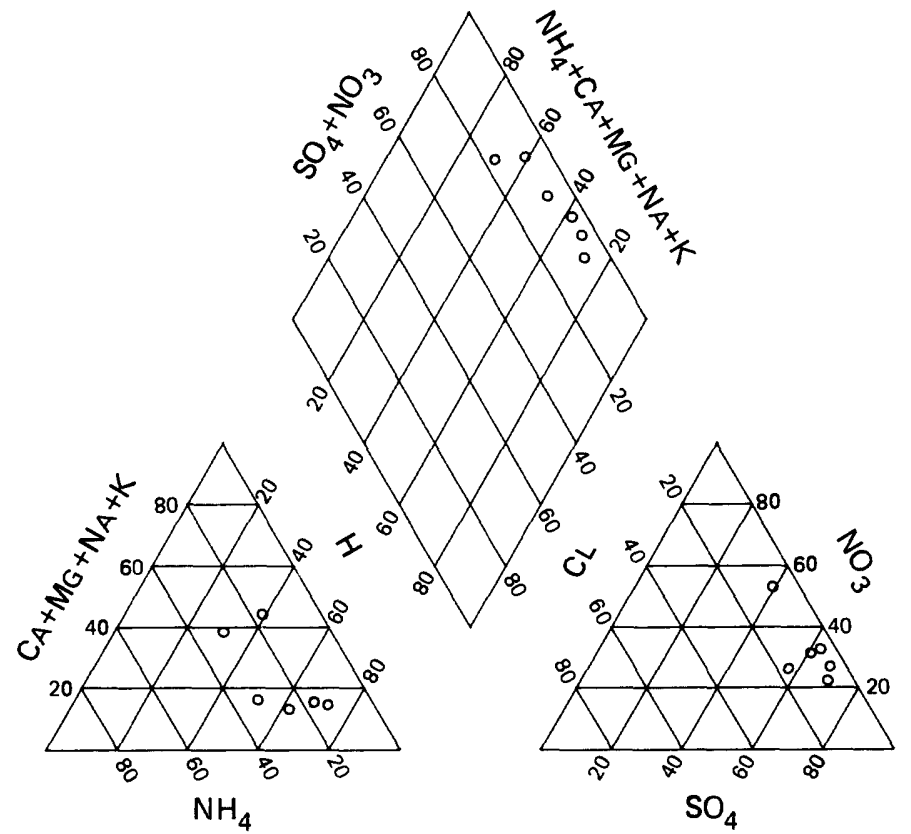

Percentage composition of major ions for site 11IL. 


\section{NATIONAL TRENDS NETWORK -- 1983 CALENDER YEAR SUMMARY DATA}

[ppt = precipitation; $\mathrm{mm}=$ millimeters; $\mathrm{cm}=$ centimeters; $\mathrm{mg}=$ milligrams; $\mathrm{L}=1$ iters;

$\mathrm{g}=$ grams; $\mathrm{m}=$ meter $\mu \mathrm{s}=$ microsiemens; cond = specific conductance $]$

STATION: Argonne, Illinois

CAL number: IL19

ADS number: $021 \mathrm{a} 01$

Station altitude above mean sea level, in meters: 229

Number of sampling intervals (days in parenthesis):

-- With ppt measurements: 52

-- When ppt occurred: 51 (371)

-- When ppt did not occur: 1 ( 7)

-- When sample volume was substituted for missing rain gage: 2 (21)

-- With chemical samples: 21 (155)
Latitude: $41^{\circ} 42^{\prime} 04^{\prime \prime}$ Longitude:

$87^{\circ} 59^{\prime} 43^{\prime \prime}$

Station summary period: $12 / 21 / 1982$ to $01 / 03 / 1984$

Length of summary period: 52 sampling intervals ( 378 days)

Percent summary period with ppt measurements:

101.9

Percent summary period with chemical samples or no ppt: 43.7

Percent of total measured ppt with chemical samples: $\quad 33.1$

Percent of total measured ppt in raingage that was

collected in the wet-sample bucket:

101.9

Total measured ppt, in m: 1198.0

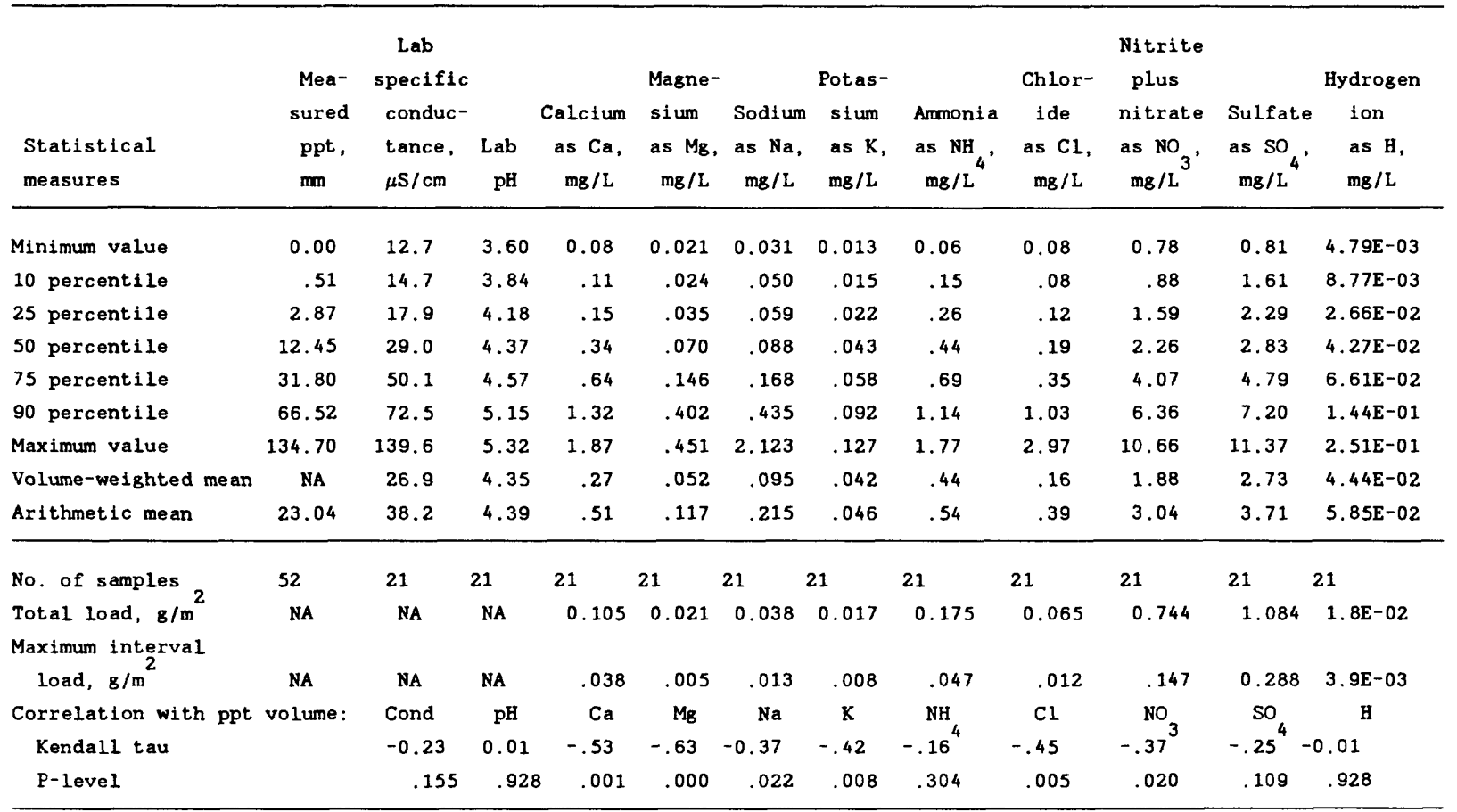

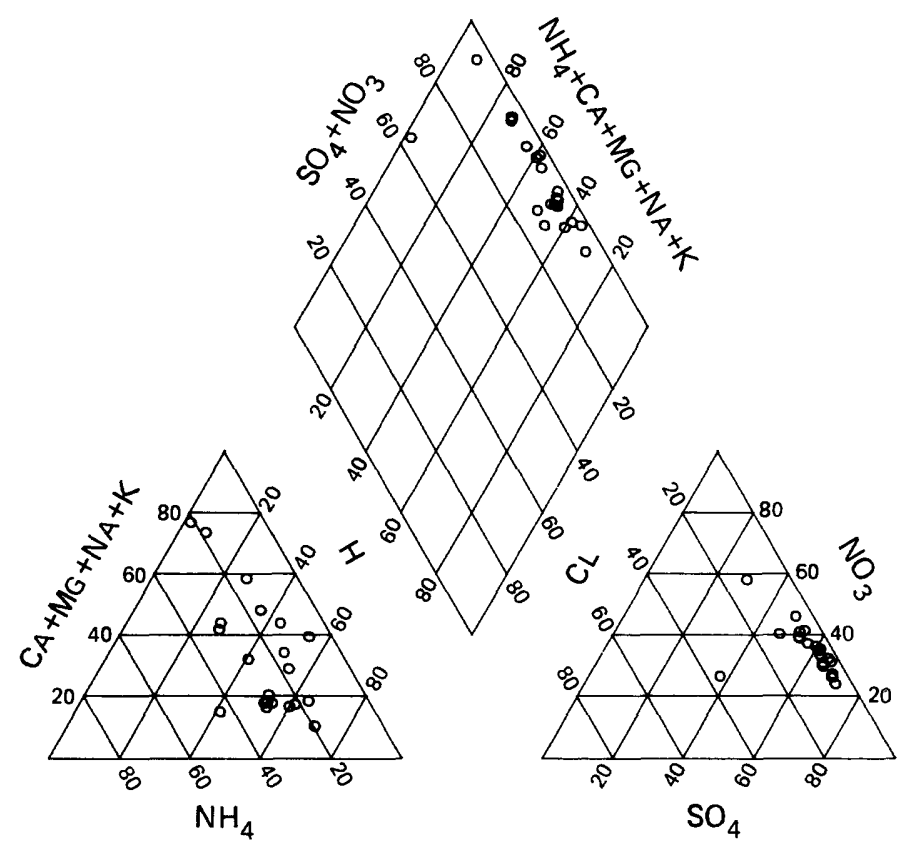

Percentage composition of major ions for site IL 19. 


\section{NATIONAL TRENDS NETWORK - 1983 CALENDER YEAR SUMMARY DATA}

lppt $=$ precipitation; $\mathrm{mm}=$ millimeters; $\mathrm{cm}=$ centimeters; $\mathrm{mg}=$ milligrams; L = liters;

$\mathbf{8}=\mathrm{grams} ; \mathrm{m}=$ meter $; \mu \mathrm{s}=$ microsiemens; cond = specific conductance $]$

STATION: Salem, Illinois

CAL number: IL47

ADS number: $161 \mathrm{a} 02$

Station altitude above mean sea level, in meters: 173

Number of sampling intervals (days in parenthesis):

-- With ppt measurements:

-- When ppt occurred:

-- When ppt did not occur:

51 (371)

44 (308)

7 (63)

-- When sample volume was substituted for missing rain gage:

-- With chemical samples:
Latitude: $38^{\circ} 38^{\prime} 36^{\prime \prime}$ Longitude: $88^{\circ} 58^{\prime} 01^{\prime \prime}$

Station summary period: $12 / 28 / 1982$ to $01 / 03 / 1984$

Length of summary period: 51 sampling intervals ( 371 days)

Percent summary period with ppt measurements:

100.0

Percent sumary period with chemical samples or no ppt: $\quad 69.8$

Percent of total measured ppt with chemical samples: 61.7

Percent of total measured ppt in raingage that was

collected in the wet-sample bucket:

105.2

Total measured ppt, in $\mathrm{mm:} 1027.4$

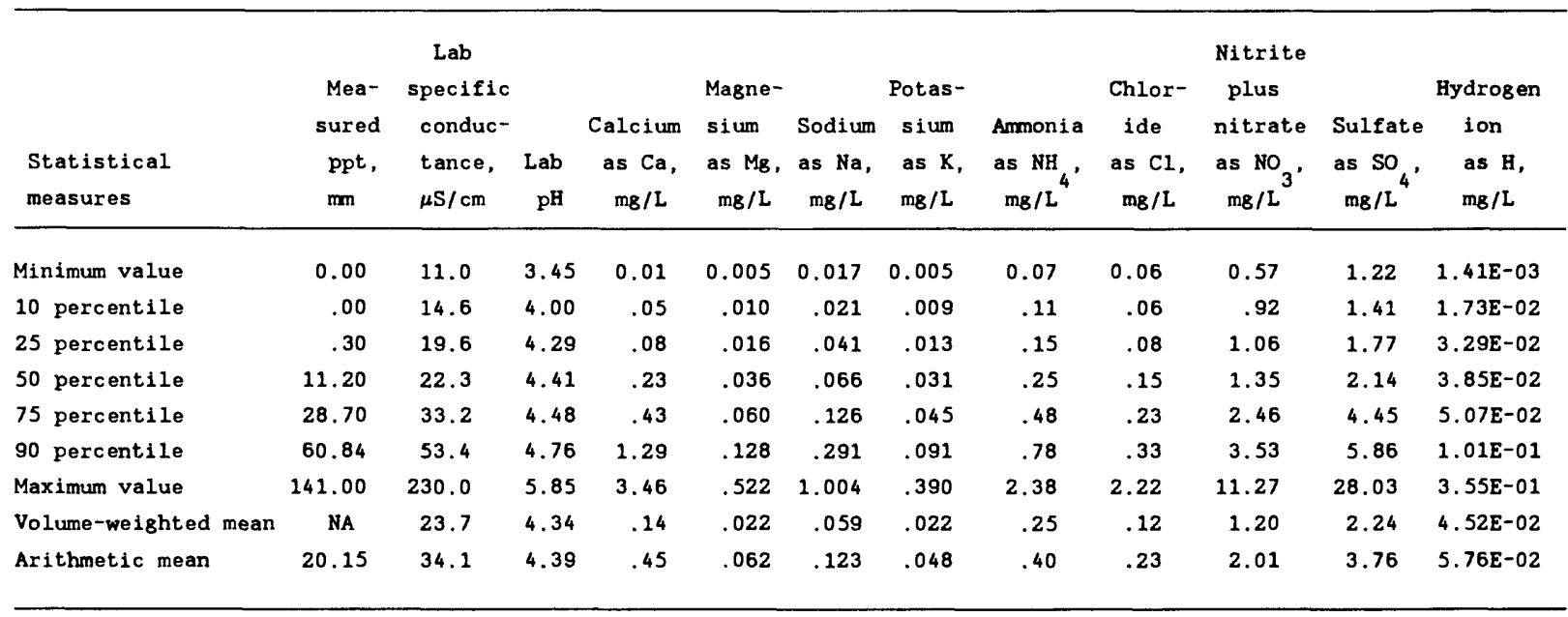

\begin{tabular}{|c|c|c|c|c|c|c|c|c|c|c|c|c|}
\hline No. of samples, & 51 & 28 & 28 & 28 & 28 & 28 & 28 & 28 & 28 & 28 & 28 & 28 \\
\hline Total load, $8 / \mathrm{m}^{2}$ & NA & NA & NA & 0.090 & 0.014 & 0.037 & 0.014 & 0.158 & 0.078 & 0.762 & 1.421 & $2.9 E-02$ \\
\hline \multicolumn{13}{|l|}{ Maximum interval } \\
\hline $10 a d, 8 / m^{2}$ & NA & NA & NA & .012 & .001 & .005 & .002 & .029 & .016 & .103 & .245 & 6. $3 E-03$ \\
\hline Correlation with ppt & volume: & Cond & $\mathrm{pH}$ & $\mathrm{Ca}$ & Mg & $\mathrm{Na}$ & $\mathbf{K}$ & NH & $\mathrm{Cl}$ & $\mathrm{NO}_{3}$ & So & $\mathbf{H}$ \\
\hline Kendall tau & & -0.26 & 0.03 & -.62 & -.67 & -.45 & -.45 & -.38 & -.37 & -.50 & -.41 & -0.03 \\
\hline P-level & & .050 & .812 & .000 & .000 & .001 & .001 & .005 & .007 & .000 & .002 & .812 \\
\hline
\end{tabular}

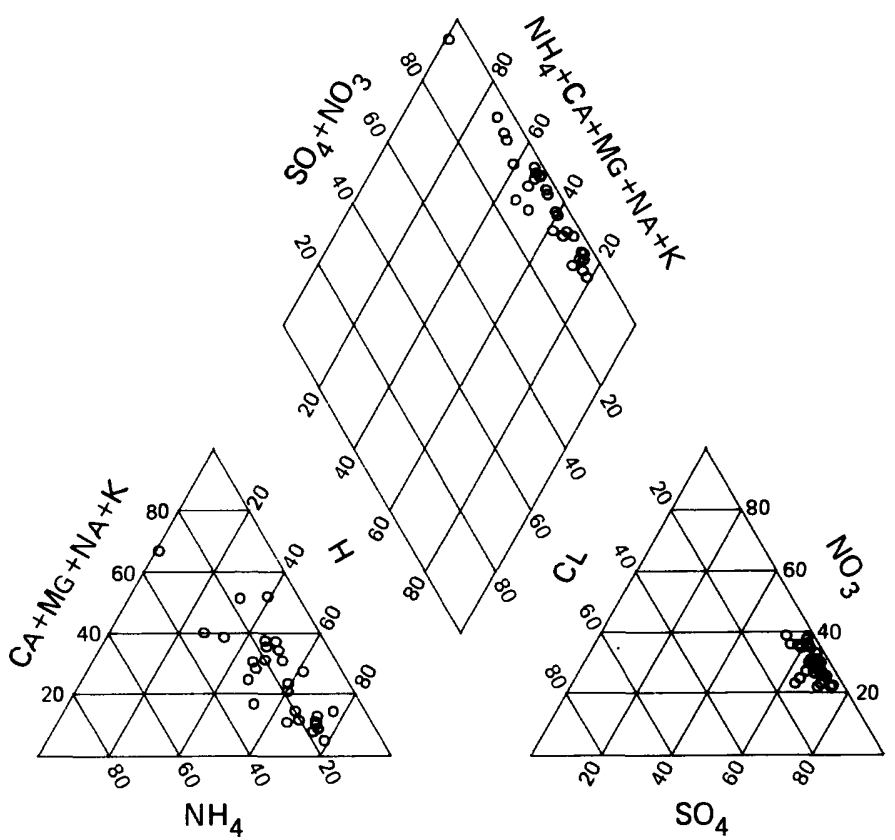

Percentage composition of major ions for site IL47. 


\section{NATIONAL TRENDS NETWORK -- 1983 CALENDER YEAR SUMMARY DATA}

[ppt = precipitation; $\mathrm{mm}=$ millimeters; $\mathrm{cm}=$ centimeters; $\mathrm{mg}=$ milligrams; L = Iiters;

g = grams; $m=$ meter; $\mu s=$ microsiemens; cond = specific conductance

STATION: Huntington, Indiana

CAl number: IN20

ADS number: $343 \mathrm{a} 00$

Station altitude above mean sea level, in meters: 244

Number of sampling intervals (days in parenthesis):

-- With ppt measurements:

-- When ppt occurred:

-- When ppt did not occur:

-- When sample volume was substituted for missing rain gage:

-- With chemical samples:
Latitude: $40^{\circ} 50^{\prime} 24^{\prime \prime}$ Longitude: $85^{\circ} 27^{\prime} 50^{\prime \prime}$

Station summary period: $08 / 22 / 1983$ to $01 / 03 / 1984$

Length of summary period: 18 sampling intervals (134 days)

Percent summary period with ppt measurements: 36.1

Percent summary period with chemical samples or no ppt: 20.8

Percent of total measured ppt with chemical samples: $\quad 74.6$

Percent of total measured ppt in raingage that was

collected in the wet-sample bucket:

65.6

Total measured ppt, in $\mathrm{mm}: 402.2$

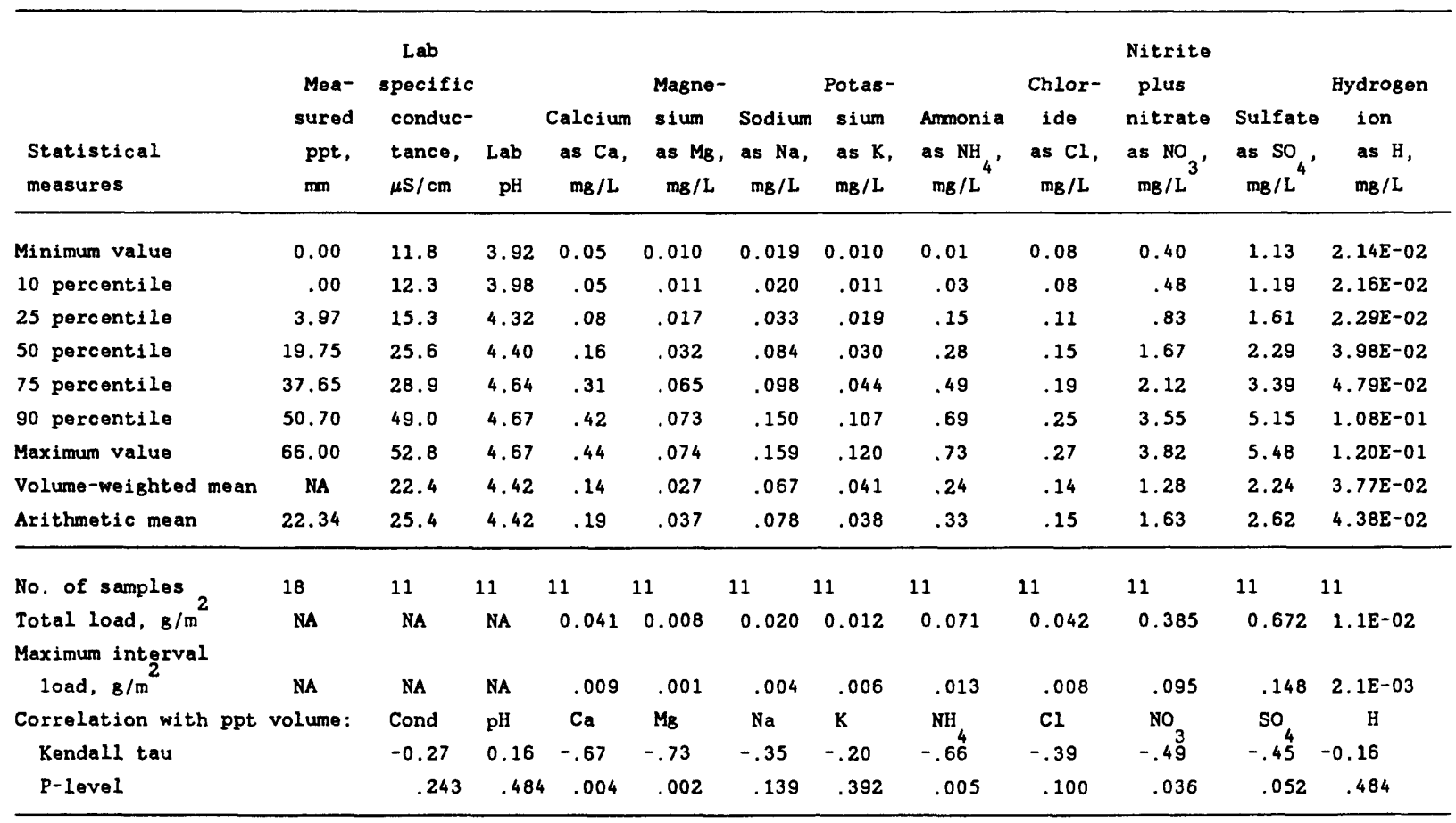

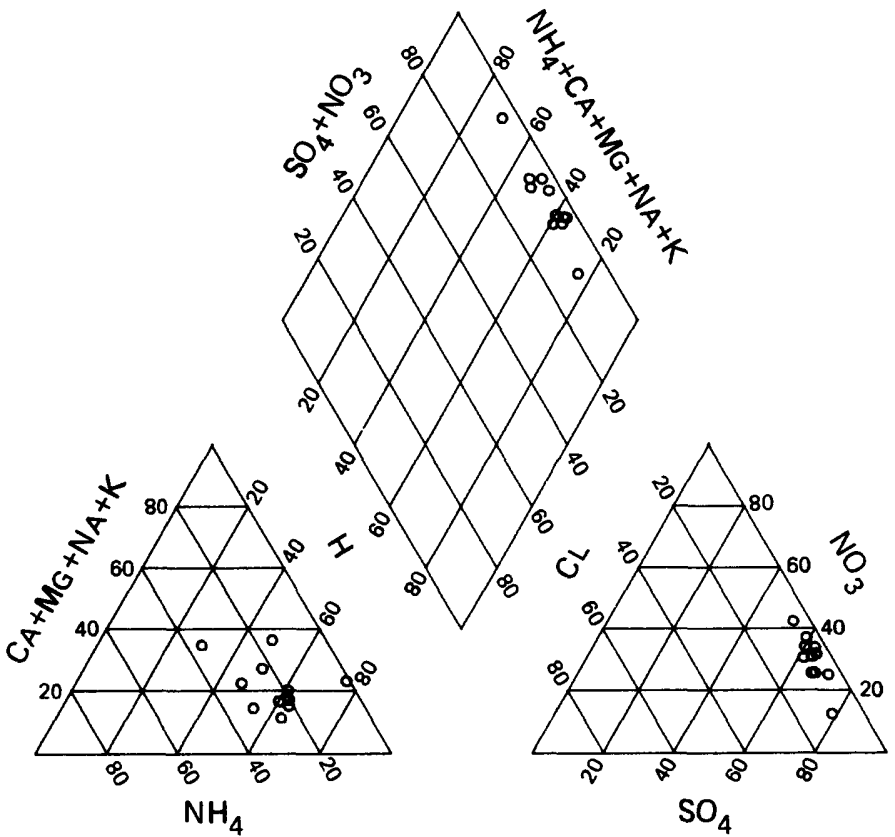

Percentage composition of major ions for site IN20. 


\section{NATIONAL TRENDS NETWORK -- 1983 CALENDER YEAR SUMMARY DATA}

[ppt $=$ precipitation; $\mathrm{mm}=$ millimeters; $\mathrm{cm}=$ centimeters; $\mathrm{mg}=$ milligrams; L = liters; $\mathbf{g}=\mathrm{grams} ; \mathrm{m}=$ meter; $\mu \mathrm{s}=$ microsiemens; cond = specific conductance]

STATION: Perryville, Kentucky

CAL number: KYO3

ADS number: $346 a 00$

Station altitude above mean sea level, in meters: 277 Number of sampling intervals (days in parenthesis)

-- With ppt measurements :

-- When ppt occurred:

-- When ppt did not occur:

-- When sample volume was substituted for missing rain gage:

-- With chemical samples:

Map ID number: 34
Latitude: $37^{\circ} 40^{\prime} 39^{\prime \prime}$ Longitude:

$84^{\circ} 57^{\prime} 25^{\prime \prime}$

Station surmary period: $11 / 29 / 1983$ to $01 / 03 / 1984$

Length of sumary period: 4 sampling intervals ( 35 days)

Percent summary period with ppt measurements: $\quad 9.4$

Percent summary period with chemical samples or no ppt: $\mathbf{7 . 5}$

Percent of total measured ppt with chemical samples: 99.0

Percent of total measured ppt in raingage that was collected in the wet-sample bucket:

98.3

Total meesured ppt, in $\mathrm{mm}: \quad 81.9$

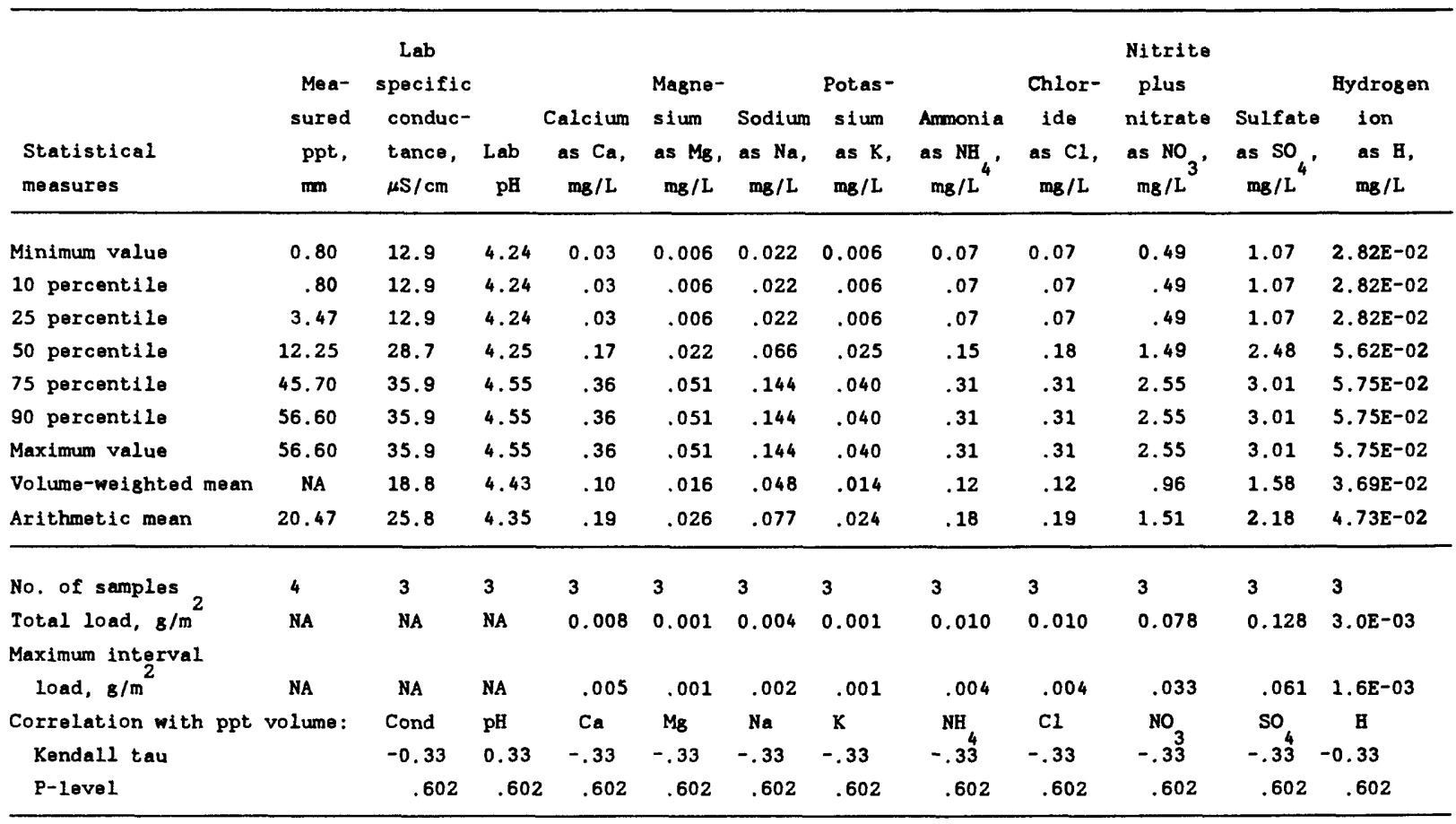

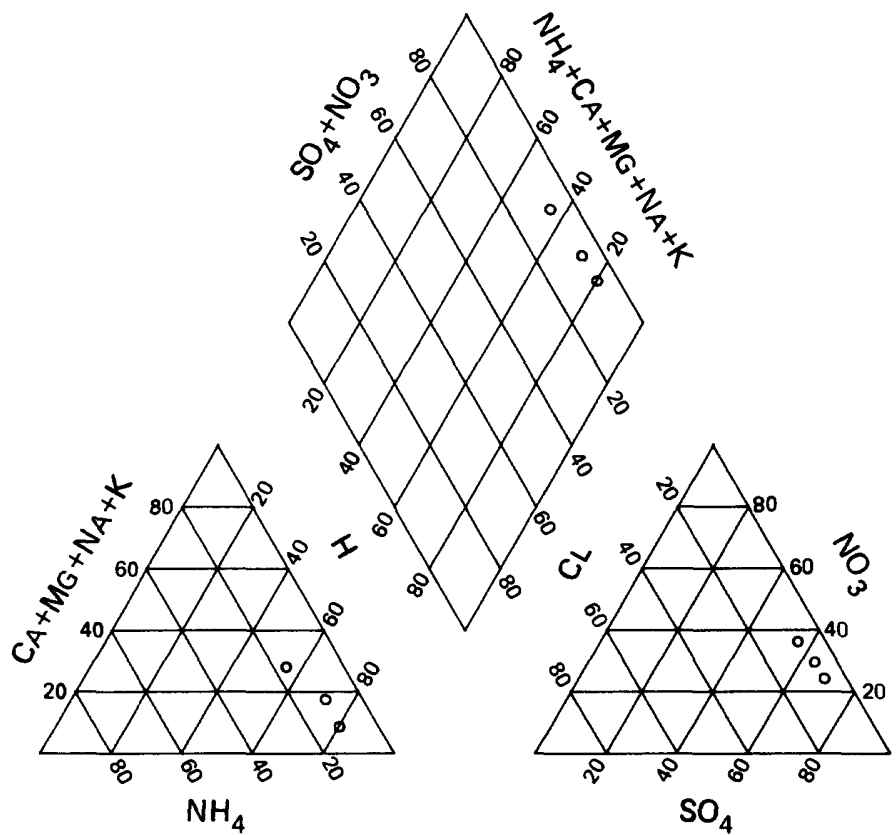

Percentage composition of major ions for site $\mathrm{KYO3}$. 


\section{NATIONAL TRENDS NETWORK - 1983 CALENDER YEAR SUMMARY DATA}

[ppt $=$ precipitation; $\mathrm{mm}=$ millimeters; $\mathrm{cm}=$ centimeters; $\mathrm{mg}=$ milligrams; $\mathrm{L}=$ Liters

$\mathbf{g}=\mathrm{grams} ; \mathrm{m}=$ meter $\boldsymbol{\mu s}=$ microsiemens; cond $=$ specific conductance $]$

STATION: Lilley Cornett Woods, Kentucky

CAL number: KY22

ADS number: $347 \mathrm{a} 00$

Map ID number: 35

Station altitude above mean sea level, in meters: 335

Number of sampling intervals (days in parenthesis):

-- With ppt measurements: $17 \quad$ (119)

-- When ppt occurred: 17 (119)

-- When ppt did not occur:

- When sample volume was substituted for missing rain gage:

- With chemical samples: $14 \quad$ (98)
Latitude: $\quad 37^{\circ} 04^{\prime} 40^{\prime \prime}$ Longitude: $82^{\circ} 59^{\prime} 37^{\prime \prime}$

Station summary period: 09/06/1983 to 01/03/1984

Length of summary period: 17 sampling intervals (119 days)

Percent summary period with ppt measurements:

32.1

Percent summary period with chemical samples or no ppt: 26.4

$\begin{array}{ll}\text { Percent of total measured ppt with chemical samples: } & 92.7\end{array}$

Percent of total measured ppt in raingage that was

collected in the wet-sample bucket:

94.8

Total measured ppt, in m: 220.0

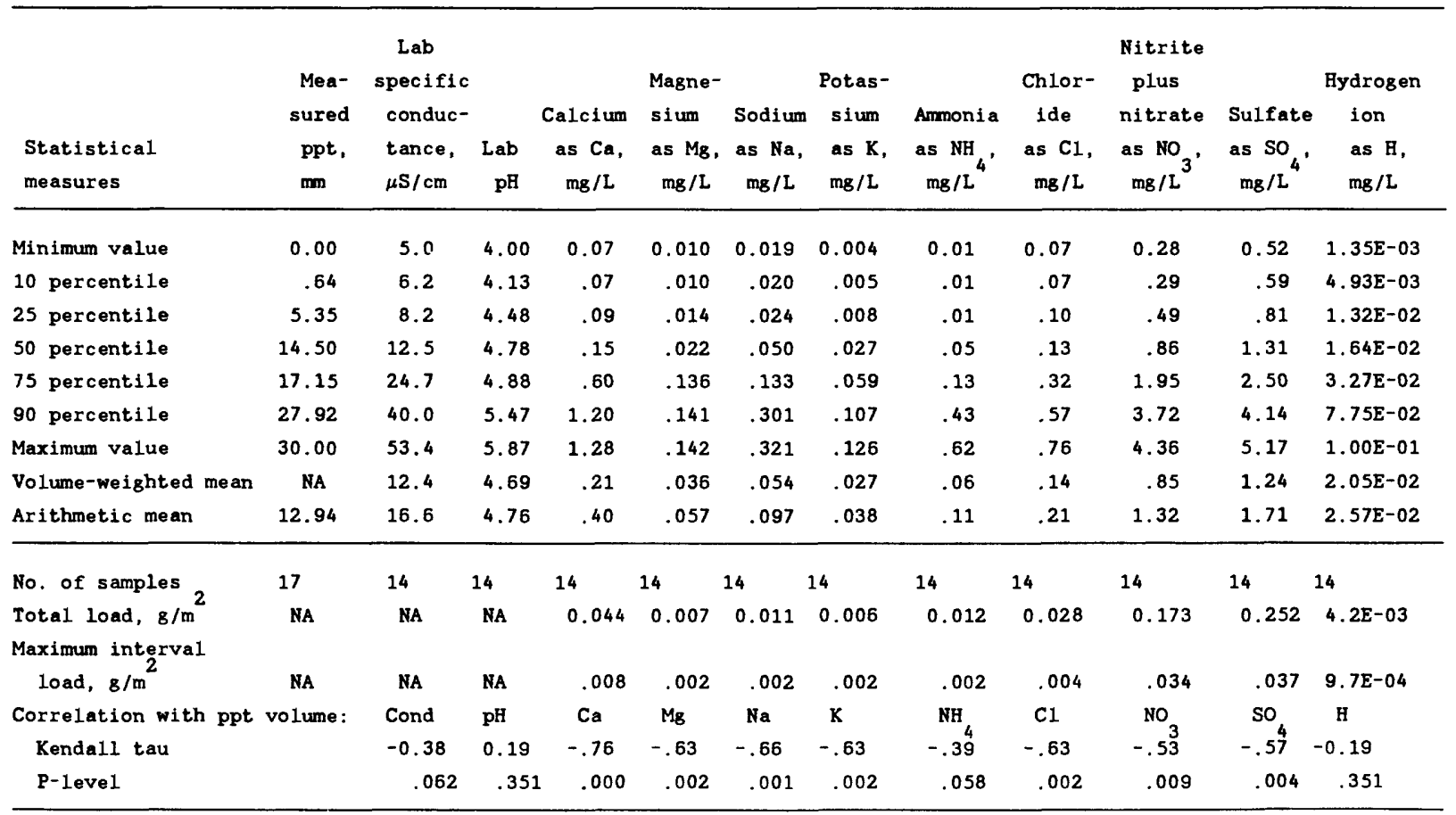

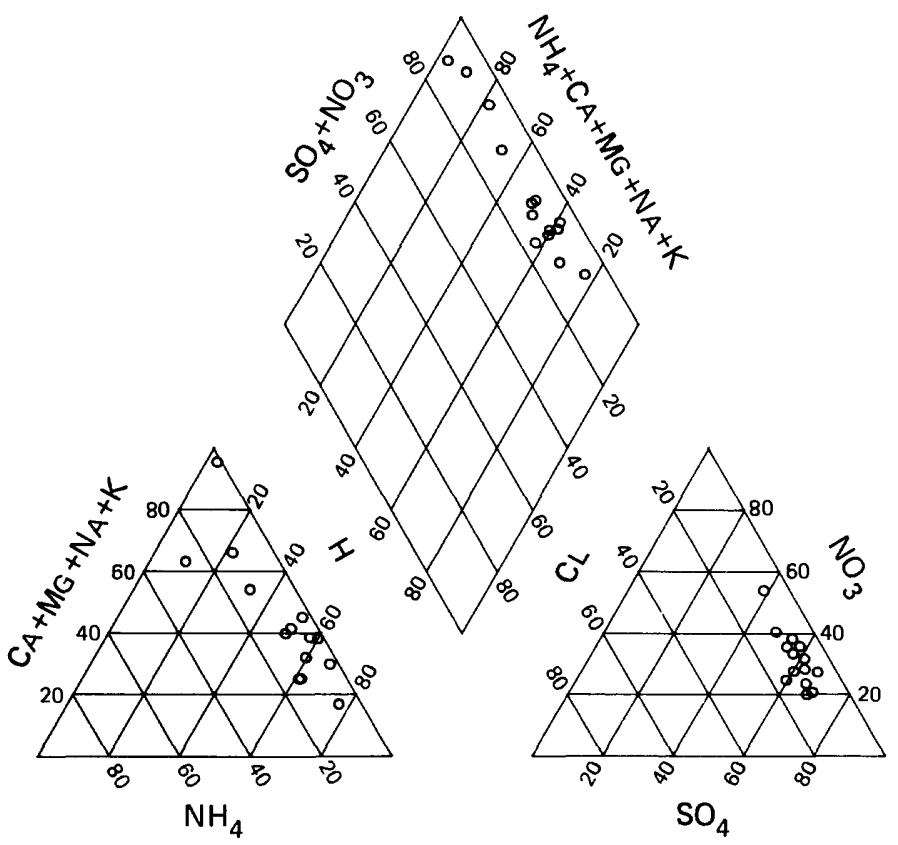

Percentage composition of major ions for site KY22. 
$[$ ppt $=$ precipitation; $\mathrm{mm}=$ millimeters $; \mathrm{cm}=$ centimeters; $\mathrm{mg}=$ milligrams; $\mathrm{L}=1$ iters; $\mathbf{g}=\mathrm{grams} ; \mathrm{m}=$ meter; $\mu \mathrm{s}=$ microsiemens; cond = specific conductance $]$

STATION: Clark State Fish Hatchery, Kentucky

CAL number: KY35

ADS number: $348 \mathrm{a} 00$

Map ID number: 36

Station altitude above mean sea level, in meters: 204 Number of sampling intervals (days in parenthesis):

-- With ppt measurements:

18 (126)

-- When ppt occurred.

(119)

-- When ppt did not occur:

$1(7)$

-- When sample volume was substituted for missing rain gage:

-- With chemical samples:
Latitude: $\quad 38^{\circ} 07^{\prime} 06^{\prime \prime}$ Longitude: $83^{\circ} 32^{\prime} 49^{\prime \prime}$

Station summary period: $08 / 30 / 1983$ to $01 / 03 / 1984$

Length of sumary period: 18 sampling intervals (126 days) Percent summary period with ppt measurements: 34.0 Percent summary period with chemical samples or no ppt: 24.5 Percent of total measured ppt with chemical samples: 85.1 Percent of total measured ppt in raingage that was collected in the wet-sample bucket:

97.9

Total measured ppt, in $\mathrm{mm:} 283.6$

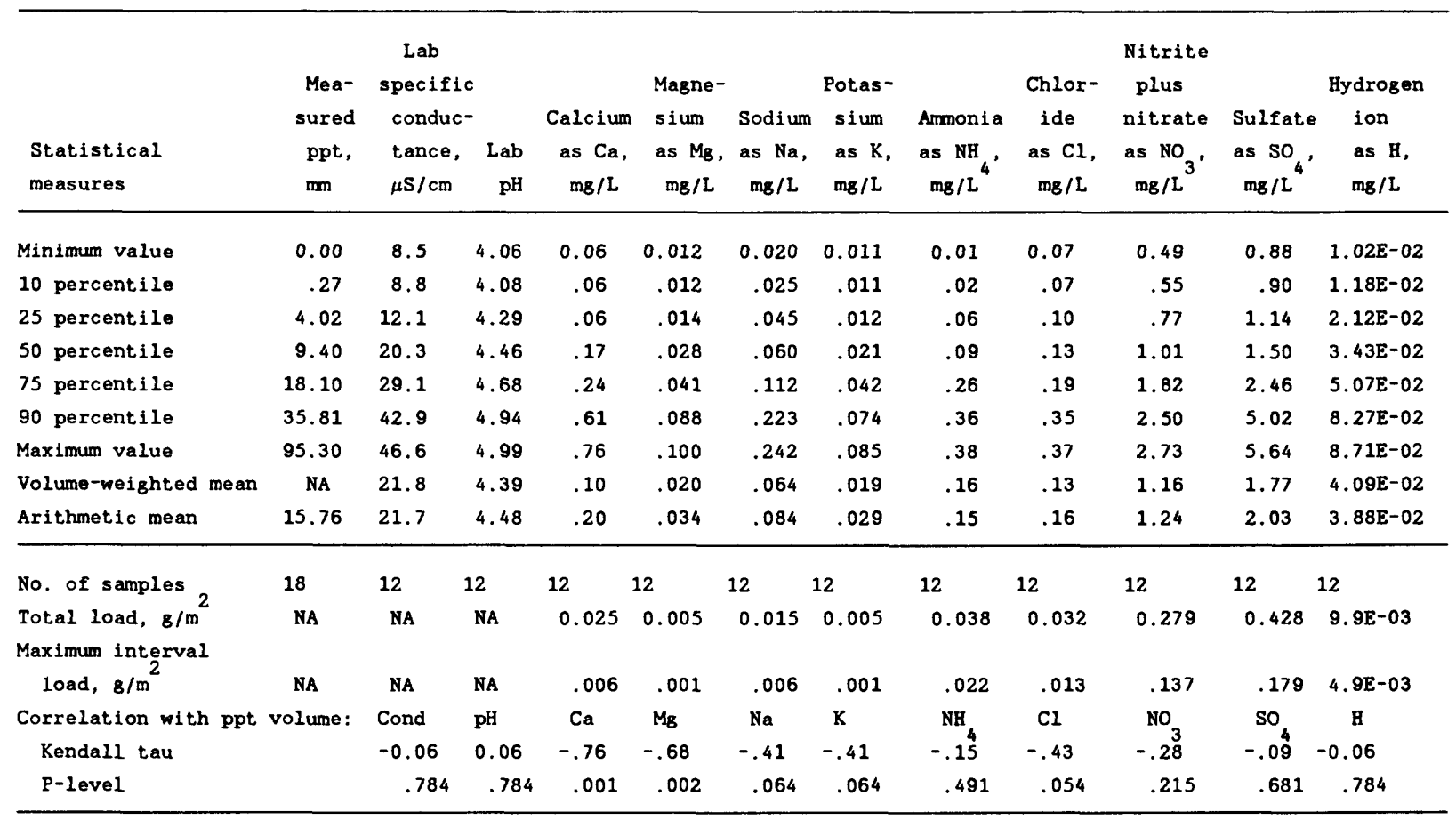

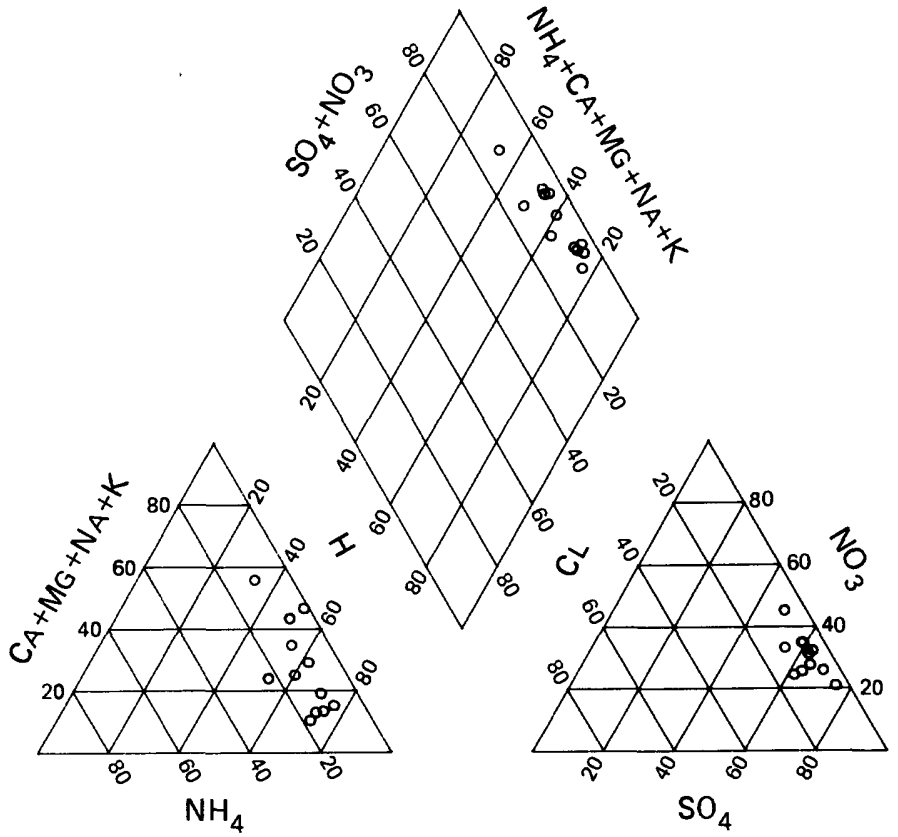

Percentage composition of major ions for site KY35. 


\section{NATIONAL TRENDS NETWORK -- 1983 CALENDER YEAR SUMMARY DATA}

[ppt = precipitation; $\mathrm{mm}=$ millimeters; $\mathrm{cm}=$ centimeters; $\mathrm{mg}=$ milligrams; L = liters;

$\mathbf{g}=$ grams; $\mathrm{m}=$ meter; $\mu \mathrm{s}=$ microsiemens; cond $=$ specific conductance

STATION: Iberie, Louisiana

CAL number: LA12

ADS number: 275a00

Station altitude above mean sea level, in meters: 6

Number of sampling intervals (days in parenthesis):

-- With ppt measurements: $49 \quad$ (364)

-- When ppt occurred: 47 (350)

-- When ppt did not occur: 2 ( 14)

-- When sample volume was substi-

tuted for missing rain gage: 1 ( 7)

-- With chemical samples: 23 (169)
Latitude: $29^{\circ} 55^{\prime} 47^{\prime \prime}$ Longitude: $91^{\circ} 42^{\prime} 54^{\prime \prime}$

Station summary period: $12 / 21 / 1982$ to $01 / 03 / 1984$

Length of summary period: 50 sampling intervals ( 378 days)

Percent summary period with ppt measurements:

98.1

Percent summary period with chemical samples or no ppt: 49.3

Percent of total measured ppt with chemical samples: $\quad 55.0$

Percent of total measured ppt in raingage that was

collected in the wet-sample bucket:

99.5

Total measured ppt, in m: 1728.6

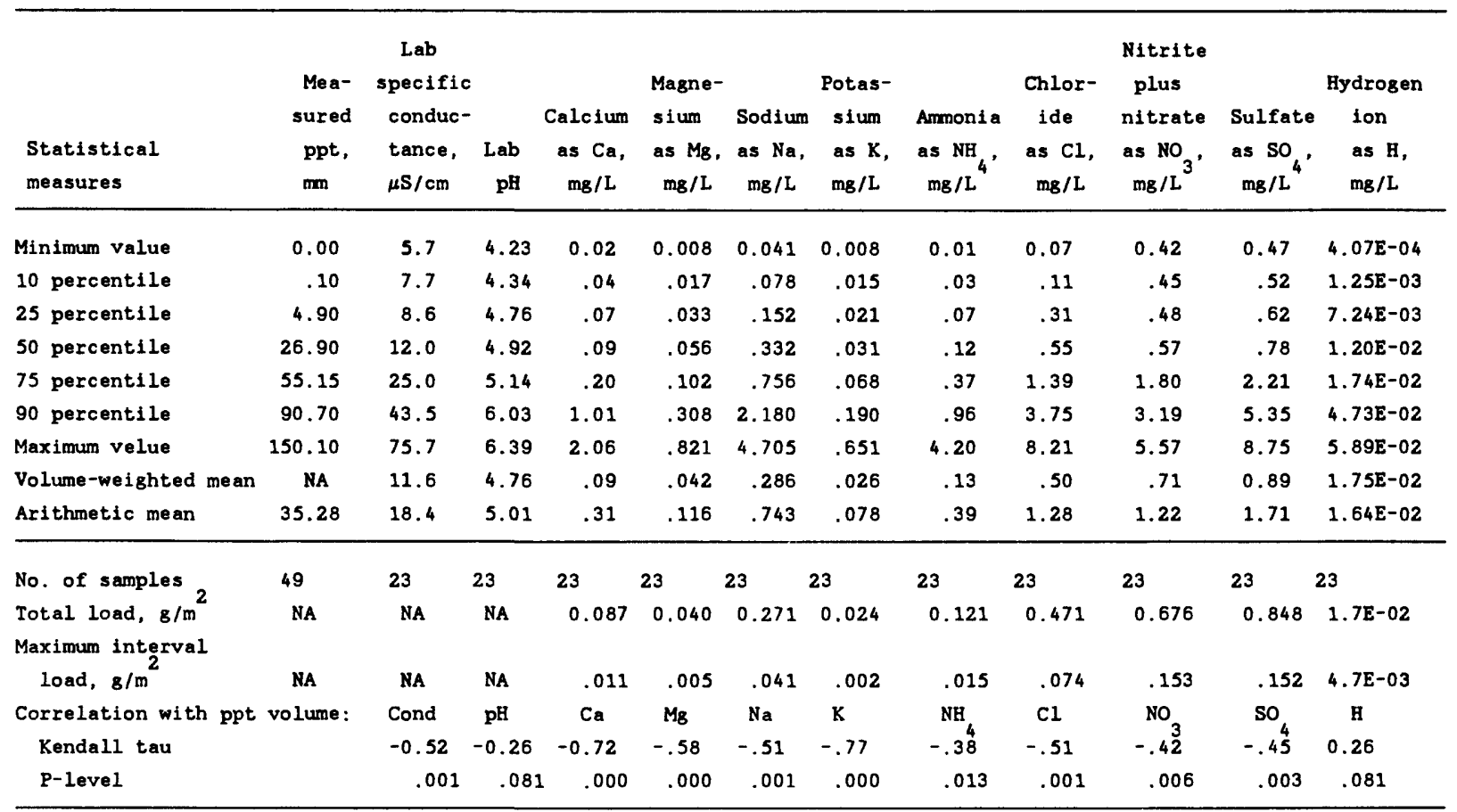

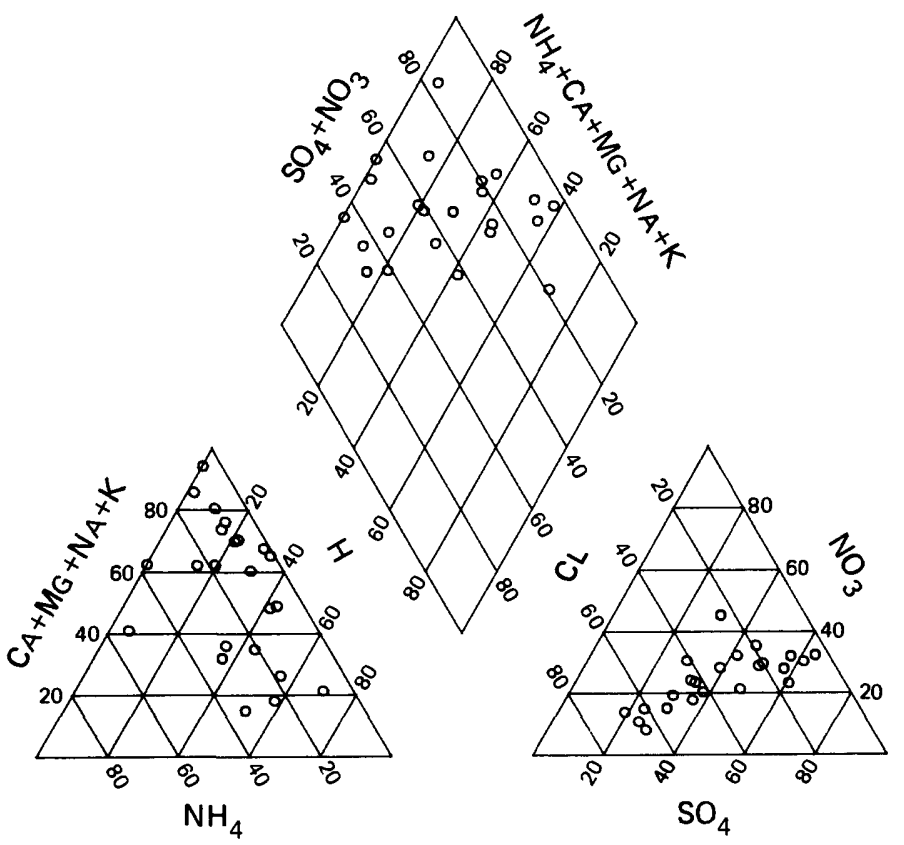

Percentage composition of major ions for site LA12. 
[ppt = precipitation; $\mathrm{mm}=$ millimeters; $\mathrm{cm}=$ centimeters; $\mathrm{mg}=\mathrm{milligrams;} \mathrm{L=11ters;}$

$g=$ grams; $m=$ meter; $\mu \mathrm{s}=$ microsiemens; cond = specific conductance]

STATION: Southeast Reasearch Station, Louisiana

Lat1tude: $30^{\circ} 48^{\prime} 41^{\prime \prime}$ Longitude: $90^{\circ} 10^{\prime} 51^{\prime \prime}$
CAL number: LA30

ADS number: 349 a00

Station altitude above mean sea level, in meters: 78 Number of sampling intarvals (days in parenthesis):

-- With ppt measuremants:

-- When ppt occurred:

-- Whan ppt did not occur:

- Whan sampla volume was substituted for missing rain gaga:

-- With chamical samples:

Map ID number: 38
Station summary period: $01 ! 18 / 1983$ to $01 / 03 / 1984$

Length of sumary perioi: 4? sampling intervals (350 days)

Percent surmary period with ppt measurements:

92.4

Percent summary period with chemical samples or no ppt: 56.1

Parcent of total measured ppt with chemical samples: 58.2

Percent of total measured ppt in rsingage that was

collected in the wet-sample bucket:

98.6

Total measured ppt, in m: 1855.1

\begin{tabular}{|c|c|c|c|c|c|c|c|c|c|c|c|c|}
\hline \multirow[b]{2}{*}{$\begin{array}{l}\text { Statistical } \\
\text { measures }\end{array}$} & \multirow[b]{2}{*}{$\begin{array}{l}\text { Mea- } \\
\text { surad } \\
\text { ppt, } \\
\text { mm }\end{array}$} & \multirow{2}{*}{$\begin{array}{c}\text { Lab } \\
\text { specific } \\
\text { conduc- } \\
\text { tance, } \\
\mu \mathrm{S} / \mathrm{cm}\end{array}$} & \multirow[b]{2}{*}{ Lab } & \multirow[b]{2}{*}{$\begin{array}{c}\text { Calcium } \\
\text { as Ca, } \\
\text { mg/L }\end{array}$} & \multirow[b]{2}{*}{$\begin{array}{l}\text { Magne- } \\
\text { sium } \\
\text { as Mg, } \\
\mathrm{mg} / \mathrm{L}\end{array}$} & \multirow[b]{2}{*}{$\begin{array}{l}\text { Sodium } \\
\text { as } \mathrm{Na} \text {, } \\
\mathrm{mg} / \mathrm{L}\end{array}$} & \multirow[b]{2}{*}{$\begin{array}{l}\text { Potas- } \\
\text { sium } \\
\text { as } K \text {, } \\
\text { mg/L }\end{array}$} & \multirow[b]{2}{*}{$\begin{array}{l}\text { Ammonia } \\
\text { as } \mathrm{NH}_{4^{\prime}} \\
\mathrm{mg} / \mathrm{L}^{\circ}\end{array}$} & \multirow[b]{2}{*}{$\begin{array}{c}\text { Chlor- } \\
\text { Ide } \\
\text { as Cl, } \\
\mathrm{mg}_{\mathrm{g}} / \mathrm{L}\end{array}$} & $\begin{array}{c}\text { Nitrite } \\
\text { plus } \\
\text { nitrate }\end{array}$ & \multirow[b]{2}{*}{$\begin{array}{l}\text { Sulfate } \\
\text { as } \mathrm{SO}^{\prime} \\
\mathrm{mg} / \mathrm{L}^{\prime}\end{array}$} & \multirow[b]{2}{*}{$\begin{array}{l}\text { Hydrogen } \\
\text { Ion } \\
\text { as } \mathrm{B}, \\
\text { mg/L }\end{array}$} \\
\hline & & & & & & & & & & $\begin{array}{l}\text { plus } \\
\text { nitrate } \\
\text { as } \mathrm{NO}_{3} \text {, } \\
\mathrm{mg} / \mathrm{L}^{3}\end{array}$ & & \\
\hline Minimum value & 0.00 & 6.8 & 4.29 & 0.02 & 0.006 & 0.044 & 0.008 & 0.05 & 0.07 & 0.41 & 0.39 & $9.12 \mathrm{E}-04$ \\
\hline 10 percentile & .17 & 8.5 & 4.43 & .03 & .015 & .063 & .012 & .09 & .17 & .43 & .68 & $3.66 \mathrm{E}-03$ \\
\hline 25 percentile & 9.37 & 10.4 & 4.58 & .08 & .032 & .175 & .025 & .15 & .27 & .57 & .97 & $7.50 \mathrm{E}-03$ \\
\hline 50 percentile & 29.85 & 13.9 & 4.82 & .13 & .052 & .314 & .042 & .20 & .47 & .88 & 1.22 & $1.51 E-02$ \\
\hline 75 percentile & 62.70 & 19.3 & 5.12 & .21 & .111 & .819 & .058 & .29 & 1.37 & 1.31 & 1.51 & 2. $60 \mathrm{E}-02$ \\
\hline 90 parcentile & 89.91 & 23.9 & 5.44 & .39 & .156 & 1.101 & .107 & .42 & 2.01 & 1.72 & 2.62 & $3.74 \mathrm{E}-02$ \\
\hline Maximum value & 185.90 & 29.1 & 6.04 & .60 & .199 & 1.350 & .289 & 2.03 & 2.32 & 2.29 & 3.20 & $5.13 E-02$ \\
\hline Volume-weightad mean & NA & 12.4 & 4.82 & .12 & .053 & .360 & .041 & .22 & .63 & .76 & 1.10 & $1.52 E-02$ \\
\hline No. of samples & 46 & 25 & 25 & 25 & 25 & 25 & 25 & 25 & 25 & 25 & 25 & 25 \\
\hline Total load, $\mathrm{g} / \mathrm{m}^{2}$ & NA & NA & NA & 0.129 & 0.057 & 0.388 & 0.044 & 0.242 & 0.679 & 0.817 & 1.193 & $1.6 E-02$ \\
\hline $\begin{array}{l}\text { Maximum interval } \\
\text { load, } 8 / \mathrm{m}^{2}\end{array}$ & NA & NA & NA & .024 & .010 & .072 & .012 & .070 & .124 & .110 & 0.160 & $2.6 \mathrm{E}-03$ \\
\hline $\begin{array}{l}\text { Correlation with ppt } \\
\text { Kendall tau }\end{array}$ & volume: & $\begin{array}{l}\text { Cond } \\
-0.43\end{array}$ & $\begin{array}{l}\mathrm{pH} \\
0.07\end{array}$ & $\begin{array}{c}\text { Ca } \\
-.33\end{array}$ & $\begin{array}{l}\mathrm{MB}_{B} \\
-.37\end{array}$ & $\begin{array}{c}\mathrm{Na} \\
-.24\end{array}$ & $\begin{array}{l}\mathrm{K} \\
-.31\end{array}$ & $\begin{array}{l}\mathrm{NH}^{4} \\
-.35\end{array}$ & $\begin{array}{c}C 1 \\
-.22\end{array}$ & $\begin{array}{l}\mathrm{NO}_{3} \\
-.42\end{array}$ & $\begin{array}{l}\text { so } \\
-.30^{4}\end{array}$ & $\begin{array}{c}\text { H } \\
-0.07\end{array}$ \\
\hline P-level & & .003 & .624 & .023 & .011 & .097 & .030 & .015 & .129 & .003 & .038 & .624 \\
\hline
\end{tabular}

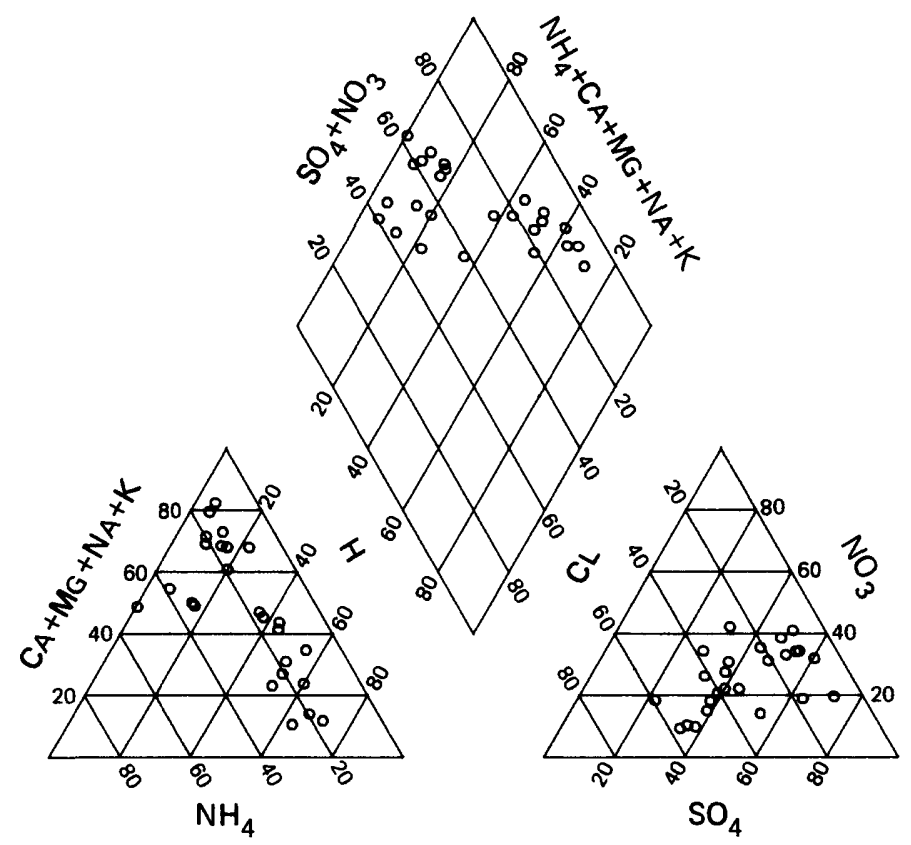

Percentage composition of major ions for site LA30. 
[ppt = precipitation; $\mathrm{mm}=$ millimeters; $\mathrm{cm}=$ centimeters; mg $=$ milligrams; $\mathrm{L}=11$ ters;

$\mathrm{g}=\mathrm{grams} ; \mathrm{m}=$ meter; $\mu \mathrm{s}=$ microsiemens; cond $=$ specific conductance $]$

STATION: Cadwell, Massachusetts

CAL number: MAOB

ADS number: $276 a 00$

Map ID number: 39

Station altitude above mean sea level, in meters: 283

Number of sampling intervals (days in parenthesis):
Latitude: $42^{\circ} 21^{\prime} 40^{\prime \prime}$ Longitude:

$72^{\circ} 23^{\prime} 27^{\prime \prime}$

Station summary period: $12 / 28 / 1982$ to $01 / 03 / 1984$

Length of summary period: 52 sampling intervals ( 371 days)

Percent summary period with ppt measurements:

100.0

-- With ppt measurements:

52 (371)

50 (357)

Percent summary period with chemical samples or no ppt:

47.2

-- When ppt occurred:

Percent of total measured ppt with chemical samples:

36.5

-- When ppt did not occur:

$2(14)$

-- When sample volume was substi-

Percent of total measured ppt in raingage that was

collected in the wet-sample bucket:

93.2

-- With chemical samples: 23 (161)

Total measured ppt, in $\mathrm{mm}: 1512.6$

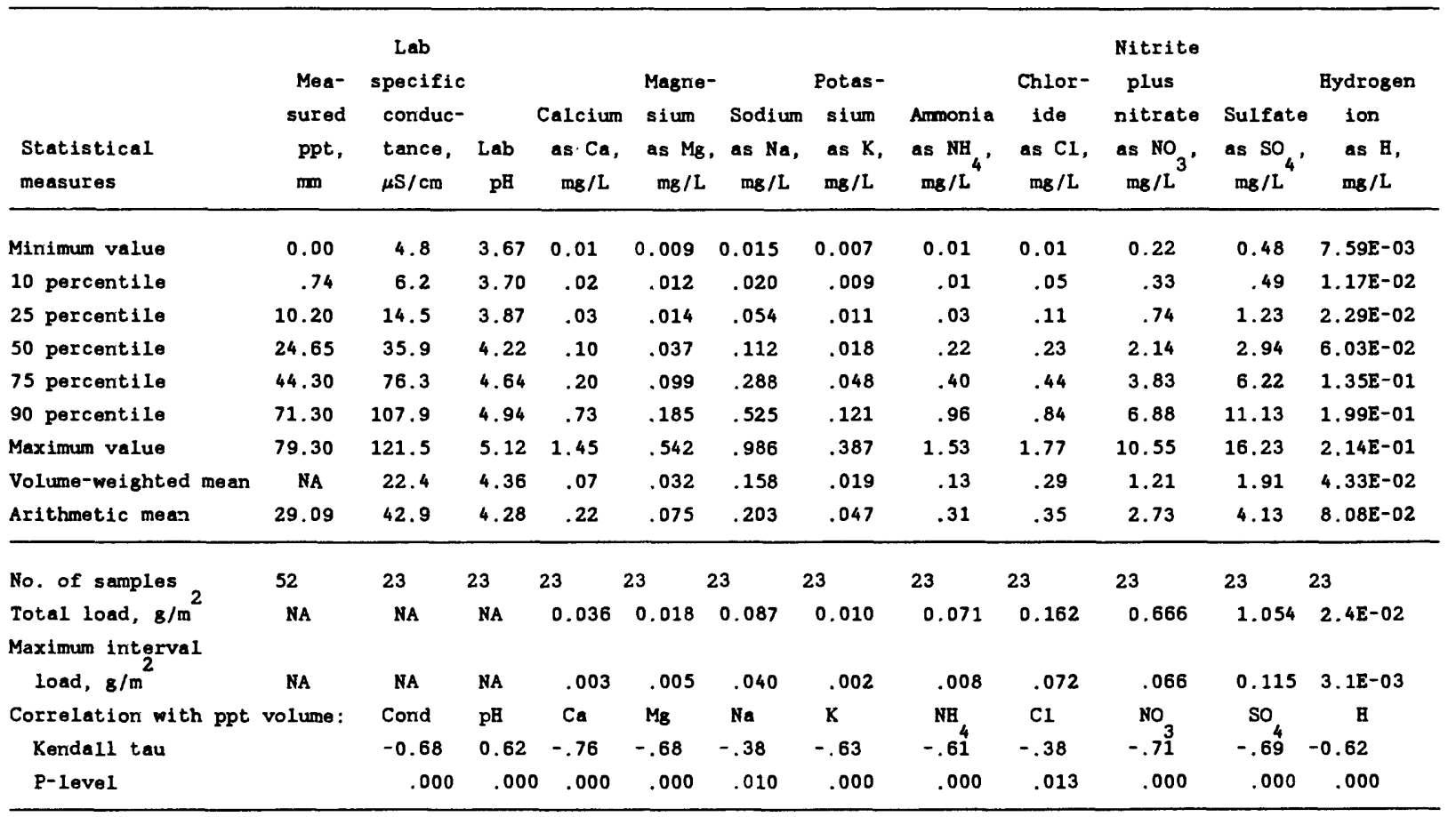

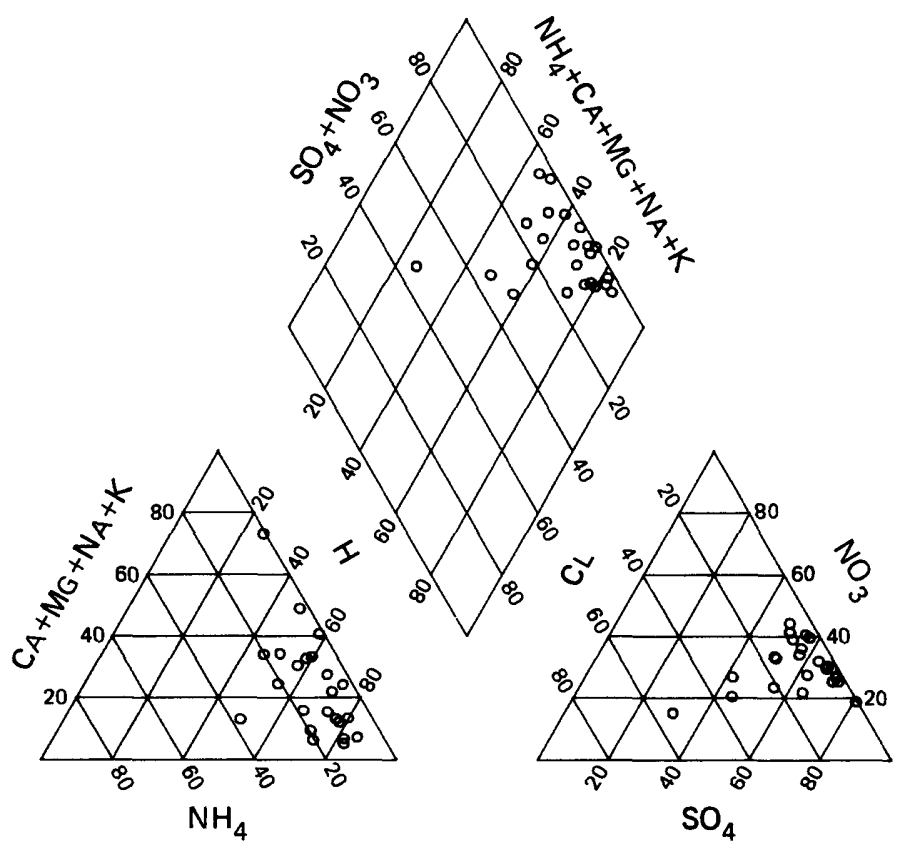

Percentage composition of major ions for site MA08. 
Ippt $=$ precipitation; $\mathrm{mm}=$ millimeters; $\mathrm{cm}=$ centimeters; $\mathrm{mg}=\mathrm{milligrams;} \mathrm{L}=1 \mathrm{iters}$; $\mathrm{B}=\mathrm{grams} ; \mathrm{m}=$ meter $; \mu \mathrm{s}=$ microsiemens; cond $=$ specific conductance $]$

STATION: Wye, Maryland

CAL number: MD13

ADS number: $350 \mathrm{a} 00$

Station altitude above mean sea level, in meters: 6 Number of sampling intervals (days in parenthesis):

-- With ppt measurements:

43 (301)

-- When ppt occurred:

-- When ppt did not occur:

41 (287)

$2(14)$

-- When sample volume was substituted for missing rain gage:

-- With chemical samples:
Latitude: $38^{\circ} 54^{\prime 4} 7^{\prime \prime}$ Longitude: $76^{\circ} 09^{\prime} 09^{\prime \prime}$

\section{Station summary period: $03 / 08 / 1983$ to $01 / 03 / 1984$}

Length of summary period: 43 sampling intervals ( 301 days)

Percent summary period with ppt measurements:

81.1

Percent summary period with chemical samples or no ppt: 71.7

Percent of total measured ppt with chemical samples: $\quad 90.5$

Percent of total measured ppt in raingage that was

collected in the wet-sample bucket:

97.0

Total measured ppt, in $\mathrm{mm}: 1134.3$

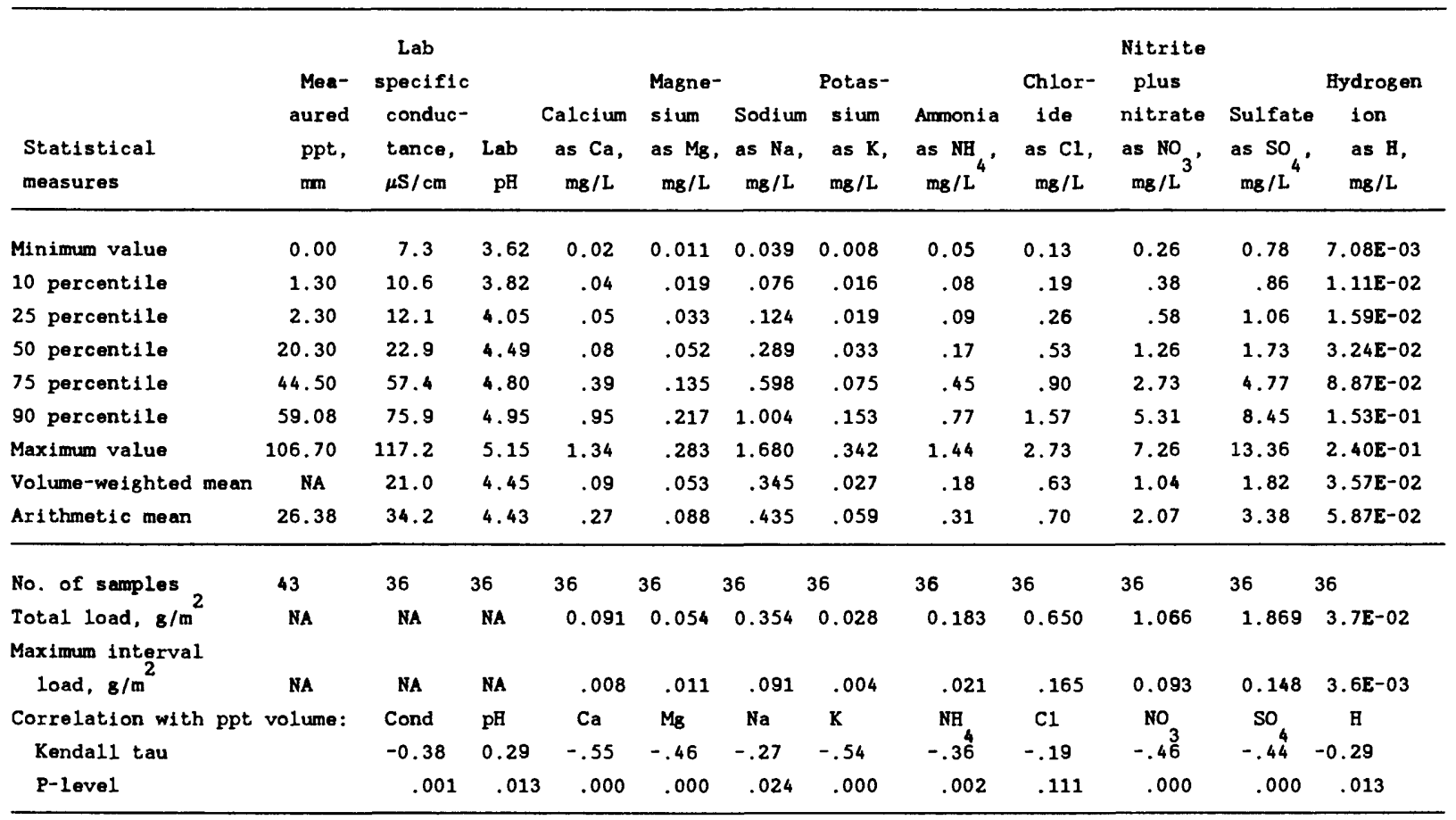

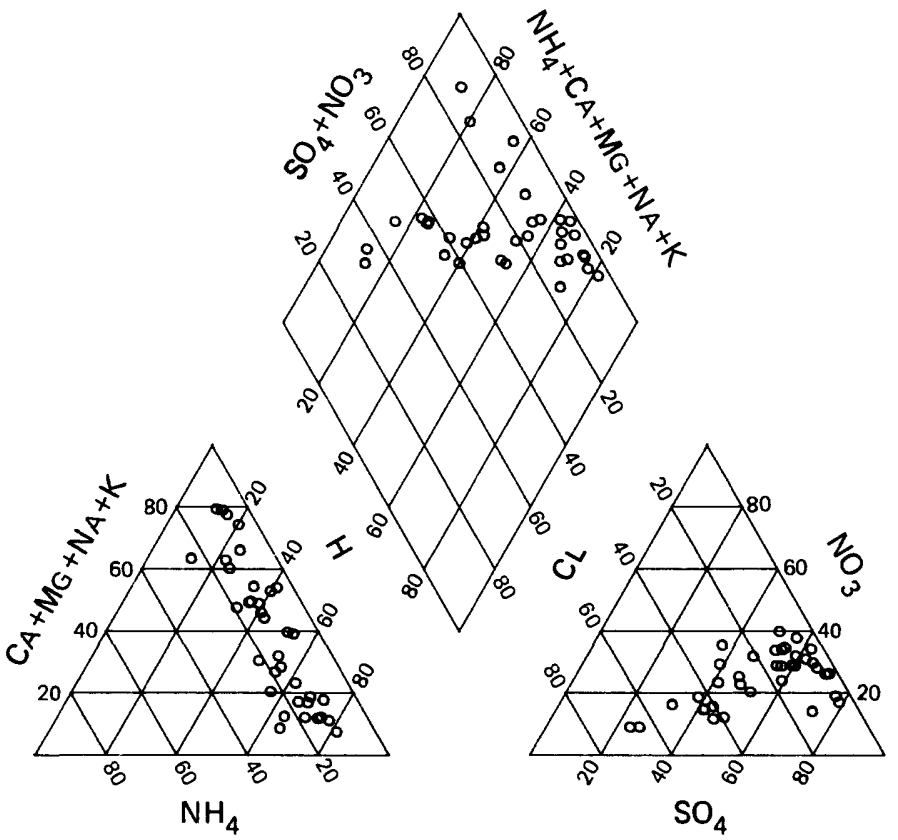

Percentage composition of major ions for site MD13. 
lppt = precipitation; $\mathrm{mm}=$ millimeters; $\mathrm{cm}=$ centimeters; $\mathrm{mg}=$ milligrams; L $=11$ ters;

8 - grams; $m$ = meter; $\mu s=$ microsiemens; cond = specific conductance $]$

STATION: Greenville Station, Maine

CAL number: MEO9

ADS number: 030201

Map ID number: 43

Station altitude above mean sea level, in meters: 322

Number of sampling intervals (days in parenthesis):

-- With ppt measurements: $53 \quad$ (371)

-- When ppt occurred: 53 (371)

-- When ppt did not occur:

( 0$)$

-- When sample volume was substituted for missing rain gage:

-- With chemical samples:

Latitude: $45^{\circ} 29^{\prime} 23^{\prime \prime}$ Longitude:

$69^{\circ} 39^{\prime} 52^{\prime \prime}$

Station summary period: $12 / 28 / 1982$ to $01 / 03 / 1984$

Length of sumary period: 53 sampling intervals ( 371 days)

Percent summary period with ppt measurements:

100.0

Percent summary period with chemical samples or no ppt: 52.8

Percent of total measured ppt with chemical samples: 60.3

Percent of total measured ppt in raingage that was

collected in the wet-sample bucket:

89.4

Total measured ppt, in m: 1453.4

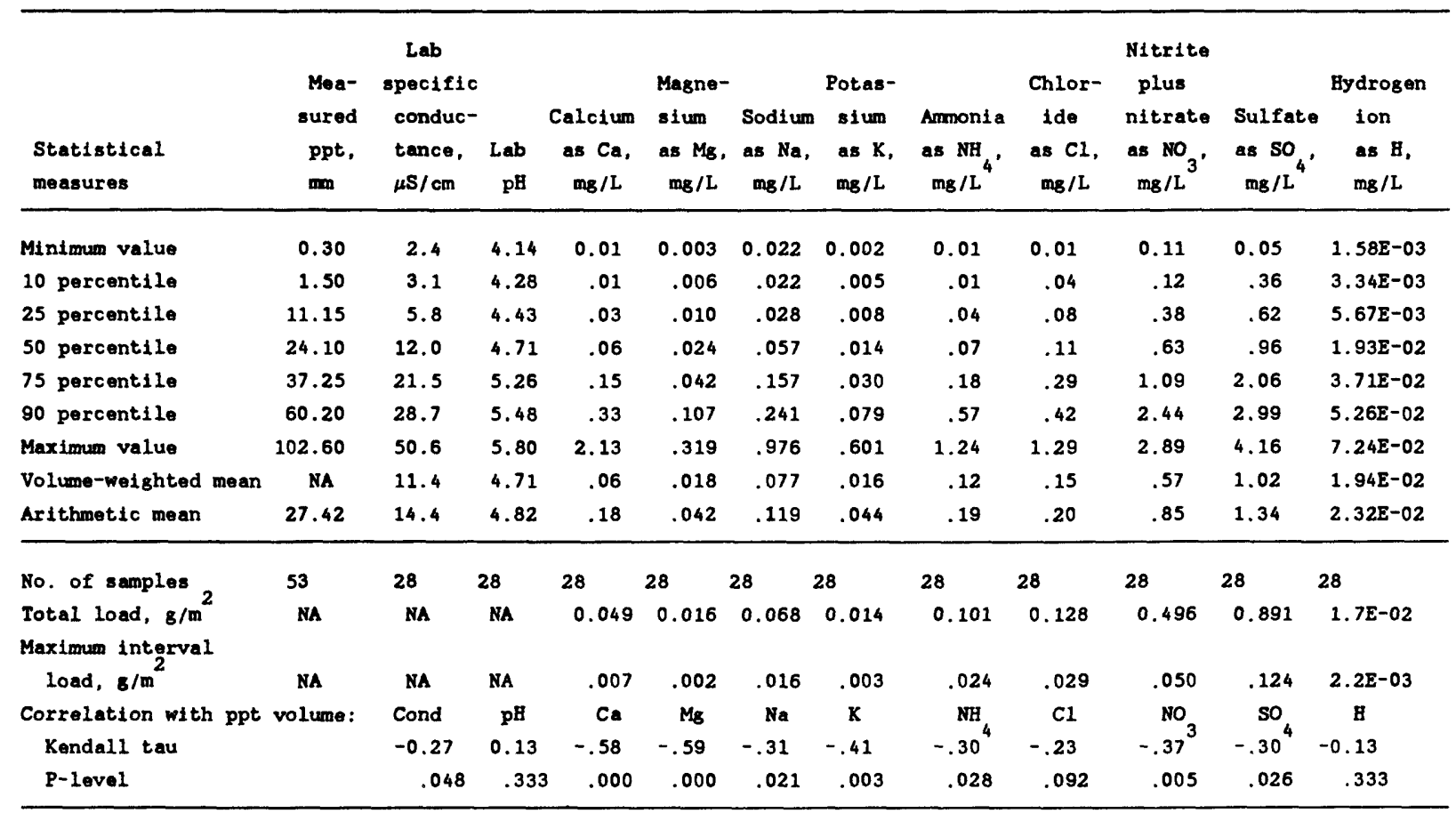

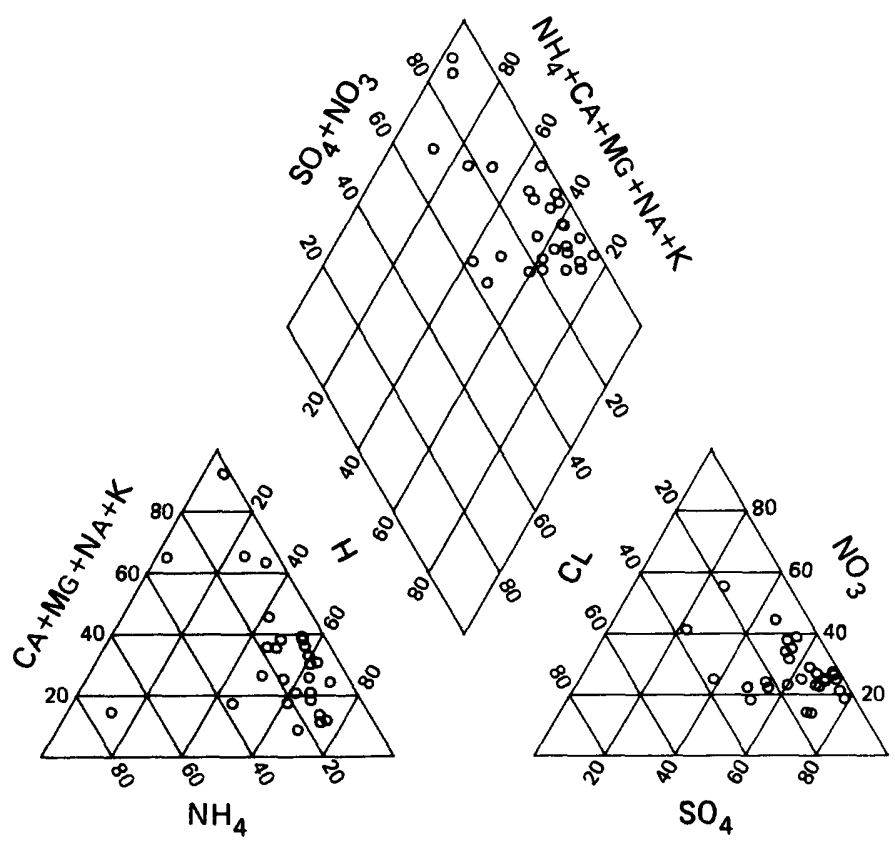

Percentage composition of major ions for site ME09. 


\section{NATIONAL TRENDS NETWORK -- 1983 CALENDER YEAR SUMMARY DATA}

lppt = precipitetion; $\mathrm{mm}=$ millimeters; $\mathrm{cm}=$ centimeters; ms = milligrams; L = liters;

$8=$ grams; $m=$ meter; $\mu s=$ microsiemens; cond = specific conductance

STATION: Acadia National Park, Maine

CAL number: ME98

ADS number: 257 s00

Map ID number: 44

Station altitude sbove mean see level, in meters: 122

Number of sampling intervals (days in parenthesis):

-- With ppt measurements :

-- When ppt occurred:

-- When ppt did not occur:

53 (365)

52 (358)

$1(7)$

-- When sample volume was substituted for missing rsin gage: 0 ( 0$)$

-- With chemical samples: $30 \quad$ (210)
Latitude: $44^{\circ} 22^{\prime} 27^{\prime \prime}$ Longitude: $68^{\circ} 15^{\prime} 39^{\prime \prime}$

Station summary period: $12 / 29 / 1982$ to $01 / 03 / 1984$

Length of summary pertod: 54 sampling intervals ( 370 days) Percent summery period with ppt measurements: 98.4 Percent summary period with chemical samples or no ppt: 58.5 Percent of total measured ppt with chemical samples: 47.7

Percent of total measured ppt in reingage that was collected in the wet-sample bucket:

92.8

Totsl messured ppt, in mm: 1936.2

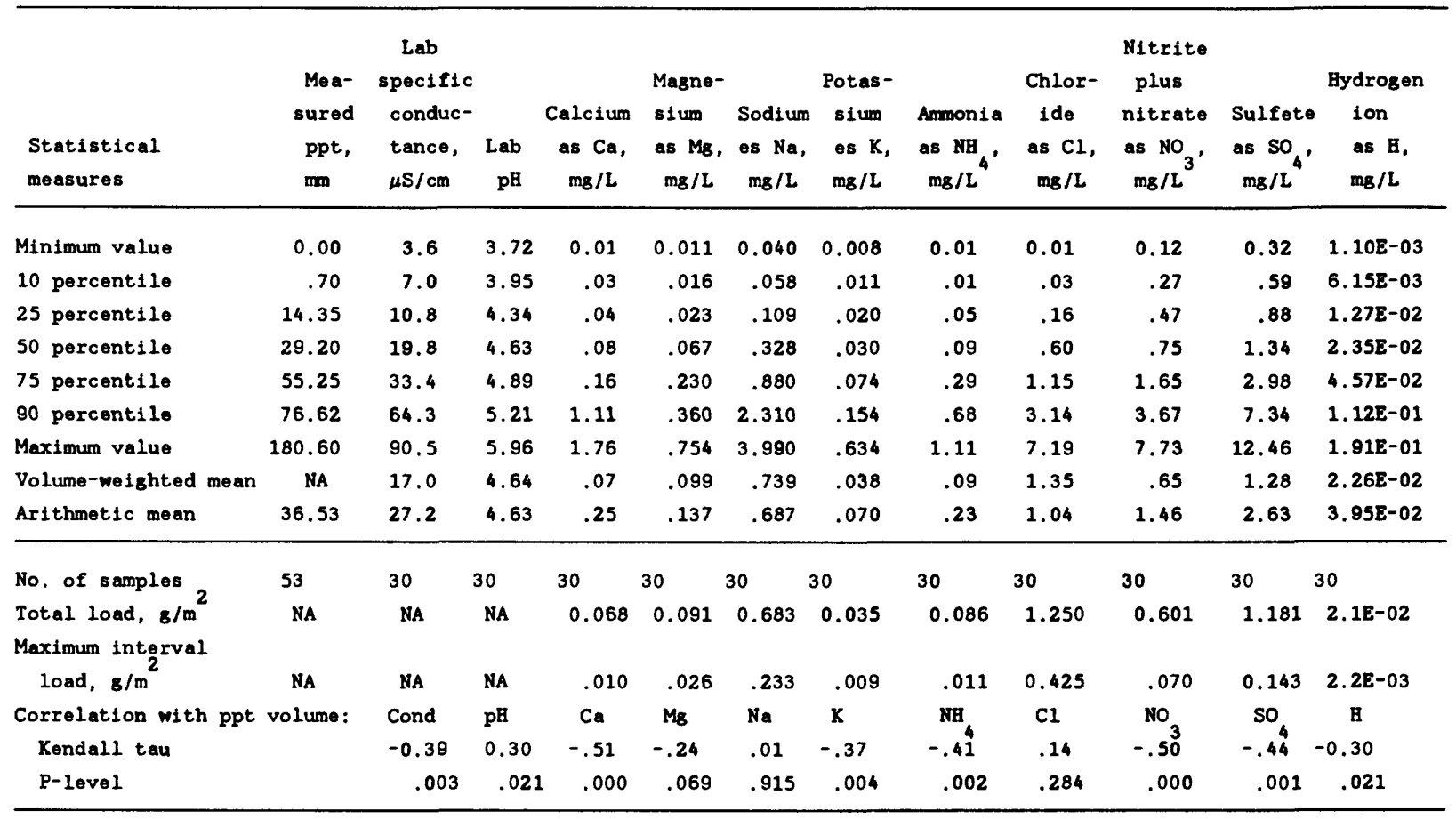

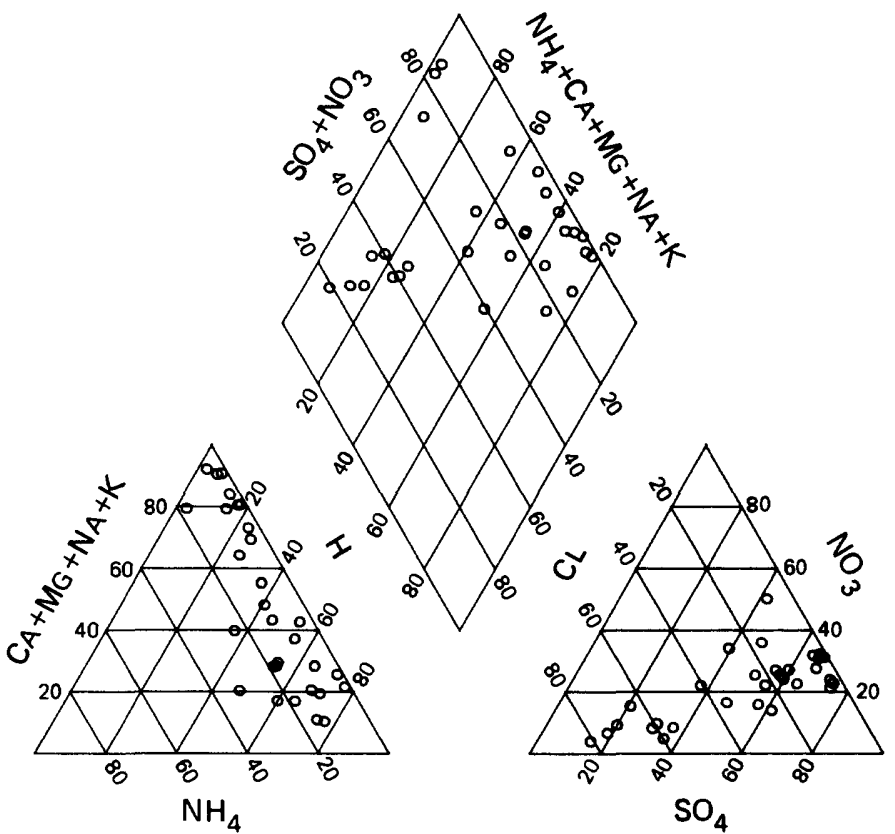

Percentage composition of major ions for site ME98. 


\section{NATIONAL TRENDS NETWORK -- 1983 CALENDER YEAR SUMMARY DATA}

lppt $=$ precipitation; $\mathrm{mm}=$ millimeters; $\mathrm{cm}=$ centimeters; $\mathrm{mg}=$ milligrams; L = liters;

8 = $\mathrm{grams} ; \mathrm{m}=$ meter; $\mu \mathrm{s}=$ microsiemens; cond = specific conductance $]$

STATION: Douglas Lake, Michigan

CAL number: MI09

ADS number: 031 a00

Station altitude above mean sea level, in meters: 233

Number of sampling intervals (days in parenthesis):

- With ppt measurements:

-- When ppt occurred.

-- When ppt did not occur:

-- When sample volume was substituted for missing rain gage:

-- With chemical samplea:

$\begin{array}{rr}52 & (371) \\ 50 & (357) \\ 2 & (14) \\ 0 & (0) \\ 29 & (211)\end{array}$

Lat1tude: $45^{\circ} 33^{\prime} 40^{\prime \prime}$ Long1tude: $84^{\circ} 40^{\prime} 42^{\prime \prime}$

Station summary period: $12 / 28 / 1982$ to $01 / 03 / 1984$

Length of summary period: 52 sampling intervals ( 371 days)

Percent sumary period with ppt measurements: 100.0

Percent summary period with chemical samples or no ppt: 60.6

Percent of total measured ppt with chemical samples: 65.6

Percent of total measured ppt in raingage that was

collected in the wet-sample bucket:

98.0

Total measured ppt, in m: 910.5

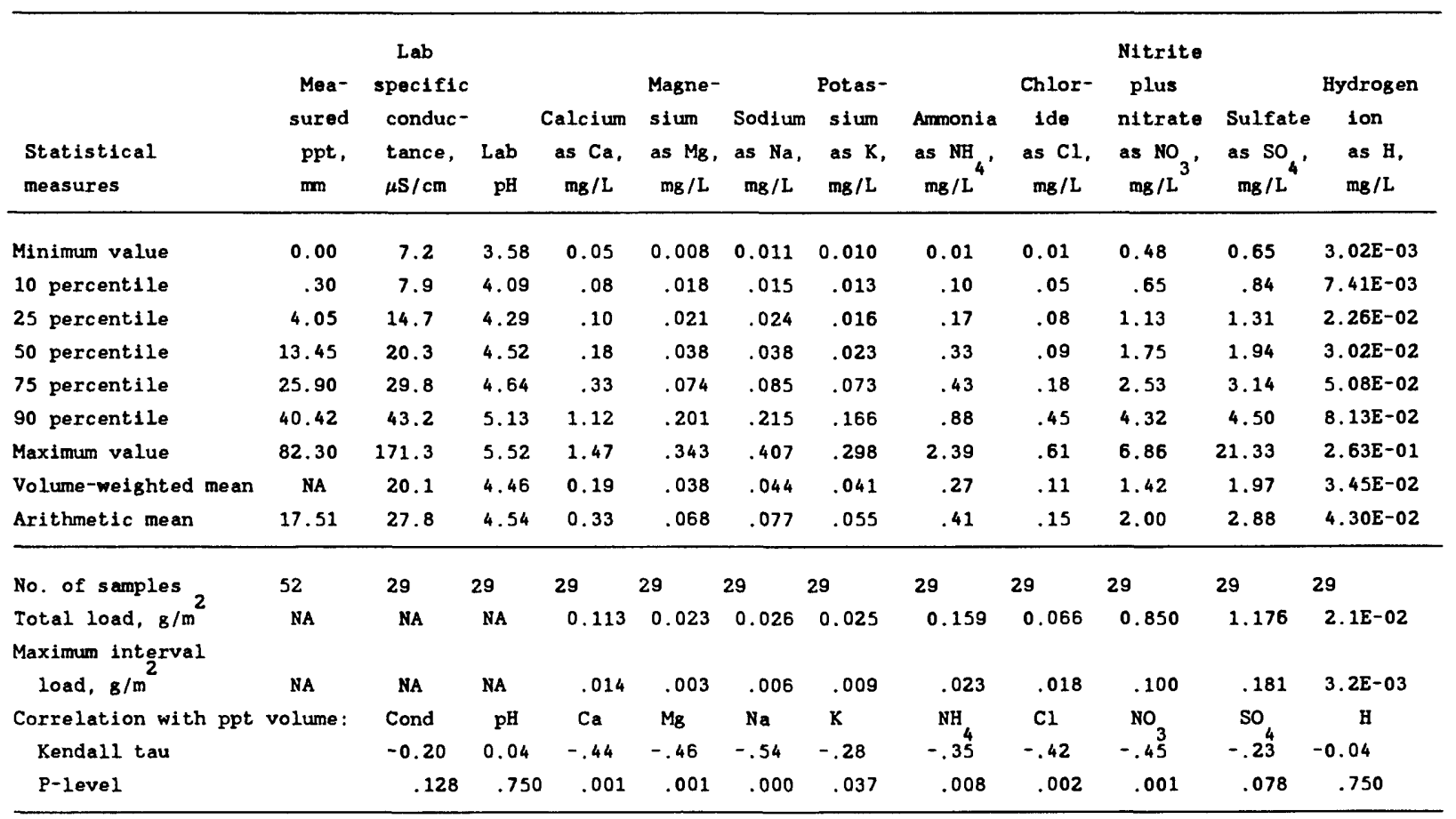

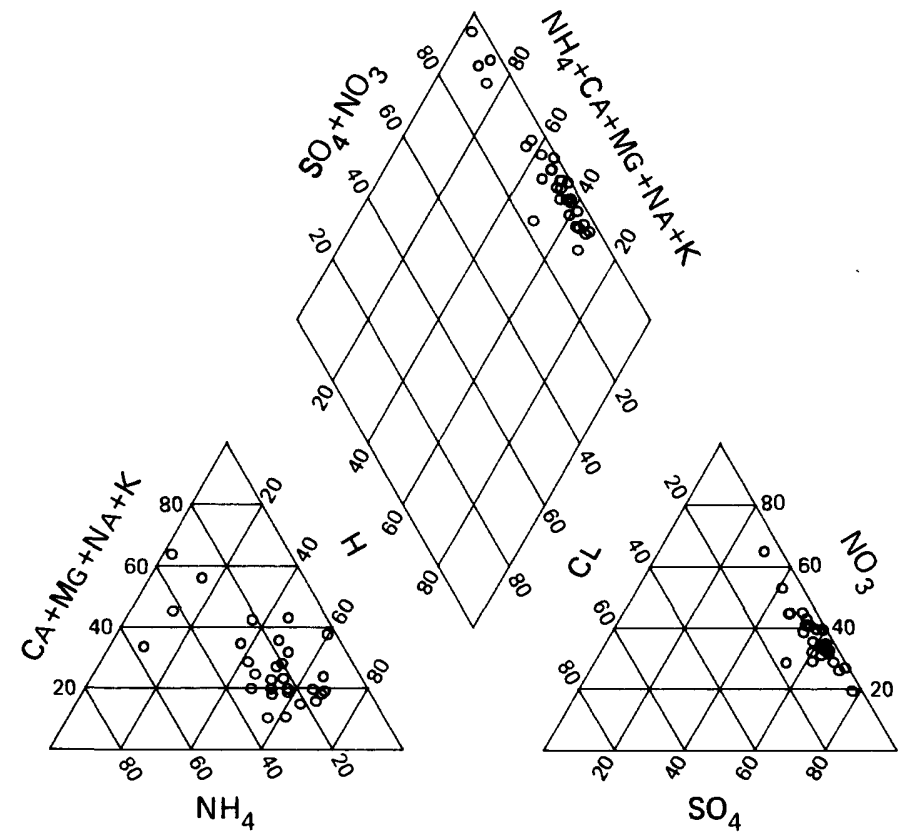

Percentage composition of major ions for site MI09. 
lppt = precipttation; $\mathrm{mm}=$ millimeters; $\mathrm{cm}=$ centimeters; $\mathrm{mg}=\mathrm{milligrams;} \mathrm{L}=1$ iters;

$g=$ grams; $m=$ meter; $\mu s=$ microsiemens; cond = specific conductance $]$

STATION: Kellog8, Michigan

CAL number: MI26

ADS number: $032 \mathrm{a} 00$

Map ID number: 46

Station altitude above mean sea level, in meters: 288 Number of sampling intervals (days in parenthesis):

-- With ppt measurements:

-- When ppt occurred:

- When ppt did not occur:

-- When sample volume was substituted for missing rain gage:

-- With chemical samples:
(362)

(14)

(14)

(210)
Latitude: $42^{\circ} 24^{\prime} 37^{\prime \prime}$ Longitude: $85^{\circ} 23^{\prime} 34^{*}$

Station summary period: $12 / 21 / 1982$ to $01 / 03 / 1984$

Length of summary period: 54 sampling intervals ( 378 days) Percent summary period with ppt measurements :

101.3 Percent summary period with chemical samples or no ppt: 60.4 Percent of total measured ppt with chemical samples: 66.3 Percent of total measured ppt in raingage that was

collected in the wet-sample bucket:

84.5

Total measured ppt, in mm: 998.4

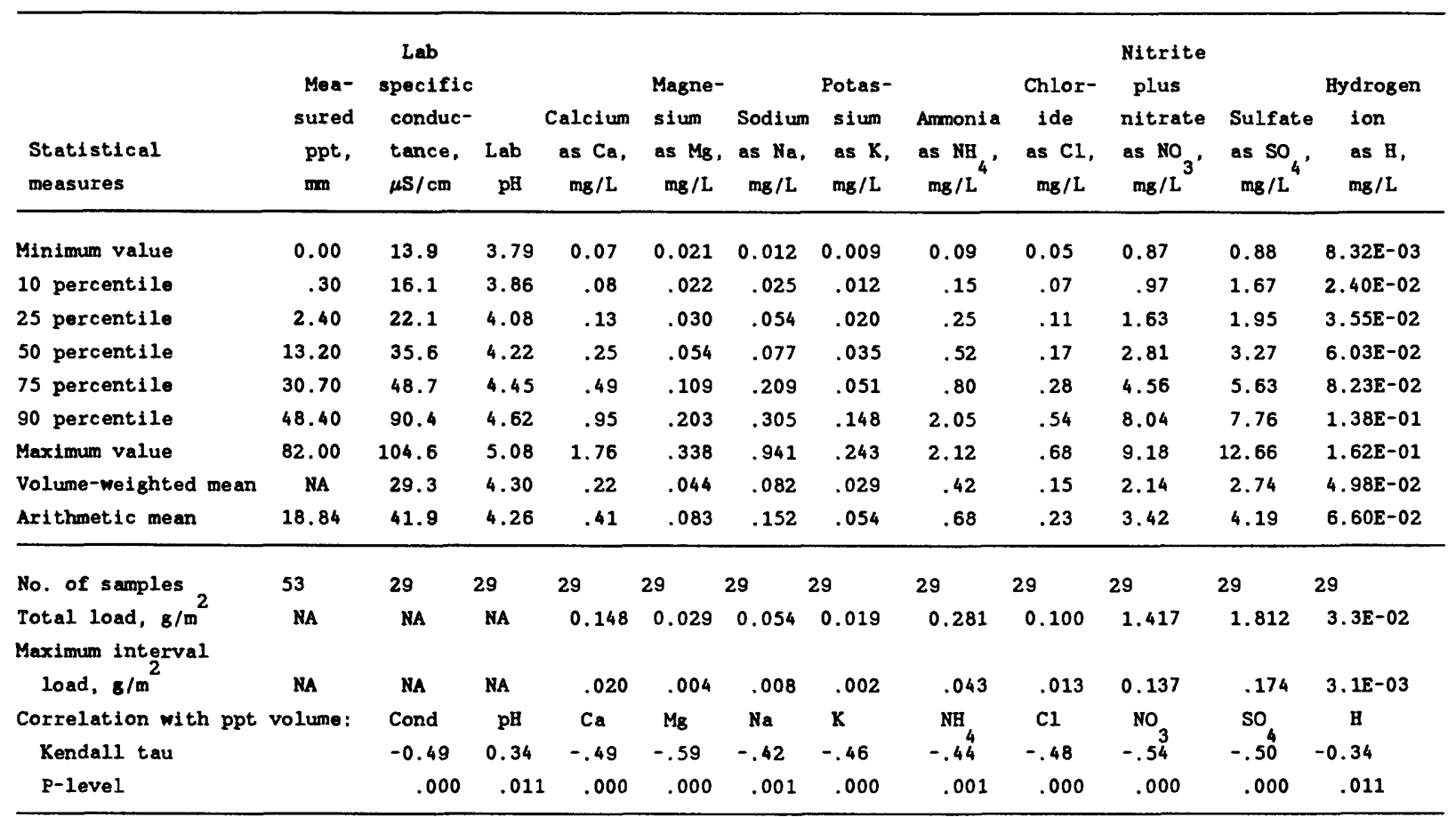

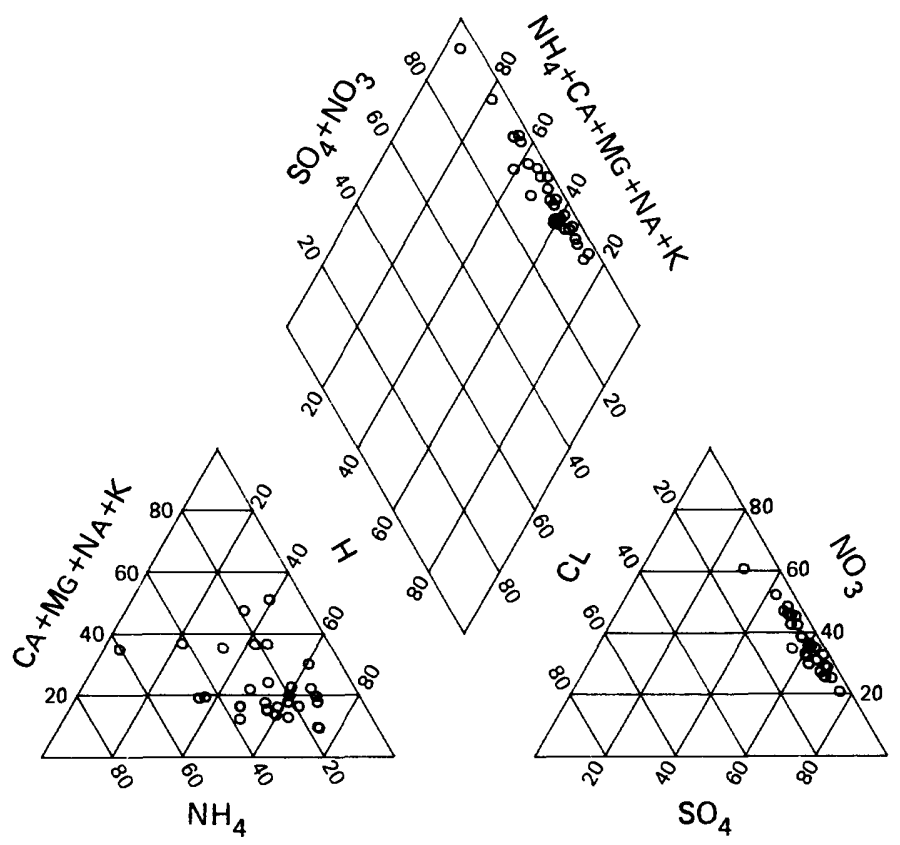

Percentage composition of major ions for site MI26. 


\section{NATIONAL TRENDS NETWORK -- 1983 CALENDER YEAR SUMMARY DATA}

[ppt = precipitation; $\mathrm{mm}=$ millimeters; $\mathrm{cm}=$ centimeters; $\mathrm{mg}=$ milligrams; L $=$ Liters;

$8=8 r a m s ; m=$ meter; $\mu \mathrm{s}=$ microsiemens; cond = specific conductance $]$

STATION: Wellston, Michigan

CAL number: MI53

ADS number: $033 \mathrm{a00}$

Station altitude above mean sea level, in meters: 292

Number of sampling intervals (days in parenthesis):

-- With ppt measurements: $39 \quad$ (273)

-- When ppt occurred:

37 (259)

-- When ppt did not occur:

$2(14)$

-- When sample volume was substituted for missing rain gage:

-- With chemical samples:
Latitude: $44^{\circ} 13^{\prime} 28^{\prime \prime}$ Longitude: $85^{\circ} 49^{\prime} 07^{\prime \prime}$

Station summary period: $12 / 28 / 1982$ to $09 / 27 / 1983$

Length of sumnary period: 39 sampling intervals (273 days)

Percent summary period with ppt measurements:

73.6

Percent summary period with chemical samples or no ppt: 66.0

Percent of total measured ppt with chemical samples: $\quad 92.6$

Percent of total measured ppt in raingage that was

collected in the wet-sample bucket:

91.1

Total measured ppt, in mm: 702.4

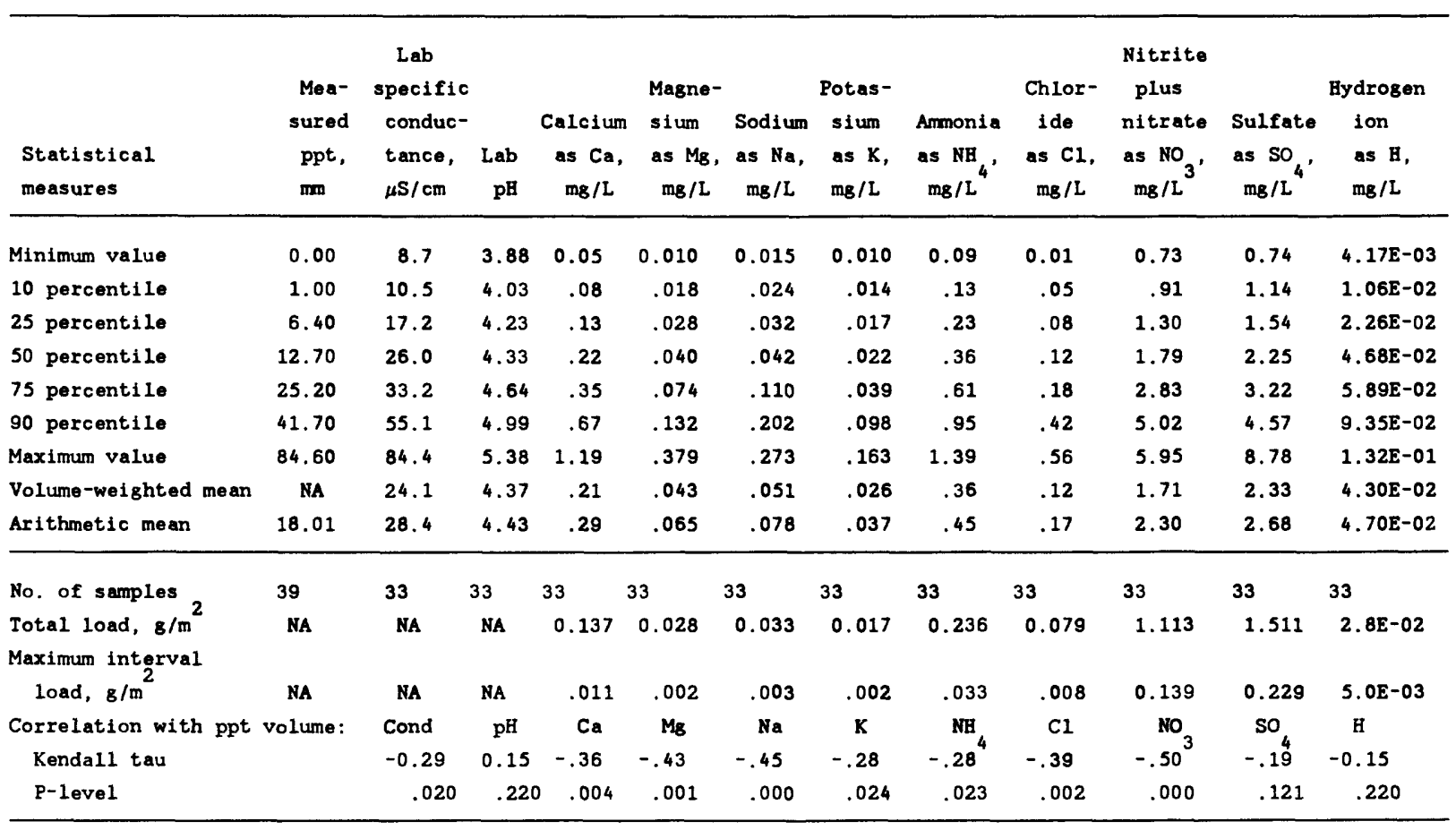




\section{NATIONAL TRENDS NETWORK - 1983 CALENDER YEAR SUMMARY DATA}

$[$ ppt $=$ precipitation; $\mathrm{mm}=$ millimeters $; \mathrm{cm}=$ centimeters; $\mathrm{mg}=\mathrm{milligrams;} \mathrm{L=} 1$ iters;

$\mathrm{g}=\mathrm{grams} ; \mathrm{m}=$ meter $\boldsymbol{\mu s}=$ microsiemens; cond = specific conductance

STATION: Wellston, Michigan

CAL number: MI53

ADS number: $033 \mathrm{a} 01$

Station altitude above mean sea level, in meters: 292

Number of sampling intervals (days in parenthesis):

-- With ppt measurements:

-- When ppt occurred:

- When ppt did not occur:

-- When sample volume was substituted for missing rain gage:

-- With chemical samples:
14 (98)

$14(98)$

$0 \quad(0)$

$0(0)$

$13(91)$
Latitude: $\quad 4^{\circ} 13^{\prime} 28^{\prime \prime}$ Longitude: $85^{\circ} 49^{\prime} 07^{\prime \prime}$

Station summary period: $09 / 27 / 1983$ to $01 / 03 / 1984$

Length of sumary period: 14 sampling intervals (98 days)

Percent summary period with ppt measurements:

26.4

Percent summary period with chemical samples or no ppt: 24.5

Percent of total measured ppt with chemical samples: $\quad 91.4$

Percent of total measured ppt in raingage that was

collected in the wet-sample bucket:

79.6

Total measured ppt, in $\mathrm{mm}: 278.3$

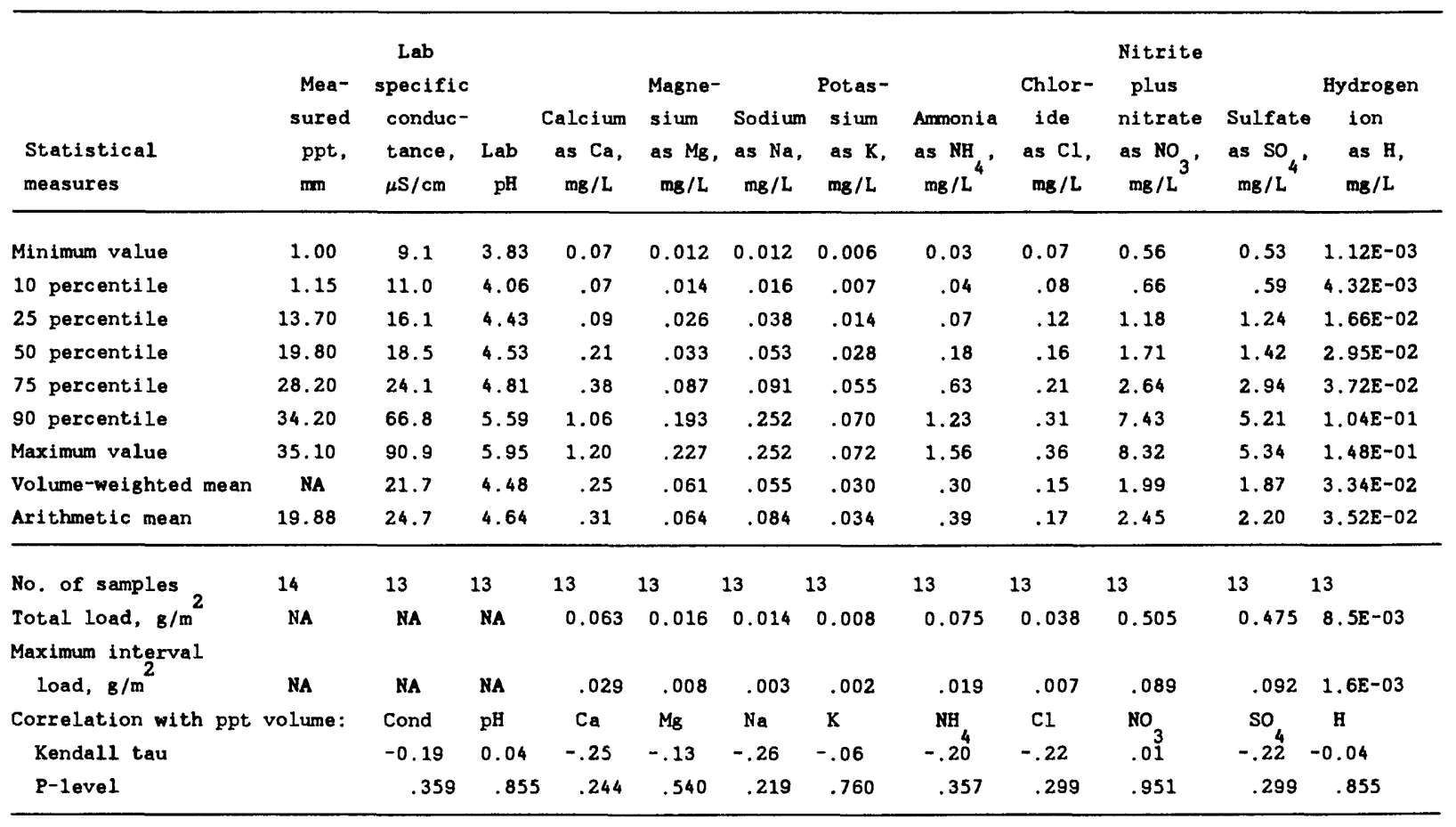


[ppt = precipitation; $\mathrm{mm}=$ mlllimeters; $\mathrm{cm}=$ centimeters; $\mathrm{mg}=\mathrm{milligrams;} \mathrm{L} \mathrm{=} \mathrm{1iters;}$

$\mathrm{g}=\mathrm{grams} ; \mathrm{m}=$ meter; $\mu \mathrm{s}=\operatorname{micros} 1$ emens; cond $=$ specific conductance $]$

STATION: Camp Ripley, Minnesota

CAL number: MN23

ADS number: $352 \mathrm{a} 00$

Stetion altitude above mean sea level, in meters: 410 Number of sampling intervels (days in parenthesis):

-- With ppt measurements:

-- When ppt occurred:

-- When ppt did not occur:

- When sample volume was substituted for missing raln gage:

-- With chemical samples:
Latitude: $46^{\circ} 14^{\prime} 58^{\prime \prime}$ Longitude: $94^{\circ} 29^{\prime} 50^{\prime \prime}$

Station summary period: $10 / 18 / 1983$ to $01 / 03 / 1984$

Length of summary period: 11 sampling intervals ( 77 days)

Percent summary period with ppt measurements:

20.8

Percent sumary period with chemical samples or no ppt: 1.9

Percent of total measured ppt with chemical samples: 17.5

Percent of totel measured ppt in raingage that was

collected in the wet-sample bucket:

91.2

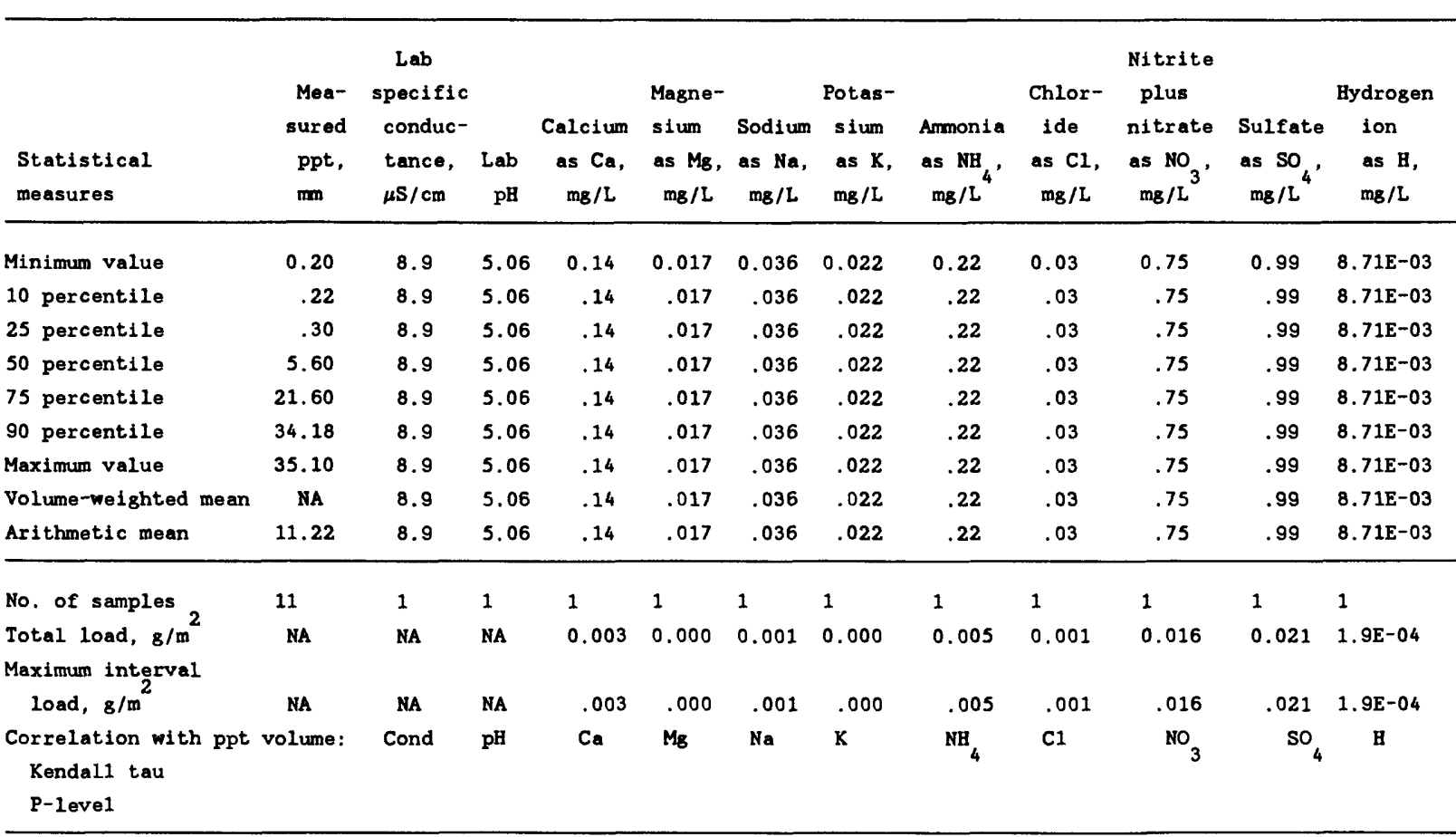

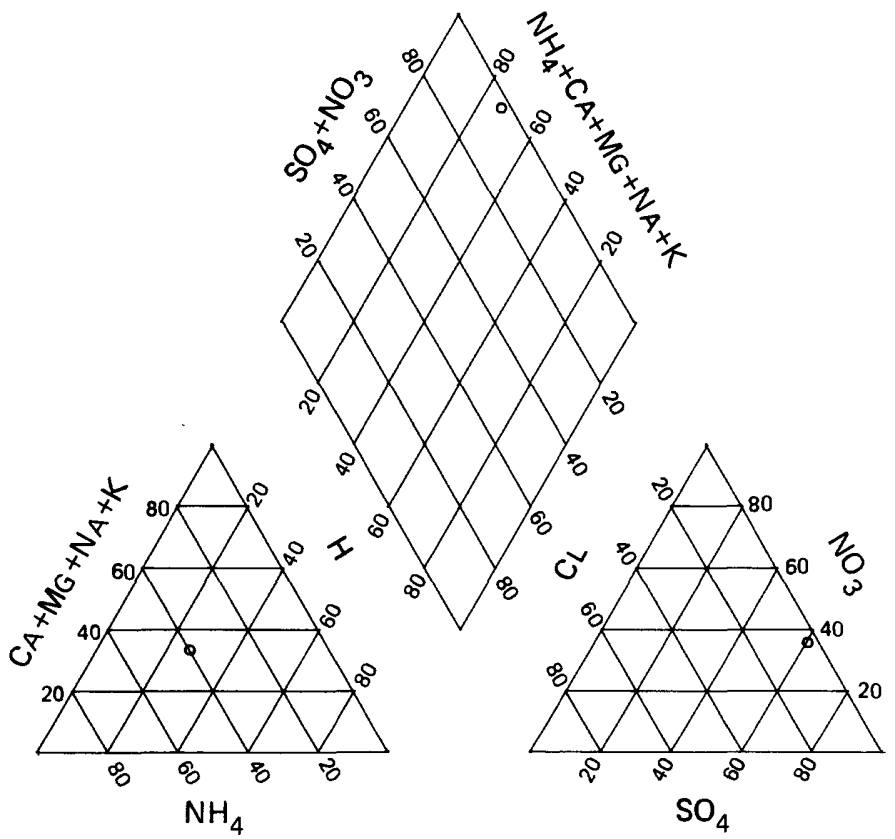

Percentage composition of major ions for site MN23. 


\section{NATIONAL TRENDS NETWORK - - 1983 CALENDER YEAR SUMMARY DATA}

[ppt $=$ precipitation; $\mathrm{mm}=$ millimeters; $\mathrm{cm}=$ centimeters; $\mathrm{mg}=\mathrm{mil1igrams;} \mathrm{L}=1 \mathrm{iters}$;

$\mathrm{g}=$ grams; $\mathrm{m}=$ meter; $\mu \mathrm{s}=$ microsiemens; cond = specific conductance

STATION: Lamberton, Minnesota

CAL number: MN27

ADS number: $035 \mathrm{a} 00$

Station altitude above mean sea level, in meters: 343

Number of sampling intervals (days in parenthesis)

-- With ppt measurements:

-- When ppt occurred:

-- When ppt did not occur:

-- When sample volume was substituted for missing rain gage:

-- With chemical samples:

Map ID number: 51
Latitude: $\quad 44^{\circ} 14^{\prime} 14^{\prime \prime}$ Longitude: $95^{\circ} 18^{\prime} 02^{\prime \prime}$

Station summary period: $12 / 29 / 1982$ to $01 / 02 / 1984$

Length of sumnary period: 53 sampling intervals ( 369 days)

Percent summary period with ppt measurements: 99.5

Percent summary period with chemical samples or no ppt: 60.4

Percent of total measured ppt with chemical samples: 63.9

Percent of total measured ppt in raingage that was

collected in the wet-sample bucket:

94.5

Total measured ppt, in $\mathrm{mm}$ : 636.2

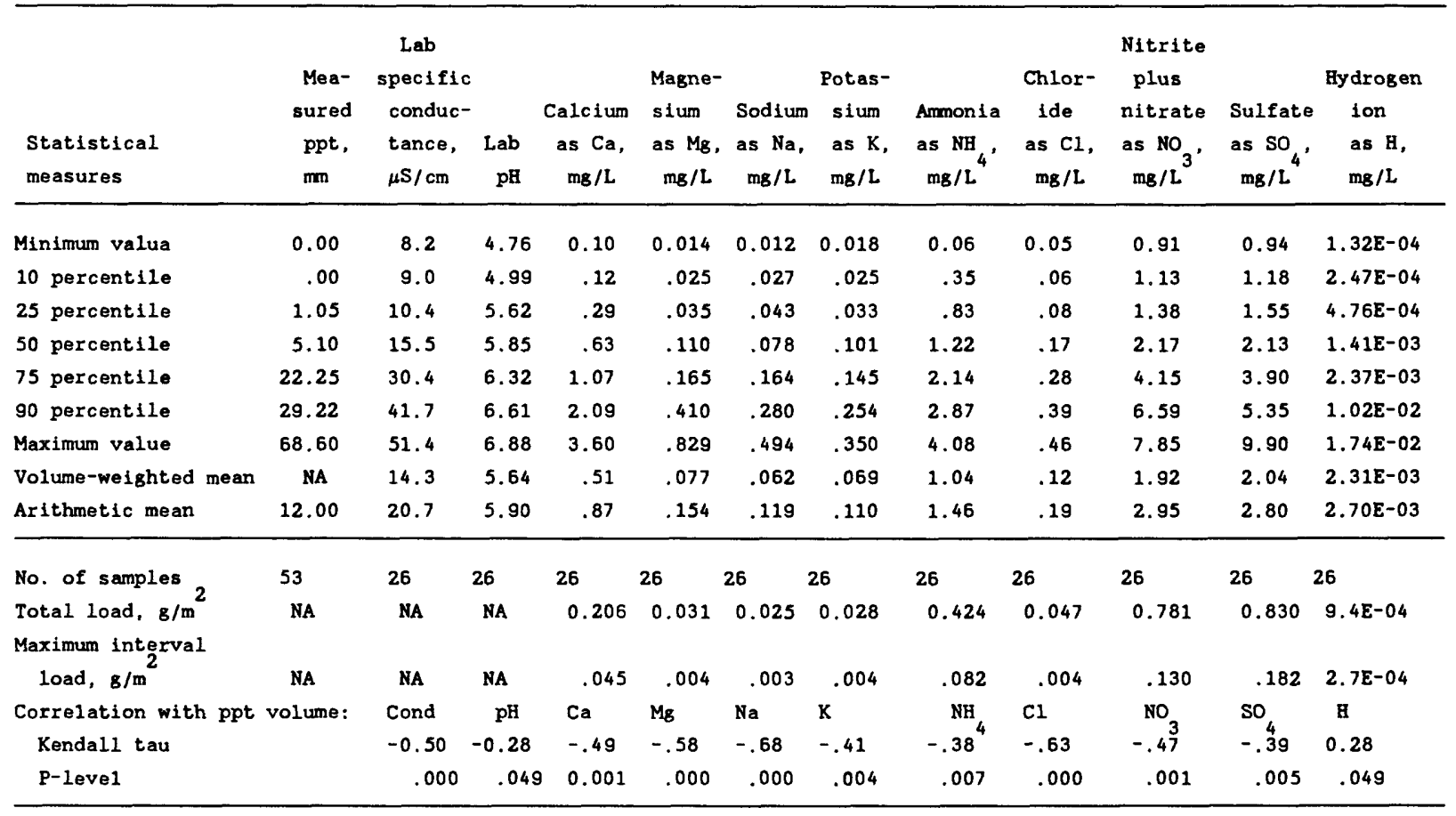

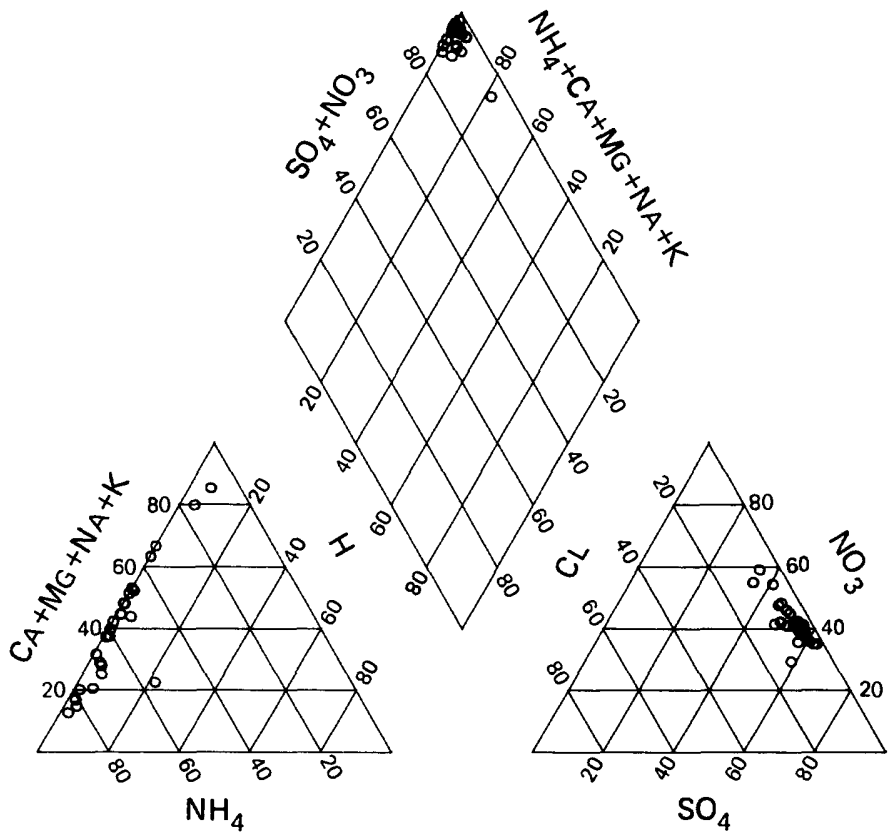

Percentage composition of major ions for site MN27. 
[ppt $=$ precipitation; $\mathrm{mm}=$ millimeters; $\mathrm{cm}=$ centimeters; $\mathrm{mg}=$ milligrams; L $=11$ ters;

8 = grams; $m=$ meter; $\mu s=$ microsiemens; cond = specific conductance $]$

STATION: Ashland, Missour1

CAL number: $M 003$

ADS number: 252000

Station altitude above mean sea level, in meters: 239

Number of sampling intervals (days in parenthesis):

-- With ppt measurements: 53 (371)

-- When ppt occurred: 51 (357)

-- When ppt did not occur: 2 ( 14)

-- When sample volume was subst1tuted for missing rain gage: 0 ( 0$)$

-- With chemical samples: 31
Latitude: $38^{\circ} 45^{\prime} 13^{\prime \prime}$ Longitude:

$92^{\circ} 11 \cdot 55^{\prime \prime}$

Station summary period: $12 / 28 / 1982$ to $01 / 03 / 1984$

Length of summary period: 53 sampling intervals ( 371 days)

Percent sumary period with ppt measurements:

100.0

Percent summary period with chemical samples or no ppt: 62.3

Percent of total measured ppt with chemical samples: $\quad 55.0$

Percent of total measured ppt in raingage that was

collected in the wet-sample bucket:

95.4

Total measured ppt, in mm: 1035.4

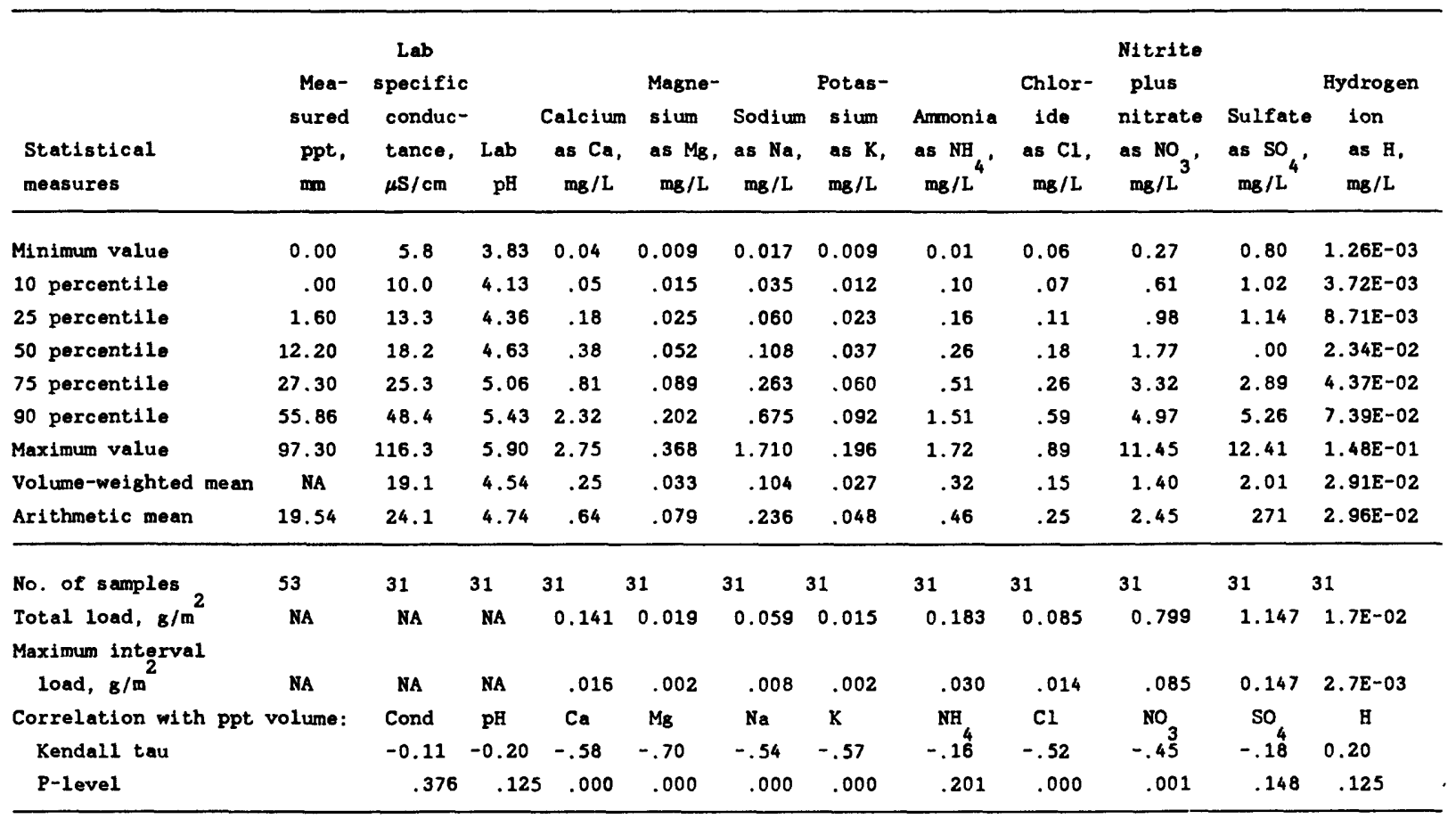

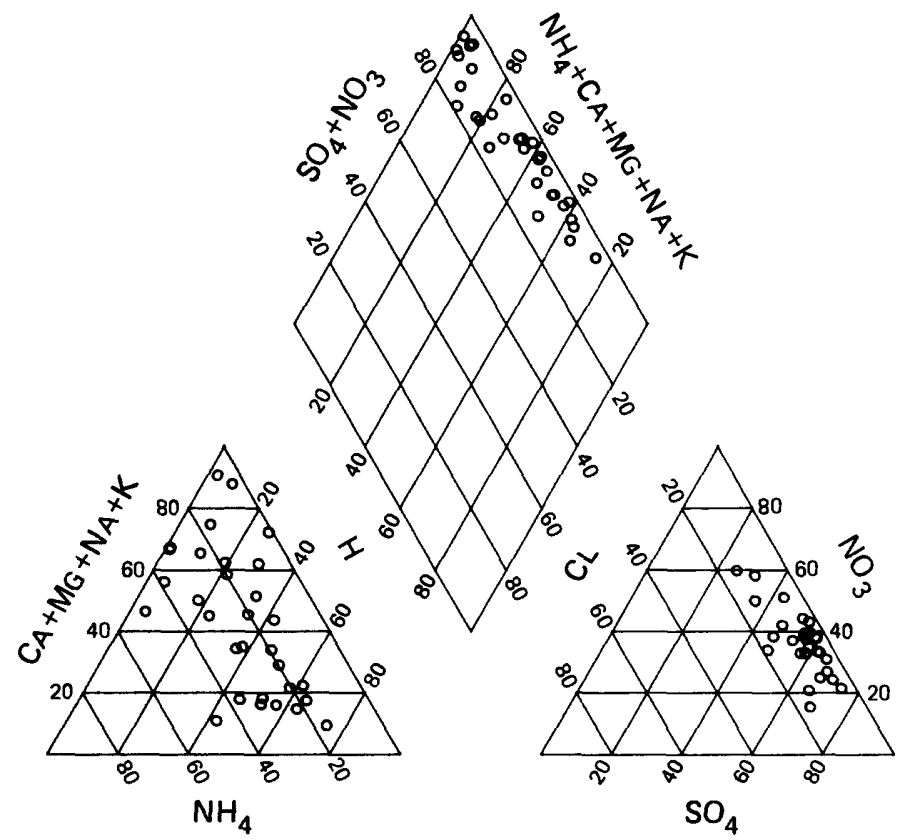

Percentage composition of major ions for site MO03. 


\section{NATIONAL TRENDS NETWORK -- 1983 CALENDER YEAR SUMMARY DATA}

Lppt $=$ precipitation; $\mathrm{mm}=$ millimeters; $\mathrm{cm}=$ centimeters; $\mathrm{mg}=\mathrm{mil1igrams;} \mathrm{L=1iters;}$

$g=$ grams; $m=$ meter; $\mu s=$ microsiemens; cond = specific conductance

STATION: Glacier National Park, Montana

CAL number: MrOS

ADS number: $037 a 00$

Station altitude above mean sea level, in meters: 968

Number of sampling intervals (days in parenthesis):

-- With ppt measurements: 51 (364)

-- When ppt occurred: 48 (343)

-- When ppt did not occur: $3 \quad$ (21)

-- When sample volume was substi-

tuted for missing rain gage: 1 ( 7)

-- With chemical samples: 22 (154)
Latitude: $48^{\circ} 30^{\prime} 37^{\prime \prime}$ Longitude: $113^{\circ} 59^{\prime} 44^{\prime \prime}$

Station summary period: $12 / 28 / 1982$ to $01 / 03 / 1984$

Length of summary period: 52 sampling intervals ( 371 days)

Percent sumary period with ppt measurements: 98.1

Percent summary period with chemical samples or no ppt: 47.2

Percent of total measured ppt with chemical samples: $\quad 34.9$

Percent of total measured ppt in raingage that was

collected in the wet-sample bucket:

85.7

Total measured ppt, in $\mathrm{mm:} 842.5$

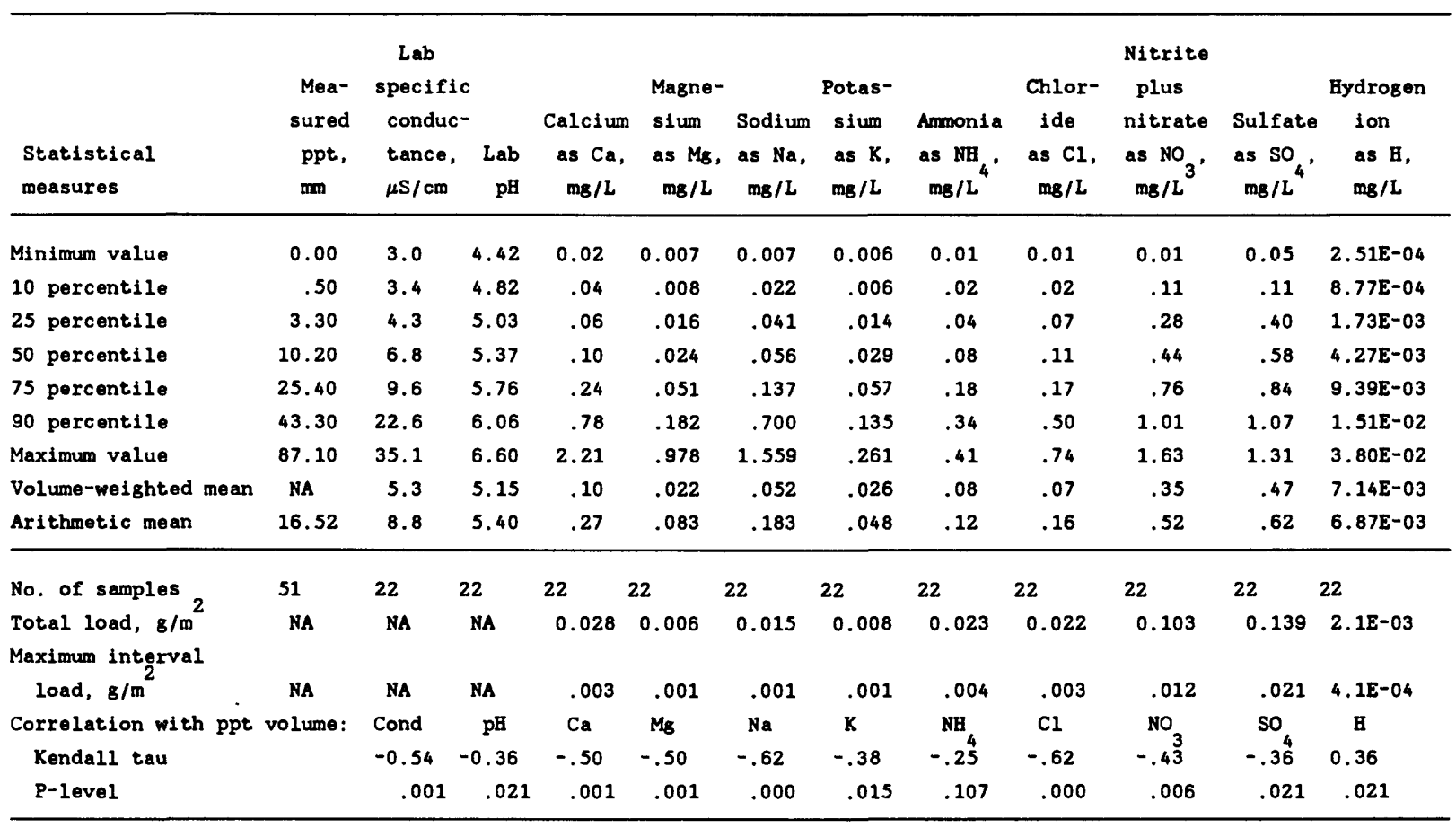

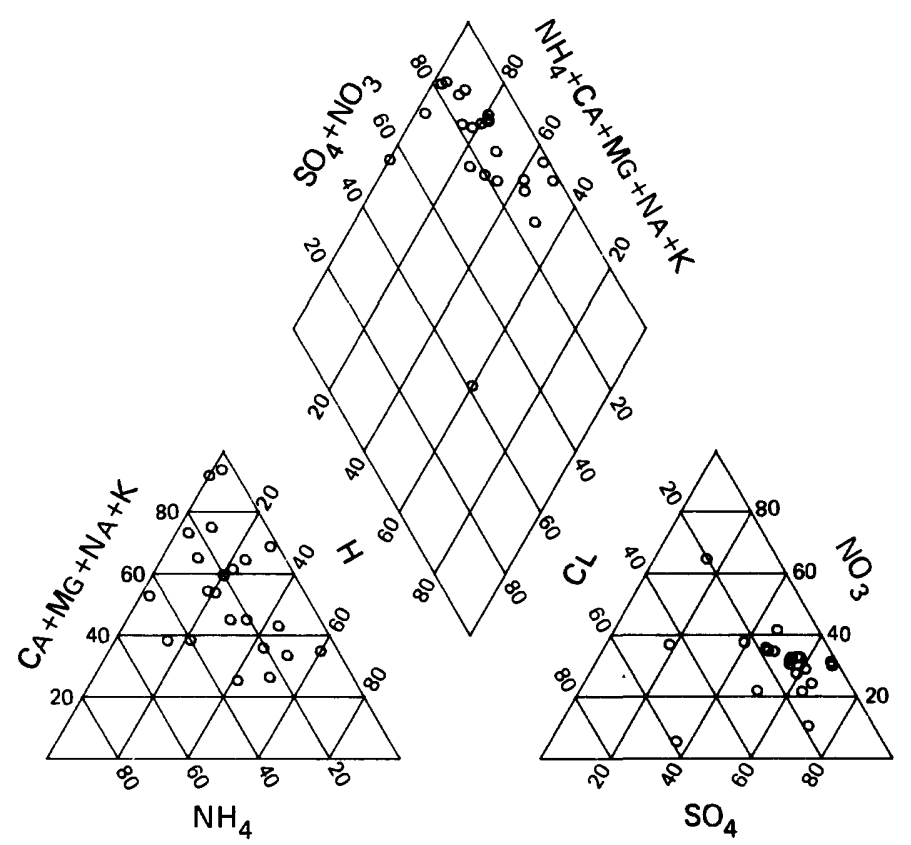

Percentage composition of major ions for site MT05. 


\section{NATIONAL TRENDS NETWORK - 1983 CALENDER YEAR SUMMARY DATA}

[ppt = precipitation; $\mathrm{mm}=$ millimeters; $\mathrm{cm}=$ centimeters; $\mathrm{mg}=$ milligrams; L = liters;

$8=8 \mathrm{rams} ; \mathrm{m}=$ meter; $\mu \mathrm{s}=$ microsiemens; cond = specific conductance $]$

STATION: Jordan Creek, North Carolina

CAL number: NC36

ADS number: $360 \mathrm{a} 00$

Station altitude above mean sea level, in meters: 132

Number of sampling intervals (days in parenthesis):

- With ppt measurements:

-- When ppt occurred:

-- When ppt did not occur:

11 ( 77)

$11(77)$

-- When sample volume was substituted for missing rain gage:

-- With chemical samples:
Latitude: $34^{\circ} 58^{\prime} 16^{\prime \prime}$ Longitude: $79^{\circ} 31^{\prime} 41^{\prime \prime}$

Station summary period: $10 / 18 / 1983$ to $01 / 03 / 1984$

Length of summary period: 11 sampling intervals ( 77 days)

$\begin{array}{ll}\text { Percent summary period with ppt measurements: } & 20.8\end{array}$

Percent summary period with chemical samples or no ppt: 17.0

Percent of total measured ppt with chemical samples: 96.9

Percent of total measured ppt in raingage that was

collected in the wet-sample bucket:

99.1

Total measured ppt, in m: 390.0

\begin{tabular}{|c|c|c|c|c|c|c|c|c|c|c|c|c|}
\hline $\begin{array}{l}\text { Statistical } \\
\text { measures }\end{array}$ & $\begin{array}{l}\text { Mea- } \\
\text { sured } \\
\text { ppt, } \\
\text { mm }\end{array}$ & $\begin{array}{l}\text { Lab } \\
\text { specific } \\
\text { conduc- } \\
\text { tance, } \\
\mu \mathrm{S} / \mathrm{cm}\end{array}$ & $\begin{array}{r}\mathrm{Lab} \\
\mathrm{pH}\end{array}$ & $\begin{array}{l}\text { Calcium } \\
\text { as Ca, } \\
\mathrm{mg} / \mathrm{L}\end{array}$ & $\begin{array}{l}\text { Magne- } \\
\text { sium } \\
\text { as } \mathrm{Mg}_{\mathrm{g}} \text {, } \\
\mathrm{mg} / \mathrm{L}\end{array}$ & $\begin{array}{l}\text { Sodium } \\
\text { as } \mathrm{Na} \text {, } \\
\mathrm{mg} / \mathrm{L}\end{array}$ & $\begin{array}{c}\text { Potas- } \\
\text { sium } \\
\text { as } \mathrm{K} \text {, } \\
\mathrm{mg} / \mathrm{L}\end{array}$ & $\begin{array}{l}\text { Ammonia } \\
\text { as } \mathrm{NH}^{\circ} \\
\mathrm{mg} / \mathrm{L}^{\circ}\end{array}$ & $\begin{array}{l}\text { Chlor- } \\
\text { ide } \\
\text { as } \mathrm{Cl} \text {, } \\
\mathrm{mg} / \mathrm{L}\end{array}$ & $\begin{array}{l}\text { Nitrite } \\
\text { plus } \\
\text { nitrate } \\
\text { as } \mathrm{NO}_{3} \text {, } \\
\mathrm{mg} / \mathrm{L}\end{array}$ & $\begin{array}{l}\text { Sulfate } \\
\text { as } \mathrm{SO}_{4} \text {, } \\
\mathrm{mg} / \mathrm{L}^{\circ}\end{array}$ & $\begin{array}{l}\text { Hydrogen } \\
\text { ion } \\
\text { as } \mathrm{H}, \\
\mathrm{mg} / \mathrm{L}\end{array}$ \\
\hline Minimum value & 0.30 & 5.5 & 4.57 & 0.02 & 0.016 & 0.088 & 0.011 & 0.01 & 0.16 & 0.21 & 0.56 & $5.75 E-03$ \\
\hline 10 percentile & 2.06 & 5.5 & 4.57 & .02 & .016 & .088 & .011 & .01 & .16 & .21 & .56 & $5.75 E-03$ \\
\hline 25 percentile & 11.70 & 7.6 & 4.72 & .04 & .021 & .130 & .013 & .04 & .23 & .37 & .68 & $9.33 E-03$ \\
\hline 50 percentile & 24.90 & 12.5 & 4.73 & .05 & .043 & .284 & .020 & .08 & .50 & .58 & 1.06 & $1.86 \mathrm{E}-02$ \\
\hline 75 percentile & 52.60 & 16.1 & 5.03 & .11 & .050 & .364 & .035 & .13 & .61 & .69 & 1.40 & $1.91 E-02$ \\
\hline 90 percentile & 104.74 & 18.4 & 5.24 & .32 & .137 & 1.140 & .049 & .19 & 2.00 & 1.08 & 1.63 & $2.69 E-02$ \\
\hline Maximum value & 109.20 & 18.4 & 5.24 & .32 & .137 & 1.140 & .049 & .19 & 2.00 & 1.08 & 1.63 & $2.69 E-02$ \\
\hline Volume-weighted mean & NA & 9.6 & 4.92 & .05 & .038 & .285 & .020 & .09 & .49 & .44 & .90 & $1.20 \mathrm{E}-02$ \\
\hline $\begin{array}{l}\text { No. of samples } \\
\text { Total load, } 8 / \mathrm{m}^{2} \\
\text { Maximum interval }\end{array}$ & $\begin{array}{l}11 \\
\text { NA }\end{array}$ & $\begin{array}{l}9 \\
\text { NA }\end{array}$ & $\begin{array}{l}9 \\
\text { NA }\end{array}$ & $\begin{array}{l}9 \\
0.019\end{array}$ & $\begin{array}{l}9 \\
0.014\end{array}$ & $\begin{array}{l}9 \\
0.108\end{array}$ & $\begin{array}{l}9 \\
0.008\end{array}$ & $\begin{array}{l}9 \\
0.035\end{array}$ & $\begin{array}{l}9 \\
0.185\end{array}$ & $\begin{array}{l}9 \\
0.166\end{array}$ & $\begin{array}{l}9 \\
0.340\end{array}$ & $\begin{array}{l}9 \\
4.5 E-03\end{array}$ \\
\hline $\begin{array}{l}\text { load, } 8 / \mathrm{m}^{2} \\
\text { Correlation with ppt } \\
\text { Kendall tau }\end{array}$ & $\begin{array}{l}\text { NA } \\
\text { volume: }\end{array}$ & $\begin{array}{l}\text { NA } \\
\text { Cond } \\
-0.61\end{array}$ & $\begin{array}{l}\mathrm{NA} \\
\mathrm{pH} \\
0.63\end{array}$ & $\begin{array}{c}.003 \\
\mathrm{Ca} \\
-.79\end{array}$ & $\begin{array}{l}.005 \\
M 8 \\
-.37\end{array}$ & $\begin{array}{l}.041 \\
\mathrm{Na} \\
-.17\end{array}$ & $\begin{array}{l}.002 \\
K \\
-.46\end{array}$ & $\begin{array}{l}.017 \\
\mathrm{NH} \\
.03\end{array}$ & $\begin{array}{l}.070 \\
C 1 \\
-.11\end{array}$ & $\begin{array}{l}.044 \\
\mathrm{NO}_{3} \\
-.83\end{array}$ & $\begin{array}{l}.092 \\
\text { so } \\
-.65\end{array}$ & $\begin{array}{l}1.1 \mathrm{E}-03 \\
\mathrm{H} \\
-0.63\end{array}$ \\
\hline P-level & & .022 & .020 & .004 & .173 & .532 & .092 & .917 & .677 & .002 & .016 & .020 \\
\hline
\end{tabular}

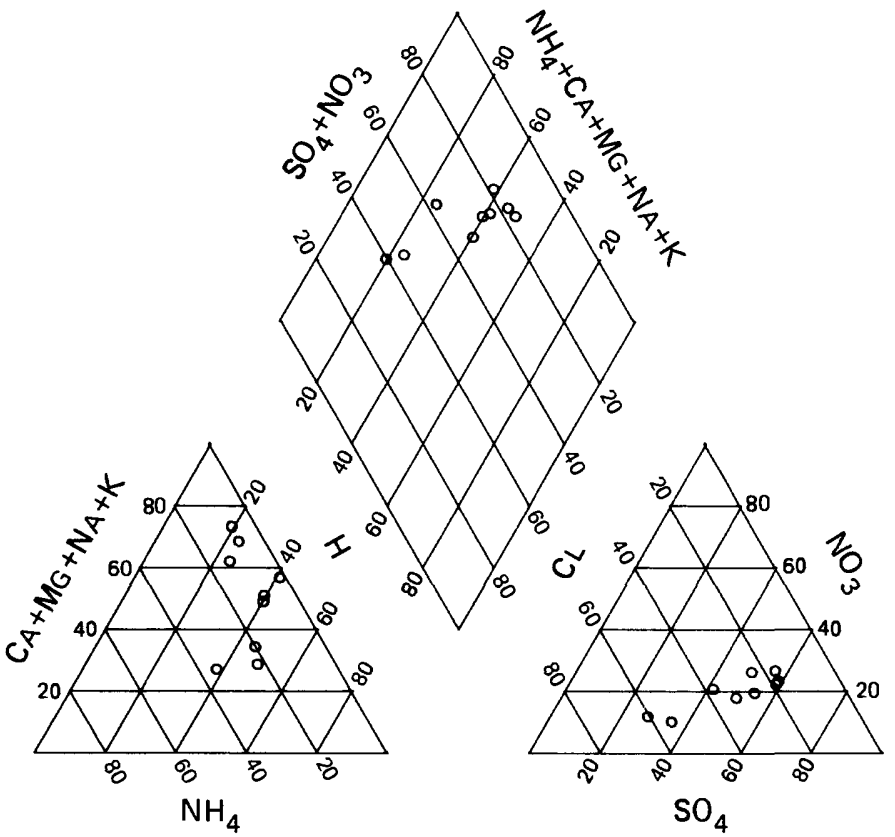

Percentage composition of major ions for site NC36. 


\section{NATIONAL TRENDS NETWORK - - 1983 CALENDER YEAR SUMMARY DATA}

$[$ ppt $=$ precipitation; $\mathrm{mm}=$ millimeters; $\mathrm{cm}=$ centimeters; $\mathrm{mg}=$ milligrams; $\mathrm{L}=11$ ters;

$\mathbf{g}=\mathrm{grams} ; \mathrm{m}=$ meter $\mu \mathrm{s}=$ microsiemens; cond $=$ specific conductance $]$

STATION: Finley (A), North Carolina

Map ID number: 60

CAL number: NC41

ADS number: $053 \mathrm{a} 02$

Station altitude above mean sea level, in meters: 119

Number of sampling intervals (days in parenthesis):

-- With ppt measurements: 19 (140)

-- When ppt occurred: 18 (133)

-- When ppt did not occur: 1 ( 7)

-- When sample volume was substituted for missing rain gage: 0 ( 0$)$

-- With chemical samples: $10 \quad$ ( 77)
Latitude: $35^{\circ} 43^{\prime} 43^{\prime \prime}$ Longitude: $78^{\circ} 40^{\prime} 52^{\prime \prime}$

Station summary period: $12 / 21 / 1982$ to $05 / 10 / 1983$

Length of summary period: 19 sampling intervals (140 days)

Percent summary period with ppt measurements: 37.7

Percent summary period with chemical samples or no ppt: 22.6

Percent of total measured ppt with chemical samples: 41.2

Percent of total measured ppt in raingage that was

collected in the wet-sample bucket:

86.3

Total measured ppt, in $\mathrm{mm}: \quad 518.1$

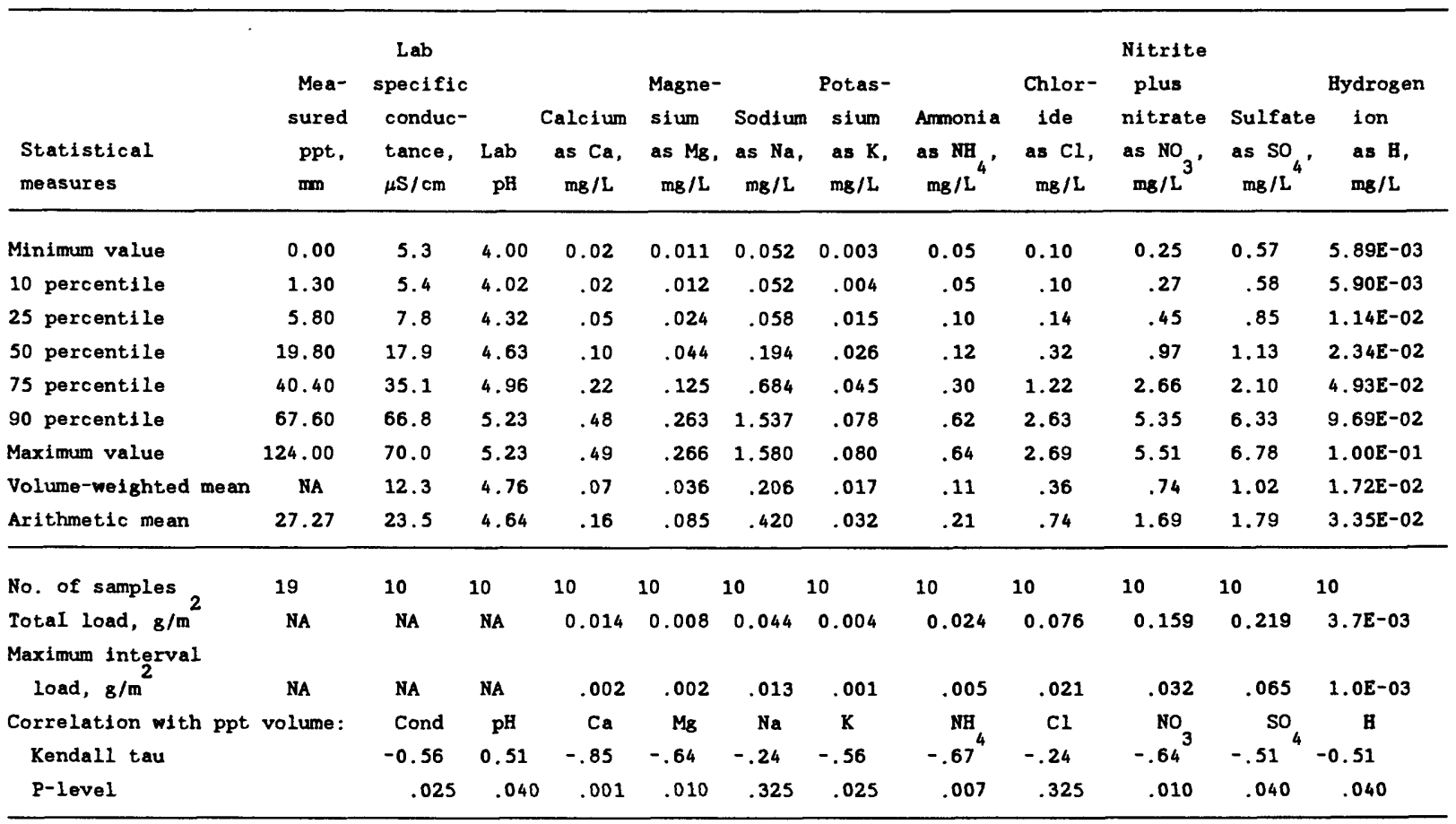


lppt $=$ precipitation; $\mathrm{mm}=$ millimeters; $\mathrm{cm}=$ centimeters; $\mathrm{mg}=$ milligrams; $L=11$ ters;

8 = 8 rams; $m=$ meter; $\mu s=$ microsiemens; cond = specific conductance $]$

STATION: Finley (A), North Carolina

CAL number: NC41

ADS number: $053 \mathrm{a03}$

Map ID number: 60

Station altitude above mean sea level, in meters: 119 Number of sampling intervals (days in parenthesis):

-- With ppt measurements:

-- When ppt occurred:

-- When ppt did not occur:

-- When sample volume was substituted for missing rain gage:

-- With chemical samples:
Latitude: $35^{\circ} 43^{\prime} 43^{\prime \prime}$ Longitude: $78^{\circ} 40^{\prime} 52^{\prime \prime}$

Station summary period: $05 / 10 / 1983$ to $01 / 03 / 1984$

Length of summary period: 34 sempling intervals (238 days)

Percent summary period with ppt measurements:

Percent summary period with chemical samples or no ppt: 56.6

Percent of total measured ppt with chemical samples: 84.2

Percent of total measured ppt in raingage that was

collected in the wet-sample bucket:

95.1

Total measured ppt, in ma: 712.3

\begin{tabular}{|c|c|c|c|c|c|c|c|c|c|c|c|c|}
\hline $\begin{array}{l}\text { Statistical } \\
\text { measures }\end{array}$ & $\begin{array}{c}\text { Mea- } \\
\text { sured } \\
\text { ppt, } \\
\text { mm }\end{array}$ & $\begin{array}{l}\text { Lab } \\
\text { specific } \\
\text { conduc- } \\
\text { tance, } \\
\mu \mathrm{S} / \mathrm{cm}\end{array}$ & $\begin{array}{r}\text { Lab } \\
\text { pH }\end{array}$ & $\begin{array}{c}\text { Calcium } \\
\text { as } \mathrm{Ca}, \\
\mathrm{mg} / \mathrm{L}\end{array}$ & $\begin{array}{l}\text { Magne- } \\
\text { sium } \\
\text { as } \mathrm{Mg} \text {, } \\
\mathrm{mg} / \mathrm{L}\end{array}$ & $\begin{array}{c}\text { Sodium } \\
\text { as } \mathrm{Na} \text {, } \\
\mathrm{mg} / \mathrm{L}\end{array}$ & $\begin{array}{l}\text { Potas- } \\
\text { sium } \\
\text { as } \mathrm{K} \text {, } \\
\mathrm{mg} / \mathrm{L}\end{array}$ & $\begin{array}{l}\text { Ammonia } \\
\text { as } \mathrm{NH} \\
\mathrm{mg} / \mathrm{L}^{\circ}\end{array}$ & $\begin{array}{l}\text { Chlor- } \\
\text { Ide } \\
\text { as } \mathrm{Cl} \text {, } \\
\mathrm{mg} / \mathrm{L}\end{array}$ & $\begin{array}{l}\text { Nitrite } \\
\text { plus } \\
\text { nitrate } \\
\text { as } \mathrm{NO}_{3} \text { ' } \\
\mathrm{mg} / \mathrm{L}\end{array}$ & $\begin{array}{l}\text { Sulfate } \\
\text { as } \mathrm{So}_{4} \text { ' } \\
\mathrm{mg} / \mathrm{L}^{2}\end{array}$ & $\begin{array}{l}\text { Bydrogen } \\
\text { ion } \\
\text { as } \mathrm{H}, \\
\mathrm{mg} / \mathrm{L}\end{array}$ \\
\hline Minimum value & 0.00 & 4.9 & 3.75 & 0.02 & 0.013 & 0.016 & 0.007 & 0.01 & 0.04 & 0.20 & 0.57 & $2.51 E-03$ \\
\hline 10 percentile & .15 & 5.7 & 4.01 & .03 & .016 & .033 & .013 & .05 & .14 & .31 & .60 & 5. 33E -03 \\
\hline 25 percentile & 3.47 & 11.6 & 4.24 & .06 & .028 & .087 & .019 & .10 & .18 & .53 & 1.16 & $1.56 \mathrm{E}-02$ \\
\hline 50 percentile & 15.25 & 20.0 & 4.48 & .10 & .039 & .146 & .031 & .19 & .24 & 1.01 & 1.62 & $3.27 E-02$ \\
\hline 75 percentile & 30.32 & 36.0 & 4.81 & .21 & .061 & .285 & .062 & .62 & .43 & 2.36 & 3.52 & $5.69 E-02$ \\
\hline 90 percentile & 47.50 & 75.4 & 5.27 & .31 & .233 & .880 & .118 & .74 & 1.64 & 2.82 & 7.59 & $9.918-02$ \\
\hline Maximum value & 94.00 & 81.7 & 5.60 & 1.21 & .411 & 1.980 & .440 & 1.27 & 3.61 & 6.40 & 12.96 & $1.78 \mathrm{E}-01$ \\
\hline Volume-wetghted mean & NA & 19.0 & 4.76 & .08 & .038 & .215 & .030 & .25 & .39 & 1.01 & 1.84 & 3.23E-02 \\
\hline Arithmetic mean & 20.95 & 26.9 & 4.56 & .17 & .069 & .306 & .061 & .33 & .55 & 1.57 & 2.82 & $4.43 E-02$ \\
\hline $\begin{array}{l}\text { No. of samples } \\
\text { Total load, } 8 / \mathrm{m}^{2}\end{array}$ & $\begin{array}{l}34 \\
\text { NA }\end{array}$ & $\begin{array}{c}28 \\
\mathrm{NA}\end{array}$ & $\begin{array}{l}28 \\
\text { NA }\end{array}$ & $\begin{array}{l}28 \\
0.046\end{array}$ & $\begin{array}{l}28 \\
0.023\end{array}$ & $\begin{array}{l}28 \\
0.129\end{array}$ & $\begin{array}{l}28 \\
0.018\end{array}$ & $\begin{array}{l}28 \\
0.150\end{array}$ & $\begin{array}{l}28 \\
0.236\end{array}$ & $\begin{array}{l}28 \\
0.608\end{array}$ & $\begin{array}{l}28 \\
1.106\end{array}$ & $\begin{array}{l}28 \\
1.9 E-02\end{array}$ \\
\hline \multicolumn{13}{|l|}{ Maximum interval } \\
\hline load, $g / \mathrm{m}^{2}$ & NA & NA & NA & .004 & .004 & .031 & .002 & .032 & .054 & .134 & 0.282 & $6.8 \mathrm{E}-03$ \\
\hline $\begin{array}{l}\text { Correlation with ppt } \\
\text { Kendall tau }\end{array}$ & volume : & $\begin{array}{l}\text { Cond } \\
-0.47\end{array}$ & $\begin{array}{l}\mathrm{pH} \\
0.39\end{array}$ & $\begin{array}{c}\mathrm{Ca} \\
-.71\end{array}$ & $\begin{array}{l}\mathrm{Mg} \\
-.61\end{array}$ & $\begin{array}{c}\mathrm{Na} \\
-.24\end{array}$ & $\begin{array}{l}\mathrm{K} \\
-.49\end{array}$ & $\begin{array}{c}\mathrm{NH}^{4} \\
-.22\end{array}$ & $\begin{array}{c}C 1 \\
-.21\end{array}$ & $\begin{array}{l}\mathrm{NO}_{3} \\
-.45\end{array}$ & $\begin{array}{c}\mathrm{SO}_{4} \\
-.44\end{array}$ & $\begin{array}{c}\mathrm{H} \\
-0.39\end{array}$ \\
\hline P-level & & .001 & .003 & .000 & .000 & .079 & .000 & .105 & .123 & .001 & .001 & .003 \\
\hline
\end{tabular}




\section{NATIONAL TRENDS NETWORK - 1983 CALENDER YEAR SUMMARY DATA}

lppt = precipitation; $\mathrm{mm}=$ millimeters; $\mathrm{cm}=$ centimeters; mg $=$ milligrams; L = Liters;

$8=$ grams; $\mathrm{m}=$ meter; $\mu \mathrm{s}=$ microsiemens; cond = specific conductance $]$

STATION: Teddy Roosevelt National Park, North Dakota CAL number: NDO7

ADS number: $062 a 00$

Map ID number: 61

Station altitude above mean sea level, in meters: 618 Number of sampling intervals (days in parenthesis):

-- With ppt measurements:

32 (245)

-- When ppt occurred:

-- When ppt did not occur:

- When sample volume was substituted for missing rain gage:

-- With chemical samples:
Latitude: $47^{\circ} 36^{\prime} 09^{\prime \prime}$ Longitude: $103^{\circ} 15^{\prime} 54^{\prime \prime}$

Station summary period: $12 / 21 / 1982$ to $08 / 30 / 1983$

Length of summary period: 33 sampling intervals (252 days)

Percent summary period with ppt measurements:

66.0

Percent summary period with chemical samples or no ppt: 47.4 Percent of total measured ppt with chemical samples: 90.7 Percent of total measured ppt in raingage that was collected in the wet-sample bucket:

Total measured ppt, in m: 223.7

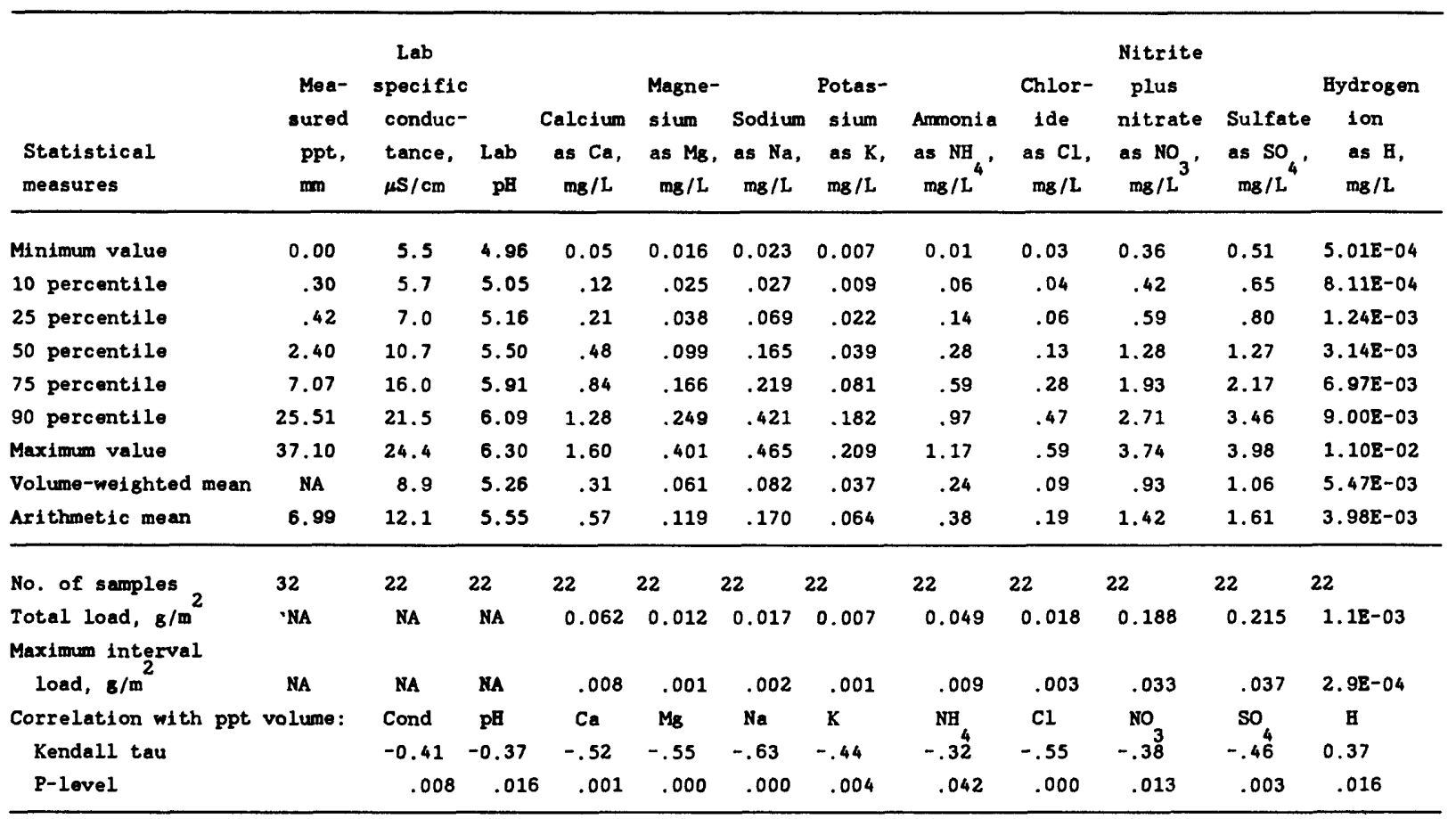


[ppt = precipitation; $\mathrm{mm}=$ millimeters; $\mathrm{cm}=$ centimeters; $\mathrm{mg}=$ milligrams; $\mathrm{L}=11$ ters;

$8=$ grams; $m=$ meter; $\mu \mathrm{s}=$ microsiemens; cond = specific conductance $]$

STATION: Teddy Roosevelt National Park, North Dakota

CAL number: ND07

ADS number: $062 \mathrm{a} 01$

Map ID number: 61

Station altitude above mean sea level, in meters: 618

Number of sampling intervals (days in parenthesis):

-- With ppt measurements:

-- When ppt occurred:

-- When ppt did not occur:

-- When sample volume was substituted for missing rain gage:

-- With chemical samples: 8 ( 56)
Latitude: $47^{\circ} 36^{\prime} 09^{\prime \prime}$ Longitude: $103^{\circ} 15^{\prime} 54^{\prime \prime}$

Station summary period: $08 / 30 / 1983$ to $01 / 03 / 1984$

Length of summary period: 18 sampling intervals (126 days)

Percent summary period with ppt measurements:

34.0

Percent summary period with chemical samples or no ppt: 18.9

Percent of total measured ppt with chemical samples: $\quad 54.8$

Percent of total measured ppt in raingage that was

collected in the wet-sample bucket:

85.6

Total measured ppt, in mm: 39.6

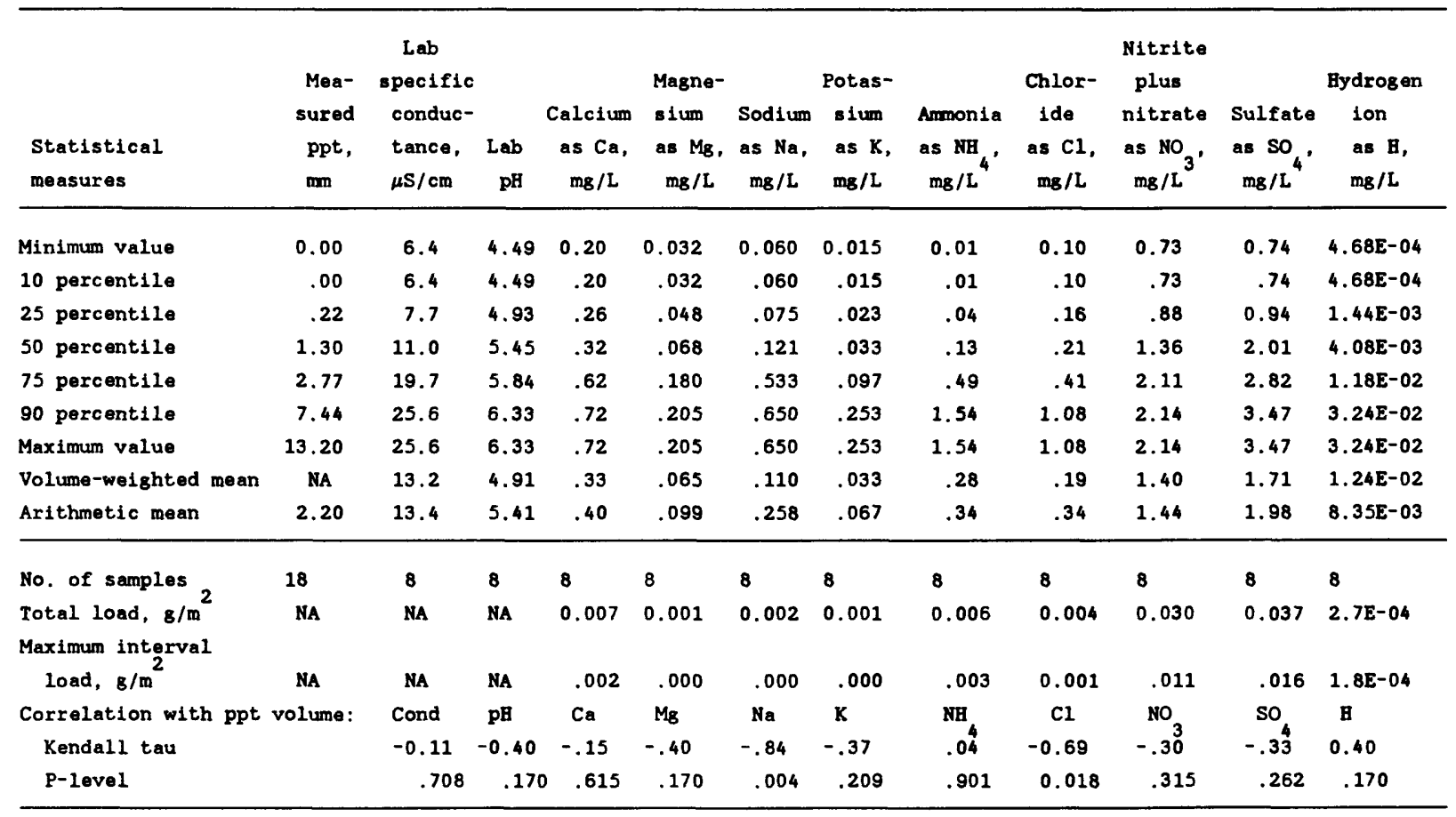


[ppt = precipitation; $\mathrm{mm}=$ millimeters; $\mathrm{cm}=$ centimeters; $\mathrm{mg}=$ milligrams; L $=11$ ters; $\mathrm{g}=\mathrm{grams} ; \mathrm{m}=$ meter; $\mu \mathrm{s}=$ microsiemens; cond = specific conductance

STATION: Icelandic, North Dakota

CAL number: ND08

ADS number: 361 a00

Station altitude above mean sea level, in meters: 308

Number of sampling intervals (days in parenthesis):

-- With ppt measurements:

-- When ppt occurred:

-- When ppt did not occur:

-- When sample volume was substituted for missing rain gage:

-- With chemical samples:
$10(70)$

9 (63)

1 ( 1$)$

0 ( 0$)$

$2(14)$
Latitude: $48^{\circ} 46^{\prime} 57^{\prime \prime}$ Longitude: $97^{\circ} 45^{\prime} 15^{\prime \prime}$

Station summary period: $10 / 25 / 1983$ to $01 / 03 / 1984$

Length of sumary period: 10 sampling intervals ( 70 days)

Percent sumary period with ppt measurements:

18.9

Percent sumary period with chemical samples or no ppt: 5.7

Percent of total measured ppt with chemical samples: 9.7

Percent of total measured ppt in raingage that was

collected in the wet-sample bucket:

38.9

Total measured ppt, in mm: 18.5

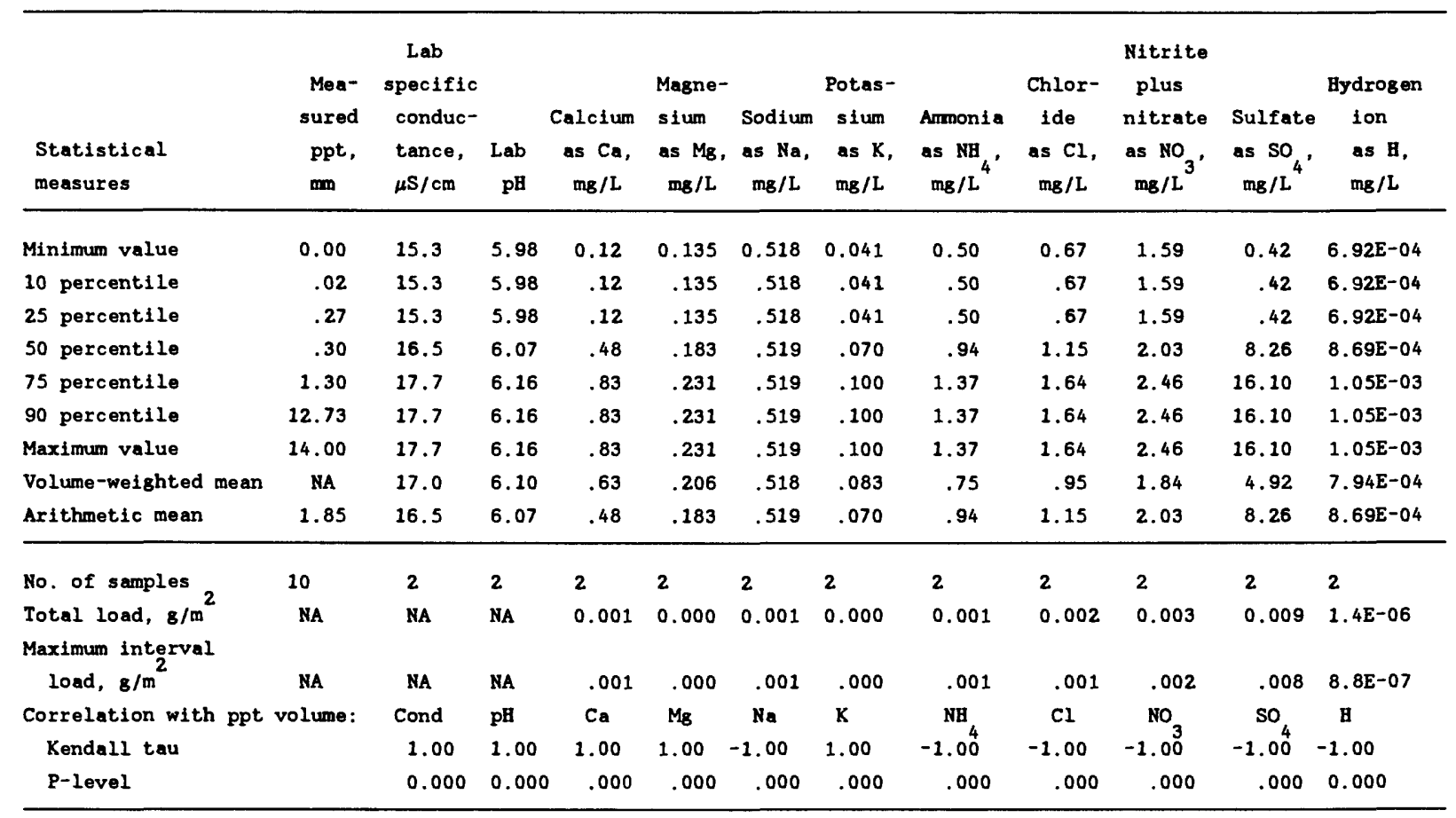

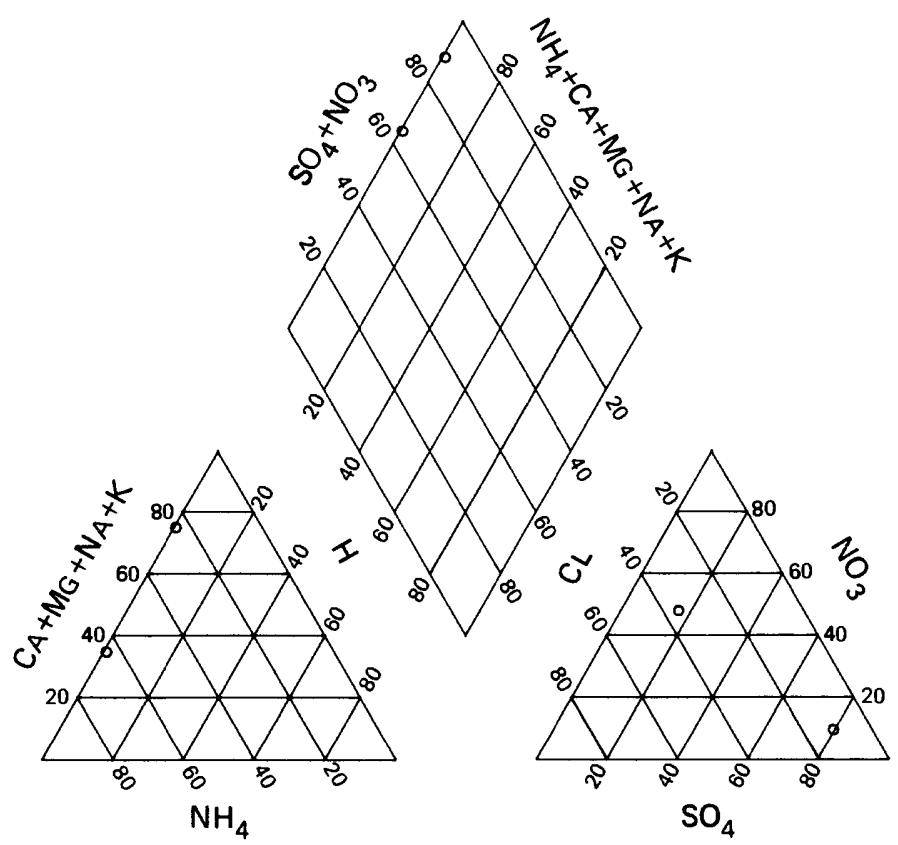

Percentage composition of major ions for site ND08. 


\section{NATIONAL TRENDS NETWORK -- 1983 CALENDER YEAR SUMMARY DATA}

Ippt = prec1p1tation; $\mathrm{mm}=$ millimeters; $\mathrm{cm}=$ cent1meters; $\mathrm{mg}=$ milligrams; L = 11ters; $g=$ grams; $m=$ meter; $\mu s=$ microsiemens; cond $=$ specific conductance $]$

STATION: Woodworth, North Dakota

CAL number: KD11

ADS number: 362,00

Station altitude above mean sea level, in meters: 0

Number of sampling intervals (days in parenthesis):

-- W1th ppt measurements :

-- When ppt occurred:

5 (35)

2 ( 14)

-- When ppt did not occur:

-- When sample volume was substituted for missing raln gage:

-- W1th chamical samples:

$0(0)$

()
Latitude: $47^{\circ} 07^{\prime} 22^{\prime \prime}$ Longitude: $99^{\circ} 14^{\prime} 02^{\prime \prime}$

Station summary period: $11 / 29 / 1983$ to $01 / 03 / 1984$

Length of summary period: 5 sampling intervals ( 35 days)

Percent sumary period with ppt measurements:

Percent sumary period with chemical samples or no ppt:

Percent of total measured ppt with valld samples:

Percent of total measured ppt in ralngage that was

collected in the wet-sample bucket:

Total measured ppt, in mm:

7.7

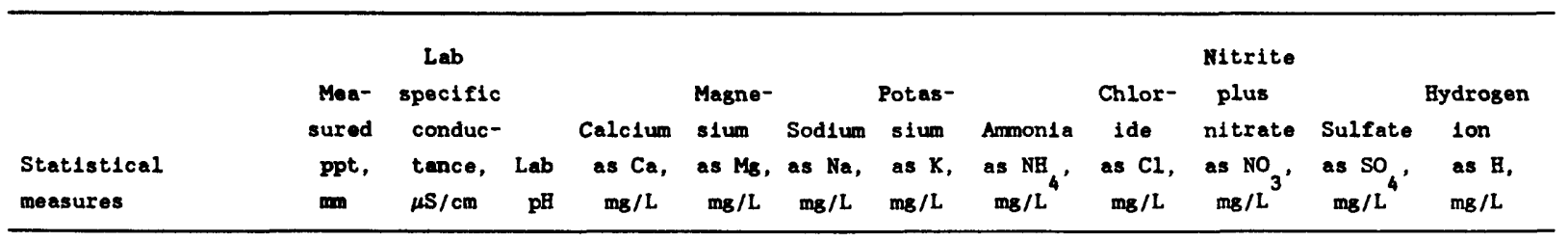

$\begin{array}{lr}\text { Minimum value } & 0.00 \\ 10 \text { percent1le } & .00 \\ 25 \text { percent1le } & .00 \\ 50 \text { percent1le } & .00 \\ 75 \text { percent1le } & 3.85 \\ 90 \text { percent1le } & 8.90 \\ \text { Maximum value } & 8.90 \\ \text { Volume-weighted mean } & \text { NA } \\ \text { Ar1thmetic mean } & 1.54\end{array}$

Arithmetic mean 1.54

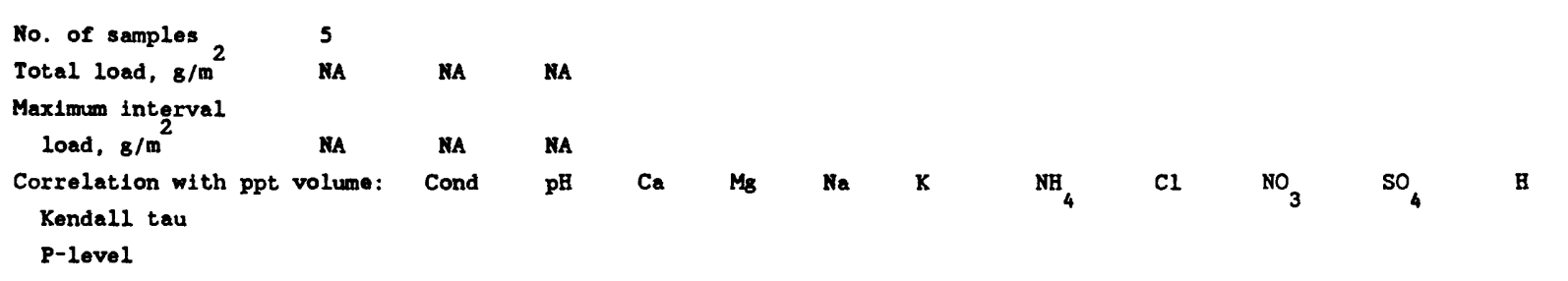




\section{NATIONAL TRENDS NETWORK -- 1983 CALENDER YEAR SUMMARY DATA}

[ppt = precipitation; $\mathrm{mm}=$ millimeters; $\mathrm{cm}=$ centimeters; $\mathrm{mg}=\mathrm{milligrams;} \mathrm{L}=11 \mathrm{ters}$; 8 = grams; $m=$ meter; $\mu \mathrm{s}=$ microsiemens; cond = specific conductance]

STATION: Mead, Nebraska

CAL number: NE15

ADS number: $038 \mathrm{a} 00$

Station altitude above mean sea level, in meters: 352

Number of sampling intervals (days in parenthesis):

-- With ppt measurements:

-- When ppt occurred:

-- When ppt did not occur:

-- When sample volume was substituted for missing rain gage:

-- With chemical samples:

Map ID number: 64
Latitude: $41^{\circ} 09^{\prime} 11^{\prime \prime}$ Longitude:

$96^{\circ} 29^{\prime} 34^{\prime \prime}$

Station sumary period: $12 / 29 / 1982$ to $09 / 06 / 1983$

Length of summary period: 36 sampling intervals (251 days)

Percent sumary period with ppt measurements: 67.6

Percent summary period with chemical samples or no ppt: 60.1

Percent of total measured ppt with chemical samples: $\quad 94.0$

Percent of total measured ppt in raingage that was

collected in the wet-sample bucket:

100.3

Total measured ppt, in $\mathrm{mm}: 463.9$

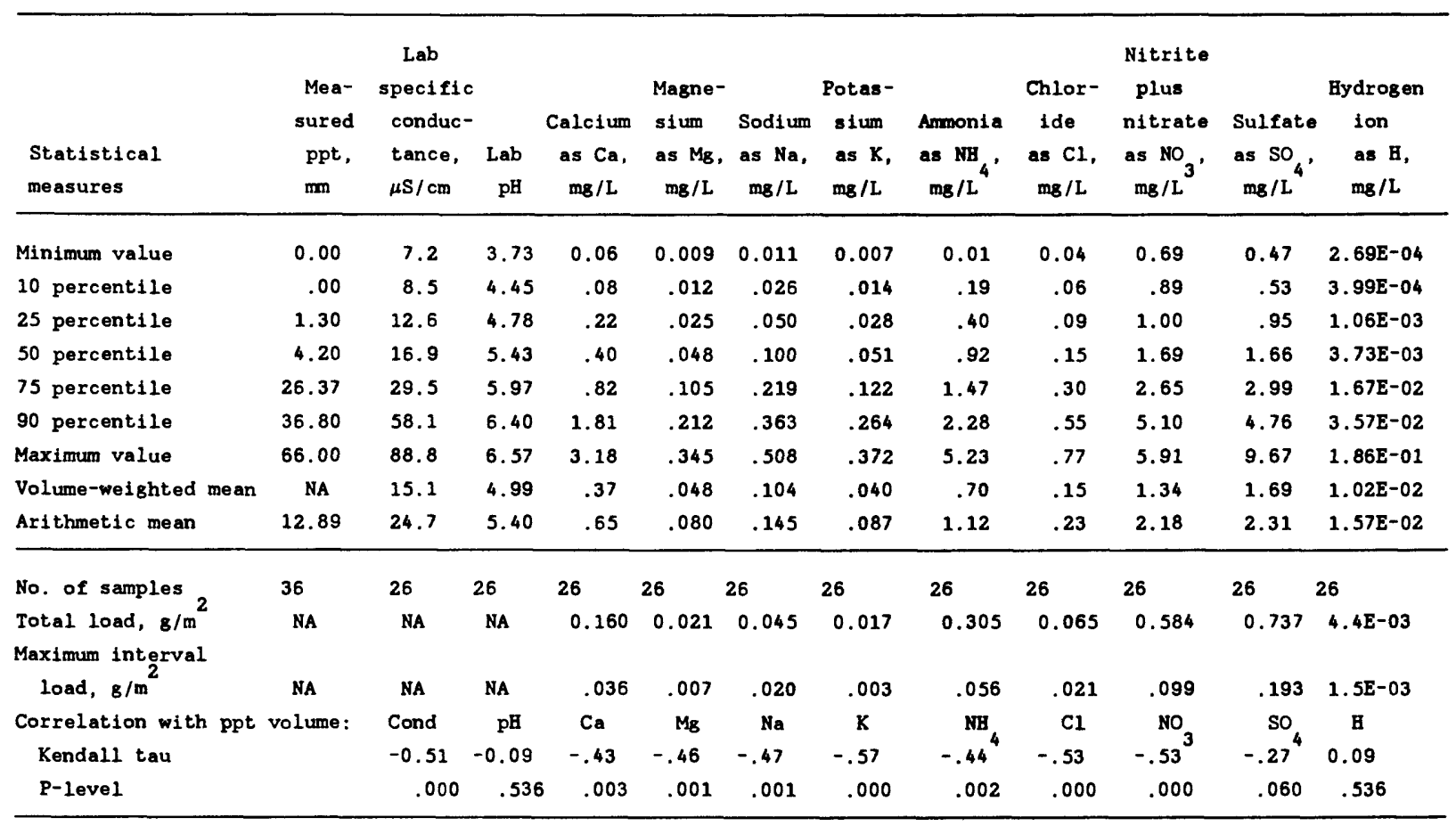




\section{NATIONAL TRENDS NETWORK -- 1983 CALENDER YEAR SUMMARY DATA}

lppt $=$ precipitation; $\mathrm{mm}=$ millimeters; $\mathrm{cm}=$ centimeters; $\mathrm{mg}=$ milligrams; L $=1$ liters; $\mathrm{B}=\mathrm{grams} ; \mathrm{m}=$ meter $\boldsymbol{\mu s}=$ microsiemens; cond = specific conductance $]$

STATION: Mead, Nebraska

CAL number: NE15

ADS number: $038 \mathrm{a} 01$

Map ID number: 64

Station altitude above mean sea level, in meters: 352

Number of sampling intervals (days in parenthesis):

-- With ppt measurements: $17 \quad$ (119)

-- When ppt occurred: $16 \quad$ (112)

-- When ppt did not occur: 1 ( 7)

-- When sample volume was substituted for missing rain gage: 0 ( 0$)$

-- With chemical samples: 9 (63)
Latitude: $41^{\circ} 09^{\prime} 11^{\prime \prime}$ Longitude: $96^{\circ} 29^{\prime} 34^{\prime \prime}$

Station summary period: $09 / 06 / 1983$ to $01 / 03 / 1984$

Length of summary period: 17 sampling intervals (119 days)

Percent summary period with ppt measurements :

32.1

Percent summary period with chemical samples or no ppt: 18.9

Percent of total measured ppt with chemical samples: 85.1

Percent of total measured ppt in raingage that was

collected in the wet-sample bucket:

94.5

Total measured ppt, in m: 197.0

\begin{tabular}{|c|c|c|c|c|c|c|c|c|c|c|c|c|}
\hline $\begin{array}{l}\text { Statistical } \\
\text { measures }\end{array}$ & $\begin{array}{l}\text { Mea- } \\
\text { sured } \\
\text { ppt, } \\
\text { mm }\end{array}$ & $\begin{array}{c}\text { Lab } \\
\text { specific } \\
\text { conduc- } \\
\text { tance, } \\
\mu \mathrm{S} / \mathrm{cm}\end{array}$ & Lab & $\begin{array}{c}\text { Calcium } \\
\text { as } \mathrm{Ca}, \\
\mathrm{mg} / \mathrm{L}\end{array}$ & $\begin{array}{l}\text { Magne- } \\
\text { sium } \\
\text { as Mg, } \\
\mathrm{mg} / \mathrm{L}\end{array}$ & $\begin{array}{c}\text { Sodium } \\
\text { as } \mathrm{Na} \text {, } \\
\mathrm{mg} / \mathrm{L}\end{array}$ & $\begin{array}{l}\text { Potas- } \\
\text { sium } \\
\text { as } \mathrm{X} \text {, } \\
\mathrm{mg} / \mathrm{L}\end{array}$ & $\begin{array}{l}\text { Ammonia } \\
\text { as } \mathrm{NH}_{4} \text {, } \\
\mathrm{mg} / \mathrm{L}^{\circ}\end{array}$ & $\begin{array}{l}\text { Chlor- } \\
\text { ide } \\
\text { as } \mathrm{Cl} \text {, } \\
\mathrm{mg} / \mathrm{L}\end{array}$ & $\begin{array}{l}\text { Nitrite } \\
\text { plus } \\
\text { nitrate } \\
\text { as } \mathrm{NO}^{\prime} \text { ' } \\
\mathrm{mg} / \mathrm{L}^{3}\end{array}$ & $\begin{array}{l}\text { Sulfate } \\
\text { as so } \\
\mathrm{mg} / \mathrm{L}^{4}\end{array}$ & $\begin{array}{c}\text { Hydrogen } \\
\text { ion } \\
\text { as } \mathrm{H}, \\
\mathrm{mg} / \mathrm{L}\end{array}$ \\
\hline Minimum value & 0.00 & 6.8 & 4.35 & 0.05 & 0.008 & 0.016 & 0.010 & 0.08 & 0.06 & 0.83 & 0.71 & $5.13 E-04$ \\
\hline 10 percentile & .00 & 6.8 & 4.35 & .05 & .008 & .016 & .010 & .08 & .06 & .83 & .71 & $5.13 E-04$ \\
\hline 25 percentile & .30 & 8.1 & 4.75 & .08 & .020 & .036 & .013 & .32 & .07 & 1.09 & 1.04 & $9.85 E-04$ \\
\hline 50 percentile & 5.10 & 10.6 & 5.80 & .49 & .034 & .053 & .048 & .63 & .11 & 1.38 & 1.33 & $1.58 \mathrm{E}-03$ \\
\hline 75 percentile & 24.10 & 28.3 & 6.01 & .64 & .064 & .190 & .090 & .98 & .24 & 2.32 & 3.78 & $1.89 \mathrm{E}-02$ \\
\hline 90 percentile & 35.82 & 31.0 & 6.29 & 2.31 & .183 & .457 & .142 & 1.44 & .47 & 4.91 & 4.85 & $4.47 E-02$ \\
\hline Maximum value & 41.90 & 31.0 & 6.29 & 2.31 & .183 & .457 & .142 & 1.44 & .47 & 4.91 & 4.85 & $4.47 E-02$ \\
\hline Volume-weighted mean & NA & 13.0 & 5.06 & .46 & .045 & .095 & .047 & .53 & .14 & 1.47 & 1.76 & $8.74 E-03$ \\
\hline Arithmetic mean & 11.59 & 15.9 & 5.43 & .57 & .052 & .125 & .056 & .65 & .17 & 1.87 & 2.17 & $1.08 \mathrm{E}-02$ \\
\hline No. of samples 2 & 17 & 9 & 9 & 9 & 9 & 9 & 9 & 9 & 9 & 9 & 9 & 9 \\
\hline $\begin{array}{l}\text { Total load, } 8 / \mathrm{m} \\
\text { Maximum interval }\end{array}$ & NA & NA & NA & 0.078 & 0.008 & 0.016 & 0.008 & 0.089 & 0.024 & 0.246 & 0.295 & $1.5 \mathrm{E}-03$ \\
\hline load, $\mathrm{g} / \mathrm{m}^{2}$ & NA & NA & NA & .031 & .003 & .008 & .003 & .015 & .009 & .055 & .060 & $7.4 \mathrm{E}-04$ \\
\hline $\begin{array}{l}\text { Correlation with ppt } \\
\text { Kendall tau }\end{array}$ & volume: & $\begin{array}{l}\text { Cond } \\
-0.29\end{array}$ & $\begin{array}{c}\mathrm{pH} \\
-0.06\end{array}$ & $\begin{array}{c}\mathrm{Ca} \\
-.11\end{array}$ & $\begin{array}{r}\mathrm{Mg} \\
-.11\end{array}$ & $\begin{array}{r}\mathrm{Na} \\
-.34\end{array}$ & $\begin{array}{c}\mathbf{x} \\
-.06\end{array}$ & $\begin{array}{r}\mathrm{NB}^{4} \\
-.40^{4}\end{array}$ & $\begin{array}{r}C 1 \\
-.29\end{array}$ & $\begin{array}{r}\text { No }^{3} \\
-.40^{3}\end{array}$ & $\begin{aligned} & \mathrm{SO}^{4} \\
-.17^{4} & \end{aligned}$ & $\begin{array}{c}\mathrm{B} \\
0.06\end{array}$ \\
\hline P-level & & .292 & .833 & .673 & .673 & .206 & .832 & .140 & .292 & .140 & .527 & .833 \\
\hline
\end{tabular}


lppt = precipitation; $\mathrm{mm}=$ millimeters; $\mathrm{cm}=$ centimeters; $\mathrm{mg}=$ milligrams; L = Iiters;

8 = grams; $m=$ meter; $\mu \mathrm{s}=$ microsiemens; cond $=$ specific conductance $]$

STATION: Biscuit Brook, New York

CAL number: NY68

ADS number: $359 \mathrm{a} 00$

Map ID number: 74

Station altitude above mean sea level, in meters: 634

Number of sampling intervals (days in parenthesis):

-- With ppt measurements:

-- When ppt occurred:

- When ppt did not occur:

12 ( 84)

$12(84)$

-- When sample volume was substituted for missing rain gage:

-- With chemical samples:
Latitude: $41^{\circ} 59^{\prime} 39^{\prime \prime}$ Longitude:

$74^{\circ} 30^{\prime} 13^{\prime \prime}$

Station summary period: $10 / 11 / 1983$ to $01 / 03 / 1984$

Length of summary period: 12 sampling intervals ( 84 days)

Percent summary period with ppt measurements:

22.6

Percent summary period with chemical samples or no ppt: 13.5

Percent of total measured ppt with chemical samples: $\quad 70.8$

Percent of total measured ppt in raingage that was

collected in the wet-sample bucket:

81.4

Total measured ppt, in m: 383.7

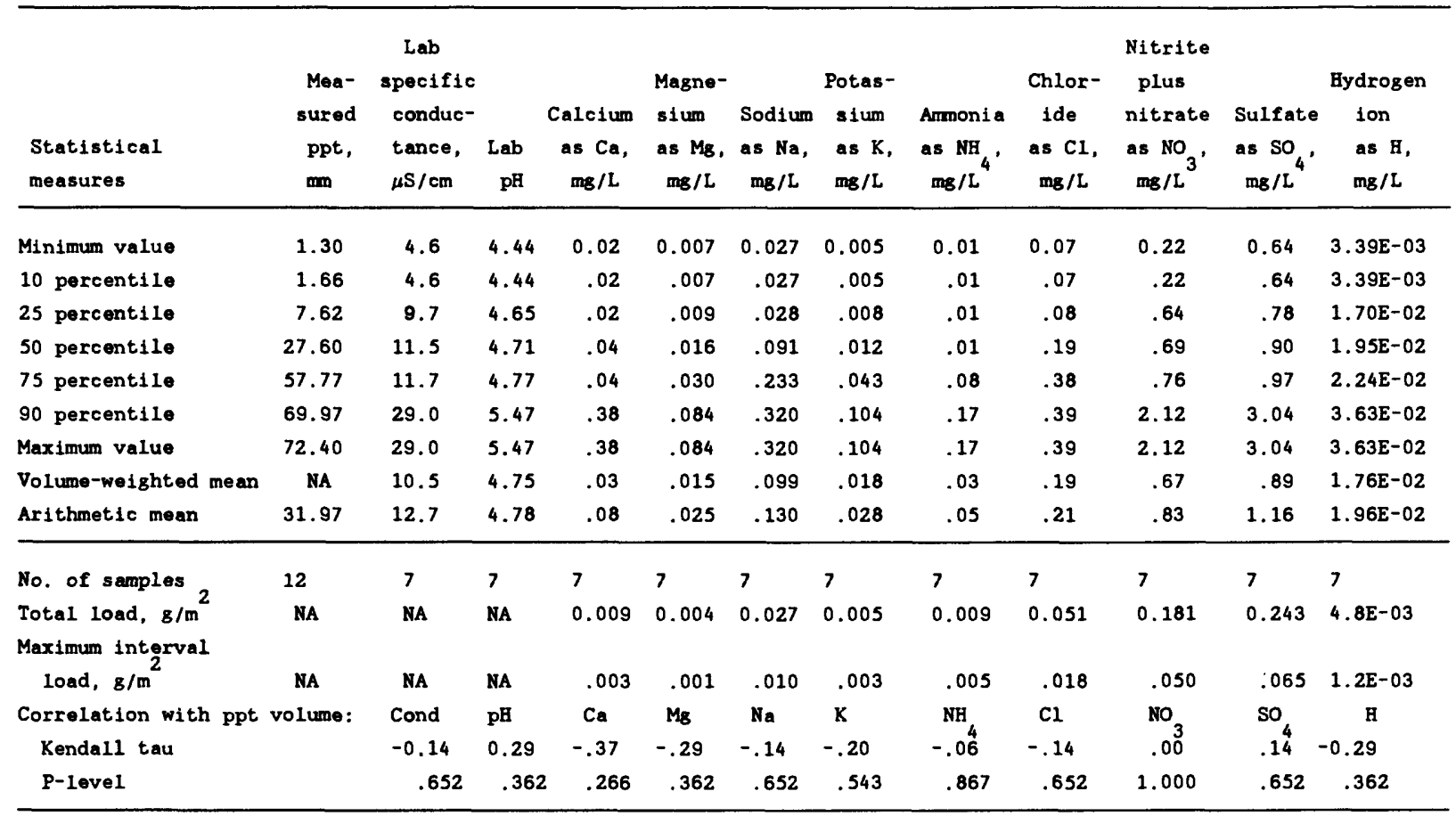

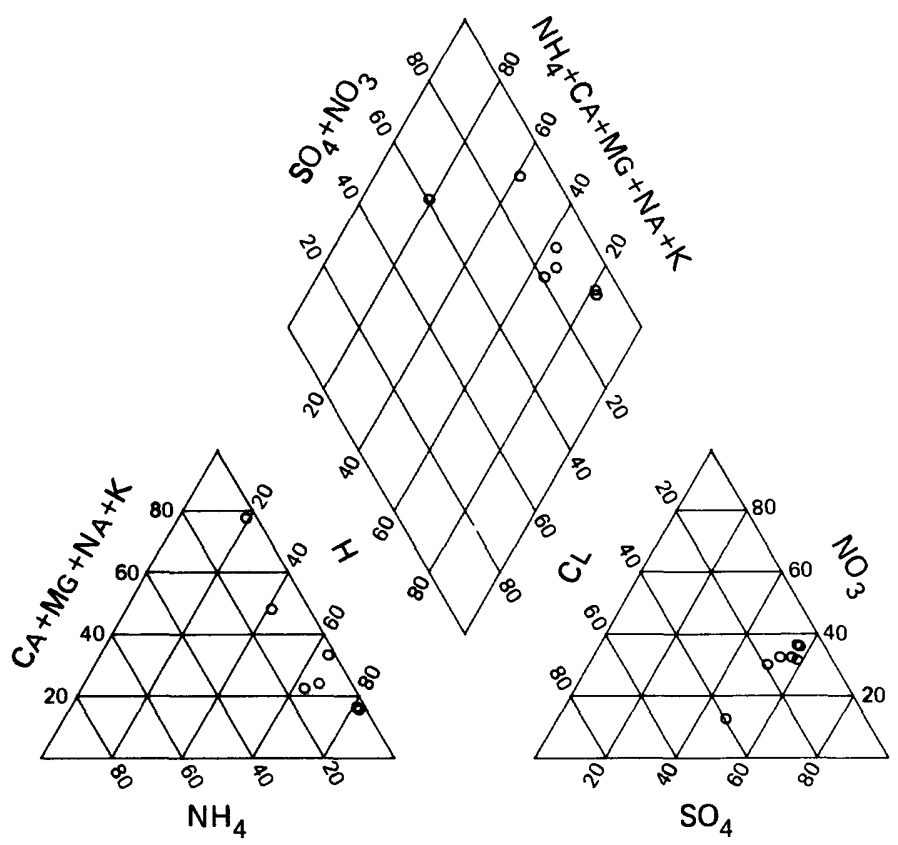

Percentage composition of major ions for site NY68. 


\section{NATIONAL TRENDS NETWORK - 1983 CALENDER YEAR SUMMARY DATA}

[ppt = precipitation; $\mathrm{mm}=$ millimeters; $\mathrm{cm}=$ centimeters; $\mathrm{mg}=$ milligrams; $\mathrm{L}=11$ ters; $8=\mathrm{grams} ; \mathrm{m}=$ meter; $\mu \mathrm{s}=$ microsiemens; $\operatorname{cond}=$ specific conductance $]$

STATION: West Point, New York

CAL number: NY99

ADS number: $358 \mathrm{a} 00$

Station altitude above mean sea level, in meters : 203

Number of sampling intervals (days in parenthesis):

-- With ppt measurements: $16 \quad$ (112)

-- When ppt occurred: $16 \quad$ (112)

-- When ppt did not occur: $\quad 0 \quad(0)$

-- When sample volume was substituted for missing rain gage: 0 ( 0 )

-- With chemical samples: $16 \quad$ (112)
Latitude: $41^{\circ} 21^{\prime} 03^{\prime \prime}$ Longitude: $74^{\circ} 02^{\prime} 54^{\prime \prime}$

Station summary period: $09 / 13 / 1983$ to $01 / 03 / 1984$

Length of sumary period: 16 sampling intervals (112 days)

Percent summary period with ppt measurements: 30.2

Percent sumary period with chemical samples or no ppt: 30.2

Percent of total measured ppt with chemical samples: 100.0

Percent of total measured ppt in raingage that was

collected in the wet-sample bucket:

96.2

Total measured ppt, in m: 633.3

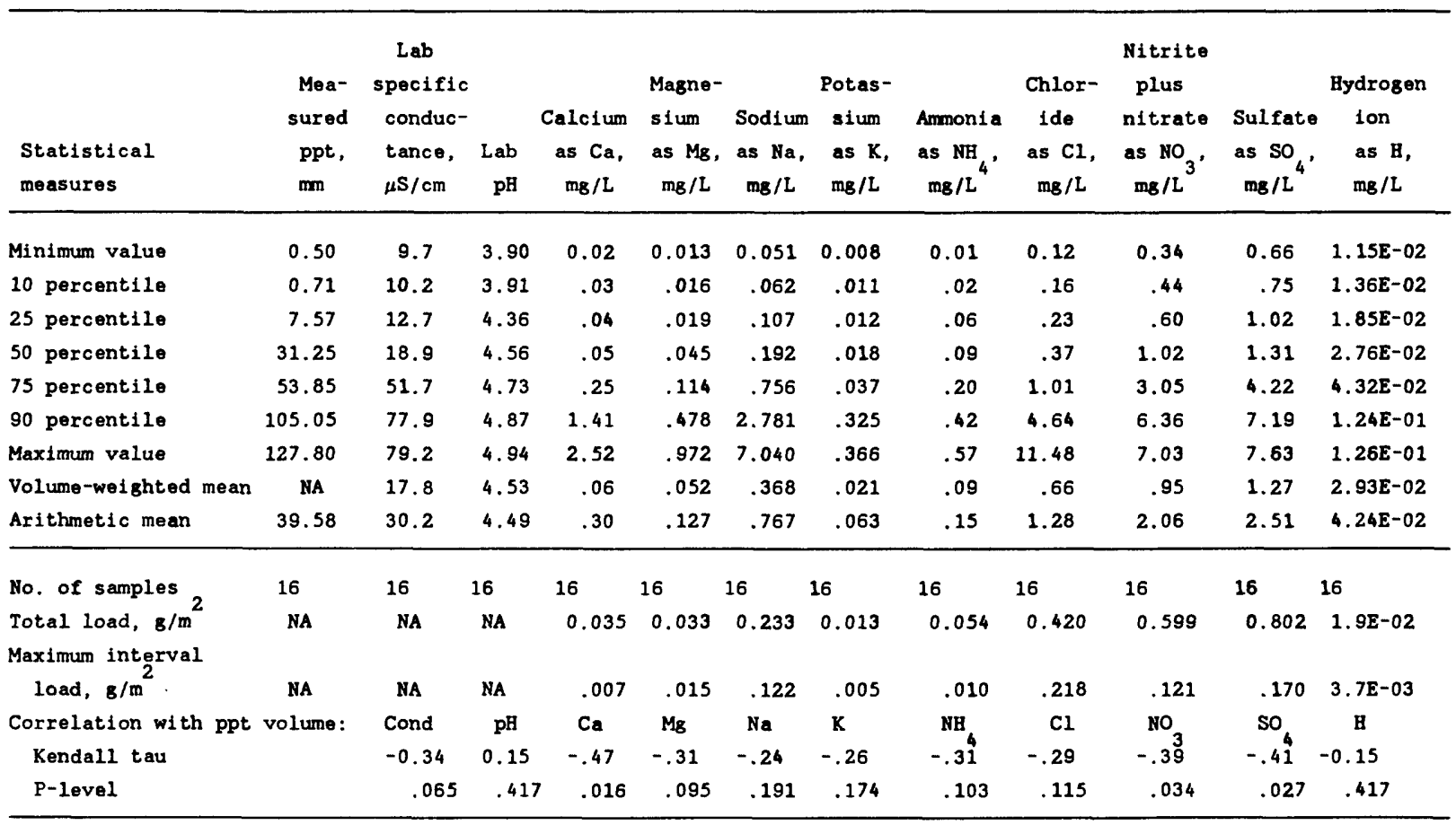

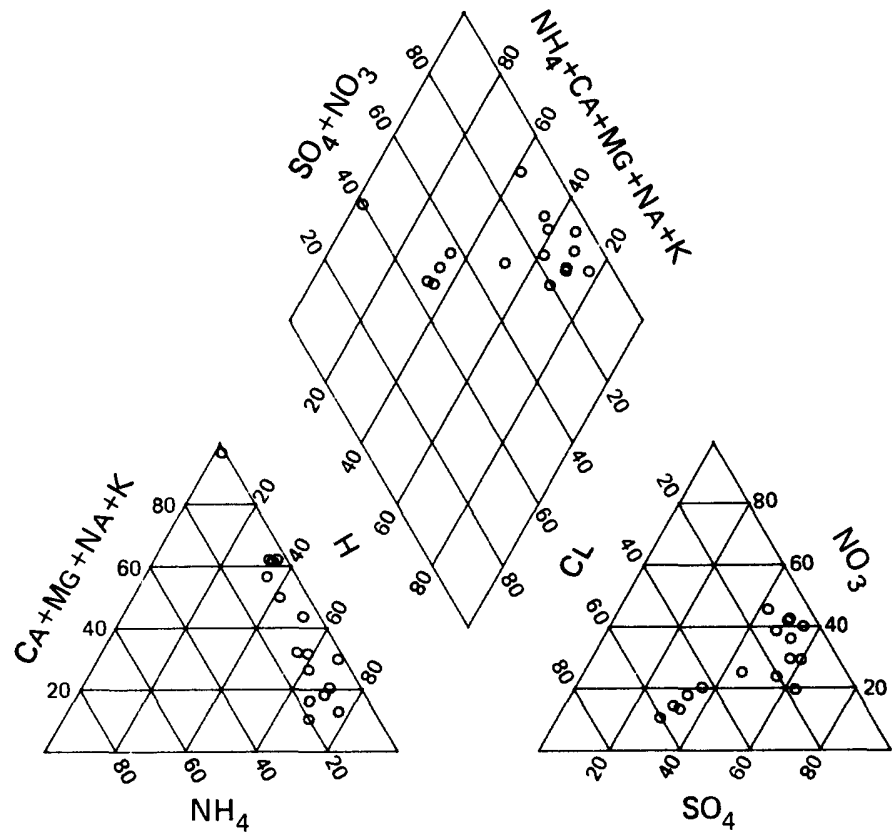

Percentage composition of major ions for site NY99. 


\section{NATIONAL TRENDS NETWORK -- 1983 CALENDER YEAR SUMMARY DATA}

lppt $=$ precipitation; $\mathrm{mm}=$ millimeters; $\mathrm{cm}=$ centimeters; $\mathrm{mg}=$ milligrams; L = liters;

$g=$ grams; $m=$ meter $; \mu s=$ microsiemens; cond $=$ specific conductance $]$

STATION: Caldwell, Ohio

CAL number: 0 OH49

ADS number: 056.00

Station altitude above mean sea level, in meters: 276

Number of sampling intervals (days in parenthesis):

-- With ppt messurements:

-- When ppt occurred: 52 (364)

-- Whan ppt did not occur: 1 ( 7)

-- When sample volume was substituted for missing rain gage:

-- with chemical samples: $32 \quad$ (224)
Latitude: $39^{\circ} 47^{\prime} 34^{\prime \prime}$ Longitude: $81^{\circ} 31^{\prime} 52^{\prime \prime}$

Station summary period: $12 / 28 / 1982$ to $01 / 03 / 1984$

Length of summary period: 53 sampling intervals ( 371 days)

Percent summary period with ppt measurements: $\quad 100.0$

Percent summary period with chemical samples or no ppt: 66.3

Percent of total measured ppt with chemical samples: 56.2

Percent of total measured ppt in raingage that was

collected in the wet-sample bucket:

99.6

Total measured ppt, in $\mathrm{mm}: 1034.2$

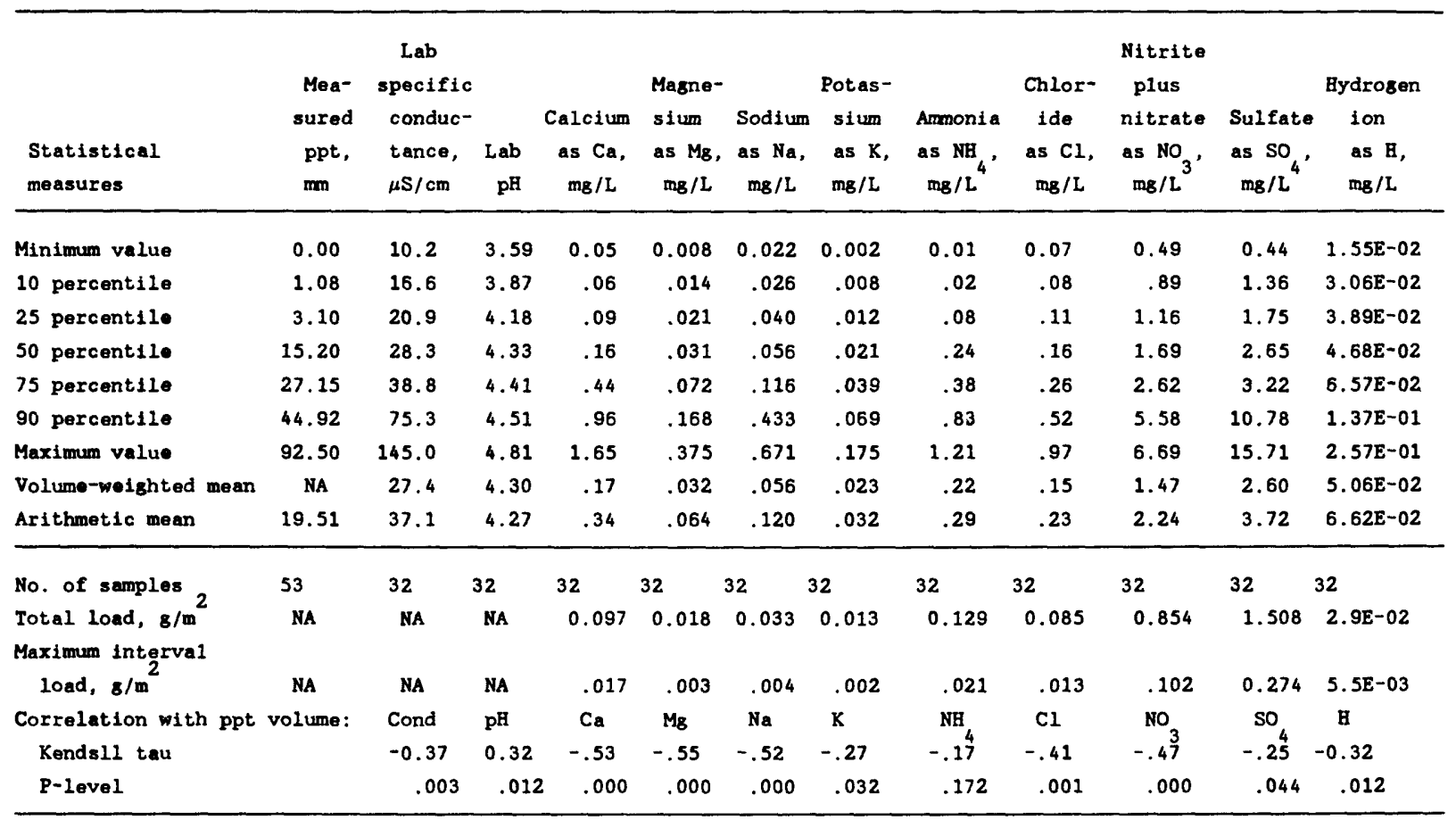

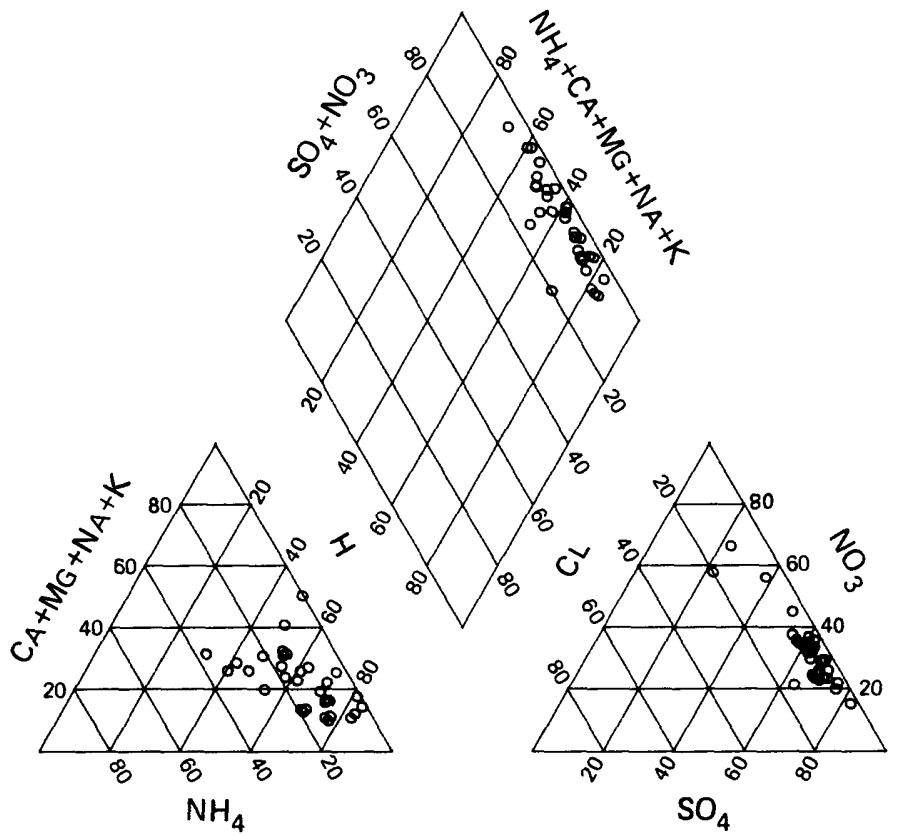

Percentage composition of major ions for site OH49. 


\section{NATIONAL TRENDS NETWORK - 1983 CALENDER YEAR SUMMARY DATA}

[ppt $=$ precipitation; $\mathrm{mm}=$ millimeters; $\mathrm{cm}=$ centimeters; $\mathrm{mg}=$ milligrams; $\mathrm{L}=1 \mathrm{iters}$;

$\mathrm{g}=\mathrm{grams} ; \mathrm{m}=$ meter; $\mu \mathrm{s}=$ microsiemens; cond = specific conductance $]$

STATION: Great Plains Apiaries, Oklahoma

Latitude: $34^{\circ} 58^{\prime} 48^{\prime \prime}$ Longitude: $97^{\circ} 31^{\prime} 16^{\prime \prime}$

CAL number: OK17

ADS number: $364 \mathrm{a} 00$

Map ID number: 80

Station altitude above mean sea level, in meters: 330

Number of sampling intervals (days in parenthesis):

-- With ppt measurements: 39 (277)

-- When ppt occurred: 33 (236)

-- When ppt did not occur: 6 ( 41)

-- When sample volume was substituted for missing rain gage: 2 ( 14 )

-- With chemical samples: 26 (190)
Station summary period: $03 / 29 / 1983$ to $01 / 03 / 1984$

Length of summary period: 42 sampling intervals (280 days)

Percent summary period with ppt measurements:

74.7

Percent summary period with chemical samples or no ppt: 62.3

Percent of total measured ppt with chemical samples: 93.0

Percent of total measured ppt in raingage that was

collected in the wet-sample bucket:

101.6

Total measured ppt, in $\mathrm{mm}: 914.9$

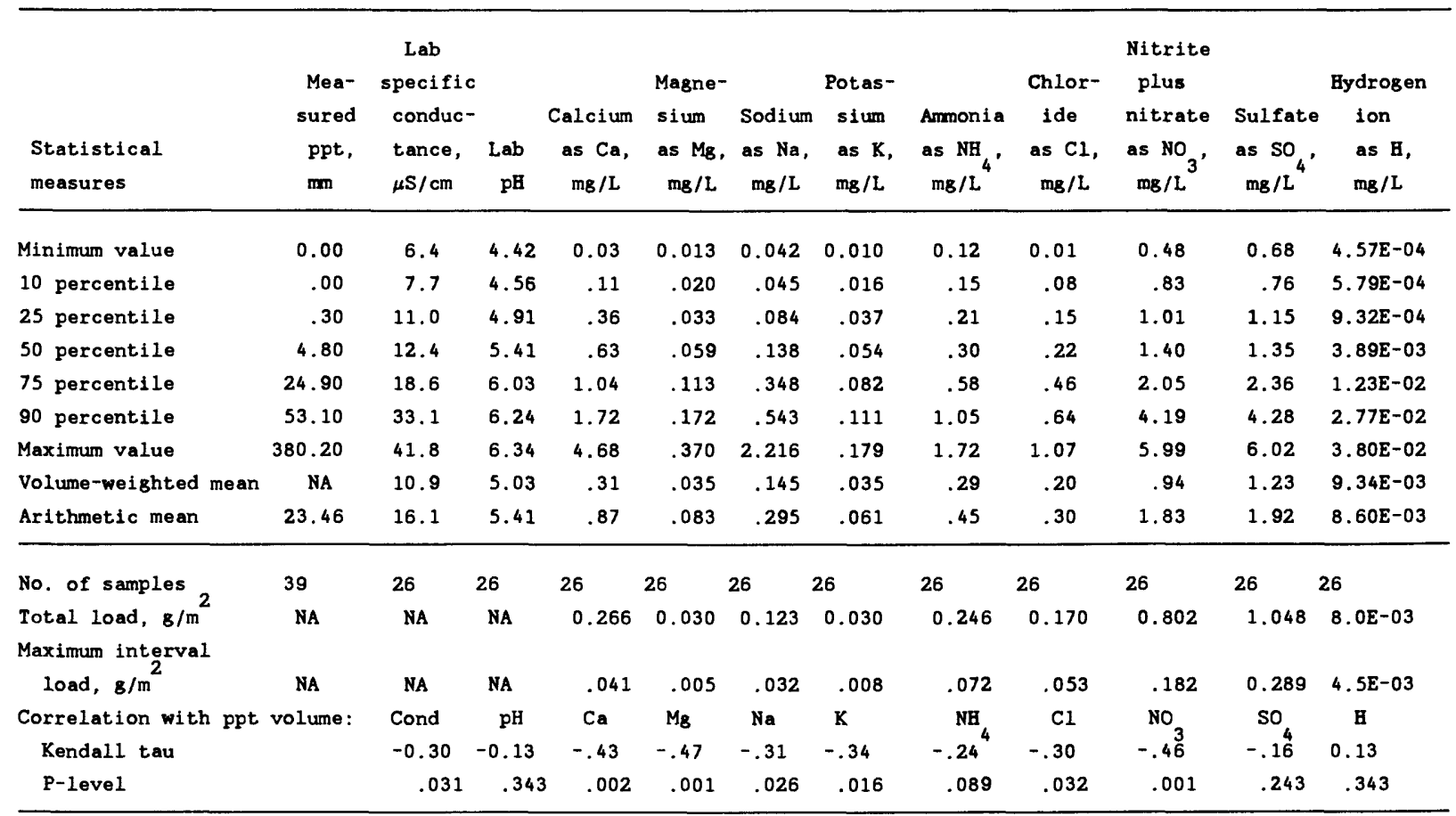

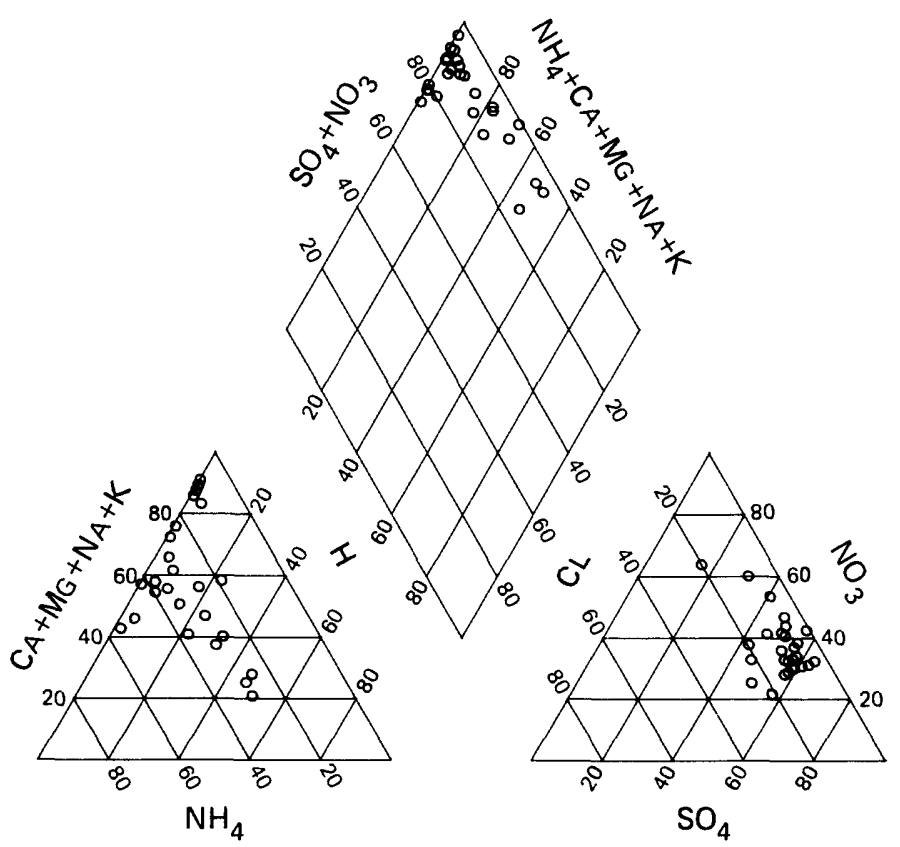

Percentage composition of major ions for site OK17. 
[ppt = precipitation; $\mathrm{mm}=$ millimeters; $\mathrm{cm}=$ centimeters; $\mathrm{mg}=$ milligrams; L $=1$ iters; 8 - grams; $m$ = meter; $\mu$ s = microsiemens; cond = specific conductance

STATION: Silver Lake Ranger, Oregon

CAL number: OR09 Map ID number: 81 ADS number: $367 a 00$

Station altitude above mean sea level, in meters: 1334 Number of sampling intervals (days in parenthesis):

-- With ppt measurements: 19 (133)

-- When ppt occurred: 15 (105)

-- When ppt did not occur: 4 ( 28)

-- When sample volume was substituted for missing rain gage: 0 ( 0 )

-- With chamical samples: $8 \quad$ ( 56)
Latitude: $43^{\circ} 07^{\prime} 22^{\prime \prime}$ Longitude: $121^{\circ} 03^{\prime} 28^{\prime \prime}$

Station summary period: $08 / 23 / 1983$ to $01 / 03 / 1984$

Length of summary period: 19 sampling intervals (133 days) Percent summary period with ppt measuraments: 35.8 Percent summary period with chemical samples or no ppt: 22.6 Percent of total measured ppt with chemical samples: 30.2 Percent of total measured ppt in raingage that was collected in the wet-sample bucket:

77.9

Total measured ppt, in $\mathrm{mm}: 186.8$

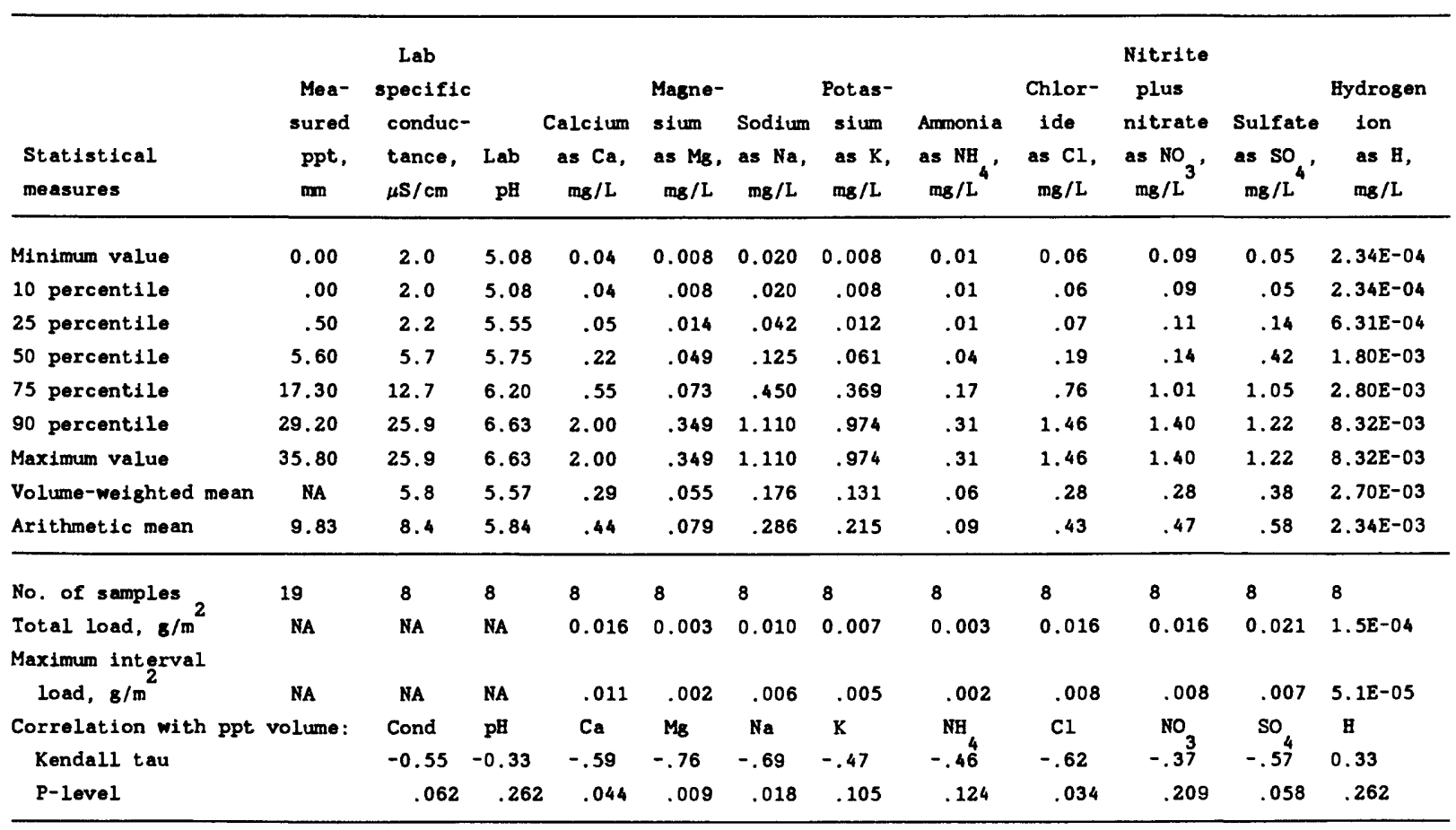

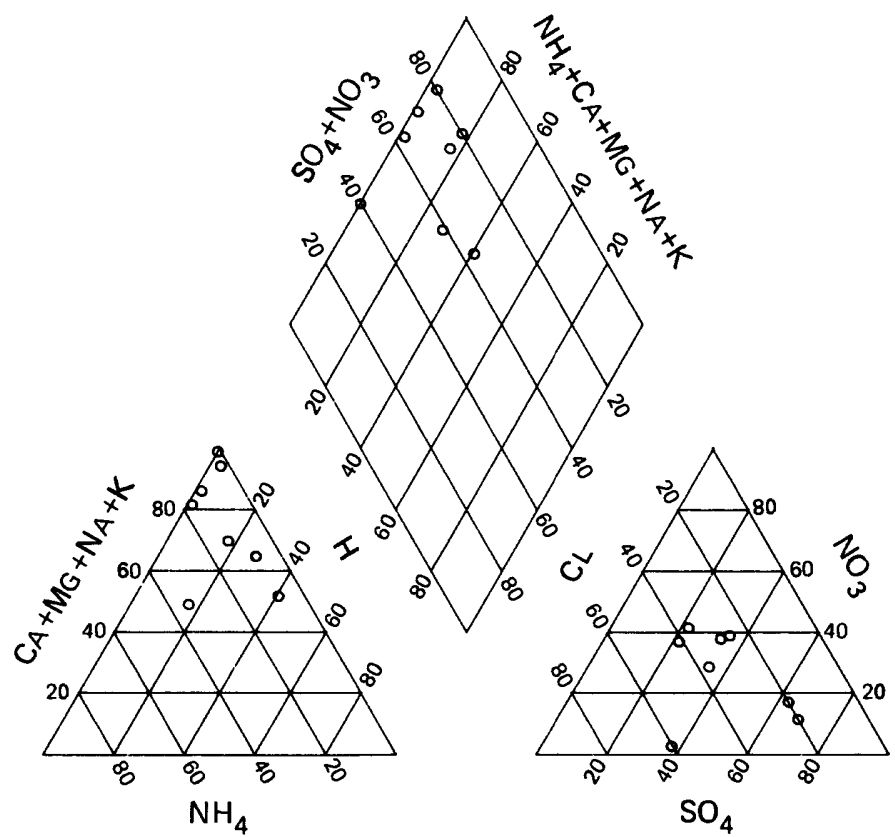

Percentage composition of major ions for site OR09. 


\section{NATIONAL TRENDS NETWORK -- 1983 CALENDER YEAR SUMMARY DATA}

Ippt = precipitation; $\mathrm{mm}=$ millimeters; $\mathrm{cm}=$ centimeters; $\mathrm{mg}=$ milligrams; L = Liters;

$8=8$ rams; $m=$ meter; $\mu \mathrm{s}=$ microsiemens; cond = specific conductance $]$

STATION: Salt Plains National Wildlife Refuge, Oklahoma CAL number: OKOO ADS number: $363 \mathrm{a} 00$ Map ID number: 79

Station altitude above mean sea level, in meters: 346 Number of sampling intervals (days in parenthesis):

-- With ppt measurements: 3 (21)

-- When ppt occurred: 2 (14)

-- When ppt did not occur: 1 ( 7)

-- When sample volume was subst1tuted for missing rain gage: 0 ( 0 )

-- With chemical samples: 1 ( 7)
Latitude: $36^{\circ} 48^{\prime} 08^{\prime \prime}$ Longitude: $\quad 98^{\circ} 12^{\prime} 37^{\prime \prime}$

Station summary period: $12 / 13 / 1983$ to $01 / 03 / 1984$

Length of summary period: 3 sampling intervals (21 days) Percent summary period with ppt measurements: 5.7

Percent surmary period with chemical samples or no ppt: 3.8 Percent of total measured ppt with chemical samples: $\quad 50.0$ Percent of total measured ppt in raingage that was collected in the wet-sample bucket:

Total measured ppt, in $\mathrm{mm}: 0.2$

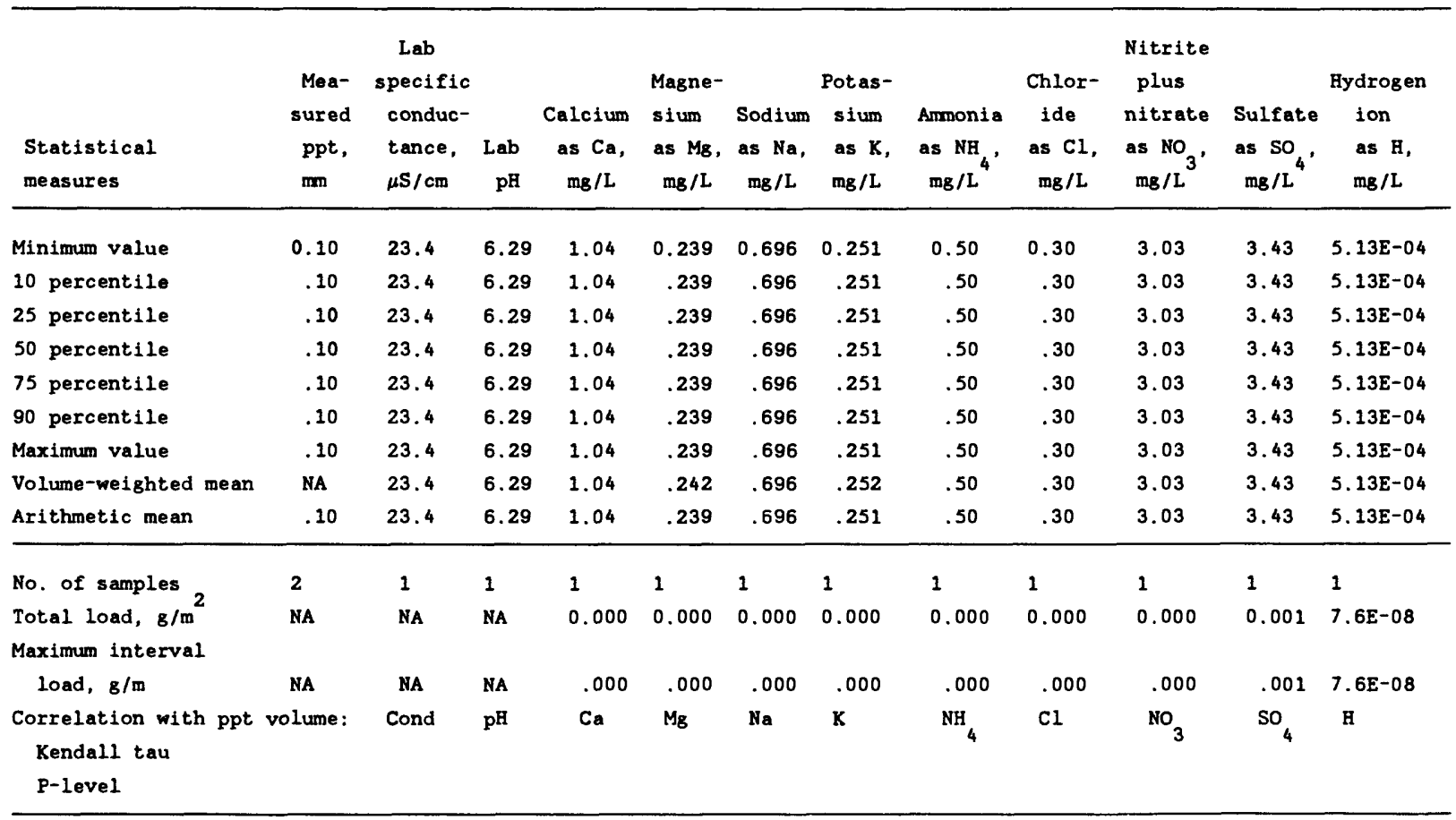

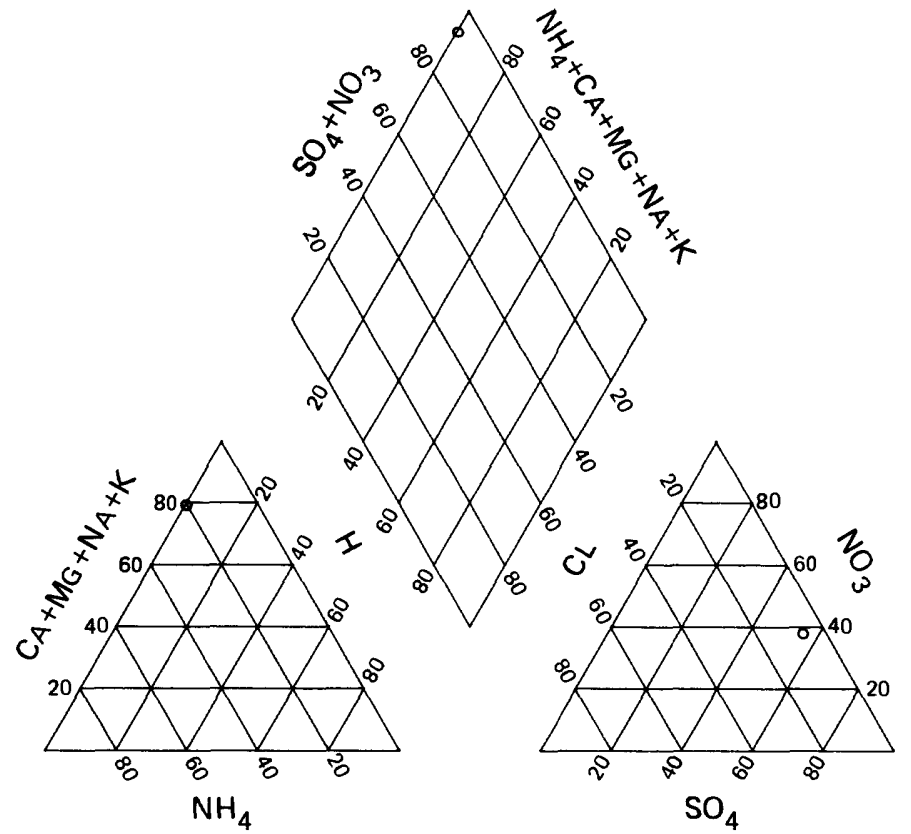

Percentage composition of major ions for site OK00. 
lppt $=$ precipitation; $\mathrm{mm}=$ millimeters; $\mathrm{cm}=$ centimeters; $\mathrm{mg}=$ milligrams; L = liters;

$\mathrm{g}=\mathrm{grams} ; \mathrm{m}=$ meter; $\mu \mathrm{s}=$ microsiemens; cond $=$ specific conductance $]$

STATION: H.J. Andrews, Oregon

CAL number: OR10

ADS number: 061a00

Station altitude above mean sea level, in meters: 472

Number of sampling intervals (days in parenthesis):

-- With ppt measurements: $53 \quad$ (371)

-- When ppt occurred. 51 (357)

-- When ppt did not occur: 2 ( 14)

-- When sample volume was substituted for missing rain gage: 0 ( 0$)$

-- With chemical samples: $32 \quad$ (225)
Latitude: $44^{\circ} 13^{\prime} 23^{\prime \prime}$ Longitude: $122^{\circ} 14^{\prime} 32^{\prime \prime}$

Station surmary period: $12 / 28 / 1982$ to $01 / 03 / 1984$

Length of summary period: 53 sampling intervals ( 371 days)

Percent summary period with ppt measurements: 100.0

Percent sumary period with chemical samples or no ppt: 64.4

Percent of total measured ppt with chemical samples: 59.4

Percent of totel measured ppt in raingage that was

collected in the wet-sample bucket:

95.8

Total measured ppt, in mo: 2587.4

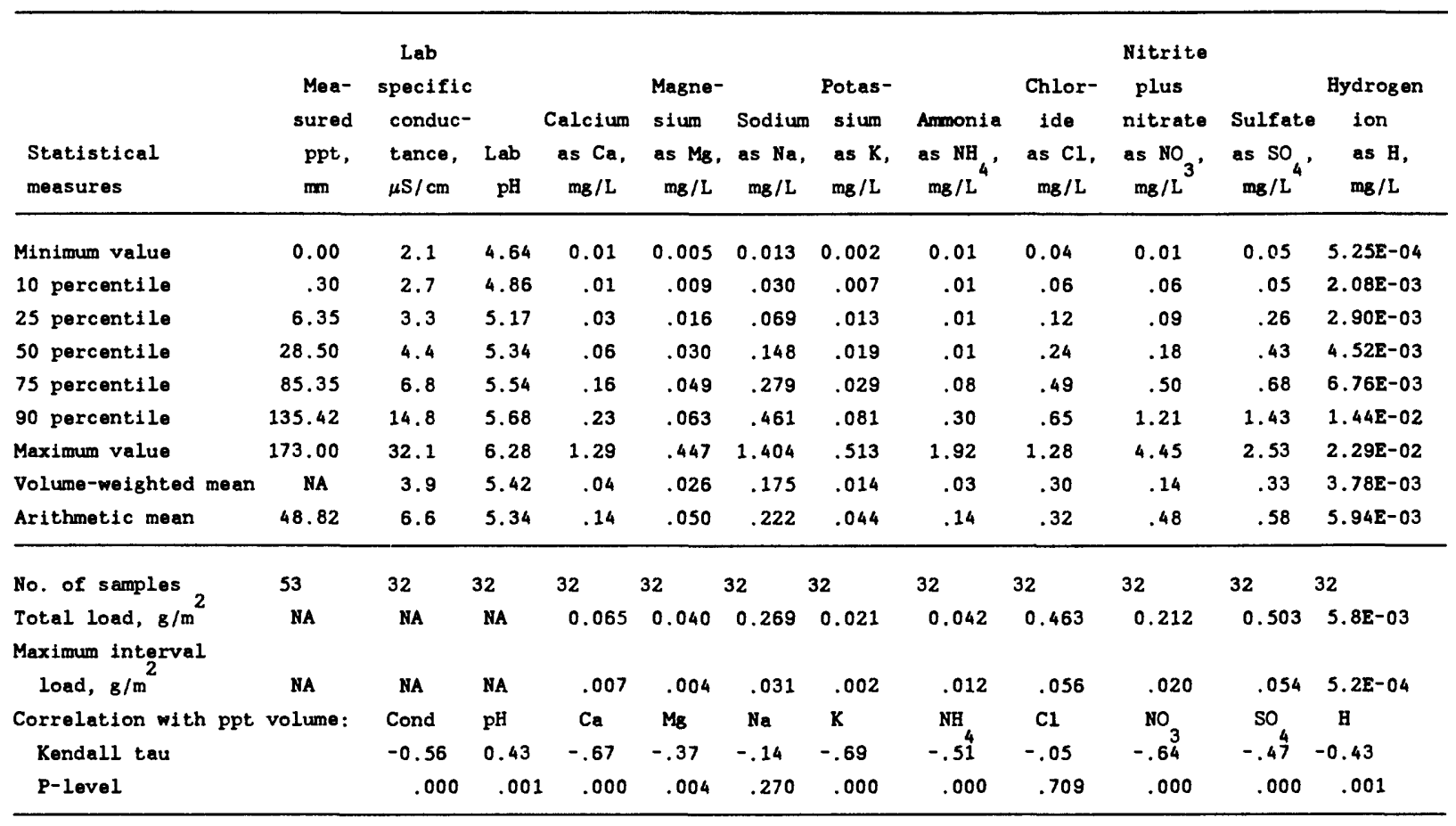

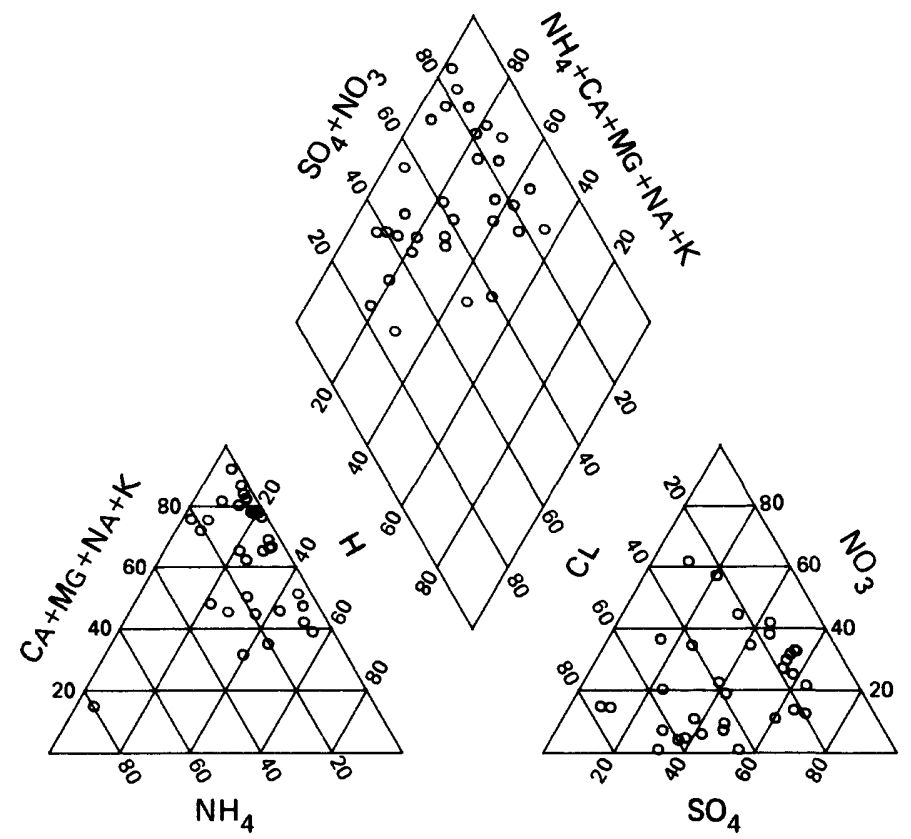

Percentage composition of major ions for site OR 10 . 
lppt $=$ precipitation; $\mathrm{mm}=$ millimeters; $\mathrm{cm}=$ centimeters; $\mathrm{mg}=$ milligrams; $\mathrm{L}=11$ ters;

$\mathrm{g}=\mathrm{grams} ; \mathrm{m}=$ meter $\boldsymbol{\mu \mathrm { s }}=\operatorname{microsiemens;}$ cond $=$ specific conductance

STATION: Hyslop, Oregon

CAL number: OR97

ADS number: $366 \mathrm{a} 00$

Map ID number: 84

Station altitude above mean sea level, in meters: 69 Number of sampling intervals (days in parenthesis):

-- With ppt measurements: $\quad 36 \quad$ (252)

-- When ppt occurred: 33 (231)

-- When ppt did not occur: 3 ( 21)

-- When sample volume was substituted for missing rain gage: 1 ( 7$)$

-- With chemical samples: 27 (189)
Latitude: $44^{\circ} 38^{\prime} 04^{\prime \prime}$ Longitude: $123^{\circ} 11^{\prime} 24^{\prime \prime}$

Station summary period: 04/26/1983 to 01/03/1984

Length of summary period: 36 sampling intervals (252 days)

Percent summary period with ppt measurements:

67.9

Percent summary period with chemical samples or no ppt: 56.6

Percent of total measured ppt with chemical samples: 94.9

Percent of total measured ppt in raingage that was

collected in the wet-sample bucket:

91.8

Total measured ppt, in m: 624.3

\begin{tabular}{|c|c|c|c|c|c|c|c|c|c|c|c|c|}
\hline $\begin{array}{l}\text { Ststistical } \\
\text { measures }\end{array}$ & $\begin{array}{l}\text { Mea- } \\
\text { sured } \\
\text { ppt, } \\
\text { mm }\end{array}$ & $\begin{array}{l}\text { Lab } \\
\text { specific } \\
\text { conduc- } \\
\text { tance, } \\
\mu \mathrm{S} / \mathrm{cm}\end{array}$ & Lab & $\begin{array}{c}\text { Calcium } \\
\text { as Ca, } \\
\mathrm{mg} / \mathrm{L}\end{array}$ & $\begin{array}{l}\text { Magne- } \\
\text { sium } \\
\text { as } \mathrm{Mg} \text {, } \\
\mathrm{mg} / \mathrm{L}\end{array}$ & $\begin{array}{l}\text { Sodium } \\
\text { as } \mathrm{Na} \text {, } \\
\mathrm{mg} / \mathrm{L}\end{array}$ & $\begin{array}{l}\text { Potas- } \\
\text { sium } \\
\text { as } \mathrm{K} \text {, } \\
\mathrm{mg} / \mathrm{L}\end{array}$ & $\begin{array}{l}\text { Ammonia } \\
\text { as } \mathrm{NH}_{\mathrm{mg}} / \mathrm{L}^{\prime}\end{array}$ & $\begin{array}{c}\text { Chlor- } \\
\text { ide } \\
\text { as Cl, } \\
\mathrm{mg} / \mathrm{L}\end{array}$ & $\begin{array}{l}\text { Nitrite } \\
\text { plus } \\
\text { nitrate } \\
\text { as } \mathrm{NO}_{3} \text {, } \\
\mathrm{mg} / \mathrm{L}\end{array}$ & $\begin{array}{l}\text { Sulfate } \\
\text { as } \mathrm{SO}_{\mathrm{mg} / \mathrm{L}^{\prime}}\end{array}$ & $\begin{array}{l}\text { Hydrogen } \\
\text { Ion } \\
\text { as } \mathrm{H}, \\
\mathrm{mg} / \mathrm{L}\end{array}$ \\
\hline Minimum value & 0.00 & 2.9 & 4.63 & 0.02 & 0.007 & 0.032 & 0.008 & 0.01 & 0.08 & 0.04 & 0.05 & $3.31 E-04$ \\
\hline 10 percentile & .21 & 3.6 & 4.93 & .05 & .014 & .060 & .015 & .01 & .12 & .12 & .25 & $6.19 E-04$ \\
\hline 25 percentile & 1.42 & 6.2 & 5.22 & .07 & .032 & .123 & .024 & .01 & .19 & .20 & .46 & $1.95 E-03$ \\
\hline 50 percentile & 7.25 & 7.0 & 5.43 & .10 & .063 & .321 & .042 & .06 & .44 & .26 & .56 & $3.72 \mathrm{E}-03$ \\
\hline 75 percentile & 28.30 & 10.2 & 5.71 & .20 & .091 & .634 & .085 & .09 & 1.07 & .70 & .86 & $6.03 \mathrm{E}-03$ \\
\hline 90 percentile & 55.62 & 16.1 & 6.22 & .41 & .142 & .974 & .123 & .26 & 1.78 & 1.29 & 1.37 & $1.18 \mathrm{E}-02$ \\
\hline Maximum value & 83.10 & 20.7 & 6.48 & .86 & .252 & 2.100 & .150 & .87 & 3.85 & 1.98 & 1.85 & $2.34 \mathrm{E}-02$ \\
\hline Volume-weighted mean & NA & 8.2 & 5.40 & .09 & .088 & .677 & .039 & .05 & 1.23 & .27 & .53 & $4.01 E-03$ \\
\hline No. of samples, & 36 & 27 & 27 & 27 & 27 & 27 & 27 & 27 & 27 & 27 & 27 & 27 \\
\hline $\begin{array}{l}\text { Total load, } \mathrm{g} / \mathrm{m}^{2} \\
\text { Maximum interval }\end{array}$ & NA & NA & NA & 0.052 & 0.052 & 0.401 & 0.023 & 0.032 & 0.727 & 0.159 & 0.315 & $2.4 \mathrm{E}-03$ \\
\hline load, $8 / \mathrm{m}^{2}$ & NA & NA & NA & .009 & .021 & .174 & .007 & .005 & .320 & .017 & .065 & $2.7 E-04$ \\
\hline $\begin{array}{l}\text { Correlation with ppt } \\
\text { Kendall tau }\end{array}$ & volume: & $\begin{array}{l}\text { Cond } \\
-0.18\end{array}$ & $\begin{array}{l}\mathrm{pH} \\
0.07\end{array}$ & $\begin{array}{l}\mathrm{Ca} \\
-.67\end{array}$ & $\begin{array}{l}\mathrm{Mg} \\
-.15\end{array}$ & $\begin{array}{l}\mathrm{Na} \\
.03\end{array}$ & $\begin{array}{l}K \\
-.47\end{array}$ & $\begin{array}{l}\mathrm{NH}_{4} \\
-.09\end{array}$ & $\begin{array}{l}\mathrm{Cl} \\
.11\end{array}$ & $\begin{array}{l}\mathrm{NO}_{3} \\
-.37\end{array}$ & $\begin{array}{l}\text { so } \\
-.35\end{array}$ & $\begin{array}{c}\mathrm{H} \\
-0.07\end{array}$ \\
\hline P-level & & .189 & .631 & .000 & .260 & .802 & .001 & .533 & .404 & .008 & .012 & .631 \\
\hline
\end{tabular}

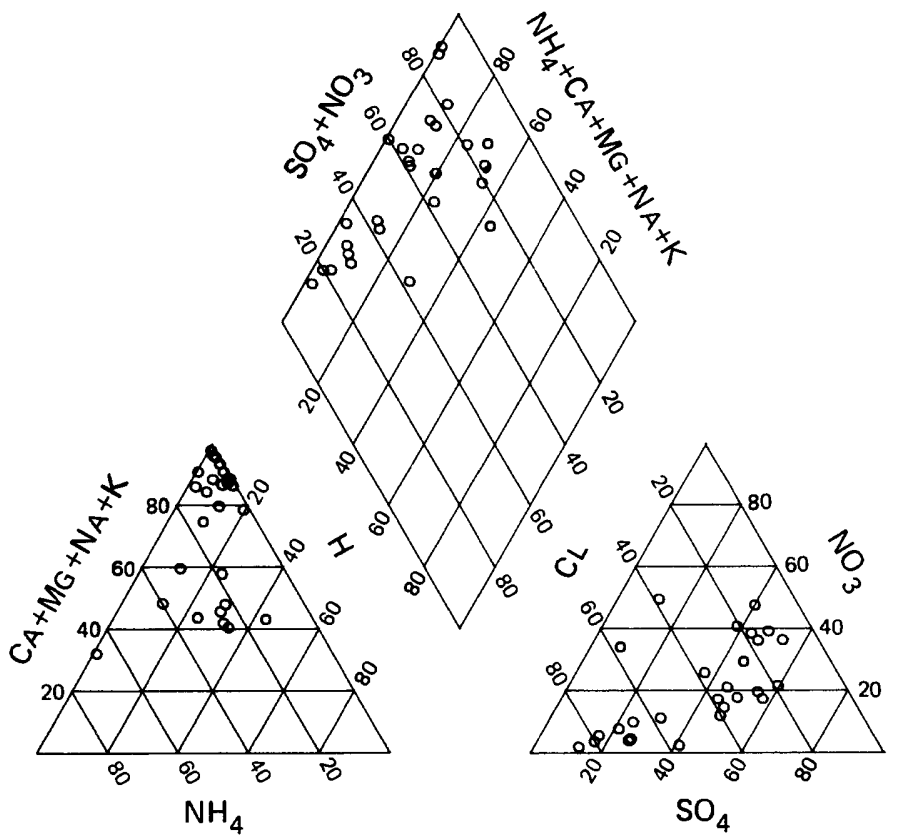

Percentage composition of major ions for site OR97. 
[ppt $=$ precipitation; $\mathrm{mm}=$ millimeters; $\mathrm{cm}=$ centimeters; $\mathrm{mg}=$ milligrams; $\mathrm{L}=1$ liters;

$\mathrm{g}=\mathrm{grams} ; \mathrm{m}=$ meter; $\mu \mathrm{s}=$ microsiemens; cond = specific conductance $]$

STATION: Schmidt Farm, Oregon

CAL number: OR99

ADS number: $060 \mathrm{a} 00$

Station altitude above mean sea level, in meters: 69

Number of sampling intervals (days in psrenthesis):

-- With ppt measurements: 17 (119)

-- When ppt occurred: 17 (119)

-- When ppt did not occur: $0 \quad(0)$

-- When sample volume was substituted for missing rain gage: 15 (105)

-- With chemical samples: 15 (105)
Latitude: $44^{\circ} 37^{\prime} 35^{\prime \prime}$ Longitude: $123^{\circ} 12^{\prime} 50^{\prime \prime}$

Station summary period: $12 / 28 / 1982$ to $04 / 26 / 1983$

Length of summary period: 17 sampling intervals ( 119 days)

Percent summary period with ppt measurements:

32.1

Percent summary period with chemical samples or no ppt: 28.3

Percent of total measured ppt with chemical samples: 95.2

Percent of total measured ppt in raingage that was

collected in the wet-sample bucket:

Total measured ppt, in $\mathrm{mm}: 611.1$

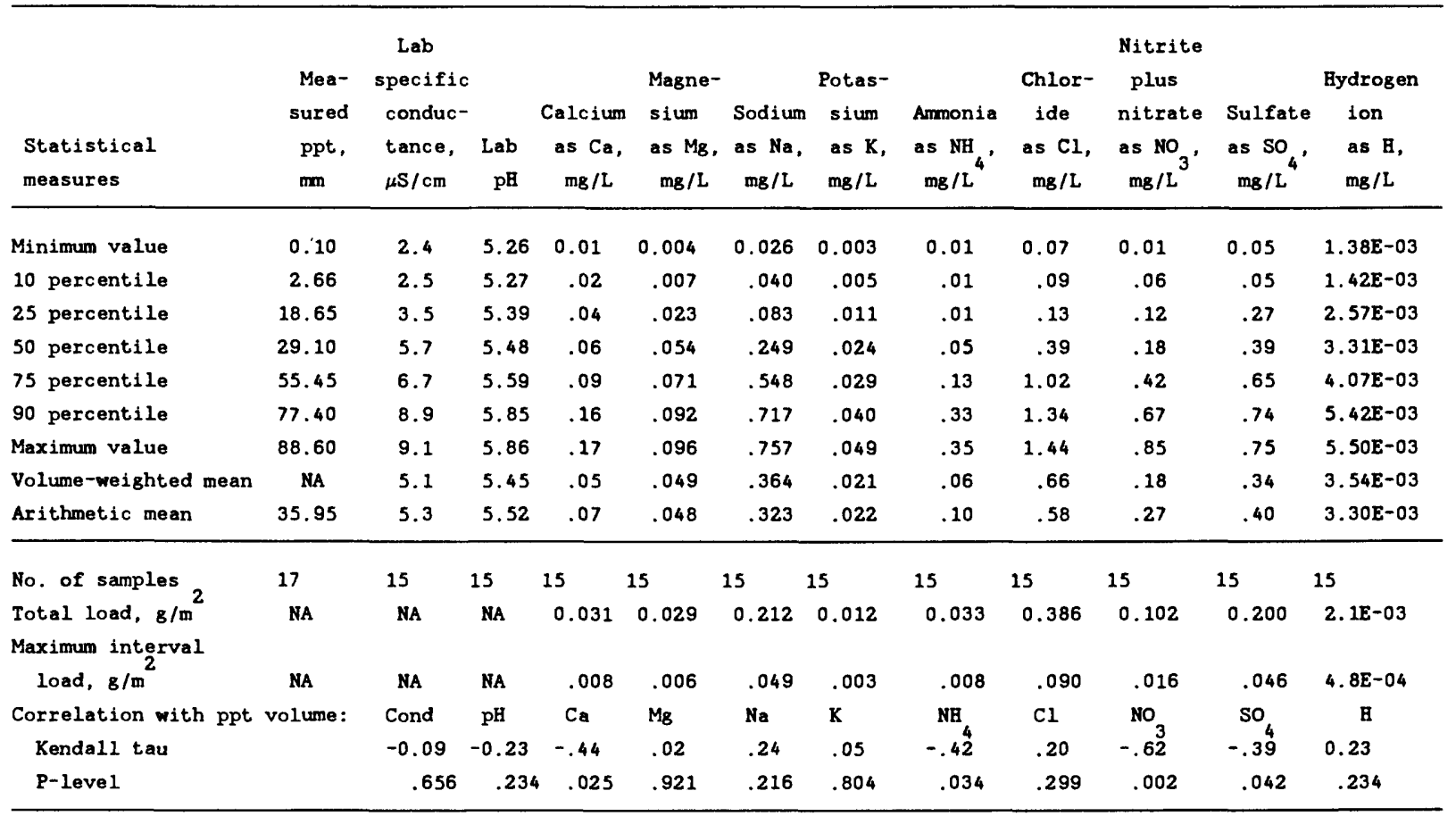

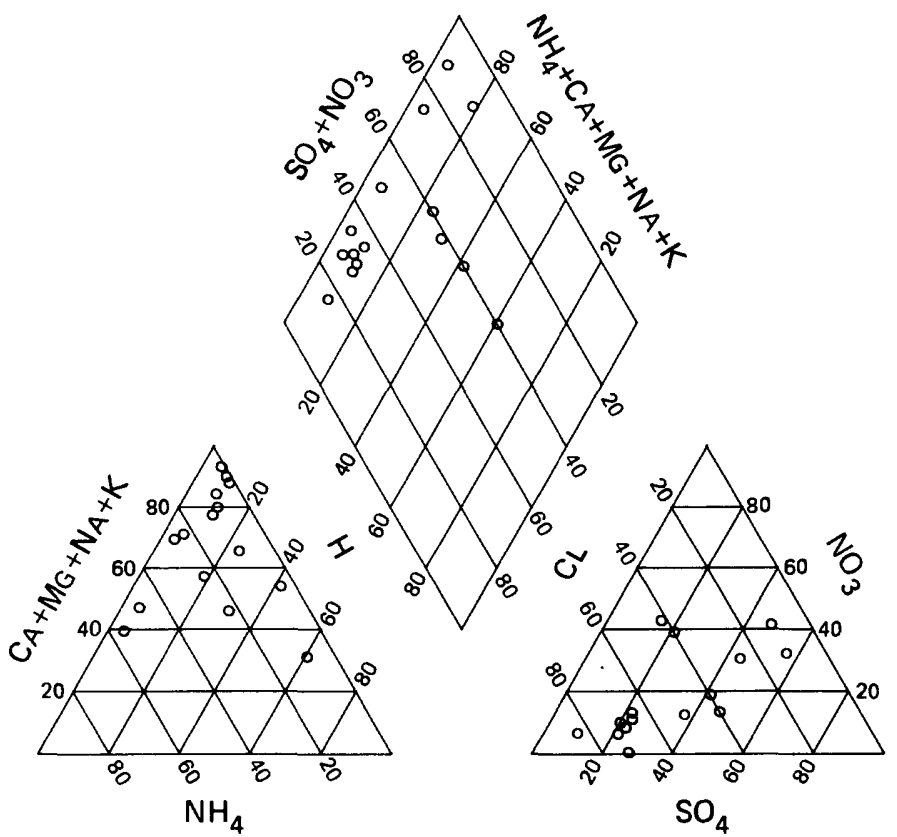

Percentage composition of major ions for site OR99. 


\section{NATIONAL TRENDS NETWORK -- 1983 CALENDER YEAR SUMMARY DATA}

[ppt = precipitation; $\mathrm{mm}=$ millimeters; $\mathrm{cm}=$ centimeters; $\mathrm{mg}=$ milligrams; L = Iiters;

$8=$ grams; $m=$ meter; $\mu \mathrm{s}=$ microsiemens; cond = specific conductance

STATION: Pennsylvania State NTH, Pennsylvania

CAL number: PA15

Map ID number: 85

ADS number: $065 \mathrm{b00}$

Station altitude above mean sea level, in meters: 393 Number of sampling intervals (days in parenthesis)

-- With ppt measurements:

-- When ppt occurred:

-- When ppt did not occur:

-- When sample volume was substituted for missing rain gage:

-- With chemical samples:
Latitude: $40^{\circ} 47^{\prime} 18^{\prime \prime}$ Longitude: $77^{\circ} 56^{\prime} 47^{\prime \prime}$

Station summary period: $06 / 07 / 1983$ to $01 / 03 / 1984$

Length of summary period: 30 sampling intervals (210 days) Percent summary period with ppt measurements:

56.6

Percent summary period with chemical samples or no ppt: 43.4

Percent of total measured ppt with chemical samples: 80.7

Percent of total measured ppt in raingage that was

collected in the wet-sample bucket:

98.0

Total measured ppt, in $\mathrm{mm}: 585.5$

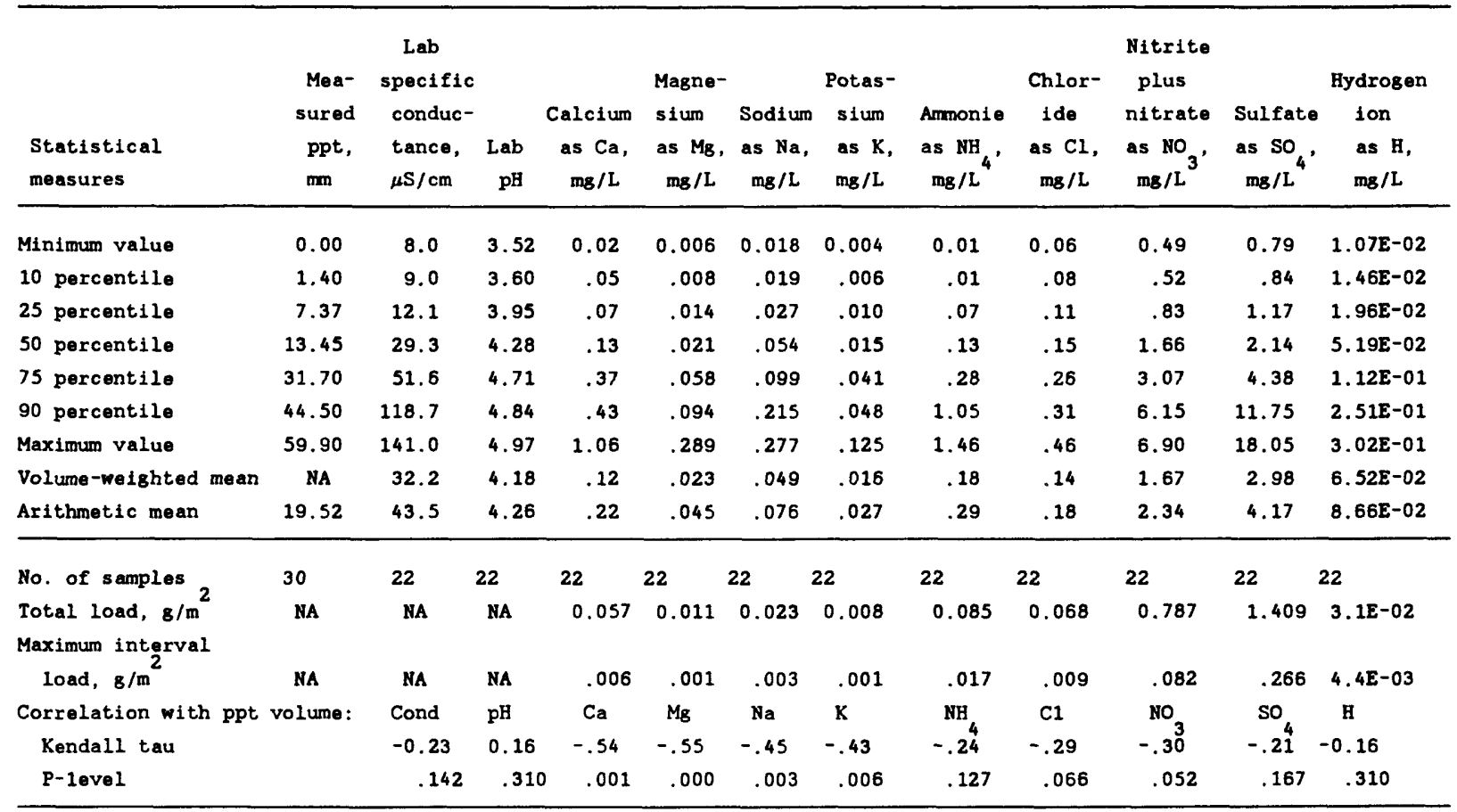

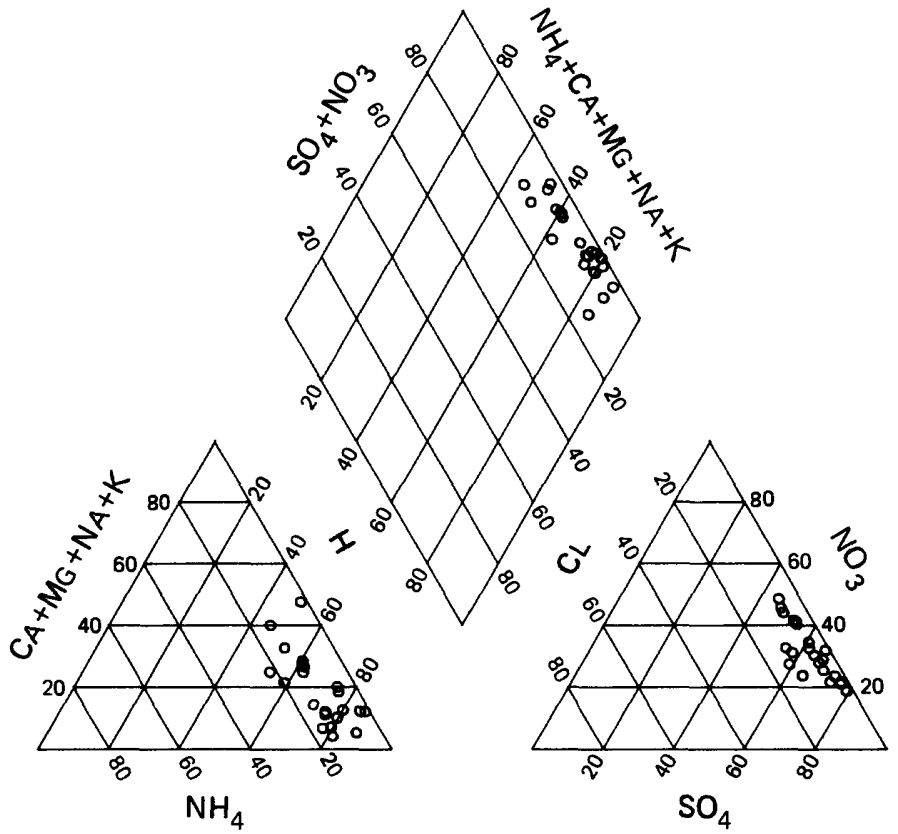

Percentage composition of major ions for site PA15. 


\section{NATIONAL TRENDS NETWORK -- 1983 CALENDER YEAR SUMMARY DATA}

[ppt $=$ precipitation; $\mathrm{mm}=$ millimeters; $\mathrm{cm}=$ centimeters; $\mathrm{mg}=$ milligrams; L $=$ liters;

$\mathrm{g}=\mathrm{grams} ; \mathrm{m}=$ meter $\boldsymbol{\mu s}=$ microsiemens; cond $=$ specific conductance $]$

STATION: Pennsylvania State NTN-2, Pennsylvania

CAL number: 15PA

ADS number: $065 \mathrm{c00}$

Station altitude above mean sea level, in meters: 393 Number of sampling intervals (days in parenthesis):

-- With ppt measurements:

-- When ppt occurred:

-- When ppt did not occur:

-- When sample volume was substituted for missing rain gage:

-- With chemical samples:
Latitude: $\quad 40^{\circ} 47^{\prime} 18^{\prime \prime}$ Longitude: $77^{\circ} 56^{\prime} 47^{\prime \prime}$

Station summary period: $10 / 04 / 1983$ to $01 / 03 / 1984$

Length of summary period: 13 sampling intervals ( 91 days) Percent summary period with ppt measurements:

Percent summary period with chemical samples or no ppt: 20.8 Percent of total measured ppt with chemical samples: 78.9 Percent of total measured ppt in raingege that was collected in the wet-sample bucket:

Total measured ppt, in man: 338.9

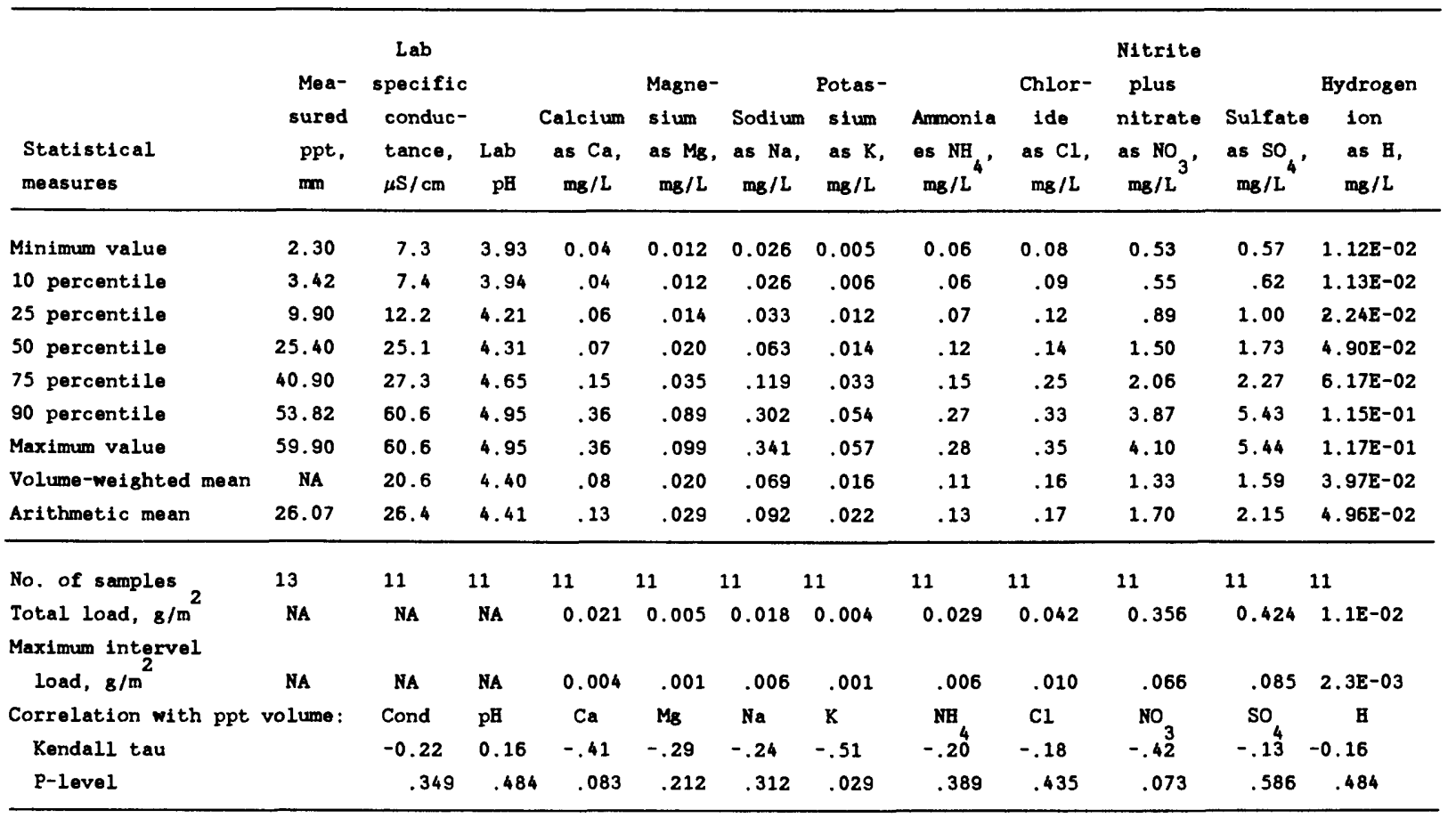

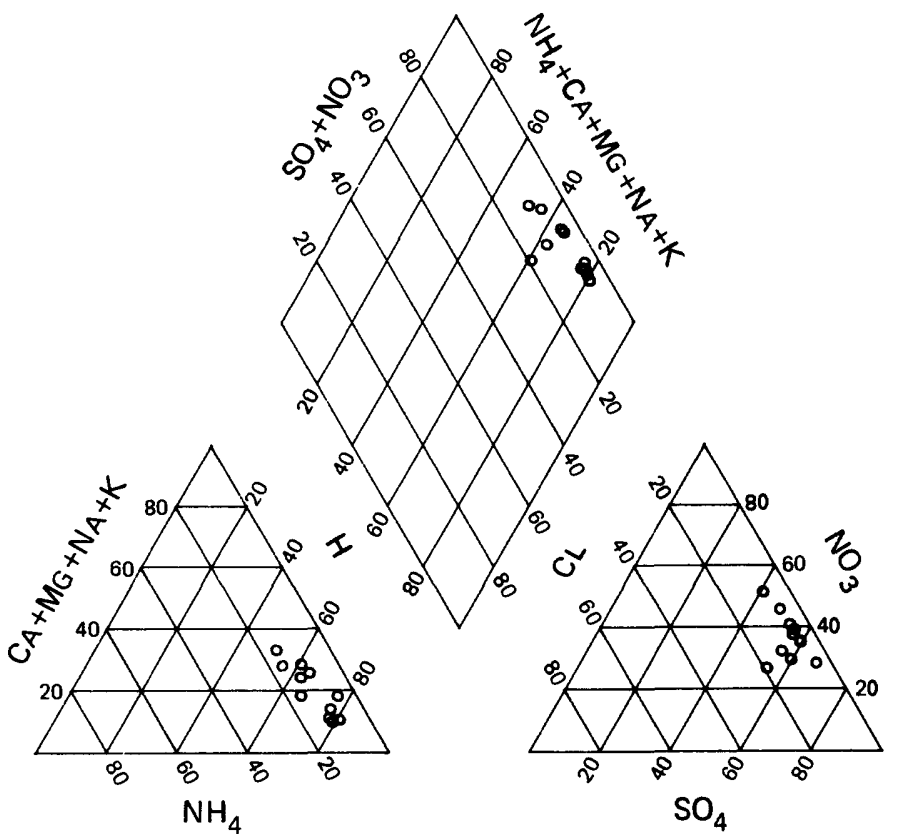

Percentage composition of major ions for site 15PA. 


\section{NATIONAL TRENDS NETWORK - - 1983 CALENDER YEAR SUMMARY DATA}

$[\mathrm{ppt}=$ precipitation; $\mathrm{mm}=$ millimeters; $\mathrm{cm}=$ centimeters; $\mathrm{mg}=$ milligrams; $\mathrm{L}=11$ ters;

$\mathrm{g}=\mathrm{grams} ; \mathrm{m}=$ meter $; \mu \mathrm{s}=$ microsiemens; cond = specific conductance $]$

STATION: Kane, Pennsylvania

CAL number: PA29

ADS number: $063 \mathrm{a} 00$

Station altitude above mean sea level, in meters: 618

Number of sampling intervals (days in parenthesis):

-- With ppt measurements:

-- When ppt occurred:

-- When ppt did not occur:

-- When sample volume was substituted for missing rain gage:

-- With chemical samples:

$\begin{array}{rr}53 & (371) \\ 52 & (364) \\ 1 & (7) \\ 0 & \left(\begin{array}{r}0 \\ 28\end{array}\right. \\ \end{array}$

Latitude: $41^{\circ} 35^{\prime} 52^{\prime \prime}$ Longitude: $78^{\circ} 46^{\prime} 04^{\prime \prime}$

Station summary period: $12 / 28 / 1982$ to $01 / 03 / 1984$

Length of summary period: 53 sampling intervals ( 371 days)

Percent summary period with ppt measurements: $\quad 100.0$

Percent summary period with chemical samples or no ppt: 54.7

Percent of total measured ppt with chemicel samples: 61.3

Percent of total measured ppt in raingage that was

collected in the wet-sample bucket:

94.8

Total measured ppt, in mm: 1281.1

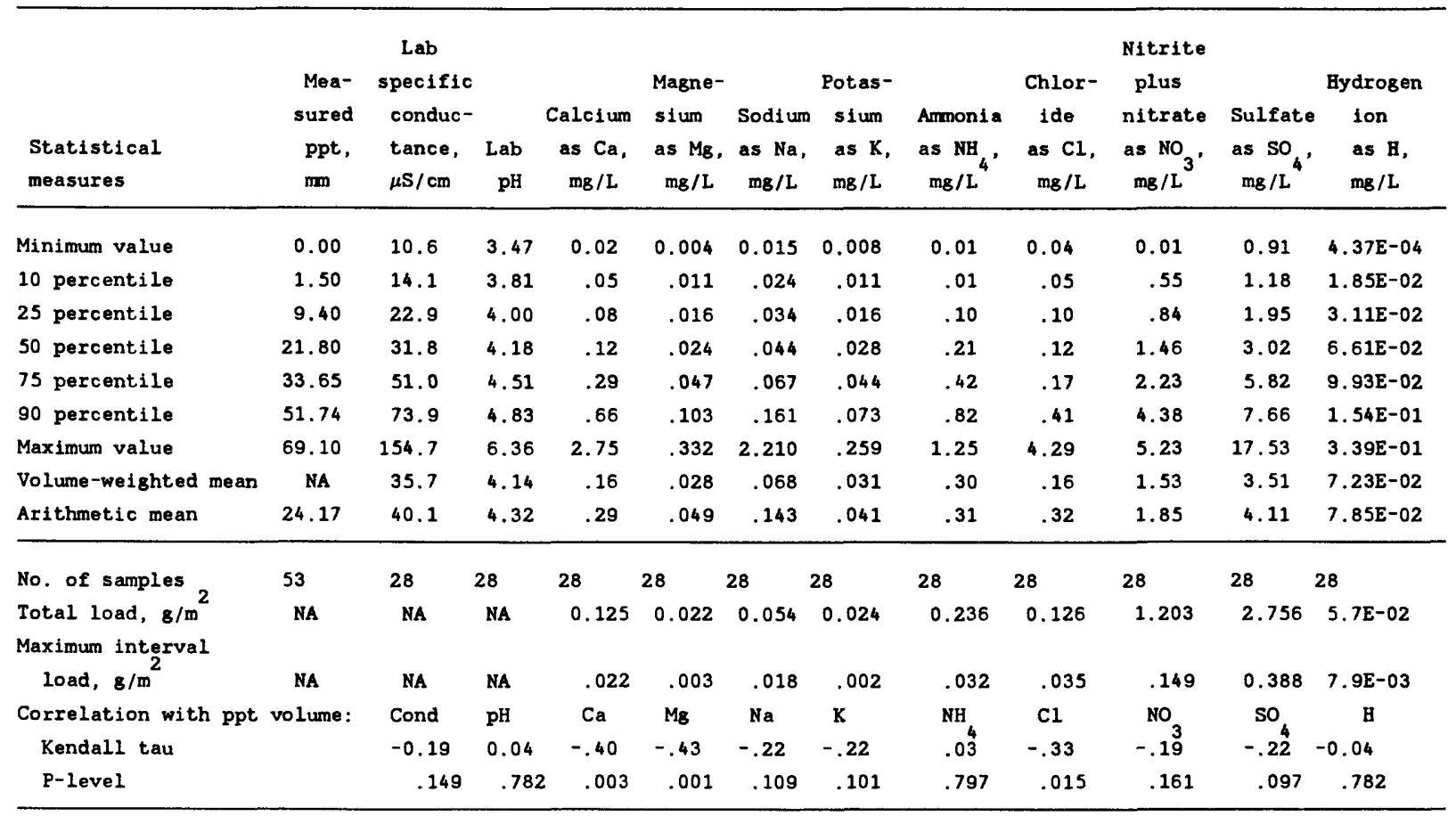

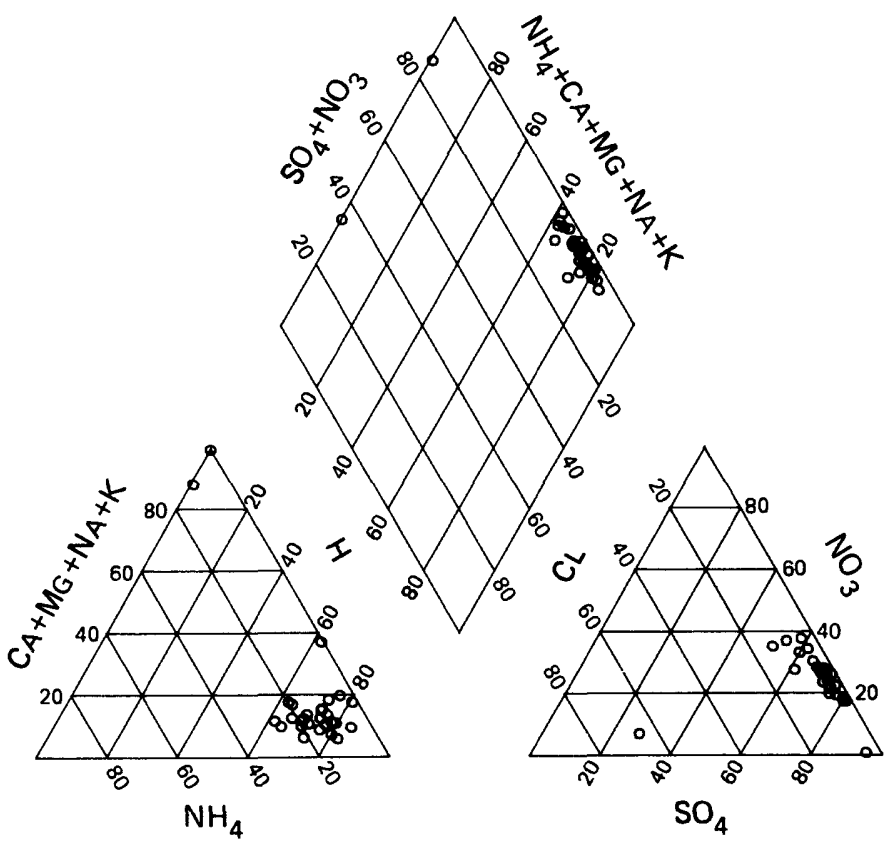

Percentage composition of major ions for site PA29. 


\section{NATIONAL TRENDS NETWORK - 1983 CALENDER YEAR SUMMARY DATA}

[ppt = precipltation; $\mathrm{mm}=$ millimeters; $\mathrm{cm}=$ centimeters; $\mathrm{mg}=$ milligrams; L = liters;

$\mathrm{g}=\mathrm{grams} ; \mathrm{m}=$ meter; $\mu \mathrm{s}=\mathrm{microsiemens} ;$ cond = specific conductance $]$

STATION: Milford, Pennsylvania (Gifford Pinchot)

CAL number: PA72

ADS number: $371 \mathrm{a} 00$

Map ID number: 88

Station altitude above mean sea level, in meters: 212

Number of sampling intervals (days in parenthesis):

-- With ppt measurements:

-- When ppt occurred:

-- When ppt did not occur:

-- When sample volume was subst1tuted for missing rain gage:

-- With chemical samples: $\quad 1$ ( 7)
Latitude: $41^{\circ} 19^{\prime} 39^{\prime \prime}$ Longitude: $74^{\circ} 49^{\prime} 13^{\prime \prime}$

Station summary period: $12 / 27 / 1983$ to $01 / 03 / 1984$

Length of sumary period: 1 sampling intervals ( 7 days)

Percent surmary period with ppt measurements:

1.9

Percent summary period with chemical samples or no ppt: 1.9

Percent of total measured ppt with chemical samples: 100.0

Percent of total measured ppt in raingage that was

collected in the wet-sample bucket:

101.2

Total measured ppt, in m: 25.4

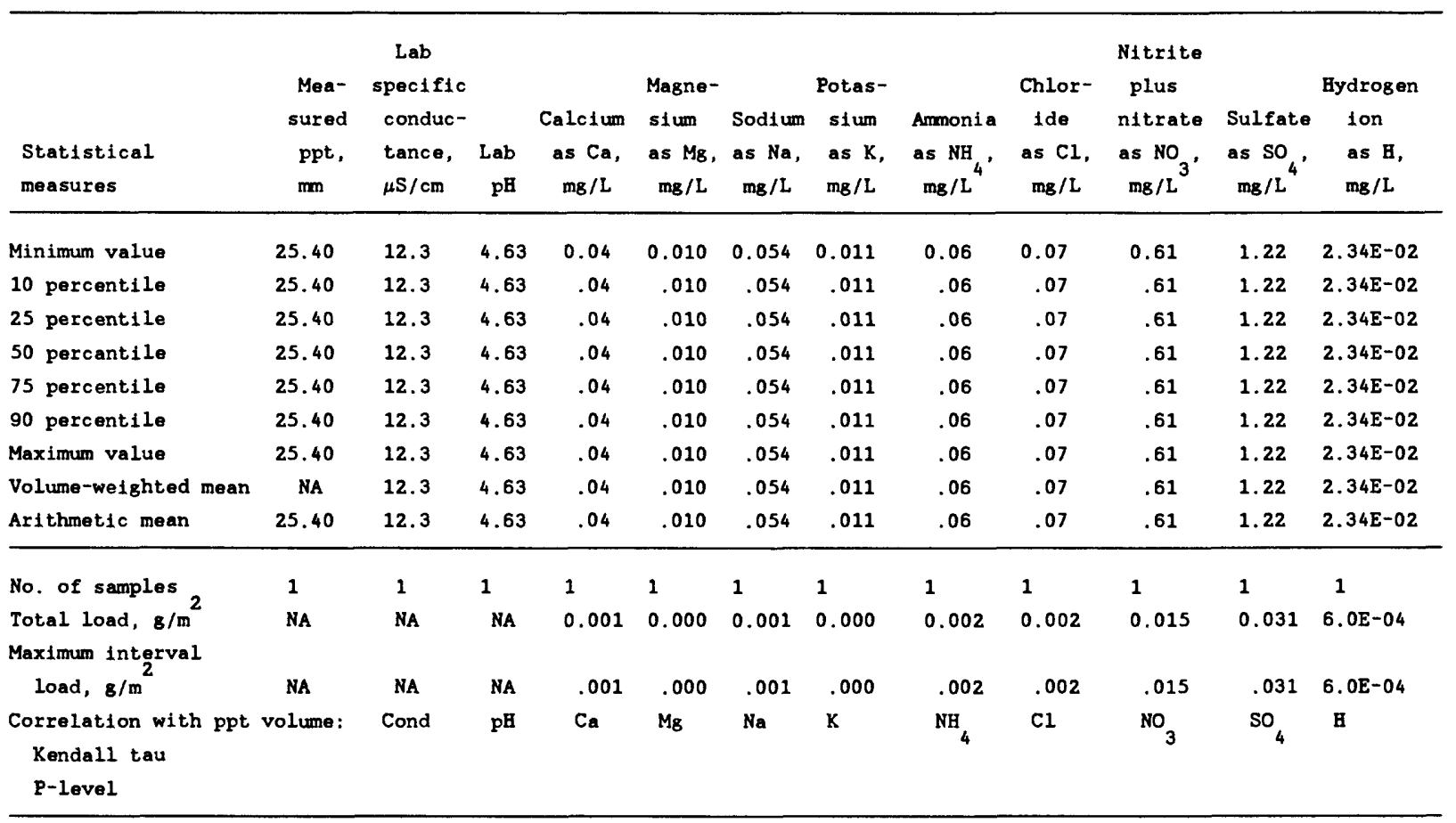

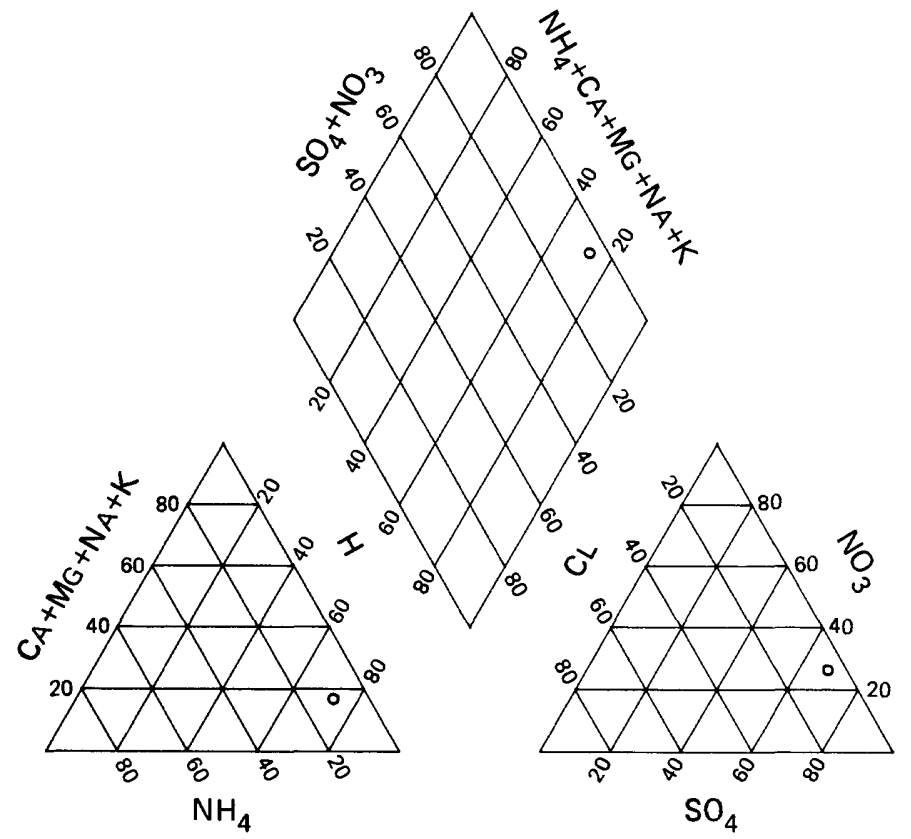

Percentage composition of major ions for site PA72. 


\section{NATIONAL TRENDS NETWORK -- 1983 CALENDER YEAR SUMMARY DATA}

[ppt = precipitation; $\mathrm{mm}=$ millimeters; $\mathrm{cm}=$ centimeters $; \mathrm{mg}=$ milligrams; $\mathrm{L}=1$ iters;

8 = 8 rams; $m=$ meter; $\mu s=$ microsiemens; cond = specific conductance $]$

STATION: Huron, South Dakota

Latitude: $44^{\circ} 23^{\prime} 02^{\prime \prime}$ Longitude: $98^{\circ} 13^{\prime} 14^{\prime \prime}$

CAL number: SDOO Mep ID number: 89

ADS number: 067 a00

Station summary period: $12 / 21 / 1982$ to $09 / 20 / 1983$

Station altitude above mean sea level, in meters: 390

Number of sampling intervals (days in perenthesis):

-- With ppt measurements: $29 \quad$ (273)

-- When ppt occurred: 28 (266)

-- When ppt did not occur: 11 ( 7)

-- When sample volume was substituted for missing rain gage: 0 ( 0$)$

-- With chemical samples: $22 \quad(210)$

Length of sumnary period: 29 sampling intervals (273 days)

Percent sumsry period with ppt measurements: 73.5

Percent sumnsry period with chemicsl samples or no ppt: 58.5

Percent of total measured ppt with chemicel samples: 91.2

Percent of total measured ppt in raingage that was

collected in the wet-sample bucket:

Total measured ppt, in mn: 383.9

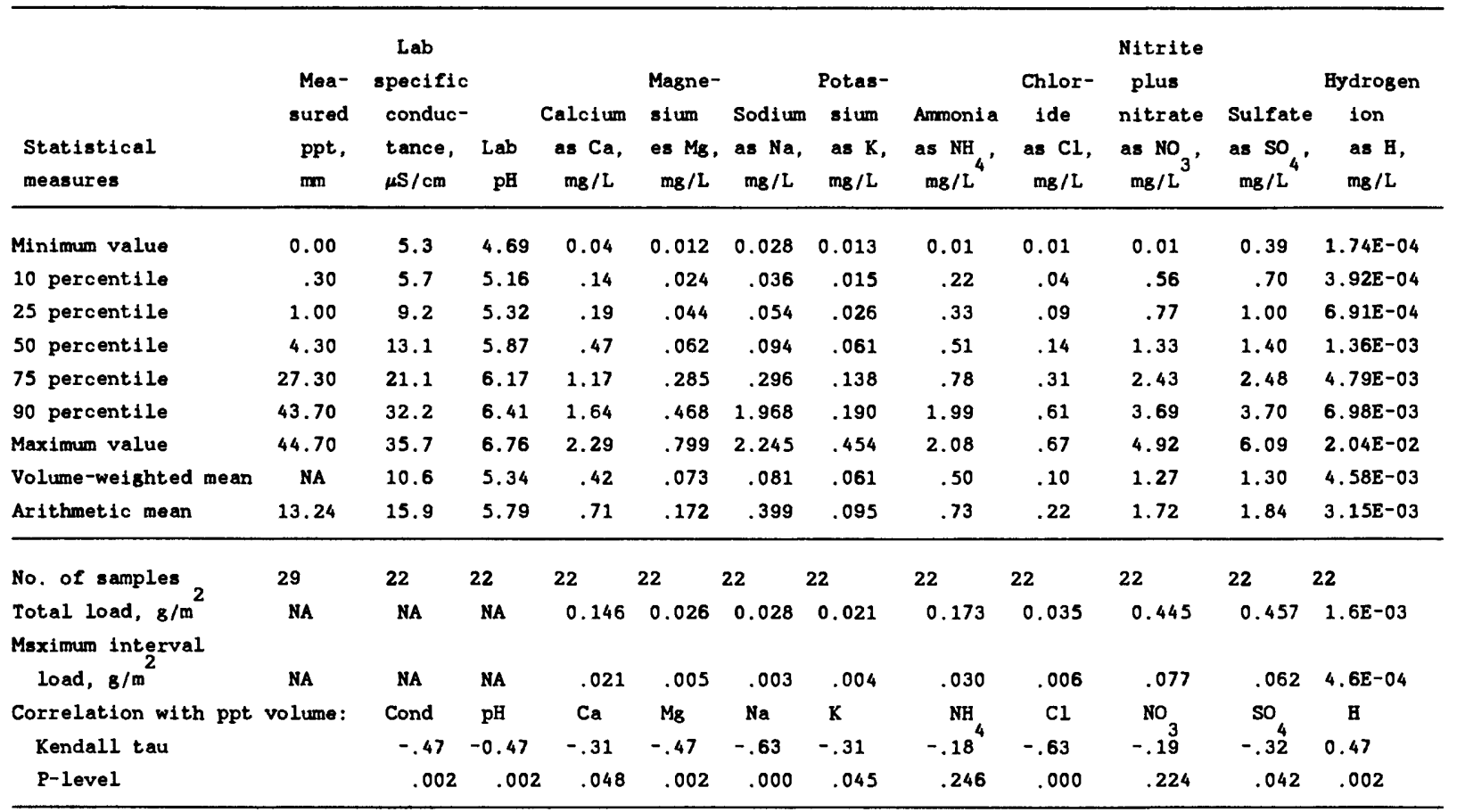

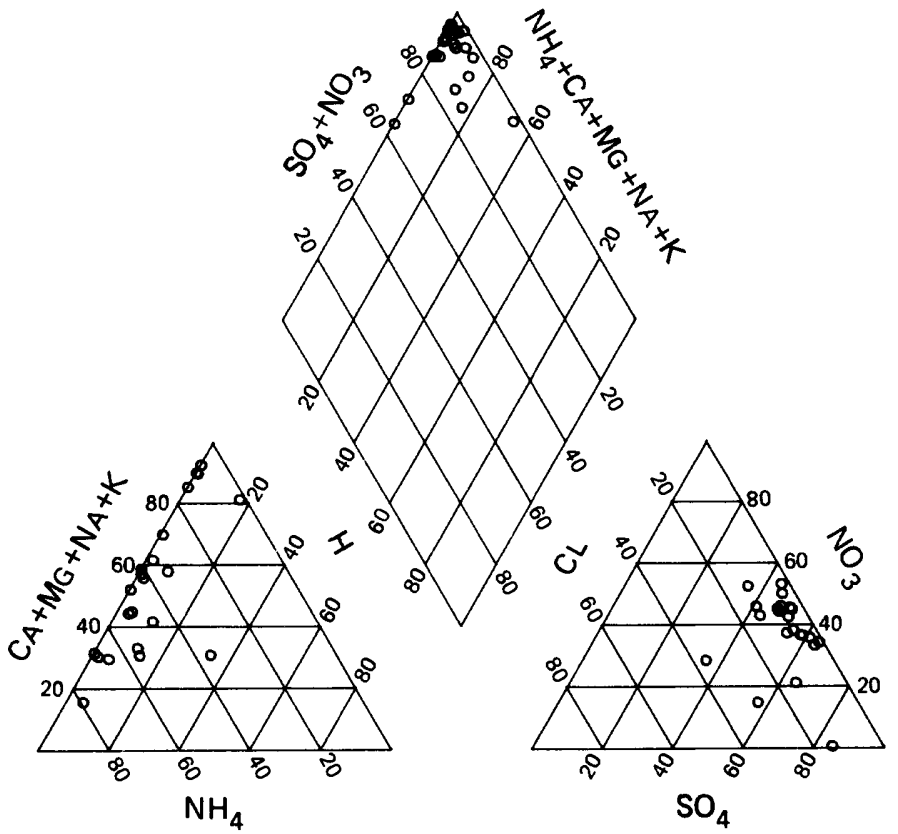

Percentage composition of major ions for site SD00. 


\section{NATIONAL TRENDS NETWORK - - 1983 CALENDER YEAR SUMMARY DATA}

[ppt = precipitation; $\mathrm{mm}=$ millimeters; $\mathrm{cm}=$ centimeters; $\mathrm{mg}=$ milligrams; $\mathrm{L}=1$ liters; $\mathrm{g}=\mathrm{grams} ; \mathrm{m}=$ meter; $\mu \mathrm{s}=$ microsiemens; cond = specific conductance]

STATION: Cottonwood, South Dakota

CAL number: SDO8

ADS number: $373 \mathrm{a} 00$

Station altitude above mean sea level, in meters: 733

Number of sampling intervals (days in parenthesis):

-- With ppt measurements:

-- When ppt occurred:

-- When ppt did not occur:

-- When sample volume was substituted for missing rain gage:

-- With chemical samples:
$11(84)$

$9(70)$

$2(14)$

$0 \quad(0)$

$5(35)$
Latitude: $43^{\circ} 56^{\prime} 57^{\prime \prime}$ Longitude: $101^{\circ} 51^{\prime} 30^{\prime \prime}$

Station summary period: $10 / 11 / 1983$ to $01 / 03 / 1984$

Length of summary period: 11 sampling intervals ( 84 days)

Percent summary period with ppt measurements:

22.6

Percent summary period with chemical samples or no ppt: 13.2

Percent of total measured ppt with chemical samples: 60.9

Percent of total measured ppt in raingage that was

collected in the wet-sample bucket:

80.9

Total measured ppt, in $\mathrm{mm}: 58.5$

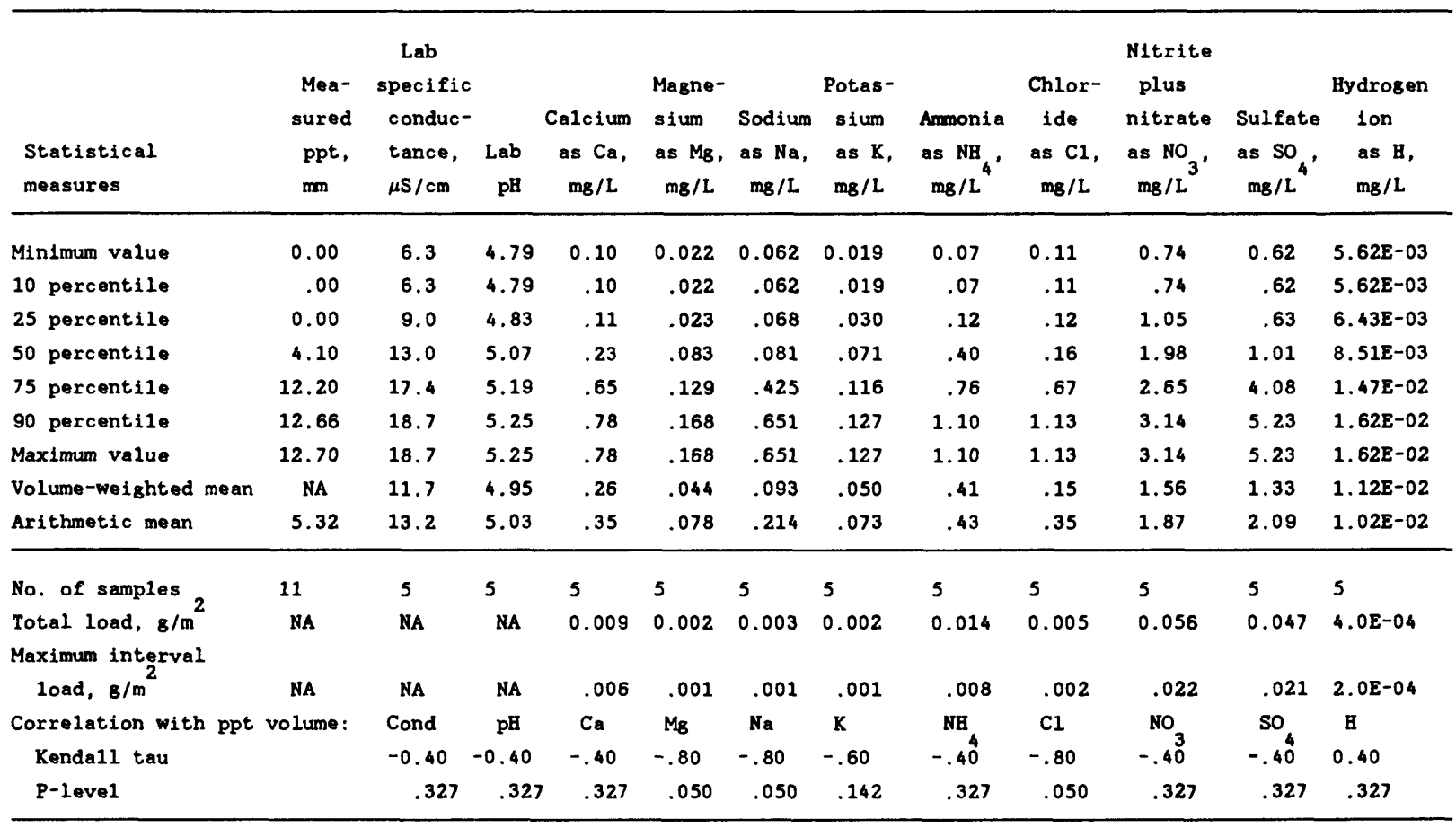

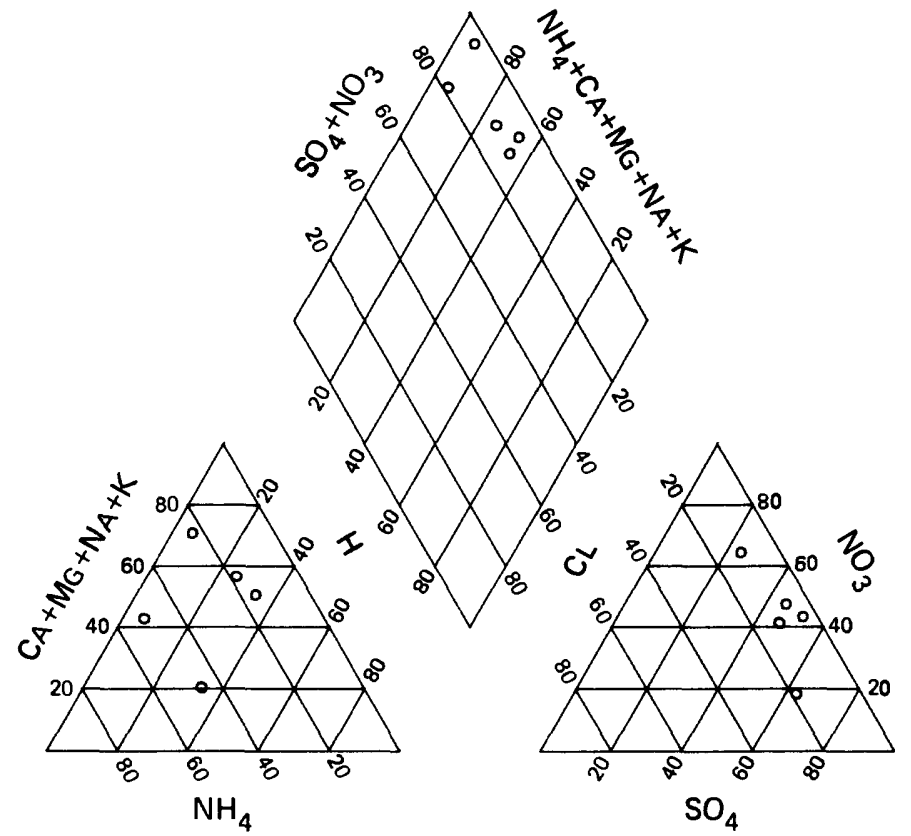

Percentage composition of major ions for site SD08. 


\section{NATIONAL TRENDS NETWORK -- 1983 CALENDER YEAR SUMMARY DATA}

lppt $=$ precipitation; $\mathrm{mm}=$ millimeters; $\mathrm{cm}=$ centimeters; $\mathrm{mg}=$ milligrams; $\mathrm{L}=1$ iters;

$\mathrm{g}=\mathrm{grams} ; \mathrm{m}=$ meter; $\mu \mathrm{s}=$ microsiemens; cond $=$ specific conductance $]$

STATION: Huron Well Field, South Dakota

CAL number: SD99

Map ID number: 91

ADS number: $372 \mathrm{a} 00$

Station altitude above mean sea level, in meters: 398

Number of sampling intervals (days in parenthesis):

-- With ppt measurements:

-- When ppt occurred.

-- When ppt did not occur:

-- When sample volume was substituted for missing rain gage:

-- With chemical samples:

$0(0)$
Latitude: $\quad 44^{\circ} 21^{\prime} 18^{\prime \prime}$ Longitude: $\quad 98^{\circ} 17^{\prime} 38^{\prime \prime}$

Station summary period: $11 / 29 / 1983$ to $01 / 03 / 1984$

Length of summary period: 5 sampling intervals ( 35 days)

Percent summary period with ppt measurements:

Percent sumary period with chemical samples or no ppt:

Percent of total measured ppt with valid samples:

Percent of total measured ppt in raingage that was

collected in the wet-sample bucket:

( ) Total measured ppt, in $\mathrm{mm}$ : 7.5

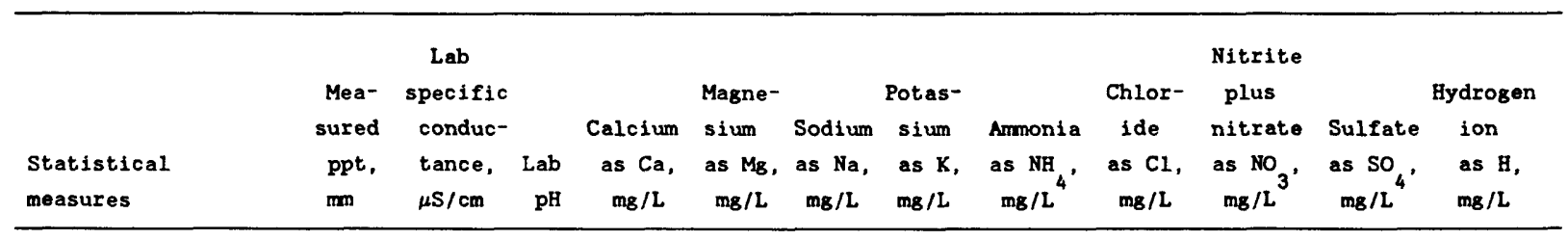

$\begin{array}{lr}\text { Minimum value } & 0.00 \\ 10 \text { percentile } & .00 \\ 25 \text { percentile } & .15 \\ 50 \text { percentile } & .30 \\ 75 \text { percentile } & 3.45 \\ 90 \text { percentile } & 6.60 \\ \text { Maximum value } & 6.60 \\ \text { Volume-weighted mean } & \text { NA } \\ \text { Arithmetic mean } & 1.50\end{array}$

Arithmetic mean 1.50

No. of samples, 5

Total load, $8 / \mathrm{m}^{2}$ NA NA NA

Maximum interval

load, $8 / \mathrm{m}^{2}$ NA NA NA

Kendall ta

P-lovel 
[ppt = precipitation; $\mathrm{mm}=$ millimeters; $\mathrm{cm}=$ centimeters; $\mathrm{mg}=\mathrm{milligrams;} \mathrm{L}=1$ iters;

$g=g r a m s ; m=$ meter $\mu \mathrm{s}=$ microsiemens; cond = specific conductance $]$

STATION: Elkmont, Tennessee

CAL number: TN11

ADS number: 028a00

Station altitude above mean sea level, in meters: 640

Number of sampling intervals (days in parenthesis):

-- With ppt measurements:

-- When ppt occurred:

- When ppt did not occur:

-- When sample volume was substituted for missing rain gage:

-- With chemical samples:
Latitude: $35^{\circ} 39^{\prime} 52^{\prime \prime}$ Longitude:

$83^{\bullet} 35^{\prime} 25^{\prime \prime}$

Station summary period: $12 / 28 / 1982$ to $01 / 03 / 1984$

Length of summary period: 51 sampling intervals (371 days)

Percent summary period with ppt measurements:

100.0

Percent summary period with chemical samples or no ppt: 63.9

Percent of total measured ppt with chemical samples: 69.1

Percent of total measured ppt in raingage that was

collected in the wet-sample bucket:

95.8

Total measured ppt, in $\mathrm{mm}: 1440.0$

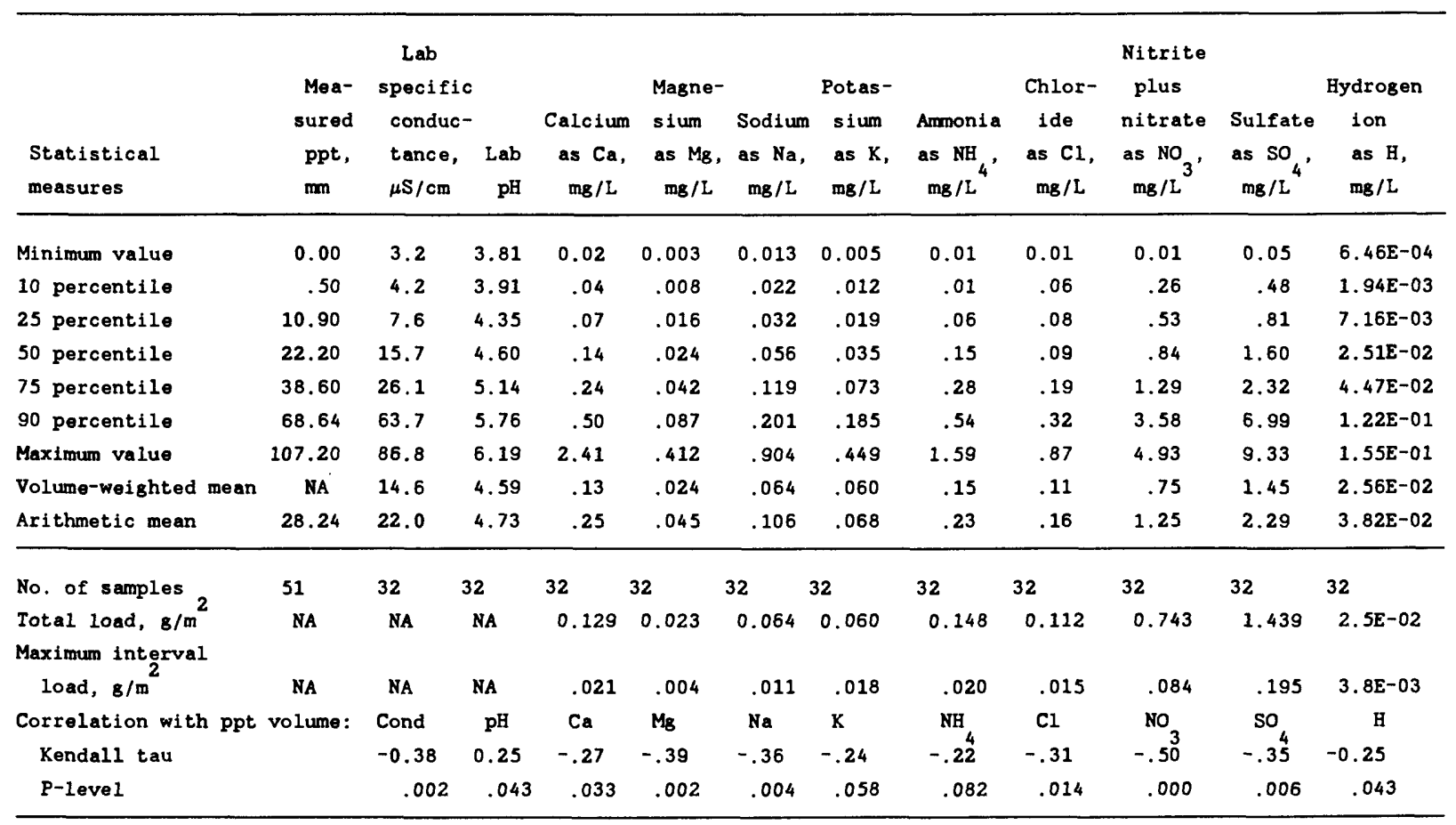

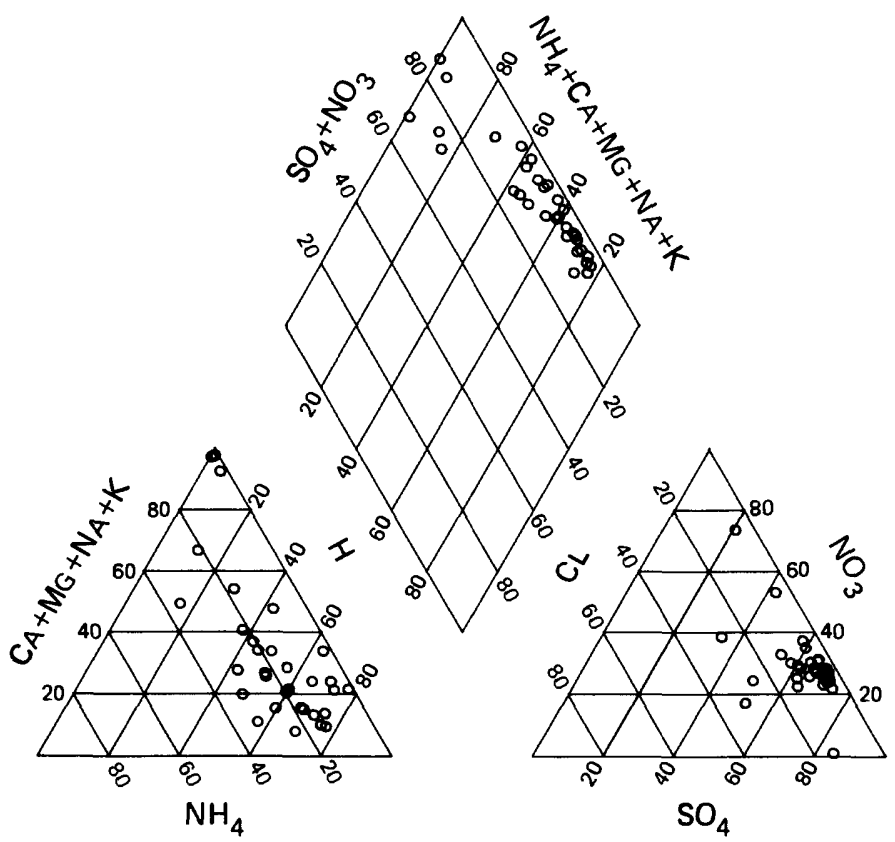

Percentage composition of major ions for site TN11. 


\section{NATIONAL TRENDS NETWORK -- 1983 CALENDER YEAR SUMMARY DATA}

lppt = precipitation; $\mathrm{mm}=$ millimeters; $\mathrm{cm}=$ centimeters; $\mathrm{mg}=\mathrm{milligrams;} \mathrm{L} \mathrm{=} \mathrm{11ters;}$

8 = grams; $m=$ meter; $\mu s=$ microsiemens; cond = specific conductance $]$

STATION: LBJ Netional Grasslands, Texas

CAL number: TX56

Map ID number: 96

Latitude: $33^{\circ} 23^{\prime} 30^{\prime \prime}$ Longitude:

$97^{\circ} 38^{\prime} 23^{\prime \prime}$

ADS number: 378.00

Station altitude above mean sea level, in meters: 312

Number of sampling intervals (days in parenthesis):

-- With ppt measurements: $14 \quad$ (105)

-- When ppt occurred:

-- When ppt did not occur:

-- When sample volume was substituted for missing rain gage:

-- With chemical samples:
12 ( 91)

2 ( 14)

$3(0)$

$9(70)$
Station summary period: $09 / 20 / 1983$ to $01 / 03 / 1984$

Length of summary period: 14 sampling intervals (105 days)

Percent summary period with ppt measurements:

Percent summary period with chemical samples or no ppt: 22.6

Percent of total measured ppt with chemical samples: $\quad 99.9$

Percent of total measured ppt in raingage that was

collected in the wet-sample bucket:

93.4

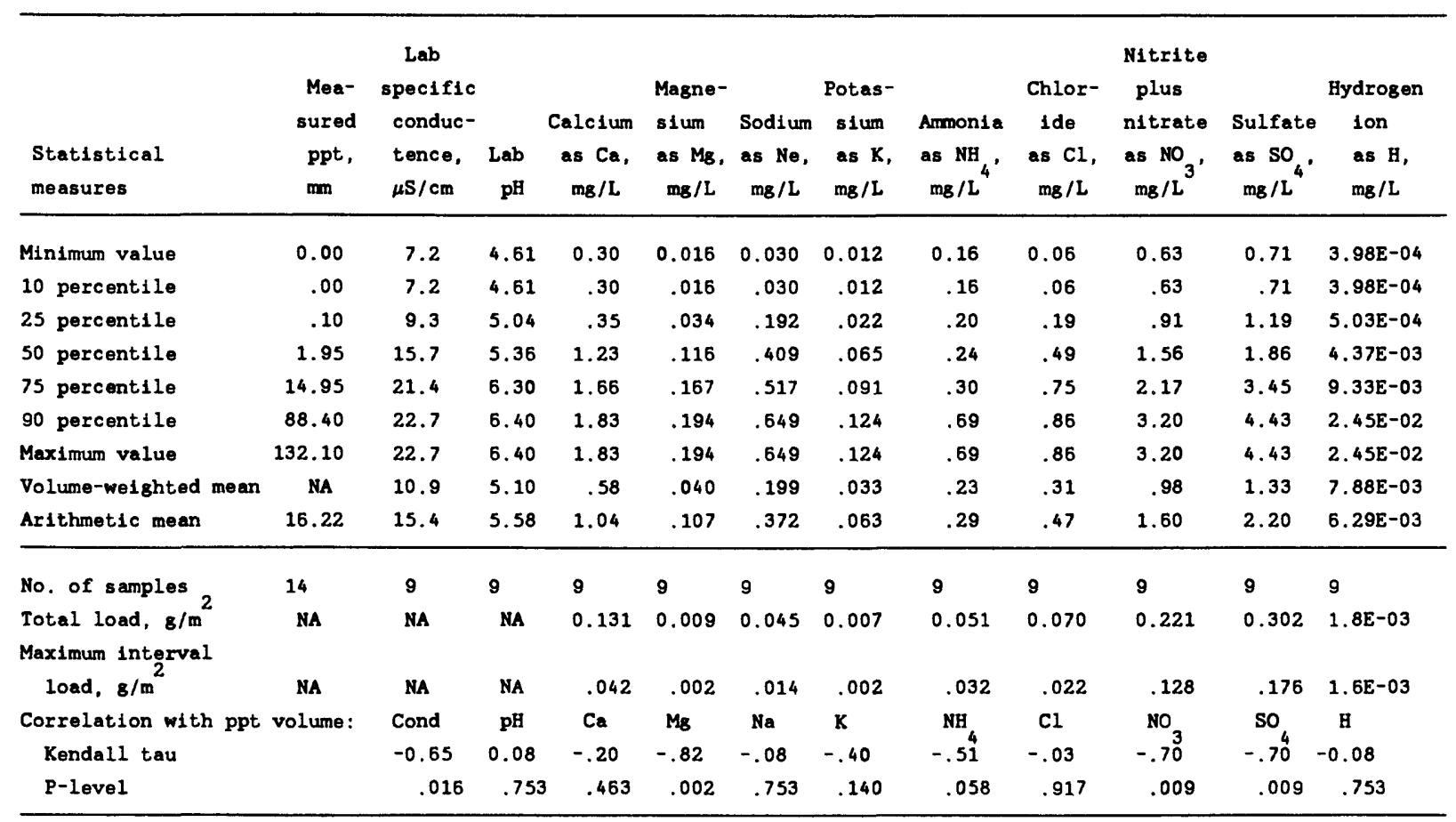

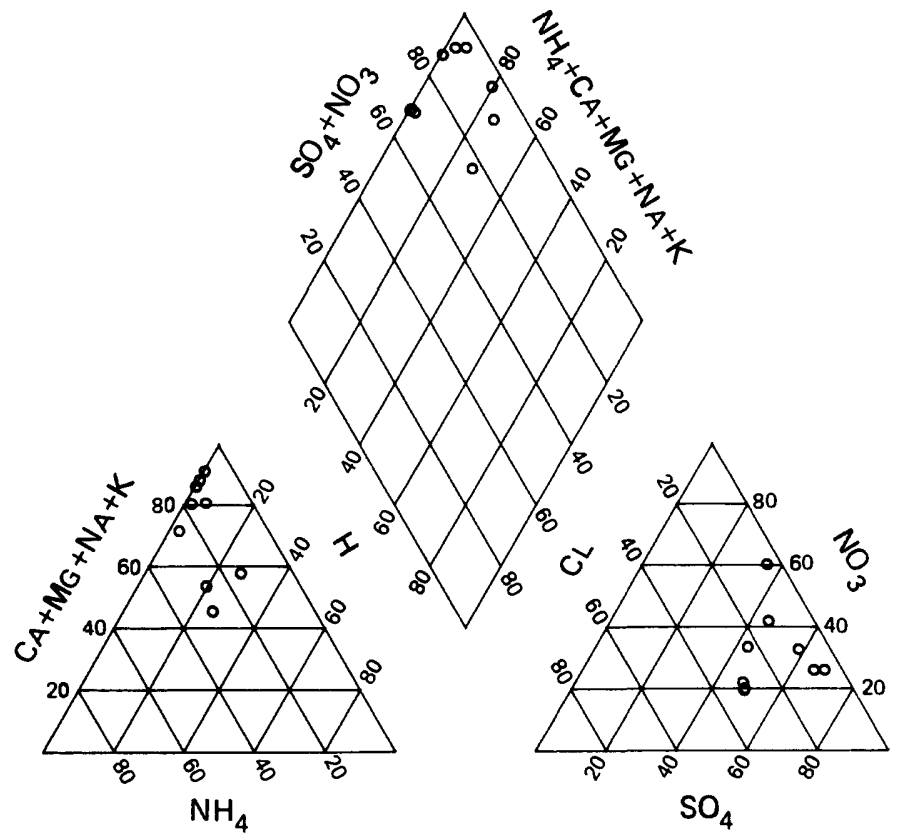

Percentage composition of major ions for site TX56. 


\section{NATIONAL TRENDS NETWORK - 1983 CALENDER YEAR SUMMARY DATA}

[ppt = precipitation; $\mathrm{mm}=$ millimeters; $\mathrm{cm}=$ centimeters; $\mathrm{mg}=\mathrm{milligrams;} \mathrm{L}=11$ ters;

$\mathrm{g}=\mathrm{grams} ; \mathrm{m}=$ meter $; \boldsymbol{\mu s}=\mathrm{microsiemens} ;$ cond $=$ specific conductance $]$

STATION: Logan, Utah

CAL number: UT01

ADS number: $357 a 00$

Station altitude above mean sea level, in meters: 1370

Number of sampling intervals (days in parenthesis):

-- With ppt measurements:

-- When ppt occurred:

-- When ppt did not occur:

-- When sample volume was substituted for missing rain gage:

-- With chemical samples:

Map ID number: 97

$4(28)$

$0(0)$

$0 \quad(0)$
Latitude: $41^{\circ} 39^{\prime} 30^{\prime \prime}$ Longitude: $111^{\circ} 53^{\prime} 49^{\prime \prime}$

Station summary period: $12 / 06 / 1983$ to $01 / 03 / 1984$

Length of summary period: 4 sampling intervals ( 28 days)

Percent summary period with ppt measurements:

Percent summary period with chemical samples or no ppt:

Percent of total measured ppt with valid samples:

Percent of total measured ppt in raingage that was collected in the wet-sample bucket:

Total measured ppt, in $\mathrm{mm}: \quad 61.6$

\begin{tabular}{|c|c|c|c|c|c|c|c|c|c|c|c|c|}
\hline \multirow[b]{4}{*}{$\begin{array}{l}\text { Statistical } \\
\text { measures }\end{array}$} & \multicolumn{3}{|c|}{ Lab } & & & & & \multicolumn{5}{|c|}{ Nitrite } \\
\hline & Mea- & specific & & & Magne- & & Potas- & & Chlor- & plus & & Hydrogen \\
\hline & sured & conduc- & & Calcium & sium & Sodium & sium & Ammoni a & ide & nitrate & Sulfate & ion \\
\hline & $\begin{array}{l}\text { ppt, } \\
\text { mm }\end{array}$ & $\begin{array}{l}\text { tance, } \\
\mu \mathrm{S} / \mathrm{cm}\end{array}$ & $\begin{array}{r}\text { Lab } \\
\mathrm{pH}\end{array}$ & $\begin{array}{c}\text { as } \mathrm{Ca} \\
\mathrm{mg} / \mathrm{L}\end{array}$ & $\begin{array}{c}\text { as } \mathrm{Mg} \text {, } \\
\mathrm{mg} / \mathrm{L}\end{array}$ & $\begin{array}{l}\text { as } \mathrm{Na} \text {, } \\
\mathrm{mg} / \mathrm{L}\end{array}$ & $\begin{array}{l}\text { as } K \text {, } \\
m g / L\end{array}$ & $\begin{array}{l}\text { as } \mathrm{NH}_{4} \text {, } \\
\mathrm{mg} / \mathrm{L}^{4}\end{array}$ & $\begin{array}{l}\text { as } C 1 \text {, } \\
\mathrm{mg} / \mathrm{L}\end{array}$ & as $\mathrm{NO}_{3}$ & ${ }_{\mathrm{mg} / \mathrm{L}^{\prime}}$ & $\begin{array}{l}\text { as } H, \\
\mathrm{mg} / \mathrm{L}\end{array}$ \\
\hline
\end{tabular}

$\begin{array}{lr}\text { Minimum value } & 4.30 \\ 10 \text { percentile } & 4.30 \\ 25 \text { percentile } & 5.90 \\ 50 \text { percentile } & 16.95 \\ 75 \text { percentile } & 23.35 \\ 90 \text { percentile } & 23.40 \\ \text { Maximum value } & 23.40 \\ \text { Volume-weighted mean } & \text { NA } \\ \text { Arithmetic mean } & 15.40\end{array}$

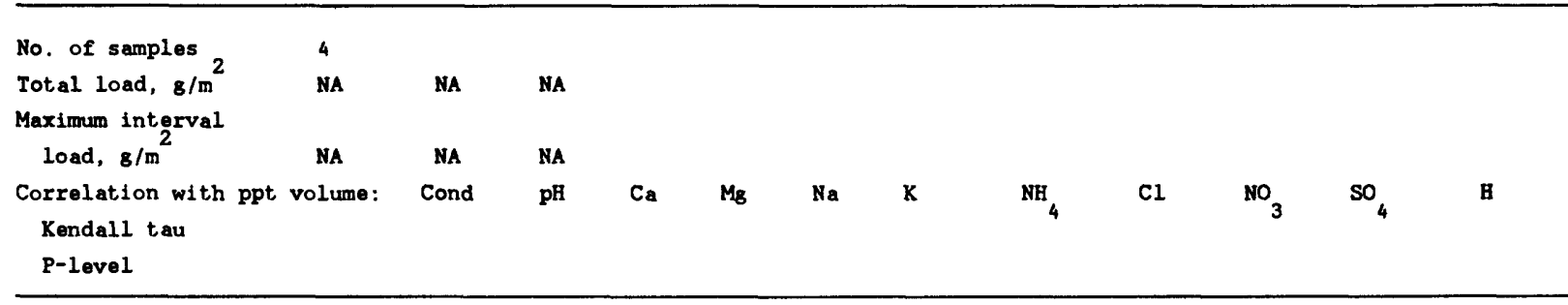


lppt = precipitation; $\mathrm{mm}=$ millimeters; $\mathrm{cm}=$ centimeters; $\mathrm{mg}=\mathrm{milligrams;} \mathrm{L}=11$ ters;

$\mathbf{8}$ = grams; $\mathbf{m}=$ meter; $\mu \mathrm{s}=$ microsiemens; cond = specific conductance $]$

STATION: Bis Meadows, Virginie

CAL number: VA28

ADS number: 250.01

Map ID number: 99

Station altitude above mean sea level, in meters: 1047

Number of sampling intervals (days in parenthesis):

-With ppt measurements: 53 (371)

-W When ppt occurred: 52 (364)

-- When ppt did not occur:

-- When sample volume was substituted for missing rain gage: $0(0)$

-- With chemical samples: 23 (161)
Latitude: $38^{\circ} 30^{\prime} 51^{\prime \prime}$ Longitude: $\quad 78^{\circ} 25^{\prime} 45^{\prime \prime}$

Station summary period: $12 / 28 / 1982$ to $01 / 03 / 1984$

Length of summary period: 53 sampling intervals ( 371 days)

Percent summary period with ppt measurements: 100.0

Percent summary period with chemical samples or no ppt: 45.3

Percent of total measured ppt with chamical samples: $\quad 56.8$

Percent of total measured ppt in raingage that was

collected in the wet-sample bucket:

100.2

Total measured ppt, in $\mathrm{mm}: 1835.1$

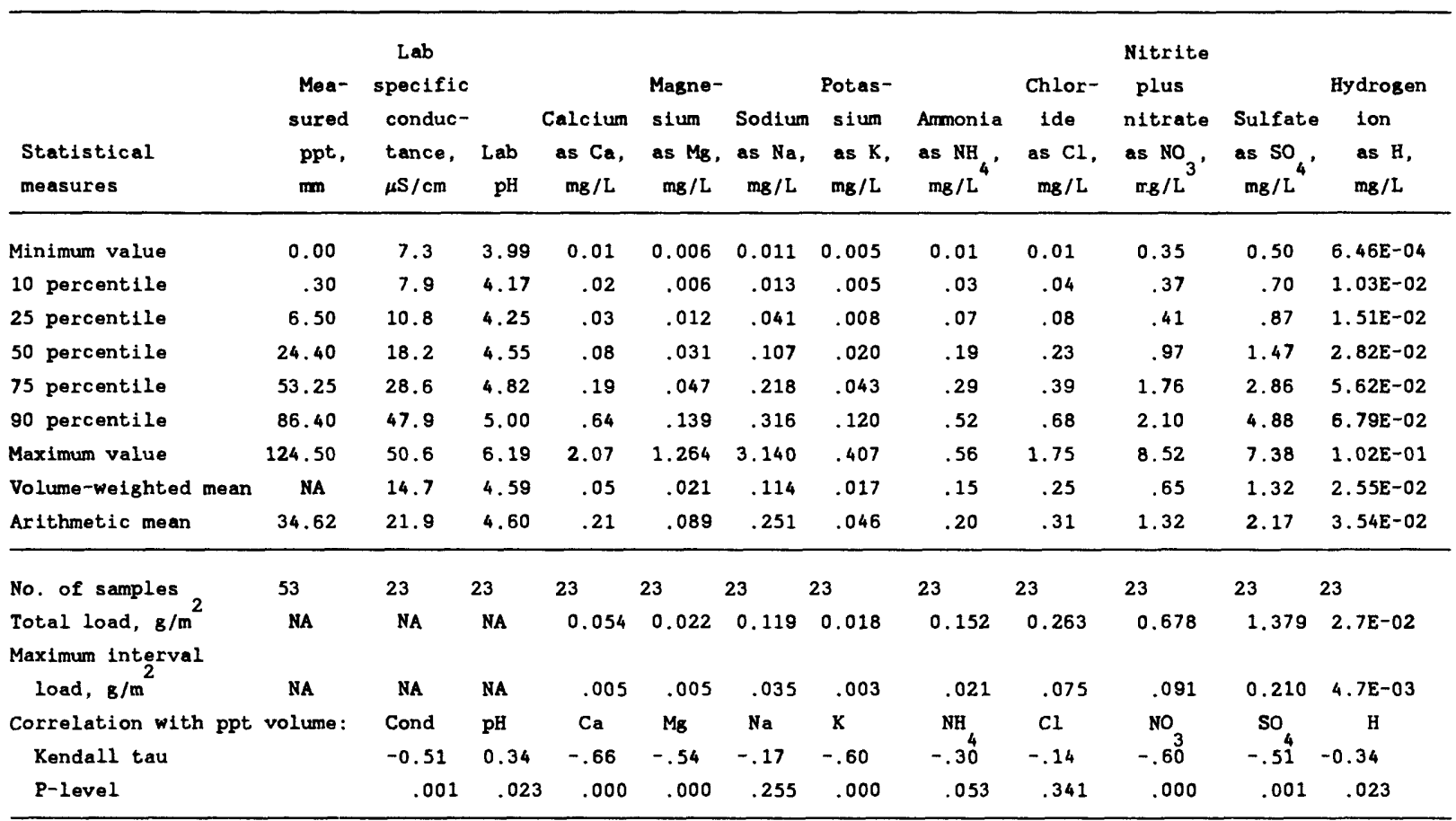

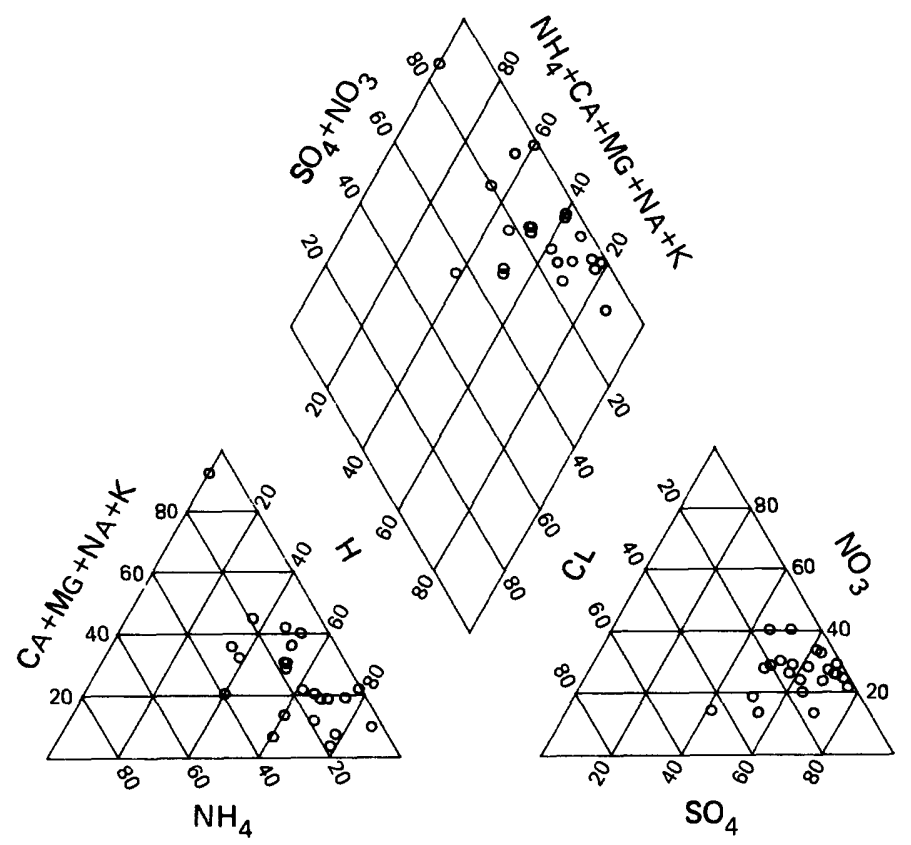

Percentage composition of major ions for site VA28. 


\section{NATIONAL TRENDS NETWORK - 1983 CALENDER YEAR SUMMARY DATA}

[ppt = precipitation; $\mathrm{mm}=$ millimeters; $\mathrm{cm}=$ centimeters; $\mathrm{mg}=$ milligrams; $\mathrm{L}=1 \mathrm{liters}$;

$\mathbf{g}=$ grams; $\mathbf{m}=$ meter $; \mu \mathrm{s}=$ microsiemens; cond = specific conductance $]$

STATION: Babcock State Park, West Virginia

CAL number: WVO4

ADS number: $379 a 00$

Map ID number: 105

Station altitude above mean sea level, in meters: 631

Number of sampling intervals (days in parenthesis):

-- With ppt measurements:

17 (119)

-- When ppt occurred:

-- When ppt did not occur:

-- When sample volume was substituted for missing rain gage:

-- With chemical samples:
Latitude: $37^{\circ} 58^{\prime} 47^{\prime \prime}$ Longitude: $80^{\circ} 56^{\prime} 59^{\prime \prime}$

Station summary period: $09 / 06 / 1983$ to $01 / 03 / 1984$

Length of summary period: 17 sampling intervals ( 119 days)

Percent summary period with ppt measurements:

32.1

Percent sumary period with chemical samples or no ppt: 18.9

Percent of total measured ppt with chemical samples: 48.2

Percent of total measured ppt in raingage that was

collected in the wet-sample bucket:

87.4

Total measured ppt, in m: 379.7

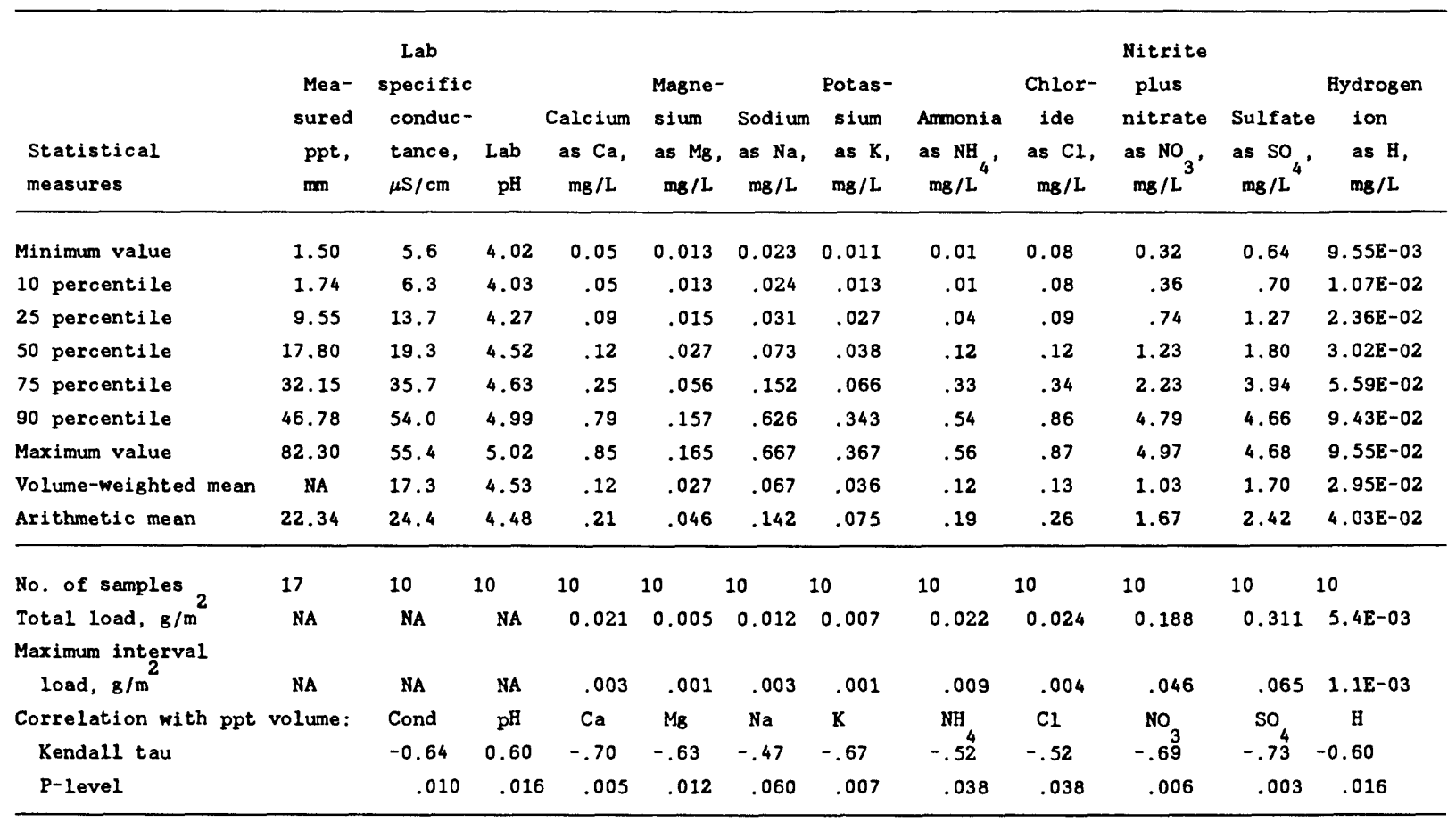

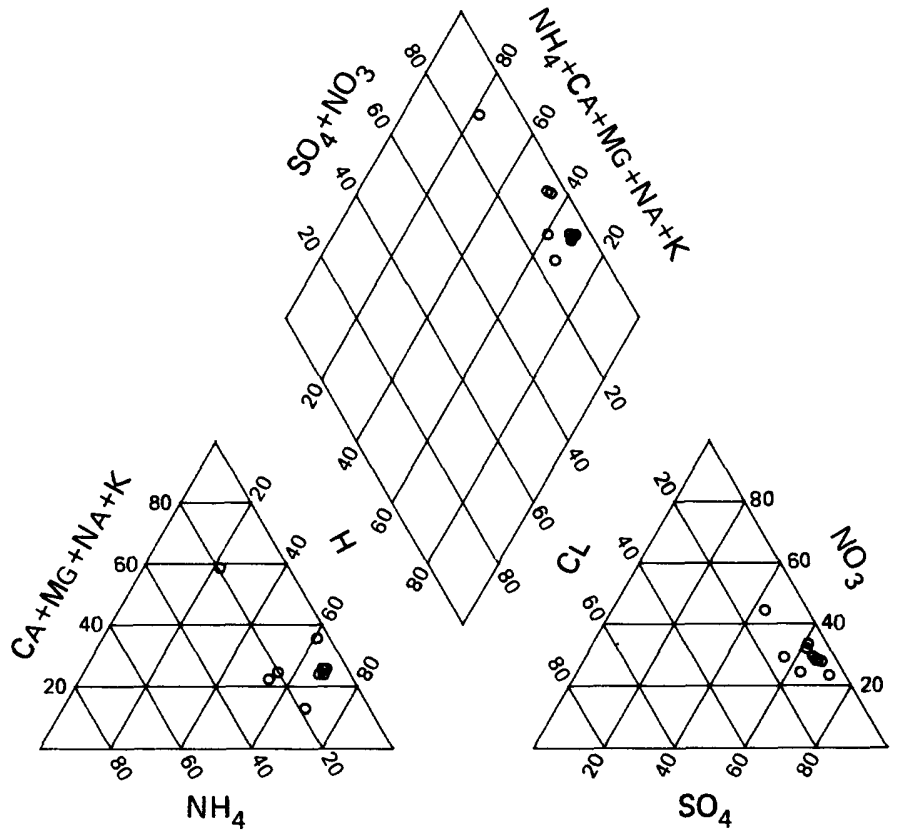

Percentage composition of major ions for site WV04. 
lppt = precipitation; $\mathrm{mm}=$ millimeters; $\mathrm{cm}=$ centimeters; $\mathrm{mg}=$ milligrams; $\mathrm{L}=11$ ters;

$8=g$ rams; $m=$ meter; $\mu s=$ microsiemens; cond = specific conductance $]$

STATION: Pinedale, Wyoming

CAL number: WYOG

ADS number: 284a00

Map ID number: 107

Station altitude above mean sea level, in meters: 238

Number of sampling intervals (days in parenthesis):

-- Wi th ppt measurements :

-- When ppt occurred:

53 (371)

-- When ppt did not occur:

52 (364)

-- When sample volume was substituted for missing rain gage:

-- With chamical samples:
Latitude: $42^{\circ} 55^{\prime} 44^{\prime \prime}$ Longitude: $109^{\circ} 47 \cdot 12^{\prime \prime}$

Station sumary period: $12 / 28 / 1982$ to $01 / 03 / 1984$

Length of summary period: 53 sampling intervals ( 371 days)

Percent summary period with ppt measurements: $\quad 100.0$

Percent summary period with chemical samples or no ppt: 62.3

Percent of total measured ppt with chemical samples: 61.5

Percent of total measured ppt in raingage that was

collected in the wet-sample bucket:

72.2

Total measured ppt, in $\mathrm{mm}: 437.4$

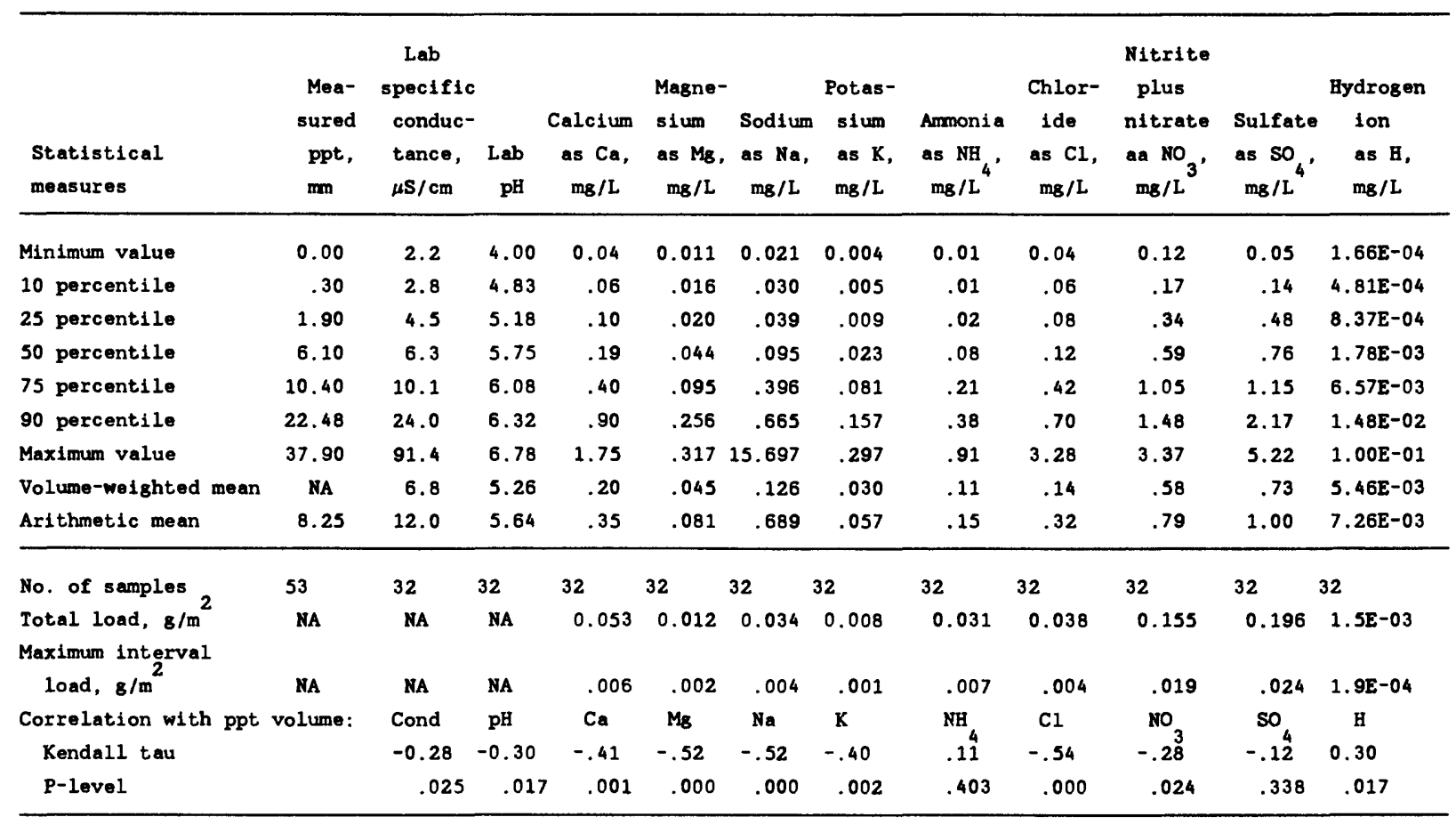

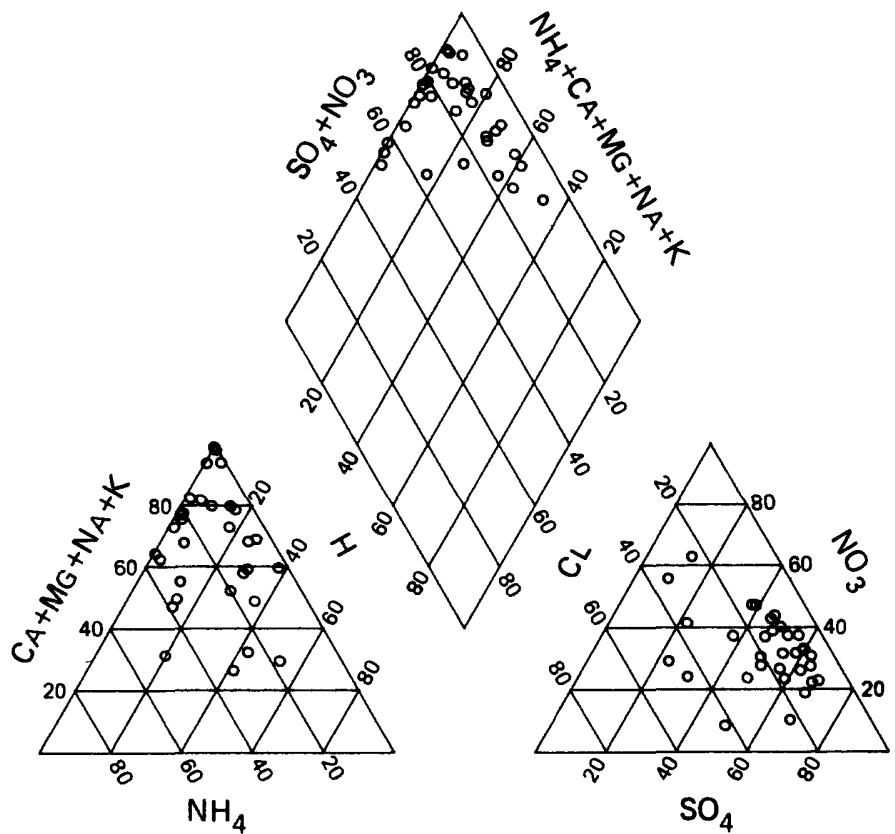

Percentage composition of major ions for site WY06. 


\section{NATIONAL TRENDS NETWORK -- 1983 CALENDER YEAR SUMMARY DATA}

lppt = precipitation; $\mathrm{mm}=$ millimeters; $\mathrm{cm}=$ centimeters $\mathrm{mg}=$ milligrams; $\mathrm{L}=11$ ters :

$8=8 \mathrm{rams} ; \mathrm{m}=$ meter $; \mu \mathrm{s}=$ microsiemens; cond $=$ specific conductance $]$

STATION: Yellowstone National Park, Wyoming

Latitude: $44^{\circ} 55^{\prime} 02^{\prime \prime}$ Longitude: $110^{\circ} 25^{\prime} 13^{\prime \prime}$

CAL number: WY08

ADS number: $078 \mathrm{a00}$

Map ID number: 108

Number of sampling intervals (days in parenthesis):

-- With ppt measurements: 51 (371)

-- When ppt occurred: 50 (364)

-- When ppt did not occur:

-- When sample volume was substituted for missing rain gage:

-- With chemical semples:
1 ( 7)

$6 \quad(42)$

19 (133)
Station summary period: $12 / 28 / 1982$ to $01 / 03 / 1984$

Length of summary period: 51 sampling intervals ( 371 days)

Percent summary period with ppt measurements:

100.0

Percent summary period with chemical samples or no ppt: 37.7

Percent of total measured ppt with chemical samples: $\quad 38.0$

Percent of total measured ppt in raingage that was

collected in the wet-sample bucket:

105.0

Total measured ppt, in mm: 347.5

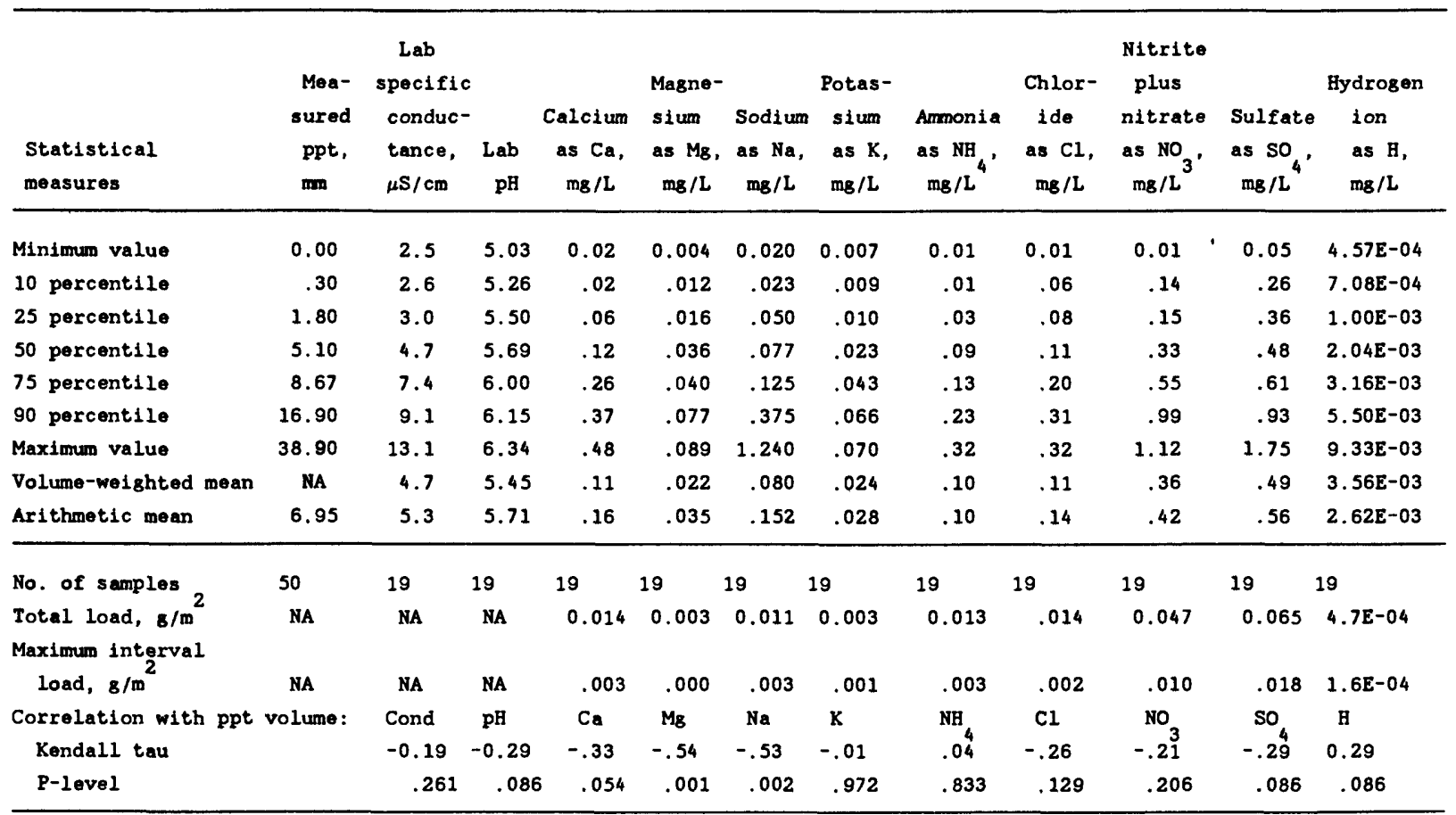

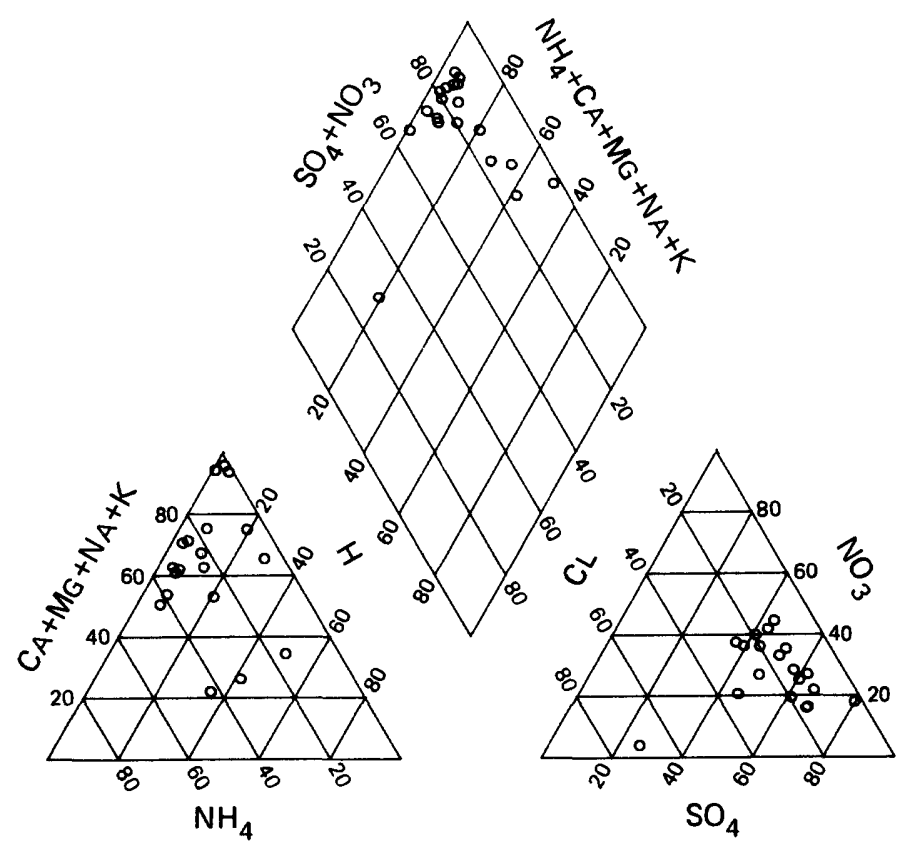

Percentage composition of major ions for site WY08. 